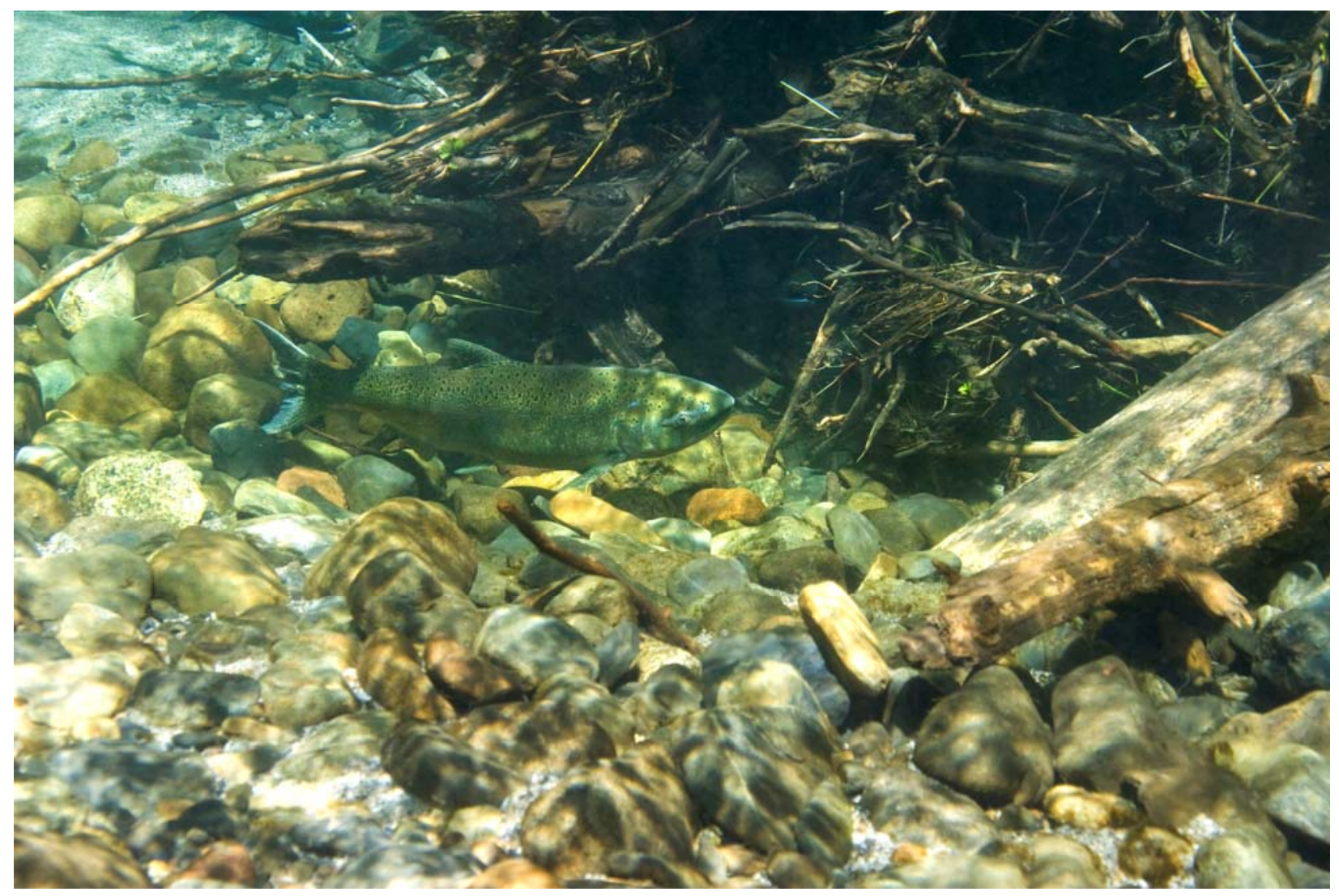

\title{
Columbia River Hatchery Reform System-Wide Report
}

February 2009

Prepared by

Hatchery Scientific Review Group

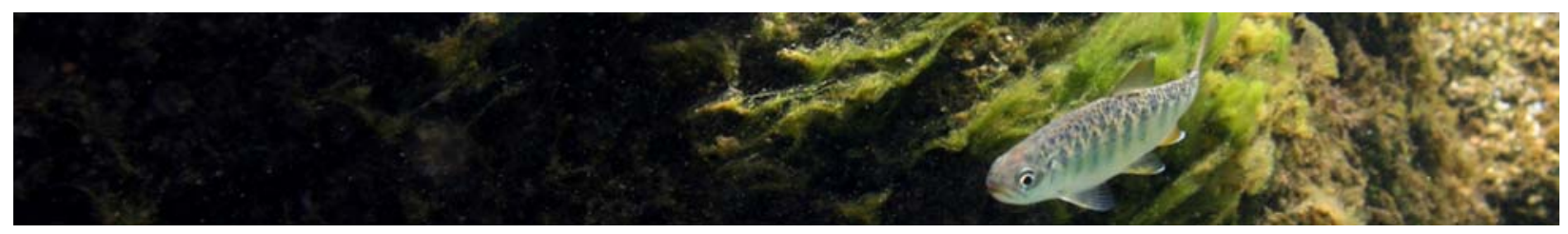




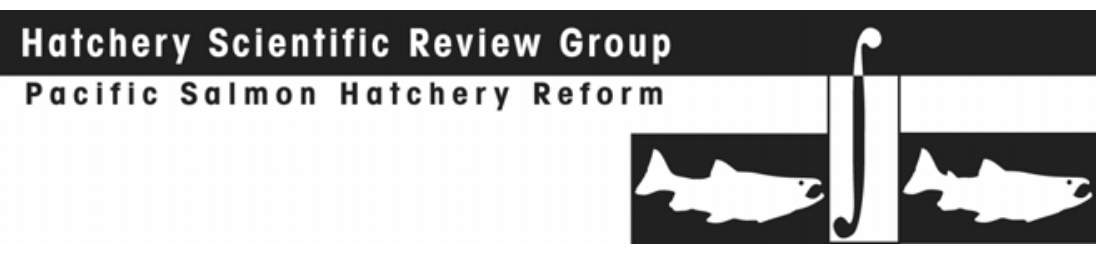

\section{Acknowledgements}

Performing this analysis and developing recommendations for over 351 salmonid populations in the Columbia River Basin would not have been possible without the knowledge, commitment and hard work of many individuals. The HSRG members extend special thanks to the contracting staff that supported them: Gary Affonso, Greg Blair, Jeff Boyce, Amy Corsini, Nancy Bond Hemming, Michael Kern, B.J. Mirk, Joan Nichol, Grant Novak, Denise Kelsey, Robyn Redekopp, Joel Rice, Shannon Riper, Jason Shappart, Jason Volk, Jim Waldo and especially Dan Warren.

Many regional fishery biologists and managers contributed both their time and expertise in meetings, tours and report reviews, notably:

\begin{tabular}{lll} 
Paul Abbot & Richard Carmichael & Rod French \\
Todd Alsbury & Mark Chilcote & Amy Gaskill \\
Bill Arnsburg & Guy Chilton & Mike Gauvin \\
John Arterburn & Bob Clubb & John Gebhards \\
Bill Bacon & Michael Coffey & Jim Gidley \\
Greg Baesler & Charlie Corrarino & Bryce Glaser \\
Ronald Ballard & Patty Crandell & Judy Gordon \\
Duane Banks & Tim Culberson & Steve Grabowski \\
Heather Bartlett & Wolf Dammers & Jenny Grace \\
Shane Bickford & Greg Davis & David Graves \\
Joe Blodgett & Doug DeHart & Tony Grover \\
Steve Boe & Greg Delwiche & Susan Gutenberger \\
Jeff Boechler & Lytle Denny & Ronald Hardy \\
Bill Bosch & Dan Diggs & Rod Harrod \\
Ken Bourne & James Dixon & Peter Hassemer \\
Ed Bowles & Speros Doulos & Steve Hays \\
Brett Boyd & Tom Dresser & Jeff Heindel \\
Robert Bradley & John Easterbrooks & John Hitron \\
Keith Braun & Bruce Eddy & Brad Houslet \\
Kat Brigham & Roger Elmore & Donna Hughes \\
Claudeo Broncho & Manuel Farinas & Jack Hurst \\
Stephen Brown & Brett Farman & Tom Iverson \\
Chris Brun & Chris Fisher & Gary James \\
Howard Burge & Randy Fisher & Loren Jensen \\
Jody Calica & Hilary Forrest & Becky Johnson \\
Dave Carie & Patrick Frazier & Dave Johnson \\
Chris Carlson & Chris Frederickson & Mark Johnson \\
& & \\
\hline & &
\end{tabular}




\section{Hatchery Scientific Review Group}

Pacific Salmon Hatchery Reform

Brian Jonasson

Rob Jones

Tod Jones

Tom Kahler

Pam Kahut

Cory Kamphouse

Jeff Keonings

Keith Keown

Sharon Kiefer

Eric Kinne

Bill Kinney

Rick Klinge

Kathryn Kostow

Chris Kozfkay

Joe Krakker

Kurt Kremers

Sara Laborde

Russ Langshaw

Mark LaRiviere

Ed Larsen

Muhammad Latif

Cindy LeFleur

Brian Leth

Stefanie Leth

Mike Lewis

Peter Lofy

John Lovrak

Kevin Malone

Larry Marchant

Jerry Marco

Craig Martin

Steve Martin

Bill Maslen

Chip McConnaha

Bruce McIntosh

Mike McLean

Gene McPherson

Glen Mendel

Alan Meyer

Guy Norman
John North

Doug Olson

Bill Otto

Allyson Ouzts Purcell

Scott Patterson

Todd Pearsons

Dan Peck

Larry Peltz

Aaron Penny

Joe Peone

Rock Peters

Chuck Peven

Patrick Phillips

Julie Pyper

Dan Rawding

Phillip Rigdon

Aaron Roberts

Phil Roger

Tom Rogers

Denny Rohl

Bob Rose

Robert Rose

Roy Sampsel

Mel Sampson

Bruce Schmidt

Mark Schuck

Jim Scott

Shaun Seaman

Bill Sharp

Sam Sharr

John Shurts

Mindy Simmons

Charles Strom

Bruce Suzumoto

Doug Taki

Larry Telles

John Thorpe

Mark Traynor

Kirk Truscott

Robert Turner
Kristi Van Leuven

Steven Vigg

Jason Vogel

Rob Walton

Paul Ward

Roger Warren

Ron Warren

Bruce Watson

John Weinheimer

Bill West

John Whalen

Geoffrey Whisler

Greg Wilke

Brian Zimmerman

Bryan Zimmerman 


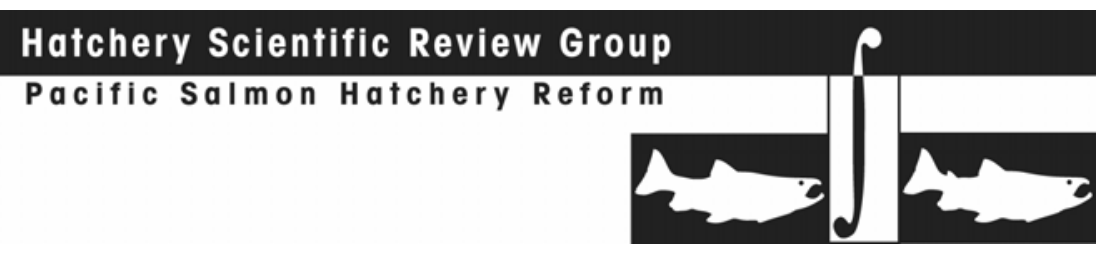

\section{Table of Contents}

Part 1 - Introduction ............................................................................................... 1

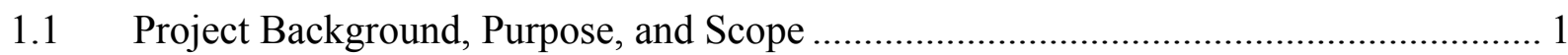

1.2 Project Organization and Implementation ............................................................. 3

Columbia River Hatchery Scientific Review Group ………..............................................

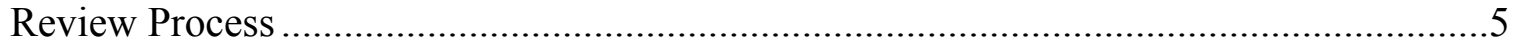

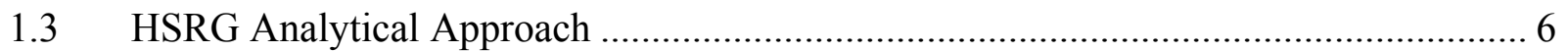

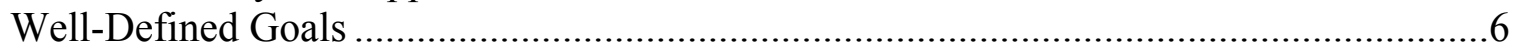

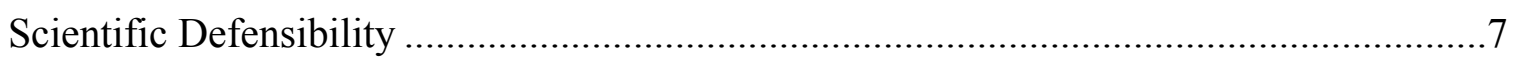

Informed Decision Making and Adaptive Management......................................................

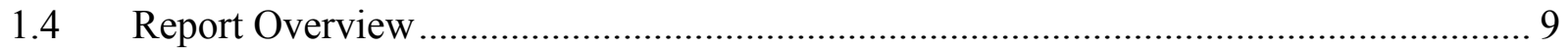

Part 2 - Summary Conclusions, Principles and System-Wide

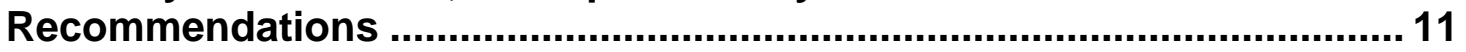

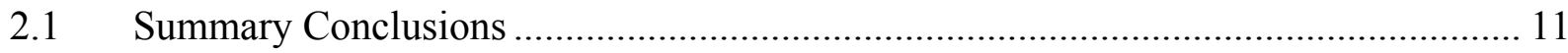

Manage Hatchery Broodstocks to Achieve Proper Genetic Integration with, or

Segregation from, Natural Populations ..............................................................12

Promote Local Adaptation of Natural and Hatchery Populations .....................................13

Minimize Adverse Ecological Interactions between Hatchery- and Natural-Origin

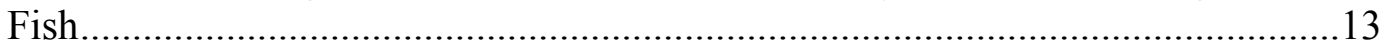

Minimize Effects of Hatchery Facilities on the Ecosystem..............................................14

Maximize Survival of Hatchery Fish ............................................................................14

2.2 Principles and System-Wide Recommendations .................................................. 14

Principle: Develop Clear, Specific, Quantifiable Harvest and Conservation Goals for

Natural and Hatchery Populations within an "All H" Context ...............................15

Principle: Design and Operate Hatchery Programs in a Scientifically Defensible

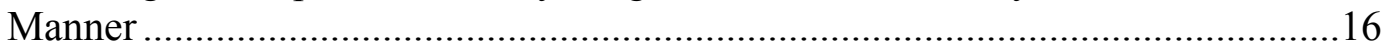

Principle: Monitor, Evaluate and Adaptively Manage Hatchery Programs ......................24

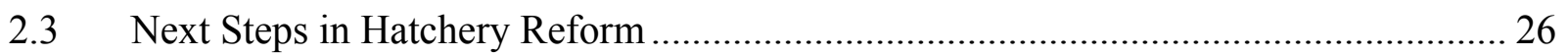

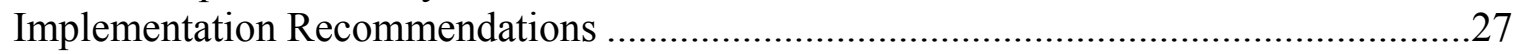

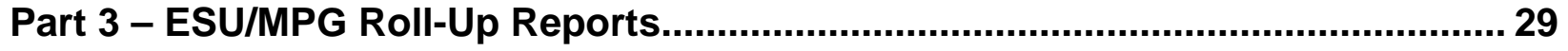

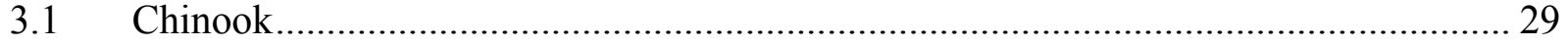

3.1.1 Lower Columbia River Chinook Salmon ESU ………………….......................29

3.1.2 Upper Willamette River Chinook Salmon ESU …………………………..........41

3.1.3 Middle Columbia River Spring-run Chinook Salmon ESU ..................................50 


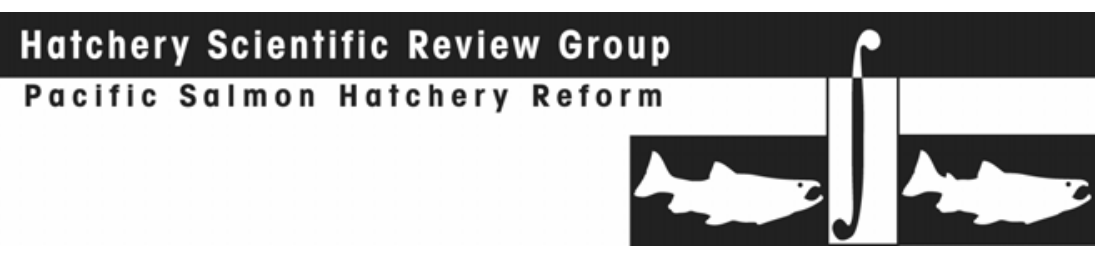

3.1.4 Deschutes River Summer/Fall-run Chinook ESU ............................................59

3.1.5 Upper Columbia River Spring Chinook ESU .....................................................64

3.1.6 Upper Columbia River Summer/Fall Chinook Salmon ESU ............................... 71

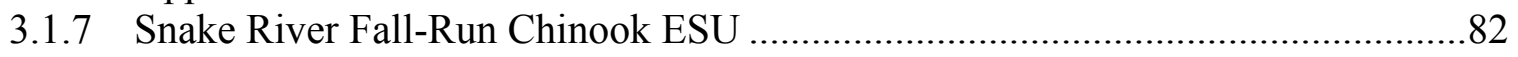

3.1.8 Snake River Spring/Summer Chinook MPG .................................................89

3.1.8.1 Upper Salmon River Chinook MPG ...................................................89

3.1.8.2 Middle Fork Salmon River Chinook MPG ...............................................98

3.1.8.3 South Fork Salmon River Chinook MPG ................................................106

3.1.8.4 Grand Ronde and Imnaha Spring Chinook MPG .................................113

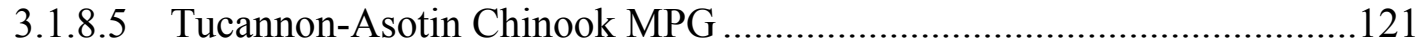

3.1.8.6 Clearwater River Spring Chinook MPG ..........................................129

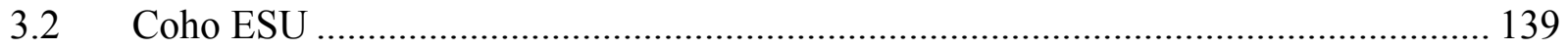

3.2.1 Lower Columbia River Coho Salmon ESU .....................................................139

3.2.2 Upper Columbia River Coho Salmon ....................................................... 151

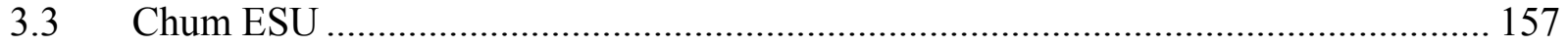

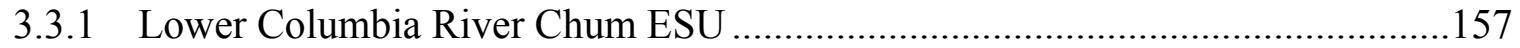

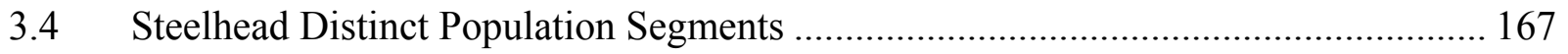

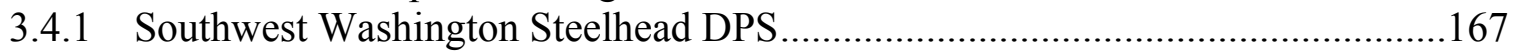

3.4.2 Lower Columbia River Steelhead DPS........................................................174

3.4.3 Upper Willamette River Winter Steelhead DPS ...........................................184

3.4.4 Middle Columbia River Steelhead DPS ............................................................193

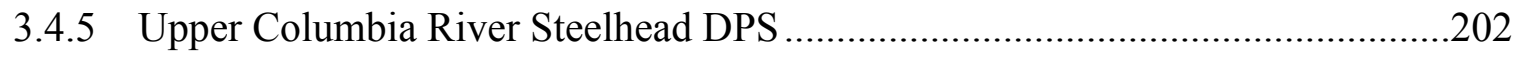

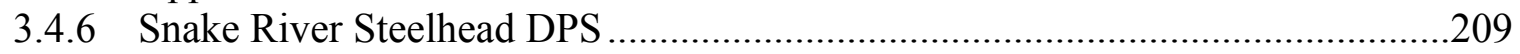

3.4.6.1 Salmon River Steelhead MPG .............................................................209

3.4.6.2 Clearwater River Steelhead MPG ...................................................219

3.4.6.3 Grande Ronde Steelhead MPG ...........................................................22

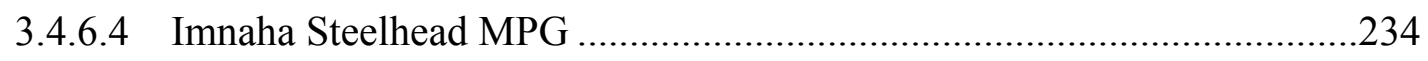

3.4.6.5 Tucannon-Asotin Steelhead MPG.....................................................2.

3.4.6.6 Hells Canyon Steelhead MPG ….....................................................249

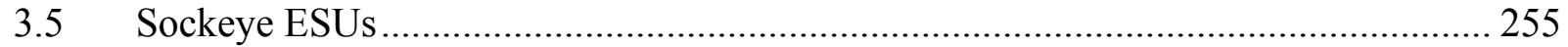

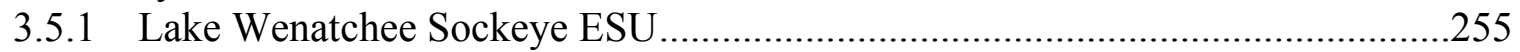

3.5.2 Snake River Sockeye ESU ...................................................................260

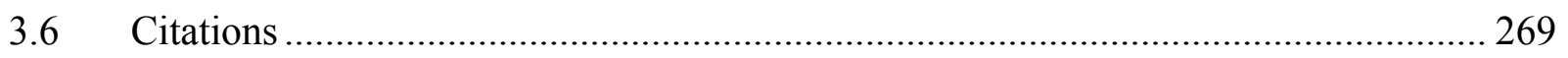




\section{Part 1 - Introduction}

\subsection{Project Background, Purpose, and Scope}

The US Congress funded the Puget Sound and Coastal Washington Hatchery Reform Project via annual appropriations to the US Fish and Wildlife Service (USFWS) beginning in fiscal year 2000. Congress established the project because it recognized that while hatcheries have a necessary role to play in meeting harvest and conservation goals for Pacific Northwest salmonids, the hatchery system was in need of comprehensive reform. Most hatcheries were producing fish for harvest primarily to mitigate for past habitat loss (rather than for conservation of at-risk populations) and were not taking into account the effects of their programs on naturally spawning populations. With numerous species listed as threatened or endangered under the Endangered Species Act (ESA), conservation of salmon in the Puget Sound area was a high priority. Genetic resources in the region were at risk and many hatchery programs as currently operated were contributing to those risks.

Central to the project was the creation of a nine-member independent scientific review panel called the Hatchery Scientific Review Group (HSRG). The HSRG was charged by Congress with reviewing all state, tribal and federal hatchery programs in Puget Sound and Coastal Washington as part of a comprehensive hatchery reform effort to:

- conserve indigenous salmonid genetic resources;

- assist with the recovery of naturally spawning salmonid populations;

- provide sustainable fisheries; and

- improve the quality and cost-effectiveness of hatchery programs.

The HSRG worked closely with the state, tribal and federal managers of the hatchery system, with facilitation provided by the non-profit organization Long Live the Kings and the law firm Gordon, Thomas, Honeywell, to successfully complete reviews of over 200 hatchery programs at more than 100 hatcheries across western Washington. That phase of the project culminated in 2004 with the publication of reports containing the HSRG's principles for hatchery reform and recommendations for Puget Sound/Coastal Washington hatchery programs, followed by the development in 2005 of a suite of analytical tools to support application of the principles (all reports and tools are available at www.hatcheryreform.us).

In 2005, Congress directed the National Oceanic and Atmospheric AdministrationFisheries (NOAA Fisheries) to replicate the Puget Sound and Coastal Washington Hatchery Reform Project in the Columbia River Basin. The HSRG was expanded to 14 members to include individuals with specific knowledge about the Columbia River salmon and steelhead populations. This second phase was initially envisioned as a oneyear review, with emphasis on the Lower Columbia River hatchery programs. It became clear however, that the Columbia River Basin needed to be viewed as an inter-connected ecosystem in order for the review to be useful. The project scope was subsequently expanded to include the entire Basin, with funding for a second year provided by the 


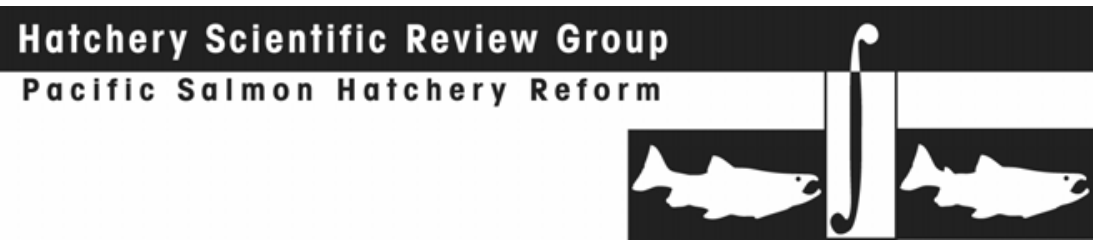

Bonneville Power Administration (BPA) under the auspices of the Northwest Power and Conservation Council's (NPCC) Fish and Wildlife Program.

The objective of the HSRG's Columbia River Basin review was to change the focus of the Columbia River hatchery system. In the past, these hatchery programs have been aimed at supplying adequate numbers of fish for harvest as mitigation primarily for hydropower development in the Basin. A new, ecosystem-based approach is founded on the idea that harvest goals are sustainable only if they are compatible with conservation goals.

The challenge before the HSRG was to determine whether or not conservation and harvest goals could be met by fishery managers and, if so, how. The HSRG determined that in order to address these twin goals, both hatchery and harvest reforms are necessary.

The HSRG approach represents an important change of direction in managing hatcheries in the region. It provides a clear demonstration that current hatchery programs can indeed be redirected to better meet both conservation and harvest goals. For each Columbia River Basin Environmentally Significant Unit (ESU), Distinct Population Segment (MPG) or Major Population Group (MPG) reviewed, the HSRG presents its findings and recommendations in the form of an HSRG solution. This package of recommended changes to current hatchery and harvest program design and operation is intended to demonstrate how the programs could be managed to significantly increase the likelihood of meeting the managers' goals for both harvest and conservation of the ESU/DPS/MPG.

The "HSRG solution" also highlights the biological principles that the HSRG believes must form the foundation for successful use of hatcheries and fisheries as management tools. Those principles are intended to provide a framework for making decisions and prioritizing investments based on clear and explicit goals, defensible science and informed and adaptive management (the HSRG's analytical approach, including these principles, is described in Section 1.3).

The HSRG review focused on hatchery programs, but took into account natural populations, survival conditions in the mainstems of the Columbia and Snake rivers and the Columbia River estuary, and harvest regimes. No review of habitat or hydroelectric measures was conducted. Nonetheless, the HSRG concluded that the value of habitat improvements (in terms of the abundance and productivity of natural populations) would increase if those improvements were preceded by hatchery reforms. Similarly, hatchery and habitat improvements would be enhanced with harvest reforms. The review did not include analysis of existing laws, policies, and agreements pertaining to either harvest or hatchery management. The flexibility contained in the adaptive management clauses of many of the agreements can accommodate reforms similar to those proposed by the HSRG.

The solutions proposed by the HSRG for Columbia Basin hatchery programs demonstrate that these programs can be redesigned to better meet conservation and harvest goals. However, the HSRG is not suggesting that these are the only solutions available to meet those goals. 


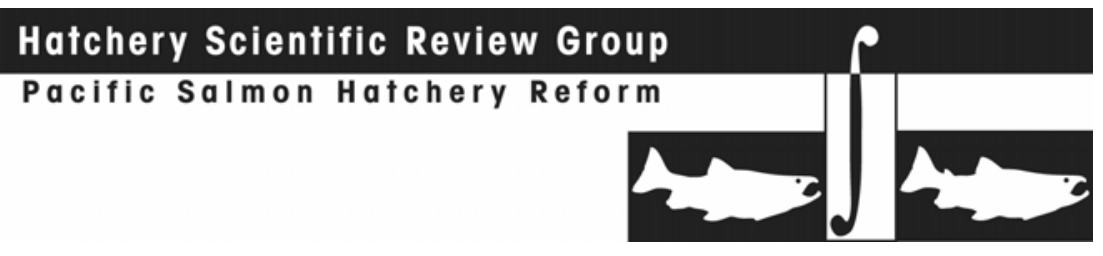

\subsection{Project Organization and Implementation}

The Columbia River Hatchery Reform Project was organized into three functional components: 1) scientific review, 2) facilitation, and 3) policy coordination. The scientific review, conducted by the HSRG, gathered and analyzed information relevant to the evaluation of hatchery programs in the Columbia River Basin. The facilitation team was responsible for project management, budgets, contracting, meeting preparation and coordination of work products. The policy coordination team provided a communications link between the HSRG and the federal, state and tribal managers of the hatchery system at the policy level.

\section{Columbia River Hatchery Scientific Review Group}

The Columbia River HSRG was composed of 14 members, nine of whom were affiliated with agencies and tribes in the Columbia River Basin. The remaining five members were unaffiliated biologists. Affiliated members did not represent their agency or tribe, but were expected to bring only their individual, scientific expertise to the table. The Chair and Vice Chair positions were filled by unaffiliated members. The intent of this structure and approach was to ensure the HSRG maintained scientific independence and impartiality, while at the same time assuring that it contained thorough knowledge of salmonid populations and hatchery programs in the Columbia River Basin.

The nine members of the HSRG selected for the Puget Sound and Coastal Washington review were chosen from a pool of candidates nominated by the American Fisheries Society. Seven of the original HSRG members continued as members of the Columbia River panel. The seven members who joined for the Columbia River review were selected by the original HSRG based on expertise and experience with hatcheries in general and Columbia River programs in particular. The Columbia River HSRG was chaired by Dr. Lars Mobrand from March 2000 to February 2008, when the current chair, Dr. Peter Paquet, began his tenure. John Barr and Lee Blankenship served as vice chairs throughout the project.

Table 1-1 lists the Columbia River HSRG members and their associated organizations; professional biographies of the members are found in Appendix B.

\section{Facilitation and Policy Components}

Facilitation of the HSRG reviews was conducted by D.J. Warren and Associates, Inc. and lead by Dan Warren. In addition to overall project management (including contracting and budgets), the facilitation team secured venues for the monthly HSRG meetings; organized facility tours; prepared, organized, and distributed meeting materials and agendas; and facilitated the meetings. The facilitation team also managed the project website and all project records. D.J Warren and Associates provided technical support to the HSRG via subcontracts to Mobrand/Jones and Stokes; Meridian Environmental, Inc.; Serverside Software; Malone Environmental Consulting; Triangle Associates, Inc.; Nancy Bond Hemming; and the Columbia River Intertribal Fish Commission.

The policy coordination team was comprised of staff from the law firm of Gordon, Thomas, Honeywell, Malanca, Peterson \& Daheim, LLP under the leadership of James Waldo. Members are identified in Table 1-2. The policy coordination team tracked the 
progress of the HSRG review and convened periodic meetings with designated policy representatives from the tribal, state, and federal management agencies.

Table 1-1. Members of the Columbia River HSRG

\begin{tabular}{|c|c|}
\hline Name & Organization \\
\hline \multicolumn{2}{|l|}{ Agency/Tribe Affiliated Members } \\
\hline Dr. Donald Campton & US Fish and Wildlife Service \\
\hline Mr. Mike Delarm & NOAA Fisheries \\
\hline Dr. David Fast & Yakama Nation \\
\hline Mr. Tom Flagg (Dr. Des Maynard, alternate) & NOAA Fisheries \\
\hline Dr. Jeffrey Gislason & Bonneville Power Administration \\
\hline Mr. Paul Kline & Idaho Department of Fish and Game \\
\hline Mr. George Nandor & $\begin{array}{l}\text { Oregon Department of Fish and Wildlife/Pacific States } \\
\text { Marine Fisheries Commission }\end{array}$ \\
\hline Dr. Peter Paquet & Northwest Power and Conservation Council \\
\hline Mr. Andy Appleby/Mr. Paul Seidel (until May 2008) & Washington Department of Fish and Wildlife \\
\hline \multicolumn{2}{|l|}{ Unaffiliated Members } \\
\hline Mr. John Barr & Independent Consultant \\
\hline Mr. H. Lee Blankenship & Northwest Marine Technology \\
\hline Dr. Trevor Evelyn & Fisheries and Oceans Canada (retired) \\
\hline Dr. Lars Mobrand & Mobrand/Jones and Stokes \\
\hline Mr. Stephen H. Smith & Stephen H. Smith Fisheries Consulting, Inc. \\
\hline
\end{tabular}

Table 1-2. Members of the Policy Coordination Team

\begin{tabular}{|l|l|}
\hline Name & Organization \\
\hline Ed Bowles & Oregon Department of Fish and Wildlife \\
\hline Kat Brigham & Confederated Tribes of the Umatilla Indian Reservation \\
\hline Gary James & Confederated Tribes of the Umatilla Indian Reservation \\
\hline Claudeo Broncho & Shoshone-Bannock Tribes of Fort Hall \\
\hline Jody Calica & Confederated Tribes of the Warm Springs Reservation \\
\hline Dan Diggs & US Fish and Wildlife Service \\
\hline Ed Schriever & Idaho Department of Fish and Game \\
\hline Becky Johnson & Nez Perce Tribe \\
\hline Dave Johnson & Nez Perce Tribe \\
\hline Phil Anderson & Washington Department of Fish and Wildlife \\
\hline Guy Norman & Washington Department of Fish and Wildlife \\
\hline Joe Peone & Confederated Tribes of the Colville Reservation \\
\hline Philip Rigdon & Yakama Nation \\
\hline Rob Jones & NOAA Fisheries \\
\hline Robert Turner & NOAA Fisheries \\
\hline Jim Waldo & Gordon, Thomas, Honeywell, Malanca, Peterson \& Daheim \\
\hline
\end{tabular}




\section{Review Process}

In order to facilitate an ecosystem-level review of such a large landscape as the US portion of the Columbia River Basin, the HSRG divided the Basin into 14 regions, based in large part on the regions defined by NPCC in 2000 (Table 1-3). The 14 regions were then grouped into 4 areas: 1) Lower Columbia, 2) Mid Columbia, 3) Upper Columbia, and 4) Snake River. The review began with the hatcheries located in the lower Columbia River area and proceeded upstream. Regional and cumulative reviews were held beginning in July 2006 and continuing through August 2008.

Table 1-3. HSRG Columbia River Basin Regions and Areas

\begin{tabular}{|l|l|l|l|}
\hline \multirow{2}{*}{ Area } & \multicolumn{2}{|c|}{ Region } & \multicolumn{2}{c|}{ Meeting Type and Date } \\
\cline { 3 - 4 } & Cowlitz & \multicolumn{1}{c|}{ Regional } & Cumulative \\
\hline Lower Columbia & Kalama and Lewis & July 2006 2006 & \\
\hline & Columbia Estuary, Washington & September 2006 & \\
\hline & Lower Columbia to Sandy, Oregon & November 2006 & \\
\hline & Columbia Estuary, Oregon & November 2006 & \\
\hline & Columbia Gorge, Washington & September 2007 & \\
\hline & Columbia Gorge, Oregon & August 2007 & \\
\hline & Willamette, Oregon & October 2007 & \\
\hline Mid Columbia & Columbia Plateau, Oregon & & November 2007 \\
\hline & Columbia Plateau, Washington & December 2007 & \\
\hline & Lower Columbia Programs Cumulative Review & January 2008 & \\
\hline Upper Columbia & Columbia Cascade, Washington & & February 2008 \\
\hline & Mid Columbia Programs Cumulative Review & April 2008 & May 2008 \\
\hline Snake River & Upper Columbia Programs Cumulative Review & & \\
\hline & Mountain Snake Salmon & June 2008 & \\
\hline & Mountain Snake Clearwater & June 2008 & August 2008 \\
\hline & Blue Mountain & July 2008 & \\
\hline & Snake River Programs Cumulative Review & & \\
\hline
\end{tabular}

The scientific review was conducted by the HSRG through a series of workshops of two types: 1) regional and 2) cumulative. Each regional workshop was preceded by initial fact-finding by the HSRG. Data were collected and assembled into draft reports on the hatchery programs and salmon and steelhead populations within the region.

The first step in each regional workshop was a field visit to facilities and watersheds. This usually took place over one to two days. Then, the HSRG met for two or three days to review data, apply its scientific framework and develop draft recommendations for hatchery programs. The pre-workshop draft population reports were revised on the basis of the information gathered during the field visits and data analysis.

The regional federal, state and tribal hatchery managers were invited at the end of each work session so the HSRG could ask any remaining questions and get the managers' 


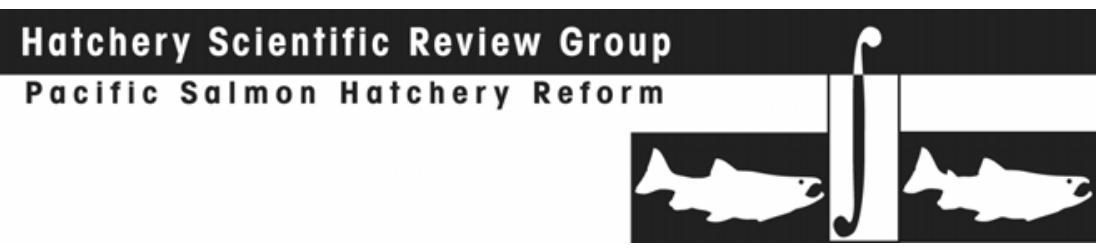

initial reaction to the draft recommendations. The HSRG captured all of this information in an electronic spreadsheet tool developed specifically for the purpose, the All " $\mathrm{H}$ " Analyzer (AHA) (see Appendix C). Information for each population was condensed in individual Population Reports (Appendix E).

When all the regional workshops within an area were completed, a cumulative workshop was held. The purpose of the cumulative workshop was to "roll up" data on all of the populations in the area, allowing the HSRG and the area fishery managers to view the "big picture" for that segment of the Columbia River Basin.

\subsection{HSRG Analytical Approach}

The HSRG based its analysis of Columbia River Basin hatchery programs on the framework described in Mobrand et al. (2006). This report identifies three principles as prerequisites for successful hatchery programs ${ }^{1}: 1$ ) well defined goals, 2) scientific defensibility, and 3) informed decision making. These principles formed the structure for the HSRG analytical approach.

\section{Well-Defined Goals}

Goals should be expressed in terms of conservation and harvest (or other values defined by the community, such as education, research, etc). Hatchery programs are tools to help meet those goals. The HSRG reviewed the Columbia River Basin hatchery programs based on its best understanding of the managers' goals for conservation and harvest.

Conservation goals apply to populations (ESUs, DPS' or MPGs) and species. They are expressed in terms of biological significance and viability. Hatchery programs can affect both biological significance and viability, and almost always ${ }^{2}$ represent a trade-off of natural productivity $\operatorname{loss}^{3}$ for abundance gain.

Viability is usually expressed in terms of population productivity, abundance, diversity, and structure (McElhany 2003). Viability goals were provided by the managers for some, but not all, natural populations.

To establish biological significance, the HSRG used the classification system adopted by the Lower Columbia Fish Recovery Board, under which all distinct salmonid populations are classified as either Primary, which are targeted for restoration to high productivity and abundance; Contributing, where small to medium improvements are needed; or Stabilizing, populations that may be maintained at current levels.

The HSRG developed a set of management standards for acceptable hatchery influence for each of these three categories. The standards are most restrictive for Primary and least restrictive for Stabilizing populations. Because of uncertainty around the effects of hatchery fish on the fitness of natural populations, the HSRG also identified some

\footnotetext{
${ }^{1}$ A successful hatchery program is one where the benefits outweigh the risks, and where a solution including a hatchery program is better from a benefit/risk standpoint than any alternative means to achieve similar goals.

2 The exception to this rule is when hatcheries are use to re-populate vacant habitat.

${ }^{3}$ This loss is generally due to reduced fitness resulting from hatchery fish spawning with wild fish.
} 


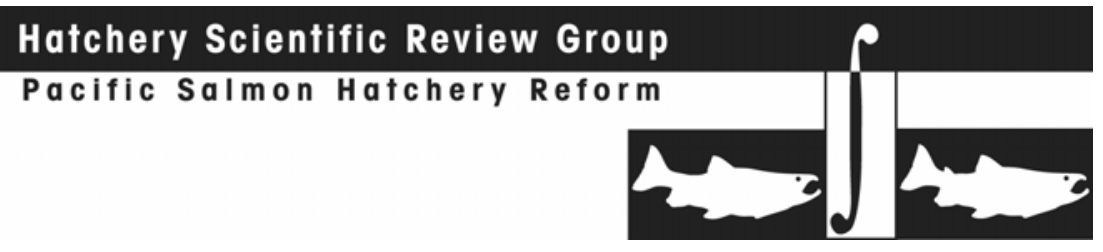

Primary populations where hatchery influence could be minimized, by establishing "hatchery-free" populations ${ }^{4}$.

Harvest goals apply to populations and fisheries. They are expressed in terms of the numbers of fish harvested by a fishery or groups of fisheries ${ }^{5}$ and/or as sustainable harvest rates on the aggregate run or selective rates on hatchery-origin and natural-origin fish.

The HSRG review and recommendations are based on the goal statements provided by the managers or found in planning documents. These goals are captured in the Population Reports (Appendix E).

\section{Scientific Defensibility}

Once the goals for the resource have been established, the scientific rationale for a hatchery program must be described in a working hypothesis that explains the expected benefits and risks from the hatchery program. The purpose, operation, and management of each hatchery program must be scientifically defensible. Assumptions under which the hatchery program will succeed must be consistent with available information.

The HSRG review identified 351 salmon and steelhead populations in the Columbia River Basin. The ecological, genetic and fishery context of each of these populations is unique. For each unique population, the purpose of each hatchery program must be identified (will it contribute to conservation and/or harvest?). Early in the planning process, the strategy for addressing the genetic relationship of the hatchery populations to the associated natural populations must be determined (will the recommended hatchery program be integrated with or segregated from the associated natural population?) ${ }^{6}$.

Using analytical procedures described in detail in Appendix C, the HSRG reviewed all current hatchery programs in the Columbia River Basin. Nearly every hatchery program was associated with a naturally spawning population. Four scenarios were examined: 1) current program, 2) no hatchery, 3) "best"7 segregated program, and 4) "best" integrated program. The solution that best met the managers' conservation and harvest goals for the population was selected as the "HSRG solution." The HSRG conclusion is that the managers' goals for conservation and harvest of each population are more likely to be met on a sustainable basis if the proposed solution is adopted than under the current hatchery scenario. Developing the HSRG solutions was an iterative process that took into account interactions and cumulative effects across all Hs (habitat, hydropower, hatcheries and harvest). As a result, the HSRG solutions were not finalized until the review of the entire Columbia River Basin was completed.

The HSRG is confident that the hypotheses and assumptions used in its analyses are consistent with facts, knowledge and information available at the time of publication of

\footnotetext{
${ }^{4}$ Recommendation 8 in Section 2.1 identifies the HSRG's broodstock management criteria for Primary, Contributing and Stabilizing populations.

${ }^{5}$ HSRG identified four groups of fisheries: marine, Columbia River below Bonneville Dam, Columbia River above Bonneville Dam, and terminal (in subbasins).

${ }^{6}$ Section 2.2 provides more information about integrated and segregated hatchery programs.

7 The "best" program was typically the one that contributed the most to harvest goals without violating the guidelines for hatchery influence on natural populations.
} 


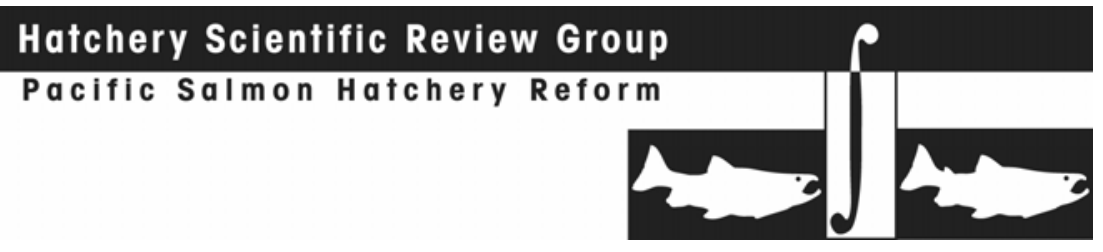

this report. However, the HSRG also acknowledges that uncertainty still exists, and there may be legitimate disagreement with certain HSRG assumptions. The HSRG developed its assumptions (analytical framework/working hypothesis) in order to provide a useful starting point. Scientists and managers are encouraged to challenge and change the assumptions as new information warrants. While the HSRG has tried to make its recommendations practical and useful within the current management environment, it did not perform analyses to determine whether recommendations are consistent with existing laws, agreements and policies. It is also important to note that the HSRG's analysis projects a long-term outcome under average conditions and is not a prediction of what might occur in any given year.

\section{Informed Decision Making and Adaptive Management}

The management of hatchery programs is an ongoing and dynamic process. As long as hatchery programs are operated, they must be adapted to changing circumstances and new information. Hatchery managers must expect change and design their decisionmaking processes accordingly. Management must be an ongoing response/feedback system. Uncertainty is unavoidable; the only thing that's certain is that the unexpected will happen.

Therefore, the HSRG recommends that the managers' decisions be informed and modified by continuous evaluations of existing programs and by new scientific information. Such an approach will require a substantial increase in scientific oversight of hatchery operations, particularly in the areas of genetic and ecological monitoring. With implementation of clear decision-making processes that respond to new information, the HSRG believes that hatcheries can be managed in a more flexible and dynamic manner that is responsive to changing environmental conditions, new scientific information, and the economic value of the resource.

Decisions about hatcheries must also be made in a broader, integrated context. The hatchery solution must better meet management goals in a benefit/risk sense than other available means. Results of monitoring and evaluation must be brought into the decisionmaking process in a clear, concise way that allows needed changes to be implemented. The process should also be structured to allow for innovation and experimentation, so hatchery programs may be responsive to new goals and concepts in fish culture.

The HSRG concluded that certain information is critical to operating hatchery programs in a responsible manner:

- Hatchery fish should not be released unless the contribution of those fish to natural spawning escapement can and will be estimated with reasonable accuracy and confidence on an annual basis.

- Contributions from each hatchery program to fisheries should be monitored annually.

- Natural spawner abundance of all populations affected by hatchery fish must be estimated each year, with the highest priority placed on Primary populations.

Specific monitoring recommendations are provided in the population reports. A proposed framework for monitoring is outlined in Appendix A (White Paper No. 5, Framework for Monitoring and Evaluating Hatchery Programs). 


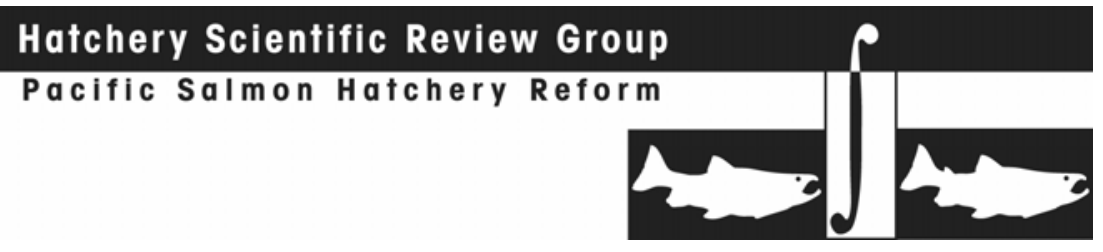

\subsection{Report Overview}

This report concludes the most comprehensive review of hatchery programs ever undertaken in the Columbia River Basin. The HSRG's analysis of all 178 Columbia Basin hatchery programs and 351 salmon and steelhead populations resulted in principles, recommendations, tools and procedures that provide a foundation for managing hatcheries more effectively into the future. The HSRG's recommendations are based on well-established biological principles and on information describing the quality and quantity of habitat used by each population, fish passage survival through the mainstem Snake and Columbia rivers, hatchery program operations, and the harvest of natural and hatchery adults. The recommendations are summarized in the body of this report, with detail presented in eight appendices. The report is organized around the following components:

- This section (Part 1) provides an introduction to the Hatchery Reform Project, including the project's background, purpose and scope; the HSRG and other entities involved; the review process and analytical approach; and this overview of the report.

- Part 2 identifies several overarching conclusions about reforms needed to current hatchery practices. Part 2 also includes three general principles for hatchery management and seventeen system-wide recommendations (recommendations that apply to hatchery programs across the Columbia River Basin) that the HSRG formulated from these summary conclusions.

- The principles and system-wide recommendations described in Part 2 are the basis for the HSRG recommendations presented in Part 3 for each Evolutionarily Significant Unit (ESU), Distinct Population Segment (DPS) or Major Population Group (MPG) in the Columbia River Basin. Part 3 provides a general description of each ESU/DPS/MPG, and the fisheries, habitat limitations and hatchery programs that affect it. Recommendations for ESU/DPS/MPG-wide hatchery program changes are summarized, as are the predicted results on conservation and harvest goals from implementing those changes. This section of the report is organized by species in the following order: Chinook (3.1), coho (3.2), chum (3.3), steelhead (3.4) and sockeye (3.5). Detailed observations and recommendations for the populations within each ESU, DPS and MPG can be found in Appendix E.

- Appendix A provides eight technical papers the HSRG prepared to summarize the scientific foundation underpinning many of its principles and recommendations. These papers address the following topics: (1) Conservation and Sustainable Harvest Through Fisheries Reform; (2) Predicted Fitness Effects of Interbreeding between Hatchery and Natural Populations of Pacific Salmon and Steelhead; (3) Antibiotics in Salmonid Aquaculture; (4) Global Climate Change and its Effects on the Columbia River Basin; (5) Framework for Monitoring and Evaluating Hatchery Programs; (6) Transition of Hatchery Programs; (7) Nutrient Enhancement to Increase Salmon Production; and (8) Outplanting and Net Pen Release of Hatchery-Origin Fish.

- Appendix B provides short biographies of each HSRG member.

- Appendix $\mathrm{C}$ describes the analytical methods and information sources used by the HSRG. The primary analytical tool is the "All H Analyzer" (AHA), a Microsoft 


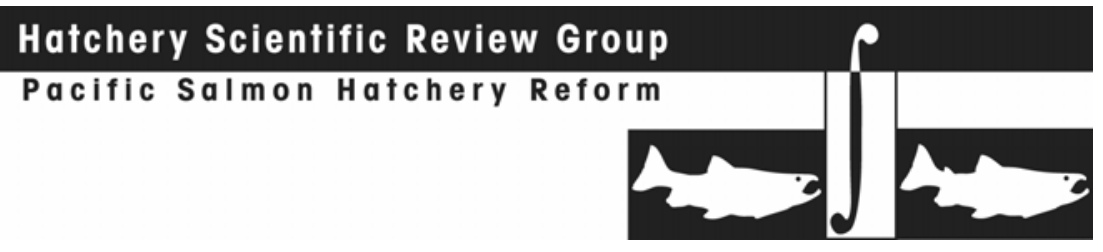

Excel-based application developed to evaluate salmon management options in the context of the four "Hs"- Habitat, (passage through the) Hydroelectric system, Harvest and Hatcheries. This tool allows managers to explore the implications of alternative ways of balancing hatcheries, harvest, habitat and hydroelectric system constraints.

- Appendix D identifies data sources by ESU/DPS/MPG for individual populations and also documents the basis for assumptions made about harvest, habitat, hydropower operations and hatcheries. A user guide to the AHA tool is provided in this appendix, with clear, step-by-step instructions for evaluating a fish population, once the AHA database is downloaded. Screen images that users will encounter are displayed and explained.

- Appendix E presents individual reports on the 351 salmon and steelhead populations in the Columbia River Basin. Each report briefly summarizes the current status of the population and provides the HSRG's observations and recommendations for that population, based on an analysis of potential management scenarios and their predicted outcomes after 60 fish generations. The organizational hierarchy of this appendix is by species, then by ESU or DPS, and then by individual population.

- Appendix F provides the verbatim comments received in response to the HSRG's invitation to the federal, state and tribal salmon managers and others to comment on the HSRG's recommendations for every population within their jurisdiction. Comments were provided through a structured, on-line questionnaire and are presented in Appendix F by species and then by ESU/DPS.

- Appendix G includes a glossary of terms used throughout this report.

- Appendix $\mathrm{H}$ describes how data and information will be managed in the future. 


\section{Part 2 - Summary Conclusions, Principles and System-Wide Recommendations}

\subsection{Summary Conclusions}

The HSRG concluded that hatcheries play an important role in the management of salmon and steelhead populations in the Columbia River Basin. Nevertheless, the traditional practice of replacing natural populations with hatchery fish to mitigate for habitat loss and mortality due to hydroelectric dams is not consistent with today's conservation principles and scientific knowledge. Hatchery fish cannot replace lost habitat or the natural populations that rely on that habitat. Therefore, hatchery programs must be viewed not as surrogates or replacements for lost habitat, but as tools that can be managed as part of a coordinated strategy to meet watershed or regional resource goals, in concert with actions affecting habitat, harvest rates, water allocation and other important components of the human environment.

The HSRG conducted the most comprehensive review of the 178 hatchery programs and 351 salmon and steelhead populations ever undertaken in the Columbia River Basin. The resulting population-specific recommendations are intended to provide scientific guidance for managing each hatchery more effectively in the future.

The benefits and risks of a hatchery program depend on the biological significance of the affected populations, and the current and future status of all factors affecting the regional ecosystem within which it operates, including fresh water and marine habitats, hydropower facilities and operations, harvest patterns, and other regional hatchery programs. Hatchery programs should be used only to the extent that they provide a better option, from the benefit/risk standpoint, than available alternative methods to meet the same or similar goals.

Hatchery reforms that improve fitness of the natural populations from the current condition (for example, by promoting local adaptation) also increase the benefit of current and future habitat improvements. Conversely, when habitat improvements are made without hatchery and harvest reforms, the resulting benefits will be less than with hatchery reform. Improvements in population fitness and productivity from hatchery reform are likely to occur on a shorter time scale than improvements from habitat actions. Given that hatchery reforms enhance habitat potential, there is no reason for these reforms to wait for future habitat improvements or harvest modifications.

Hatchery management must be aligned with harvest management and vice versa. The HSRG has demonstrated that increasing selective harvest on hatchery-origin fish can have a conservation benefit (population fitness and productivity), economic benefit (increased harvest) and increase the value of current habitat and habitat improvements.

The HSRG has reached several critical, overarching conclusions regarding areas where current hatchery and harvest practices need to be reformed. Managers should:

- Manage hatchery broodstocks to achieve proper genetic integration with, or segregation from, natural populations;

- Promote local adaptation of natural and hatchery populations; 


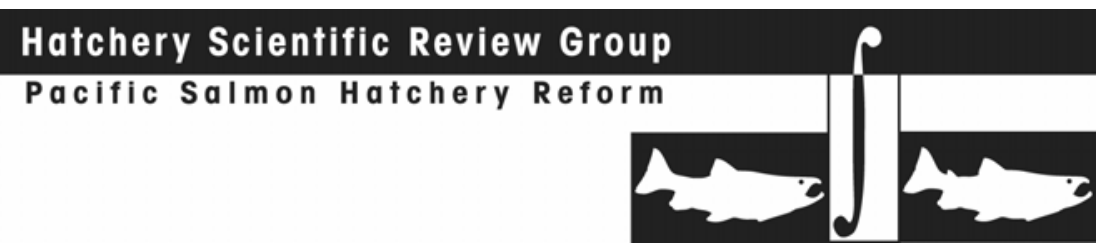

- Minimize adverse ecological interactions between hatchery- and natural-origin fish;

- Minimize effects of hatchery facilities on the ecosystem in which they operate; and

- Maximize the survival of hatchery fish.

Each of these conclusions (summarized below) must be addressed through policy, management, research and monitoring.

\section{Manage Hatchery Broodstocks to Achieve Proper Genetic Integration with, or Segregation from, Natural Populations}

Hatchery programs should be managed as either genetically integrated with, or segregated from, the natural populations they most directly influence. A fundamental purpose of an integrated hatchery program is to increase abundance, while minimizing the genetic divergence of a hatchery broodstock from a naturally spawning population. An integrated program is intended to maintain the genetic characteristics of a local, natural population among hatchery-origin fish by minimizing the genetic effects of domestication. This is expected to reduce the genetic risks that hatchery-origin fish may pose to the naturally spawning population.

The intent of a segregated hatchery program is to maintain a genetically distinct hatchery population. The only way to reduce risk (genetic and ecological) to natural populations from segregated programs is to minimize the contribution of hatchery fish to natural spawning. The HSRG established standards for hatchery contribution to natural spawning based on the biological significance of the natural populations.

The integrated and segregated strategies both have strengths and weaknesses, so the decision about which strategy to follow must be determined on a case-by-case basis. While the primary purpose of most integrated hatchery programs is to contribute to harvest, they may also contribute to conservation by providing a demographic safety net for the natural population ${ }^{8}$. But they can pose a risk to natural populations if the size of the hatchery program exceeds the size of the associated natural spawning population. On the other hand, segregated hatchery programs can pose significant genetic and ecological risks to natural populations if they reproduce naturally with wild fish. The primary way to reduce these risks from segregated programs is to reduce the number of hatchery fish spawning in the natural environment.

The ideal integrated or segregated hatchery program is nearly impossible to achieve in practice. Because hatchery fish have lower reproductive fitness (even when they come

\footnotetext{
${ }^{8}$ Supplementation is a term frequently used when referring to hatchery programs where the intent is for hatcheryorigin fish to spawn in the wild and make a contribution to conservation, e.g., RASP 1991. The HSRG concluded that this may be possible in some circumstances, but such programs should always be accompanied by comprehensive monitoring and evaluation efforts. In the past, attempts to identify the general conditions under which these net benefits to the population occur have failed (RASP 1991) because generalization is impossible due to the unique environmental conditions in which each population exists. Programs should, therefore, be evaluated on an individual basis where population status and the unique habitat, harvest, hatchery, and hydropower conditions are taken into account. It should be noted, however, that integrated conservation programs are most likely to increase the abundance of natural-origin spawners when natural productivity is relatively low and habitat capacity is high.
} 


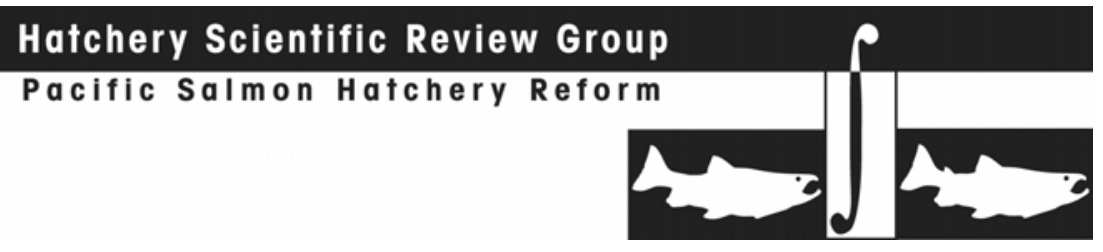

from well-integrated programs), they represent a fitness risk to a natural population (if one is present) when they spawn in the natural environment. Yet as noted above, hatchery fish on the spawning grounds may confer a net conservation benefit when the demographic extinction risk is high.

In order to address the fitness risks posed by hatchery fish, the HSRG adopted a set of standards for hatchery influence on natural populations. These standards, which vary depending on the biological significance of the population, are intended to support recovery of natural populations while retaining overall harvest benefits. They are also designed to be simple to implement and monitor. The HSRG also proposes methods for achieving those standards.

\section{Promote Local Adaptation of Natural and Hatchery Populations}

The biological principle behind the broodstock standards for both integrated and segregated populations is promoting local adaptation. A major concern with many current hatchery programs is that they have been operated in a manner that disrupts the natural selection for population characteristics that are tailored to local environmental conditions. Proper integration or segregation of hatchery programs is the recommended means to minimize the adverse effects of hatcheries on local adaptation of natural populations. Local adaptation of hatchery populations is achieved by using local broodstock (indigenous, in the case of integrated programs; locally returning in the case of segregated programs) and avoiding transfer of hatchery fish among watersheds. It is important to promote local adaptation because it maximizes the viability and productivity of the population and maintains biological diversity within and between populations. Local adaption is also important to enable populations to adjust to changing environmental conditions, for example through climate change.

\section{Minimize Adverse Ecological Interactions between Hatchery- and Natural-Origin Fish}

Another important concern associated with hatchery programs is ecological interaction between hatchery and natural fish such as competition for feeding and spawning locations, predation of hatchery fish upon natural-origin fish and the potential transfer of disease from hatchery to natural-origin fish. One way to address these interactions is for hatchery programs to be operated so the released fish are segregated from their natural counterparts in time and space. Alternatively, hatchery fish can be reared and released to be as biologically similar to their natural counterparts as possible, although the latter approach does not always preclude the adverse effects of competition.

For example, competition between hatchery and natural steelhead juveniles in the Columbia River Basin is of concern to the HSRG, with adverse effects on the natural population having been documented (e.g., Kostow 2008). The concern is that although hatchery steelhead may compete effectively at the juvenile stage, they appear to have inferior reproductive success. Juvenile hatchery steelhead can also residualize ${ }^{9}$,

\footnotetext{
${ }^{9}$ Hatchery steelhead juveniles sometimes fail to migrate to the ocean after release; instead they remain in the freshwater (residualize).
} 


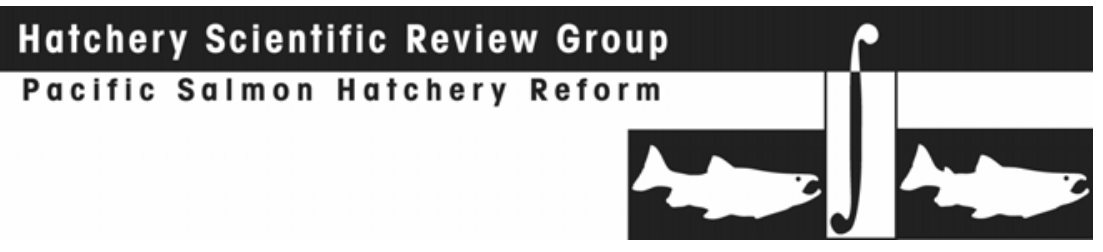

increasing competitive interactions ${ }^{10}$. Size, time, age, location and method of release of hatchery fish affect the severity of this risk. Predation of hatchery fish upon other salmonids is less well understood, but generally assumed to be less significant than competition.

Hatchery fish can also pose a disease threat to natural-origin fish both before and after their release from the hatchery. To avoid this threat, hatcheries should adopt fish culture practices that minimize or avoid disease risks. Suggested practices include providing suitable water supplies, low rearing densities, appropriate feeds and feeding protocols, careful sanitary procedures, avoiding out-of-basin fish transfers and screening for, then limiting the use of broodstock with high levels of pathogens. Antibiotics should be judiciously used when necessary (Appendix A, Antibiotics in Salmonid Aquaculture).

\section{Minimize Effects of Hatchery Facilities on the Ecosystem}

Facilities operated in support of hatchery programs (traps, weirs, water intake screens and hatchery effluent discharges) can have adverse effects on salmonid populations and other aquatic species. The HSRG noted that, for the most part, existing laws and regulations related to facilities and operations are adequate to protect the environment. Not all facilities, however, are in compliance with those laws and regulations. It is important that those facilities be identified and brought into compliance. Recognizing that weirs and traps have a legitimate role in controlling hatchery strays that could affect naturally spawning populations, the HSRG encourages the use of low impact weirs (temporary structures with controlled passage and that are appropriately staffed) that have minimal effect on natural populations and their habitats.

\section{Maximize Survival of Hatchery Fish}

In order for hatchery programs to effectively contribute to harvest and/or conservation, the reproductive success and survival of hatchery releases must be high relative to those of naturally spawning populations. The primary performance measurement for hatchery programs should be the total adults produced (harvest plus escapement) per adult spawned at the hatchery. All too often in the past, hatcheries have been evaluated based on the number of smolts released.

\subsection{Principles and System-Wide Recommendations}

The principles and system-wide recommendations that follow represent the key findings of the HSRG in its review of Columbia River Basin hatcheries. The more closely hatchery programs adhere to these principles and recommendations, the greater the likelihood of their contribution to the managers' harvest and conservation goals. The HSRG's three principles for hatchery management are presented below, with each of 17 system-wide recommendations (applicable to programs across the Columbia River Basin hatchery system) listed under the principle from which it is derived. These principles and system-wide recommendations are the basis for the HSRG solutions presented in Part 3 ESU/MPG Roll-Up Reports section of this report. The ESU reports are not presented as

\footnotetext{
${ }^{10}$ The HSRG analysis accounted for competition by life stage for naturally spawning fish through density dependent (Beverton-Holt type) mortality factors from fish spawning in the wild.
} 


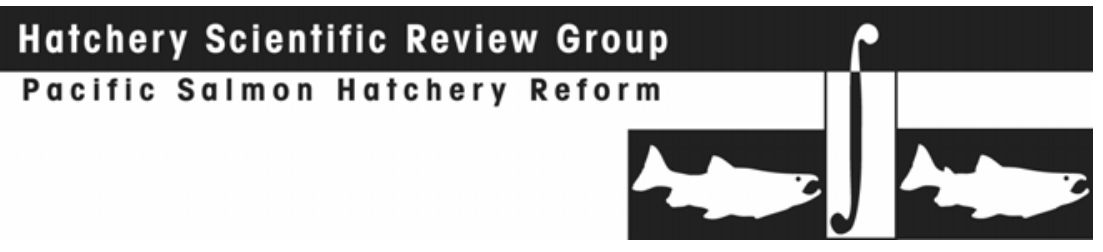

the only possible solution for those populations, but rather as a clear demonstration that current hatchery programs can be redirected to better meet both conservation and harvest goals.

\section{Principle: Develop Clear, Specific, Quantifiable Harvest and Conservation Goals for Natural and Hatchery Populations within an "All H" Context}

During its reviews, the HSRG observed that goals for fish populations were not always explicitly communicated and/or fully understood by the managers and operators of hatchery programs. These goals should be quantified, where possible, and expressed in terms of values to the community (harvest, conservation, education, research, etc.). At times, goals have been expressed in terms of the numbers of smolts to be released without specifying whether or how this hatchery production contributes to harvest and/or conservation. Hatchery production numbers may be the means of contributing to harvest and/or conservation values, but they are not endpoints. When population goals are clearly defined in terms of conservation and harvest, hatcheries can be managed as tools to help meet those goals.

To be successful, hatcheries should be used as part of a comprehensive strategy where habitat, hatchery management and harvest are coordinated to best meet resource management goals that are defined for each population in the watershed. Hatcheries are by their very nature a compromise - a balancing of benefits and risks to the target population, other populations, and the natural and human environment affected by the hatchery program. Use of a hatchery program is appropriate when benefits significantly outweigh the risks and when the benefit/risk mix from the program is more favorable than the benefits and risks associated with non-hatchery strategies for meeting the same goals.

The HSRG offers the following three system-wide recommendations for defining goals for natural and hatchery populations. It should be noted that the HSRG review and population-specific recommendations found in Appendix E of this report are based on the HSRG's interpretation of goal statements provided by the managers or found in their planning documents.

Recommendation 1: Express conservation goals in terms of a population's biological significance (Primary, Contributing, Stabilizing) and viability (natural-origin spawning abundance and productivity)

Different definitions of biological significance are used by the managers throughout the Columbia River Basin. In an effort to provide a consistent analysis, the HSRG applied the designations for biological significance and population viability used by the Lower Columbia River Fish Recovery Board to describe salmon and steelhead populations (LCFRB 2004).

- Primary: populations must achieve at least high viability

- Contributing: populations must achieve at least medium viability

- Stabilizing: populations must maintain at least current viability

- Viability goals should be expressed in terms of population productivity and abundance

- Viability goals should also take into account spatial structure and diversity 


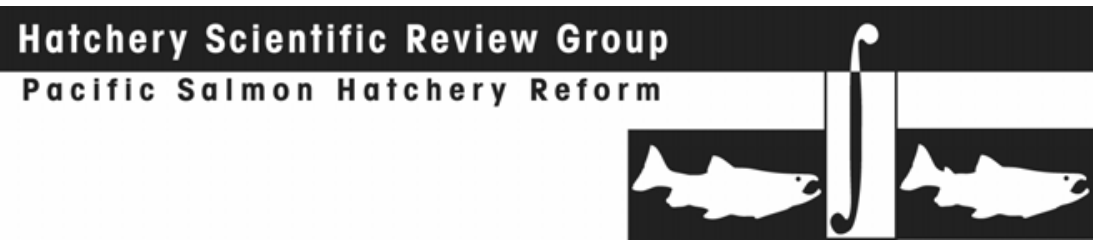

The designation of a population as Primary, Contributing or Stabilizing is a policy decision; however, for its analysis, the HSRG made assumptions based on the status of each population and goal statements provided by the managers or found in planning documents.

\section{Recommendation 2: Express harvest goals in terms of a population's contribution to specific fisheries}

Harvest goals should be expressed quantitatively where possible, either in terms of catch (number of fish) in specific fisheries (e.g., tributary sport or other terminal fisheries), or as mixed-stock, pre-terminal, sustainable harvest rates.

Recommendation 3: Ensure goals for individual populations are coordinated and compatible with those for other populations in the Columbia River Basin

Many important populations of salmon and steelhead do not meet the conservation expectations identified by managers. Achieving these expectations requires that population goals be developed that consider other populations in the Columbia River Basin, watershed or ESU. Efforts to harvest abundant hatchery fish from one population can impact natural fish in another population; hatchery strays can and do interact with natural populations from different locations within a region. The contribution of each hatchery program to the cumulative impact of all hatchery programs in the Basin also needs to be considered.

\section{Principle: Design and Operate Hatchery Programs in a Scientifically Defensible Manner}

Once a set of well-defined population goals has been identified, the scientific rationale for a hatchery program in terms of benefits and risks must be formulated, explaining how the program expects to achieve its goals. The purpose, operation, and management of each hatchery program must be scientifically defensible. The strategy chosen must be consistent with current scientific knowledge. Where there is uncertainty, hypotheses and assumptions should be articulated.

In general, scientific defensibility will occur at three stages:

1) during the deliberation stage, to determine whether a hatchery should be built and/or a specific hatchery program initiated;

2) during the planning and design stage for a hatchery or hatchery program; and

3) during the operations stage.

This approach ensures a scientific foundation for hatchery programs, a means for addressing uncertainty, and a method for demonstrating accountability. Documentation for each program should include a description of analytical methods and should be accompanied with citations from the scientific literature. The analytical approach used by the HSRG in its review is described in Appendix C. This approach is intended to serve as an example and a starting point in an evolving process. Standard reports that document the rationale for hatchery programs should be developed. HSRG recommendations 4 through 13 are aimed at ensuring scientifically defensible hatchery programs. 


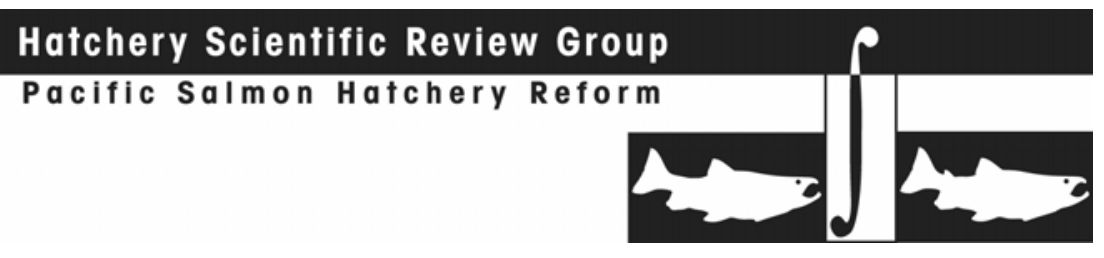

Recommendation 4: Identify the purpose of the hatchery program (i.e., conservation, harvest or both)

Once the goals for a population have been established, it is necessary to identify the purpose of hatchery programs affecting that population. A conservation program is one that is compatible with goals for biological significance (Primary or Contributing) and viability (productivity, abundance, diversity and spatial structure) of a population. A harvest program is one that contributes to specific fisheries at specified rates or harvest numbers, and is compatible with identified conservation objectives for all populations.

In the past, the purpose of many hatchery programs was described as the release of specified numbers of juveniles, without identifying whether those releases were intended to achieve conservation goals, harvest goals, or both. Unless the purpose of a hatchery program is clear, it is not possible to effectively design, operate or evaluate the program.

Recommendation 5: Explicitly state the scientific assumptions under which a program contributes to meeting the stated goals

Once population goals have been defined and the purpose(s) of a hatchery program (harvest, conservation, or both) have been established, the scientific rationale for the program must be documented. The scientific rationale explains, in terms of benefits and risks, how the hatchery program is expected to achieve its purpose. The purpose, operation and management of the program must be scientifically defensible and the chosen strategy must be consistent with current scientific knowledge. Where there is uncertainty, hypotheses and assumptions should be documented, so those assumptions can be evaluated and modified as new information becomes available. Documentation should include citations from the scientific literature and analytical tools that take into account the various factors that will affect the success of the program (predation assumptions, cumulative effects, etc.) ${ }^{11}$. This approach ensures a scientific foundation for hatchery programs, a means to address uncertainty, and a method to demonstrate accountability.

\section{Recommendation 6: Select an integrated or segregated broodstock management strategy based on} population goals and hatchery program purpose

One of the most critical needs in hatchery reform is to improve hatchery broodstock management. Hatchery programs should be managed as either genetically integrated with, or segregated from, the natural populations they most directly influence (Appendix A, Implementing and Transitioning Hatchery Programs). A fundamental purpose of most integrated hatchery programs is to increase abundance for harvest, while minimizing the genetic divergence and reproductive fitness differences between the hatchery broodstock and the naturally spawning population. In some cases, integrated programs also serve as

\footnotetext{
${ }^{11}$ For example, the HSRG used the Beverton-Holt production function to capture effects of habitat, harvest, and hatchery factors on survival by life stage. The effect of hatchery-origin spawners on productivity of the naturally spawning population was based on the Ford fitness model as adapted by Campton and Busack (personal communication with D. Campton). The specific assumptions used in these calculations were entered into the AHA spreadsheet. An example of assumptions used and their expected outcome is shown in Table D-2 of Appendix D. The biological specifications document prepared by Yakima/Klickitat Fisheries Program (Hager and Costello 1999) is another example of how scientific accountability can be documented.
} 


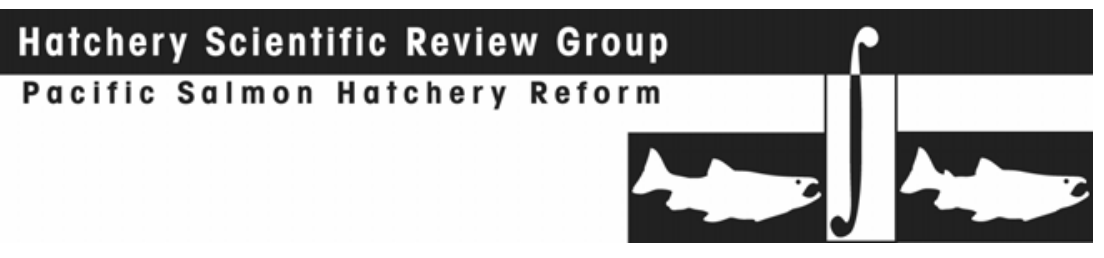

a demographic safety net to vulnerable natural populations. An integrated program is intended to maintain the genetic characteristics of a locally adapted natural population and minimize the potential genetic effect of domestication. To achieve this, at a minimum, the proportion of hatchery broodstock comprised of natural-origin fish $(\mathrm{pNOB})$ has to be greater than the proportion of the natural spawning population that is made up of hatchery-origin fish (pHOS).

For segregated hatchery programs, the intent is to maintain a genetically distinct hatchery population that is isolated from natural populations. Ideally, fish from this type of hatchery program would be propagated solely from hatchery returns and not allowed to spawn with the natural population. The primary intent of a segregated program is to create a hatchery-adapted population to meet goals for harvest.

The biological principle behind the broodstock standards for both integrated and segregated populations is local adaptation, i.e., allowing a population to adapt to the environment it inhabits. Disruption of local adaptation continues to be a major concern with many current hatchery programs because programs have often been operated in a manner that disrupts the natural selection for population characteristics that are tailored to the local environmental conditions. Proper integration and segregation of hatchery programs is the HSRG's recommended means for minimizing adverse effects of hatcheries on local adaptation.

The typical benefit of reforming broodstock management is that abundance goals for conservation and harvest can be met while at the same time improving the productivity of natural populations. Many current hatchery programs have been responsible for loss of fitness and genetic diversity through the influence of maladapted hatchery-origin fish on the spawning grounds. Hatchery fish on the spawning grounds always represent a compromise between the demographic benefits and the genetic risk, even when they come from a well-integrated program. The HSRG concluded that when its broodstock management standards for an integrated or segregated program are met and managers' abundance goals are achieved, the benefits of the hatchery program outweigh the risks. ${ }^{12}$ The HSRG also recommends establishing hatchery-free populations as a means of reducing the genetic and ecological risks to an MPG or ESU. These hatchery-free populations provide both a hedge against unknown or poorly understood hatchery influences and a reference for future changes in abundance and productivity of all populations.

\section{Recommendation 7: Size hatchery programs based on population goals and as part of an "all H" strategy}

A hatchery program should be sized to achieve abundance goals for harvest and conservation, while reducing the effects on natural populations from straying, ecological interactions and from collecting more natural broodstock than the population can support. The appropriate size of an integrated or segregated program is directly related to the productivity and abundance of the natural population, taking into account the effects of harvest, hydropower operations and habitat conditions. The abundance and productivity

12 For more information on the integrated/segregated concept, standards and implementation methods, see Section B-3 (Management Goals for Hatchery Broodstocks: Genetic Integration Versus Segregation) of the HSRG April 2004 report, and the technical discussion papers on integrated and segregated hatchery programs, all available at the HSRG's website, www.hatcheryreform.us. 


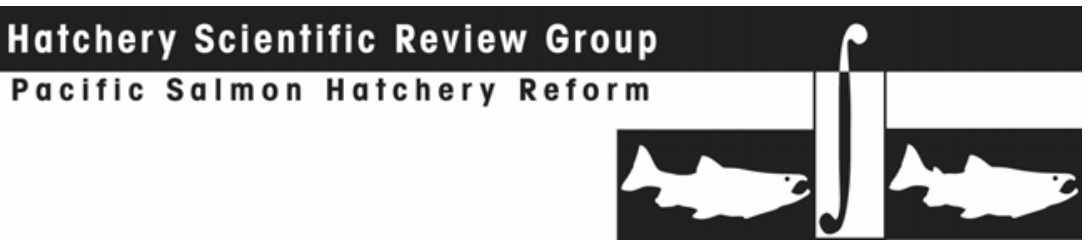

of the natural population, as well as the ability to fully harvest hatchery-origin fish, determine the effect of hatchery straying on the natural population. This, in turn, determines the proper size of a hatchery program.

Concerns about ecological interactions can be addressed in part by making the hatchery program as small as possible, while assuring that benefits from the program still outweigh the risks. Time, size, age and location of released hatchery fish also affect straying, survival and ecological interactions. When a hatchery program is sized appropriately, the demographic benefits to harvest and/or conservation outweigh the genetic and ecological risks ${ }^{13}$.

It is not uncommon within the Columbia River Basin for excessive adult surpluses to return to a hatchery. These surpluses - the consequence of incorrectly sized programs and/or under-harvesting of hatchery fish-have led to lost economic benefit, unneeded expenditure for production, and increased conservation concerns. The HSRG recommends that managers size their hatchery and harvest programs to reduce these surpluses and use some of the surplus fish to provide ecological benefit through nutrient enhancement of streams and rivers (Appendix A, Nutrient Enhancement of Freshwater Streams to Increase Production of Pacific Salmon). Specific program recommendations to rectify excessive surpluses are identified in the population reports (Appendix E).

Recommendation 8: Manage harvest, hatchery broodstock, and natural spawning escapement to meet HSRG standards appropriate to the affected natural population's designation

Effectively managing harvest, hatchery broodstock and natural spawning escapement is essential to controlling genetic risks due to straying of hatchery adults. Straying can result in fitness loss in natural populations. To limit these risks and meet conservation goals, the HSRG developed quantitative standards for the proportion of natural-origin spawners made up of hatchery-origin fish ( $\mathrm{pHOS}$ ), the proportion of hatchery broodstock derived from natural-origin fish ( $\mathrm{pNOB}$ ), and the proportionate natural influence (PNI) on an integrated population that results from the combination of $\mathrm{pHOS}$ and $\mathrm{pNOB}$.

The designation of a population as Primary, Contributing or Stabilizing is a policy decision; however, for its analysis, the HSRG made assumptions based on the status of each population and manager's objectives. Standards used by the HSRG for broodstock management are as follows:

\section{HSRG criteria for hatchery influence on Primary populations}

- The proportion of effective hatchery-origin spawners (pHOS) should be less than 5\% of the naturally spawning population, unless the hatchery population is integrated with the natural population.

- For integrated populations, the proportion of natural-origin adults in the broodstock should exceed pHOS by at least a factor of two, corresponding to a PNI (proportionate natural influence) value of 0.67 or greater and pHOS should be less than 0.30 .

\footnotetext{
${ }^{13}$ The proposed Klickitat coho harvest program, for example, is designed to maximize survival through local adaptation, and reduce straying and ecological interactions by reducing the number of fish released and acclimating the fish downstream of the current release site.
} 


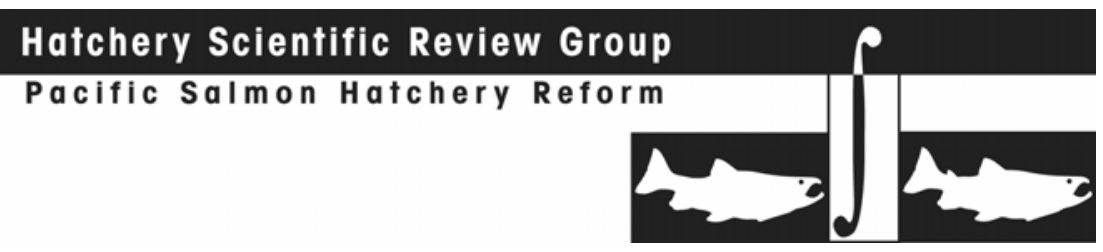

HSRG criteria for hatchery influence on Contributing populations

- The proportion of effective hatchery-origin spawners (pHOS) should be less than $10 \%$ of the naturally spawning population, unless the hatchery population is integrated with the natural population.

- For integrated populations, the proportion of natural-origin adults in the broodstock should exceed pHOS, corresponding to a PNI value of 0.50 or greater and $\mathrm{pHOS}$ should be less than 0.30 .

HSRG criteria for hatchery influence on Stabilizing populations

- The current operating conditions were considered adequate to meet conservation goals. No criteria were developed for proportion of effective hatchery-origin spawners (pHOS) or PNI.

In order to meet these standards, the number of hatchery fish on the spawning grounds must be monitored and controlled. It is possible to accomplish this by reducing or totally eliminating hatchery fish. These options, however, would severely reduce most fisheries and the associated economic and cultural benefits, as well as reduce the demographic benefits provided by hatchery programs. Eliminating hatchery programs would not allow most populations to meet conservation goals for abundance.

The HSRG's analysis showed that both conservation goals and harvest goals could be met with an appropriate combination of reduced hatchery production, selective harvest of hatchery fish, and/or selective removal of hatchery adults with tributary traps or weirs. Marking or tagging all hatchery fish so that they are easily distinguished (in real time) from natural-origin fish is a basic requirement for selective harvest, as well as for monitoring and achieving desired levels of pHOS, pNOB and PNI. ${ }^{14}$

\section{Recommendation 9: Manage the harvest to achieve full use of hatchery-origin fish}

Many salmon fisheries can be restructured to increase the beneficial harvest of hatchery salmon, while reducing the adverse biological effects of excessive numbers of hatchery fish spawning in the wild. Hatchery fish from harvest programs need an external mark (adipose fin-clip) so they can be distinguished from natural-origin fish and selectively harvested in various fisheries.

Many current fisheries are incapable of harvesting available adult hatchery salmon without over-harvesting natural populations. Harvest of hatchery salmon predominantly occurs in mixed stock fisheries, where harvest rates are restricted to protect weaker natural populations. Consequently, significant economic benefits are unrealized, hatcheries often get large surpluses of returning salmon that are of little benefit to the

\footnotetext{
${ }^{14}$ The HSRG's review of the Lower Columbia River Chinook ESU (see Part 3 of this report) provides an example of harvest and broodstock management changes that would result in appropriate pHOS and PNI standards consistent with conservation goals, while simultaneously increasing harvest over current levels. The HSRG's proposal would (1) reduce hatchery production by three percent and move it to terminal release areas where selective fisheries could occur; (2) increase selective harvest in the ocean, mainstem and terminal areas; and (3) add two weirs. These solutions project an increase in overall harvest while contributing to conservation objectives by increasing natural productivity by $75 \%$ and natural-origin spawner abundance by $25 \%$ for Primary populations.
} 


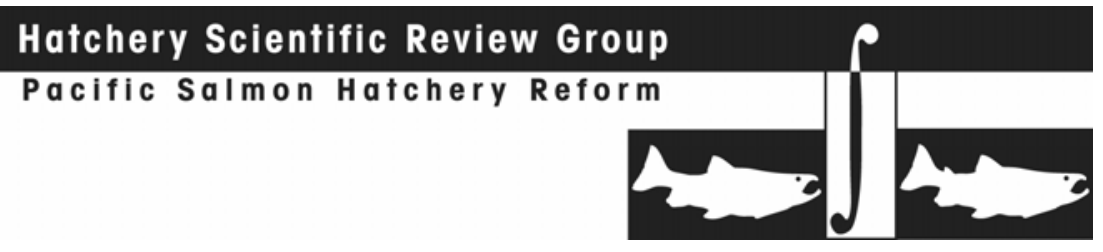

public, and many natural spawning salmon populations are swamped with excessive escapement of hatchery fish, depressing the natural populations' viability.

Because salmon survival in any given year can vary by an order of magnitude, fisheries must be flexible enough to harvest highly variable numbers of hatchery salmon. In many cases, if fisheries are not managed to remove more hatchery salmon, hatchery programs need to be reduced or terminated to avoid adverse effects on natural populations.

To both increase salmonid harvests and minimize adverse biological effects on natural populations, the HSRG recommends that most fisheries be managed as selective fisheries, where marked hatchery fish are retained and unmarked fish are released with minimal mortality. Selective commercial fishing gear needs to be developed and assessed for use in the Columbia River Basin. Additionally, the HSRG recommends that more hatchery fish be transferred to and acclimated in terminal fishing locales, where they can be harvested in known stock fisheries with little mortality to other populations. ${ }^{15}$

\section{Recommendation 10: Ensure all hatchery programs have self-sustaining broodstocks}

Many current hatchery programs import juveniles from out-of-subbasin sources. This practice inhibits local adaptation, which is important to long-term productivity and sustainable harvest of both natural and hatchery populations. The practice of importing broodstock and juveniles to a number of outplanting locations also contributes to the loss of genetic diversity within and among populations. Use of local broodstock and in-basin rearing promotes selection for traits favorable to survival in the local environment and improves homing fidelity, thereby reducing straying risks to other populations. ${ }^{16}$ In this context, the same biological principles used to manage wild populations should be used to manage hatchery populations. Exceptions to this are the designated terminal area fisheries, where the intent is to harvest all returning adults (e.g., Youngs Bay).

Recommendation 11: Coordinate hatchery programs within the Columbia River Basin ecosystem to account for the effects of all hatchery programs on each natural population and each hatchery program on all natural populations

Columbia River Basin fish production needs to be regionally coordinated if system-wide conservation and harvest goals are to be met. Regional coordination would allow oversight of the effects of all hatchery programs on each natural population and the effects of each hatchery program on all natural populations. The focus should be on limiting negative ecological and genetic impacts of harvest production on naturally

\footnotetext{
${ }^{15}$ One example of the HSRG's suggested solution is for Youngs Bay coho (see Part 3.2 of this report). The HSRG projected that annual harvests at the Youngs Bay terminal fishery site could increase by 12,000 coho and hatchery surpluses could be decreased by a similar amount if an additional 1 million hatchery fish were transferred to the site. The HSRG also recommends that the Washington coastal and lower Columbia River sport and commercial Chinook fisheries be managed selectively. By doing so, harvest of threatened wild Lower Columbia River Chinook would be reduced by about $36 \%$ under HSRG projections. Similarly, hatchery fish harvest would increase by about $13 \%$ and wild summer Chinook harvest would decline by about $7 \%$ if the Columbia River sport and terminal summer Chinook fisheries were managed as selective.

${ }^{16}$ An example is the Wenatchee coho reintroduction program. Lower Columbia broodstock was replaced with inbasin adults in an effort to select for population traits that could withstand the rigors of migration over seven additional mainstem dams into the upper Wenatchee watershed.
} 


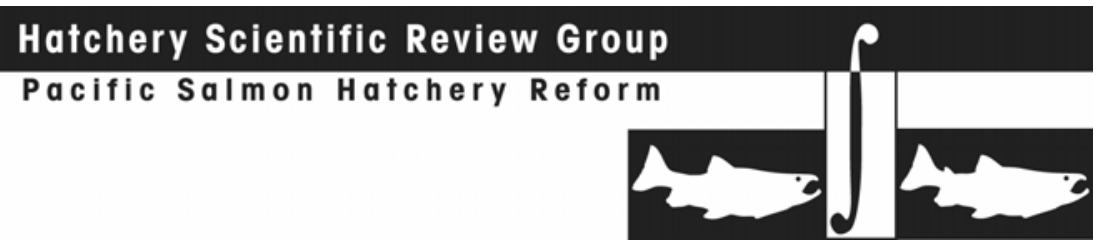

rearing populations, and ensuring that system-wide hatchery propagation does not overwhelm individual, biologically significant, natural populations.

The anadromous fish released in each subbasin will interact with wild and hatchery fish from other subbasins as they migrate through the downstream corridor, estuary and ocean. In some cases, these interactions may be positive (i.e., hatchery fish may provide food for natural populations or for predators that would normally prey on natural populations). In other cases, effects could be negative. Hatchery fish may compete for food and space, attract predators, or prey on natural and hatchery fish from other subbasins. Negative interactions can also be genetic. Hatchery fish from one subbasin may stray and spawn with fish in other subbasins, reducing the natural population's fitness.

The effects of these ecological interactions are heightened as the cumulative number of hatchery fish released into the Columbia River Basin for harvest increases. Therefore, in order to minimize the negative ecological impacts on stocks of special concern, overall anadromous fish production should be limited to the minimum number needed to meet system-wide harvest and conservation goals of the various managers. In addition, the combined natural and hatchery production should take into account the carrying capacity of the migratory corridor, estuary and ocean. Meeting these system-wide limitations on production requires coordination of the number of anadromous fish released by all hatchery operators in the Columbia River Basin. The result of this type of coordination could be invaluable in achieving conservation, while maintaining or increasing harvest.

Basin-wide coordination would require that regional decision-makers have convenient access to reports showing population goals, current status of populations and fisheries, and expected and realized contributions from hatchery programs. This information should be up to date and easily accessible via the Internet. It should be possible to view the information at several levels - by population, ESU and species - for the entire Columbia River Basin. ${ }^{17}$

\section{Recommendation 12: Assure that facilities are constructed and operated in compliance with environmental} laws and regulations

Hatchery facilities include adult collection, spawning, incubation and rearing and release facilities as well as structures to remove and discharge water. These structures are usually located in riparian areas or within streams and can affect habitat quality and quantity, as well as the use of habitat by juvenile and adult fish. Hatchery structures can create obstacles to migration for juvenile and adult fish, change instream flow, alter riparian habitat and diminish water quality through hatchery discharges.

Water for hatchery use is often drawn from an adjacent stream via pumps or gravity. Improperly designed and maintained water intakes can impinge migrant or resident juveniles on hatchery screens or cause fish to be trapped in hatchery facilities. Structures such as adult weirs and water intake dams can also block natural passage of salmonids to spawning or rearing areas. Water diverted from adjacent streams for fish culture

\footnotetext{
${ }^{17}$ The AHA tool described in Appendix $\mathrm{C}$ is a good starting point for developing this capability. The implementation recommendations described in Section 2.2 would also help support a coordinated decision-making process that is responsive to information feedback.
} 


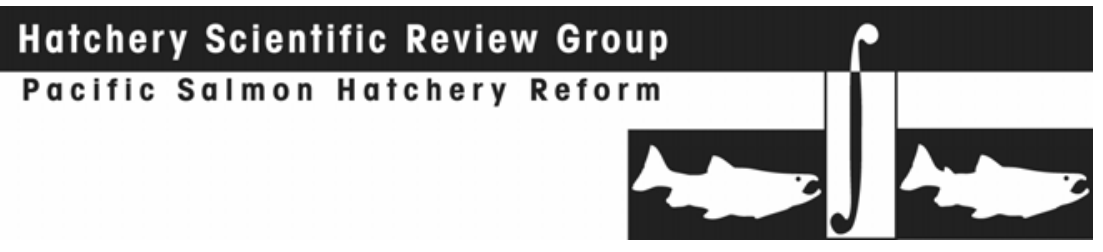

purposes is often returned downstream and can reduce the amount of water for juvenile rearing and upstream adult migration between the area of intake and discharge. Hatchery discharge can also diminish water quality below the point of discharge through changes in temperature, settleable and suspended solids, chemical composition, and presence of therapeutic drugs.

The HSRG has noted that, for the most part, existing laws and regulations related to facilities and operations are adequate to protect the environment; however, not all facilities are in compliance with those laws and regulations. It is important that those facilities come into compliance. If hatchery facilities and operations are not in compliance with environmental laws and regulations, the consequence could be loss of natural production. In addition, failure to comply with these requirements could lead to closure of facilities and the loss of any harvest or conservation benefit derived from the programs.

\section{Recommendation 13: Maximize survival of hatchery fish consistent with conservation goals}

Maximizing the survival of hatchery fish enables conservation programs to accelerate their rebuilding efforts. It allows production hatcheries to reduce their ecological impacts on natural populations. Conservation hatcheries producing juveniles with high survival generate more spawners on the spawning grounds. This, in turn, accelerates the rate at which recovery programs move toward meeting their goals. Production programs may have to reduce release numbers to decrease negative ecological impacts on natural populations. Increasing post-release survival can offset this reduction and enable managers to meet their harvest goals.

There are many approaches to increasing fish survival. The release of fish at the appropriate time, size, age and location can significantly increase their recruitment to fisheries and natural escapement. Releasing rapidly migrating smolts rather than fry increases survival and reduces negative ecological interactions in the freshwater environment. Similarly, the release of healthy fish produces more fish for harvest and less opportunity to spread disease to natural populations. Improving water quality and reducing loading and density during rearing are also proven tools used by fish culturists to enhance fish survival. Adoption of volitional release (allowing smolts to outmigrate when they are ready, rather than "forcing" them out at a preset date) with removal of residuals (fish that do not outmigrate) may increase the long-term survival of released fish, while decreasing negative ecological interactions with natural populations. Proper acclimation and imprinting of hatchery juveniles can reduce straying and enhance survival to the desired location for their harvest or artificial spawning. ${ }^{18}$

Developing and adopting these and other culture and release practices that maximize fish survival and minimize negative ecological interactions by reducing production release numbers, can aid conservation programs in rebuilding runs and reducing the conflict between harvest programs and conservation goals for natural populations.

\footnotetext{
${ }^{18}$ Many of the HSRG solutions provided in Appendix E for upper Columbia Basin releases (such as Wenatchee coho) encourage local adaptation. This should produce higher survival and allow managers to meet their conservation and harvest goals with lower release numbers. Increasing the release size of spring Chinook in the Grande Ronde subbasin provides another example that should lead to higher survival and accelerate recovery.
} 


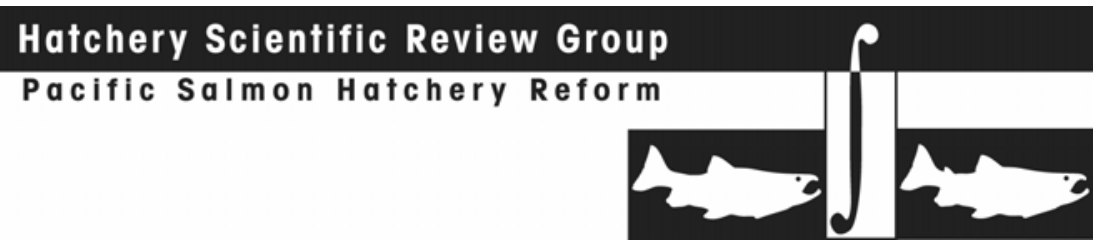

\section{Principle: Monitor, Evaluate and Adaptively Manage Hatchery Programs}

In addition to establishing resource goals (the first principle) and a defensible scientific rationale for a hatchery program (the second principle), the HSRG recommends that the managers' decisions be informed and modified by continuous evaluation of existing programs, changing circumstances and new scientific information. Systems affected by hatchery programs are dynamic and complex; therefore, uncertainty is unavoidable. The only thing certain is that the unexpected will occur. Managing hatchery programs is an ongoing and dynamic process.

Hatchery managers' decision-making processes must include provisions to monitor the results of their programs and identify when environmental conditions or scientific knowledge has changed. Climate change and human population growth are examples of the factors that must be taken into consideration in the future. New data will change our understanding of the ecological and genetic impacts of hatchery programs. Recognizing these changes should lead directly to changes in hatchery operations.

This approach will require a substantial increase in scientific oversight of hatchery operations, particularly in the areas of genetic and ecological monitoring. The process should be structured to allow directed research, innovation and experimentation, so hatchery programs may be effectively modified to better contribute to new goals and incorporate new concepts in fish culture practice.

Recommendation 14: Regularly review goals and performance of hatchery programs in a transparent, regional, "all-H" context

The HSRG recommends that the managers' decisions be informed and modified by periodic evaluations of existing programs in light of new scientific information. This evaluation process should be on-going to allow incorporation of new knowledge as soon as possible. Comprehensive reviews of hatchery programs should be conducted at regularly scheduled intervals.

The 2008 Federal Columbia River Power System Biological Opinion (NMFS 2008e) requires periodic reviews at five and ten year intervals, to monitor progress toward implementing actions and assessing progress towards achieving expected benefits. These types of periodic reviews assess the region's implementation progress and allow consideration of new information and adjustment of plans to achieve managers' objectives. Hatcheries should also be subject to comprehensive review every five years. This review should include hatchery operation and performance, as well as hatchery program performance standards, to ensure continued consistency with overall population goals. $^{19}$

For many programs, this approach will require a substantial increase in scientific oversight of hatchery operations, particularly in the areas of genetic and ecological monitoring. Well-defined, responsive decision-making processes will need to be in place to accommodate new information and recommendations resulting from these hatchery reviews. These periodic reviews will help keep the region focused on hatchery reform implementation and will help monitor benefits and risks over time.

\footnotetext{
${ }^{19}$ To facilitate these regional reviews, all HSRG data sets and reports, as well as the AHA tools, are available through the publically accessible Hatchery Reform web site, www.hatcheryreform.us.
} 


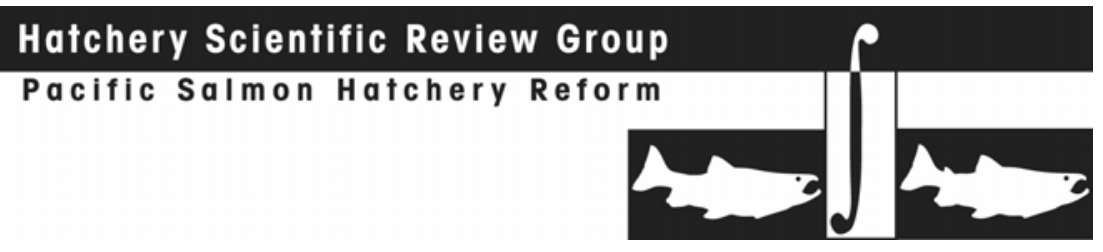

The HSRG believes that hatcheries can be managed in a more flexible and dynamic manner in response to changing environmental conditions, new scientific information, and the changing economic value of the resource. Decisions about hatcheries must also be made in a broader, integrated context and hatchery solutions must meet the test of being better, in a benefit-risk sense, than alternative available means to meet similar goals. Results of monitoring and evaluation must be brought into the decision-making process in a clear and concise way, so needed changes can be implemented. This responsive process should be structured to allow for innovation and experimentation, so hatchery programs may incorporate new goals and concepts in fish culture practice.

The HSRG has concluded that certain information is critical to operating hatchery programs in a responsible manner. Hatchery fish should not be released unless the contribution of those fish to natural spawning escapement can and will be estimated with reasonable accuracy on an annual basis. Contribution from each hatchery program to fisheries should also be monitored annually. Increased tagging rates and improved sampling of fisheries and spawning escapement will be needed to assure sufficient accuracy in estimating contributions of specific hatchery programs to harvest and natural spawning. Natural spawner abundance of populations affected by hatchery fish should be estimated each year, with the highest priority placed on Primary populations. ${ }^{20}$

\section{Recommendation 15: Place a priority on research that develops solutions to potential problems and} quantifies factors affecting relative reproductive success and long-term fitness of populations influenced by hatcheries

Hatcheries have demonstrated that they can successfully provide fish for harvest. Scientific uncertainty remains about the reproductive success of hatchery-origin fish in the wild. A growing body of research has shown that traditional hatchery practices produce adults that may exhibit lower reproductive success in nature than locally adapted natural fish. In addition, it appears that a number of natural populations continue to have low productivity and are at risk of going extinct.

Hatcheries have played a role in preserving some at-risk populations in the short term, but the longer-term effects are unknown. Hatcheries will continue to be used to preserve natural populations in the foreseeable future. Current research is focused on quantifying the relative reproductive success between hatchery- and natural-origin fish using traditional practices, but has not attempted to identify factors or test solutions to improve upon this performance.

The environmental phenotypic component (i.e., the reproductive success of first generation hatchery-origin fish) needs further investigation for different species and culture conditions. Also, long-term fitness loss as a function of the proportion of hatchery fish in natural spawning populations and the proportion of natural fish in the hatchery broodstock must be addressed, among other factors. Future research should be prioritized to identify factors causing reduced fitness and reproductive success of hatchery fish and investigate whether changes to fish culture practices can overcome these problems.

\footnotetext{
${ }^{20}$ Specific monitoring recommendations are provided in the population reports (Appendix E). A proposed framework for monitoring is outlined in Appendix A (Framework for Monitoring and Evaluating Hatchery Programs).
} 


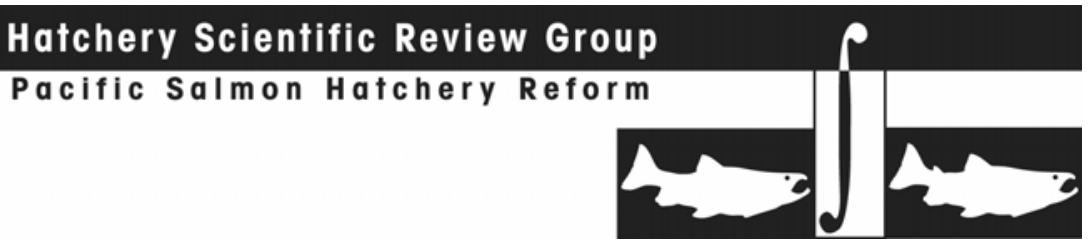

Recommendation 16: Design and operate hatcheries and hatchery programs with the flexibility to respond to changing conditions

The concept of adaptive management is well established in the Columbia River Basin. Adaptive management is a structured, iterative process of optimal decision-making in the face of uncertainty, aimed at reducing uncertainty over time through system monitoring and evaluation. The HSRG developed its recommendations using analyses based on best available scientific knowledge, reasonable assumptions where information was lacking, and management goals (as understood by the group). The HSRG's recommendations are based on the interactions among and between hydropower and hatchery operations, as well as harvest and habitat variables. The analytical methods used to develop those recommendations will need to be updated, and management decisions adapted accordingly as new knowledge is gained through the implementation, monitoring and evaluation of hatchery reform. It will be important for hatchery managers to design and operate hatchery programs with the flexibility to respond to both new knowledge and changing conditions. This is likely to be increasingly important in light of changing climate conditions (Appendix A, Global Climate Change and its Effects on the Columbia River Basin).

\section{Recommendation 17: Discontinue or modify programs if risks outweigh the benefits}

Many of the Columbia River Basin hatchery programs were initiated in the 1950s and 1960 s and were designed to support high levels of harvest. The importance of maintaining viable natural populations was not well understood and was not a priority during the development of hatchery infrastructure, especially in much of the Columbia River Basin. Scientific information since then has shown that hatchery fish can pose significant risks to natural populations if managed improperly. In addition, recent Endangered Species Act (ESA) listings of salmon and steelhead have elevated conservation of viable natural populations to a management priority. Many of the hatchery programs designed to support a single harvest objective must be modified to also achieve conservation goals for natural populations. Both conservation and harvest goals can be achieved if resources are provided to modify these hatchery programs. Without these investments, programs will have to be reduced or discontinued, in order to achieve the conservation goals. This will result in loss of harvest benefits.

\subsection{Next Steps in Hatchery Reform}

Hatchery design, programming and reform often occur simultaneously within the Columbia River Basin due to the myriad funding, regulatory and management entities and forums. These activities are complicated by the large number of Basin hatchery programs (178) and populations (351) across multiple political jurisdictions. If hatchery benefits and risks are to be scientifically assessed, a common language and framework is needed within the Basin to ensure such critical work is efficiently and effectively completed. To that end, the HSRG recommends application of its implementation framework.

The framework consists of the scientific principles, assessment tools and the 17 systemwide recommendations. These will be available and maintained on a public web site to ensure a consistent and transparent assessment for management and reform of hatchery programs. The HSRG recommends that the fishery managers use the HSRG's program- 


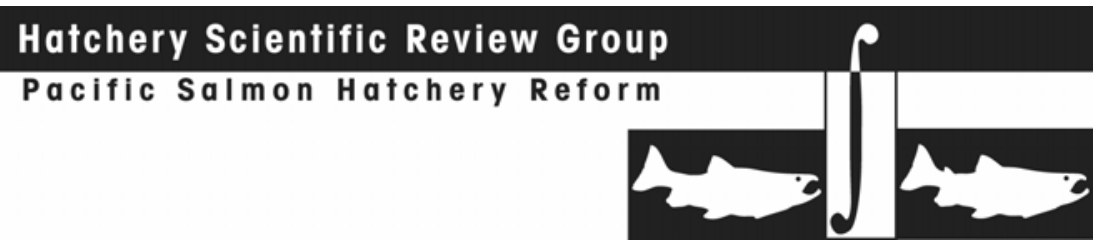

specific population reports, data sets and analytical tools as a starting point for future hatchery assessments.

Institutionalizing an implementation framework is critical to achieving meaningful and sustained reform, and to optimizing long-term management. In addition to its scientific underpinnings, this framework is also beneficial because it allows managers and their constituents to consider future hatchery reforms and affected fisheries in a quantitative manner. It allows sound scientific principles and standards to be applied using sets of comprehensive parameter values and stated assumptions for individual populations and the ecosystem as a whole. Being able to assess future management scenarios will allow managers and constituents to more easily visualize future options and adapt current management to achieve greater biological and social benefits while reducing biological and social risks.

\section{Implementation Recommendations}

Hatchery management and the reforms recommended by the HSRG could affect many entities in the Columbia River Basin. Fishery managers; funding authorities such as utilities, the Bonneville Power Administration and Congress; and regulators such as NOAA Fisheries will all have important roles in implementation of hatchery reform. Hatchery reform is also important to the Northwest Power and Conservation Council (NPCC) which is mandated to develop a comprehensive fish and wildlife program. Additionally, proper hatchery management affects the full range of land and water use and users in the Columbia River Basin, since hatchery practices greatly influence the success of, and investment in, habitat protection and restoration for steelhead and salmon conservation. The entire region, therefore, has a stake in hatchery reform and the HSRG's recommendations.

The work of the HSRG will add significant value to fisheries management only if the principles and system-wide recommendations are fully integrated into everyday hatchery and harvest planning and operations. To this end, the HSRG provides the following recommendations for implementation:

- The region's hatchery managers should incorporate the HSRG implementation framework into their ongoing hatchery program planning and reviews. This framework is, at this time, the most comprehensive method available to programmatically review hatchery programs and apply the best available scientific information in a methodical and consistent manner. In its current ESA consultations on each hatchery program, NOAA Fisheries should include assessment of hatchery programs by applying the HSRG standards, tools and data in development of the Hatchery and Genetic Management Plans (HGMPs). HGMPs should also address how each hatchery program incorporates the HSRG's system-wide recommendations (Section 2.2). The HSRG tools will allow consultations on hatchery management to be quantitatively integrated into an All-H or ecosystem management context along with population effects from hydropower, harvest and habitat. NOAA should also fully consider the HSRG solutions presented in individual population reports (Appendix E) in its reviews with each hatchery operator. 


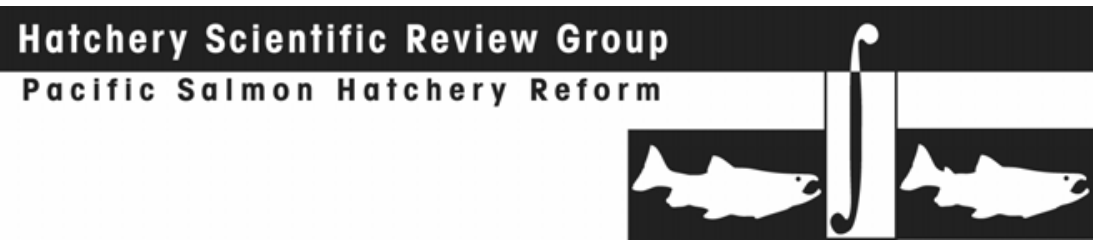

- The HSRG encourages the regional hatchery funding entities (utilities, BPA, Army Corps of Engineers, Bureau of Reclamation, NOAA and USFWS) to adopt the HSRG framework and system-wide recommendations as a basis for future funding and accountability of their respective hatchery mitigation or enhancement programs. Similarly, the NPCC is encouraged to integrate the HSRG framework and the 17 system-wide recommendations into its three-step hatchery planning process, along with previous independent scientific guidance on hatchery programs from the Independent Science Advisory Board and Independent Scientific Review Panel.

- An implementation plan, as well as maintaining and updating the current data sets and population reports, is needed to fully realize the substantial benefits of adopting the HSRG framework. The HSRG recommends that the hatchery operators make a commitment to maintain and update data sets and analytical tools, and that the hatchery funding entities and NPCC include annual information updates as a requirement for, and a component of, hatchery program funding.

- The publicly-accessible website housing the HSRG framework, data sets and analytical tools will require a permanent home and long-term funding, which has yet to be secured. This is critical to ensuring that the data set is up to date. The website must include the HSRG tools and data sets, so that hatchery managers can access them, create and update population reports, and make the reports available to the funding entities, NOAA, the NPCC and the public. The data sets will also need to be accessible for watershed and mainstem passage planning groups to update critical habitat and passage survival information. The HSRG had to apply many assumptions in its assessment of hatchery programs. As scientific knowledge evolves from ongoing research, these assumptions will need to be documented and changed. The HSRG tools readily allow for such revisions.

- Finally, implementation of the HSRG recommendations involves regular programmatic performance reviews of hatchery programs. While hatchery operators should review programs annually, the HSRG recommends a regional performance review of hatchery programs that assesses program performance against the managers' goals, the HSRG standards and system-wide recommendations. These reviews could be undertaken at the Provincial level and scheduled so that hatchery programs in each Province are publicly reviewed every five years. The reviews could accomplish necessary oversight for a number of processes, including funding, ESA regulation, consistency with NPCC's program, consistency with the US $v$. Oregon management plan, independent scientific oversight, and for public accountability. As part of the scientific oversight, each hatchery program should be rated on its conservation and harvest performance objectives and its adherence to the HSRG system-wide recommendations. 


\section{Part 3 - ESU/MPG Roll-Up Reports}

\subsection{Chinook}

\subsubsection{Lower Columbia River Chinook Salmon ESU}

This section provides an overview of the Lower Columbia River Chinook Salmon Evolutionarily Significant Unit (ESU). It contains a general description of the ESU, fisheries, habitat limitations and hatchery programs that affect it. Overall recommendations for ESU-wide hatchery program changes are summarized, as are the results of implementing those changes on conservation and harvest goals. Detailed conclusions and recommendations for each population in the ESU can be found in the Appendix E.

\subsubsection{HSRG Population Guidelines}

In order to meet conservations goals for the ESU, numerous threats to these populations need to be addressed, including risks from hatchery programs. The key to controlling genetic and ecological risks due to straying and fitness loss is to manage hatchery broodstock and natural spawning escapement such that the natural habitat (and not the hatchery environment) drives the adaptation and productivity of the naturally spawning population. This is achieved by operating either (a) integrated programs where the proportion of natural-origin adults in the broodstock (pNOB) exceeds the proportion of hatchery-origin fish on the spawning grounds (pHOS); or (b) segregated programs where the contribution of hatchery fish to natural spawning is kept low (pHOS $<5 \%$ to $<10 \%$ depending on the population designation). The HSRG developed criteria for hatchery influence for three population types based on the importance of the population to the recovery of the ESU. The Lower Columbia River Salmon Recovery Plan (LCFRB 2004) classified populations as Primary, Contributing, or Stabilizing. These designations are meant to reflect the conservation importance of a population within the ESU from most important (Primary), to moderately important (Contributing), to least important (Stabilizing). HSRG recommendations show how hatchery programs can be operated consistent with these designations based on the following standards:

HSRG criteria for hatchery influence on Primary populations

- The proportion of effective hatchery-origin spawners (pHOS) should be less than 5\% of the naturally spawning population, unless the hatchery population is integrated with the natural population.

- For integrated populations, the proportion of natural-origin adults in the broodstock should exceed pHOS by at least a factor of two, corresponding to a PNI (proportionate natural influence) value of 0.67 or greater and pHOS should be less than 0.30 . 


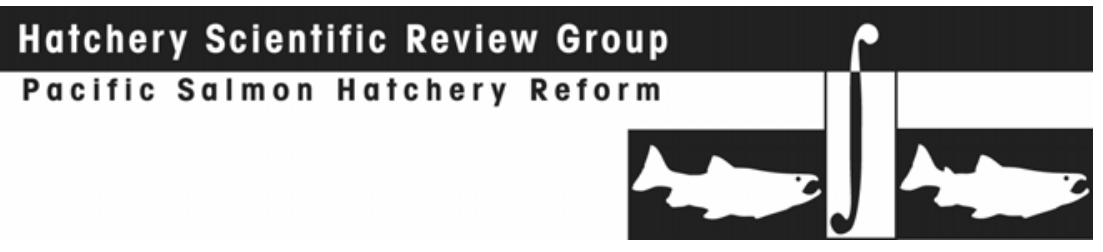

HSRG criteria for hatchery influence on Contributing populations

- The proportion of effective hatchery-origin spawners (pHOS) should be less than $10 \%$ of the naturally spawning population, unless the hatchery population is integrated with the natural population.

- For integrated populations, the proportion of natural-origin adults in the broodstock should exceed pHOS, corresponding to a PNI value of 0.50 or greater and $\mathrm{pHOS}$ should be less than 0.30 .

HSRG criteria for hatchery influence on Stabilizing populations

- The current operating conditions are considered adequate to meet conservation goals. No criteria were developed for proportion of effective hatchery-origin spawners (pHOS) or PNI.

\subsubsection{Current Conditions}

\section{Conservation}

The Lower Columbia River Chinook salmon ESU includes all naturally spawned populations from the mouth of the Columbia River upstream to and including the White Salmon River in Washington and the Hood River in Oregon. Additionally, this ESU includes naturally spawning Chinook in the Willamette River upstream to Willamette Falls (exclusive of the spring-run Chinook salmon in the Clackamas River), as well as 17 artificial propagation programs. There are six major population groups in this ESU, including 31 historical populations, seven of which are extirpated or nearly so (NMFS 2008a). Of the 31 populations in the ESU, 27 are considered to be at "high" or "very high" for risk of extinction, while only one is considered to be at "low" risk of extinction (NMFS 2008b).

Historically, this ESU has been managed for harvest, and conservation has not been a high priority. With the recent listing of these populations under the ESA, conservation has been elevated to a higher management priority and will require changes in hatcheries, harvest and habitat actions to be successful. Delisting criteria have not been established, but the Draft Recovery Plan suggests recovery will require that at least two populations in each of the life history strata and each of the three geographical strata (Coast, Cascade, and Gorge ecological zones) have a high probability of persistence. Representative populations need to be preserved, but not every historical population needs to be restored. Those selected for restoration should include "core" populations that are highly productive "legacy" populations that represent historical genetic diversity, and dispersed populations that minimize susceptibility to catastrophic events.

The Lower Columbia River Salmon Recovery Plan provides an example of a recovery scenario that categorizes individual populations in terms of three levels of contribution to recovery: Primary; Contributing; and Stabilizing (LCFRB 2004). Primary populations would be restored to high or high+ viability. Contributing populations would be restored to medium viability, and stabilizing populations would be maintained at current levels (i.e., likely low viability). In this recovery scenario, 14 populations are designated as Primary populations, 5 populations as Contributing populations, and the remaining 12 
populations are designated as Stabilizing (Table 1). Currently, five populations meet the HSRG guidelines for a Primary designation and 26 meet Stabilizing guidelines.

Table 1. Population designations for the Lower Columbia River Chinook ESU and HSRG broodstock criteria achieved for each population under current conditions and the HSRG recommended hatchery management solution.

\begin{tabular}{|c|c|c|c|}
\hline \multirow[b]{2}{*}{ Population } & \multirow[b]{2}{*}{ Designation $^{1}$} & \multicolumn{2}{|c|}{ HSRG Criteria Met $^{2}$} \\
\hline & & Current & HSRG Solution \\
\hline Columbia Estuary_Clatskanie Fall Chinook & Primary & Stabilizing & Contributing \\
\hline Cowlitz_Coweeman Fall Chinook & Primary & Primary & Primary \\
\hline Cowlitz_Upper Cowlitz Spring Chinook & Primary & Stabilizing & Primary \\
\hline Elochoman Fall Chinook & Primary & Stabilizing & Primary \\
\hline Grays Fall Chinook & Primary & Stabilizing & Primary \\
\hline Hood Spring Chinook & Primary & Stabilizing & Contributing \\
\hline Kalama Fall Chinook & Primary & Stabilizing & Stabilizing \\
\hline Kalama Spring Chinook & Primary & Stabilizing & Stabilizing \\
\hline Lewis_East Fork Lewis Fall Chinook (Tule) & Primary & Stabilizing & Primary \\
\hline Lewis_North Fork Lewis Fall Chinook (Lower River Brights) & Primary & Primary & Primary \\
\hline Lewis_NF Lewis Spring Chinook & Primary & Stabilizing & Stabilizing \\
\hline Sandy Fall Chinook (Late) & Primary & Primary & Primary \\
\hline Sandy Spring Chinook & Primary & Primary & Primary \\
\hline Washougal Fall Chinook & Primary & Stabilizing & Primary \\
\hline Columbia Estuary_Mill-Abernathy-Germany Fall Chinook & Contributing & Stabilizing & Stabilizing \\
\hline Cowlitz_Lower Cowlitz Fall Chinook & Contributing & Stabilizing & Primary \\
\hline White Salmon Fall Chinook (Tule) & Contributing & Stabilizing & Stabilizing \\
\hline White Salmon Spring Chinook & Contributing & Stabilizing & Stabilizing \\
\hline Willamette_Clackamas Fall Chinook & Contributing & Stabilizing & Stabilizing \\
\hline Columbia Estuary_Big Creek Fall Chinook (Tule) & Stabilizing & Stabilizing & Stabilizing \\
\hline Columbia Estuary_Chinook River Fall Chinook & Stabilizing & Stabilizing & Stabilizing \\
\hline Columbia Estuary_Scapoose Fall Chinook & Stabilizing & Stabilizing & Stabilizing \\
\hline Columbia Estuary_Youngs Bay Tribs Fall Chinook & Stabilizing & Stabilizing & Stabilizing \\
\hline Columbia Gorge_Tributaries Fall Chinook (Tule- Oregon) & Stabilizing & Stabilizing & Stabilizing \\
\hline Cowlitz_Toutle Fall Chinook & Stabilizing & Stabilizing & Primary \\
\hline Hood Fall Chinook & Stabilizing & Stabilizing & Stabilizing \\
\hline Little White Salmon Fall Chinook (Tule) & Stabilizing & Stabilizing & Stabilizing \\
\hline Lower Columbia_LC Tribs Fall Chinook (Tule-Oregon) & Stabilizing & Stabilizing & Stabilizing \\
\hline Sandy Fall Chinook (Early) & Stabilizing & Primary & Primary \\
\hline Wind Fall Chinook (Tule) & Stabilizing & Stabilizing & Stabilizing \\
\hline Wind Spring Chinook & Stabilizing & Stabilizing & Stabilizing \\
\hline \multicolumn{4}{|c|}{$\begin{array}{l}1 \text { Using the naming protocol of the Lower Columbia River Salmon Recovery Plan (LCFRB 2004), populations were classified based on } \\
\text { information provided to the HSRG as Primary, Contributing, or Stabilizing. These designations are meant to reflect the conservation } \\
\text { importance of a population within the ESU from most important (Primary- bold, red), to moderately important (Contributing-bold, blue), to } \\
\text { least important (Stabilizing). }\end{array}$} \\
\hline \multicolumn{4}{|c|}{$\begin{array}{l}2 \text { The HSRG developed criteria for hatchery influence for the three population designations from low influence (Primary), moderate influence } \\
\text { (Contributing) to high influence (Stabilizing). }\end{array}$} \\
\hline
\end{tabular}




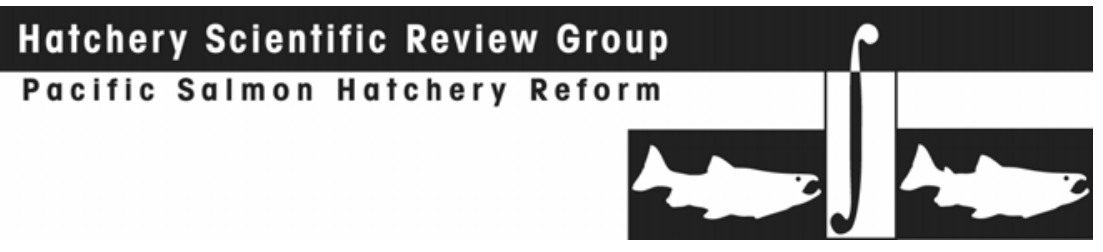

Current Harvest

Lower Columbia River Chinook are harvested in non-selective ocean fisheries throughout their migratory range from Alaska to Oregon. In-river fisheries for fall Chinook have been non-selective, while fisheries for spring Chinook have been partially selective. Harvest rates vary substantially in location and exploitation rate by Chinook run-type (i.e., fall, late-fall, or spring-run). Prior to the early 1990s, the total exploitation rates averaged $69 \%, 56 \%$, and $50 \%$ for fall, late-fall, and spring-run Chinook, respectively. More recently, the total exploitation rate has averaged $49 \%, 38 \%$, and $27 \%$ for fall, latefall, and spring-run Chinook respectively (NMFS 2008a).

\section{Current Habitat}

NMFS identified degraded estuarine and nearshore habitat, floodplain connectivity and function, channel structure and complexity, riparian areas and large woody debris recruitment, stream substrate, stream flow and fish passage as the major habitat factors limiting the recovery of this ESU (NMFS 2008a). Freshwater habitat is in poor condition in many subbasins because of forest practices, urbanization, and agriculture (Myers et al. 1998). In addition, dams constructed on the large lower Columbia tributaries have eliminated access to a substantial portion of spring-run Chinook salmon spawning habitat, with a lesser impact on fall-run Chinook salmon habitat (Myers et al. 1998). However, as part of FERC hydropower relicensing, Chinook are currently being reintroduced above several major dams, such as in the Cowlitz and Lewis river subbasins.

\section{Current Hatchery Programs}

Nineteen hatchery programs operate in this ESU, releasing approximately 53.8 million spring and fall Chinook. Most of the programs are in tributaries of the ESU, but several net-pen programs for harvest are located off-channel in the Columbia River. Nine spring Chinook programs release approximately 6.9 million fish, and ten fall Chinook programs release approximately 46.9 million fish (Table 2). The original purpose of most programs in the lower Columbia River was to increase harvest; however, restoration of natural populations has recently been elevated as a priority and most programs are now inconsistent with stated conservation objectives.

The HSRG and others have concluded that a major concern with these programs is the effect hatchery strays have on the long-term fitness of naturally spawning populations. Currently in the lower Columbia, hatchery fish dominate natural Chinook escapement. In most populations, over $50 \%$ of the fish effectively spawning in the wild are hatchery fish (pHOS). Hatchery contribution to natural spawning is generally not as high in the 17 populations that do not receive direct hatchery releases; however, many of these are small populations, so straying from programs in other watersheds or net-pens still constitutes a significant impact. Although programs provide significant harvest benefits, and in some cases, help preserve genetic resources in the ESU, there are many poorly segregated and poorly integrated programs. 

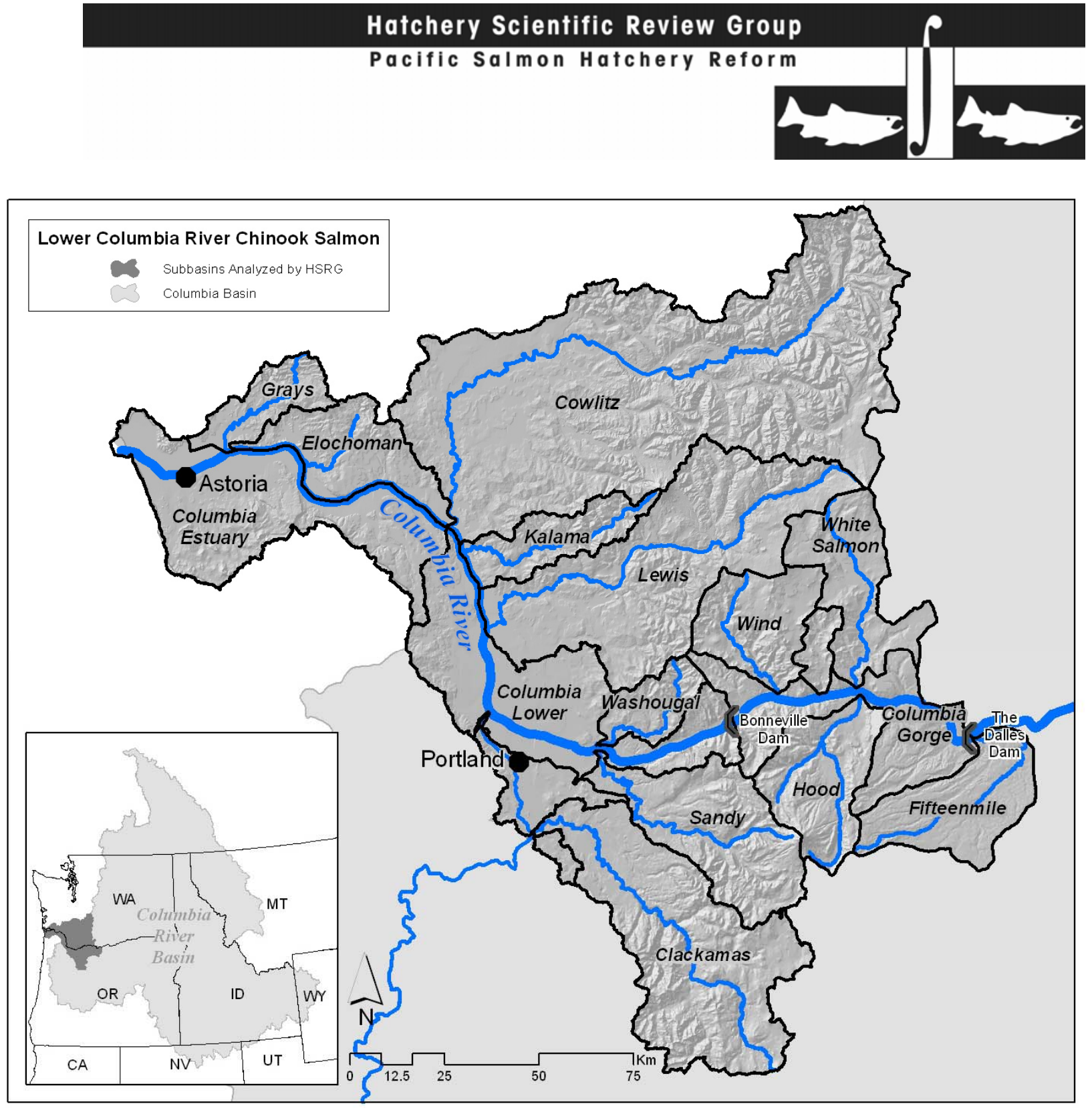

Long-term domestication of hatchery fish has reduced the productivity of some wild stocks in areas where significant numbers of hatchery fish spawn. This effect is greatest on fall Chinook populations. For spring Chinook, the majority of the habitat in Washington was affected by tributary dams and virtually all production in the Washington portion of the lower Columbia River is of hatchery origin. The Cowlitz and Lewis river populations would be extirpated if not for the hatchery programs (NMFS 2008a). In Oregon's portion of the ESU, a natural population exists in the Sandy River and an extirpated population existed in the Hood River. Reintroduction efforts using hatchery-origin fish are occurring in the Cowlitz, Lewis, and Hood rivers.

Estimates of PNI and pHOS under current conditions show that only five populations in the ESU meet the HSRG criteria for a Primary designation: (1) Coweeman River fall Chinook; (2) North Fork Lewis lower river bright fall Chinook; (3) Sandy River spring Chinook; (4) Sandy River early fall Chinook; and (5) Sandy River late fall Chinook. The 
remaining Primary and Contributing populations only meet the broodstock criteria for Stabilizing populations (Table 1).

Table 2. Hatchery releases and types of programs for Lower Columbia River Chinook ESU.

\begin{tabular}{|c|c|c|c|c|c|c|}
\hline \multirow[b]{2}{*}{ Population/Program Name } & \multicolumn{3}{|c|}{ Current $(1,000 \mathrm{~s})$} & \multicolumn{3}{|c|}{ HSRG Solution $(1,000 \mathrm{~s})$} \\
\hline & Type & Purpose & \# Released & Type & Purpose & $\begin{array}{c}\# \\
\text { Released } \\
\end{array}$ \\
\hline $\begin{array}{l}\text { Columbia Estuary_ Big Creek Fall Chinook (Tules- } \\
\text { Hatchery) }\end{array}$ & Seg & Harv & $5,826.6$ & Seg & Harv & $5,826.6$ \\
\hline Columbia Estuary_Big Creek Fall Chinook (Tules) & None & NA & 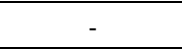 & None & NA & \\
\hline Columbia Estuary_Chinook River Fall Chinook & None & NA & - & None & NA & - \\
\hline Columbia Estuary_Clatskanie Fall Chinook & None & NA & - & None & NA & - \\
\hline $\begin{array}{l}\text { Columbia Estuary_Deep River Spring Chinook (Cowlitz- } \\
\text { Merwin-Grays-Hatchery) }\end{array}$ & Seg & Harv & 362.3 & Seg & Harv & 362.3 \\
\hline Columbia Estuary_Mill-Aber-Germ Fall Chinook & Non & NA & - & None & NA & - \\
\hline $\begin{array}{l}\text { Columbia Estuary_Mill-Aber-Germ Fall Chinook (HSRG } \\
\text { Hatchery) }\end{array}$ & Seg & Harv & - & Seg & Harv & $1,023.8$ \\
\hline Columbia Estuary_Scapoose Fall Chinook & None & NA & - & None & NA & - \\
\hline $\begin{array}{l}\text { Columbia Estuary_Youngs Bay Fall Chinook (Rogue } \\
\text { Brights CEDC SAFE-Hatchery) }\end{array}$ & Seg & Harv & $1,174.1$ & Seg & Harv & $3,342.9$ \\
\hline $\begin{array}{l}\text { Columbia Estuary_Youngs Bay Spring Chinook (CEDC } \\
\text { SAFE-Willamette-Hatchery) }\end{array}$ & Seg & Harv & 850.1 & Seg & Harv & 850.1 \\
\hline Columbia Estuary_Youngs Bay Tribs Fall Chinook & None & NA & - & None & NA & - \\
\hline $\begin{array}{l}\text { Columbia Gorge_Spring Creek Fall Chinook (Tules- } \\
\text { Hatchery) }\end{array}$ & Seg & Harv & $15,044.9$ & Seg & Harv & $15,044.9$ \\
\hline $\begin{array}{l}\text { Columbia Gorge_Tributaries Fall Chinook (Tules- } \\
\text { Oregon) }\end{array}$ & None & NA & - & None & NA & - \\
\hline Cowlitz_Coweeman Fall Chinook & None & NA & - & None & NA & - \\
\hline Cowlitz_Lower Cowlitz Fall Chinook & Int & Harv & $4,807.4$ & Int & Harv & $4,370.4$ \\
\hline Cowlitz_Toutle Fall Chinook & None & NA & - & Int & Harv & $1,561.4$ \\
\hline Cowlitz_Toutle Fall Chinook (Hatchery) & Seg & Harv & $2,500.4$ & Seg & NA & - \\
\hline Cowlitz_Upper Cowlitz Spring Chinook & Int & NA & $1,263.6$ & Int & NA & - \\
\hline $\begin{array}{l}\text { Cowlitz_Upper Cowlitz Spring Chinook (HSRG } \\
\text { Hatchery) }\end{array}$ & Seg & Harv & - & Seg & Harv & $1,263.6$ \\
\hline Elochoman Fall Chinook & Int & Harv & $2,072.1$ & Int & Cons & 188.4 \\
\hline Grays Fall Chinook & None & NA & - & Int & Cons & 94.2 \\
\hline Hood Fall Chinook & None & NA & - & None & NA & - \\
\hline Hood Spring Chinook & Seg & Cons & 125.9 & Int & Cons & 147.0 \\
\hline Kalama Fall Chinook & None & NA & - & Int & NA & - \\
\hline Kalama Fall Chinook (Hatchery) & Seg & Harv & $5,040.0$ & Seg & Harv & $5,040.0$ \\
\hline Kalama Spring Chinook & Int & Harv & 501.3 & None & NA & - \\
\hline Kalama Spring Chinook (HSRG Hatchery) & Seg & Harv & - & Seg & Harv & 501.3 \\
\hline Lewis_EF Lewis Fall Chinook (Tule) & None & NA & - & None & NA & - \\
\hline Lewis_NF Lewis Fall Chinook (Lower River Brights) & None & NA & - & None & NA & - \\
\hline Lewis_NF Lewis Spring Chinook & None & Both & - & Int & Both & - \\
\hline Lewis_NF Lewis Spring Chinook (Hatchery) & Seg & Harv & $1,351.4$ & Seg & Harv & $1,188.0$ \\
\hline Little White Salmon Fall Chinook (Tule) & None & None & - & None & NA & - \\
\hline
\end{tabular}




\begin{tabular}{|c|c|c|c|c|c|c|}
\hline \multirow[b]{2}{*}{ Population/Program Name } & \multicolumn{3}{|c|}{ Current $(1,000 \mathrm{~s})$} & \multicolumn{3}{|c|}{ HSRG Solution $(1,000 \mathrm{~s})$} \\
\hline & Type & Purpose & \# Released & Type & Purpose & $\begin{array}{c}\# \\
\text { Released } \\
\end{array}$ \\
\hline Little White Salmon Fall Chinook (URB-Hatchery) & Seg & Harv & $2,007.2$ & Seg & Harv & $2,007.2$ \\
\hline Little White Salmon Spring Chinook (Hatchery) & Seg & Harv & $1,005.2$ & Seg & Harv & 1.005 .2 \\
\hline Lower Columbia_Bonneville Fall Chinook (Hatchery) & Seg & Harv & $4,493.1$ & Seg & Harv & $4,493.1$ \\
\hline Lower Columbia_LC Tribs Fall Chinook (Tules-Oregon) & None & NA & - & None & NA & - \\
\hline Sandy Fall Chinook (Early) & None & NA & - & None & NA & - \\
\hline Sandy Fall Chinook (Late) & None & NA & - & None & NA & - \\
\hline Sandy Spring Chinook & Int & Harv & 300.5 & $\operatorname{lnt}$ & Harv & 300.7 \\
\hline Washougal Fall Chinook & Int & $\mathrm{NA}$ & - & Int & Harv & $1,123.2$ \\
\hline Washougal Fall Chinook (HSRG-Hatchery) & Seg & Harv & $4,002.6$ & Seg & Harv & 919.0 \\
\hline White Salmon Fall Chinook (Tule) & None & NA & - & None & NA & - \\
\hline White Salmon Spring Chinook & None & NA & - & None & $\mathrm{NA}$ & - \\
\hline Willamette_Clackamas Fall Chinook & None & $\mathrm{NA}$ & - & None & NA & - \\
\hline Wind Fall Chinook (Tule) & None & $\mathrm{NA}$ & - & None & NA & - \\
\hline Wind Spring Chinook & None & NA & - & None & NA & - \\
\hline Wind Spring Chinook (Hatchery) & Seg & Harv & $1,145.0$ & Seg & Harv & $1,404.4$ \\
\hline Total all Populations/Programs & & & $53,873.6$ & & & $52,057.4$ \\
\hline
\end{tabular}

\subsubsection{HSRG Solutions}

\section{Conservation Outcomes}

Under the HSRG solution, 12 populations would meet the criteria for a Primary designation and two meet Contributing criteria; however, some individual population solutions diverged from the goals for the 14 Primary and 5 Contributing populations identified in Table 1. Two primary factors differentiate the HSRG solution from the identified goals. First, the habitat capacity and productivity of some populations appeared inconsistent with designated goals (examples being the Kalama fall and spring Chinook populations). For some of these situations, the HSRG recommends that managers consider changing the designation goal to better align with habitat potential. Second, designations for some populations assume successful reintroduction above dams that have blocked habitat for decades, although the introduction programs have not yet started (examples being North Fork Lewis River spring Chinook and White River spring Chinook). In the populations planned for future reintroduction, there was no information on which to base an assessment.

Figure 1 compares the proportion of hatchery-origin fish on the spawning grounds (pHOS) and the proportionate natural influence (PNI) for current and proposed (HSRG) scenarios for Primary populations as designated under the recovery plan. Under current conditions, only four populations designated as Primary in the recovery plan meet the hatchery influence criteria for this designation. One population (Sandy early fall Chinook) designated as Stabilizing in the recovery plan currently also meets the hatchery influence criteria for a Primary population. 


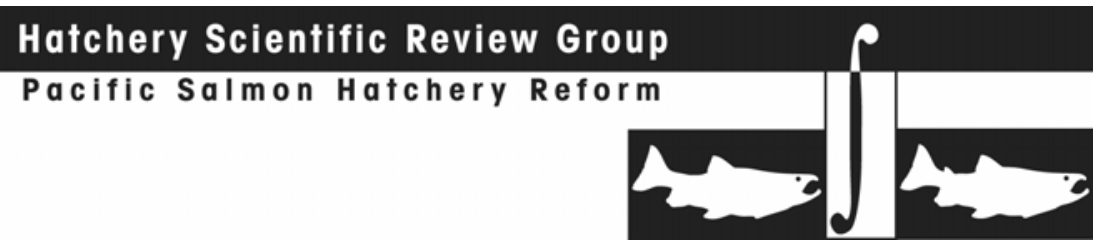

Figure 1 also compares the proportion of hatchery-origin fish on the spawning grounds (pHOS) and the proportionate natural influence (PNI) for current and proposed (HSRG) scenarios for populations designated by the recovery plan as Contributing populations. Under current conditions, none of the five populations meet the hatchery influence criteria for this designation. Under the HSRG solution, one of these populations (Lower Cowlitz fall Chinook) improves in terms of hatchery influence to meet the criteria for a Primary population. The solution does not improve the hatchery influence for the remaining four Contributing populations and they remain Stabilizing populations.

Figure 2 compares the relationship of spawner abundance and productivity between current and HSRG-proposed scenarios for the Primary and Contributing Chinook populations in the Lower Columbia Chinook ESU. For Primary populations, productivity increases significantly in eight of the populations, with an average increase of approximately $74 \%$. In six of the populations, productivity under the HSRG solution is nearly double or more than current levels. For Contributing populations, productivity increases significantly in four of the populations, with an average increase of approximately $65 \%$. In two populations, productivity under the HSRG solution more than doubles current levels.

For Primary populations, the number of natural-origin spawners under the HSRG solution increases in ten of the populations by an average of about $25 \%$ above the current condition. For Contributing populations, the number of natural-origin spawners under the HSRG solution increases in three of the populations an average of more than $100 \%$ above the current condition. For the combined Primary and Contributing populations across the ESU, the HSRG solution has the potential to increase natural-origin spawning by nearly 8,000 fish.

\section{Harvest Outcomes under the HSRG Solutions}

Figure 3 displays current and estimated changes in harvest (marine, mainstem Columbia River and terminal areas) that could occur following implementation of the management solutions proposed by the HSRG.

Compared to the current condition, the total harvest in ocean, mainstem Columbia River, and terminal areas is relatively unchanged under the HSRG solution. Distribution in fisheries did change, with an approximately $20 \%$ reduction in ocean catch, an $80 \%$ increase in mainstem catch, and a $60 \%$ increase in terminal area catch. For terminal and mainstem harvest areas, the increased harvest depicted in Figure 3 primarily resulted from shifting some hatchery production to Select Area Fishery locations with higher adult survival and by implementing selective fisheries.

\section{Hatchery Program Changes under the HSRG Solutions}

In this ESU, the HSRG made multiple recommendations to improve the contribution of hatchery programs to both harvest and conservation. In the case of segregated programs, recommendations are made to improve the ability to control hatchery fish on the spawning grounds so that harvest benefits can be maintained while improving naturalorigin spawning abundance and productivity. These recommendations include installing weirs in specific drainages where straying limits the ability to meet conservation goals. Recommendations are also made to move production from some tributaries into larger 


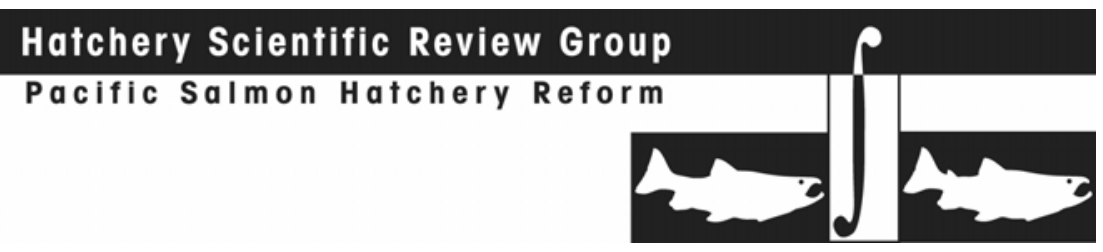

segregated harvest programs in Select Area Fishery Evaluation areas, where excess hatchery fish can be removed by applying higher harvest rates. In several cases, reducing the reliance on imported out-of-basin broodstock or rearing is recommended to improve homing and increase productivity.

For integrated programs, the HSRG recommendations generally increase the proportion of natural-origin fish used in hatchery broodstock and control the contribution of hatchery-origin fish to natural spawning areas. This improves natural-origin spawning abundance and productivity. In some cases, meeting the criteria for the population designation requires reducing program size. In two locations (Elochoman River and Grays River), the HSRG recommended that the Elochoman and Grays rivers either convert from a large segregated harvest program to a smaller conservation program, or initiate a conservation program for a Primary population. More emphasis on monitoring and evaluation programs to accurately estimate straying is also recommended.

In the HSRG solution, total hatchery production in the ESU is reduced from 53.8 million spring and fall Chinook to 52 million fish, a reduction of approximately 3\%. Spring Chinook releases increase slightly from 6.9 million to 7.0 million fish. Fall Chinook releases are reduced from approximately 46.9 million to 45 million fish, a reduction of approximately $4 \%$.

In order to maintain harvest benefits while achieving population conservation goals, the HSRG recommends harvest changes in marine, mainstem Columbia River and terminal areas. These changes should be implemented along with hatchery program changes. The HSRG also suggests managers consider changing some recovery scenario population designations in the lower Columbia Chinook ESU that appear to be inconsistent with available habitat information and population potential. The HSRG offers alternative conservation designations for the managers to consider.

The HSRG evaluated how harvest changes could improve population viability and productivity while maintaining or improving harvest. For its solution, the HSRG recommends increasing selective harvest in Washington and Oregon marine waters and the mainstem Columbia River below Bonneville Dam. Specifically for fall Chinook, we assume a 20\% marine non-selective harvest rate in Canadian and Alaskan waters and a $20 \%$ selective harvest rate on hatchery fish in Washington and Oregon marine waters (2:1 selective differential). In the mainstem Columbia River, the HSRG assumed a 20\% selective harvest rate on hatchery fish and a 5:1 selective differential. For terminal harvest rates, the HSRG generally used harvest rates supplied by the managers.

In addition, the HSRG recommends that managers either adopt or continue an ESU-wide strategy for control of bacterial kidney disease. 


\section{Hatchery Scientific Review Group}

Pacific Salmon Hatchery Reform

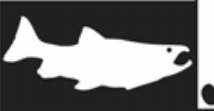

\section{Primary Populations}

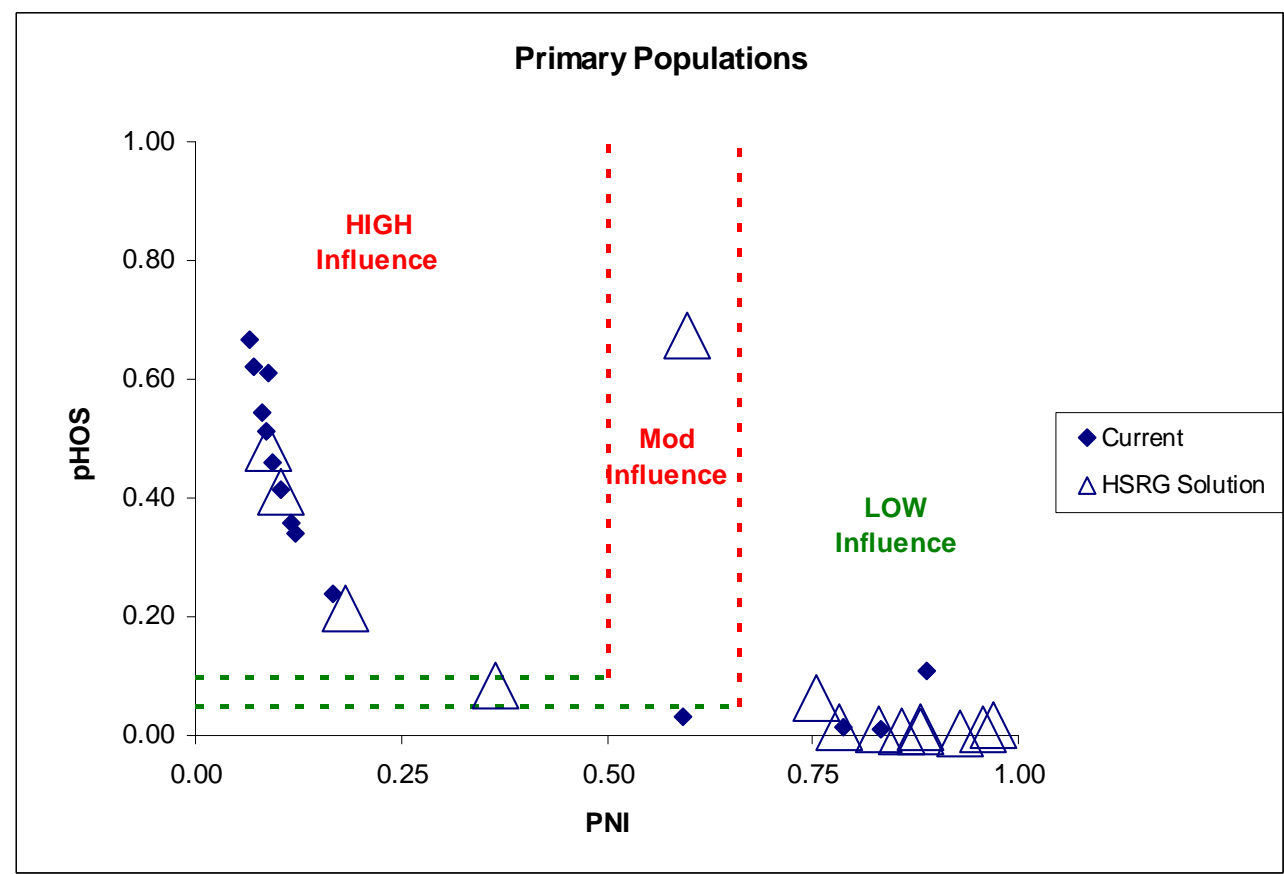

- Current

$\triangle$ HSRG Solution
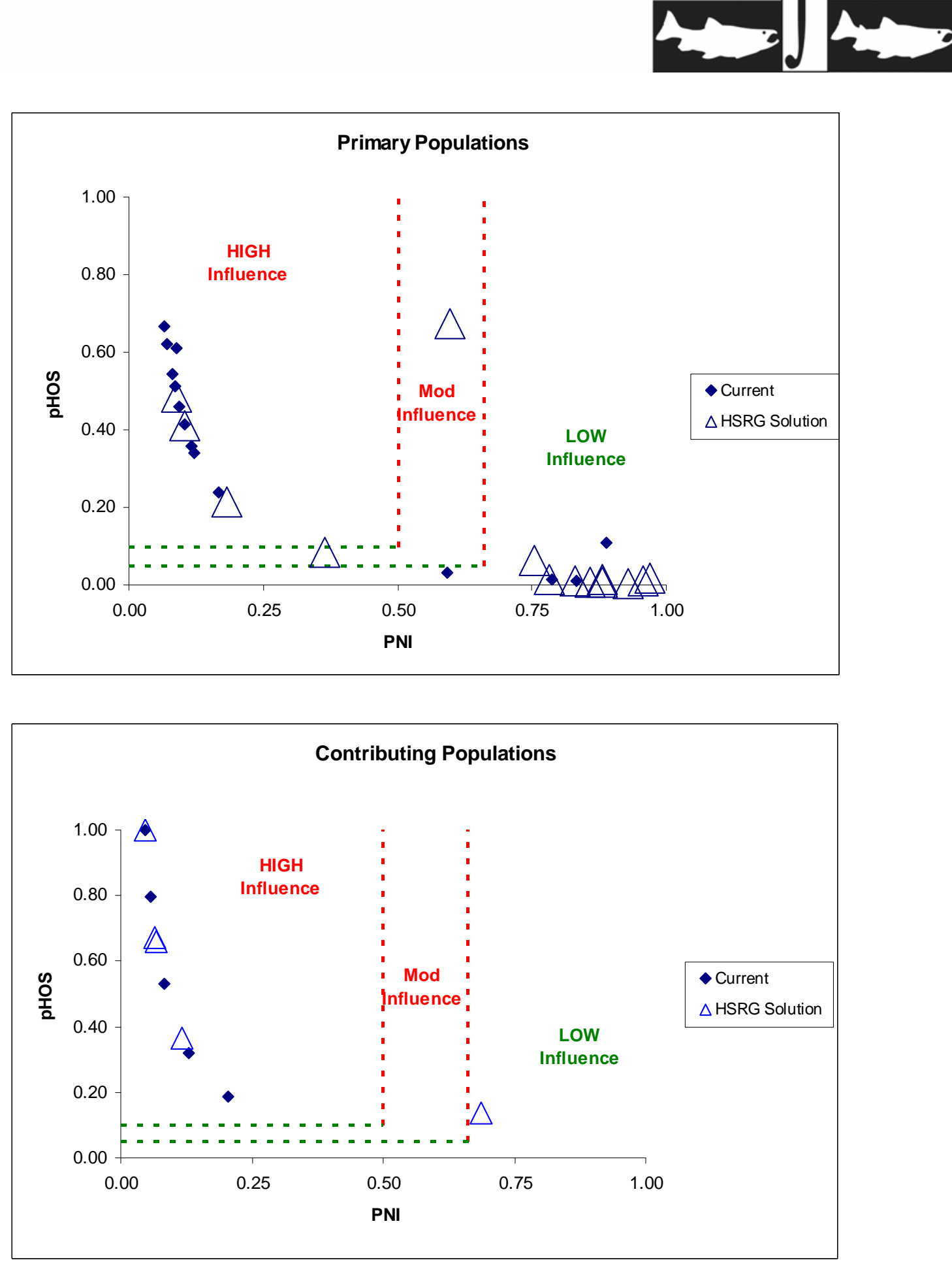

Figure 1. Relationship of the proportion of the fish on the spawning grounds that are of hatchery origin (pHOS) and the proportionate natural influence index (PNI) for Primary (top panel) and Contributing (bottom panel) Chinook populations in the Lower Columbia River ESU. Solid diamonds represent values for current programs and open triangles represent values for the HSRG recommended hatchery management solution. 


\section{Hatchery Scientific Review Group}

Pacific Salmon Hatchery Reform
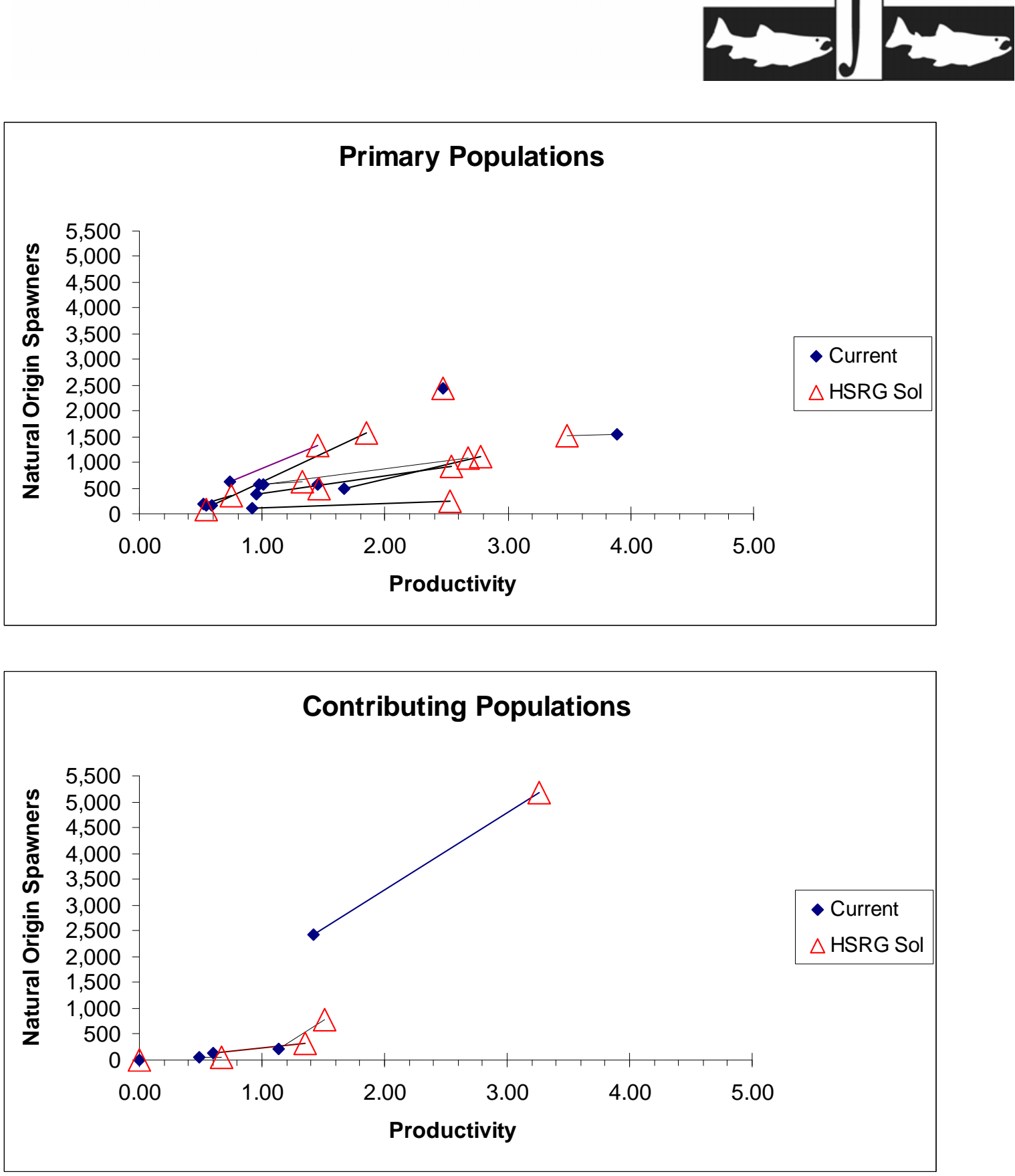

Figure 2. Productivity and spawner abundance for Primary (top panel) and Contributing (bottom panel) Chinook populations in the Lower Columbia River ESU. Solid diamonds represent existing productivity and spawner abundance levels, and triangles represent the HSRG recommended hatchery management solution. Lines connect current with HSRG solution for a particular population.

Note: Figure 2 does not include Lewis River or Clatskanie populations. 


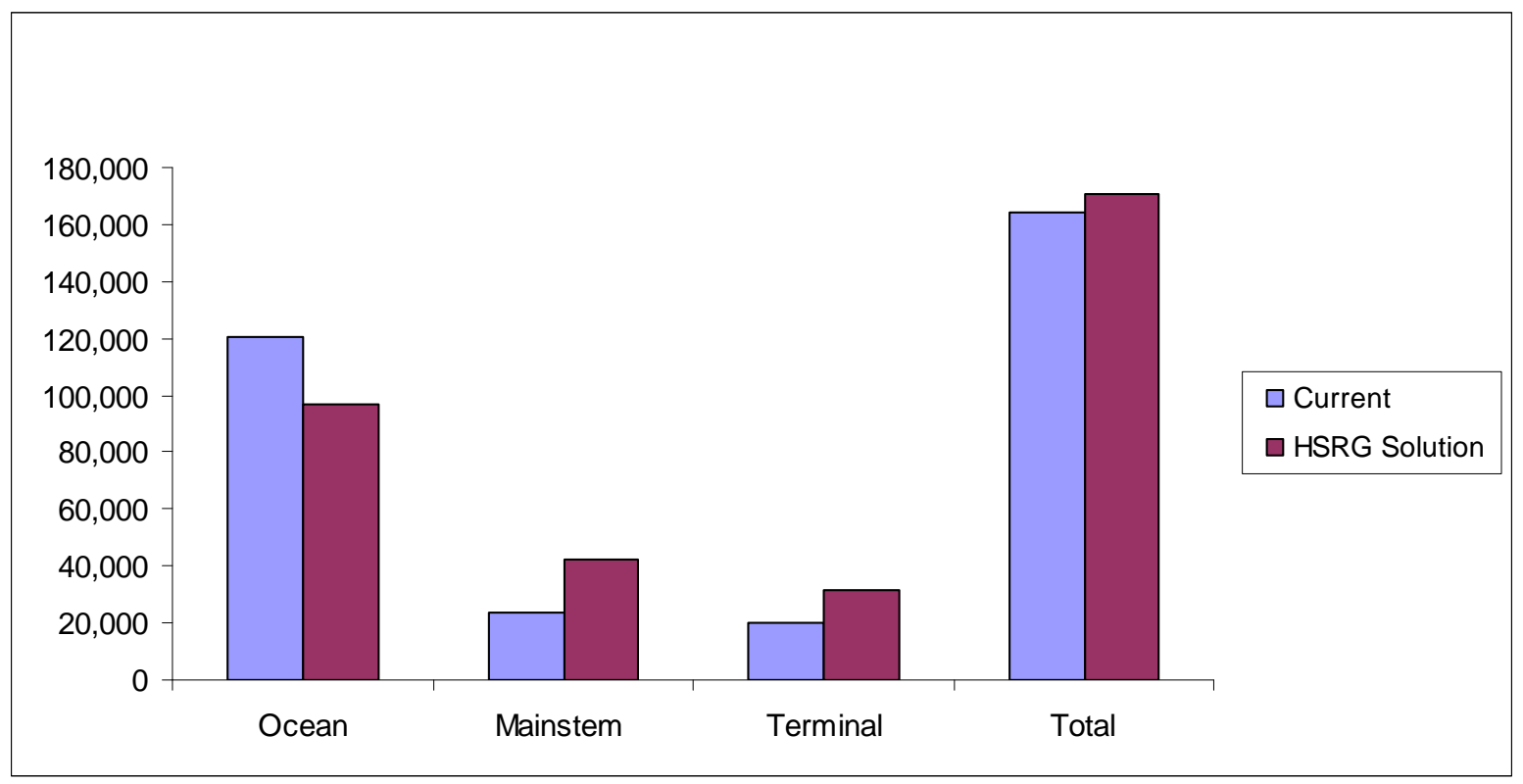

Figure 3. Estimated marine, mainstem Columbia, and terminal harvest under current and HSRG recommended hatchery management solution for Lower Columbia River Chinook ESU.

\section{Summary and Conclusions}

In order to be consistent with their conservation goals, managers need to implement both hatchery and harvest reforms. Implementing these reforms in the Lower Columbia Chinook ESU increases productivity and abundance of natural populations and can maintain harvest at current levels.

Aligning hatchery programs with conservation goals will require implementing effective integrated or segregated hatchery broodstock protocols to achieve the standards described by the HSRG. For segregated programs, the number of hatchery-origin fish spawning naturally will need to be limited. In some cases, this will require nearly total exclusion of hatchery fish from natural populations through use of weirs or a combination of weirs and selective harvest. For integrated programs, this requires including the appropriate number of natural-origin fish in hatchery broodstock as well as controlling the contribution of hatchery fish to natural spawning areas. Hatchery infrastructure modifications will be needed to accomplish this.

Increased selective fisheries will be necessary in marine, terminal and mainstem areas to maintain current harvest numbers. Achieving these harvest benefits will also require developing harvest methods and gear for commercial freshwater fisheries to enable selective removal of hatchery fish with low mortality to natural fish. Maintaining harvest levels in this ESU also requires increasing the availability and harvest of fish where they are spatially and temporally segregated from natural populations (i.e., Select Area Fishery sites). Without increases in selective fisheries, solutions to meet conservation goals will require reduced hatchery production and catch.

The HSRG also concludes that (a) hatchery and harvest reforms alone will not achieve recovery of listed populations (habitat improvements are also necessary), and (b) the 


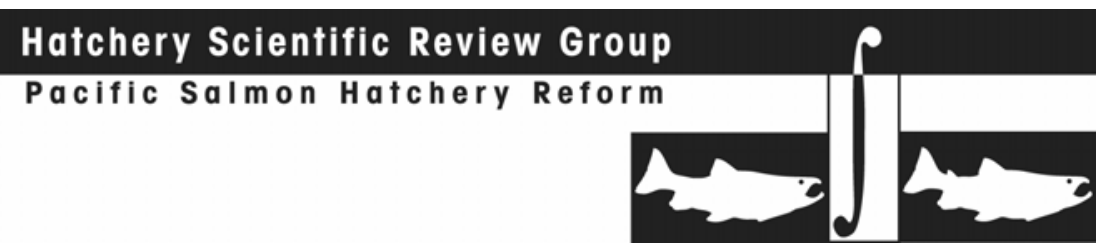

effectiveness of habitat actions will be greatly increased if they are combined with hatchery and harvest reforms. Under the HSRG assumptions, analysis of the Primary populations in the Lower Columbia Chinook ESU suggests that the benefits of habitat quality improvements would more than double if combined with hatchery reforms. Unless hatchery and harvest reforms are implemented, the potential benefits of current or improved habitat cannot be fully realized.

\subsubsection{Upper Willamette River Chinook Salmon ESU}

This section provides an overview of the Upper Willamette River Chinook Salmon ESU. It contains a general description of the ESU, fisheries, habitat limitations and hatchery programs that affect it. Overall recommendations for ESU-wide hatchery program changes are summarized, as are the effects of implementing those changes on conservation and harvest goals. Detailed conclusions and recommendations for each population in the ESU can be found in the Appendix E. In this overview, a population is included that is not considered part of an ESU (Upper Willamette fall Chinook).

\subsubsection{HSRG Population Guidelines}

In order to meet conservations goals for the ESU, numerous threats to these populations need to be addressed, including risks from hatchery programs. The key to controlling genetic and ecological risks due to straying and fitness loss is to manage hatchery broodstock and natural spawning escapement such that the natural habitat (and not the hatchery environment) drives the adaptation and productivity of the naturally spawning population. This is achieved by operating either (a) integrated programs where the proportion of natural-origin adults in the broodstock (pNOB) exceeds the proportion of hatchery-origin fish on the spawning grounds (pHOS); or (b) segregated programs where the contribution of hatchery fish to natural spawning is kept low (pHOS $<5 \%$ to $<10 \%$ depending on the population designation). The HSRG developed criteria for hatchery influence for three population types based on the importance of the population to the recovery of the ESU. This was done to provide a consistent method of reviewing populations and programs across the Columbia River Basin. The population designations used by the HSRG (Primary, Contributing, or Stabilizing) were adopted after discussions with managers and followed those developed in the Lower Columbia River Salmon Recovery Plan (LCFRB 2004). These designations are meant to reflect the conservation importance of a population within the ESU from most important (Primary), to moderately important (Contributing), to least important (Stabilizing). HSRG recommendations show how hatchery programs can be operated consistent with these designations based on the following standards:

\section{HSRG criteria for hatchery influence on Primary populations}

- The proportion of effective hatchery-origin spawners (pHOS) should be less than 5\% of the naturally spawning population, unless the hatchery population is integrated with the natural population.

- For integrated populations, the proportion of natural-origin adults in the broodstock should exceed $\mathrm{pHOS}$ by at least a factor of two, corresponding to a PNI (proportionate natural influence) value of 0.67 or greater and pHOS should be less than 0.30 . 
HSRG criteria for hatchery influence on Contributing populations

- The proportion of effective hatchery-origin spawners (pHOS) should be less than $10 \%$ of the naturally spawning population, unless the hatchery population is integrated with the natural population.

- For integrated populations, the proportion of natural-origin adults in the broodstock should exceed pHOS, corresponding to a PNI value of 0.50 or greater and $\mathrm{pHOS}$ should be less than 0.30 .

HSRG criteria for hatchery influence on Stabilizing populations

- Current operating conditions are considered adequate to meet conservation goals. No criteria were developed for proportion of effective hatchery-origin spawners ( $\mathrm{pHOS}$ ) or PNI.

\subsubsection{Current Conditions}

\section{Conservation}

The Upper Willamette River Chinook salmon ESU is listed as threatened under the federal ESA and includes seven populations. These are all naturally spawned populations of spring-run Chinook in the Clackamas River, the Willamette River and its tributaries above Willamette Falls, as well as seven artificial propagation programs.

Historically, there were seven demographically independent populations of spring Chinook salmon in this ESU: Clackamas, Molalla/Pudding, Calapooia, North Santiam, South Santiam, McKenzie, and Middle Fork Willamette (Meyers et al. 2003). The McKenzie River produced roughly $40 \%$ of the spring Chinook run above Willamette Falls (Mattson 1948). Today, four core populations survive in the Clackamas, North Santiam, McKenzie and Middle Fork Willamette subbasins. Each of these historically sustained large numbers of fish and may have the intrinsic capacity to sustain large populations into the future (McElhany et al. 2003). The McKenzie subbasin population represents an important element of the genetic legacy of the Upper Willamette ESU. The McKenzie population has been the least influenced by intra- or inter-basin transfers of hatchery stocks and is thought to retain a relatively high degree of adaptation to local watershed conditions (Willamette Restoration Initiative 2004).

According to the Technical Recovery Team (TRT) for Upper Willamette River Chinook, two populations are effectively extinct (NMFS 2007). Five of the seven populations (Molalla, North Santiam, South Santiam, Calapooia, and Middle Fork Willamette) included in the ESA-listing are considered to be at "very high" risk of extinction, one (McKenzie) is considered to be at a "moderate" risk of extinction, and one (Clackamas) is considered to be at "low" risk of extinction (McElhany et al. 2007). Delisting criteria have not been established, but the TRT suggests that delisting will require that at least four of the seven populations (consisting or core and genetic legacy populations) reach a low or very low risk of extinction (NMFS 2007).

The HSRG assigned a Primary population designation to three spring Chinook populations: Clackamas River, McKenzie River, and North Santiam River. Two populations (Middle Fork Willamette and South Santiam) were designated as 
Contributing populations. The Calapooia, Coast Fork Willamette, and Molalla River populations were designated as Stabilizing populations (Table 1).

Table 1. Population designations for the Upper Willamette River Chinook ESU and HSRG broodstock criteria achieved for each population under current conditions and the HSRG recommended hatchery management solution.

\begin{tabular}{|c|c|c|c|}
\hline \multirow[b]{2}{*}{ Population } & \multirow[b]{2}{*}{ Designation $^{1}$} & \multicolumn{2}{|c|}{ HSRG Criteria Met ${ }^{2}$} \\
\hline & & Current & HSRG Solution \\
\hline Clackamas Spring Chinook & Primary & Primary & Primary \\
\hline McKenzie Spring Chinook & Primary & Primary & Primary \\
\hline North Santiam Spring Chinook & Primary & Stabilizing & Stabilizing \\
\hline Middle Fork Willamette Spring Chinook & Contributing & Stabilizing & Stabilizing \\
\hline South Santiam Spring Chinook & Contributing & Stabilizing & Contributing \\
\hline Calapooia Spring Chinook & Stabilizing & Stabilizing & Stabilizing \\
\hline Coast Fork Spring Chinook & Stabilizing & Stabilizing & Stabilizing \\
\hline Molalla Spring Chinook & Stabilizing & Stabilizing & Stabilizing \\
\hline
\end{tabular}

1 Using the naming protocol of the Lower Columbia River Salmon Recovery Plan (LCFRB 2004), populations were classified based on information provided to the HSRG as Primary, Contributing, or Stabilizing. These designations are meant to reflect the conservation importance of a population within the ESU from most important (Primary- bold, red), to moderately important (Contributing-bold, blue), to least important (Stabilizing).

2 The HSRG developed criteria for hatchery influence for the three population designations from low influence (Primary), moderate influence (Contributing) to high influence (Stabilizing).

\section{Current Harvest}

Upper Willamette River Chinook salmon are harvested in non-selective ocean fisheries in southeast Alaska and northern Canada, in partially selective fisheries in the mainstem Columbia and entirely selective fisheries in Willamette River and tributaries (NMFS 2008c). The harvest rate on Upper Willamette River Chinook in ocean fisheries has averaged $11 \%$ in recent years (NMFS 2008c). The allowable harvest rate on unmarked Chinook in all freshwater fisheries is $15 \%$, specified by the Fisheries Management and Evaluation Plan for spring Chinook (as reported in NMFS 2008c). Hatchery programs for Upper Willamette River Chinook provide significant harvest opportunities. Actual freshwater harvest on natural-origin Chinook has ranged from 9 to $12 \%$ in recent years (NMFS 2008c); however, current harvest rates are believed to be reduced to a point where harvest no longer limits recovery (NMFS 2008c).

\section{Current Habitat}

Development, agriculture and forestry practices have substantially degraded habitat conditions in portions of the Upper Willamette ESU (NMFS 2008d). Habitat in the mainstem Willamette River and lower reaches of all the tributaries is moderately to severely degraded (NMFS 2008d). Only two of the watersheds that support discrete Chinook populations (Clackamas and McKenzie rivers) currently contain sufficient habitat that is still accessible and of sufficient quality to produce significant numbers of natural-origin spring Chinook (NMFS 2008c). Specific habitat concerns related to Chinook production vary by subbasin, but include reduced habitat complexity, reduced access to off-channel habitat, reduced floodplain function and connectivity, loss of 


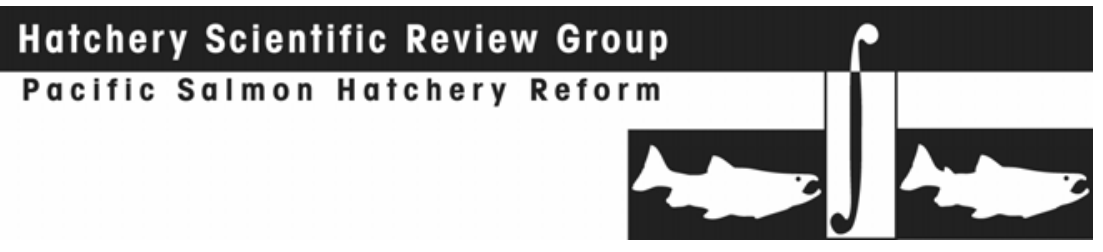

holding pools, elevated water temperatures, insufficient stream flows, toxic water pollutants, and altered substrate compositions (NMFS 2008d).

One of the primary habitat limiting factors within the Upper Willamette River Chinook ESU is lack of access to important historical spawning and rearing tributaries. This is attributed to flood control and hydropower development, primarily the 13 dams operated by the U.S. Army Corps of Engineers (ACOE) on five of the largest tributaries in the ESU. Habitat conditions above these dams, although not pristine, represent the best available habitat for spawning, incubation, and early rearing by spring Chinook (NMFS 2008a). As stipulated in a recent ESA consultation on the ACOE 13-dam complex, over the next 15 years, fish passage facilities at priority dams in four major tributaries will be evaluated and modifications implemented (NMFS 2008c).

\section{Current Hatchery Programs}

There are currently six hatchery programs operating in the ESU. The ESU is dominated by poorly integrated programs due to low numbers of natural-origin fish resulting from blocked habitat in the subbasin. Programs provide significant harvest benefits, and in many cases, help preserve genetic resources in the ESU. Integrated harvest programs are operated on the Middle Fork Willamette, McKenzie, Molalla, North Santiam, and South Santiam rivers. A segregated harvest program is operated on Clackamas River. Approximately 4.5 million spring Chinook are released from the five integrated programs, and nearly 1.1 million spring Chinook are released from the segregated program (Table 2).

Hatcheries have been used as a management tool in the Willamette River subbasin for over 100 years, including mitigation for production lost due to dams (NMFS 2008d). Every population in the Upper Willamette River Chinook ESU is currently affected by a hatchery program. Hatchery-origin fish outnumber natural-origin spawners in nearly all populations. Even the natural spawning population in the Calapooia River (which does not receive direct hatchery releases) is estimated to be comprised of over $50 \%$ out-ofbasin hatchery-origin strays. While counts of adult hatchery- and natural-origin spring Chinook over Willamette Falls since 1946 have increased, approximately $90 \%$ of the total return is now hatchery fish (NMFS 2008a). According to NMFS (2008a), six of the Chinook populations included in the ESA-listed ESU are at risk for genetic introgression due to the high proportions of hatchery-origin fish on the spawning grounds.

Estimates of PNI and pHOS under current conditions show that only two of the Primary populations in the ESU (Clackamas and McKenzie rivers) meet the broodstock criteria for their population designation. The remaining Primary and Contributing populations (North Santiam, Middle Fork Willamette, and South Santiam rivers) only meet the broodstock criteria for Stabilizing populations (Table 1). 

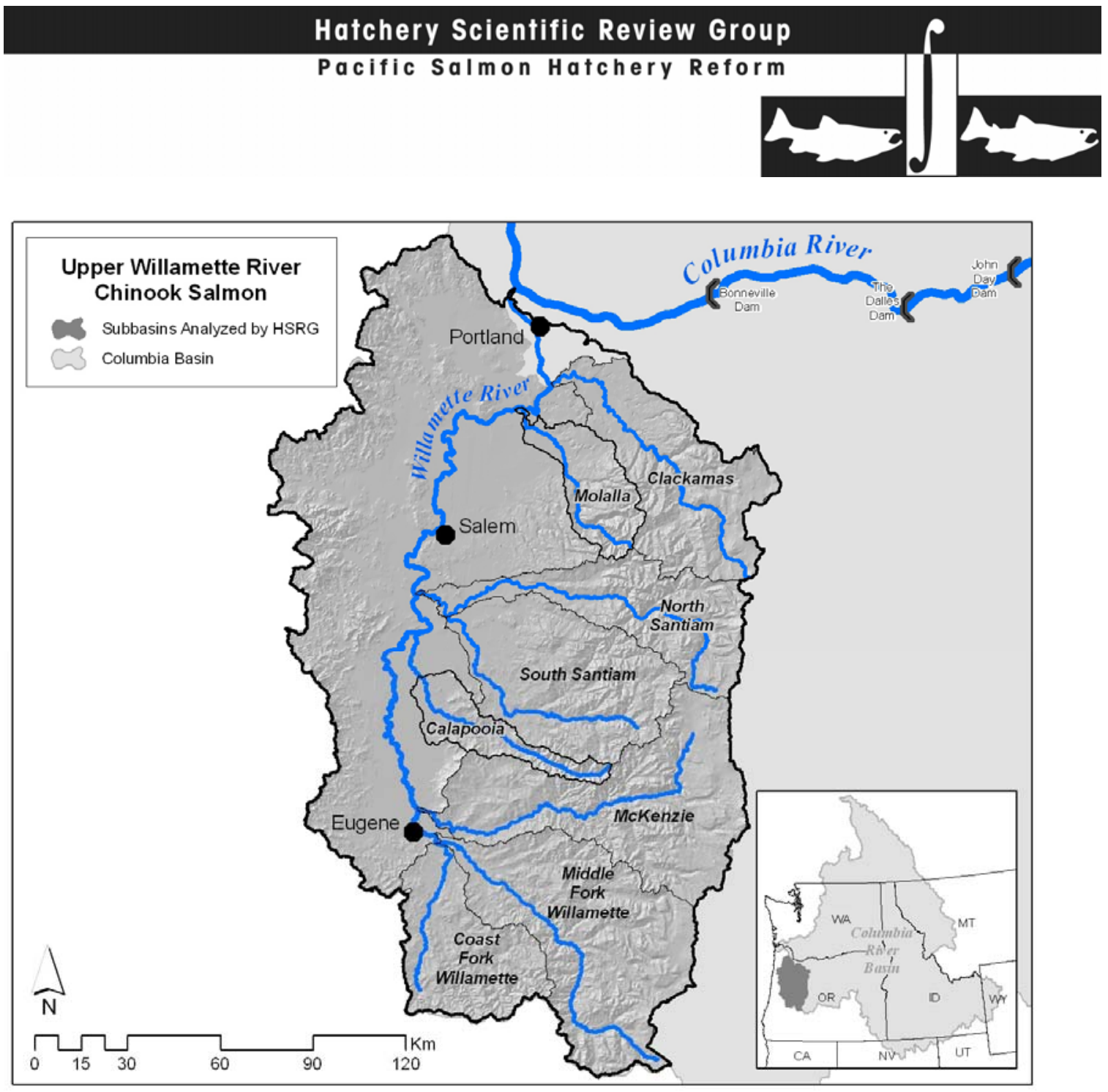

Table 2. Hatchery releases and types of programs for Upper Willamette River Chinook ESU.

\begin{tabular}{|l|c|c|c|c|c|c|}
\hline \multirow{2}{*}{ Population/Program Name } & \multicolumn{3}{|c|}{ Current (1,000s) } & \multicolumn{2}{c|}{ HSRG Solution (1,000s) } \\
\cline { 2 - 7 } & Type & Purpose & $\begin{array}{c}\# \\
\text { Released }\end{array}$ & Type & Purpose & $\begin{array}{c}\# \\
\text { Released }\end{array}$ \\
\hline Calapooia Spring Chinook & None & NA & - & None & NA & - \\
\hline Clackamas Spring Chinook & None & NA & - & None & NA & - \\
\hline Clackamas Spring Chinook (Hatchery) & Seg & Harv & $1,077.8$ & Seg & Harv & $1,077.8$ \\
\hline Coast Fork Spring Chinook & None & NA & - & None & NA & - \\
\hline Middle Fork Willamette Spring Chinook & Int & Both & $1,256.6$ & Int & Both & $1,256.6$ \\
\hline McKenzie Spring Chinook & Int & Both & $1,265.6$ & Int & Both & $1,265.6$ \\
\hline Molalla Spring Chinook & Int & Both & 99.1 & Int & Both & 99.1 \\
\hline North Santiam Spring Chinook & Int & Both & 752.2 & Int & Both & 752.2 \\
\hline South Santiam Spring Chinook & Int & Both & $1,123.2$ & Int & Both & $1,022.3$ \\
\hline Total all Populations/Programs & & & $\mathbf{5 , 5 7 4 . 4}$ & & & $\mathbf{5 , 4 7 3 . 5}$ \\
\hline
\end{tabular}




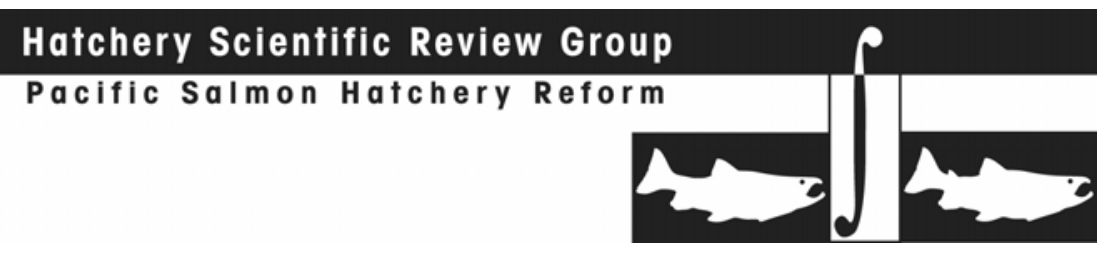

\subsubsection{HSRG Solutions}

Options for improving the integrated hatchery programs in this ESU are limited due to the low number of natural-origin fish in the subbasin. This is generally the result of limited access to quality habitat cut off by flood control and hydropower development. Options for improving hatchery programs or achieving conservation goals are limited until this issue is addressed. Contribution to conservation was improved for one population by improving broodstock collection and reducing the size of its integrated harvest program.

\section{Conservation Outcomes under the HSRG Solutions}

Figure 1 compares the proportion of fish on the spawning grounds that are of hatchery origin (pHOS) and the proportionate natural influence (PNI) for current and proposed (HSRG) scenarios for Primary and Contributing populations. The HSRG solution did not change the status of the three primary populations (Clackamas, McKenzie, and North Santiam). Hatchery programs in the Clackamas and McKenzie rivers are currently meeting the standards of Primary populations for segregated (Clackamas River; pHOS $<.05$ ) and integrated (McKenzie River; PNI > 0.67) programs. The status of the remaining Primary population (North Santiam River) could not be improved because of limited habitat availability and this population will continue to have high hatchery influence until passage conditions are improved. This program acts as a gene bank for this population and should be continued.

The HSRG solutions change the status of one Contributing population. By improving broodstock collection efficiency, the proportion of natural-origin fish in the hatchery broodstock and slightly reducing the hatchery program, the South Santiam River program improves to be consistent with designation as a Contributing population (PNI $>0.5)$. The status of the remaining Contributing population (Middle Fork Willamette River) could not be improved because of limited habitat availability. This population will continue to have high hatchery influence until passage conditions improve, and in fact, without continuing the hatchery program, it appears that this population would become extinct. The Middle Fork Willamette River hatchery program acts as a gene bank for this population and should be continued.

Figure 2 compares spawner abundance and productivity relationships between current and HSRG-proposed scenarios for the three Primary and two Contributing spring Chinook populations in the Willamette Chinook ESU. Since broodstock management could only be improved for the Contributing population in the South Santiam River, this is the only population showing an improvement in productivity and abundance.

\section{Harvest Outcomes under the HSRG Solutions}

Figure 3 describes current and estimated changes in harvest (marine, mainstem Columbia River and terminal areas) that would occur following implementation of the management solutions proposed by the HSRG. Harvest numbers and distribution remain essentially the same as the current condition since few hatchery programs were modified. 
Hatchery Program Changes under the HSRG Solutions

Table 2 shows the current size of each hatchery program as well as its size under the HSRG solution. In this ESU, the size of only one program would change. The South Santiam program achieves the criteria for a Contributing population by increasing the proportion of natural-origin broodstock from $10 \%$ to $12 \%$, improving broodstock collection efficiency and slightly reducing program size from approximately 1.12 million to 1.02 million smolts.

ESU-wide, the managers appear to have developed a successful strategy for control of bacterial kidney disease. The HSRG recommends that they continue this strategy.

In addition to the above recommendations, the HSRG noted the need for facility upgrades in several locations to improve adult collection, holding, and handling. Juvenile acclimation facilities could also be improved in the North Santiam River.

\section{Summary and Conclusions}

Options for achieving conservation goals and improving several hatchery programs are limited due to low natural production potential resulting from inaccessible habitat. The two populations that have substantial habitat available currently meet the standards for Primary populations (McKenzie and Clackamas). For the remaining populations, the HSRG solution focuses on improvements to current hatchery programs.

The HSRG solutions identified ways to improve the productivity and abundance of one population (South Santiam).

Harvest distribution and numbers are maintained at current levels.

The HSRG was unable to develop a solution that increases natural-origin returns to the ESU given the currently accessible habitat. Unless fish passage is provided at tributary dams, the likelihood of achieving conservation objectives in this ESU is poor. If currently inaccessible habitat becomes available in the future, managers should reassess their programs and modify them to take advantage of additional habitat productivity and capacity. 


\section{Hatchery Scientific Review Group}

Pacific Salmon Hatchery Reform
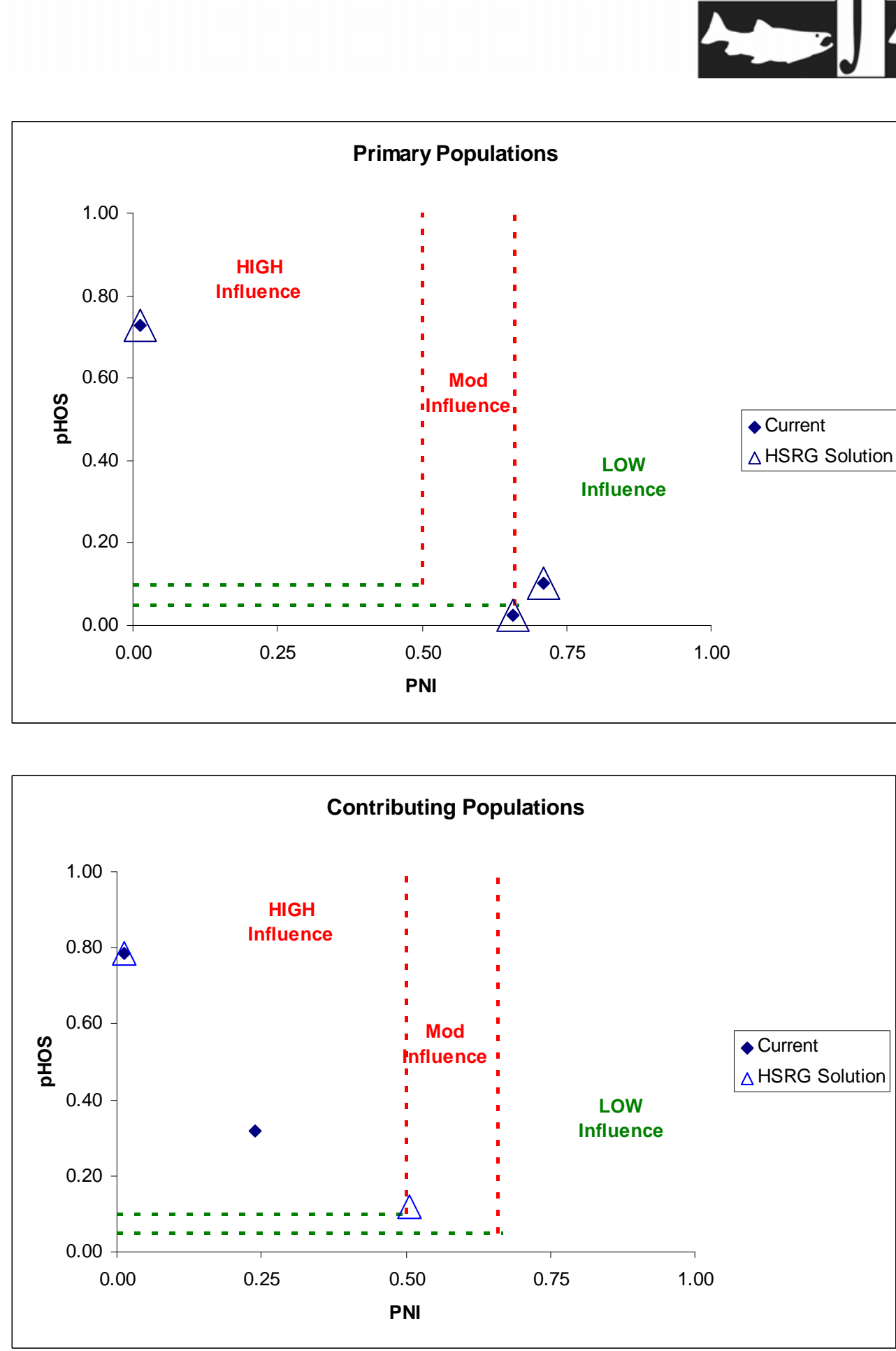

Figure 1. Relationship of the proportion of the fish on the spawning grounds that are of hatchery origin (pHOS) and the proportionate natural influence index (PNI) for Primary (top panel) and Contributing (bottom panel) Chinook populations in the Upper Willamette River ESU. Solid diamonds represent values for current programs and open triangles represent values for the HSRG recommended hatchery management solution. 


\section{Hatchery Scientific Review Group}

Pacific Salmon Hatchery Reform
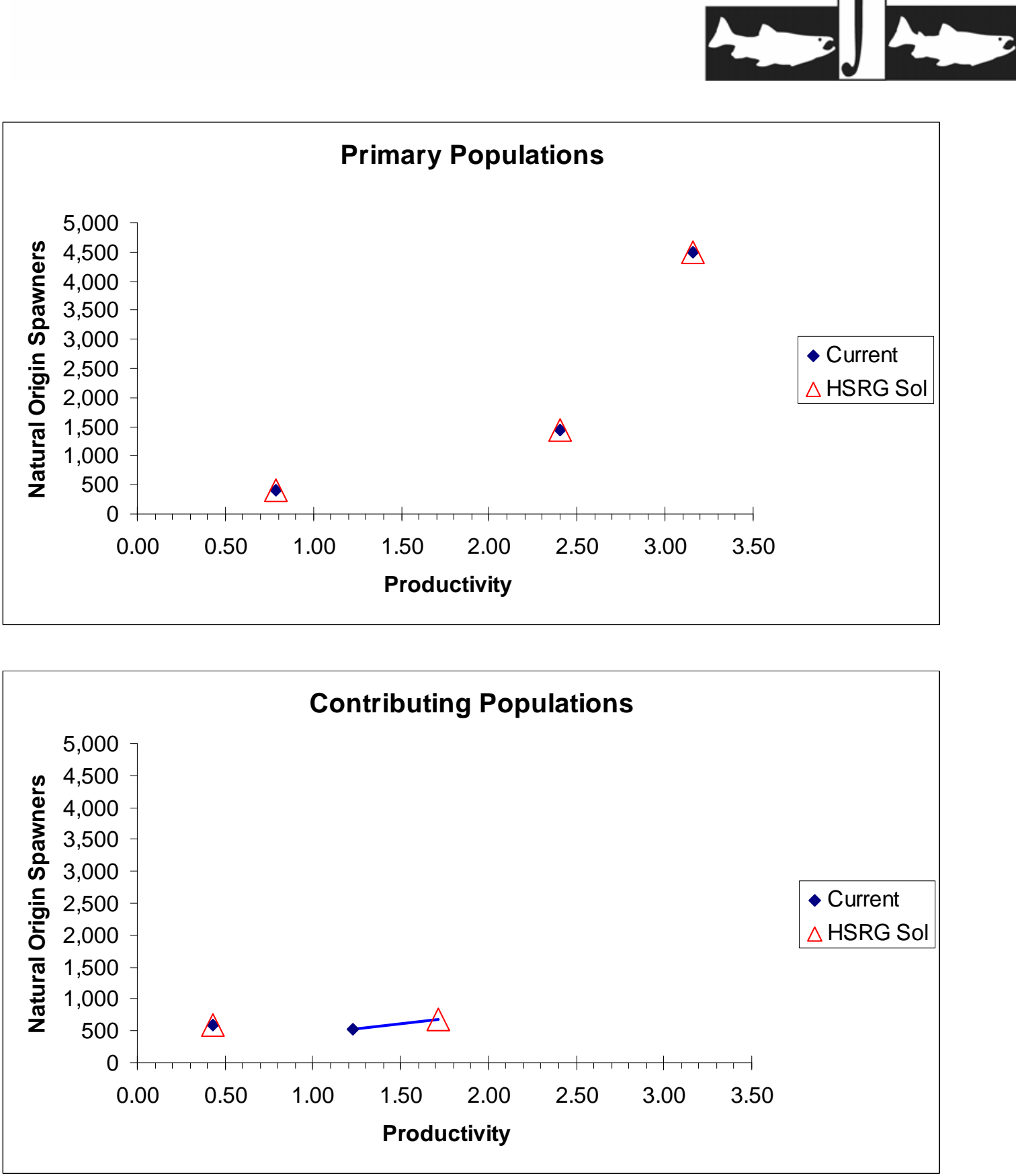

Figure 2. Productivity and spawner abundance for Primary (top panel) and Contributing (bottom panel) Chinook populations in the Upper Willamette River ESU. Solid diamonds represent existing productivity and spawner abundance levels, and triangles represent the HSRG recommended hatchery management solution. Lines connect current with HSRG solution for a particular population. 

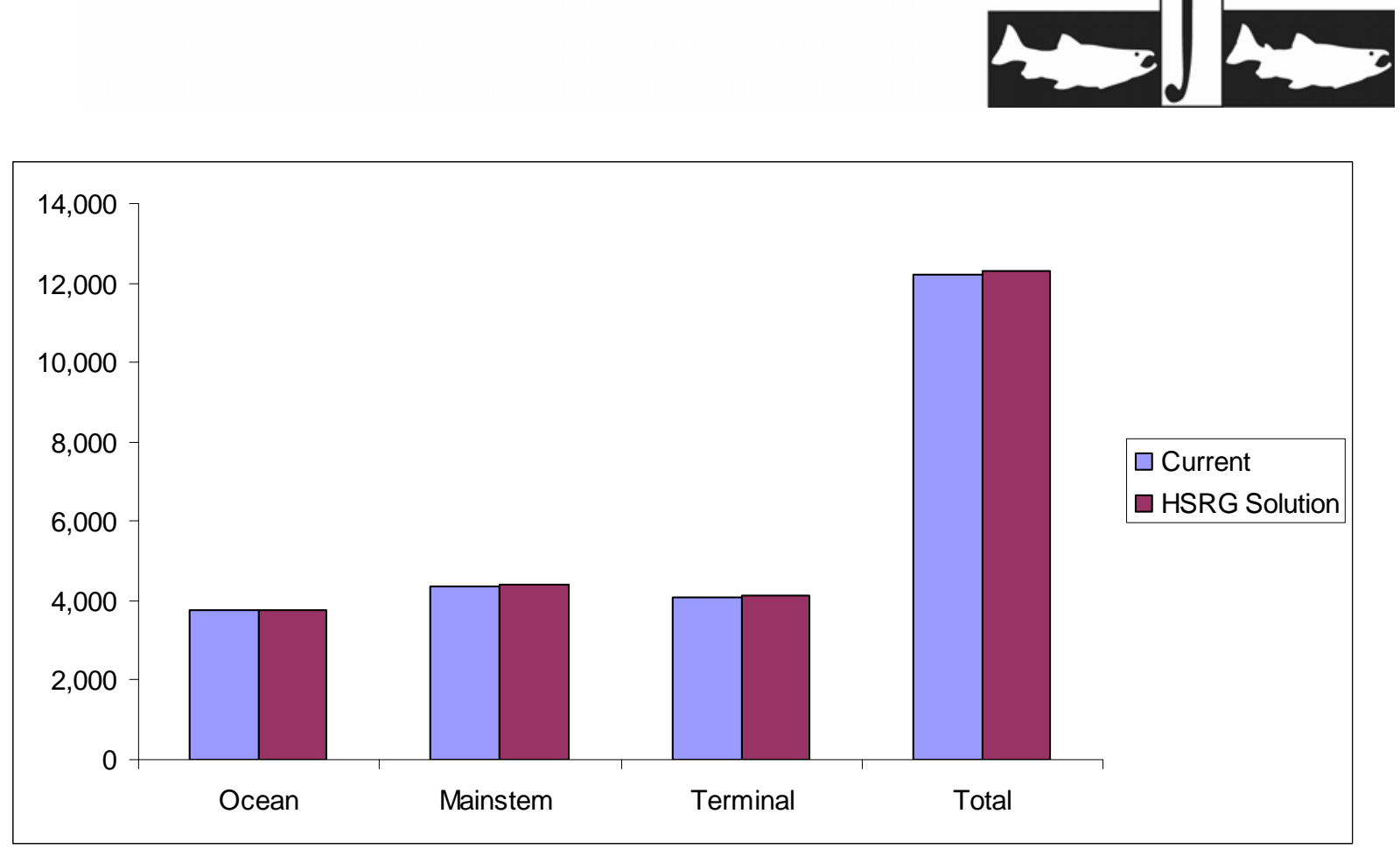

Figure 3. Estimated marine, mainstem Columbia, and terminal harvest under current and HSRG recommended hatchery management solution for Upper Willamette River Chinook ESU.

\subsubsection{Middle Columbia River Spring-run Chinook Salmon ESU}

This section provides an overview of the Middle Columbia River spring Chinook ESU. It contains a general description of the ESU, fisheries, habitat limitations and hatchery programs that affect it. Overall recommendations for ESU-wide hatchery program changes are summarized as are the results of implementing these changes on conservation and harvest goals. Detailed conclusions and recommendations for each population in the ESU can be found in the Appendix E.

\section{HSRG Population Guidelines}

In order to meet conservations goals for the ESU, numerous threats to these populations need to be addressed, including risks from hatchery programs. The key to controlling genetic and ecological risks due to straying and fitness loss is to manage hatchery broodstock and natural spawning escapement such that the natural habitat (and not the hatchery environment) drives the adaptation and productivity of the naturally spawning population. This is achieved by operating either (a) integrated programs where the proportion of natural-origin adults in the broodstock (pNOB) exceeds the proportion of hatchery-origin fish on the spawning grounds (pHOS); or (b) segregated programs where the contribution of hatchery fish to natural spawning is kept low (pHOS $<5 \%-<10 \%$ depending on the population designation). The HSRG developed criteria for hatchery influence for three population types based on the importance of the population to the recovery of the ESU. This was done to provide a consistent method of reviewing populations and programs across the Columbia River Basin. The population designations 


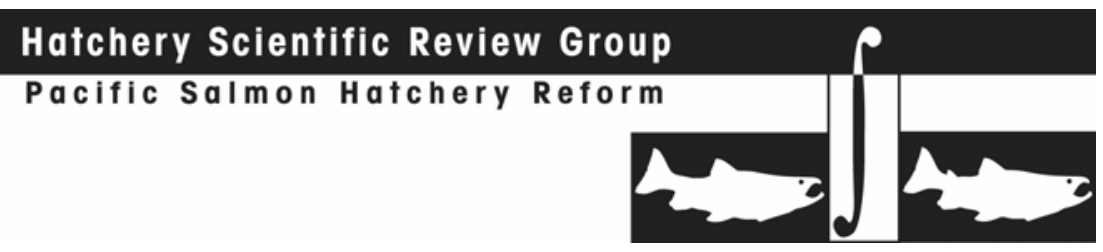

used by the HSRG (Primary, Contributing, or Stabilizing) were adopted after discussions with managers and followed those developed in the Lower Columbia River Salmon Recovery Plan (LCFRB 2004). These designations are meant to reflect the conservation importance of a population within the ESU from most important (Primary), to moderately important (Contributing), to least important (Stabilizing). HSRG recommendations show how hatchery programs can be operated consistent with these designations based on the following standards:

HSRG criteria for hatchery influence on Primary populations

- The proportion of effective hatchery-origin spawners (pHOS) should be less than 5\% of the naturally spawning population, unless the hatchery population is integrated with the natural population.

- For integrated populations, the proportion of natural-origin adults in the broodstock should exceed pHOS by at least a factor of two, corresponding to a PNI (proportionate natural influence) value of 0.67 or greater and pHOS should be less than 0.30 .

HSRG criteria for hatchery influence on Contributing populations:

- The proportion of effective hatchery-origin spawners (pHOS) should be less than $10 \%$ of the naturally spawning population, unless the hatchery population is integrated with the natural population.

- For integrated populations, the proportion of natural-origin adults in the broodstock should exceed $\mathrm{pHOS}$, corresponding to a PNI value of 0.50 or greater and $\mathrm{pHOS}$ should be less than 0.30 .

HSRG criteria for hatchery influence on Stabilizing populations

- The current operating conditions were considered adequate to meet conservation goals. No criteria were developed for proportion of effective hatchery-origin spawners (pHOS) or PNI.

\subsubsection{Current Conditions}

\section{Conservation}

The Mid-Columbia River spring-run Chinook salmon ESU includes all naturally spawned populations of spring-run Chinook in Columbia River tributaries from the Klickitat River upstream to and including the Yakima River (excluding the Snake River Basin). The HSRG analysis of Mid-Columbia River Chinook included 10 discrete populations, but did not include the historical populations from the upper Deschutes River subbasin which were extirpated when habitat was blocked by construction of a hydropower dam.

The ESU was determined by NMFS not to warrant listing under the ESA on March 9, 1998 despite the fact that several historical populations have been extirpated (Myers et al. 1998). Five extant populations (three in the John Day River subbasin and two in the Yakima River subbasin) are managed for natural production. Two populations (Umatilla and Walla Walla) were extirpated early in the 1900s, but spring Chinook salmon are being reintroduced into these areas. The remaining three populations (Klickitat, Upper Yakima, and Deschutes) are affected by integrated hatchery programs. The John Day 


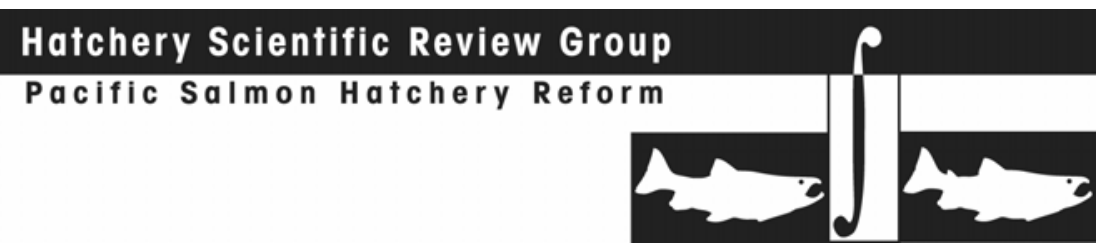

and Yakima River subbasins have the largest populations in the ESU; these are predominantly comprised of naturally produced Chinook (Myers et al. 1998). Despite low abundances relative to estimated historical levels, long-term trends in abundance have been relatively stable, with an approximately even mix of upward and downward trends in populations (Myers et al. 1998).

For the purpose of this analysis, the HSRG assigned a Primary population designation to seven populations and three were designated as Contributing populations (the Upper Mainstem John Day, Umatilla and Walla Walla populations) (Table 1).

\section{Current Harvest}

Middle Columbia River Chinook are managed for both conservation and harvest goals. Harvest occurs predominately in mainstem Columbia River and terminal areas. Few Mid-Columbia River Chinook are harvested in ocean fisheries. The 2008-2017 United States v. Oregon Management Agreement defines mainstem Columbia River harvest rates that are abundance-based and uses a sliding scale harvest rate schedule (5.5\% to $17 \%)$ for natural-origin spring Chinook returning to the Snake River Basin.

Sport fisheries occur in the mainstem Columbia River and terminal areas and target adipose fin-clipped hatchery fish. Non-tribal commercial fisheries occur in the lower Columbia River below Bonneville Dam and are partially selective. The Tribal fisheries occur in Zone 6 (Columbia River above Bonneville Dam) and terminal areas and are nonselective.

Table 1. Population designations for the Middle Columbia Chinook ESU and HSRG broodstock criteria achieved for each population under current conditions and the HSRG recommended hatchery management solution.

\begin{tabular}{|l|c|c|c|}
\hline \multirow{2}{*}{ Population } & \multirow{2}{*}{${\text { HSRG Criteria } \text { Met }^{2}}$} & \multicolumn{2}{|c|}{} \\
\cline { 3 - 4 } & Designation & Current & HSRG Solution $^{1}$ \\
\hline Deschutes Spring Chinook & Primary & Contributing & Primary \\
\hline John Day Middle Fork John Day Spring Chinook & Primary & Primary & Primary \\
\hline John Day North Fork John Day Spring Chinook & Primary & Primary & Primary \\
\hline Klickitat Spring Chinook & Primary & Stabilizing & Primary \\
\hline Yakima American Spring Chinook & Primary & Primary & Primary \\
\hline Yakima Naches Spring Chinook & Primary & Primary & Primary \\
\hline Yakima Upper Yakima Spring Chinook & Primary & Primary & Primary \\
\hline John Day Upper Mainstem John Day Spring Chinook & Contributing & Primary & Primary \\
\hline Umatilla Spring Chinook & Contributing & Stabilizing & Contributing \\
\hline Walla Walla Spring Chinook & Contributing & Stabilizing & Contributing \\
\hline
\end{tabular}

1 Using the naming protocol of the Lower Columbia River Salmon Recovery Plan (LCFRB 2004), populations were classified based on information provided to the HSRG as Primary, Contributing, or Stabilizing. These designations are meant to reflect the conservation importance of a population within the ESU from most important (Primary- bold, red), to moderately important (Contributing-bold, blue), to least important (Stabilizing).

2 The HSRG developed criteria for hatchery influence for the three population designations from low influence (Primary), moderate influence (Contributing) to high influence (Stabilizing). 


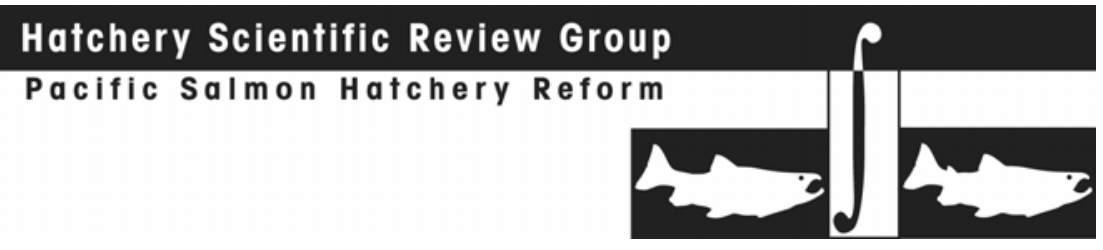

Current Habitat

The quality of habitat in this ESU varies greatly from highly degraded to high quality. Mainstem Columbia River dams disrupt migration corridors and affect flow regimes and estuarine habitat (Myers et al. 1998). Within the range of the Middle Columbia River Chinook ESU, spawning and rearing habitat has been reduced by agriculture including water withdrawals, grazing, and riparian vegetation management (Myers et al. 1998). The Pelton-Round Butte Dam complex is the only large artificial barrier to spawning areas for spring Chinook salmon in the ESU. This facility is thought to have eliminated a natural population in the upper Deschutes River subbasin (Nehlsen 1995). As an outcome of FERC relicensing, Chinook are being reintroduced upstream of this hydropower complex. Major fish passage projects are also under development at natural blockages in the Klickitat River subbasin. Native populations were extirpated in the Umatilla and Walla Walla rivers due to water withdrawals, and spring Chinook salmon are being reintroduced to these areas.

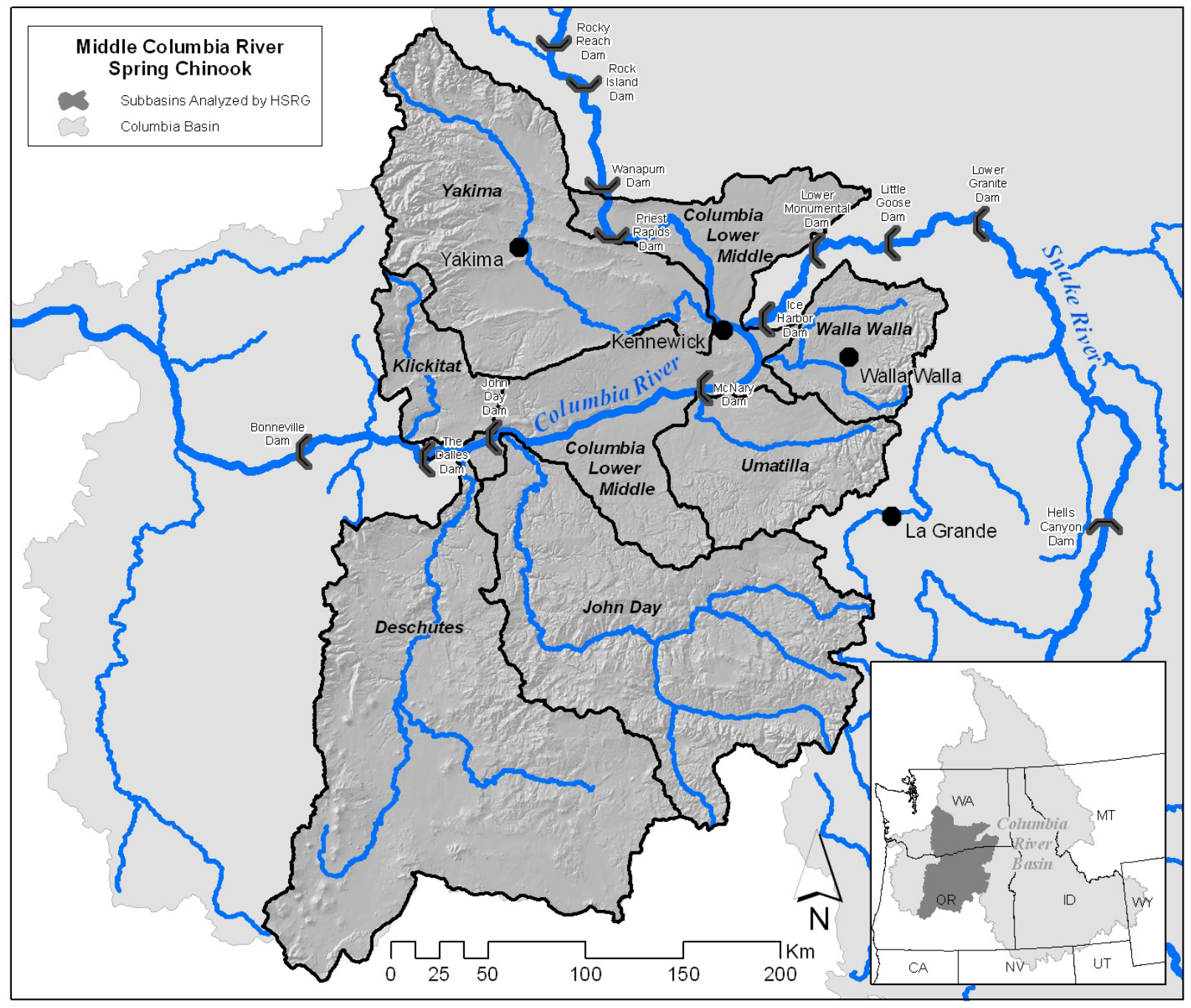




\section{Current Hatchery Programs}

There are seven spring Chinook salmon hatchery programs in this ESU. The largest populations with hatchery programs are well integrated (in the Upper Yakima River and Deschutes), three programs are poorly integrated, and two are operated as segregated harvest programs (Table 2). Hatchery stocks used in this ESU were derived from local populations except for the two reintroduction programs (Umatilla and Walla Walla) and one of the segregated programs. Collectively, these programs release approximately 4.2 million spring Chinook salmon and account for a substantial proportion of total escapement to the region (Myers 1998). Hatchery fish comprise a high percentage of returning adults in all of the subbasins except for the John Day, which is managed for natural production.

Table 2. Hatchery releases and types of programs for Middle Columbia River Chinook ESU.

\begin{tabular}{|l|c|c|c|c|c|c|}
\hline \multirow{2}{*}{ Population/Program Name } & \multicolumn{3}{|c|}{ Current (1,000s) } & \multicolumn{3}{c|}{ HSRG Solution (1,000s) } \\
\cline { 2 - 7 } & Type & Purpose & $\begin{array}{c}\text { No. } \\
\text { Released }\end{array}$ & Type & Purpose & $\begin{array}{c}\text { Noleased } \\
\text { Relaty }\end{array}$ \\
\hline Deschutes Spring Chinook & Int & Both & 746.9 & Int & Both & 746.9 \\
\hline Deschutes Spring Chinook (Round Butte-Hatchery) & Seg & Harv & 320.6 & Seg & Harv & 320.6 \\
\hline John Day Middle Fork John Day Spring Chinook & None & NA & - & None & NA & - \\
\hline John Day North Fork John Day Spring Chinook & None & NA & - & None & NA & - \\
\hline John Day Upper Mainstem John Day Spring Chinook & None & NA & - & None & NA & - \\
\hline Klickitat Spring Chinook & Int & Both & 831.2 & Int & Both & 800.8 \\
\hline Yakima American Spring Chinook & None & NA & - & None & NA & - \\
\hline Yakima Naches Spring Chinook & None & NA & - & None & NA & - \\
\hline Yakima Upper Yakima Spring Chinook & Int & Both & 810.7 & Int & Both & 810.7 \\
\hline Umatilla Spring Chinook & Int & Both & 925.2 & Int & Both & 277.6 \\
\hline Umatilla Spring Chinook (Stepping Stone Hatchery) & Seg & Harv & - & Seg & Harv & 562.2 \\
\hline Walla Walla Spring Chinook & Int & Cons & 249.5 & Int & Cons & 198.5 \\
\hline $\begin{array}{l}\text { Columbia Lower Middle Mainstem Columbia Spring } \\
\text { Chinook (Ringold via LWS-Hatchery) }\end{array}$ & Seg & Harv & 487.1 & Seg & Harv & 486.8 \\
\hline Total all Populations/Programs & & & $\mathbf{4 , 3 7 1 . 2}$ & & & $\mathbf{4 , 2 0 4 . 0}$ \\
\hline
\end{tabular}

There are ten populations in this ESU. Estimates of PNI and pHOS under current conditions indicate that the six populations meet broodstock criteria for a Primary designation and one meets the criteria for a Contributing designation. The remaining three populations meet the criteria for Stabilizing populations; however, two of the three populations (Umatilla and Walla Walla) were extirpated and hatchery programs are being used for reintroduction (Table 1).

\subsubsection{HSRG Solutions}

Implementing HSRG recommendations is expected to result in broodstock management that achieves a Primary designation for two additional populations and a Contributing designation for two additional populations compared to current conditions. Conservation benefits are achieved for this ESU while slightly increasing harvest from current conditions. 


\section{Conservation Outcomes under the HSRG Solutions}

Figure 1 compares the proportion of hatchery-origin (pHOS) fish on the spawning grounds and the proportionate natural influence (PNI) for Primary and Contributing populations under the managers' goals and the proposed HSRG scenarios. The HSRG solution achieves criteria for all Primary and Contributing populations (Table 1). No recommendations were made for the five populations currently managed for natural production that are achieving the standards for Primary populations. The HSRG solution allows the three populations currently meeting Stabilizing standards to improve enough to meet the standards for Primary (Klickitat) and Contributing (Umatilla and Walla Walla) designations. Smaller improvements would occur for two populations (Deschutes and Upper Yakima).

Figure 2 compares spawner abundance and productivity relationships between current and HSRG-proposed scenarios. Large improvements in productivity are expected for one Primary and two Contributing populations. Smaller productivity improvements occur in two Primary populations. Natural spawner abundance remains approximately the same for the ESU; however, minor reductions or increases occur for some individual populations.

\section{Harvest Outcome under the HSRG Solutions}

Figure 3 illustrates current and estimated changes in harvest and the distribution of the harvest (ocean, mainstem and terminal) following implementation of the HSRG recommendations. The HSRG scenarios would not change the current harvest distribution but may slightly increase harvest due to the productivity gains for some of the populations.

\section{Hatchery Program Changes under the HSRG Solutions}

Table 2 shows the current size of each hatchery program as well as program size under the HSRG solution. The HSRG solutions slightly reduce production in this ESU; however, much of this resulted from the managers' decision to eliminate low survival parr releases in the Klickitat subbasin. Reductions also will occur in the Walla Walla subbasin over the long term once a locally returning broodstock is established. The HSRG recommendations for the near term are to maintain the current Walla Walla program.

The primary focus of the HSRG recommendations is to improve the integration of four of the hatchery programs by incorporating additional natural-origin fish into the broodstock. This allows broodstock management to conform with HSRG guidelines for Primary and Contributing populations designations. 


\section{Hatchery Scientific Review Group}

Pacific Salmon Hatchery Reform
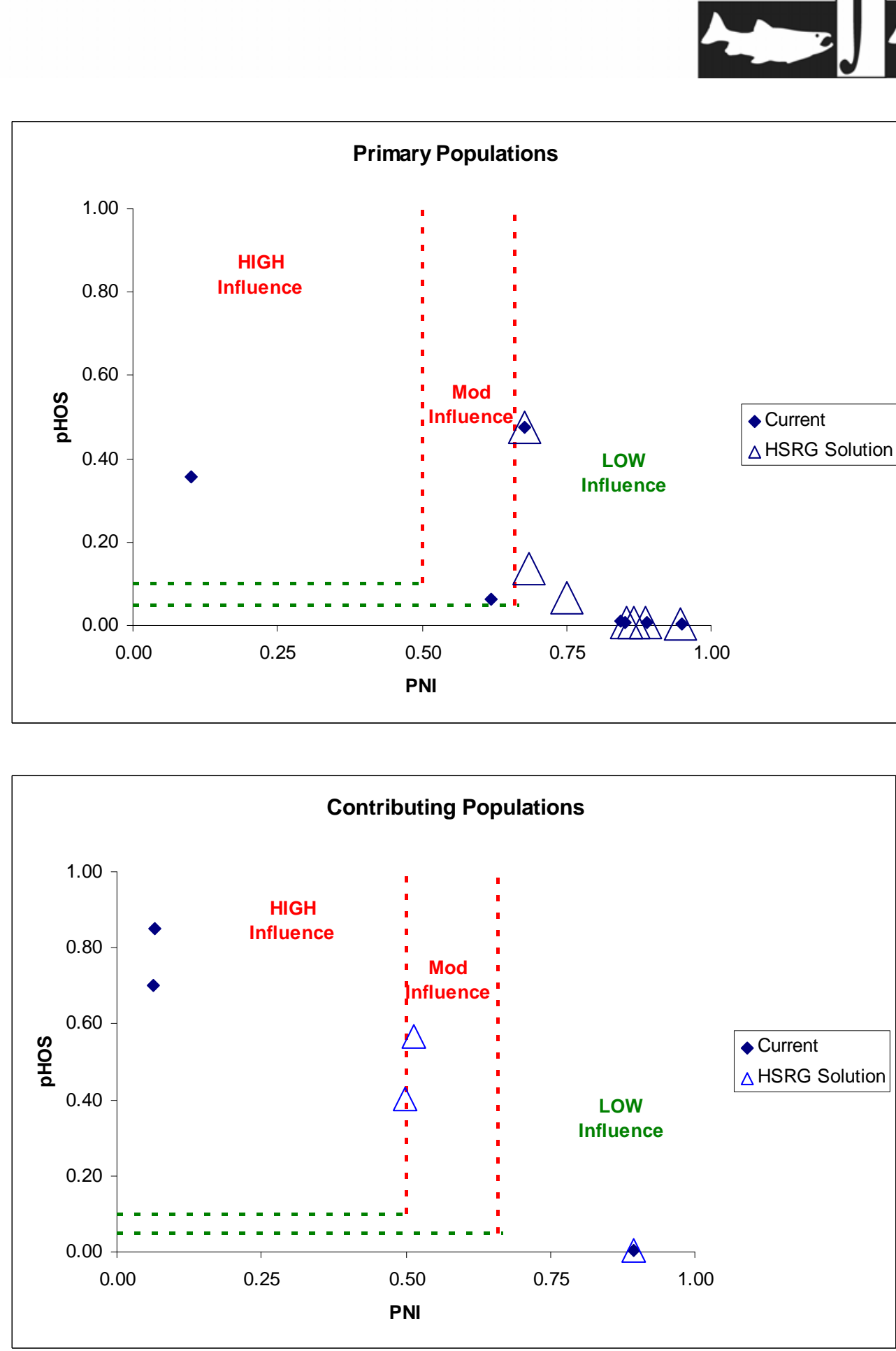

Figure 1. Relationship of the proportion of the fish on the spawning grounds that are of hatchery origin (pHOS) and the proportionate natural influence index (PNI) for Primary (top panel) and Contributing (bottom panel) Chinook populations in the Middle Columbia River ESU. Solid diamonds represent values for current programs and open triangles represent values for the HSRG recommended hatchery management solution. 


\section{Hatchery Scientific Review Group}

Pacific Salmon Hatchery Reform
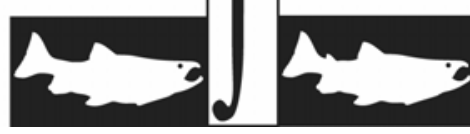

\section{Primary Populations}

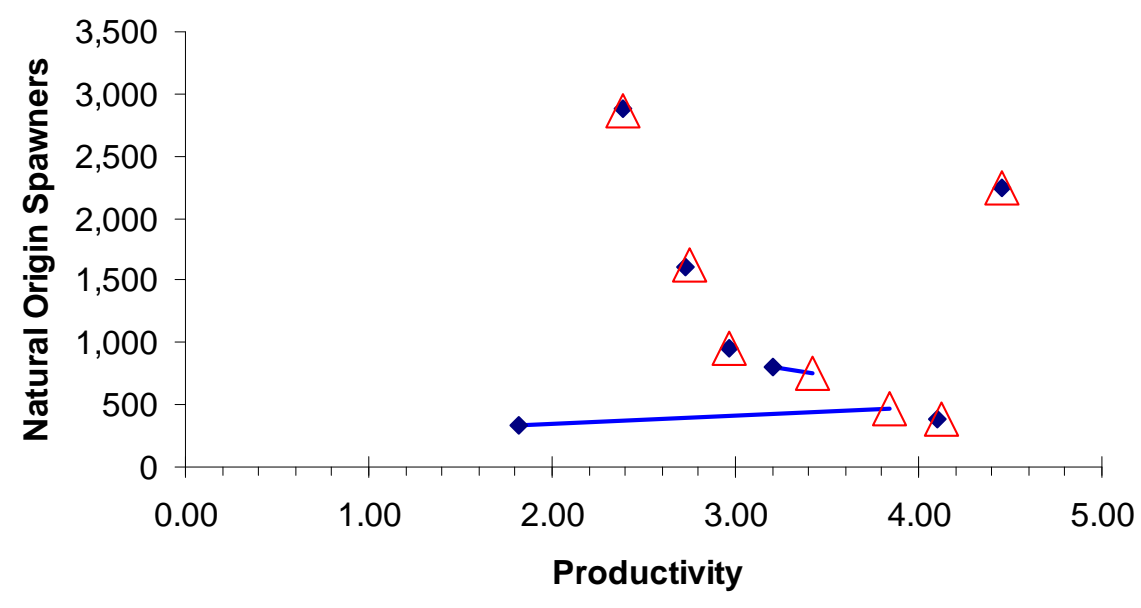

\section{Contributing Populations}

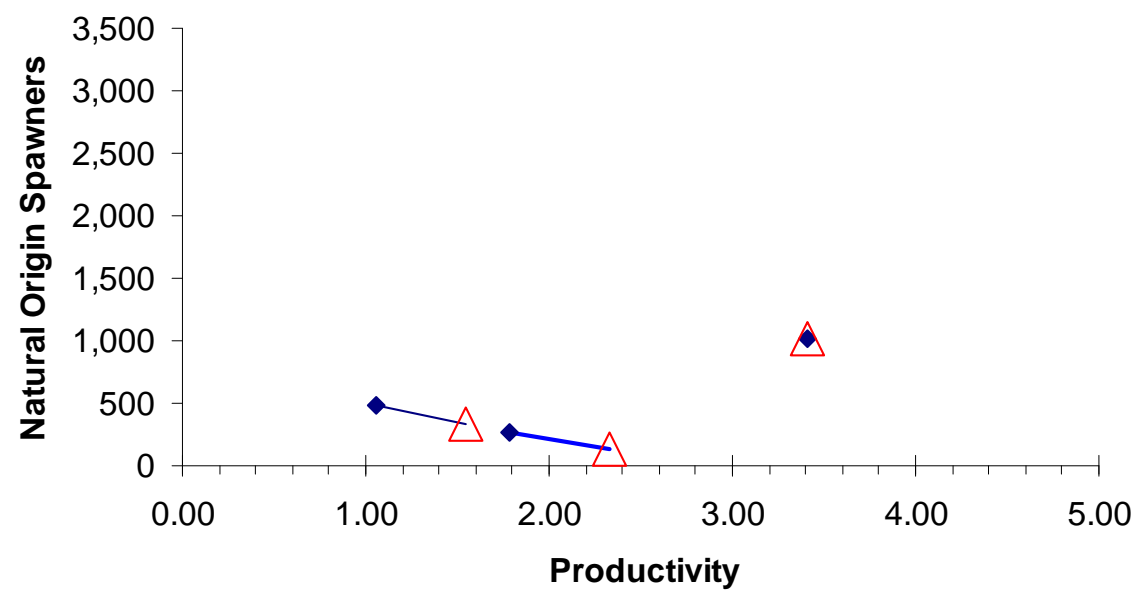

Figure 2. Productivity and spawner abundance for Primary (top panel) and Contributing (bottom panel) Chinook populations in the Middle Columbia River ESU. Solid diamonds represent existing productivity and spawner abundance levels, and triangles represent the HSRG recommended hatchery management solution. Lines connect current with HSRG solution for a particular population. The HSRG recommended hatchery management solution includes projected improved fish passage survival in the Snake and Columbia mainstem migration corridor (FCRPS Biological Opinion May 5, 2008). 

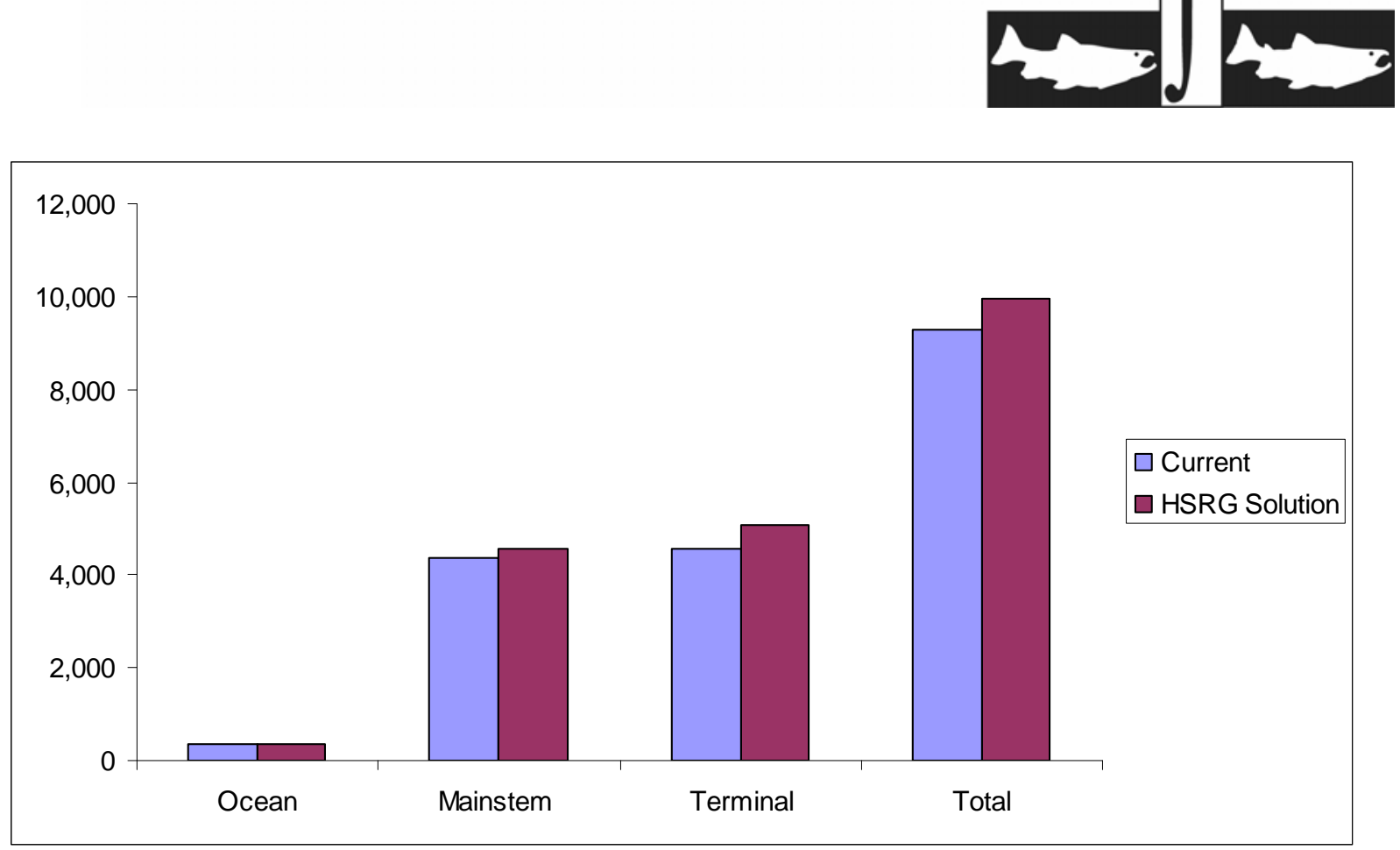

Figure 3. Estimated marine, mainstem Columbia, and terminal harvest under current and HSRG recommended hatchery management solution for Middle Columbia River Chinook ESU. The HSRG recommended hatchery management solution includes projected improved fish passage survival in the Snake and Columbia mainstem migration corridor (FCRPS Biological Opinion May 5 , 2008).

\section{Summary and Conclusions}

Overall, populations in the Middle Columbia River Chinook ESU are in better condition than in many other Columbia Basin ESUs, as reflected by the unlisted ESA status of the 10 populations. Of these populations, five are managed for natural production with no direct hatchery releases occurring in these subbasins (Table 2). The HSRG solutions improve integration of hatchery with natural fish in four of the five integrated programs, which is expected to increase productivity. The HSRG scenarios maintain current harvest levels and distribution.

The HSRG also concludes that the effectiveness of habitat actions will be greatly increased if combined with hatchery and harvest reforms. For example, the analysis of the Primary Klickitat spring Chinook population suggests that the benefits of habitat quality improvements would increase by five times if combined with hatchery reforms. Unless hatchery and harvest reforms are implemented, the potential benefits of current or improved habitat cannot be fully realized. 


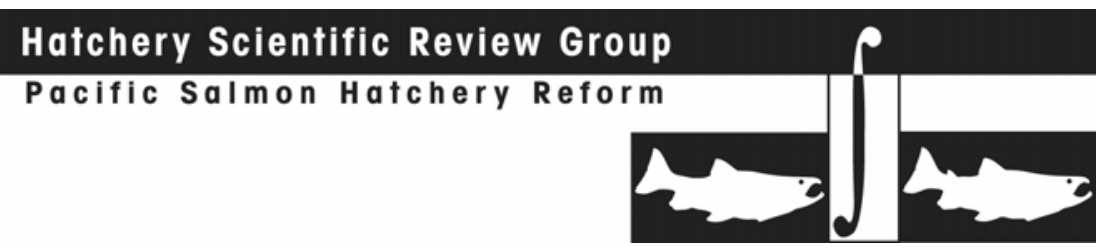

\subsubsection{Deschutes River Summer/Fall-run Chinook ESU}

This section provides an overview of the Deschutes River Summer/Fall Chinook ESU. It contains a general description of the ESU, fisheries, habitat limitations and hatchery programs that affect it. Overall recommendations for ESU-wide hatchery program changes are summarized as are the results of implementing these changes on conservation and harvest goals. Detailed conclusions and recommendations for the sole population in the ESU (Deschutes River Summer/Fall Chinook) can be found in the Appendix E.

\subsubsection{HSRG Population Guidelines}

In order to meet conservations goals for the ESU, numerous threats to these populations need to be addressed, including risks from hatchery programs. The key to controlling genetic and ecological risks due to straying and fitness loss is to manage hatchery broodstock and natural spawning escapement such that the natural habitat (and not the hatchery environment) drives the adaptation and productivity of the naturally spawning population. This is achieved by operating either (a) integrated programs where the proportion of natural-origin adults in the broodstock ( $\mathrm{pNOB}$ ) exceeds the proportion of hatchery-origin fish on the spawning grounds (pHOS); or (b) segregated programs where the contribution of hatchery fish to natural spawning is kept low (pHOS $<5 \%$ to $<10 \%$ depending on the population designation). The HSRG developed criteria for hatchery influence for three population types based on the importance of the population to the recovery of the ESU. This was done to provide a consistent method of reviewing populations and programs across the Columbia River Basin. The population designations used by the HSRG (Primary, Contributing, or Stabilizing) were adopted after discussions with managers and followed those developed in the Lower Columbia River Salmon Recovery Plan (LCFRB 2004). These designations are meant to reflect the conservation importance of a population within the ESU from most important (Primary), to moderately important (Contributing), to least important (Stabilizing). HSRG recommendations show how hatchery programs can be operated consistent with these designations based on the following standards:

\section{HSRG criteria for hatchery influence on Primary populations}

- The proportion of effective hatchery-origin spawners (pHOS) should be less than 5\% of the naturally spawning population, unless the hatchery population is integrated with the natural population.

- For integrated populations, the proportion of natural-origin adults in the broodstock should exceed pHOS by at least a factor of two, corresponding to a PNI (proportionate natural influence) value of 0.67 or greater and pHOS should be less than 0.30 .

HSRG criteria for hatchery influence on Contributing populations

- The proportion of effective hatchery-origin spawners (pHOS) should be less than $10 \%$ of the naturally spawning population, unless the hatchery population is integrated with the natural population. 
- For integrated populations, the proportion of natural-origin adults in the broodstock should exceed $\mathrm{pHOS}$, corresponding to a PNI value of 0.50 or greater and $\mathrm{pHOS}$ should be less than 0.30 .

HSRG criteria for hatchery influence on Stabilizing populations

- The current operating conditions were considered adequate to meet conservation goals. No criteria were developed for proportion of effective hatchery-origin spawners (pHOS) or PNI.

\subsubsection{Current Conditions}

\section{Conservation}

The Deschutes River summer/fall-run Chinook salmon ESU includes all naturally spawned populations of Chinook salmon from the Deschutes River, excluding the Deschutes spring-run Chinook population. The ESU includes reaches of the Deschutes River subbasin downstream of the Pelton-Round Butte Project. It is comprised of a single population that is distinct from other nearby populations in the Snake and Columbia rivers. In 1999, the ESU was determined by NMFS not to warrant listing under the ESA because it boasts one of the healthiest runs of wild fall Chinook salmon remaining in the Columbia River Basin. The summer/fall-run is of natural origin and maintained by natural production; annual adult returns are approximately 9,200 fish. A summer Chinook run is thought to have once returned to the Deschutes; however, this run is believed to have been lost after construction of the Pelton-Round Butte Project.

For the purposes of this review, the HSRG designated the sole population as Primary (Table 1).

Table 1. Population designations for the Deschutes Summer-Fall Chinook ESU and HSRG broodstock criteria achieved under current conditions and the HSRG recommended hatchery management solution.

\begin{tabular}{|l|c|c|c|}
\hline & & \multicolumn{2}{|c|}{ HSRG Criteria Met ${ }^{2}$} \\
\hline Population & Designation ${ }^{1}$ & Current & HSRG Solution $^{\text {Primary }}$ \\
\hline Deschutes Fall Chinook & Primary & Primary & Primary \\
\hline
\end{tabular}

1 Using the naming protocol of the Lower Columbia River Salmon Recovery Plan (LCFRB 2004), populations were classified based on information provided to the HSRG as Primary, Contributing, or Stabilizing. These designations are meant to reflect the conservation importance of a population within the ESU from most important (Primary- bold, red), to moderately important (Contributing-bold, blue), to least important (Stabilizing).

2 The HSRG developed criteria for hatchery influence for the three population designations from low influence (Primary), moderate influence (Contributing) to high influence (Stabilizing).

\section{Current Harvest}

Deschutes Fall Chinook are harvested in non-selective ocean fisheries and in the mainstem Columbia River. In the Deschutes River, they are harvested in a subsistence tribal dipnet fishery and, when run sizes allow, a recreational fishery. Harvest rates for the various fisheries provided to the HSRG indicate that the population currently supports a substantial annual harvest. 


\section{Current Habitat}

The Deschutes fall Chinook population spawns and rears in the lower 100 miles of the mainstem river. Construction of the Pelton-Round Butte hydropower complex may have eliminated several miles of spawning and rearing habitat, but the bulk of the historic habitat remains available to the population. No spawning has been noted in any of the tributaries to the Deschutes.

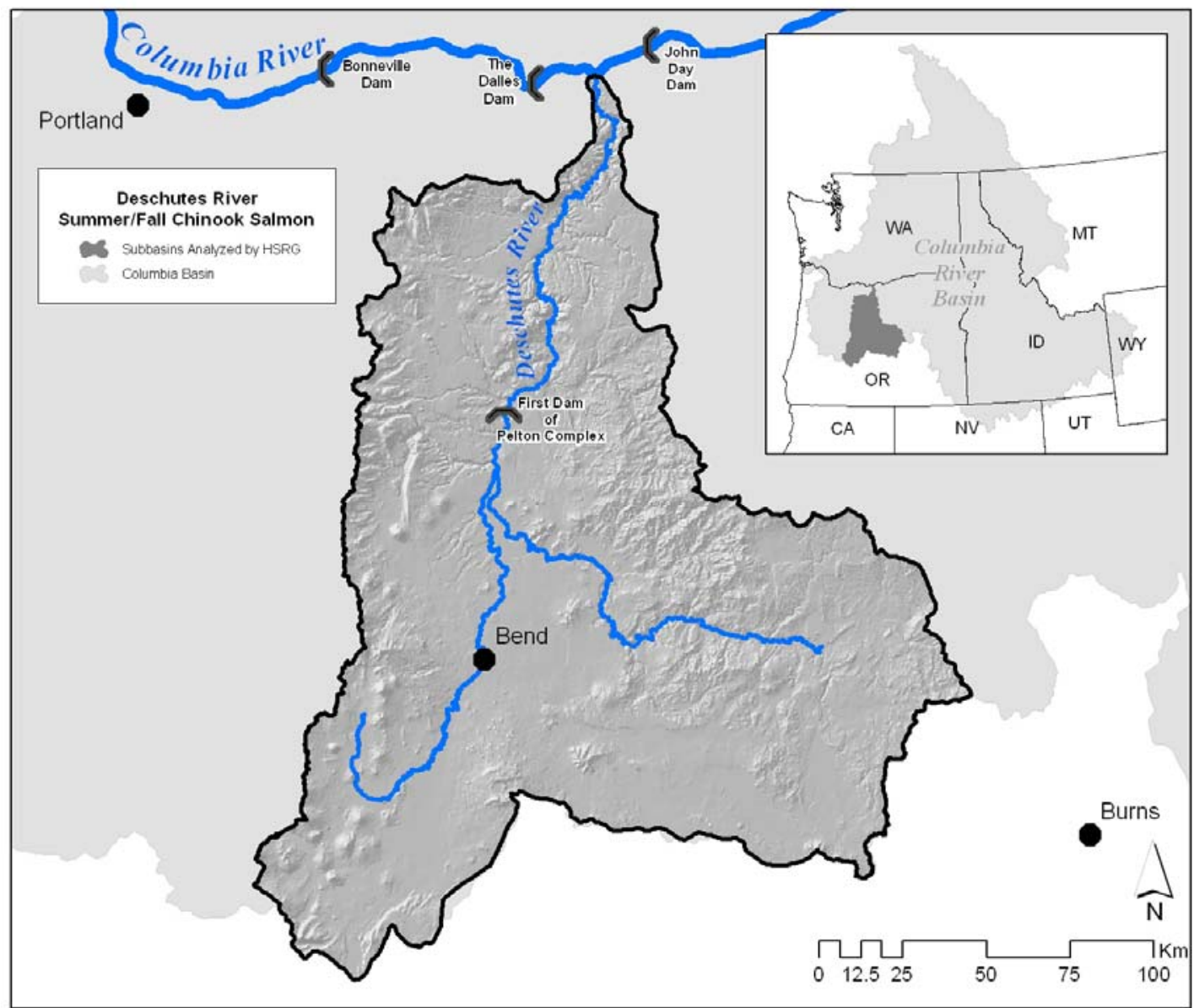

\section{Current Hatchery Programs}

No summer/fall Chinook hatchery programs currently operate in the Deschutes River. The Deschutes summer/fall Chinook population is a natural one and is sustained entirely by natural production.

The Deschutes River Chinook ESU is one of the healthiest runs of wild fall Chinook salmon remaining in the Columbia River Basin. Straying of summer/fall Chinook from hatchery programs outside of the Deschutes River is minimal (pHOS 1\%). Strays therefore do not currently pose a significant genetic threat to the population. 
Table 2. Hatchery releases and types of programs for Deschutes Summer-Fall Chinook ESU.

\begin{tabular}{|l|c|c|c|c|c|c|}
\hline \multirow{2}{*}{$\begin{array}{l}\text { Population/Program } \\
\text { name }\end{array}$} & \multicolumn{3}{|c|}{ Current (1,000s) } & \multicolumn{3}{c|}{ HSRG Solution (1,000s) } \\
\cline { 2 - 7 } & Type & Purpose & \# Released & Type & Purpose & \# Released \\
\hline Deschutes Fall Chinook & None & N/A & - & None & N/A & - \\
\hline
\end{tabular}

\subsubsection{HSRG Solutions}

There are no hatchery programs associated with this ESU and the HSRG provided no recommendations. Mainstem passage assumptions in the Biological Opinion (FCRPS 2008) result in a slight increase in productivity, abundance and harvest (Figures 2 and 3).

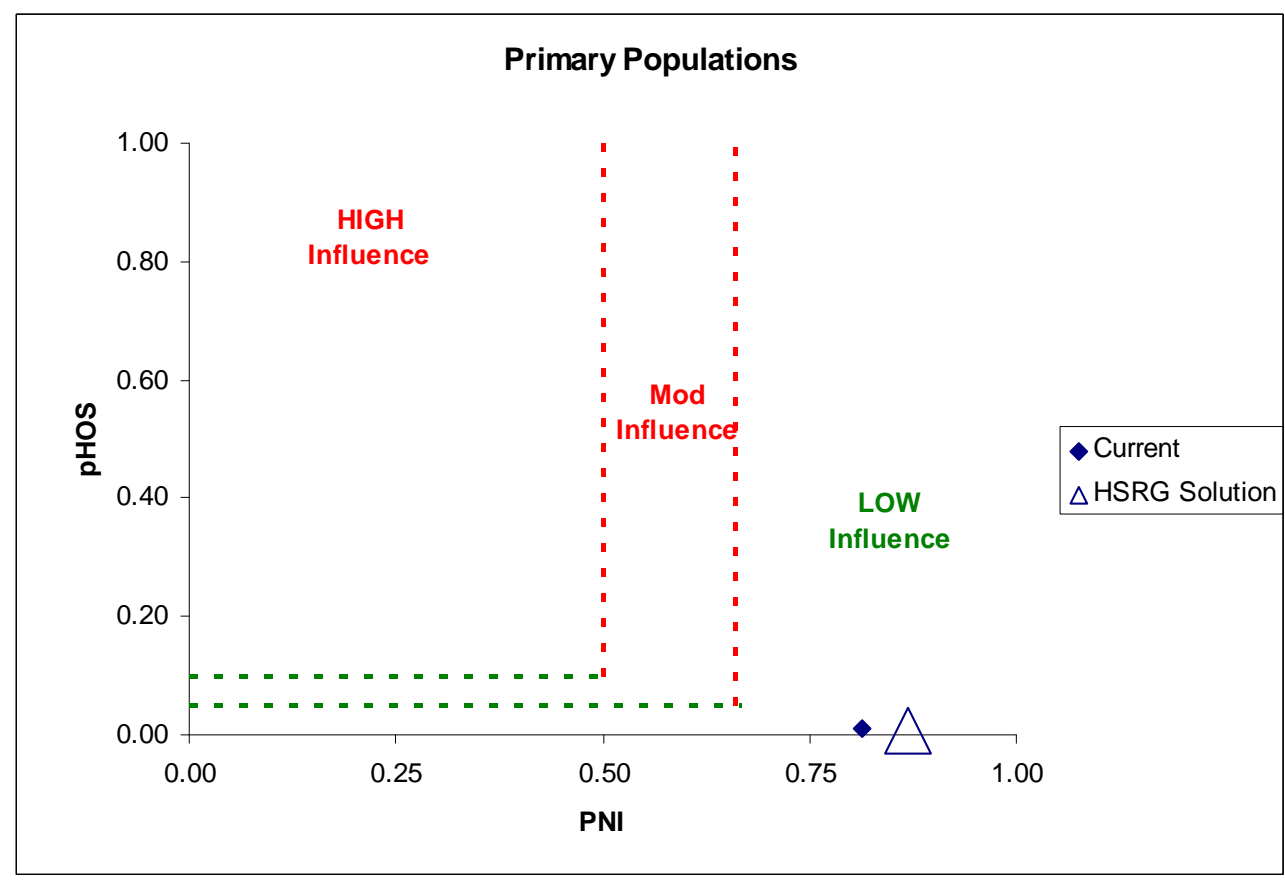

Figure 1. Relationship of the proportion of the fish on the spawning grounds that are of hatchery origin (pHOS) and the proportionate natural influence index (PNI) for Primary Summer-Fall Chinook population in the Deschutes River ESU. Solid diamonds represent values for current programs and open triangles represent values for the HSRG recommended hatchery management solution. 

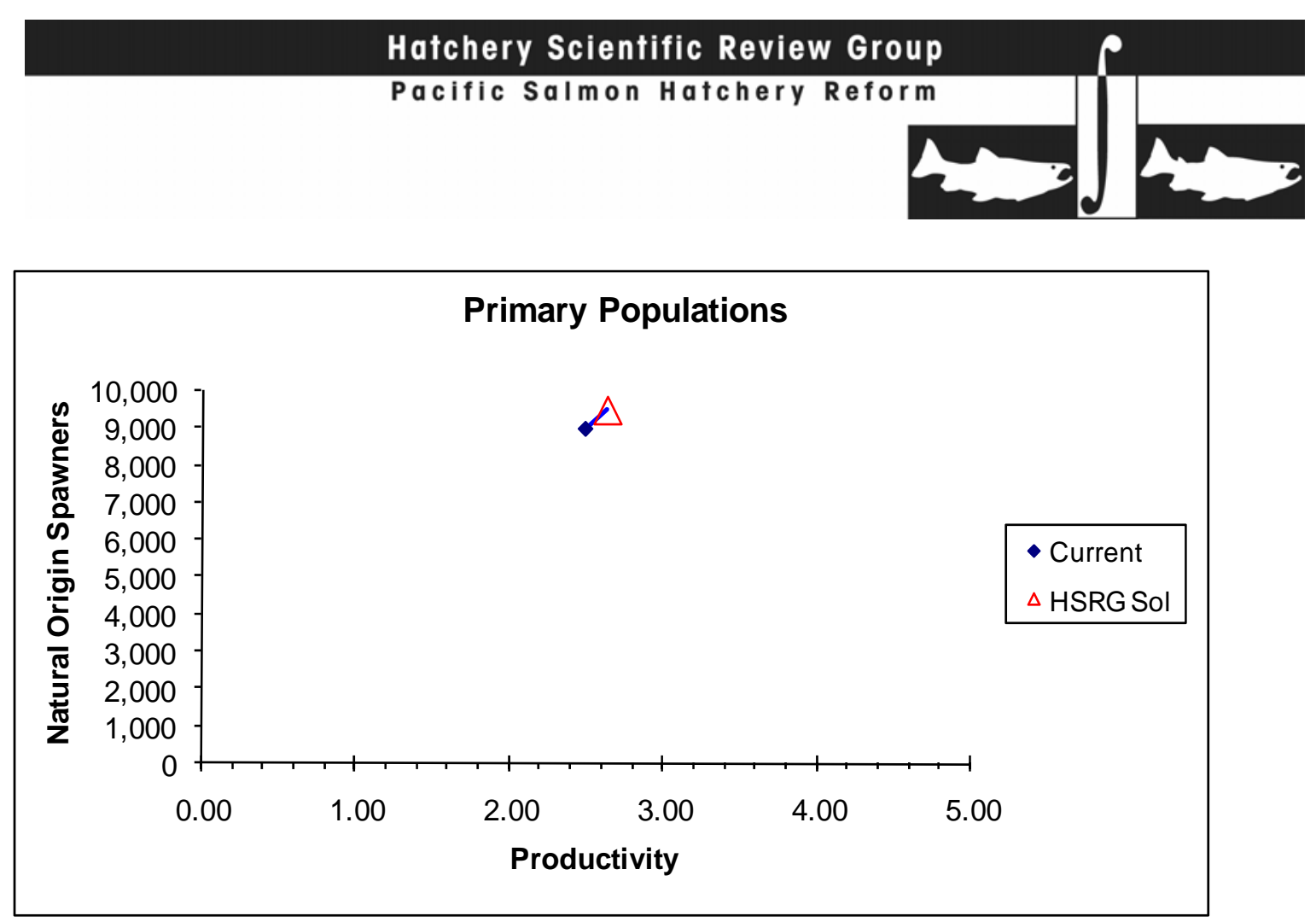

Figure 2. Productivity and spawner abundance for the Primary Summer-Fall Chinook population in the Deschutes River ESU. Solid diamonds represent existing productivity and spawner abundance levels, and triangles represent the HSRG recommended hatchery management solution. Lines connect current with HSRG solution for a particular population. The HSRG recommended hatchery management solution includes projected improved fish passage survival in the Snake and Columbia mainstem migration corridor (FCRPS Biological Opinion May 5, 2008).

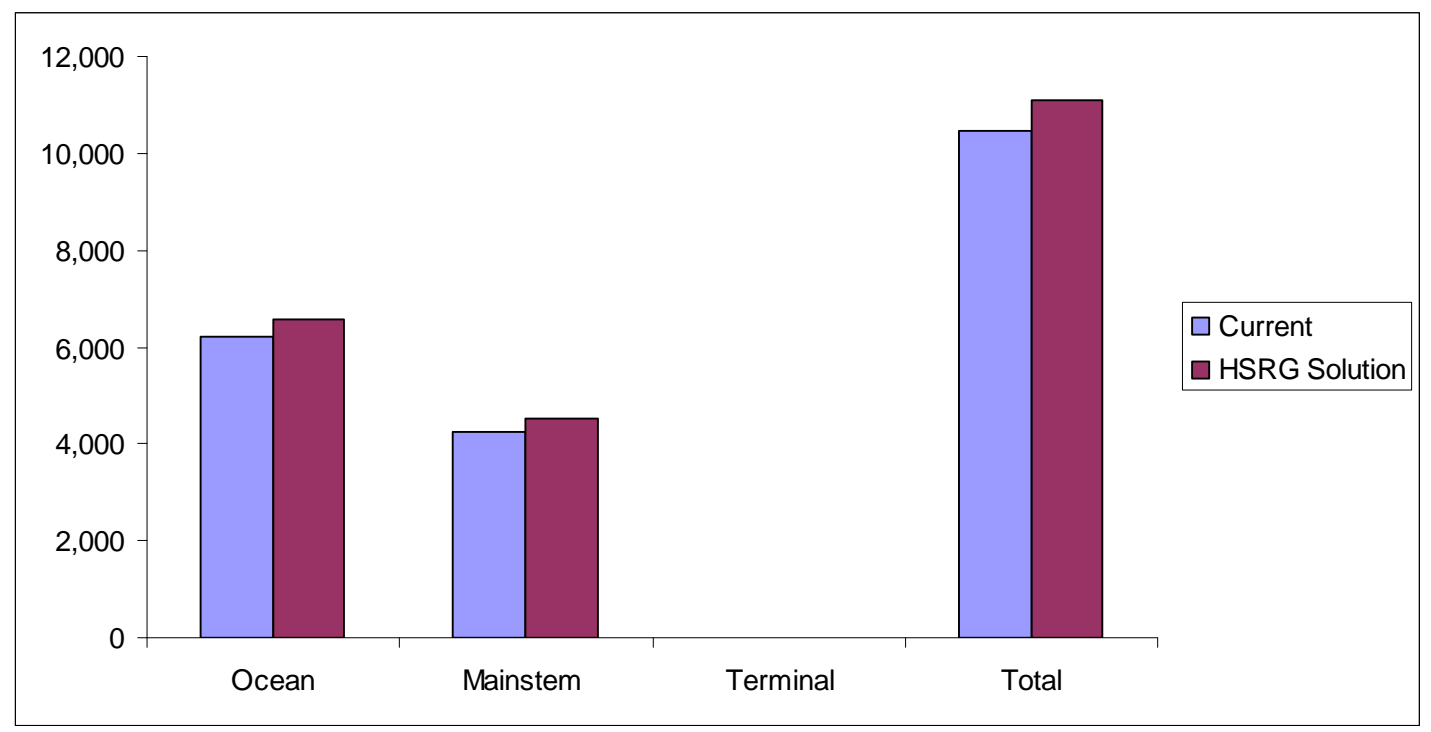

Figure 3. Estimated marine, mainstem Columbia, and terminal harvest under current and HSRG recommended hatchery management solution for Deschutes Summer-Fall Chinook ESU. The HSRG recommended hatchery management solution includes projected improved fish passage survival in the Snake and Columbia mainstem migration corridor (FCRPS Biological Opinion May $5,2008)$. 
This is a healthy natural population and the HSRG provides no specific recommendations.

\subsubsection{Upper Columbia River Spring Chinook ESU}

This section provides an overview of the Upper Columbia River Spring Chinook Salmon ESU. This ESU contains the Okanogan, Methow, Entiat, and Wenatchee subbasins. It contains a general description of the ESU, fisheries, habitat limitations and hatchery programs that affect it. Overall recommendations for ESU-wide hatchery program changes are summarized, as are the results of implementing those changes on conservation and harvest goals. Detailed conclusions and recommendations for each population in the ESU can be found in the Appendix E.

\subsubsection{HSRG Population Guidelines}

In order to meet conservations goals for the ESU, numerous threats to these populations need to be addressed, including risks from hatchery programs. The key to controlling genetic and ecological risks due to straying and fitness loss is to manage hatchery broodstock and natural spawning escapement such that the natural habitat (and not the hatchery environment) drives the adaptation and productivity of the naturally spawning population. This is achieved by operating either (a) integrated programs where the proportion of natural-origin adults in the broodstock (pNOB) exceeds the proportion of hatchery-origin fish on the spawning grounds (pHOS); or (b) segregated programs where the contribution of hatchery fish to natural spawning is kept low (pHOS $<5 \%-<10 \%$ depending on the population designation). The HSRG developed criteria for hatchery influence for three population types based on the importance of the population to the recovery of the ESU. This was done to provide a consistent method of reviewing populations and programs across the Columbia River Basin. The population designations used by the HSRG (Primary, Contributing, or Stabilizing) were adopted after discussions with managers and followed those developed in the Lower Columbia River Salmon Recovery Plan (LCFRB 2004). These designations are meant to reflect the conservation importance of a population within the ESU from most important (Primary), to moderately important (Contributing), to least important (Stabilizing). HSRG recommendations show how hatchery programs can be operated consistent with these designations based on the following standards:

\section{HSRG criteria for hatchery influence on Primary populations}

- The proportion of effective hatchery-origin spawners (pHOS) should be less than 5\% of the naturally spawning population, unless the hatchery population is integrated with the natural population.

- For integrated populations, the proportion of natural-origin adults in the broodstock should exceed pHOS by at least a factor of two, corresponding to a PNI (proportionate natural influence) value of 0.67 or greater and pHOS should be less than 0.30 . 
HSRG criteria for hatchery influence on Contributing populations

- The proportion of effective hatchery-origin spawners (pHOS) should be less than $10 \%$ of the naturally spawning population, unless the hatchery population is integrated with the natural population.

- For integrated populations, the proportion of natural-origin adults in the broodstock should exceed pHOS, corresponding to a PNI value of 0.50 or greater and $\mathrm{pHOS}$ should be greater than 0.30 .

HSRG criteria for hatchery influence on Stabilizing populations

- The current operating conditions were considered adequate to meet conservation goals. No criteria were developed for proportion of effective hatchery-origin spawners (pHOS) or PNI.

\subsubsection{Current Conditions}

\section{Conservation}

The Upper Columbia River spring Chinook salmon ESU is considered to be one major population group (MPG) and was listed as endangered under the Endangered Species Act (ESA) in 1999. The ESA-defined Upper Columbia River Chinook ESU includes all naturally spawned populations of Chinook salmon in all reaches accessible to Chinook salmon in Columbia River tributaries upstream of the Rock Island Dam and downstream of Chief Joseph Dam in Washington (excluding the Okanogan River), and in portions of the mainstem Columbia River in this region. The ESU also includes six artificial propagation programs. Within the ESU are three extant populations (Methow, Entiat, and Wenatchee) and one extinct population (Okanogan). All of the extant populations have a "high" long-term extinction risk (NMFS 2008e). Both the Methow and Wenatchee populations have recovery goals of 2,000 naturally-produced spawners; the Entiat population has a goal of 500 naturally-produced spawners. Efforts are underway to reintroduce spring Chinook in the Okanogan subbasin, where the native run was extirpated.

For the purposes of this review, the HSRG divided the Methow population into two subcomponents and the Wenatchee populations into three subcomponents. The HSRG designated all populations and sub-components as Primary except Okanogan spring Chinook, which is designated as a Stabilizing population (Table 1).

\section{Current Harvest}

The ocean fishery mortality affecting Upper Columbia River spring Chinook is low, and for practical purposes, is assumed to be zero (NMFS 2008e). Incidental take occurs in mainstem Columbia River spring season fisheries, which are intended to target harvestable hatchery and natural-origin stocks. The Columbia River fisheries are limited to assure that incidental take of Upper Columbia River spring Chinook does not exceed a rate of 17\% (range 5.5-17\%); the average take in recent years has been 10.7\% (NMFS 2008e). Limited terminal fisheries have occurred in recent decades, primarily on fish returning to hatcheries. 
Table 1. Population designations for the Upper Columbia Spring Chinook ESU and HSRG broodstock criteria achieved for each population under current conditions and the HSRG recommended hatchery management solution.

\begin{tabular}{|l|c|c|c|}
\hline \multirow{2}{*}{ Population } & \multirow{2}{*}{ Designation ${ }^{1}$} & \multicolumn{2}{|c|}{ HSRG Criteria Met $^{2}$} \\
\cline { 3 - 4 } & Current & HSRG Solution \\
\hline Entiat Spring Chinook & Primary & Stabilizing & Primary \\
\hline Methow (Methow-Chewuch) Spring Chinook & Primary & Stabilizing & Stabilizing \\
\hline Methow (Twisp) Spring Chinook & Primary & Stabilizing & Stabilizing \\
\hline Wenatchee (Chiwawa) Spring Chinook & Primary & Stabilizing & Primary \\
\hline Wenatchee (Nason) Spring Chinook & Primary & Stabilizing & Contributing \\
\hline Wenatchee (White) Spring Chinook & Primary & Stabilizing & Contributing \\
\hline Okanogan Spring Chinook & Stabilizing & Stabilizing & Stabilizing \\
\hline
\end{tabular}

1 Using the naming protocol of the Lower Columbia River Salmon Recovery Plan (LCFRB 2004), populations were classified based on information provided to the HSRG as Primary, Contributing, or Stabilizing. These designations are meant to reflect the conservation importance of a population within the ESU from most important (Primary- bold, red), to moderately important (Contributing-bold, blue), to least important (Stabilizing).

2 The HSRG developed criteria for hatchery influence for the three population designations from low influence (Primary), moderate influence (Contributing) to high influence (Stabilizing).

3 Although hatchery influence is low, this population only meets Stabilizing criteria.

\section{Current Habitat}

Throughout the ESU, major habitat factors contributing to population decline include dams that have blocked fish passage (such as Chief Joseph Dam) and others that have eliminated habitat access. For example, spring Chinook salmon were extirpated from the Okanogan River by the 1930s due in large part to impassable dams and irrigation withdrawals in the Okanogan subbasin. Tributary habitat has been degraded by land uses such as forestry and agriculture, resulting in reduced stream flow, riparian vegetation loss, excess sedimentation, and loss of off-channel habitat and complexity.

Actions have been implemented in recent years to address some of these limiting factors, such as improving passage at mainstem Columbia River dams and acquiring water rights to increase streamflow. NMFS completed consultation on a 50-year incidental take permit for the State of Washington's Forest Practices Habitat Conservation Plan (HCP). The HCP will lead to a gradual improvement in habitat conditions on state forest lands within the ESU, removing barriers to migration, restoring hydrologic processes, increasing the number of large trees in riparian zones (a source of shade and large woody debris), improving stream bank integrity, and reducing fine sediment inputs (NMFS 2000f).

\section{Current Hatchery Programs}

Five integrated and two segregated hatchery programs operate in the ESU in the Methow and Wenatchee subbasins. Currently the integrated programs release approximately 960,000 spring Chinook smolts per year and the segregated programs release about 2.3 million smolts each year (Table 2). The integrated programs have both conservation and harvest goals. The goals of the two segregated programs are to support harvest. In addition, a captive brood program is associated with the White River population 


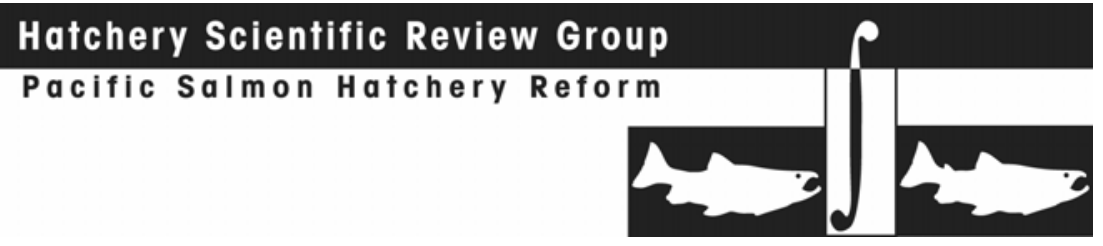

component (Wenatchee River) and is in the process of transitioning to an anadromous brood program.

Spring Chinook hatchery programs operate in two of the four subbasins. Estimates of PNI and pHOS under current conditions show that none of the three Primary populations (with sub-components) in the ESU meet the broodstock criteria for this population designation (Table 1). The only non-Primary population in the ESU is the Okanogan spring Chinook population, where a reintroduction program is planned. Overall, in recent years, stray hatchery fish, composite broodstock, low proportion of natural-origin fish in some broodstocks, and a high proportion of hatchery fish on the spawning grounds are factors that have contributed to populations not meeting the broodstock standards. While hatchery programs have reduced the short-term extinction risk for populations in Wenatchee and the Methow subbasins, these programs have imposed a loss of fitness. A segregated spring Chinook program in the Entiat subbasin was discontinued in 2007 because of the threat posed by the high proportion of out-or-basin Carson Hatchery fish spawning with the natural population (NMFS 2008e).

A large new hatchery complex at Chief Joseph Dam is in the final stages of design. This program will focus on Chinook species returning to the Okanogan subbasin.

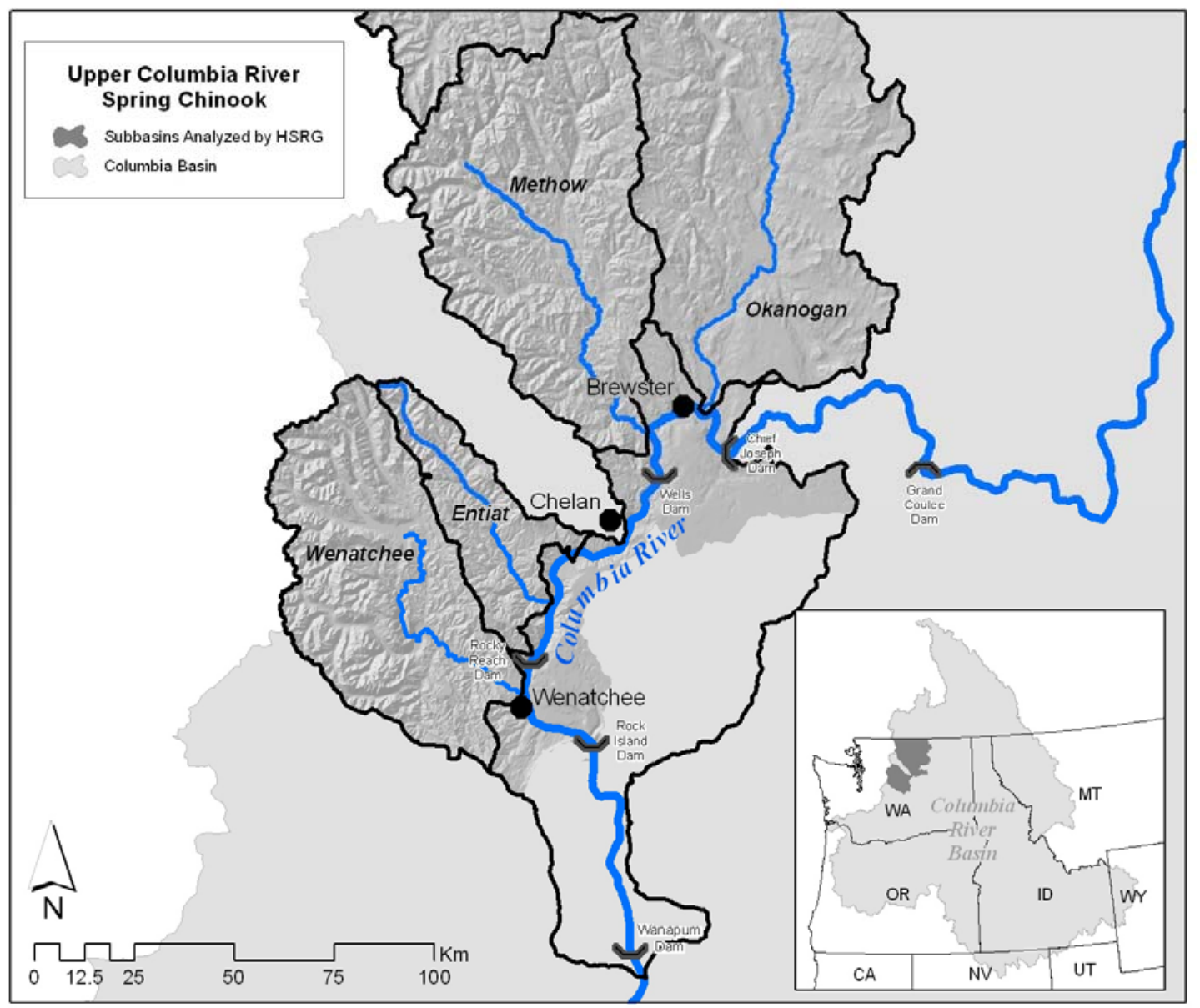


Table 2. Hatchery releases and types of programs for Upper Columbia Spring Chinook ESU.

\begin{tabular}{|l|c|c|c|c|c|c|}
\hline \multirow{2}{*}{\begin{tabular}{l} 
Population/Program Name \\
\cline { 2 - 8 }
\end{tabular}} & \multicolumn{3}{|c|}{ Current (1,000s) } & \multicolumn{3}{c|}{ HSRG Solution (1,000s) } \\
\hline & Type & Purpose & $\begin{array}{c}\# \\
\text { Released }\end{array}$ & Type & Purpose & $\begin{array}{c}\# \\
\text { Released }\end{array}$ \\
\hline Wenatchee (Chiwawa) Spring Chinook & Int & Cons & 351.5 & Int & Cons & 149.1 \\
\hline Wenatchee (Nason) Spring Chinook & Int & Cons & - & Int & Cons & 149.1 \\
\hline $\begin{array}{l}\text { Wenatchee (White) Spring Chinook } \\
\text { Hatchery }\end{array}$ & Int & Cons & 65.9 & Int & Cons & 149.1 \\
\hline Entiat Spring Chinook & Seg & Harv & $1,650.2$ & Seg & Harv & $1,650.2$ \\
\hline Entiat Spring Chinook (NFH)- Hatchery & None & NA & - & None & NA & - \\
\hline Methow (Methow-Chewuch) Spring Chinook & Seg & Harv & - & Seg & Harv & - \\
\hline Methow (Twisp) Spring Chinook & Int & Cons & 359.1 & Int & Cons & 359.1 \\
\hline Methow Spring Chinook (Winthrop Hatchery) & Int & Cons & 183.0 & Int & Cons & 183.0 \\
\hline Okanogan Spring Chinook & Seg & Harv & 601.5 & Seg & Harv & 601.5 \\
\hline Total all Populations/Programs & None & NA & - & Int & Cons & 53.9 \\
\hline
\end{tabular}

\subsubsection{3}

\section{HSRG Solutions}

Options for improving the integrated hatchery programs are possible although limited by the low number of natural-origin fish in this ESU. Contribution to conservation could be improved for Wenatchee spring Chinook (and its sub-populations) by improving broodstock collection and limiting hatchery-origin fish on the spawning grounds. For the Entiat population, better control of out-of-basin hatchery-origin fish is needed. In the Methow subbasin, the HSRG looked at various hatchery scenarios that could improve productivity of the sub-populations, but could not significantly increase abundance of natural-origin spawners under current habitat conditions. This is generally the result of limited habitat quality (productivity) and quantity (capacity).

\section{Conservation Outcomes under the HSRG Solutions}

Figure 1 compares the proportion of fish on the spawning grounds that are of hatchery origin (pHOS) and the proportionate natural influence (PNI) for current and HSRG proposed scenarios for Primary and Contributing populations. The HSRG solution reduces the hatchery influence in two of the three Primary populations (Entiat, Wenatchee and sub-populations) (Figure 1) and improves the productivity (Figure 2). The status of the remaining Primary population (Methow, with sub-populations) could not be improved because of limited available habitat. This population will continue to have high hatchery influence (and low productivity) until habitat and passage conditions at dams are improved. Despite the high hatchery influence, this program acts as a gene bank for this population and should be continued.

Harvest Outcomes under the HSRG Solutions

Figure 3 describes current and estimated changes in harvest (marine, mainstem Columbia River and terminal areas) that would occur following implementation of the management solutions proposed by the HSRG. In this case, the HSRG identified opportunities to increase harvest on excess hatchery fish using selective mainstem and terminal harvest. 
Hatchery Program Changes under the HSRG Solutions

Table 2 shows the current size of each hatchery program as well as their size under the HSRG solution. For this ESU, the total number of smolts released increased slightly (currently 3.211 vs. 3.295 million smolts).

In the Wenatchee subbasin, hatchery releases into the White River increase from 65,000 to 150,000 smolts; Nason Creek increases from 0 to 149,000 smolts; and the Chiwawa decreases from 430,000 to 149,000 . The HSRG also provided an alternative scenario for releases into the Chiwawa River. The segregated program at Leavenworth is also maintained at the current number.

In the Methow subbasin, production was maintained and the HSRG recommendations focused on improvements to the current programs. The Okanogan River will be affected by a newly proposed reintroduction program expected to produce approximately 900,000 smolts (this was not factored into the HSRG's analysis).

Additionally, the HSRG recommends that managers adopt a BKD control program including culling of high titer broodstock to assist in the control of bacterial kidney disease where needed.

The HSRG notes the need for additional adult collection facilities in several locations (Methow and Okanogan) to improve the ability to collect unharvested hatchery-origin fish.

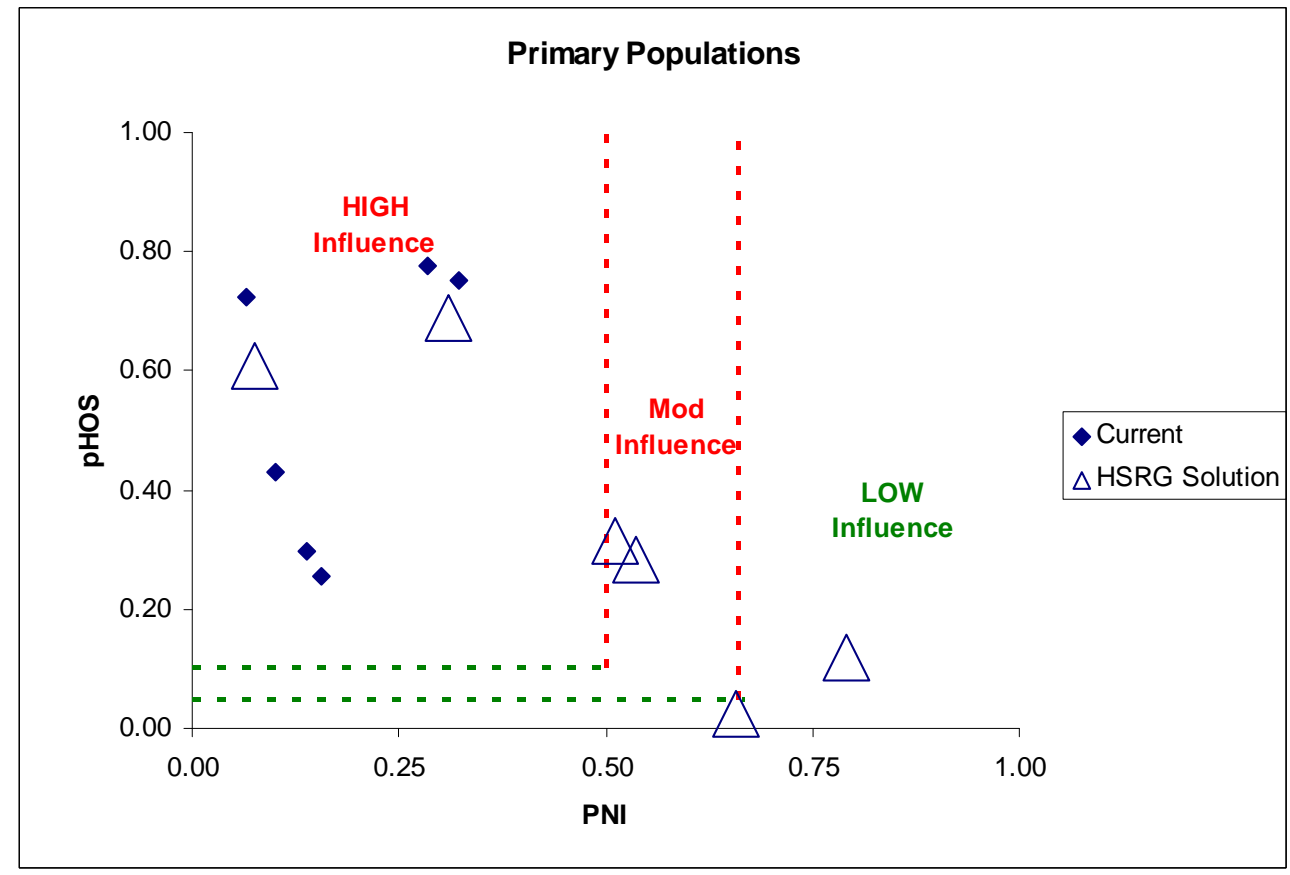

Figure 1. Relationship of the proportion of the fish on the spawning grounds that are of hatchery origin (pHOS) and the proportionate natural influence index (PNI) for Primary Spring Chinook populations in the Upper Columbia River ESU. Solid diamonds represent values for current programs and open triangles represent values for the HSRG recommended hatchery management solution. 


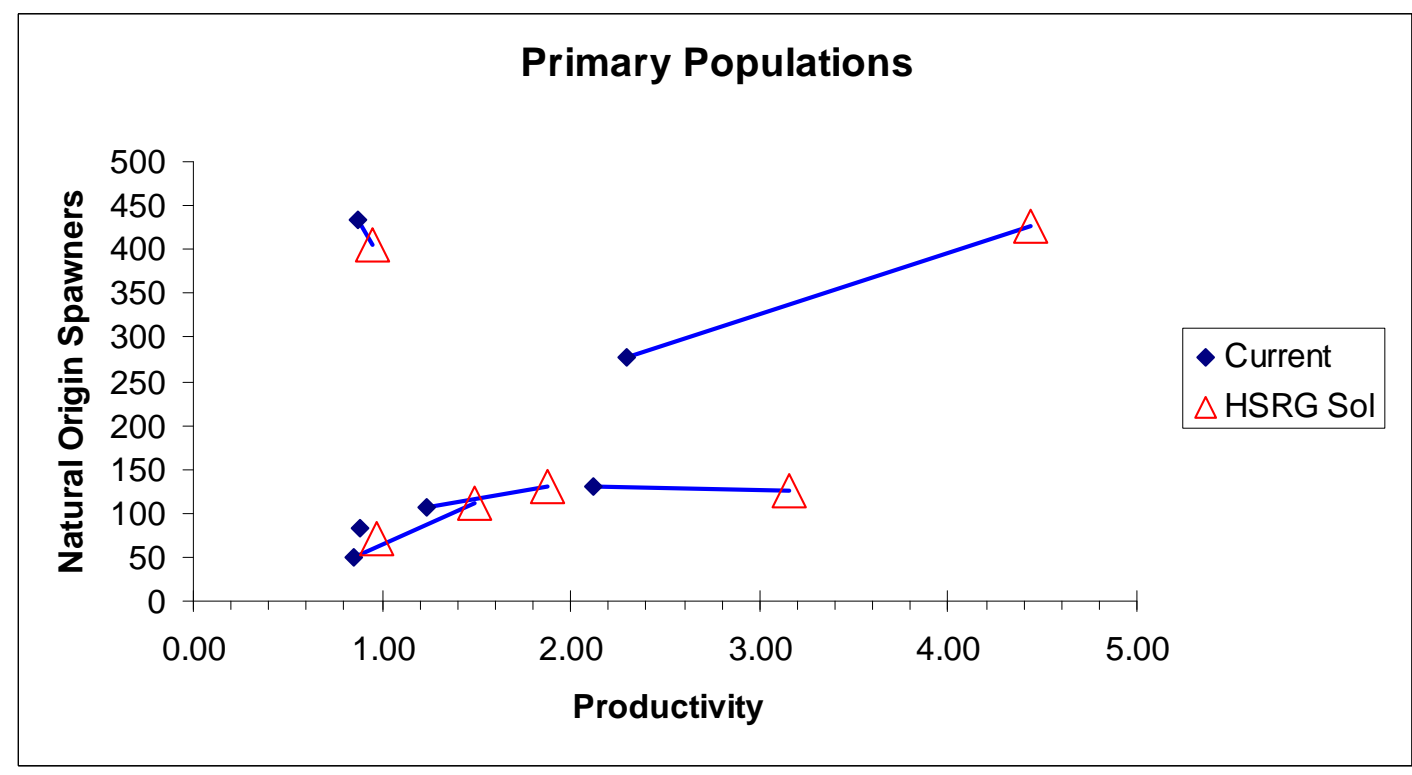

Figure 2. Productivity and spawner abundance for Primary Spring Chinook populations in the Upper Columbia ESU. Solid diamonds represent existing productivity and spawner abundance levels, and triangles represent the HSRG recommended hatchery management solution. Lines connect current with HSRG solution for a particular population. The HSRG recommended hatchery management solution includes projected improved fish passage survival in the Snake and Columbia mainstem migration corridor (FCRPS Biological Opinion May 5, 2008).

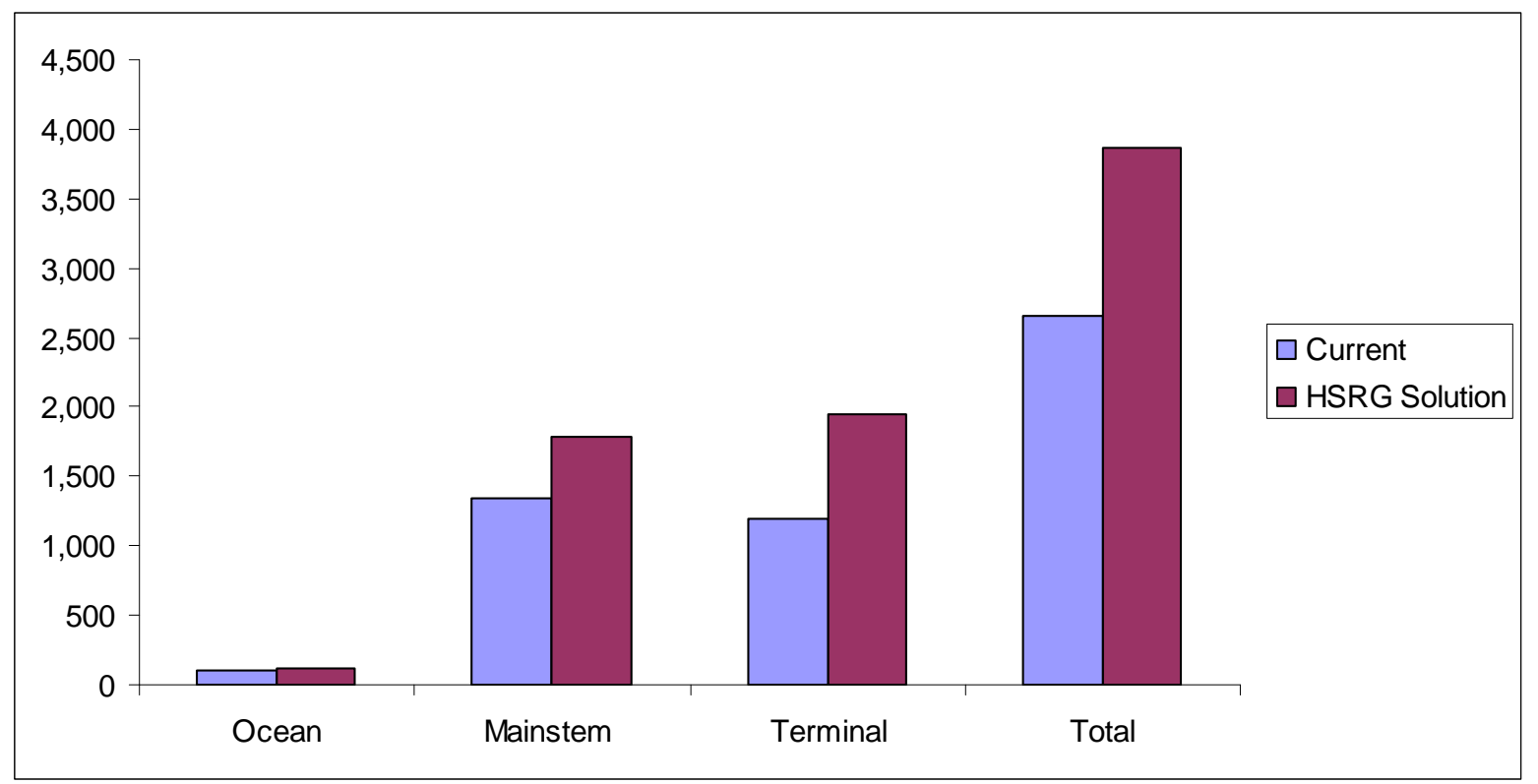

Figure 3. Estimated marine, mainstem Columbia, and terminal harvest under current and HSRG recommended hatchery management solution for Upper Columbia Spring Chinook ESU. The HSRG recommended hatchery management solution includes projected improved fish passage survival in the Snake and Columbia mainstem migration corridor (FCRPS Biological Opinion May 5, 2008). 


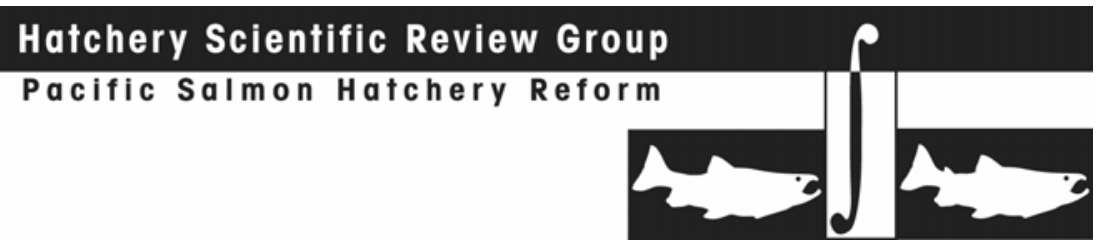

3.1.5.4

Summary and Conclusions

The Upper Columbia Spring Chinook ESU contains three extant populations, the Methow, Wenatchee and Entiat. Each is identified as a Primary population. Both the Wenatchee and Methow contain sub-populations that add to the difficulty of implementing proper broodstock management. In the Wenatchee, the HSRG was able to provide solutions to increase both the productivity and the abundance of NORs in each of the sub-populations. This can be done by increasing the number of NORs in the hatchery brood and limiting HORs on the spawning grounds. In the Methow subbasin, limited habitat capacity and productivity and an inability to control HORs (other than the Twisp River weir) prevented the HSRG from developing solutions to increase NOR abundance under existing conditions.

The abundance of natural-origin escapement will vary from year to year. In order to balance the demographic risk (low overall abundance) against genetic risks (too much hatchery influence), the HSRG recommends managing $\mathrm{pHOS}$ and $\mathrm{pNOB}$ on a "sliding scale", while still assuring that PNI and pHOS objectives are met on average over generations.

The HSRG identified opportunities to increase harvest by selectively targeting excess hatchery fish.

The HSRG also concludes that the effectiveness of habitat actions will be greatly increased if combined with hatchery and harvest reforms. For example, the analysis of the Primary populations in this ESU suggests that the benefits of habitat quality improvements would more than double if combined with hatchery reforms. Unless hatchery and harvest reforms are implemented, the potential benefits of current or improved habitat cannot be fully realized.

\subsubsection{Upper Columbia River Summer/Fall Chinook Salmon ESU}

This section provides an overview of the Upper Columbia River Summer/Fall Chinook Salmon ESU. It contains a general description of the ESU, fisheries, habitat limitations and hatchery programs that affect it. Overall recommendations for ESU-wide hatchery program changes are summarized as are the results of implementing those changes on conservation and harvest goals. Detailed conclusions and recommendations for each population in the ESU can be found in the Appendix E.

\subsubsection{HSRG Population Guidelines}

In order to meet conservations goals for the ESU, numerous threats to these populations need to be addressed, including risks from hatchery programs. The key to controlling genetic and ecological risks due to straying and fitness loss is to manage hatchery broodstock and natural spawning escapement such that the natural habitat (and not the hatchery environment) drives the adaptation and productivity of the naturally spawning population. This is achieved by operating either (a) integrated programs where the proportion of natural-origin adults in the broodstock (pNOB) exceeds the proportion of hatchery-origin fish on the spawning grounds (pHOS); or (b) segregated programs where the contribution of hatchery fish to natural spawning is kept low (pHOS $<5 \%-<10 \%$ depending on the population designation). The HSRG developed criteria for hatchery influence for three population types based on the importance of the population to the 


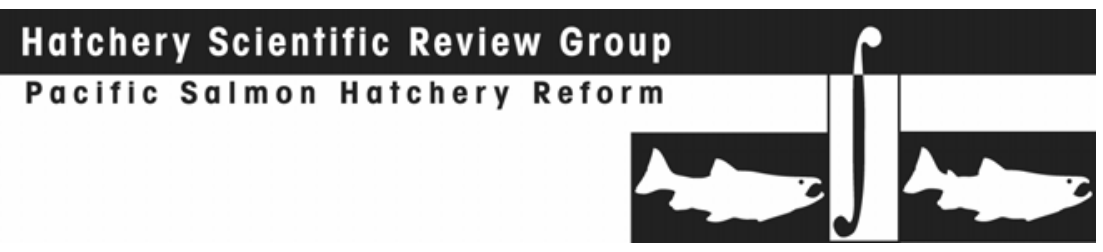

recovery of the ESU. This was done to provide a consistent method of reviewing populations and programs across the Columbia River Basin. The population designations used by the HSRG (Primary, Contributing, or Stabilizing) were adopted after discussions with managers and followed those developed in the Lower Columbia River Salmon Recovery Plan (LCFRB 2004). These designations are meant to reflect the conservation importance of a population within the ESU from most important (Primary), to moderately important (Contributing), to least important (Stabilizing). HSRG recommendations show how hatchery programs can be operated consistent with these designations based on the following standards:

HSRG criteria for hatchery influence on Primary populations

- The proportion of effective hatchery-origin spawners (pHOS) should be less than 5\% of the naturally spawning population, unless the hatchery population is integrated with the natural population.

- For integrated populations, the proportion of natural-origin adults in the broodstock should exceed pHOS by at least a factor of two, corresponding to a PNI (proportionate natural influence) value of 0.67 or greater and $\mathrm{pHOS}$ should be less than 0.30 .

HSRG criteria for hatchery influence on Contributing populations

- The proportion of effective hatchery-origin spawners (pHOS) should be less than $10 \%$ of the naturally spawning population, unless the hatchery population is integrated with the natural population.

- For integrated populations, the proportion of natural-origin adults in the broodstock should exceed pHOS, corresponding to a PNI value of 0.50 or greater and $\mathrm{pHOS}$ should be less than 0.30 .

HSRG criteria for hatchery influence on Stabilizing populations:

- The current operating conditions were considered adequate to meet their conservation goals. No criteria were developed for proportion of effective hatchery-origin spawners (pHOS) or PNI.

\subsubsection{Current Conditions}

\section{Conservation}

The Upper Columbia River summer/fall Chinook Salmon ESU includes all naturally spawned populations of summer- and fall-run Chinook salmon in the Columbia River and tributaries upstream of the confluence of the Snake and Columbia rivers to Chief Joseph Dam (with the exception of Chinook that spawn in the Marion Drain in the Yakima subbasin). This ESU includes populations in the Yakima, Wenatchee, Entiat, Methow, and Okanogan subbasins, as well as populations that spawn within the Columbia River mainstem, including the Hanford Reach. In 1998, NMFS determined that the Upper Columbia River summer/fall Chinook ESU did not warrant listing. Nehlsen et al. (1991) identified six stocks as extinct. WDF et al. (1993) identified 10 stocks within the ESU, of which three were considered to be of native origin and predominantly sustained by 


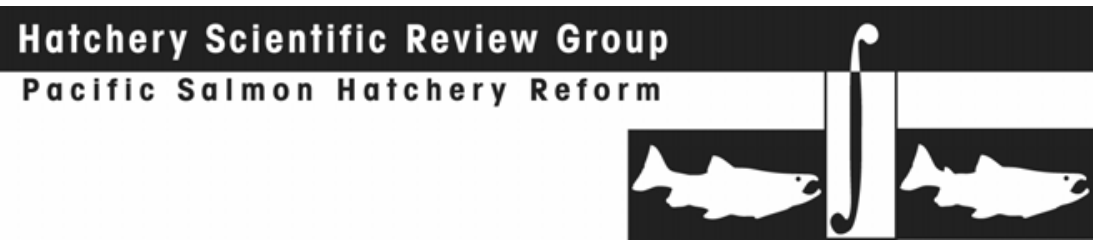

natural production. Long-term trends for the three largest populations are positive, while those for the smaller populations are a mix of positive and negative.

For the purposes of the HSRG analysis, ten populations were identified (including the Yakima Marion Drain population). In addition to the subbasins listed above, the HSRG included the Klickitat and Umatilla fall Chinook populations in this report because they originated from upriver bright fall Chinook hatchery populations. The HSRG designated three populations as Primary, three as Contributing, and four as Stabilizing (Table 1).

\section{Current Harvest}

The harvest of Upper Columbia River summer / fall Chinook is significant, with the total exploitation rate (ocean and freshwater) ranging from $45 \%$ to over $50 \%$ for the fall run component under current conditions. In marine waters, these summer/fall Chinook are targeted in Alaskan, Canadian and Washington coastal fisheries. In the Columbia River, the U.S. vs. Oregon Fish Management Plan establishes harvest rates and treaty: nontreaty allocations based on total run abundance (hatchery and natural). A WDFW/Colville Tribes Agreement allocates the subsequent non-treaty harvest between lower river and tributary fisheries, and between non-treaty tribal and sport/commercial. Except for the Colville tribal fishery, none of the current fisheries are selective.

For the summer run component, ocean exploitation is in excess of $30 \%$. For subsequent freshwater fisheries, the US vs. Oregon agreement specifies an aggregate abundancebased harvest rate schedule (hatchery and natural combined) for fisheries in the Columbia Basin. Harvest rates under this agreement will range from $7 \%$ when returns are low $(5,000)$ to $58.6 \%$ when returns are greater than 100,000 . There are many graduated steps between the lower and upper harvest bounds which are based on the aggregate run (hatchery and natural combined). Increased hatchery production in the future could result in increased harvest irrespective of abundance of natural-origin fish. Under these assumptions, the HSRG believes that exploitation of summer Chinook will be excessive and likely not compatible with viable natural populations. An overall exploitation rate of up to $70 \%$ on natural Chinook populations located above 7 to 9 dams, combined with degraded tributary habitat and high pHOS can be expected to threaten natural population viability.

Table 1. Population designations for the Upper Columbia River Summer/Fall Chinook and HSRG broodstock criteria achieved for each population under current conditions and the HSRG recommended hatchery management solution.

\begin{tabular}{|c|c|c|c|}
\hline \multirow[b]{2}{*}{ Population } & \multirow[b]{2}{*}{ Designation $^{1}$} & \multicolumn{2}{|c|}{ HSRG Criteria Met ${ }^{2}$} \\
\hline & & Current & $\begin{array}{l}\text { HSRG } \\
\text { Solution }\end{array}$ \\
\hline Columbia Lower Middle Hanford Fall Chinook (Priest Rapids Upriver Brights) & Primary & Stabilizing & Primary \\
\hline Okanogan-Similkameen Summer Chinook & Primary & Contributing & Primary \\
\hline Wenatchee Summer Chinook & Primary & Primary & Primary \\
\hline Yakima Fall Chinook & Contributing & Stabilizing & Stabilizing \\
\hline Entiat Summer-Fall Chinook (Late Run) & Stabilizing & Stabilizing & Stabilizing \\
\hline Methow Summer Chinook & Stabilizing & Stabilizing & Stabilizing \\
\hline
\end{tabular}




\begin{tabular}{|c|c|c|c|}
\hline \multirow[b]{2}{*}{ Population } & \multirow[b]{2}{*}{ Designation $^{1}$} & \multicolumn{2}{|c|}{ HSRG Criteria Met ${ }^{2}$} \\
\hline & & Current & $\begin{array}{l}\text { HSRG } \\
\text { Solution }\end{array}$ \\
\hline Upper Middle Columbia Mainstem Summer Chinook & Stabilizing & Stabilizing & Contributing \\
\hline Umatilla Fall Chinook ${ }^{3}$ & Contributing & Stabilizing & Contributing \\
\hline Yakima-Marion Drain Fall Chinook ${ }^{3}$ & Contributing & Stabilizing & Stabilizing \\
\hline Klickitat Fall Chinook ${ }^{3}$ & Stabilizing & Stabilizing & Stabilizing \\
\hline
\end{tabular}

1 Using the naming protocol of the Lower Columbia River Salmon Recovery Plan (LCFRB 2004), populations were classified based on information provided to the HSRG as Primary, Contributing, or Stabilizing. These designations are meant to reflect the conservation importance of a population within the ESU from most important (Primary- bold, red), to moderately important (Contributing-bold, blue), to least important (Stabilizing).

2 The HSRG developed criteria for hatchery influence for the three population designations from low influence (Primary), moderate influence (Contributing) to high influence (Stabilizing).

3 Population is not part of the ESU but is included here due to geographic proximity. Recent genetic and biological data suggest that Marion Drain fish may be better managed as part of an aggregate rather than a separate population (TN 2009).

\section{Current Habitat}

Access to a substantial portion of historical spawning and rearing habitat is blocked by Chief Joseph and Grand Coulee dams, and habitat below Chief Joseph Dam is inundated by several mainstem Columbia hydroelectric projects. Dams on the upper Okanagan River in Canada also block access to spawning and rearing habitat. Tributary habitat issues related to irrigation diversions and hydroelectric development, as well as degraded riparian and instream habitat from various land uses and livestock grazing, are widespread throughout the ESU, but vary by subbasin.

\section{Current Hatchery Programs}

The populations of Upper Columbia River summer/fall Chinook are heavily influenced by hatchery programs, high exploitation rates and significant dam mortalities. Large numbers of Chinook salmon are released into this ESU and adjoining populations; hatchery influences vary among subbasins. Currently there are six integrated programs that release approximately 8.8 million juvenile Chinook into this ESU and adjoining populations annually (Table 2). Seven segregated programs release about 12.1 million Chinook annually. Managers have not identified population objectives for the ESU. Analysis of recent population information indicates that only the Wenatchee population is being managed to the standards of a Primary population. The Okanogan-Similkameen population is currently managed as a Contributing population (Table 1). All remaining populations, including Hanford fall Chinook, currently meet standards for Stabilizing populations. 

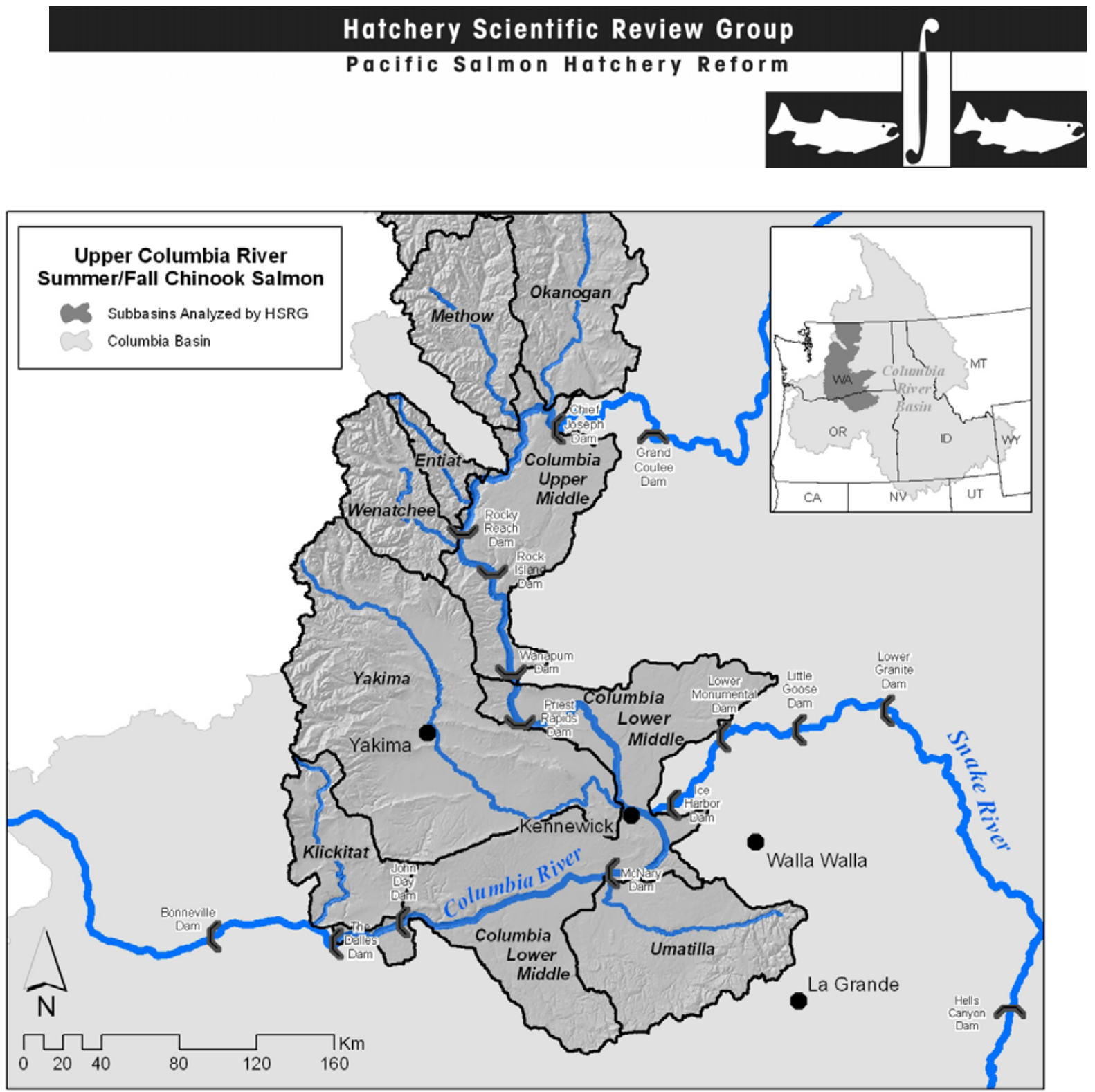

Table 2. Hatchery releases and types of programs for Upper Columbia River Summer/Fall Chinook ESU.

\begin{tabular}{|l|c|c|c|c|c|c|}
\hline \multirow{2}{*}{\begin{tabular}{|c|c|c|c|c|} 
Population/Program Name \\
\cline { 2 - 7 }
\end{tabular}} & \multicolumn{3}{|c|}{ Current (1,000s) } & \multicolumn{2}{c|}{ HSRG Solution (1,000s) } \\
\hline Yakima Fall Chinook & Purpose & $\begin{array}{c}\text { Noleased } \\
\text { Rel }\end{array}$ & Type & Purpose & $\begin{array}{c}\text { No. } \\
\text { Released }\end{array}$ \\
\hline $\begin{array}{l}\text { Yakima Fall Chinook (Little White Salmon- } \\
\text { Hatchery) }\end{array}$ & Seg & Harv & $1,701.0$ & Seg & Harv & - \\
\hline $\begin{array}{l}\text { Columbia Lower Middle Hanford Fall Chinook } \\
\text { (Priest Rapids Upriver Brights) }\end{array}$ & Int & Harv & $6,691.2$ & Int & Harv & $10,218.5$ \\
\hline $\begin{array}{l}\text { Columbia Lower Middle Columbia Fall Chinook } \\
\text { (URB-Ringold-Hatchery) }\end{array}$ & Seg & Harv & $3,499.5$ & Seg & Harv & - \\
\hline Wenatchee Summer Chinook & Int & Both & 737.1 & Int & Both & 737.1 \\
\hline Entiat Summer-Fall Chinook (Late Run) & None & NA & - & None & NA & - \\
\hline Methow Summer Chinook & None & NA & - & None & NA & - \\
\hline Upper Middle Columbia Mainstem Summer & None & NA & - & Int & Both & 803.0 \\
\hline
\end{tabular}




\begin{tabular}{|l|c|c|c|c|c|c|}
\hline \multirow{2}{*}{\begin{tabular}{l} 
Population/Program Name \\
\cline { 2 - 7 }
\end{tabular}} & \multicolumn{3}{|c|}{ Current (1,000s) } & \multicolumn{2}{c|}{ HSRG Solution (1,000s) } \\
\hline Chinook & Purpose & $\begin{array}{c}\text { No. } \\
\text { Released }\end{array}$ & Type & Purpose & $\begin{array}{c}\text { No. } \\
\text { Released }\end{array}$ \\
\hline Methow Summer Chinook (Wells Hatchery) & Seg & Harv & 340.8 & Seg & Harv & 340.8 \\
\hline $\begin{array}{l}\text { Upper Middle Columbia Summer Chinook (Wells } \\
\text { Hatchery) }\end{array}$ & Seg & Harv & 803.0 & Seg & Harv & - \\
\hline $\begin{array}{l}\text { Upper Middle Columbia Mainstem Summer } \\
\text { Chinook (Turtle Rock-Hatchery) }\end{array}$ & Seg & Harv & $1,277.9$ & Seg & Harv & 600.4 \\
\hline Okanogan-Similkameen Summer Chinook & Int & Both & 574.1 & Int & Both & 911.2 \\
\hline Klickitat Fall Chinook & None & NA & - & None & NA & - \\
\hline Klickitat Fall Chinook (URB-Hatchery) & Seg & Harv & $3,867.2$ & Seg & Harv & $3,436.0$ \\
\hline Umatilla Fall Chinook & Int & Both & 399.2 & Int & Both & 479.0 \\
\hline Umatilla Fall Chinook (Stepping Stone Hatchery) & Seg & Harv & 648.0 & Seg & Harv & 411.5 \\
\hline Yakima: Marion Drain Fall Chinook & Int & Cons & 20.5 & Int & Cons & 20.5 \\
\hline Total all Populations/Programs & & & $\mathbf{2 0 , 9 0 6 . 0}$ & & & $19,968.2$ \\
\hline
\end{tabular}

\subsubsection{HSRG Solutions}

The HSRG recommended solutions for populations of Upper Columbia River summer/fall Chinook involve significant reforms in both hatchery and harvest practices, and adopting conservation management principles that will ensure long-term viability of this ESU. First, managers should consider adopting HSRG designations for populations that will ensure conservation of the ESU. This can be done while also increasing harvest opportunities. Second, throughout the ESU, hatchery broodstock must be collected only from local populations and integrated with known natural-origin fish in the proportions needed to achieve the designated population standards. This requires marking all hatchery fish and, in some locations, developing wild fish collection methods. Thirdly, given the high exploitation of this ESU and excessive spawning of hatchery fish, selective fishing methods need to be adopted wherever possible.

Minor reductions in the overall numbers of hatchery fish released will achieve the recommended population standards while providing harvest gains. With the planned increases in hatchery programs (Chief Joseph and Chelan River), hatchery and harvest reforms consistent with the HSRG standards are even more necessary to achieve managers' conservation and harvest objectives.

The HSRG recommends that managers analyze genetic data from existing samples to determine population structure of summer/fall Chinook in the upper Columbia region. While not ESA-listed, the ESU should still be managed consistent with conservation principles that promote long-term viability. The ESU is heavily influenced by hatchery programs with future plans resulting in substantially increased hatchery production. A sufficient number of populations need to managed as Primary with PNI greater than 0.67.

More careful broodstock management is necessary to promote population structure and diversity in this ESU. Broodstock for integrated programs need to be collected locally (not at mainstem dams) and throughout the entire run. Methods also need to be developed to collect local natural-origin Chinook to improve pNOB in integrated 


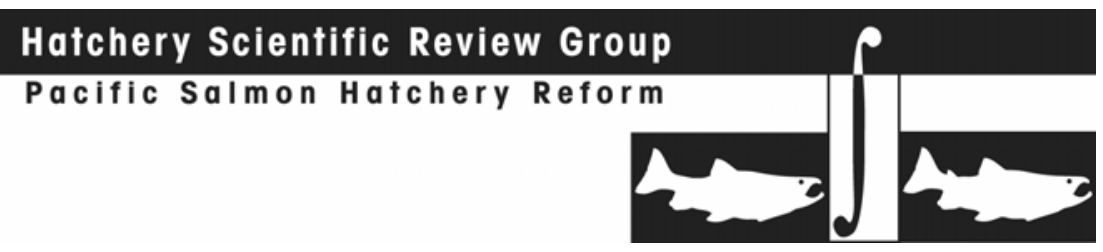

hatchery programs. Hatchery fish need to be adipose fin-clipped to ascertain pHOS and facilitate removal of excess hatchery fish through selective fisheries or other methods.

In order to improve the viability and productivity of natural Upper Columbia River summer Chinook populations, the HSRG recommends that all freshwater sport fisheries be immediately managed as selective fisheries. The Colville Tribes' growing ceremonial and substance fishery should also continue to develop its selective capacity. Research on selective gears for commercial fishing should commence immediately.

\section{Conservation Outcomes under the HSRG Solutions}

Figure 1 compares the proportion of fish on the spawning grounds that are of hatchery origin (pHOS) and the proportionate natural influence (PNI) for current and HSRG proposed scenarios for Primary and Contributing populations. The HSRG solution reduces the hatchery influence in two of the three Primary populations (Hanford Reach and Okanogan) (Figure 1) and significantly improves their productivity (Figure 2). The status of the remaining Primary population (Wenatchee) was only marginally improved because it is currently meeting the standards for this designation (PNI), although the pHOS is somewhat high. The level of hatchery influence decreases for the three Contributing populations, but productivity only increases marginally given current habitat conditions. One of the three Contributing populations improves sufficiently to meet those standards.

Figure 2 demonstrates substantial increases in natural-origin Chinook abundance and productivity that should be achievable with adoption of population standards and subsequent hatchery and harvest reforms recommended by the HSRG.

\section{Harvest Outcomes under the HSRG Solutions}

Figure 3 describes current and estimated changes in harvest (marine, mainstem Columbia River and terminal areas) that would occur following implementation of the management solutions proposed by the HSRG. In this case, since the HSRG solutions require removing a high percentage of hatchery-origin fish, thus providing opportunities for increases in selective mainstem and terminal harvest of hatchery fish. 


\section{Hatchery Scientific Review Group}

Pacific Salmon Hatchery Reform
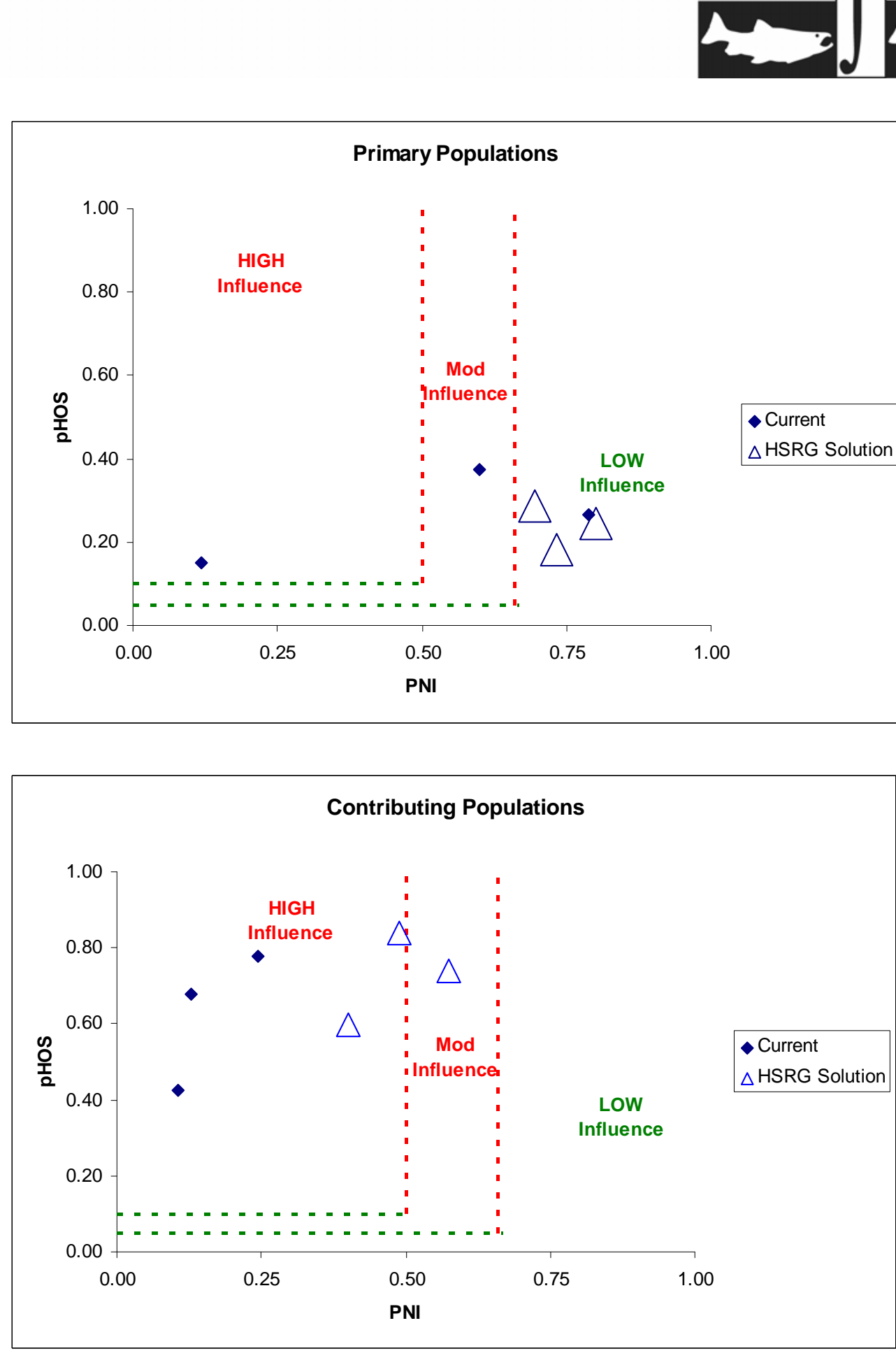

Figure 1. Relationship of the proportion of the fish on the spawning grounds that are of hatchery origin (pHOS) and the proportionate natural influence index (PNI) for Primary (top panel) and Contributing (bottom panel) summer/fall Chinook populations in the Upper Columbia River ESU. Solid diamonds represent values for current programs and open triangles represent values for the HSRG recommended hatchery management solution. 


\section{Hatchery Scientific Review Group}

Pacific Salmon Hatchery Reform
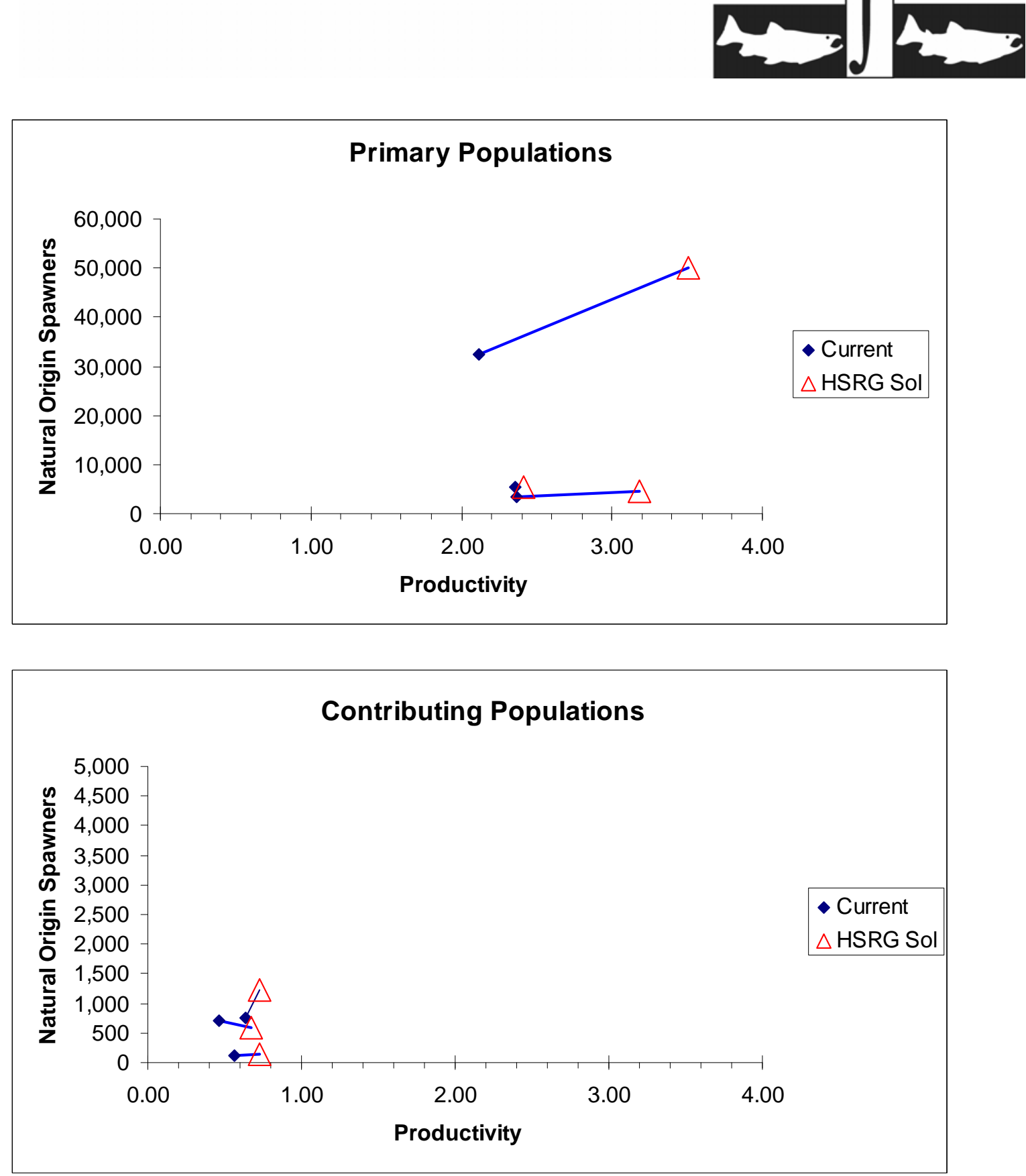

Figure 2. Productivity and spawner abundance for Primary (top panel) and Contributing (bottom panel) summer/fall Chinook populations in the Upper Columbia River ESU. Solid diamonds represent existing productivity and spawner abundance levels, and triangles represent the HSRG recommended hatchery management solution. Lines connect current with HSRG solution for a particular population. The HSRG recommended hatchery management solution includes projected improved fish passage survival in the Snake and Columbia mainstem migration corridor (FCRPS Biological Opinion May 5, 2008). 


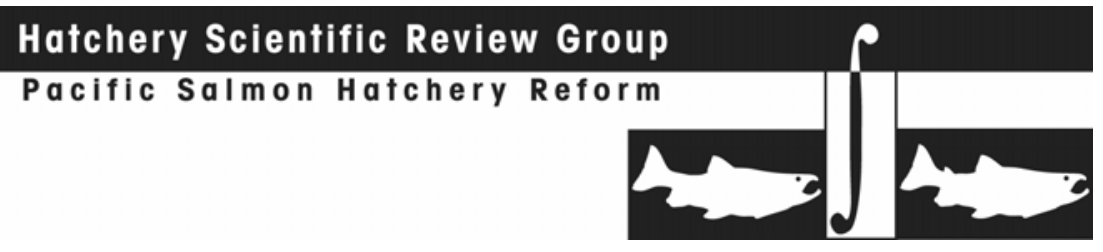

The HSRG solutions predict increased harvest in all fishing areas due to (a) increased productivity in the natural populations that is gained from controlling $\mathrm{pHOS}$, and (b) from immediately implementing selective fishing in freshwater sport and terminal tribal fisheries. Additional harvest benefits are possible as more selectivity is adopted in additional fisheries, particularly the non-treaty commercial fishery.

The sport fisheries are capable of readily switching to selectivity. The Colville Tribes initiated selective fishing in 2008 and are planning to fish with predominately selective gear in the future. In considering the value of selective fishing in meeting the managers' conservation and harvest objectives, the HSRG assumed (a) 10\% release mortality for selective sport fisheries, (2) 5\% release mortality for Colville Tribes selective fishing, and (c) $75 \%$ marked HORs in the run.

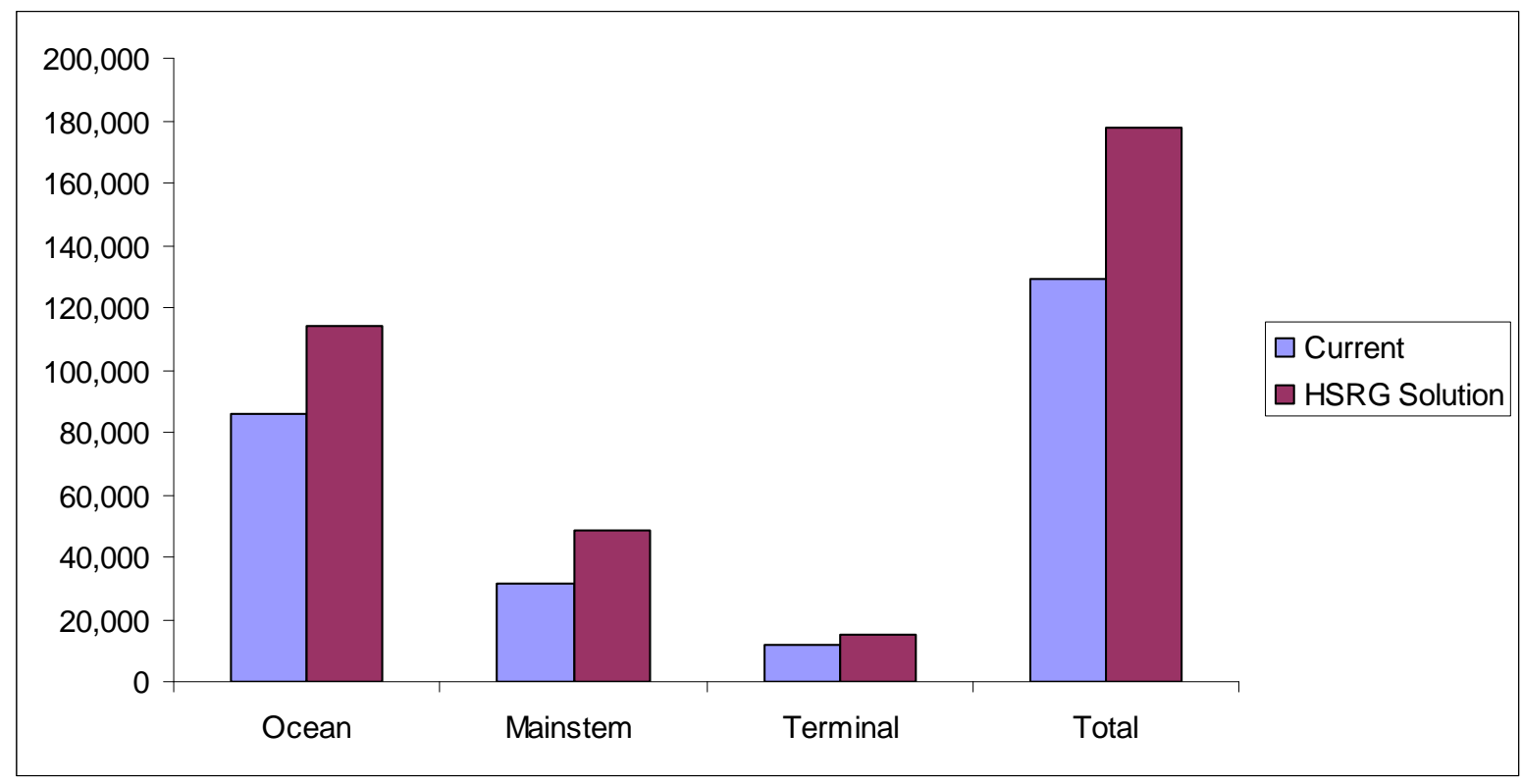

Figure 3. Estimated marine, mainstem Columbia, and terminal harvest under current and HSRG recommended hatchery management solution for Upper Columbia River Summer/Fall Chinook ESU.

\section{Hatchery Program Changes under the HSRG Solutions}

Table 2 shows the current size of each hatchery program as well as their size under the HSRG solution. The HSRG solution significantly improves four populations in this ESU by improving integration with natural fish and controlling $\mathrm{pHOS}$.

For the Similkameen program in the Okanogan subbasin, broodstock should be collected locally and from throughout the run. With proper broodstock management and planned terminal selective fishing, this program size could increase and still meet the standards of a Primary population.

For the Methow subbasin, managers need to first assess whether fish returning to this river have the productivity and capacity to be managed as a distinct population or if the population is only supported by the ongoing Wells Hatchery. A Contributing designation would be appropriate should managers decide to operate the Methow subbasin as a 


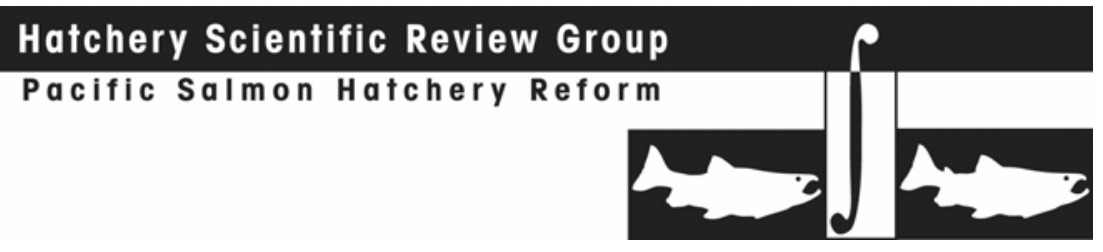

distinct population with program changes similar to those of the Okanogan: collect local broodstock from throughout the run. If the Methow is not a distinct population at this time and viability of the ESU does not require it to be designated as such, then managers could operate the Carlton Pond program as a component of a Wells Hatchery segregated program.

Determining the management status of the mainstem spawning aggregate in the upper Columbia River is critical to deciding the appropriate operation of Wells Hatchery. If the mainstem spawners are not a distinct population, then Wells Hatchery should be operated as a segregated program using hatchery-origin fish as broodstock and keeping stray rates to a minimum in the Methow and Okanogan rivers. If the mainstem aggregate is managed as a distinct population, then Wells Hatchery should be managed as an integrated program with broodstock collection consistent with achieving standards of a Contributing or Primary population.

No Chinook hatchery program size changes are recommended in the Entiat and Wenatchee rivers.

The HSRG recommends that the Priest Rapids and Ringold programs use only local broodstock and adipose fin-clip all hatchery releases to facilitate broodstock management, monitoring of $\mathrm{pHOS}$, and to allow selective removal of hatchery fish. These hatchery changes would allow management consistent with a Primary population designation. Given the limitations of the Ringold facility to collect hatchery returns, investments in expansion are encouraged at the Priest Rapids facility.

For the Yakima River program, the HSRG recommends that managers prioritize developing an approach to collect local broodstock. All juveniles should be marked for broodstock and harvest management, and pHOS should be consistent with whatever population designation the managers decide for Yakima River fall Chinook.

\subsubsection{4}

\section{Summary and Conclusions}

The HSRG solutions for populations of Upper Columbia River summer/fall Chinook involve significant reforms in both hatchery and harvest practices, and adopting conservation management principles that would ensure long-term viability of this ESU. A number of hatchery program changes are recommended that would greatly improve population productivities.

Hatchery reforms alone will not allow this ESU to provide its full harvest potential consistent with conservation objectives. Developing additional selective fisheries will be essential to provide increased harvest benefits identified by the HSRG in a manner that helps promotes conservation of the natural populations. The HSRG recommends that all freshwater sport fisheries be managed as selective and the Colville Tribes' growing ceremonial and subsistence fishery should continue to develop its selective capacity. Research on selective fishing gears for commercial fishing should also commence immediately.

Given the high exploitation rate for summer/fall Chinook, the HSRG recommends that fishery managers review the capacity of Upper Columbia River summer Chinook populations to tolerate current and expected future high exploitation rates and adopt 


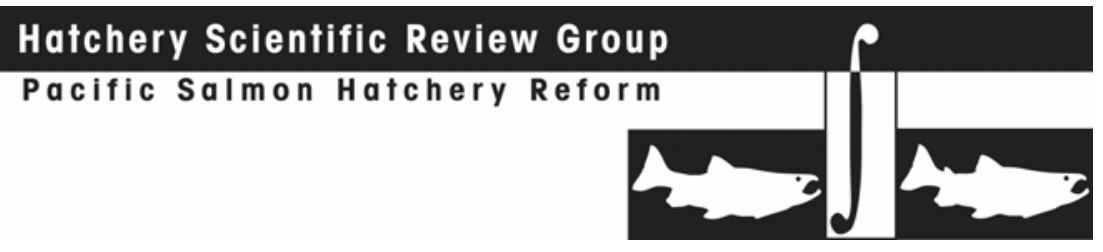

fisheries management and hatchery production strategies that are compatible with species conservation and survival.

The HSRG concludes that the effectiveness of habitat actions would greatly increase if combined with hatchery and harvest reforms. Analysis of the Primary populations in the Upper Columbia spring Chinook ESU suggests that the benefits of habitat quality improvements would more than double if combined with hatchery reforms. Unless hatchery and harvest reforms are implemented, the potential benefits of current or improved habitat cannot be fully realized.

\subsubsection{Snake River Fall-Run Chinook ESU}

This section provides an overview of the Snake River Fall-Run Chinook Salmon ESU. It contains a general description of the ESU, fisheries, habitat limitations and hatchery programs that affect it. Overall recommendations for ESU-wide hatchery program changes are summarized, as are the results of implementing those changes on conservation and harvest goals. Detailed conclusions and recommendations for each population in the ESU can be found in the Appendix E.

\subsubsection{HSRG Population Guidelines}

In order to meet conservations goals for the ESU, numerous threats to these populations need to be addressed, including risks from hatchery programs. The key to controlling genetic and ecological risks due to straying and fitness loss is to manage hatchery broodstock and natural spawning escapement such that the natural habitat (and not the hatchery environment) drives the adaptation and productivity of the naturally spawning population. This is achieved by operating either (a) integrated programs where the proportion of natural-origin adults in the broodstock ( $\mathrm{pNOB}$ ) exceeds the proportion of hatchery-origin fish on the spawning grounds (pHOS); or (b) segregated programs where the contribution of hatchery fish to natural spawning is kept low (pHOS $<5 \%-<10 \%$ depending on the population designation). The HSRG developed criteria for hatchery influence for three population types based on the importance of the population to the recovery of the ESU. This was done to provide a consistent method of reviewing populations and programs across the Columbia River Basin. The population designations used by the HSRG (Primary, Contributing, or Stabilizing) were adopted after discussions with managers and followed those developed in the Lower Columbia River Salmon Recovery Plan (LCFRB 2004). These designations are meant to reflect the conservation importance of a population within the ESU from most important (Primary), to moderately important (Contributing), to least important (Stabilizing). HSRG recommendations show how hatchery programs can be operated consistent with these designations based on the following standards:

\section{HSRG criteria for hatchery influence on Primary populations}

- The proportion of effective hatchery-origin spawners (pHOS) should be less than 5\% of the naturally spawning population, unless the hatchery population is integrated with the natural population.

- For integrated populations, the proportion of natural-origin adults in the broodstock should exceed pHOS by at least a factor of two, corresponding to a PNI 


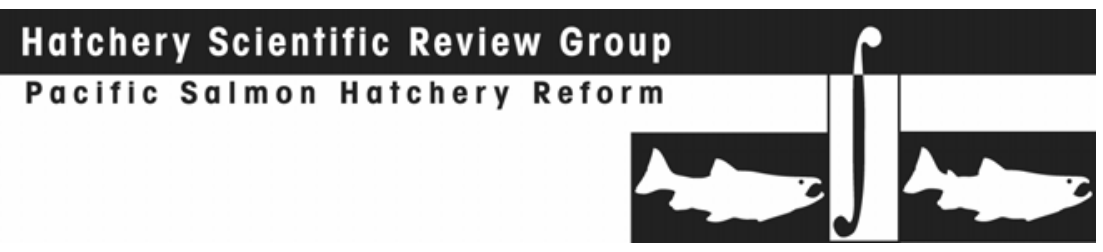

(proportionate natural influence) value of 0.67 or greater and pHOS should be less than 0.30 .

HSRG criteria for hatchery influence on Contributing populations:

- The proportion of effective hatchery-origin spawners (pHOS) should be less than $10 \%$ of the naturally spawning population, unless the hatchery population is integrated with the natural population.

- For integrated populations, the proportion of natural-origin adults in the broodstock should exceed pHOS, corresponding to a PNI value of 0.50 or greater and $\mathrm{pHOS}$ should be less than 0.30 .

HSRG criteria for hatchery influence on Stabilizing populations:

- The current operating conditions were considered adequate to meet their conservation goals. No criteria were developed for proportion of effective hatchery-origin spawners (pHOS) or PNI.

\subsubsection{Current Conditions}

\section{Conservation}

The Snake River fall Chinook salmon ESU was listed as threatened under the federal Endangered Species Act in 1992. The ESU includes all naturally spawned populations of fall-run Chinook salmon in the mainstem Snake River below Hells Canyon Dam, and in the Tucannon, Grande Ronde, Imnaha, Salmon, and Clearwater rivers, and includes four artificial propagation programs. The ESU is considered to be a single population. The construction of Swan Falls Dam (1901) and the Hells Canyon Complex (1958-1967) extirpated two historical populations within this ESU (NMFS 2008e). The one remaining population has a "moderate" to "high" long-term extinction risk and is heavily supplemented by an artificial propagation program (NMFS 2008e). The Interior Columbia TRT recommended a minimum goal for recovery of 3,000 natural spawners.

The HSRG designated the Snake River fall Chinook population as Primary (Table 1). 
Table 1. Population designations for the Snake River Fall Chinook ESU and HSRG broodstock criteria achieved under current conditions and the HSRG recommended hatchery management solution.

\begin{tabular}{|l|c|c|c|}
\hline \multirow{2}{*}{ Population } & & \multicolumn{2}{|c|}{ HSRG Criteria Met $^{*}$} \\
\cline { 3 - 4 } & Designation & Current & HSRG $^{2}$ Solution \\
\hline Snake Hells Canyon Fall Chinook & Primary & Stabilizing & Stabilizing \\
\hline
\end{tabular}

1 Using the naming protocol of the Lower Columbia River Salmon Recovery Plan (LCFRB 2004), populations were classified based on information provided to the HSRG as Primary, Contributing, or Stabilizing. These designations are meant to reflect the conservation importance of a population within the ESU from most important (Primary- bold, red), to moderately important (Contributing-bold, blue), to least important (Stabilizing).

${ }^{2}$ The HSRG developed criteria for hatchery influence for the three population designations from low influence (Primary), moderate influence (Contributing) to high influence (Stabilizing).

\section{Current Harvest}

Snake River fall Chinook salmon are harvested in non-selective ocean fisheries and in fall fisheries in the mainstem Columbia River. The total ocean fishery harvest rate averaged 31\% from 1992 to 2006 (NMFS 2008e). Since 1996, the Columbia River fisheries have been subject to a total harvest limit of approximately $31 \%$. The total exploitation rate (harvest mortality for the combined ocean and in-river fisheries) averaged $75 \%$ from 1986 to 1991 , and $45 \%$ from 1992 to 2006 . Future mainstem harvest rates will be set on an abundance-based scale based partially on Snake River naturalorigin fish.

\section{Current Habitat}

The primary limiting habitat factor for this ESU is limited access to spawning and rearing areas. A series of mainstem Snake River dams block access to the upper Snake River, which has significantly reduced spawning and rearing habitat. Historically, the primary fall-run Chinook salmon spawning areas were located on the upper mainstem Snake River (NMFS 2008e), but now only 10 to $15 \%$ of the historical spawning habitat of this ESU remains. In addition, the four lower Snake River dams have converted riverine habitat to reservoir habitat for 147 miles and in doing so, decreased water velocity and habitat complexity. Other factors such as forestry, grazing, and agricultural practices have resulted in widespread degradation to the remaining accessible stream habitat throughout the ESU, although conditions vary by subbasin (NMFS 2008e). While plans and policies are being implemented to improve stream habitat, no plan exists to restore passage for fall Chinook upstream of the lower Snake River dams. 

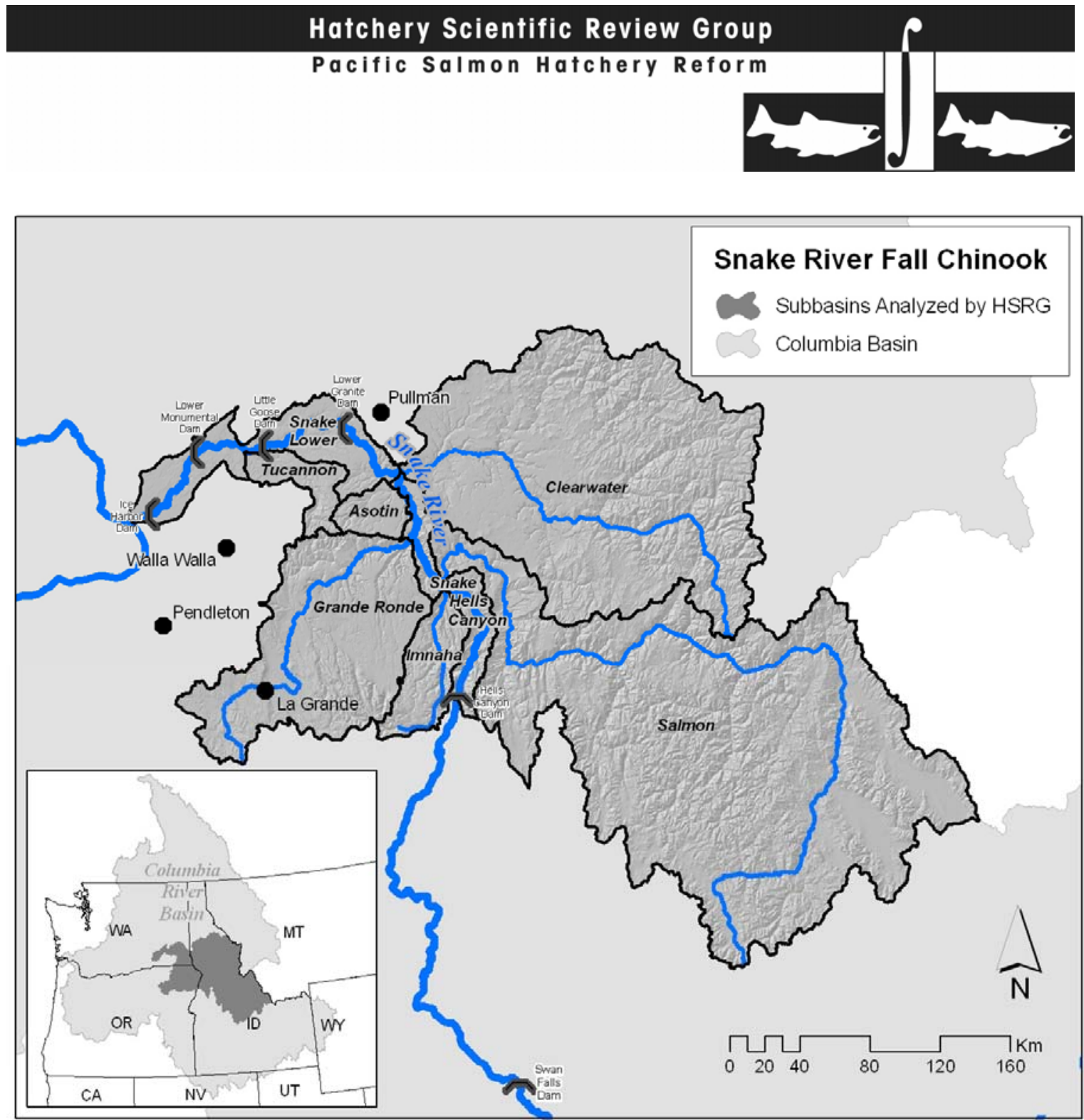

\section{Current Hatchery Programs}

Hatcheries play a major role in the production of Snake River fall Chinook. The Lower Snake River Compensation Plan was put in place in 1976 to mitigate for the loss of adult Snake River fall Chinook salmon. Currently there is one poorly integrated hatchery program in the Snake River Fall Chinook ESU that releases approximately 5.8 million juvenile Chinook annually at a number of locations (Table 2). Hatchery fish make up the majority of the adult returns each year. Good et al. (2005) characterized the risk to genetic diversity as "moderately high" for Snake River fall Chinook due to the loss of diversity associated with extinct populations and the significant hatchery influence on the extant population.

Estimates of PNI and pHOS under current conditions show that the single population within this ESU does not meet broodstock criteria for a Primary or Contributing population designation. Current broodstock management meets the criteria for a Stabilizing population designation (Table 1). Hatchery fish affect every major spawning aggregate within the single extant population. 
Table 2. Hatchery releases and types of programs for Snake River Fall Chinook ESU.

\begin{tabular}{|l|c|c|c|c|c|c|}
\hline \multirow{2}{*}{$\begin{array}{l}\text { Population/Program } \\
\text { Name }\end{array}$} & \multicolumn{3}{|c|}{ Current (1,000s) } & \multicolumn{3}{c|}{ HSRG Solution (1,000s) } \\
\cline { 2 - 7 } & Type & Purpose & \# Released & Type & Purpose & \# Released \\
\hline $\begin{array}{l}\text { Snake Hells Canyon Fall } \\
\text { Chinook }\end{array}$ & Int & Both & $5,802.7$ & Int & Both & $5,802.7$ \\
\hline
\end{tabular}

\subsubsection{3}

\section{HSRG Solutions}

The HSRG looked at various hatchery scenarios that could improve productivity while meeting the standards for a Primary or Contributing population. Various alternatives were considered that could increase fitness and productivity, but none increased abundance of natural-origin fish and all would result in significant loss of harvest benefits. Loss of a majority of historical habitat and relatively low productivity constrains the ability to meet conservation goals. Given these conditions, the HSRG recommendations focused on near-term improvements to the current program.

\section{Conservation Outcomes under the HSRG Solutions}

Figure 1 compares the proportion of fish on the spawning grounds that are of hatchery origin (pHOS) and the proportionate natural influence (PNI). The HSRG solution results in minimal change to pHOS and PNI from current conditions, but improves spatial structure and local adaptation that should improve productivity.

Figure 2 compares spawner abundance and productivity relationships between current and HSRG-proposed scenarios. The HSRG scenario would be expected to have a positive effect on productivity over time as broodstock protocols are implemented that allowed local adaptation to the differing habitats (Clearwater and Snake rivers). However, the relatively minor improvement in productivity presented in Figure 2 is primarily the result of assumed future passage improvements at mainstem hydroelectric facilities and not the result of improvements to the hatchery programs.

\section{Harvest Outcomes under the HSRG Solutions}

Figure 3 describes current and estimated changes in harvest (in marine, mainstem Columbia River, and terminal areas) that would occur following implementation of the solutions proposed by the HSRG. The HSRG solution maintains current harvest levels in the marine and mainstem Columbia River. In addition, the HSRG identified an opportunity to develop a new terminal selective fishery targeting hatchery fish that would increase total harvest.

\section{Hatchery Program Changes under the HSRG Solutions}

Current hatchery programs are being managed consistent with the standards for a Stabilizing designation and implementing the HSRG recommendations would not change this condition for the reasons stated above. The HSRG recommendations focus on three key areas to improve upon the current programs:

Improve broodstock management to help promote spatial structure, local adaptation, and improve productivity. This recommendation will require developing broodstock collection capabilities within the Clearwater River and the Snake River (upstream of the confluence with the Clearwater River). Given the lack of adult collection facilities in 
these areas, the HSRG recommends that managers test and deploy live capture selective fishing gear to accomplish this objective.

Adipose fin-clip all hatchery fish to provide an opportunity to implement a selective terminal fishery and to properly manage broodstock.

Implement strategies to control bacterial kidney disease where these strategies are not already in place.

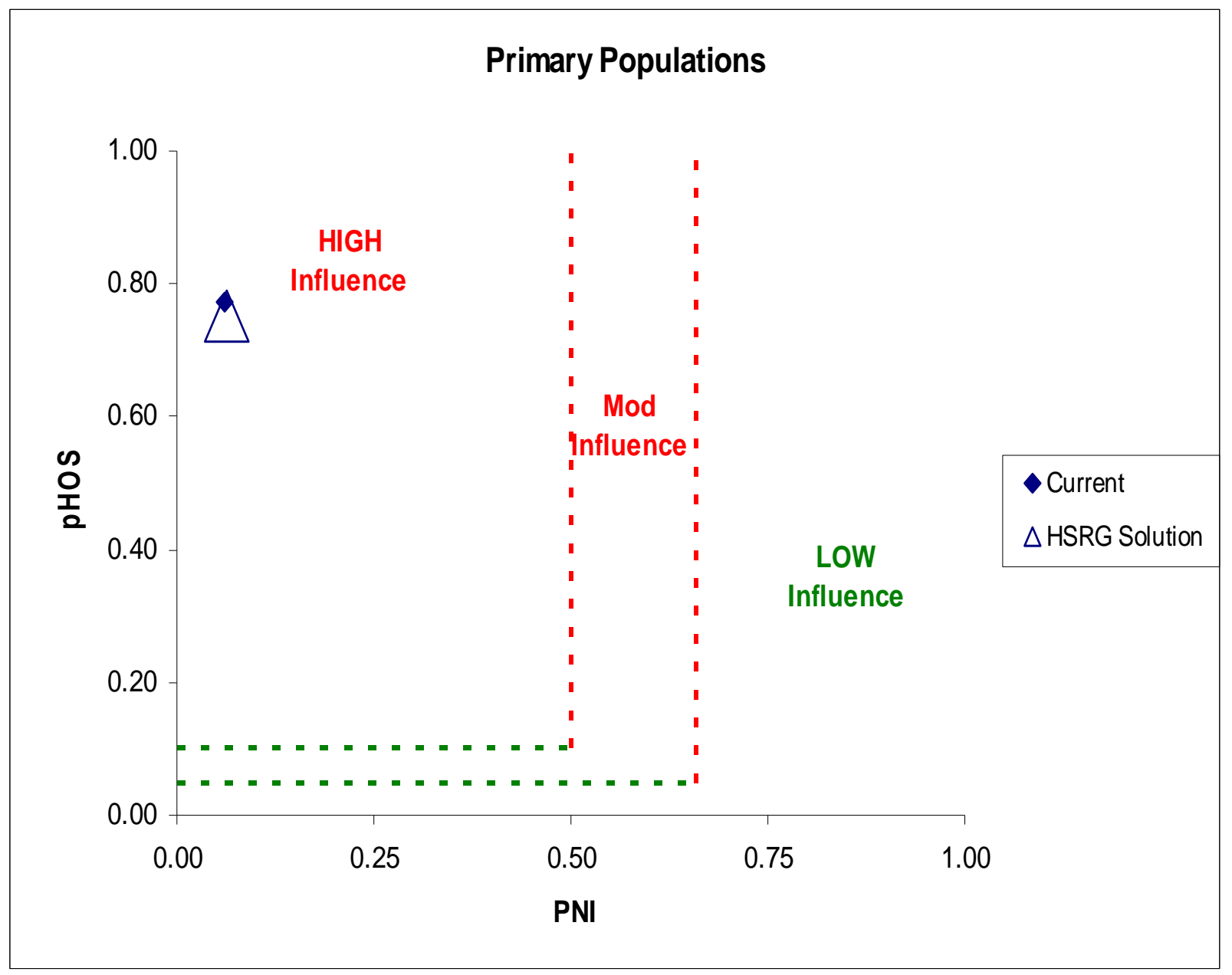

Figure 1. Relationship of the proportion of the fish on the spawning grounds that are of hatchery origin (pHOS) and the proportionate natural influence index (PNI) for Primary fall Chinook populations in the Snake River ESU. Solid diamonds represent values for current programs and open triangles represent values for the HSRG recommended hatchery management solution. 


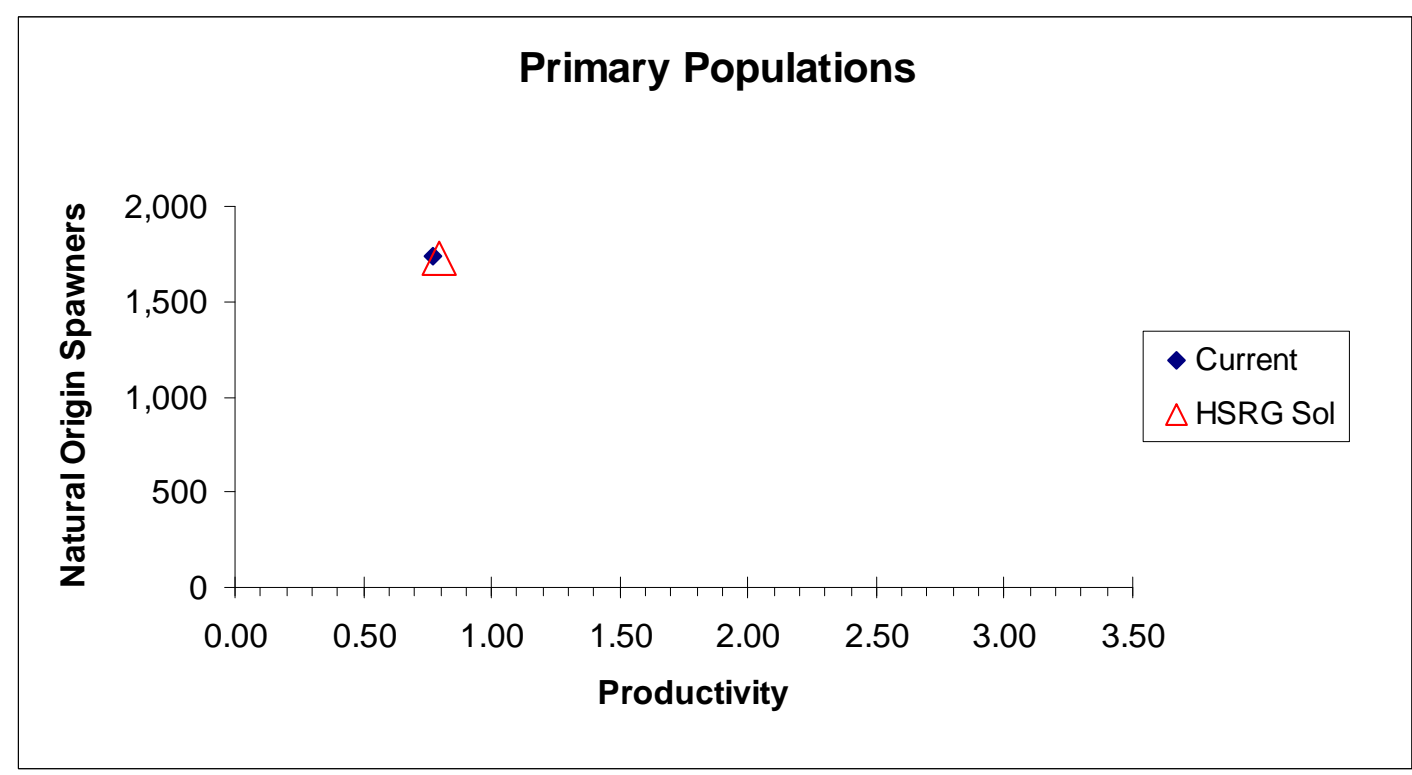

Figure 2. Productivity and spawner abundance for Primary fall Chinook populations in the Snake River ESU. Solid diamonds represent existing productivity and spawner abundance levels, and triangles represent the HSRG recommended hatchery management solution. Lines connect current with HSRG solution for a particular population. The HSRG recommended hatchery management solution includes projected improved fish passage survival in the Snake and Columbia mainstem migration corridor (FCRPS Biological Opinion May 5, 2008).

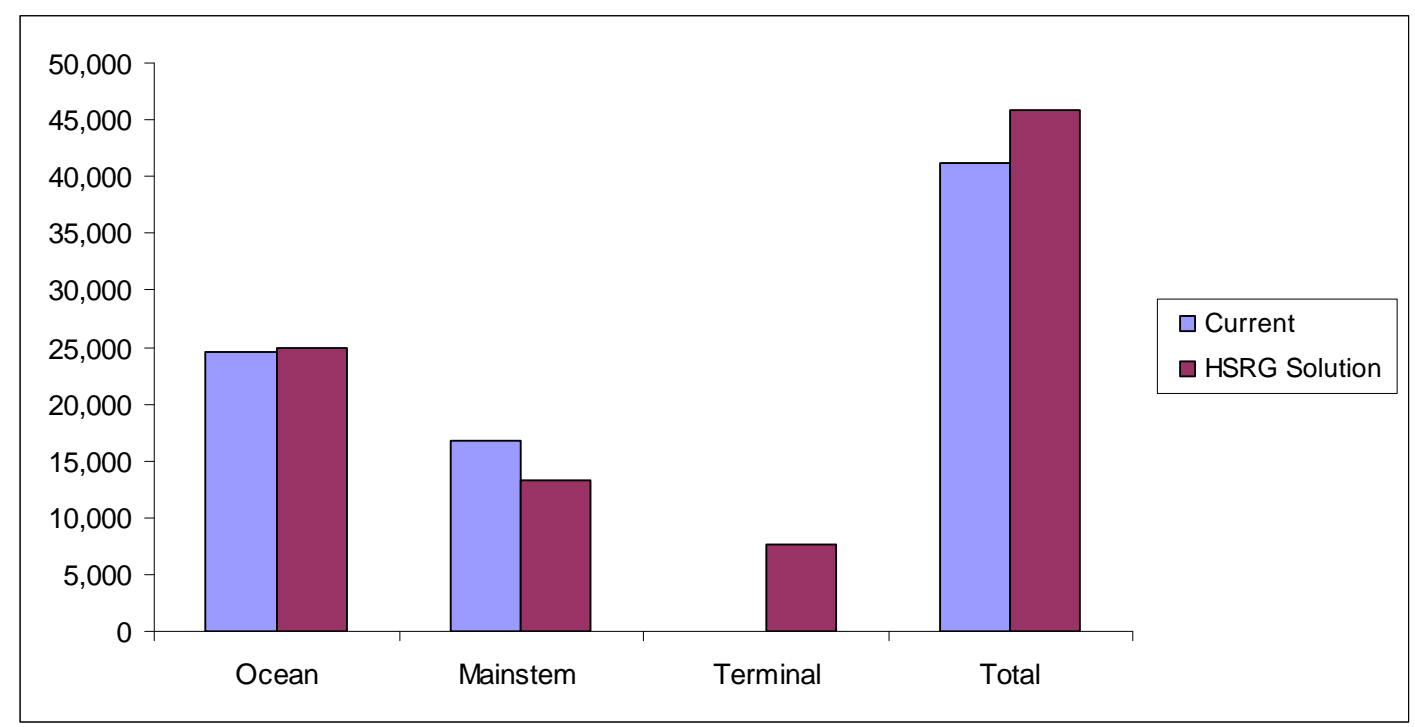

Figure 3. Estimated marine, mainstem Columbia, and terminal harvest under current and HSRG recommended hatchery management solution for Snake River Fall Chinook ESU. The HSRG recommended hatchery management solution includes projected improved fish passage survival in the Snake and Columbia mainstem migration corridor (FCRPS Biological Opinion May 5, 2008). 


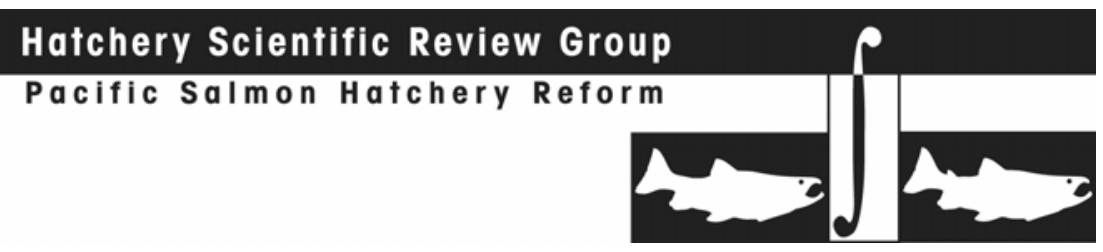

3.1.7.4

Summary and Conclusions

Managers identified conservation and harvest objectives for this ESU. The current hatchery program is oriented toward achieving both objectives, but integration with the natural-origin fish is poor.

The HSRG considered alternatives that could increase fitness and productivity, but none of these alternatives increased abundance of natural-origin fish, and all would result in significant loss of harvest benefits. Therefore, the HSRG focused on near-term improvements to the current hatchery program to promote spatial structure, local adaptation and provide additional harvest opportunities while maintaining the abundance of natural-origin spawners. Specifically, it is recommended that separate broodstocks be developed for the Clearwater and mainstem Snake River. In addition, population management would benefit if all hatchery fish were marked with an adipose fin-clip and a selective terminal harvest was implemented on returning hatchery fish.

\subsubsection{Snake River Spring/Summer Chinook MPG}

\subsubsection{Upper Salmon River Chinook MPG}

This section provides an overview of the Upper Salmon River Chinook Major Population Group (MPG). It contains a general description of the MPG, fisheries, habitat limitations and hatchery programs that affect it. Overall recommendations for MPG-wide hatchery program changes are summarized as are the results of implementing these changes on conservation and harvest goals. Detailed conclusions and recommendations for each population in the MPG can be found in the Appendix E.

3.1.8.1.1

\section{HSRG Population Guidelines}

In order to meet conservations goals for the ESU, numerous threats to these populations need to be addressed, including risks from hatchery programs. The key to controlling genetic and ecological risks due to straying and fitness loss is to manage hatchery broodstock and natural spawning escapement such that the natural habitat (and not the hatchery environment) drives the adaptation and productivity of the naturally spawning population. This is achieved by operating either (a) integrated programs where the proportion of natural-origin adults in the broodstock (pNOB) exceeds the proportion of hatchery-origin fish on the spawning grounds (pHOS); or (b) segregated programs where the contribution of hatchery fish to natural spawning is kept low (pHOS $<5 \%$ to $<10 \%$ depending on the population designation). The HSRG developed criteria for hatchery influence for three population types based on the importance of the population to the recovery of the ESU. This was done to provide a consistent method of reviewing populations and programs across the Columbia River Basin. The population designations used by the HSRG (Primary, Contributing, or Stabilizing) were adopted after discussions with managers and followed those developed in the Lower Columbia River Salmon Recovery Plan (LCFRB 2004). These designations are meant to reflect the conservation importance of a population within the ESU from most important (Primary), to moderately important (Contributing), to least important (Stabilizing). HSRG recommendations show how hatchery programs can be operated consistent with these designations based on the following standards: 
HSRG criteria for hatchery influence on Primary populations:

- The proportion of effective hatchery-origin spawners (pHOS) should be less than 5\% of the naturally spawning population, unless the hatchery population is integrated with the natural population.

- For integrated populations, the proportion of natural-origin adults in the broodstock should exceed pHOS by at least a factor of two, corresponding to a PNI (proportionate natural influence) value of 0.67 or greater and pHOS should be less than 0.30 .

HSRG criteria for hatchery influence on Contributing populations:

- The proportion of effective hatchery-origin spawners (pHOS) should be less than $10 \%$ of the naturally spawning population, unless the hatchery population is integrated with the natural population.

- For integrated populations, the proportion of natural-origin adults in the broodstock should exceed $\mathrm{pHOS}$, corresponding to a PNI value of 0.50 or greater and $\mathrm{pHOS}$ should be less than 0.30 .

HSRG criteria for hatchery influence on Stabilizing populations:

- The current operating conditions were considered adequate to meet conservation goals. No criteria were developed for proportion of effective hatchery-origin spawners (pHOS) or PNI.

\subsection{Current Conditions}

\section{Conservation}

The Upper Salmon River Chinook MPG is in the Snake River Spring/Summer Chinook ESU and was listed as threatened under the Endangered Species Act in 1992. As defined by the ESA, the MPG includes eight extant populations: North Fork Salmon River, Lemhi River, Pahsimeroi River, Yankee Fork, Valley Creek, East Fork Salmon River, Lower Salmon River and the Salmon River Upper Mainstem above Redfish. For this analysis, the HSRG also includes the extinct Panther Creek population in the MPG.

The Lemhi River population is considered at "high" risk for both spatial structure and diversity. All other populations are considered at "low" or "moderate" risk (NMFS 2008e). The long-term risk of extinction is considered "high" for the Lemhi River, Yankee Fork, East Fork Salmon River, and Pahsimeroi River. Chinook salmon in the Pahsimeroi River are considered summer-run and are distinct genetically from other Chinook populations in the Upper Salmon River (UWFWS 2008).

For the purposes of this review, the HSRG assigned three populations as Primary, four populations as Contributing, and two populations as Stabilizing (Table 1).

\section{Current Harvest}

The 2008-2017 United States v. Oregon Management Agreement defines mainstem Columbia River harvest rates that are abundance-based and use a sliding scale schedule $(5.5 \%-17 \%)$ for natural-origin spring Chinook returning to the Snake River Basin. Ocean fishing mortality on the ESA listed Snake River spring/summer Chinook ESU is 


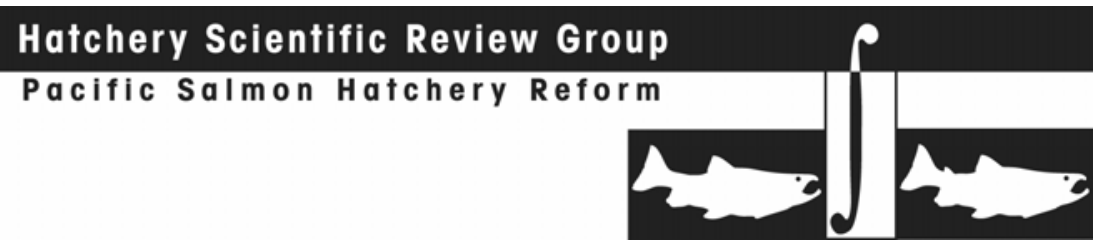

assumed to be zero (NMFS 2008e). Sport fisheries in the mainstem Columbia River and terminal areas target adipose fin-clipped hatchery fish. Non-tribal commercial fisheries occur in the lower Columbia River below Bonneville Dam and are partially selective. Non-selective tribal fisheries occur in Zone 6 (Columbia River above Bonneville Dam) and terminal areas. Prior to this year, non-tribal fishing in the upper Salmon River has not occurred since 1977, although limited tribal harvest has occurred in recent years.

Table 1. Population designations for the Upper Salmon River Chinook MPG and HSRG broodstock criteria achieved for each population under current conditions and the HSRG recommended hatchery management solution.

\begin{tabular}{|c|c|c|c|}
\hline \multirow[b]{2}{*}{ Population } & \multirow[b]{2}{*}{ Designation ${ }^{1}$} & \multicolumn{2}{|c|}{ HSRG Criteria Met ${ }^{2}$} \\
\hline & & Current & HSRG Solution \\
\hline 25-Salmon-Lemhi River Spring Chinook & Primary & Primary & Primary \\
\hline 26-Salmon-Pahsimeroi Summer Chinook & Primary & Stabilizing & Primary \\
\hline 31-Salmon-Upper Salmon Mainstem Spring Chinook & Primary & Contributing & Primary \\
\hline 24-Salmon-North Fork Salmon River Spring Chinook & Contributing & Contributing & Stabilizing \\
\hline 27-Salmon-Lower Salmon Mainstem Spring Chinook & Contributing & Contributing & Contributing \\
\hline 28-Salmon-East Fork Salmon River Spring-Summer Chinook & Contributing & Primary & Primary \\
\hline 30-Salmon-Valley Spring Chinook & Contributing & Contributing & Contributing \\
\hline 29-Salmon-Yankee Fork Spring Chinook & Stabilizing & Stabilizing & Stabilizing \\
\hline 32-Salmon-Panther Creek Spring Chinook (Extirpated) & Stabilizing & Stabilizing & Stabilizing \\
\hline
\end{tabular}

1 Using the naming protocol of the Lower Columbia River Salmon Recovery Plan (LCFRB 2004), populations were classified based on information provided to the HSRG as Primary, Contributing, or Stabilizing. These designations are meant to reflect the conservation importance of a population within the MPG from most important (Primary- bold, red), to moderately important (Contributing-bold, blue), to least important (Stabilizing).

2 The HSRG developed criteria for hatchery influence for the three population designations from low influence (Primary), moderate influence (Contributing) to high influence (Stabilizing).

\section{Current Habitat}

Habitat conditions vary widely throughout the upper Salmon River watershed. There are large areas where the composition, structure, and function of the aquatic, wetland, and riparian ecosystems is relatively undisturbed by anthropogenic effects; however, mining, livestock grazing, and timber harvest, along with other human impacts, have negatively affected habitat in the MPG (USFWS 2008). Twelve percent of the total stream length in the Upper Salmon River watershed is identified as impaired by sedimentation. The North Fork region is characterized by altered riparian habitats, increased water temperatures, and reduced stream bank stability. Other limiting factors in the MPG include low stream flows and disconnected tributaries, high stream temperatures, and fish passage issues.

Planned projects that may affect habitat in the MPG include culvert replacement, construction or modification of bridges, riparian zone rehabilitation, bank stabilization, and fish passage barrier removal. The scheduled removal of a barrier on the Upper Lemhi River will restore fish passage to 144 miles of rearing habitat and will increase flows 7 to $12 \mathrm{cfs}$ over at least three miles. Federal agencies are implementing numerous other projects within the range of Snake River spring/summer Chinook salmon that will improve access to blocked habitat, prevent entrainment into irrigation systems, increase channel complexity, and create thermal refuges. These projects will benefit the viability of the affected populations by improving abundance, productivity, and spatial structure. 

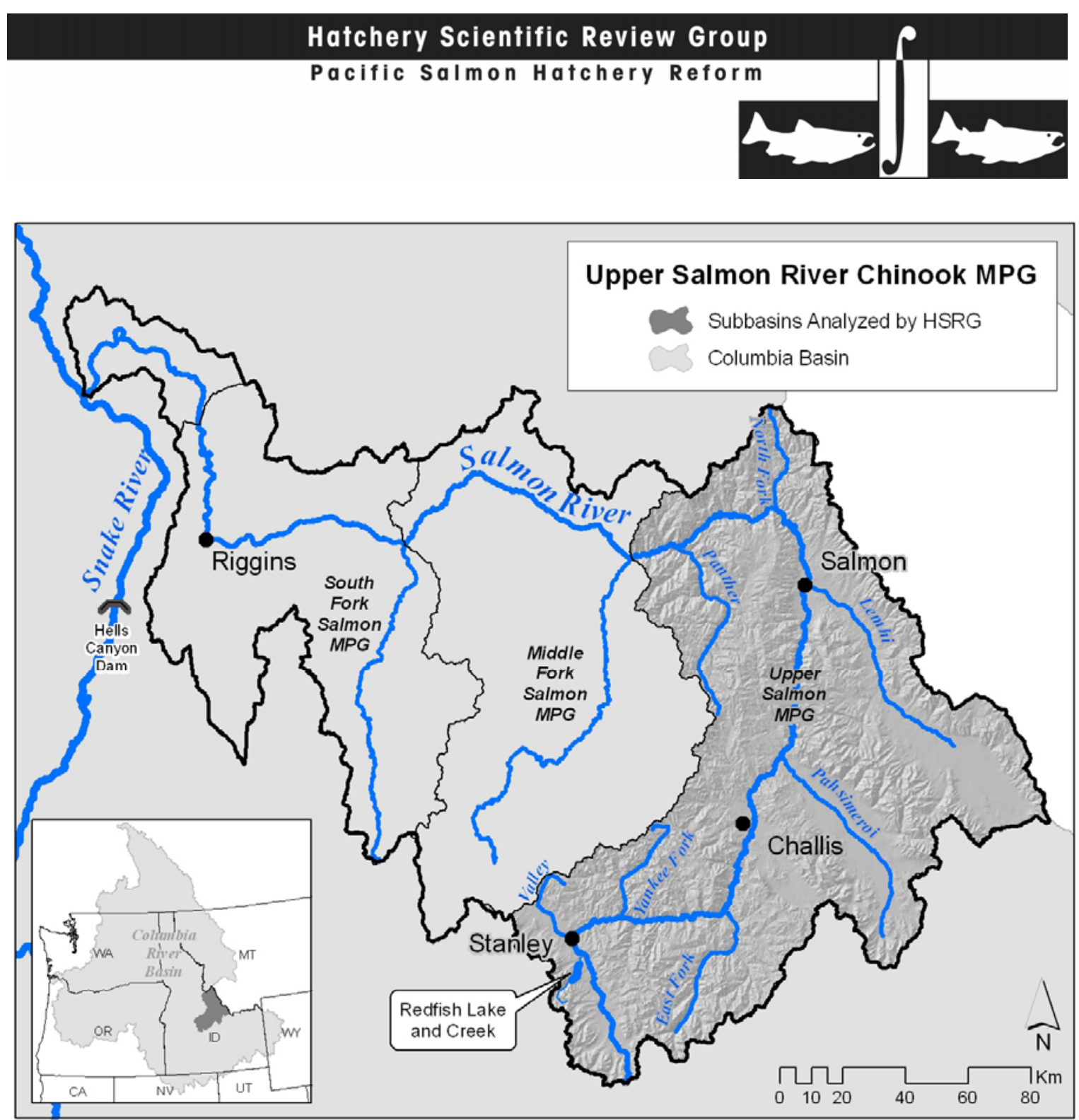

\section{Current Hatchery Programs}

Segregated hatchery programs operate in the Upper Mainstem Salmon River and Pahsimeroi River that release approximately 2 million spring Chinook smolts per year (Table 2). Both programs are intended to support harvest and have a secondary conservation purpose. In addition, the Eagle Research Hatchery and NOAA Fisheries Manchester Marine Laboratory are operated as integrated captive rearing programs (releasing 100-200 adults annually) intended to support research.

Associated with the U.S. vs. Oregon settlement, managers are discussing options to develop new locally adapted Chinook salmon broodstock programs in specific drainages in the upper Salmon River (e.g., Yankee Fork and Panther Creek). The HSRG did not analyze outcomes associated with this planning process.

Estimates of PNI and pHOS under current conditions identify two populations within the MPG that meet the standards of a Primary population (Lemhi River and East Fork Salmon River); four populations that meet the standards of a Contributing population (Upper Salmon River Mainstem, North Fork Salmon River, Lower Salmon River Mainstem, and Valley Creek); and three populations that meet the standards of a 
Stabilizing population (Pahsimeroi River, Yankee Fork Salmon River, and Panther Creek) (Table 1). Panther Creek is classified by the Interior Columbia Technical Recovery Team (ICTRT) as extirpated.

Table 2. Hatchery releases and types of programs for Upper Salmon River Chinook MPG.

\begin{tabular}{|l|c|c|c|c|c|c|}
\hline \multirow{2}{*}{\begin{tabular}{l} 
Population/Program Name \\
\cline { 2 - 7 }
\end{tabular}} & \multicolumn{3}{|c|}{ Current (1,000s) } & \multicolumn{2}{c|}{ HSRG Solution (1,000s) } \\
\hline 25-Salmon_Lemhi River Spring Chinook & None & NA & $\begin{array}{c}\# \\
\text { Released }\end{array}$ & Type & Purpose & $\begin{array}{c}\# \\
\text { Released }\end{array}$ \\
\hline 26-Salmon_Pahsimeroi Summer Chinook & None & NA & - & Int & BA & - \\
\hline $\begin{array}{l}\text { 26A-Salmon_Pahsimeroi Summer Chinook } \\
\text { (Pahsimeroi Hatchery) }\end{array}$ & Seg & Harv & 999.4 & Seg & Harv & $1,045.0$ \\
\hline $\begin{array}{l}\text { 31-Salmon_Upper Salmon Mainstem Spring } \\
\text { Chinook }\end{array}$ & None & NA & - & Int & Both & 197.4 \\
\hline $\begin{array}{l}\text { 31A-Salmon_Upper Salmon Mainstem Spring } \\
\text { Chinook (Sawtooth Hatchery) }\end{array}$ & Seg & Harv & $1,034.9$ & Seg & Harv & $1,223.0$ \\
\hline $\begin{array}{l}\text { 24-Salmon_North Fork Salmon River Spring } \\
\text { Chinook }\end{array}$ & None & NA & - & None & NA & - \\
\hline $\begin{array}{l}\text { 27-Salmon_Lower Salmon Mainstem Spring } \\
\text { Chinook }\end{array}$ & None & NA & - & None & NA & - \\
\hline $\begin{array}{l}\text { 28-Salmon_East Fork Salmon River Spring- } \\
\text { Summer Chinook }\end{array}$ & None & NA & - & None & NA & - \\
\hline 30-Salmon_Valley Spring Chinook & None & NA & - & None & NA & - \\
\hline 29-Salmon_Yankee Fork Spring Chinook & None & NA & - & None & NA & - \\
\hline $\begin{array}{l}\text { 32-Salmon_Panther Creek Spring Chinook } \\
\text { (Extirpated) }\end{array}$ & None & NA & - & None & NA & - \\
\hline Total all Populations/Programs & & & $\mathbf{2 , 0 3 4 . 3}$ & & & $\mathbf{2 , 7 5 0 . 5}$ \\
\hline
\end{tabular}

\subsection{HSRG Solutions}

The HSRG did not recommend alternatives for seven of the nine populations within this MPG that do not currently have an associated hatchery program. Several options were considered for the two populations (Pahsimeroi and Upper Salmon) with segregated hatchery programs, including various degrees of integrating natural- and hatchery-origin adults. Implementing the HSRG recommendations is expected to result in broodstock management that achieves a Primary designation for these populations (Table 1).

\section{Conservation Outcomes under the HSRG Solution}

Figure 1 compares the proportion of hatchery-origin fish (pHOS) on the spawning grounds and the proportionate natural influence (PNI) for Primary and Contributing populations under current and proposed (HSRG) scenarios. For populations where hatchery programs are in place (Pahsimeroi Summer Chinook and Upper Salmon Mainstem Spring Chinook), PNI values increase substantially. Values for pHOS remain stable or increase marginally for other populations within the MPG. The integrated components of both programs provide a valuable safety net for these populations.

Figure 2 compares the proportion of natural-origin fish on the spawning grounds (NOS) with the estimated productivity of Primary and Contributing populations for current and 


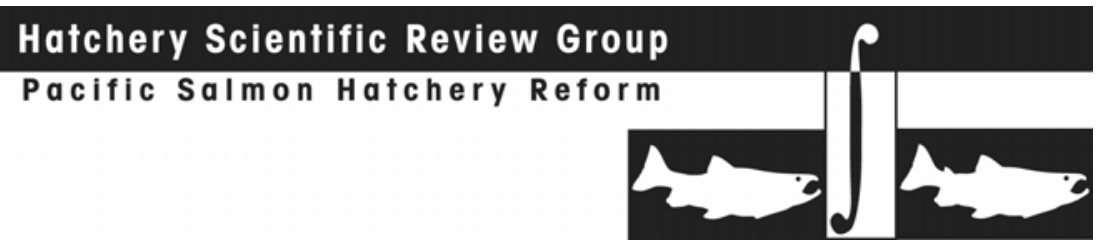

proposed (HSRG) scenarios. For the Pahsimeroi Summer Chinook and Upper Salmon Mainstem Spring Chinook populations (where hatchery programs are in place), substantial improvement in abundance of natural-origin adults and productivity is projected. The HSRG developed integrated hatchery solutions for these two programs. Values for natural-origin adult abundance and productivity for other populations within the MPG improves marginally or remains constant.

\section{Harvest Outcomes under the HSRG Solution}

Figure 3 illustrates current and estimated changes in harvest (in marine, mainstem Columbia River and terminal areas) expected to occur following implementation of the management solutions proposed by the HSRG. For the Upper Salmon River MPG, mainstem and terminal harvest increases for hatchery-origin fish in the Pahsimeroi Summer Chinook and Upper Salmon Mainstem Spring Chinook populations. Projected increases in harvest are due primarily to increased program size (e.g., smolt releases) and projected increases in productivity and adult abundance resulting from the implementation of HSRG solutions.

\section{Hatchery Program Changes under the HSRG Solution}

The low abundance of natural-origin fish and the large hatchery programs in the Pahsimeroi and Upper Salmon River limit options to improve programs in these systems. For the Pahsimeroi River population, the HSRG recommends that managers implement a two-stage stepping stone program to support the natural population and to provide harvest. This approach is suggested because of low productivity and abundance of natural-origin fish; therefore, the entire harvest program could not be integrated with a high proportionate natural influence. The recommended program would consist of an integrated conservation component producing approximately 285,000 smolts. Integrated adult returns not needed to maintain the integrated broodstock would be used as broodstock for the second stage harvest component to produce approximately one million smolts (Table 2). This approach maintains some genetic continuity between the harvest component and natural fish returning to the system. 


\section{Hatchery Scientific Review Group}

Pacific Salmon Hatchery Reform
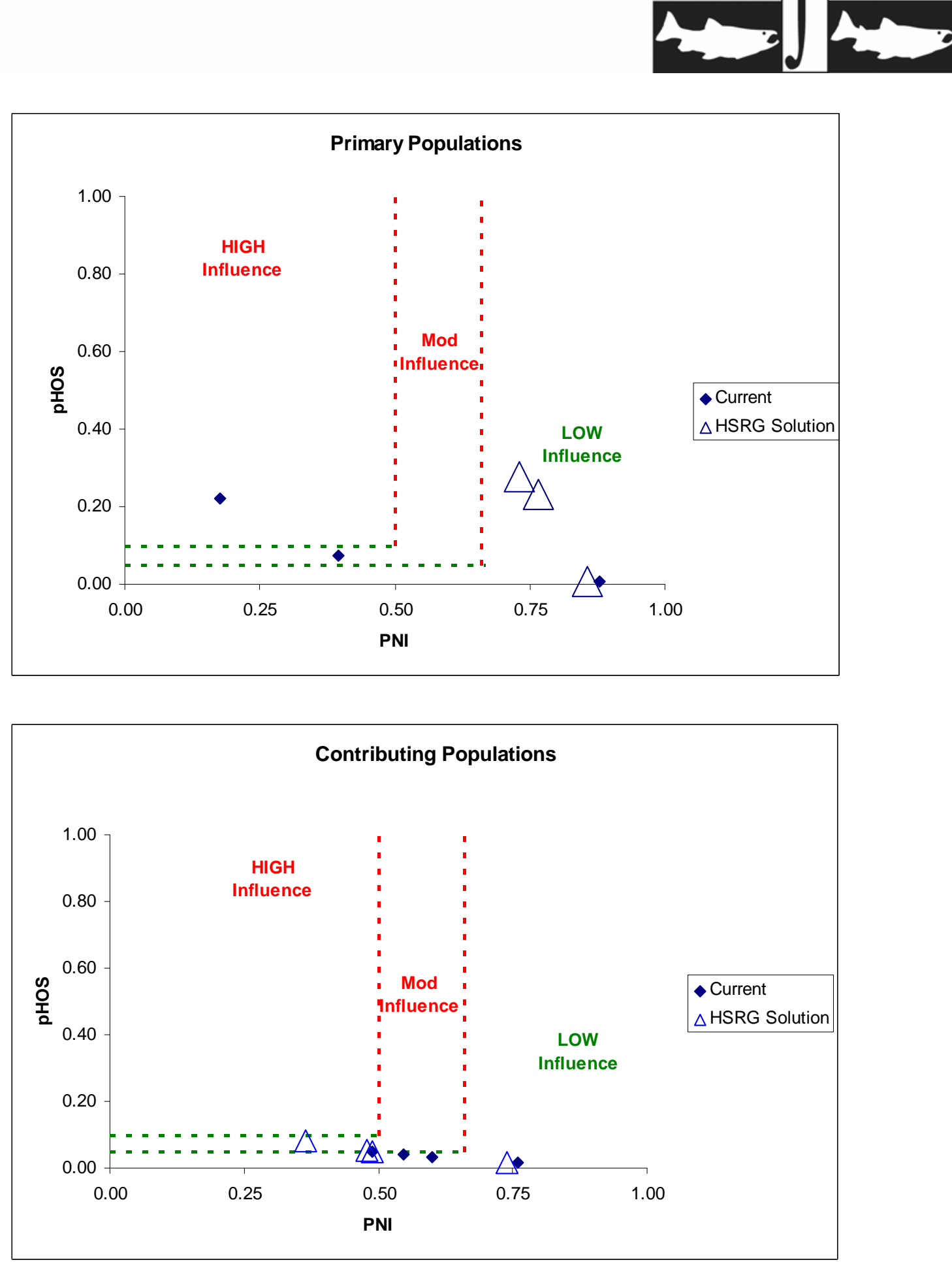

Figure 1. Relationship of the proportion of the fish on the spawning grounds that are of hatchery origin (pHOS) and the proportionate natural influence index (PNI) for Primary (top panel) and Contributing (bottom panel) Chinook populations in the Upper Salmon River MPG. Solid diamonds represent values for current programs and open triangles represent values for the HSRG recommended hatchery management solution. 


\section{Hatchery Scientific Review Group}

Pacific Salmon Hatchery Reform
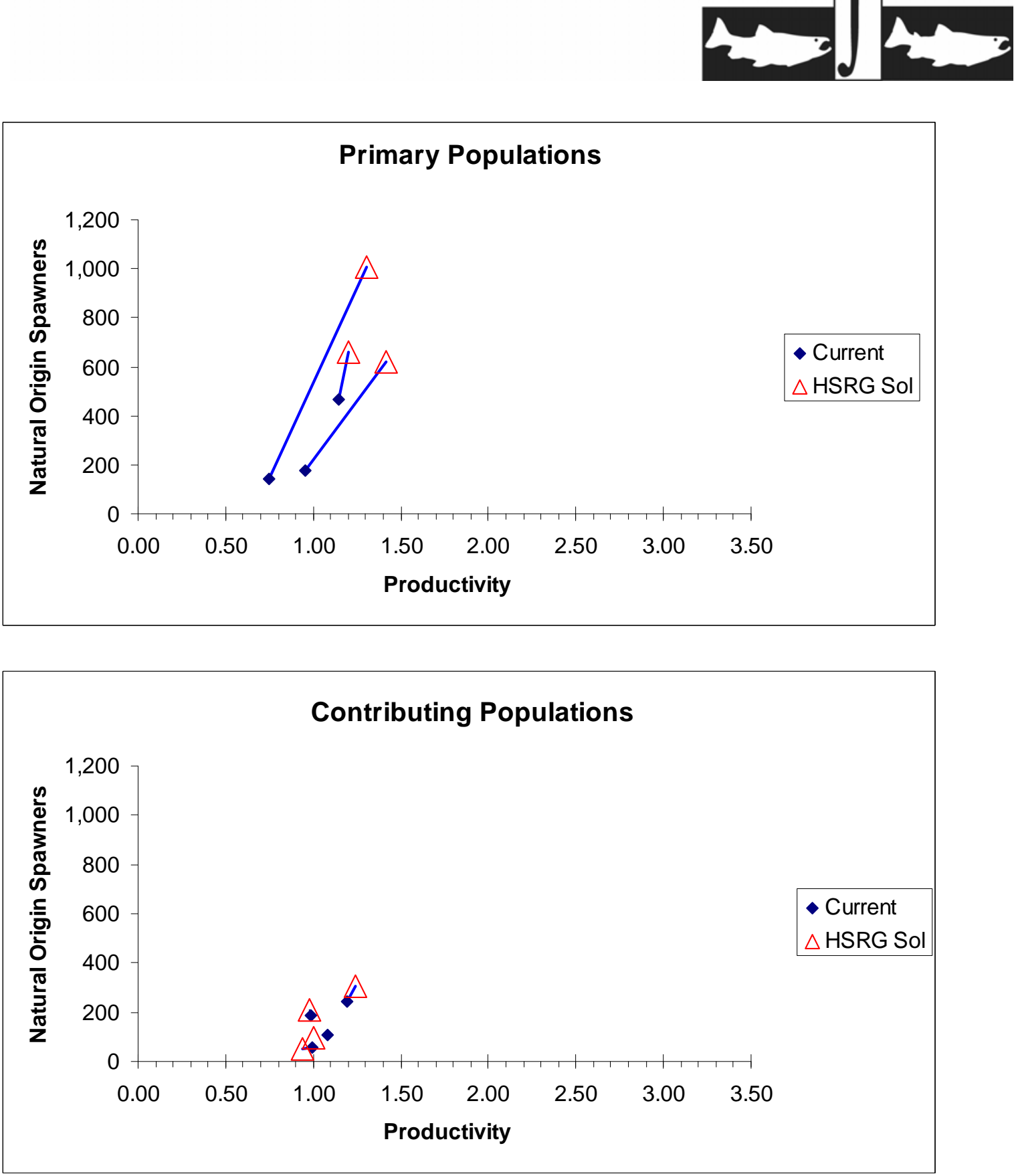

Figure 2. Productivity and spawner abundance for Primary (top panel) and Contributing (bottom panel) Chinook populations in the Upper Salmon River MPG. Solid diamonds represent existing productivity and spawner abundance levels, and triangles represent the HSRG recommended hatchery management solution. Lines connect current with HSRG solution for a particular population. The HSRG recommended hatchery management solution includes projected improved fish passage survival in the Snake and Columbia mainstem migration corridor (FCRPS Biological Opinion May 5, 2008). 

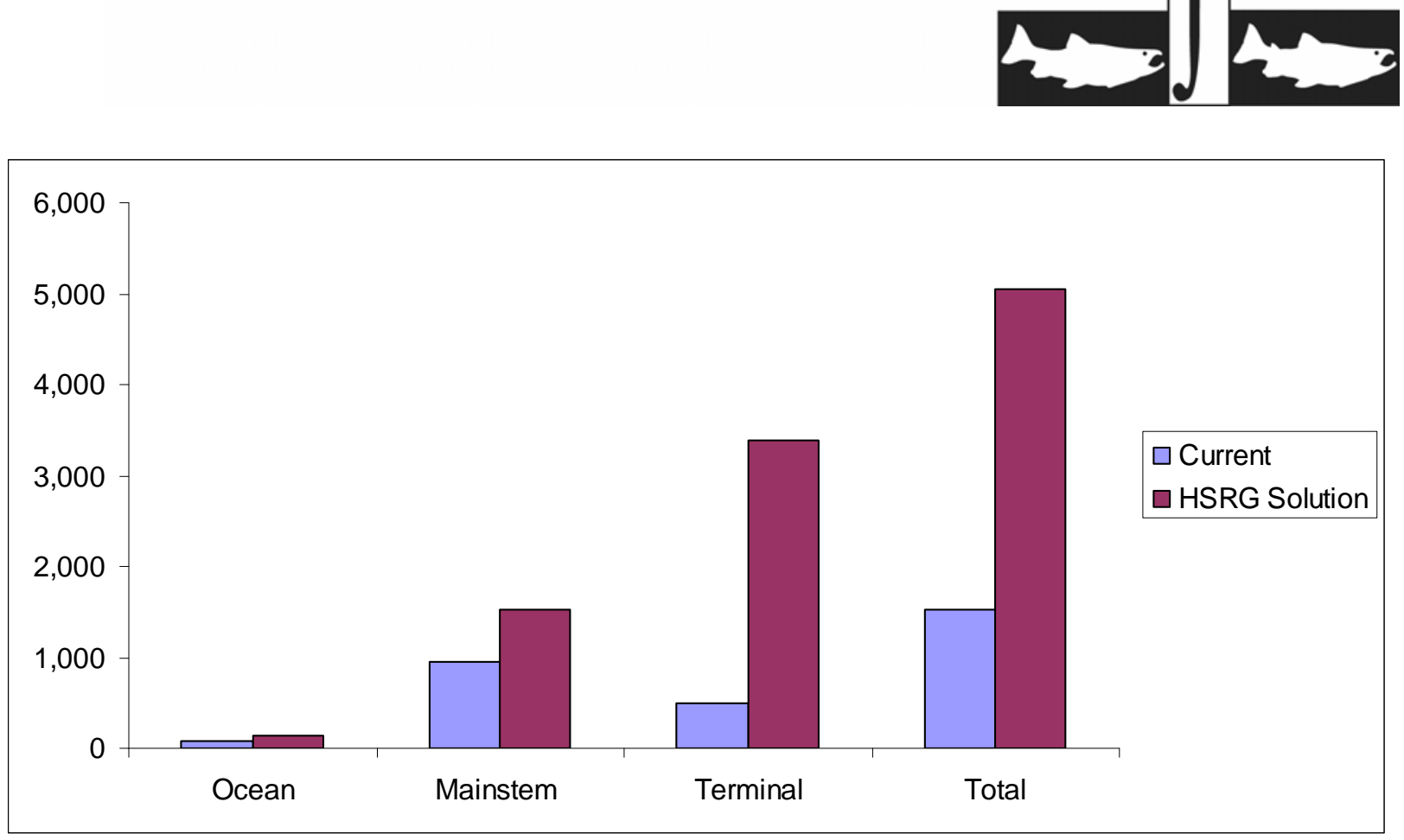

Figure 3. Estimated marine, mainstem Columbia, and terminal harvest under current and HSRG recommended hatchery management solution for Upper Salmon River Chinook MPG. The HSRG recommended hatchery management solution includes projected improved fish passage survival in the Snake and Columbia mainstem migration corridor (FCRPS Biological Opinion May 5, 2008).

For the Upper Salmon River, the HSRG recommends that managers implement a small $(\sim 200,000$ smolts $)$ integrated conservation program to support and increase natural spawning abundance (Table 2$)$. A separate segregated program ( $\sim 1.2$ million smolts) would be operated to address mitigation and harvest objectives. Broodstock for this program would be sourced completely from adult returns from the segregated program and would not rely on adult returns from the integrated program, as in the "stepping stone" program used in the Pahsimeroi River.

For this MPG, the total number of smolts could increase from current releases of approximately 2,000,000 to 2,700,000 annually (Table 2). The majority of this increase is projected to occur in the Upper Salmon Mainstem population.

\subsection{Summary and Conclusions}

The HSRG solution enables two additional populations to meet the standards for a Primary designation and provides an important safety net for the affected populations while increasing harvest opportunities.

The abundance of natural-origin escapement will vary from year to year. In order to balance the demographic risk (low overall abundance) against genetic risks (too much hatchery influence), the HSRG recommends managing pHOS and pNOB on a "sliding scale", while still assuring that PNI and pHOS objectives are met on average over generations. 


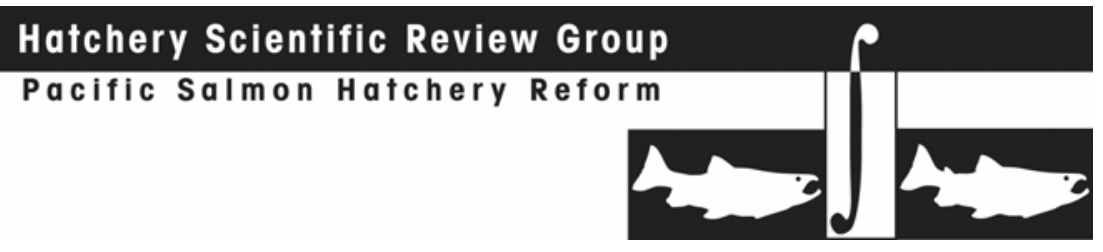

The HSRG recommends that managers continue to monitor status and trend information for natural populations of Chinook salmon as well as presence/absence and the proportion of hatchery fish in natural production areas.

The HSRG also concluded that the effectiveness of habitat actions would be greatly increased if combined with hatchery and harvest reforms. Analysis of the Primary populations in the Upper Salmon River Chinook MPG suggests that the benefits of habitat quality improvements would more than triple if combined with hatchery reforms. Unless hatchery and harvest reforms are implemented, the potential benefits of current or improved habitat cannot be fully realized.

\subsubsection{Middle Fork Salmon River Chinook MPG}

This section provides an overview of the Middle Fork Salmon River Chinook MPG. It contains a general description of the MPG, fisheries, habitat limitations and hatchery programs that affect it. Overall recommendations for MPG-wide hatchery program changes are summarized, as are the results of implementing those changes on conservation and harvest goals. Detailed conclusions and recommendations for each population in the MPG can be found in the Appendix E.

3.1.8.2.1

\section{HSRG Population Guidelines}

In order to meet conservations goals for the MPG, numerous threats to these populations need to be addressed, including risks from hatchery programs. The key to controlling genetic and ecological risks due to straying and fitness loss is to manage hatchery broodstock and natural spawning escapement such that the natural habitat (and not the hatchery environment) drives the adaptation and productivity of the naturally spawning population. This is achieved by operating either (a) integrated programs where the proportion of natural-origin adults in the broodstock (pNOB) exceeds the proportion of hatchery-origin fish on the spawning grounds (pHOS); or (b) segregated programs where the contribution of hatchery fish to natural spawning is kept low (pHOS $<5 \%$ to $<10 \%$ depending on the population designation). The HSRG developed criteria for hatchery influence for three population types based on the importance of the population to the recovery of the MPG. This was done to provide a consistent method of reviewing populations and programs across the Columbia River Basin. The population designations used by the HSRG (Primary, Contributing, or Stabilizing) were adopted after discussions with managers and followed those developed in the Lower Columbia River Salmon Recovery Plan (LCFRB 2004). These designations are meant to reflect the conservation importance of a population within the ESU from most important (Primary), to moderately important (Contributing), to least important (Stabilizing). HSRG recommendations show how hatchery programs can be operated consistent with these designations based on the following standards:

\section{HSRG criteria for hatchery influence on Primary populations:}

- The proportion of effective hatchery-origin spawners (pHOS) should be less than 5\% of the naturally spawning population, unless the hatchery population is integrated with the natural population.

- For integrated populations, the proportion of natural-origin adults in the broodstock should exceed pHOS by at least a factor of two, corresponding to a PNI 


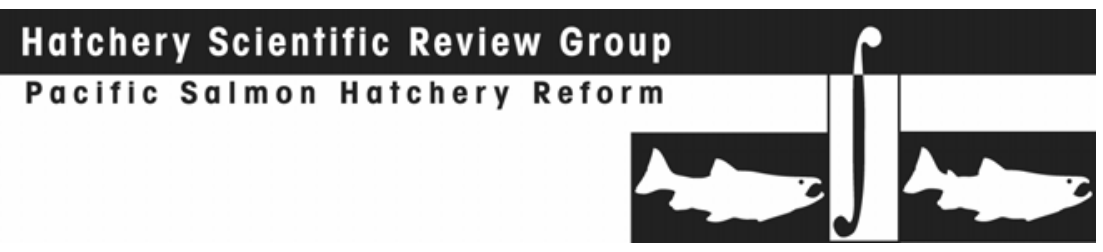

(proportionate natural influence) value of 0.67 or greater and pHOS should be less than 0.30 .

HSRG criteria for hatchery influence on Contributing populations:

- The proportion of effective hatchery-origin spawners (pHOS) should be less than $10 \%$ of the naturally spawning population, unless the hatchery population is integrated with the natural population.

- For integrated populations, the proportion of natural-origin adults in the broodstock should exceed pHOS, corresponding to a PNI value of 0.50 or greater and $\mathrm{pHOS}$ should be less than 0.30 .

HSRG criteria for hatchery influence on Stabilizing populations:

- The current operating conditions were considered adequate to meet conservation goals. No criteria were developed for proportion of effective hatchery-origin spawners (pHOS) or PNI.

\subsection{Current Conditions}

\section{Conservation}

The Middle Fork Salmon River Chinook Salmon MPG is in the Snake River Spring/Summer Chinook Salmon ESU which was listed as threatened under the Endangered Species Act in 1992. As defined by the ESA and the HSRG, the MPG includes Chamberlain Creek, Big Creek, Camas Creek, Loon Creek, Marsh Creek, Bear Valley Creek, Sulphur Creek and the Upper and Lower Middle Fork Salmon River populations. Current risk associated with spatial structure and diversity is rated as "very low" to "moderate" for all populations (NMFS 2008e). Big and Loon creeks support summer-run populations; the other seven populations within the MPG are considered spring-run. Chamberlain Creek has some distinct genetic characteristics and is located in a significant geographic position between the Middle and South Forks of the Salmon River.

The HSRG designated all populations as Primary except the Lower Mainstem SpringSummer Chinook populations, which are designated as Contributing (Table 1). 
Table 1. Population designations for the Middle Fork Salmon River Chinook MPG and HSRG broodstock criteria achieved for each population under current conditions and the HSRG recommended hatchery management solution.

\begin{tabular}{|l|c|c|c|}
\hline & & \multicolumn{2}{|c|}{ HSRG Criteria Met $^{2}$} \\
\cline { 3 - 4 } Population & Designation & Current & HSRG Solution \\
\hline 14-Salmon_Chamberlain Creek Spring Chinook & Primary & Primary & Primary \\
\hline 15-Salmon_Big Creek Spring Chinook & Primary & Primary & Primary \\
\hline 17-Salmon_Camas Creek Spring Chinook & Primary & Primary & Primary \\
\hline 18-Salmon_Loon Creek Spring Chinook & Primary & Primary & Primary \\
\hline 19+23-Salmon_Middle Fork-Upper Mainstem Spring-Summer Chinook & Primary & Primary & Primary \\
\hline 20-Salmon_Sulphur Creek Spring Chinook & Primary & Primary & Primary \\
\hline 21-Salmon_Bear Valley Spring Chinook & Primary & Primary & Primary \\
\hline 22-Salmon_Marsh Creek Spring Chinook & Primary & Primary & Primary \\
\hline 16-Salmon_Middle Fork-Lower Mainstem Spring-Summer Chinook & Contributing & Primary & Contributing \\
\hline
\end{tabular}

1 Using the naming protocol of the Lower Columbia River Salmon Recovery Plan (LCFRB 2004), populations were classified based on information provided to the HSRG as Primary, Contributing, or Stabilizing. These designations are meant to reflect the conservation importance of a population within the MPG from most important (Primary- bold, red), to moderately important (Contributing-bold, blue), to least important (Stabilizing).

2 The HSRG developed criteria for hatchery influence for the three population designations from low influence (Primary), moderate influence (Contributing) to high influence (Stabilizing).

\section{Current Harvest}

The Middle Fork Salmon River is reported to have historically supported 27\% of Idaho's Chinook salmon sport harvest. The ocean fishery mortality on Snake River spring/summer Chinook is very low and, for practical purposes, assumed to be zero (NMFS 2008e). Incidental harvest of Snake River spring/summer Chinook occurs in spring and summer season fisheries in the mainstem Columbia River that target harvestable hatchery and natural-origin stocks. The fisheries on harvestable runs are limited to ensure that incidental take of ESA-listed Snake River spring/summer Chinook does not exceed a rate of from 5.5 to $17 \%$. This incidental take of natural-origin upriver spring/summer Chinook has averaged 10.2\% since 2001 (NMFS 2008e).

\section{Current Habitat}

From 1930 to 1980, this watershed was managed as a primitive area. In 1980, it was designated the Frank Church - River of No Return Wilderness. As a result, most tributaries are in relatively pristine condition. Bear Valley, Marsh, Camas, Marble, Big, and Loon creeks are outside the wilderness area and are recovering from the historical effects of mining, grazing, logging, and road building. Wildfires burned approximately 310,000 acres of forested habitat within the South Fork and Middle Fork Salmon River MPGs in 2007. As a result, NOAA Fisheries expects that instream habitats will experience increased temperatures, sedimentation, and large woody debris delivery in the near term (NMFS 2008e). 


\section{Current Hatchery Programs}

This MPG is located primarily in National Forest and wilderness areas and has been managed by Idaho Department of Fish and Game as a natural production area with no hatchery releases. The managers did not identify any planned hatchery programs for this MPG and none were analyzed by the HSRG (Table 2).

Estimates of PNI and pHOS under current conditions indicate that all nine populations within this MPG are meeting Primary population designation standards (Table 1).

Table 2. Hatchery releases and types of programs for Middle Fork Salmon River Chinook MPG.

\begin{tabular}{|c|c|c|c|c|c|c|}
\hline \multirow[b]{2}{*}{ Population/Program name } & \multicolumn{3}{|c|}{ Current $(1,000 \mathrm{~s})$} & \multicolumn{3}{|c|}{ HSRG Solution $(1,000 s)$} \\
\hline & Type & Purpose & $\begin{array}{c}\# \\
\text { Released }\end{array}$ & Type & Purpose & $\begin{array}{c}\# \\
\text { Released }\end{array}$ \\
\hline 14-Salmon Chamberlain Creek Spring Chinook & None & NA & - & None & NA & - \\
\hline 15-Salmon_Big Creek Spring Chinook & None & NA & - & None & NA & - \\
\hline 17-Salmon_Camas Creek Spring Chinook & None & NA & - & None & NA & - \\
\hline 18-Salmon_Loon Creek Spring Chinook & None & NA & - & None & NA & - \\
\hline $\begin{array}{l}\text { 19+23-Salmon_Middle Fork-Upper Mainstem } \\
\text { Spring-Summer Chinook }\end{array}$ & None & NA & - & None & NA & - \\
\hline 20-Salmon_Sulphur Creek Spring Chinook & None & NA & - & None & NA & - \\
\hline 21-Salmon_Bear Valley Spring Chinook & None & NA & - & None & NA & - \\
\hline 22-Salmon_Marsh Creek Spring Chinook & None & NA & - & None & NA & - \\
\hline $\begin{array}{l}\text { 16-Salmon_Middle Fork Lower Mainstem Spring- } \\
\text { Summer Chinook }\end{array}$ & None & NA & - & None & NA & - \\
\hline
\end{tabular}



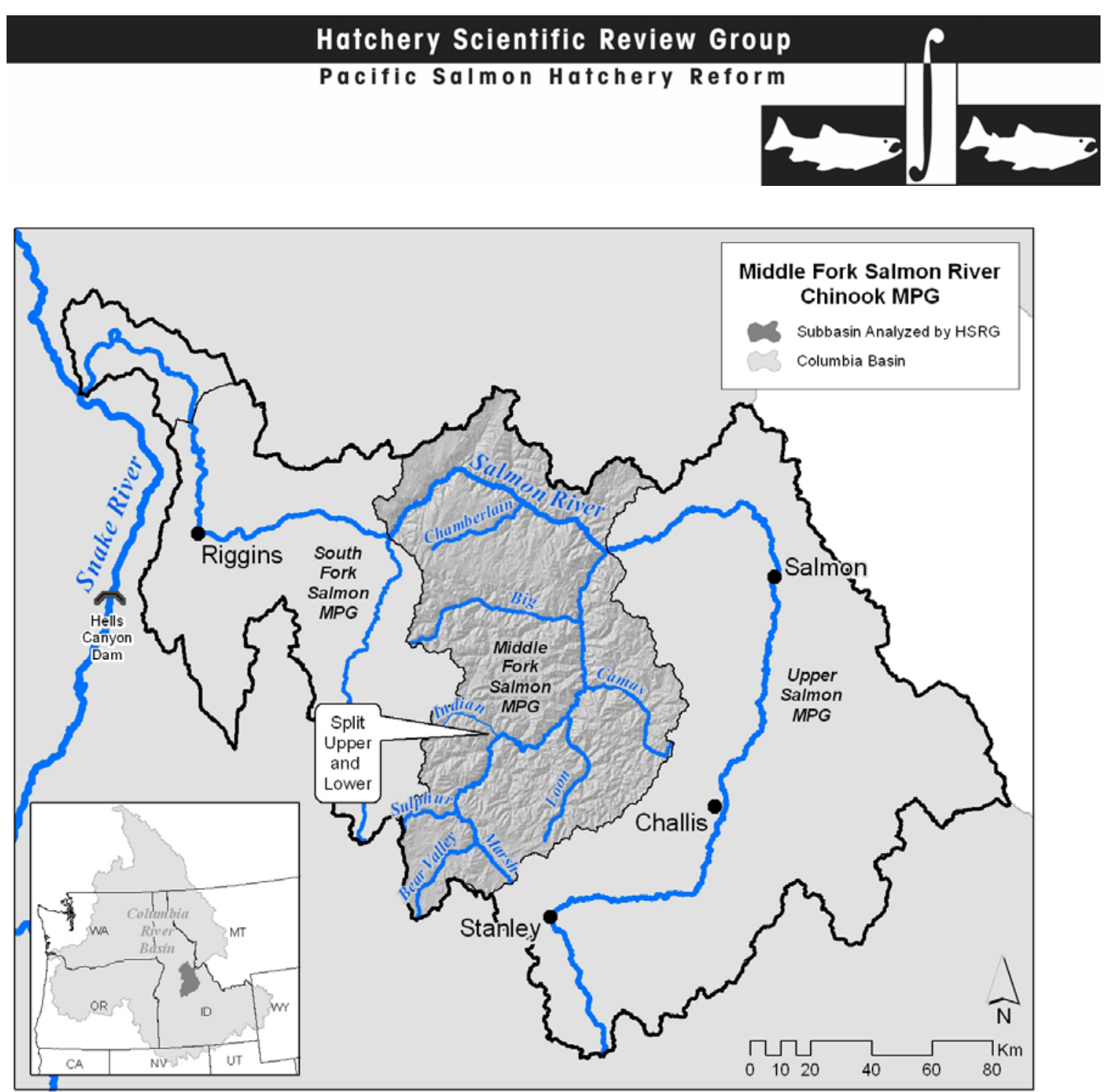

3.1.8.2.3

HSRG Solutions

Managers have identified a strategy for Middle Fork Salmon River Chinook salmon that emphasizes maintaining existing natural spawning populations. Because no releases of hatchery-origin Chinook salmon occur within the MPG and no new hatchery programs are planned, the HSRG did not analyze alternative solutions for this MPG.

The HSRG-defined designations for eight of the nine populations within this MPG remain unchanged (designated as Primary) under the HSRG solutions. However, the Lower Mainstem Middle Fork Salmon River population will no longer meet the standards of a Primary population designation but will meet the standards of a Contributing designation. This change occurs because of projected increases in production and survival in two of the hatchery programs in the Upper Salmon River which result in more hatchery adults returning to the Salmon River and more strays to this population.

\section{Conservation Outcomes under the HSRG Solutions}

Figure 1 compares the proportion of fish on the spawning grounds that are of hatchery origin (pHOS) and the proportionate natural influence (PNI) for Primary and 
Contributing populations under current and proposed (HSRG) scenarios. Because this MPG is managed for natural production, and because straying is reported to be absent or very minor, $\mathrm{pHOS}$ is zero for all populations except the Middle Fork Salmon River Lower Mainstem population, where pHOS is estimated at 7\% under HSRG solutions.

Figure 2 compares the proportion of natural-origin fish on the spawning grounds (NOS) with the estimated population productivity for Primary and Contributing populations under current and proposed (HSRG) scenarios. Minor improvements in abundance and productivity are predicted for the eight Primary populations within this MPG due to projected improvements in mainstem Snake and Columbia river passage survival (FCRPS Biological Opinion May 5, 2008). The estimated abundance and productivity for the one Contributing population (Lower Mainstem Middle Fork Salmon River) decreases marginally.

\section{Harvest Outcomes under the HSRG Solutions}

Figure 3 illustrates current and estimated changes in harvest (from marine, mainstem Columbia River and terminal areas) that would occur following implementation of the management solutions proposed by the HSRG. While no solutions were specifically analyzed for populations within this MPG, minor increases in incidental harvest were projected as a result of survival improvements in the mainstem Snake and Columbia rivers (FCRPS Biological Opinion May 5, 2008). Harvest of fish from this MPG is generally incidental to that on other targeted components of the spring/summer Chinook run.

\section{Hatchery Program Changes under the HSRG Solutions}

The Middle Fork Salmon River is managed for natural production (as a wild fish management zone). No hatchery-origin juvenile Chinook salmon are released within this MPG (Table 2). 


\section{Hatchery Scientific Review Group}

Pacific Salmon Hatchery Reform
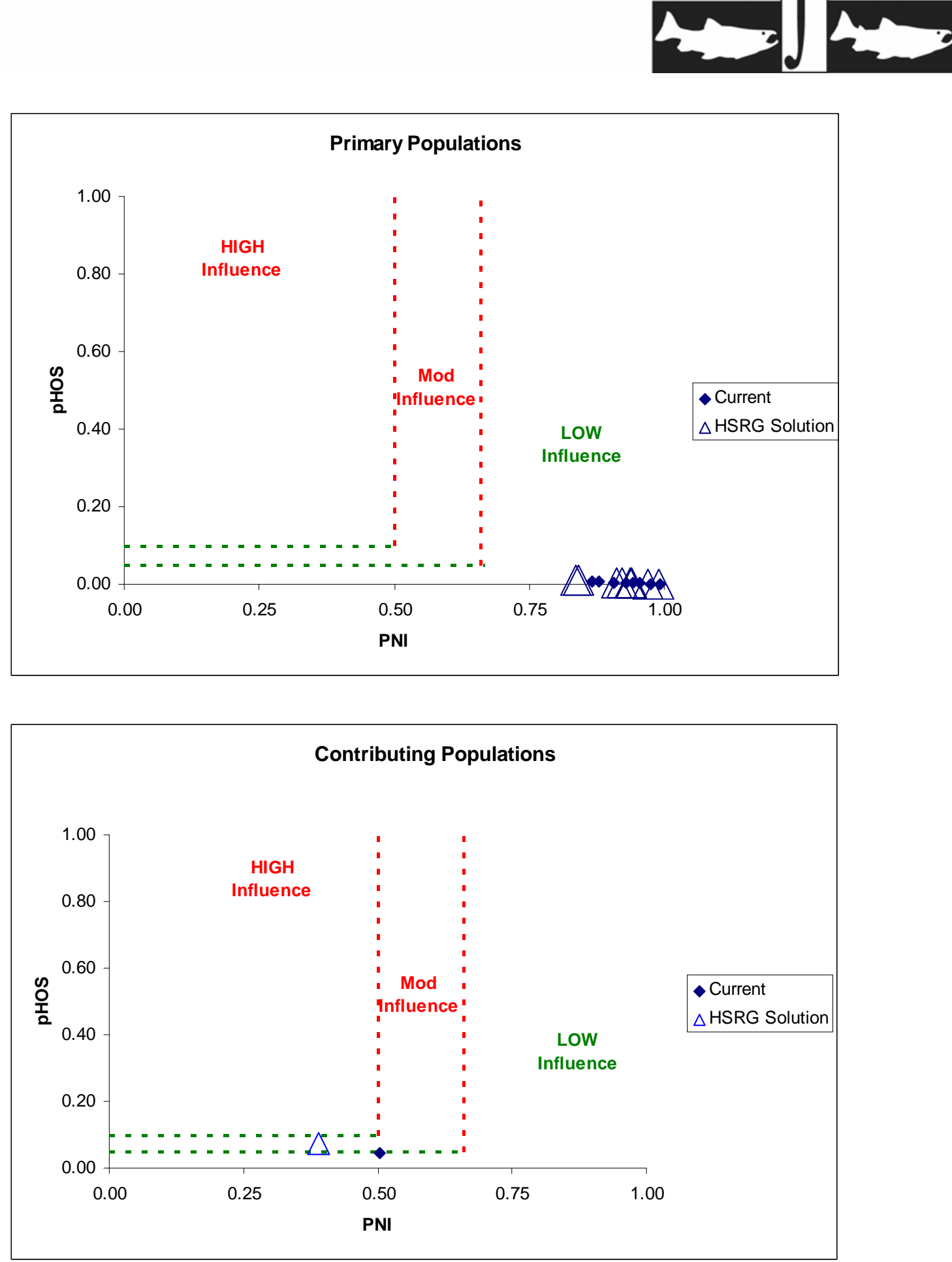

Figure 1. Relationship of the proportion of the fish on the spawning grounds that are of hatchery origin (pHOS) and the proportionate natural influence index (PNI) for Primary (top panel) and Contributing (bottom panel) Chinook populations in the Middle Fork Salmon River MPG. Solid diamonds represent values for current programs and open triangles represent values for the HSRG recommended hatchery management solution. 


\section{Hatchery Scientific Review Group}

Pacific Salmon Hatchery Reform
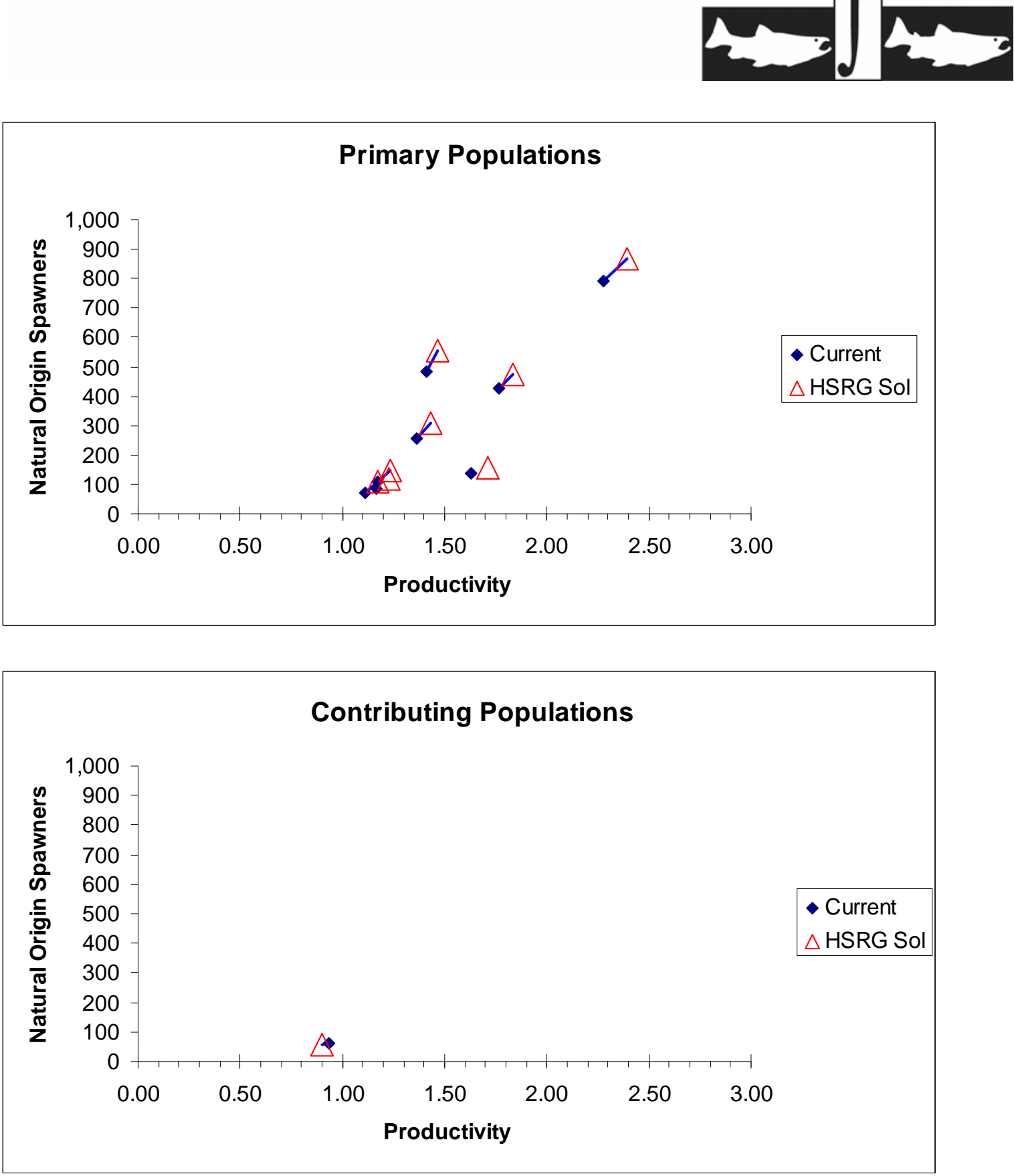

Figure 2. Productivity and spawner abundance for Primary (top panel) and Contributing (bottom panel) Chinook populations in the Middle Fork Salmon River MPG. Solid diamonds represent existing productivity and spawner abundance levels, and triangles represent the HSRG recommended hatchery management solution. Lines connect current with HSRG solution for a particular population. The HSRG recommended hatchery management solution includes projected improved fish passage survival in the Snake and Columbia mainstem migration corridor (FCRPS Biological Opinion May 5, 2008). 

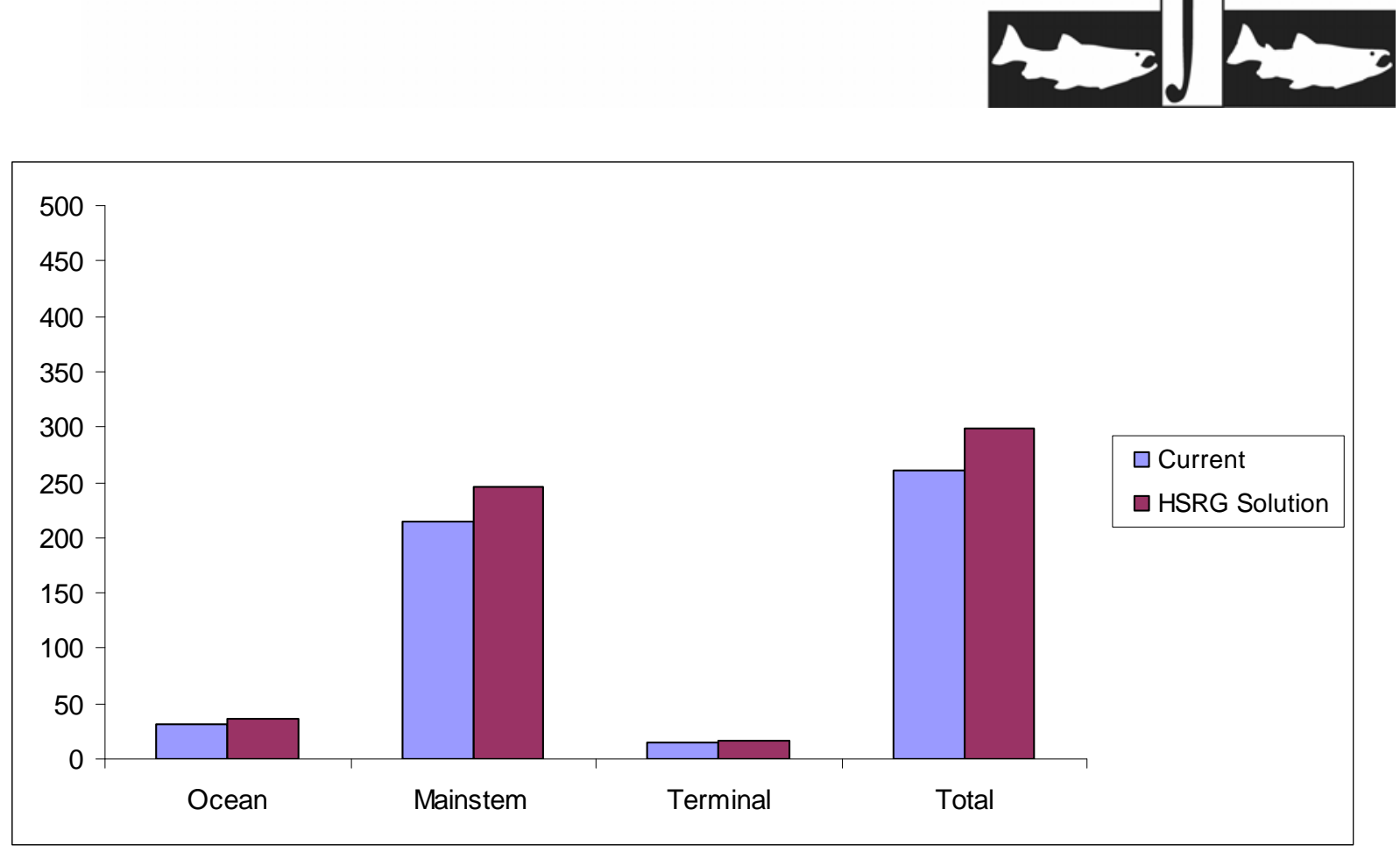

Figure 3. Estimated marine, mainstem Columbia, and terminal harvest under current and HSRG recommended hatchery management solution for Middle Fork Salmon River MPG. The HSRG recommended hatchery management solution includes projected improved fish passage survival in the Snake and Columbia mainstem migration corridor (FCRPS Biological Opinion May 5, 2008).

The HSRG recognizes and supports the strategic use of wild salmon management zones as an important component to a balanced conservation strategy for the Snake River Spring/Summer ESU.

The HSRG recommends that managers continue to monitor status and trend information for natural populations of Chinook salmon as well as presence/absence and the proportion of hatchery fish in natural production areas.

\subsubsection{South Fork Salmon River Chinook MPG}

This section provides an overview of the South Fork Salmon River Chinook MPG. It contains a general description of the MPG, fisheries, habitat limitations and hatchery programs that affect it. Overall recommendations for MPG-wide hatchery program changes are summarized as are the results of implementing these changes on conservation and harvest goals. Detailed conclusions and recommendations for each population in the MPG can be found in the Appendix E.

\subsection{HSRG Population Guidelines}

In order to meet conservations goals for the MPG, numerous threats to these populations need to be addressed, including risks from hatchery programs. The key to controlling genetic and ecological risks due to straying and fitness loss is to manage hatchery broodstock and natural spawning escapement such that the natural habitat (and not the hatchery environment) drives the adaptation and productivity of the naturally spawning population. This is achieved by operating either (a) integrated programs where the 


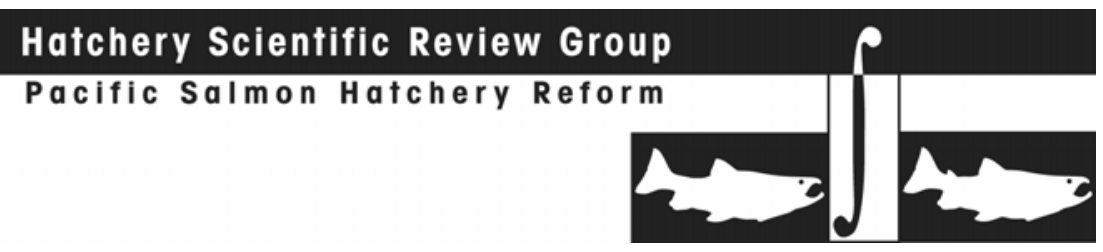

proportion of natural-origin adults in the broodstock (pNOB) exceeds the proportion of hatchery-origin fish on the spawning grounds (pHOS); or (b) segregated programs where the contribution of hatchery fish to natural spawning is kept low (pHOS $<5 \%$ to $<10 \%$ depending on the population designation). The HSRG developed criteria for hatchery influence for three population types based on the importance of the population to the recovery of the ESU. This was done to provide a consistent method of reviewing populations and programs across the Columbia River Basin. The population designations used by the HSRG (Primary, Contributing, or Stabilizing) were adopted after discussions with managers and followed those developed in the Lower Columbia River Salmon Recovery Plan (LCFRB 2004). These designations are meant to reflect the conservation importance of a population within the MPG from most important (Primary), to moderately important (Contributing), to least important (Stabilizing). HSRG recommendations show how hatchery programs can be operated consistent with these designations based on the following standards:

\section{HSRG criteria for hatchery influence on Primary populations}

- The proportion of effective hatchery-origin spawners (pHOS) should be less than 5\% of the naturally spawning population, unless the hatchery population is integrated with the natural population.

- For integrated populations, the proportion of natural-origin adults in the broodstock should exceed pHOS by at least a factor of two, corresponding to a PNI (proportionate natural influence) value of 0.67 or greater and pHOS should be less than 0.30 .

HSRG criteria for hatchery influence on Contributing populations

- The proportion of effective hatchery-origin spawners (pHOS) should be less than $10 \%$ of the naturally spawning population, unless the hatchery population is integrated with the natural population.

- For integrated populations, the proportion of natural-origin adults in the broodstock should exceed pHOS, corresponding to a PNI value of 0.50 or greater and $\mathrm{pHOS}$ should be less than 0.30 .

HSRG criteria for hatchery influence on Stabilizing populations

- The current operating conditions were considered adequate to meet conservation goals. No criteria were developed for proportion of effective hatchery-origin spawners (pHOS) or PNI.

\subsection{Current Conditions}

\section{Conservation}

The South Fork Salmon River Chinook Salmon MPG is in the Snake River Spring/Summer Chinook Salmon ESU which was listed as threatened under the Endangered Species Act in 1992. The MPG includes four populations: the Little Salmon River, Secesh River, East Fork of the South Fork Salmon River and the South Fork Salmon River mainstem populations. NOAA Fisheries includes the Little Salmon and 


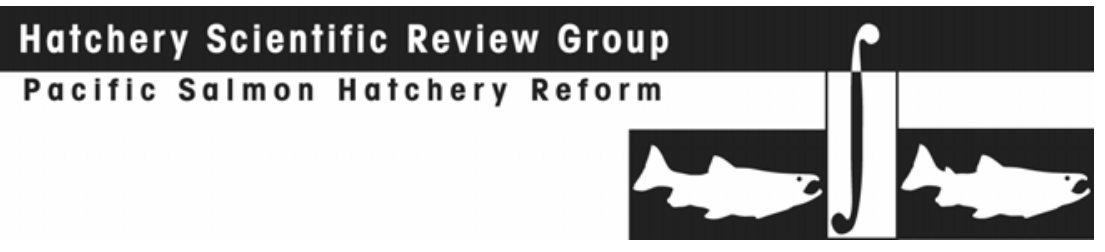

Lower Salmon River Spring/ Summer Chinook with the South Fork Salmon River MPG for the purpose of ESA recovery planning.

For the purpose of this analysis, the HSRG assigned three populations as Primary and one as Stabilizing (Table 1).

Table 1. Population designations for the South Fork Salmon River Chinook MPG and HSRG broodstock criteria achieved for each population under current conditions and the HSRG recommended hatchery management solution.

\begin{tabular}{|c|c|c|c|}
\hline \multirow[b]{2}{*}{ Population } & \multirow[b]{2}{*}{ Designation $^{1}$} & \multicolumn{2}{|c|}{ HSRG Criteria Met ${ }^{2}$} \\
\hline & & Current & HSRG Solution \\
\hline 11-Salmon SF Salmon Summer Chinook & Primary & Stabilizing & Primary \\
\hline 12-Salmon_Secesh Spring Chinook & Primary & Primary & Primary \\
\hline 13-Salmon_EF-SF Johnson Creek Summer Chinook & Primary & Primary & Primary \\
\hline 10-Salmon_Little Salmon Spring-Summer Chinook & Stabilizing & Stabilizing & Stabilizing \\
\hline
\end{tabular}

1 Using the naming protocol of the Lower Columbia River Salmon Recovery Plan (LCFRB 2004), populations were classified based on information provided to the HSRG as Primary, Contributing, or Stabilizing. These designations are meant to reflect the conservation importance of a population within the MPG from most important (Primary- bold, red), to moderately important (Contributing-bold, blue), to least important (Stabilizing).

2 The HSRG developed criteria for hatchery influence for the three population designations from low influence (Primary), moderate influence (Contributing) to high influence (Stabilizing).

\section{Current Harvest}

South Fork Salmon River Chinook MPG is managed for both conservation and harvest objectives. Harvest occurs predominately in mainstem Columbia River and terminal areas. Few South Fork Salmon River Chinook are harvested in ocean fisheries. The 2008-2017 United States vs. Oregon Management Agreement defines mainstem Columbia River harvest rates. One of the controlling factors in this abundance-based sliding scale harvest rate schedule (5.5\% to $17 \%)$ is based on natural-origin spring/summer Chinook salmon returning to the Snake River Basin. Terminal harvest rates are also managed on a sliding scale based on the abundance of natural-origin returns.

A partially selective non-tribal commercial fishery occurs in the lower Columbia River below Bonneville Dam. The tribal fishery is in Zone 6 (Columbia River above Bonneville Dam) and terminal areas and is non-selective. Sport fisheries occur in the mainstem Columbia River and terminal areas, targeting adipose-fin-clipped hatchery fish. Salmon fishing in the South Fork Salmon River was terminated between 1975 and 1997, but has occurred since then.

\section{Current Habitat}

The hydrology of the South Fork Salmon River watershed has not been significantly altered. However, the aquatic habitat is still recovering from catastrophic sediment impacts that occurred in the mid-1960s when unusually high precipitation, combined with logging and road construction, resulted in massive silt contributions to the river. Twentyone percent $(21 \%)$ of the total stream length in the South Fork Salmon River watershed is currently impaired by sedimentation (USFWS 2008). The watershed is federally classified as "roadless" for management purposes, but service roads generally occur 


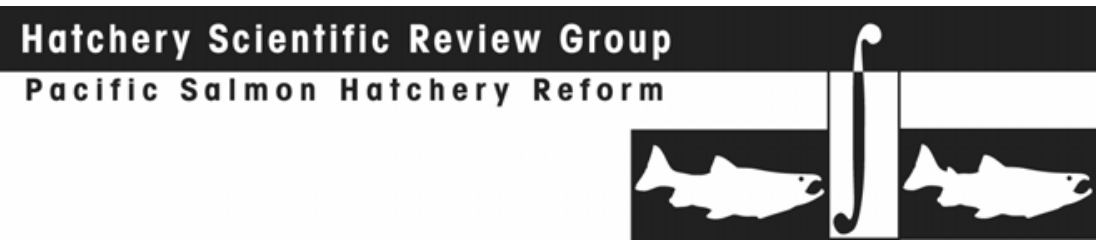

immediately adjacent to waterways and are a source of silt. In addition, wild fires burned large areas of the watershed during the last decade. Timber harvests in the South Fork Salmon watershed historically had great impacts: approximately $37 \%$ of the watershed has not been affected by logging, while the remaining $63 \%$ is evenly divided among low, moderate, and high logging effects (USFWS 2008). Within the South Fork Salmon River, the East Fork is the most habitat-limited due to reduced riparian area quality, decreased stream bank stability from roads, and residual impacts from mining, including the leaching of heavy metals from mine sites. Localized livestock grazing occurs in the most important Chinook salmon spawning areas of Johnson Creek (USFWS 2008).

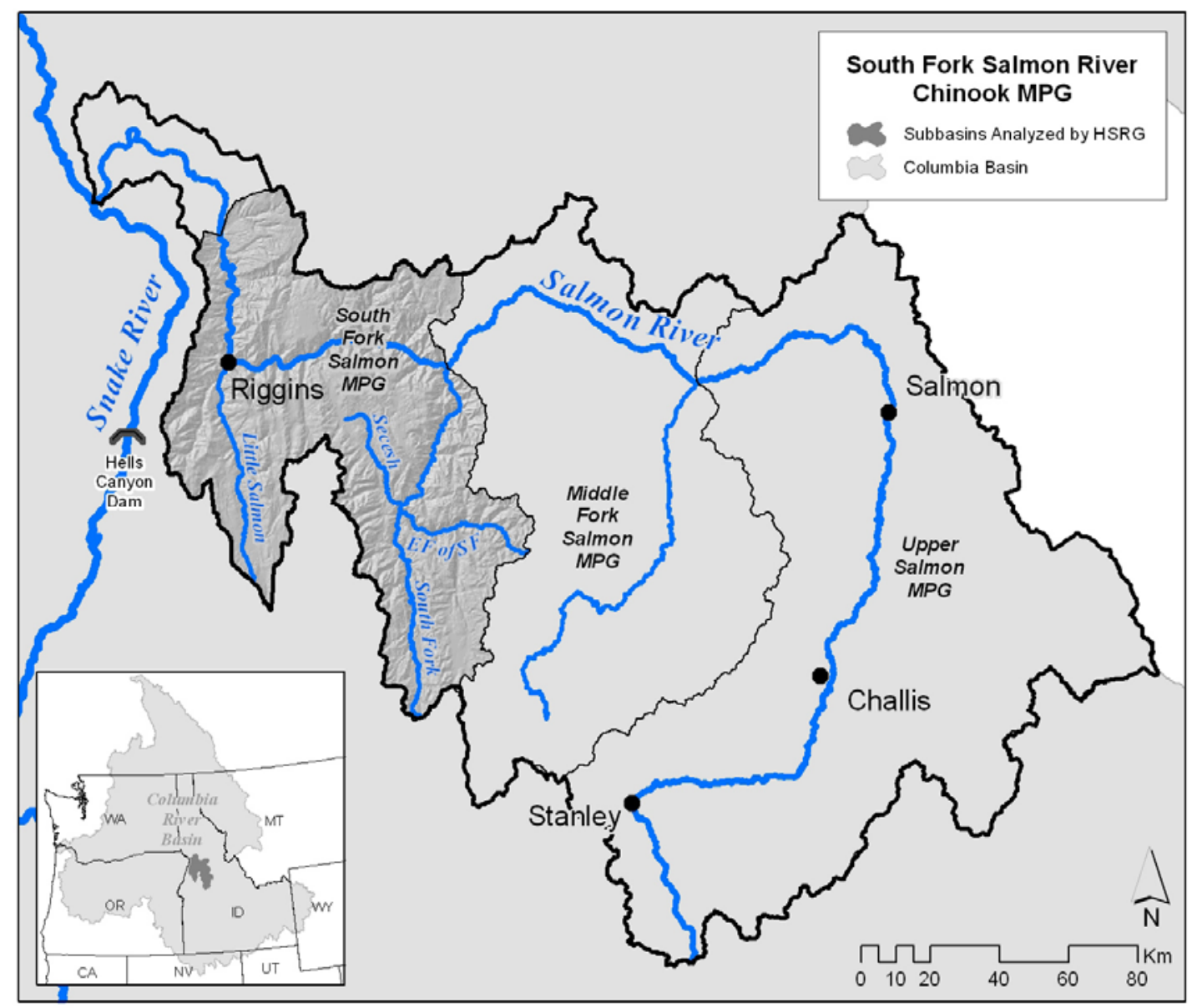

\section{Current Hatchery Programs}

Three of the four populations in this MPG have hatchery programs (Little Salmon, South Fork Salmon and the East Fork-South Fork Johnson Creek). The Secesh and a major portion of the Little Salmon population (Rapid River upstream of the hatchery) are managed for natural production. Segregated hatchery programs have harvest objectives and occur within the Little Salmon and South Fork Salmon rivers. The integrated 
program on East Fork-South Fork Johnson Creek has both conservation and harvest goals.

Two of the three hatchery programs were developed from stocks originating from local populations in the South Fork and East Fork-South Fork Johnson Creek. The third program (Rapid River Hatchery located within the Little Salmon subbasin) uses fish that originated from returns to the upper Snake River Basin and likely includes some local stock contribution. Collectively, these programs release approximately 3.9 million spring/summer Chinook salmon (Table 2) and account for a substantial proportion of total escapement and most of the terminal harvest in this MPG.

Estimates of PNI and pHOS under current conditions indicate that two of the four populations meet broodstock criteria for a Primary designation. Two populations currently meet a Stabilizing designation; however, one population (Little Salmon) has a large segment set aside for natural production (Table 1).

Table 2. Hatchery releases and types of programs for South Fork Salmon River Chinook MPG.

\begin{tabular}{|c|c|c|c|c|c|c|}
\hline \multirow[b]{2}{*}{ Population/Program Name } & \multicolumn{3}{|c|}{ Current $(1,000 \mathrm{~s})$} & \multicolumn{3}{|c|}{ HSRG Solution $(1,000 \mathrm{~s})$} \\
\hline & Type & Purpose & $\begin{array}{c}\text { No. } \\
\text { Released }\end{array}$ & Type & Purpose & $\begin{array}{c}\text { No. } \\
\text { Released }\end{array}$ \\
\hline 11-Salmon SF Salmon Summer Chinook & None & NA & - & Int & & 253.8 \\
\hline $\begin{array}{l}\text { 11A-Salmon_SF Salmon Summer Chinook (McCall- } \\
\text { Hatchery) }\end{array}$ & Seg & Harv & $1,060.9$ & Seg & & 752.9 \\
\hline 12-Salmon_Secesh Spring Chinook & None & NA & - & None & & - \\
\hline 13-Salmon EF-SF Johnson Creek Summer Chinook & Int & Cons & 101.8 & Int & & 101.8 \\
\hline 10-Salmon_Little Salmon Spring-Summer Chinook & None & NA & & None & & - \\
\hline $\begin{array}{l}\text { 10A-Salmon_Little Salmon Spring Chinook (Rapid } \\
\text { River-Hatchery) }\end{array}$ & Seg & Harv & $2,736.6$ & Seg & & $2,736.6$ \\
\hline $\begin{array}{l}\text { Snake Hells Canyon Spring Chinook (Oxbow } \\
\text { Hatchery) }\end{array}$ & Seg & Harv & 299.5 & Seg & Harv & 299.5 \\
\hline Total all Populations/Programs & & & $4,198.8$ & & & $4,144.7$ \\
\hline
\end{tabular}

\subsection{HSRG Solutions}

Implementation of HSRG recommendations are expected to result in broodstock management that achieves a Primary designation for one additional population. One population (Little Salmon) remains consistent with a Stabilizing designation; however, a large segment of the Little Salmon population (upstream of Rapid River Hatchery) would continue to be managed for natural production and low hatchery influence. HSRG solutions result in conservation benefits and maintain harvest near current levels.

\section{Conservation Outcomes under the HSRG Solution}

Figure 1 compares the proportions of hatchery-origin fish on the spawning grounds (pHOS) and the proportionate natural influence (PNI) for the managers' goals and proposed HSRG solutions for Primary and Contributing populations. The HSRG solution makes significant improvements to one population (South Fork Salmon) and moves the population from a high hatchery influence to low influence. Implementation of HSRG solutions would allow population goals to be met for all four populations in this MPG 
(see Table 1) and three of the four populations would fall in the low hatchery influence zone (Figure 1).

Figure 2 compares spawner abundance and productivity relationships between current and HSRG-proposed scenarios. Large improvements in productivity and abundance are expected to occur in one of the Primary populations with minor increases in the other two populations. Natural spawner abundance will increase for this MPG.

\section{Harvest Outcomes under the HSRG Solution}

Figure 3 illustrates current and estimated changes in harvest and the harvest distribution in ocean, mainstem and terminal fisheries following implementation of the HSRG recommendations. The HSRG solutions maintain the current harvest distribution but may slightly reduce harvest due to the small reduction in releases from McCall Hatchery (South Fork Salmon population).

\section{Hatchery Program Changes under the HSRG Solution}

Table 2 shows the current size of each hatchery program as well as their size under the HSRG solution. The HSRG made recommendations to change one of the three hatchery programs (South Fork Salmon - McCall Hatchery) in this MPG, a program that is currently managed as a segregated harvest program, but has a high pHOS. The HSRG recommends that it transition to an integrated program with an associated "stepping stone" harvest component (see the population report in Appendix E for details). The total juvenile release size would decrease by less than 5 percent (about 50,000 smolts) from current production levels to achieve the standards for a Primary population designation.

The HSRG made no recommendations that would change the East Fork-South Fork Johnson Creek summer Chinook program. It is well integrated and meets the broodstock standards for a Primary designation. This population has low productivity and a moderate abundance of NORs. In this situation, the hatchery program appears to be providing a benefit to the population by increasing the abundance of NORs.

The segregated harvest program on the Little Salmon River (Rapid River) is being managed as a terminal fishing area and the HSRG made no recommendations to change this program. 

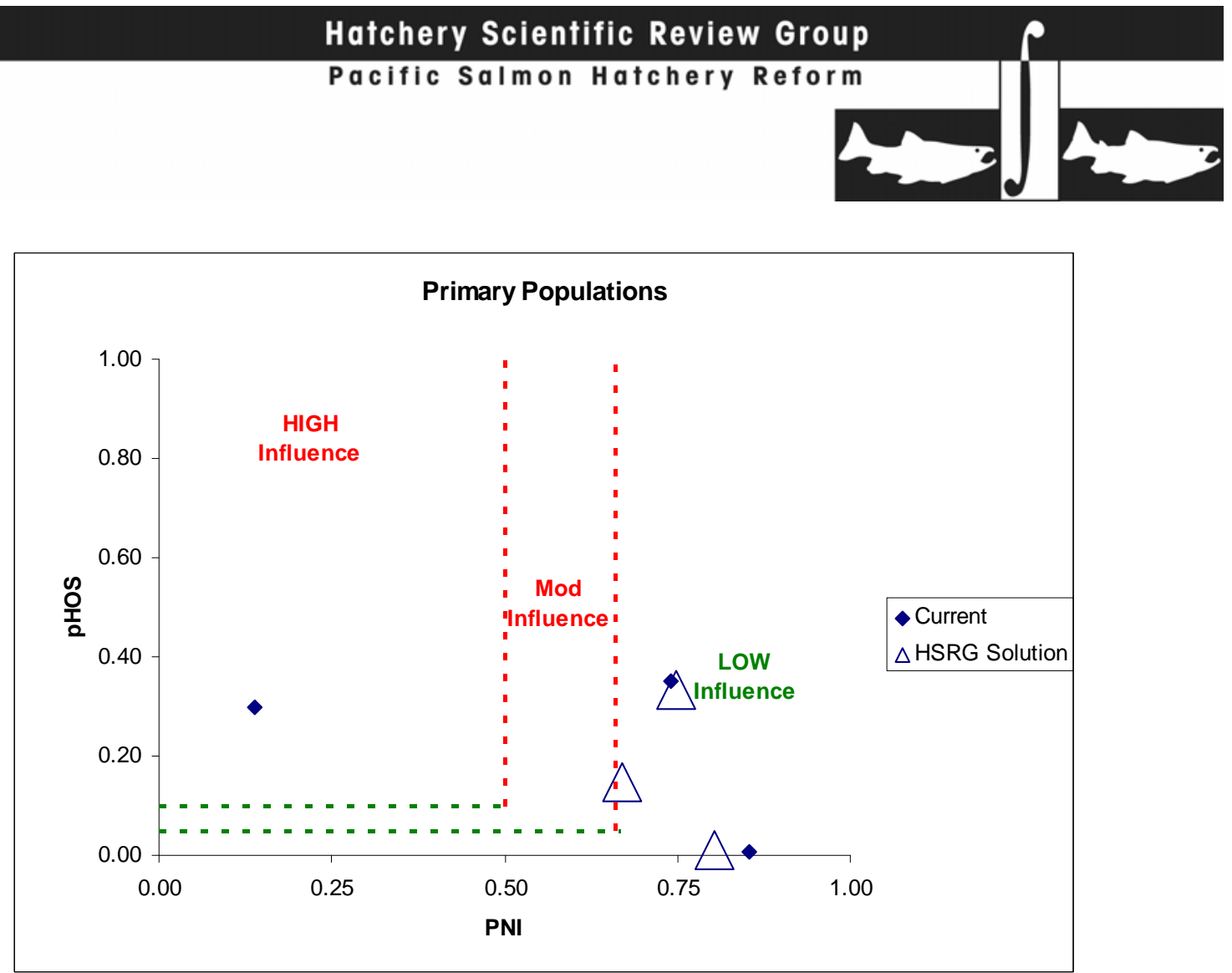

Figure 1. Relationship of the proportion of the fish on the spawning grounds that are of hatchery origin (pHOS) and the proportionate natural influence index (PNI) for Primary Chinook populations in the South Fork Salmon River MPG. Solid diamonds represent values for current programs and open triangles represent values for the HSRG recommended hatchery management solution.

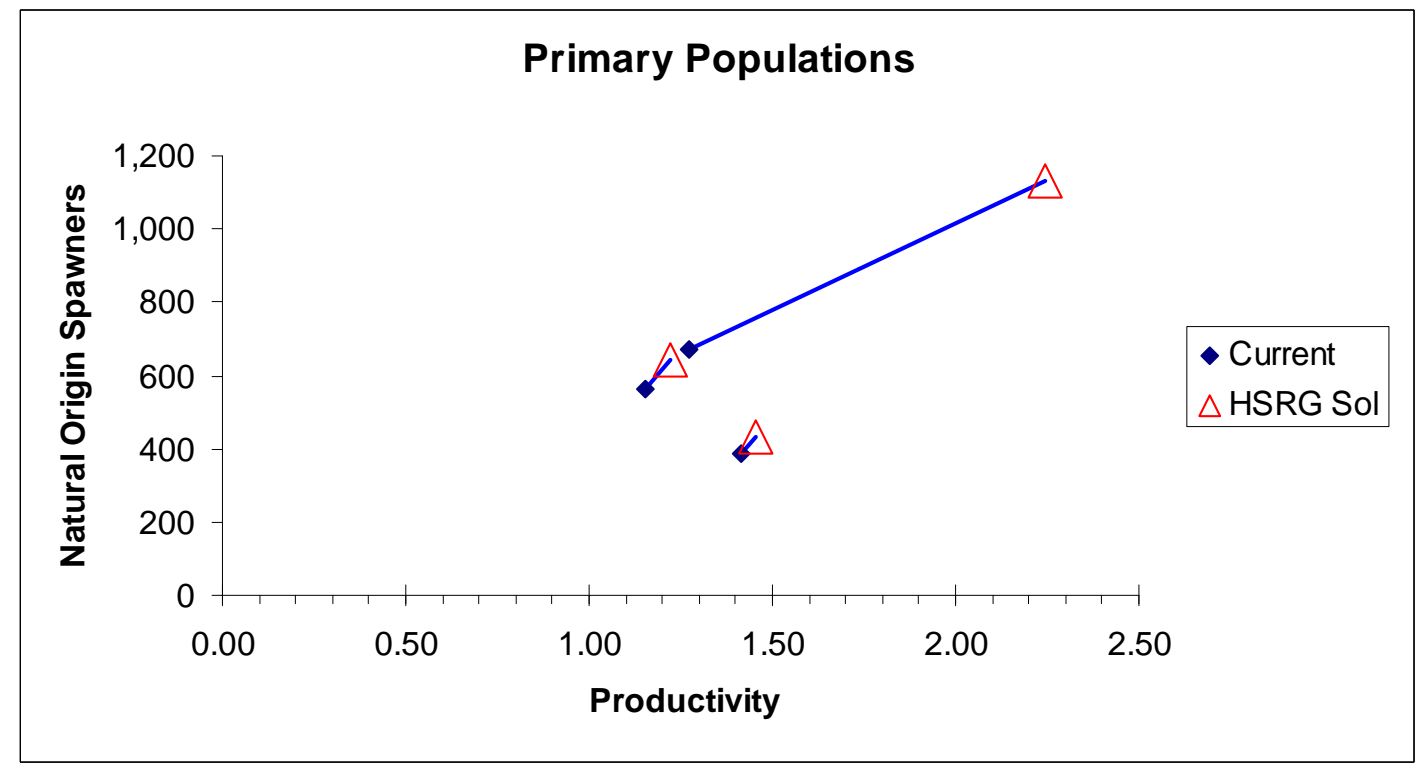

Figure 2. Productivity and spawner abundance for Primary Chinook populations in the South Fork Salmon River MPG. Solid diamonds represent existing productivity and spawner abundance levels, and triangles represent the HSRG recommended hatchery management solution. Lines connect current with HSRG solution for a particular population. The HSRG recommended hatchery management solution includes projected improved fish passage survival in the Snake and Columbia mainstem migration corridor (FCRPS Biological Opinion May 5, 2008). 


\section{Hatchery Scientific Review Group}

Pacific Salmon Hatchery Reform

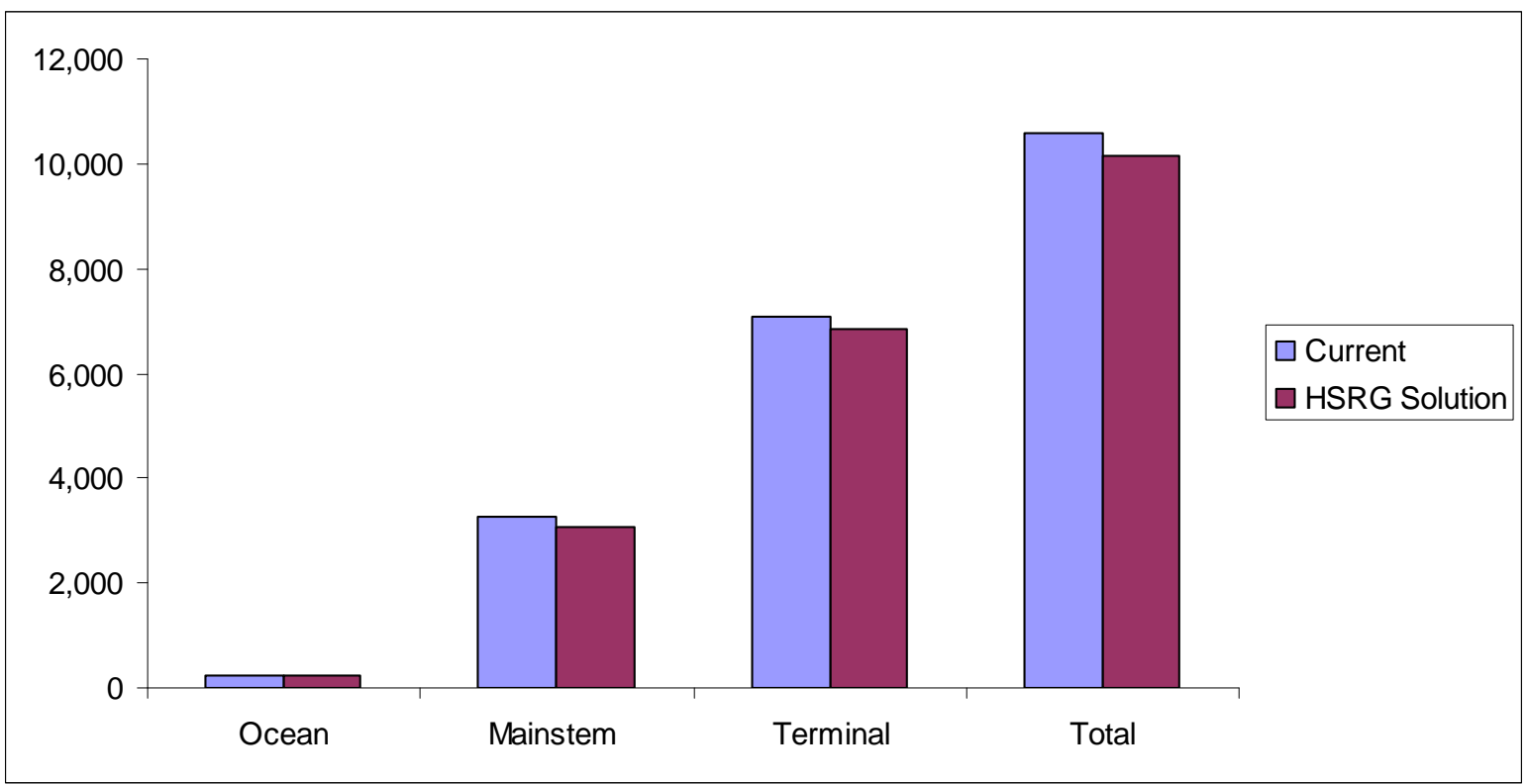

Figure 3. Estimated marine, mainstem Columbia, and terminal harvest under current and HSRG recommended hatchery management solution for South Fork Salmon River MPG. The HSRG recommended hatchery management solution includes projected improved fish passage survival in the Snake and Columbia mainstem migration corridor (FCRPS Biological Opinion May 5, 2008).

Conservation and harvest objectives were defined for the four populations in this MPG. One population is managed as a terminal fishing area (Little Salmon), one is managed for natural production (Secesh), and two have hatchery programs (South Fork Salmon and East Fork-South Fork Johnson Creek). The Johnson Creek program is providing a demographic benefit.

The HSRG solution affects one program (South Fork Salmon) for which the recommendation is to alter broodstock management to develop a well integrated conservation program and an associated segregated "stepping stone" program to maintain harvest opportunities.

The HSRG generally concludes that (a) hatchery and harvest reforms alone will not achieve recovery of listed populations (habitat improvements are also necessary), and (b) effectiveness of habitat actions will increase if they are combined with hatchery and harvest reforms. The analysis of the Primary populations in the South Fork Salmon River Chinook MPG suggests that the benefits of habitat quality improvements would more than triple if combined with hatchery reforms. Unless hatchery and harvest reforms are implemented, the potential benefits of current or improved habitat cannot be fully realized.

\subsubsection{Grand Ronde and Imnaha Spring Chinook MPG}

This section provides an overview of the Grand Ronde - Imnaha Chinook MPG. It contains a general description of the MPG, fisheries, habitat limitations and hatchery 


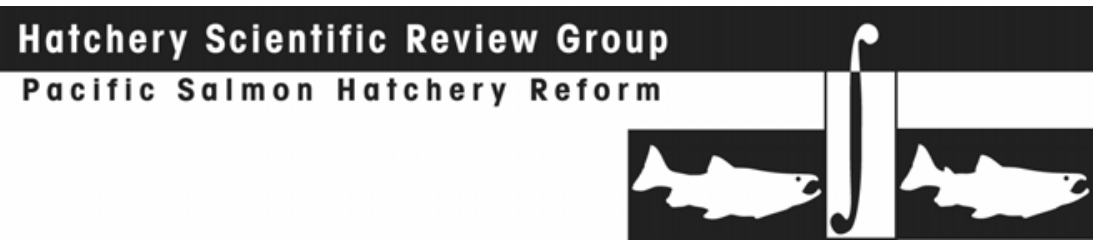

programs that affect it. Overall recommendations for MPG-wide hatchery program changes are summarized, as are the results of implementing those changes on conservation and harvest goals. Detailed conclusions and recommendations for each population in the MPG can be found Appendix E.

3.1.8.4.1

\section{HSRG Population Guidelines}

In order to meet conservations goals for the MPG, numerous threats to these populations need to be addressed, including risks from hatchery programs. The key to controlling genetic and ecological risks due to straying and fitness loss is to manage hatchery broodstock and natural spawning escapement such that the natural habitat (and not the hatchery environment) drives the adaptation and productivity of the naturally spawning population. This is achieved by operating either (a) integrated programs where the proportion of natural-origin adults in the broodstock (pNOB) exceeds the proportion of hatchery-origin fish on the spawning grounds (pHOS); or (b) segregated programs where the contribution of hatchery fish to natural spawning is kept low (pHOS $<5 \%$ to $<10 \%$ depending on the population designation). The HSRG developed criteria for hatchery influence for three population types based on the importance of the population to the recovery of the ESU. This was done to provide a consistent method of reviewing populations and programs across the Columbia River Basin. The population designations used by the HSRG (Primary, Contributing, or Stabilizing) were adopted after discussions with managers and followed those developed in the Lower Columbia River Salmon Recovery Plan (LCFRB 2004). These designations are meant to reflect the conservation importance of a population within the MPG from most important (Primary), to moderately important (Contributing), to least important (Stabilizing). HSRG recommendations show how hatchery programs can be operated consistent with these designations based on the following standards:

\section{HSRG criteria for hatchery influence on Primary populations}

- The proportion of effective hatchery-origin spawners (pHOS) should be less than 5\% of the naturally spawning population, unless the hatchery population is integrated with the natural population.

- For integrated populations, the proportion of natural-origin adults in the broodstock should exceed pHOS by at least a factor of two, corresponding to a PNI (proportionate natural influence) value of 0.67 or greater and $\mathrm{pHOS}$ should be less than 0.30 .

HSRG criteria for hatchery influence on Contributing populations:

- The proportion of effective hatchery-origin spawners (pHOS) should be less than $10 \%$ of the naturally spawning population, unless the hatchery population is integrated with the natural population.

- For integrated populations, the proportion of natural-origin adults in the broodstock should exceed $\mathrm{pHOS}$, corresponding to a PNI value of 0.50 or greater and $\mathrm{pHOS}$ should be less than 0.30 . 


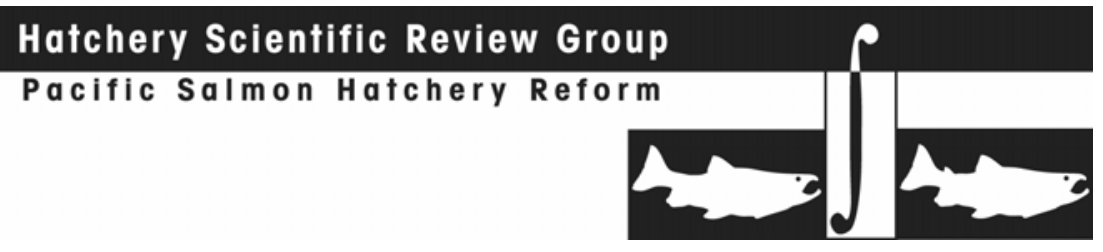

HSRG criteria for hatchery influence on Stabilizing populations:

- The current operating conditions were considered adequate to meet conservation goals. No criteria were developed for proportion of effective hatchery-origin spawners (pHOS) or PNI.

Table 1. Population designations for the Grande Ronde/lmnaha Spring Chinook MPG and HSRG broodstock criteria achieved for each population under current conditions and the HSRG recommended hatchery management solution.

\begin{tabular}{|l|c|c|c|}
\hline \multirow{2}{*}{ Population } & & \multicolumn{2}{|c|}{${\text { HSRG Criteria } \text { Met }^{2}}$} \\
\cline { 3 - 4 } & Designation & Current & HSRG Solution \\
\hline 3-Grande Ronde_Wenaha Spring Chinook & Primary & Primary & Primary \\
\hline 6-Grande Ronde_Minam Spring Chinook & Primary & Contributing & Primary \\
\hline 7-Grande Ronde_Lostine Spring Chinook & Primary & Contributing & Primary \\
\hline 9-Imnaha Spring-Summer Chinook & Primary & Stabilizing & Primary \\
\hline Grande Ronde_Catherine Creek Spring Chinook & Primary & Stabilizing & Primary \\
\hline Grande Ronde_Lookingglass Creek Spring Chinook & Stabilizing & Stabilizing & Stabilizing \\
\hline Grande Ronde_Upper Grande Ronde Spring Chinook & Stabilizing & Stabilizing & Stabilizing \\
\hline
\end{tabular}

1 Using the naming protocol of the Lower Columbia River Salmon Recovery Plan (LCFRB 2004), populations were classified based on information provided to the HSRG as Primary, Contributing, or Stabilizing. These designations are meant to reflect the conservation importance of a population within the MPG from most important (Primary- bold, red), to moderately important (Contributing-bold, blue), to least important (Stabilizing).

2 The HSRG developed criteria for hatchery influence for the three population designations from low influence (Primary), moderate influence (Contributing) to high influence (Stabilizing).

\subsection{Current Conditions}

\section{Conservation}

The Grande Ronde/Imnaha Chinook Salmon MPG is in the Snake River Spring/Summer Chinook ESU and was listed as threatened under the Endangered Species Act in 1992. As defined by the ESA, the MPG includes populations in the Wenaha River, Catherine Creek, Minam River, Lostine/Wallowa River, Big Sheep Creek, Lookingglass Creek, the Imnaha River mainstem, and the Grande Ronde River mainstem. Both Big Sheep Creek and Lookingglass Creek populations are considered functionally extirpated. The HSRG did not include Big Sheep Creek as a population in its review. Current risk associated with spatial structure and diversity is rated as "low" to "moderate" for all populations except the Upper Grande Ronde, which is at a "high" spatial structure risk because of unoccupied major and minor spawning areas due to very low abundance levels (NMFS 2008e). The Upper Grande Ronde population is also rated as "high" for long-term extinction risk (NMFS 2008e).

For the purpose of this analysis the HSRG assigned five populations as Primary and two as Stabilizing (Table 1). 


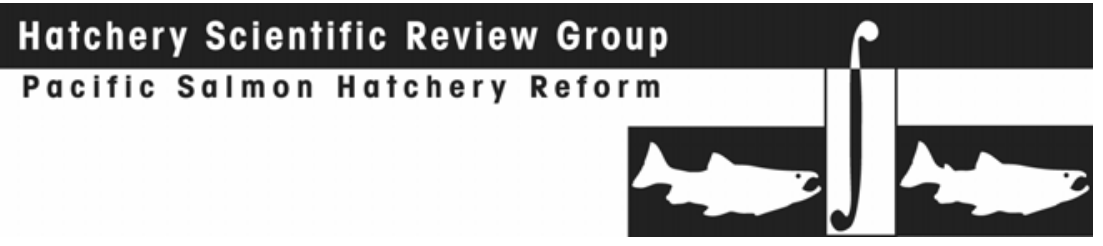

Current Harvest

The ocean fishery mortality on Grande Ronde-Imnaha River spring/summer Chinook is very low and, for practical purposes, assumed to be zero (NMFS 2008e). Incidental harvest of these fish occurs in spring and summer season fisheries in the mainstem Columbia River that target harvestable hatchery and natural-origin stocks. The fisheries on harvestable runs are limited to ensure that harvest of ESA-listed Snake River Spring/Summer Chinook does not exceed 5.5 to $17 \%$. The incidental take of naturalorigin upriver spring/summer Chinook has averaged 10.2\% since 2001 (NMFS 2008e).

\section{Current Habitat}

Land uses such as agriculture, forestry, mining and grazing have altered habitat throughout the MPG. For example, re-routing and diking the Grande Ronde River eliminated over 50 miles of habitat in the Grande Ronde Valley. Some watersheds, such as the Wenaha, have been protected for over 100 years and are in nearly pristine condition. In general, land uses have increased erosion and sedimentation, degraded riparian condition, reduced stream flows and channel complexity, increased water temperature, and water quality degradation.

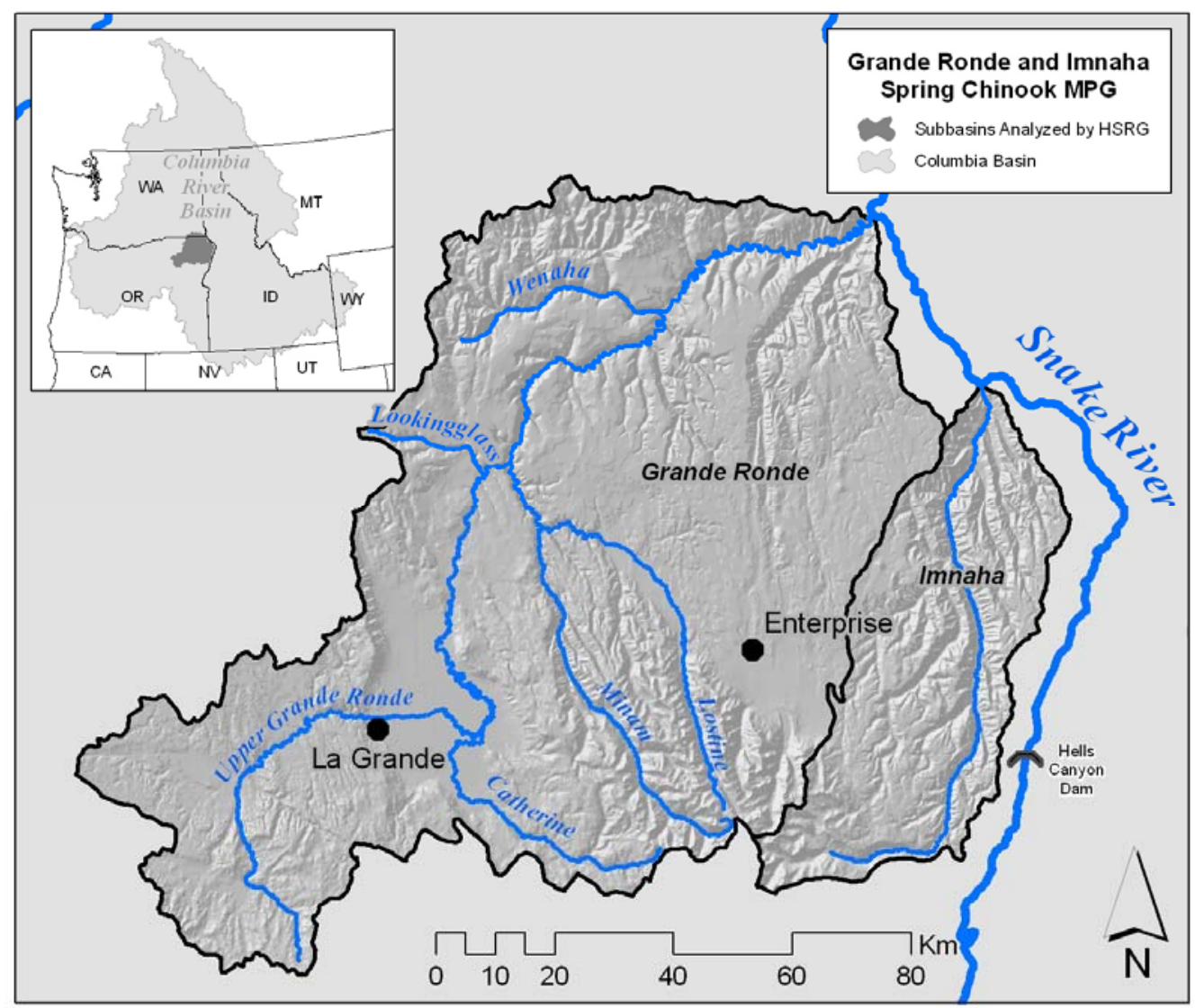




\section{Current Hatchery Programs}

The Grande Ronde spring/summer hatchery has four integrated programs that release a total of 880,000 Chinook to the Upper Grande Ronde, Catherine Creek, Lostine River, and Lookingglass Creek annually. The Imnaha Hatchery is an integrated program that releases approximately 360,000 Chinook to the Imnaha River annually. The Minam and Wenaha rivers have no hatchery programs; however, the Minam River population is more influenced by stray hatchery-origin spawners than the Wenaha population. Managers are operating these hatchery programs as safety nets for most of the affected populations to reduce the short-term risk of extinction.

\section{Effects of Hatchery Programs on Natural Populations}

Hatchery broodstock from outside the MPG were used historically within the Grande Ronde (i.e., Rapid River and Carson stock were used at Lookingglass Creek). Hatchery reforms have eliminated the use of broodstock originating from outside the area and ESU and have reduced straying. The outcome of these management actions is decreased risk of fitness loss and loss of genetic diversity associated with straying of hatchery fish into the wild.

Table 2. Hatchery releases and types of programs for Grande Ronde/Imnaha Spring Chinook MPG.

\begin{tabular}{|l|c|c|c|c|c|c|}
\hline \multirow{2}{*}{ Population/Program Name } & \multicolumn{3}{|c|}{ Current (1,000s) } & \multicolumn{3}{c|}{ HSRG Solution (1,000s) } \\
\cline { 2 - 8 } & Type & Purpose & \# Released & Type & Purpose & \# Released \\
\hline 3-Grande Ronde-Wenaha Spring Chinook & None & NA & - & None & NA & - \\
\hline 6-Grande Ronde-Minam Spring Chinook & None & NA & - & None & NA & - \\
\hline 7-Grande Ronde-Lostine Spring Chinook & Int & Cons & 249.5 & Int & Cons & 249.5 \\
\hline 9-Imnaha Spring-Summer Chinook & Int & Both & 359.2 & Int & Both & 113.4 \\
\hline $\begin{array}{l}\text { 9a-Imnaha Spring-Summer Chinook (stepping stone } \\
\text { program) }\end{array}$ & Seg & Harv & - & Seg & Harv & 246.2 \\
\hline Grande Ronde-Catherine Creek Spring Chinook & Int & Cons & 130.0 & Int & Cons & 75.6 \\
\hline Grande Ronde-Lookingglass Creek Spring Chinook & Int & Both & 249.5 & Int & Both & 325.1 \\
\hline Grande Ronde-Upper Grande Ronde Spring Chinook & Int & Cons & 251.0 & Int & Cons & 251.0 \\
\hline Total all Populations/Programs & & & $\mathbf{1 , 2 3 9 . 2}$ & & & $\mathbf{1 , 2 6 0 . 8}$ \\
\hline
\end{tabular}

\section{Current Status of Populations Relative to HSRG Criteria}

Estimates of proportionate natural influence (PNI) and proportion of hatchery-origin spawners (pHOS) under current conditions show that only one of the five Primary populations in the MPG (Wenaha River) meets the HSRG broodstock criteria for this designation. Two of the Primary populations (Minam River and Lostine River) meet the broodstock criteria for Contributing populations and two Primary populations (Catherine Creek and Imnaha River) meet the criteria for Stabilizing populations. Two populations (Lookingglass Creek and Upper Grande Ronde River) are designated as Stabilizing populations. The Upper Grande Ronde River population is limited by habitat productivity and has a very low abundance of natural-origin spawners. The Lookingglass Creek population has been extirpated. The introduced, naturally spawning population 


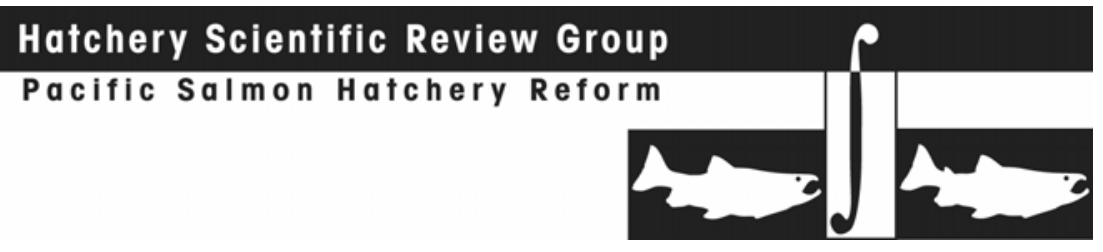

originated from hatchery fish and is heavily influenced by hatchery-origin fish from Lookingglass Hatchery releases in the creek.

3.1.8.4.3

\section{HSRG Solutions}

The HSRG solutions focus primarily on developing better management capabilities for broodstock and adult escapement in some populations within this MPG. The HSRG acknowledges that managers have sliding scale plans in place for broodstock and escapement management, but facility constraints limit their ability to fully implement the plans. Solutions for these populations are to improve weir efficiencies to reduce hatchery-origin spawners in the wild. The HSRG recommends increasing smolt size at release for all of these hatchery programs to improve returns of hatchery-origin fish. In addition, the solution reduces smolt releases into Catherine Creek and reallocates them into Lookingglass Creek. In the Imnaha River, it is recommended that a stepping stone program be implemented, consisting of a conservation program with an associated harvest program. Providing efficient adult collection weirs for the Imnaha and Lostine programs is an important element in operating the programs properly and further reducing hatchery strays, resulting in increased fitness and productivity of the populations. The HSRG solutions are expected to meet the criteria for the five populations designated by the managers as Primary and the two populations designated as Stabilizing.

\section{Conservation Outcomes under the HSRG Solutions}

Figure 1 compares the proportion of hatchery-origin fish on the spawning grounds (pHOS) and the proportionate natural influence (PNI) for current and proposed (HSRG) scenarios for Primary and Contributing populations. The HSRG solutions change the status of four of the seven populations. The Minam and Lostine river populations change from Contributing to meeting the standards for a Primary designation. The Imnaha River and Catherine Creek populations change from Stabilizing to Primary. Habitat limitations do not allow the Upper Grande Ronde River population to improve. The Wenaha River population remains unchanged as a Primary population. The Minam River population benefits from reduced hatchery-origin strays.

Hatchery influence is reduced in all five of the Primary populations in this MPG. Productivity and PNI values are significantly improved for the Lostine River, Imnaha River, Catherine Creek and the Minam populations (Figure 1).

Figure 2 compares the number of natural-origin spawners on the spawning grounds to their productivity for current and proposed (HSRG Solution) scenarios for Primary populations. Total natural-origin spawner abundance and productivity improves for the five Primary populations in the MPG under the HSRG solution.

\section{Harvest Outcomes under the HSRG Solutions}

Figure 3 describes current and estimated changes in harvest (in marine, mainstem Columbia River and terminal areas) that would occur following implementation of the management solutions proposed by the HSRG. In this case, total harvest increases, primarily in the terminal harvest areas in tribal and sport fisheries. 


\section{Hatchery Program Changes under the HSRG Solutions}

Table 2 shows the current size of each hatchery program as well as their size under the HSRG solution. The size of the Imnaha River program remains the same, but is divided between an integrated conservation program and a new stepping stone harvest program. Catherine Creek smolt releases are reduced and Lookingglass Creek smolt releases are increased to provide more harvest. The Lostine River and Upper Grande Ronde River smolt releases remain unchanged. Also, the HSRG recommends that smolt size at release be increased for all the hatchery programs to increase survival rates.

The HSRG recommends improving weirs in the Imnaha and Lostine rivers and eliminating adult outplants to the Wallowa River and Hurricane Creek to reduce hatchery-origin spawners in the wild. The acclimation facility for the Upper Grande Ronde program should be properly sized to meet smolt acclimation needs. The HSRG suggests that managers explore ways to reduce high pre-spawning mortality of adults returning to the Upper Grande Ronde.

The HSRG recommends that the Upper Grande Ronde program continue to be operated as a safety net until the habitat improves enough to increase productivity and abundance.

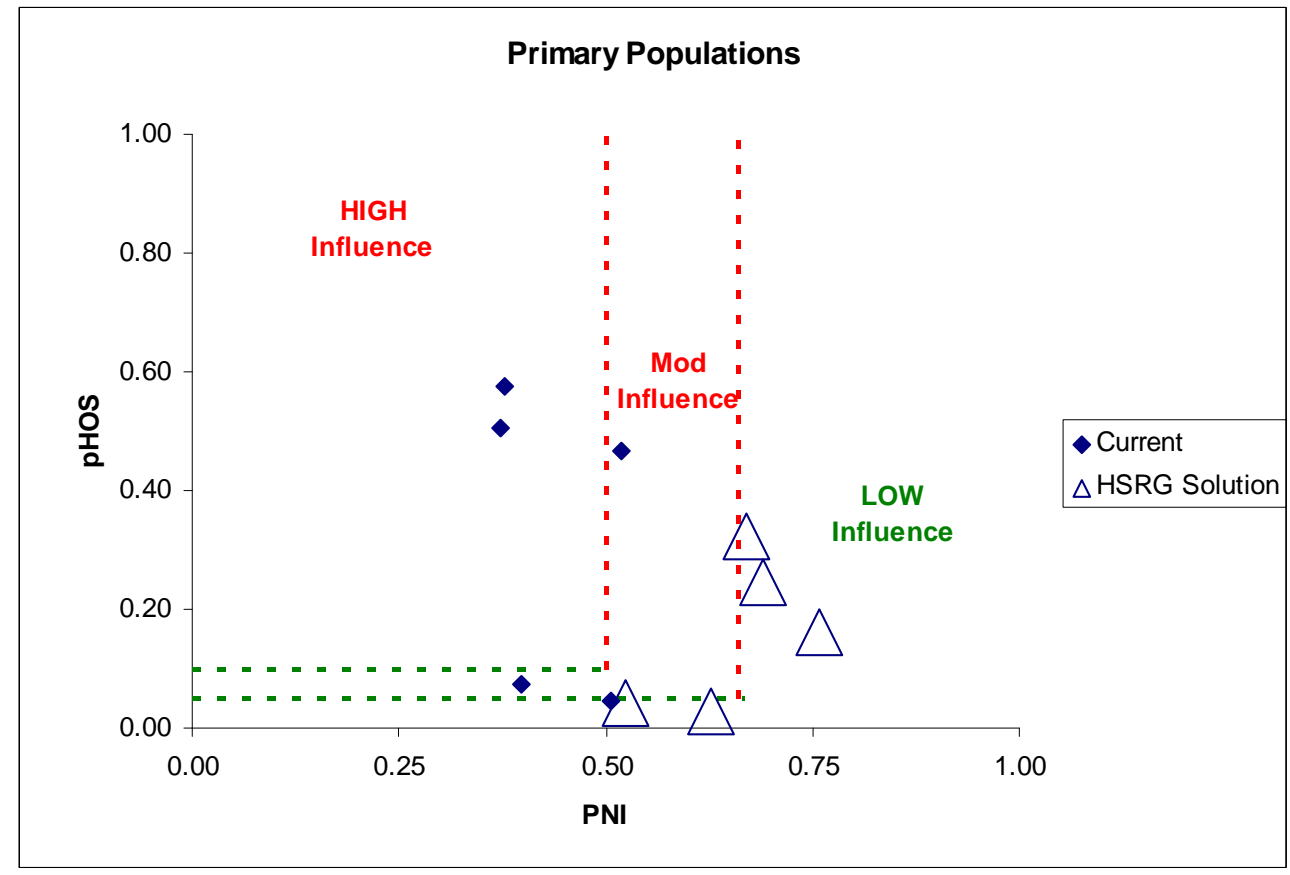

Figure 1. Relationship of the proportion of the fish on the spawning grounds that are of hatchery origin (pHOS) and the proportionate natural influence index (PNI) for Primary spring Chinook populations in the Grande Ronde/Imnaha MPG. Solid diamonds represent values for current programs and open triangles represent values for the HSRG recommended hatchery management solution. 


\section{Hatchery Scientific Review Group}

Pacific Salmon Hatchery Reform
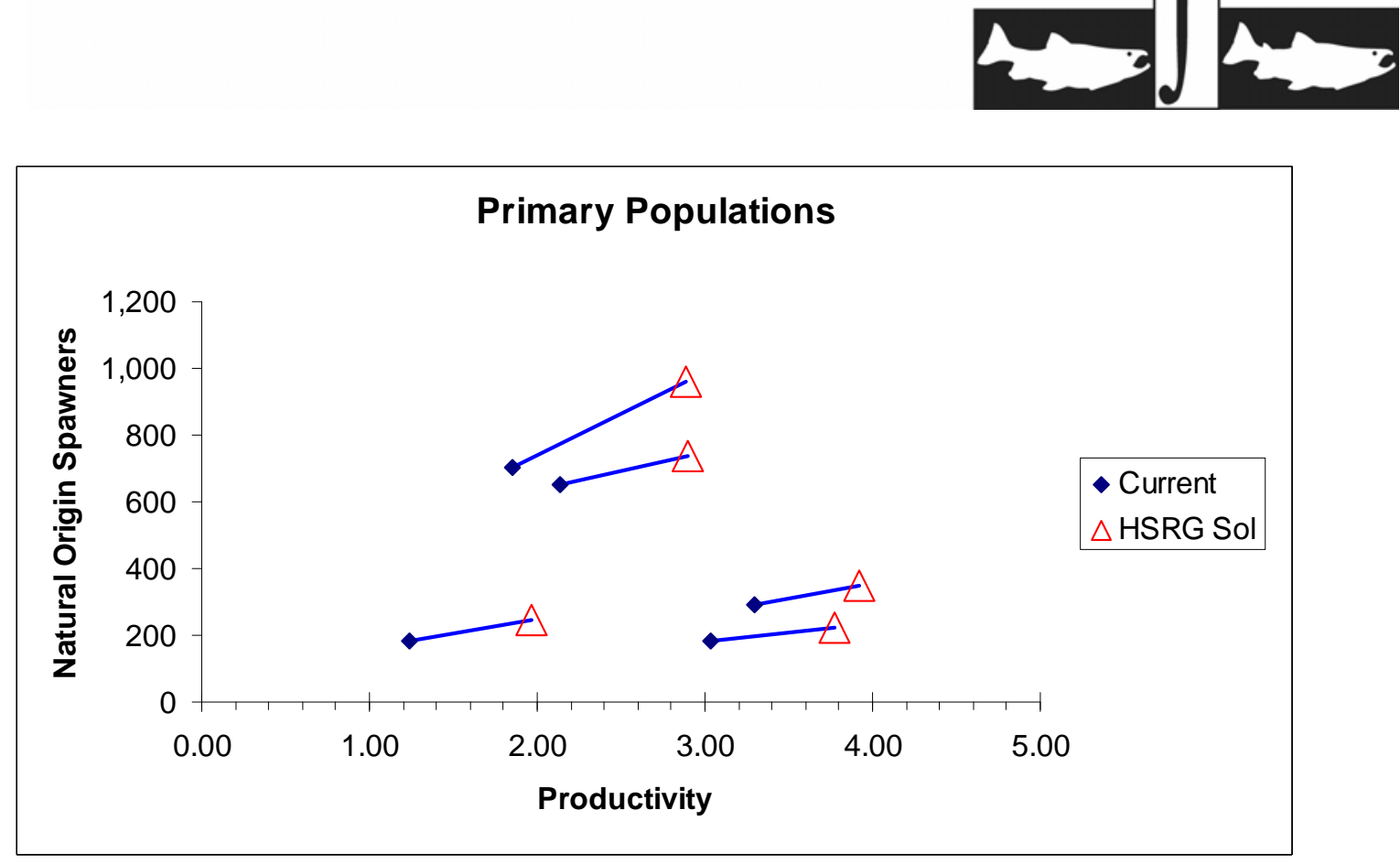

Figure 2. Productivity and spawner abundance for Primary spring Chinook populations in the Grande Ronde/Imnaha MPG. Solid diamonds represent existing productivity and spawner abundance levels, and triangles represent the HSRG recommended hatchery management solution. Lines connect current with HSRG solution for a particular population. The HSRG recommended hatchery management solution includes projected improved fish passage survival in the Snake and Columbia mainstem migration corridor (FCRPS Biological Opinion May 5, 2008).

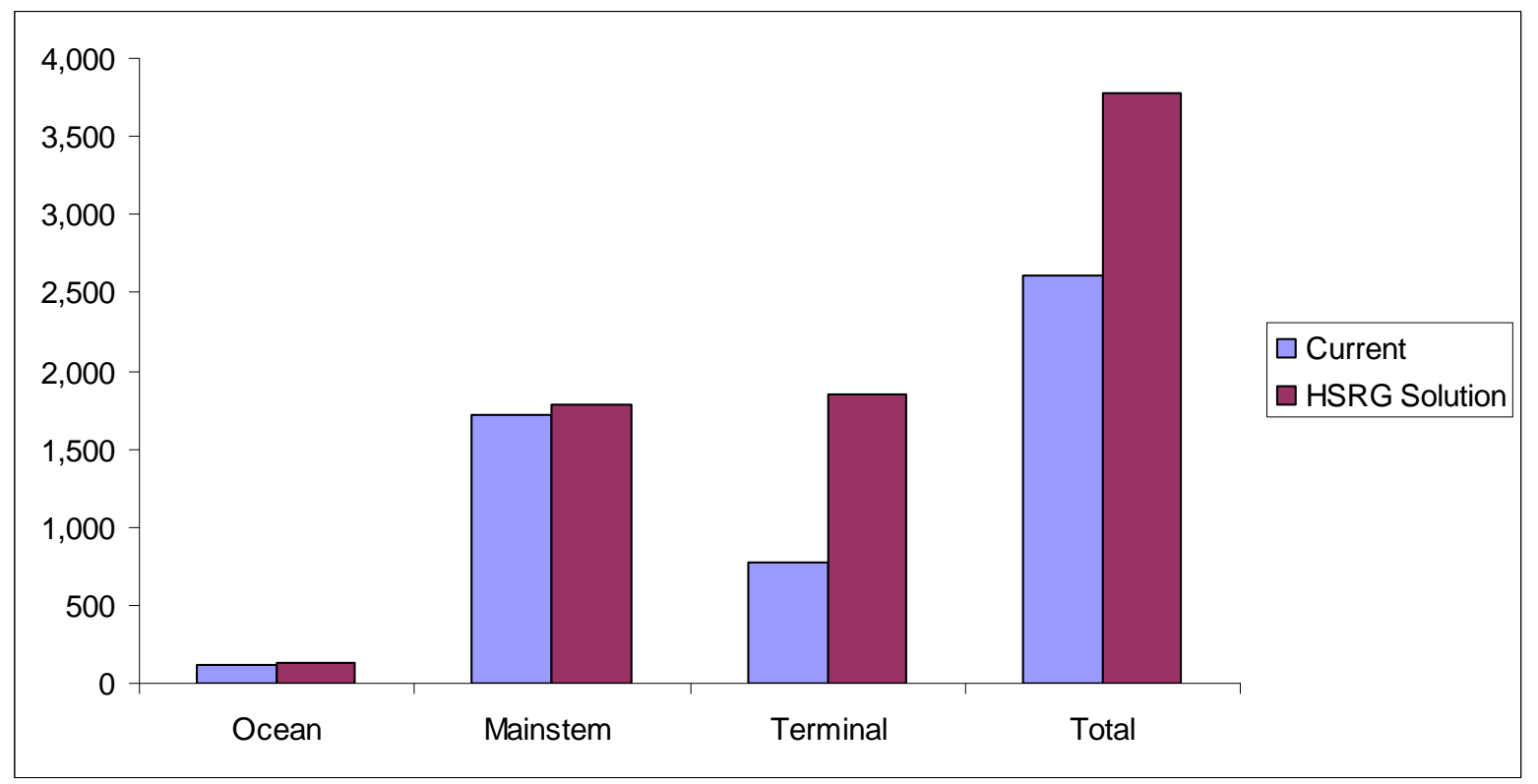

Figure 3. Estimated marine, mainstem Columbia, and terminal harvest under current and HSRG recommended hatchery management solution for Grande Ronde/Imnaha Spring Chinook MPG. The HSRG recommended hatchery management solution includes projected improved fish passage survival in the Snake and Columbia mainstem migration corridor (FCRPS Biological Opinion May 5, 2008). 


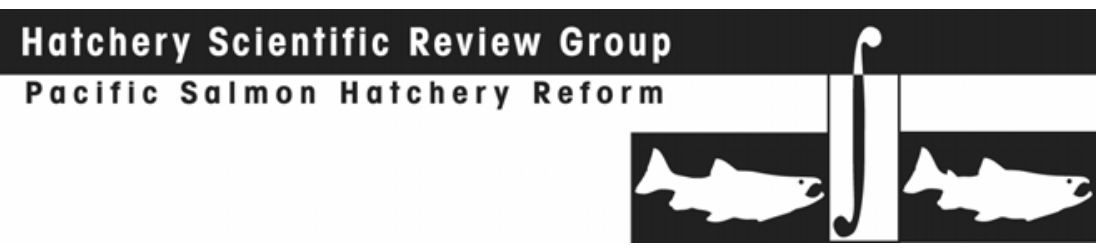

3.1.8.4.4

Summary and Conclusions

The HSRG recommendations provide solutions that meet designations for five Primary and two Stabilizing populations in this MPG. HSRG solutions focused on developing better broodstock and escapement management capabilities through improved fish weirs on the Imnaha River and the Lostine River, while also reducing outplanting of hatcheryorigin adults. Total hatchery smolt releases do not change substantially under the HSRG recommendations; however, smolt release numbers are reduced in Catherine Creek and increased in Lookingglass Creek. Because of low habitat productivity in the Upper Grande Ronde River, the HSRG was unable to craft a solution to improve the population designation from Stabilizing.

The HSRG agrees with the managers' designation of Lookingglass Creek as an appropriate terminal harvest location that would add little risk to natural populations in this MPG.

The HSRG recommendations would increase the abundance of natural-origin spawners by approximately $20 \%$ in the MPG compared to the current program.

The HSRG also concluded that the effectiveness of habitat actions would be greatly increased if combined with hatchery and harvest reforms. For example, the analysis of the Primary populations in this ESU suggests that the benefits of habitat quality improvements would more than double if combined with hatchery reforms. Unless hatchery and harvest reforms are implemented, the potential benefits of current or improved habitat cannot be fully realized.

\subsubsection{Tucannon-Asotin Chinook MPG}

This section provides an overview of the Tucannon-Asotin Chinook MPG. It contains a general description of the MPG, fisheries, habitat limitations and hatchery programs that affect it. Overall recommendations for MPG-wide hatchery program changes are summarized as are the results of implementing these changes on conservation and harvest goals. Detailed conclusions and recommendations for each population in the MPG can be found in the Appendix E.

\subsubsection{1}

\section{HSRG Population Guidelines}

In order to meet conservations goals for the MPG, numerous threats to these populations need to be addressed, including risks from hatchery programs. The key to controlling genetic and ecological risks due to straying and fitness loss is to manage hatchery broodstock natural spawning escapement such that the natural habitat (and not the hatchery environment) drives the adaptation and productivity of the naturally spawning population. This is achieved by operating either (a) integrated programs where the proportion of natural-origin adults in the broodstock exceeds the proportion of hatcheryorigin fish on the spawning grounds ( $\mathrm{pNOB}>\mathrm{pHOS}$ ); or (b) segregated programs where the contribution of hatchery fish to natural spawning is kept low (pHOS $<5 \%$ to $<10 \%$ depending on the population designation). The HSRG developed criteria for hatchery influence for three population types based on the importance of the population to the recovery of the MPG. Using the naming protocol of the Lower Columbia River Salmon Recovery Plan (LCFRB 2004), populations were classified based on information provided to the HSRG as Primary, Contributing, or Stabilizing. These designations are 


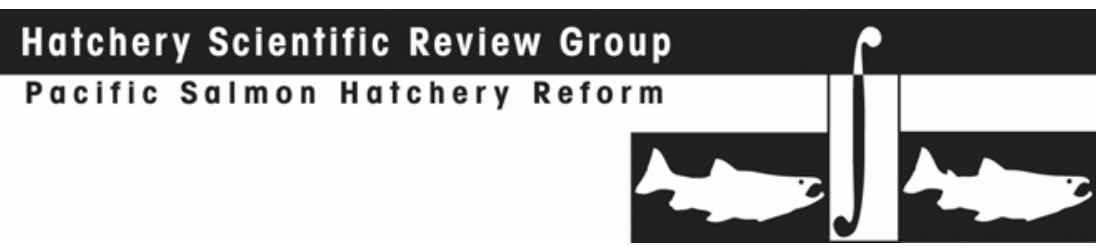

meant to reflect the conservation importance of a population within the MPG from most important (Primary), to moderately important (Contributing), to least important (Stabilizing). HSRG recommendations show how hatchery programs can be operated consistent with these designations based on the following standards:

HSRG criteria for hatchery influence on Primary populations

- For segregated programs, the proportion of effective hatchery-origin spawners on the spawning grounds (pHOS) should be less than $5 \%$ of the naturally spawning population.

- For integrated populations, the proportion of natural-origin adults in the broodstock (pNOB) should exceed pHOS by at least a factor of two, corresponding to a proportionate natural influence $(\mathrm{PNI})$ value of 0.67 or greater with pHOS levels no greater than $30 \%$.

HSRG criteria for hatchery influence on Contributing populations

- For segregated programs, the proportion of effective hatchery-origin spawners on the spawning grounds (pHOS) should be less than $10 \%$ of the naturally spawning population.

- For integrated populations, the proportion of natural-origin adults in the broodstock (pNOB) should exceed $\mathrm{pHOS}$, corresponding to a PNI value of $>0.50$ with $\mathrm{pHOS}$ levels no greater than $30 \%$ and pHOS should be less than 0.30 .

HSRG criteria for hatchery influence on Stabilizing populations:

- The current operating conditions were considered adequate to meet conservation goals. No criteria were developed for proportion of effective hatchery-origin spawners (pHOS) or PNI.

\subsection{Current Conditions}

\section{Conservation}

The Tucannon/Asotin Chinook Salmon MPG is in the Snake River Spring/Summer Chinook Salmon ESU and was listed as threatened under the Endangered Species Act in 1992. As defined by the ESA and the HSRG, the MPG includes Asotin Creek and the Tucannon River. The Tucannon River population is listed as extant; the Asotin population is functionally extirpated. The long-term risk of extinction is considered "high" for the Tucannon population (NMFS 2008e).

For the purpose of this analysis the HSRG assigned a Primary population designation for the Tucannon population and a Stabilizing designation for the Asotin population (Table $1)$.

Table 1. Population designations for the Tucannon/Asotin Chinook MPG and HSRG broodstock criteria achieved for each population under current conditions and the HSRG recommended hatchery management solution.

\begin{tabular}{|c|c|c|c|}
\hline \multirow[b]{2}{*}{ Population } & \multirow[b]{2}{*}{ Desianation ${ }^{1}$} & \multicolumn{2}{|c|}{ HSRG Criteria Met $^{2}$} \\
\hline & & Current & HSRG Solution \\
\hline
\end{tabular}




\begin{tabular}{|l|c|c|c|}
\hline 1-Tucannon Spring Chinook & Primary & Contributing & Contributing \\
\hline 2-Asotin Spring-Summer Chinook & Stabilizing & Stabilizing & Contributing \\
\hline
\end{tabular}

1 Using the naming protocol of the Lower Columbia River Salmon Recovery Plan (LCFRB 2004), populations were classified based on information provided to the HSRG as Primary, Contributing, or Stabilizing. These designations are meant to reflect the conservation importance of a population within the MPG from most important (Primary- bold, red), to moderately important (Contributing-bold, blue), to least important (Stabilizing).

2 The HSRG developed criteria for hatchery influence for the three population designations from low influence (Primary), moderate influence (Contributing) to high influence (Stabilizing).

\section{Current Harvest}

The ocean fishery mortality on Snake River spring/summer and Upper Columbia spring Chinook is very low and for practical purposes, assumed to be near zero (NMFS 2008e). Harvest occurs predominately in the mainstem Columbia River. The 2008-2017 United States $v$. Oregon Management Agreement defines abundance-based mainstem Columbia River harvest rates that use a sliding scale harvest rate schedule $(5.5 \%-17 \%)$ for naturalorigin spring Chinook returning to the Snake River Basin. The incidental take of naturalorigin upriver spring/summer Chinook has averaged 10.2\% since 2001 (NMFS 2008e).

\section{Current Habitat}

Conversion of floodplains and riparian forest buffers to agricultural fields and residences, and channel modifications including straightening, diking, and bank armoring have dramatically altered the lower portions of the Tucannon River and Asotin Creek. Logging, conversion of perennial grasslands to annually planted dry cropland, and grazing have led to increased runoff and erosion of fine sediment throughout the region. Habitat conditions are generally fair to poor on private lands in the lower portions of these watersheds. Mid-elevation reaches are generally in fair condition, with patches of degradation. Conditions on public lands in headwater areas, particularly the WenahaTucannon Wilderness Area, are generally fair to good. The largest pools and significant levels of spawning gravel are generally found in the middle or lower portions of the watersheds where alterations of stream channels, removal of riparian vegetation, and surface water withdrawals (which exacerbate naturally low summer stream flows) have combined to increase water temperatures above the tolerance levels of salmonids. Fine sediment deposition is also a problem in these low gradient stream reaches. Habitat restoration efforts have been taking place since the mid-1990s, largely beginning with the development of "Model Watershed Plans" for the Asotin Creek, Tucannon River and Pataha Creek watersheds. 


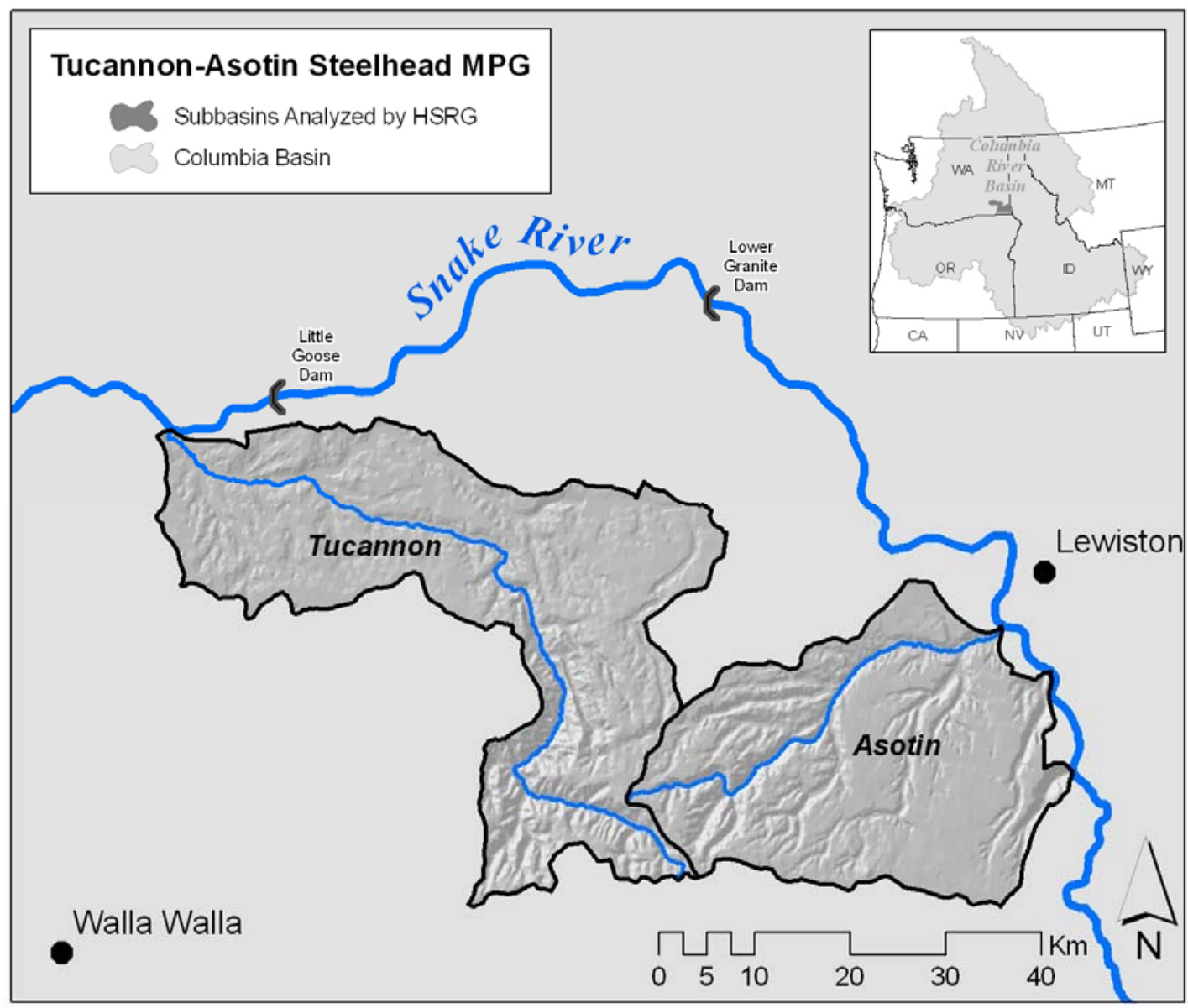

\section{Current Hatchery Programs}

The Tucannon Spring Chinook hatchery program is integrated and currently releases approximately 132,000 juvenile Chinook annually (Table 2). This program was initiated to mitigate for the loss of spring Chinook in the Snake River due to hydroelectric projects. Additional smolts have been released from the captive brood program. This captive brood program is being phased out and the last hatchery adults will return in 2011. Future plans are to expand total releases to 225,000 smolts. There are no spring/summer Chinook hatchery programs in the Asotin Creek population, but managers have plans to reintroduce spring Chinook into that creek (reintroduction was not analyzed by the HSRG).

Table 2. Hatchery releases and types of programs for Tucannon/Asotin Chinook MPG.

\begin{tabular}{|l|c|c|c|c|c|c|}
\hline \multirow{2}{*}{ Population/Program Name } & \multicolumn{3}{|c|}{ Current (1,000s) } & \multicolumn{3}{c|}{ HSRG Solution (1,000s) } \\
\cline { 2 - 7 } & Type & Purpose & \# Released & Type & Purpose & \# Released \\
\hline 1-Tucannon Spring Chinook & Int & Both & 132.6 & Int & Both & 163.4 \\
\hline 2-Asotin Spring-Summer Chinook & None & NA & - & None & NA & - \\
\hline Total all Populations/Programs & & & 132.6 & & & 163.4 \\
\hline
\end{tabular}




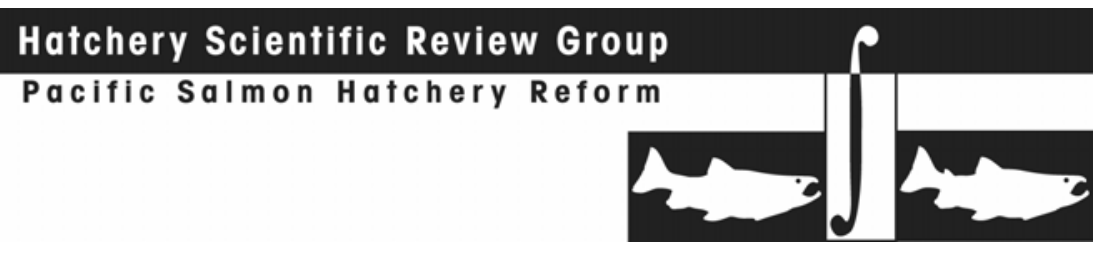

Estimates of PNI and pHOS under current conditions show that the single extant population in this MPG (Tucannon) does not meet the standards for a Primary population designation. It meets the standards for a Contributing population (Table 1) for PNI but not for $\mathrm{pHOS}$ (pHOS is greater than 30\%). The only other population in the MPG (Asotin spring Chinook) was recently classified by the Interior Columbia Technical Recovery Team as functionally extirpated; however, there are plans for a reintroduction program. Managers reported high proportions of hatchery and wild Tucannon spring Chinook bypassing the Tucannon River and being detected passing Lower Granite Dam.

3.1.8.5.3 HSRG Solutions

Options for improving the integrated hatchery program in this MPG are limited due to the low number of natural-origin fish, limited habitat and the straying of both natural- and hatchery-origin fish above Lower Granite Dam. The HSRG looked at various hatchery scenarios that could improve productivity of the sub-populations, but could not significantly increase abundance of natural-origin spawners under current habitat conditions. This is generally the result of limited quality (productivity) and quantity (capacity) of habitat and approximately $50 \%$ of returning adults bypassing the Tucannon River.

\section{Conservation Outcomes under the HSRG Solution}

Figure 1 compares the proportion of hatchery-origin fish on the spawning grounds (pHOS) and the proportionate natural influence (PNI) for current and proposed (HSRG) scenarios for Primary and Contributing populations. The HSRG observed that until habitat improves, it would be difficult to achieve the standards of a Primary population. The short-term demographic benefits of this program outweigh the need to achieve a Primary standard. Because the HSRG solution was analyzed as a Contributing population, and the population currently meets this standard, little improvement in productivity is shown (Figure 2). As previously noted, approximately $50 \%$ of natural and hatchery adults may be bypassing the Tucannon River. Until this issue is addressed, the conservation objective for this population is unlikely to be met.

\section{Harvest Outcomes under the HSRG Solution}

Figure 3 describes current and estimated changes in harvest (in marine, mainstem Columbia River and terminal areas) that would occur following implementation of the management solutions proposed by the HSRG. The HSRG solution includes projected improved fish passage survival in the Snake and Columbia mainstem migration corridor (FCRPS Biological Opinion May 5, 2008). Improved fish passage survival is responsible for most of the small harvest increase shown in Figure 3.

\section{Hatchery Program Changes under the HSRG Solution}

Table 2 shows the current size of each hatchery program as well as their size under the HSRG solution. The HSRG suggests that this population be managed as a Contributing population in the short term until factors affecting productivity and the lack of homing fidelity (both wild and hatchery fish) are addressed. This would accommodate a 160,000 smolt program. The HSRG recommends that spring Chinook observed at the Lyons 
Ferry Hatchery outfall be collected and their origin determined. Those identified as Tucannon-origin fish should be incorporated into the existing program. Fish of unknown origin should be returned to the river. In addition, the HSRG recommends developing long-term rearing capabilities within the Tucannon River subbasin. The HSRG also recommends that managers adopt a bacterial kidney disease control program that includes the culling of high titer broodstock to assist in the control of BKD.

\section{Summary and Conclusions}

Habitat productivity and capacity for this population as well as the high proportion of adults which bypass the Tucannon River limit the options available in the near term. The HSRG suggests that this population be managed as a Contributing population in the short term until factors affecting productivity and the lack of homing fidelity (both wild and hatchery fish) are addressed. This would accommodate a 160,000 smolt program.

The abundance of natural-origin escapement will vary from year to year. In order to balance the demographic risk (low overall abundance) against genetic risks (too much hatchery influence), the HSRG recommends managing pHOS and pNOB on a "sliding scale", while still assuring that PNI and pHOS objectives are met on average over generations.

The HSRG recommends that spring Chinook observed at the Lyons Ferry Hatchery outfall be collected and their origin determined. Those identified as Tucannon-origin fish should be incorporated into the existing program. Fish of unknown origin should be returned to the river.

The HSRG recommends developing long-term rearing capabilities within the Tucannon River subbasin. 


\section{Hatchery Scientific Review Group}

Pacific Salmon Hatchery Reform
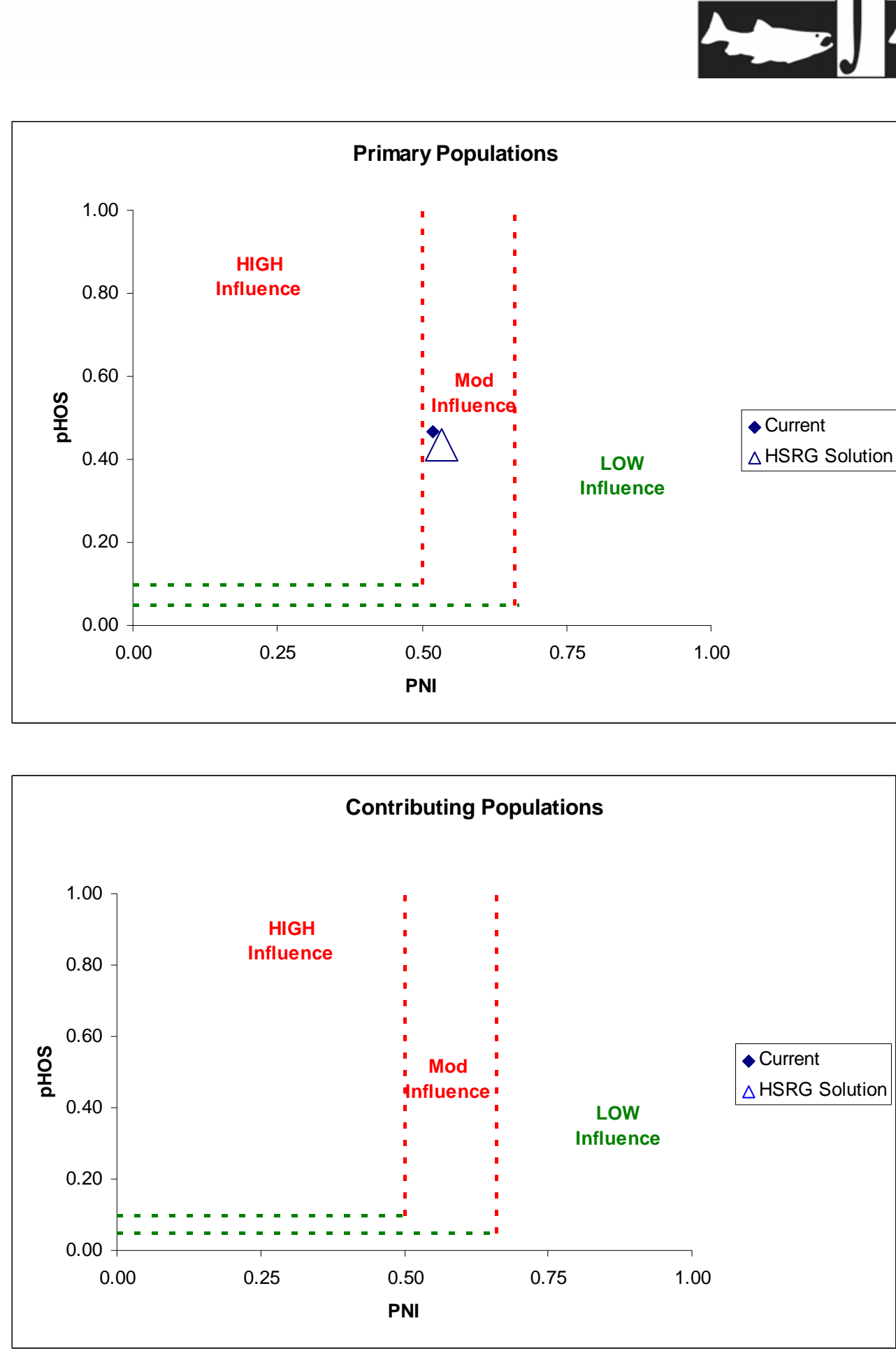

Figure 1. Relationship of the proportion of the fish on the spawning grounds that are of hatchery origin (pHOS) and the proportionate natural influence index (PNI) for Primary (top panel) and Contributing (bottom panel) Chinook populations in the Tucannon/Asotin MPG. Solid diamonds represent values for current programs and open triangles represent values for the HSRG recommended hatchery management solution. 


\section{Hatchery Scientific Review Group}

Pacific Salmon Hatchery Reform

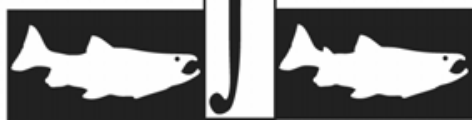

\section{Primary Populations}

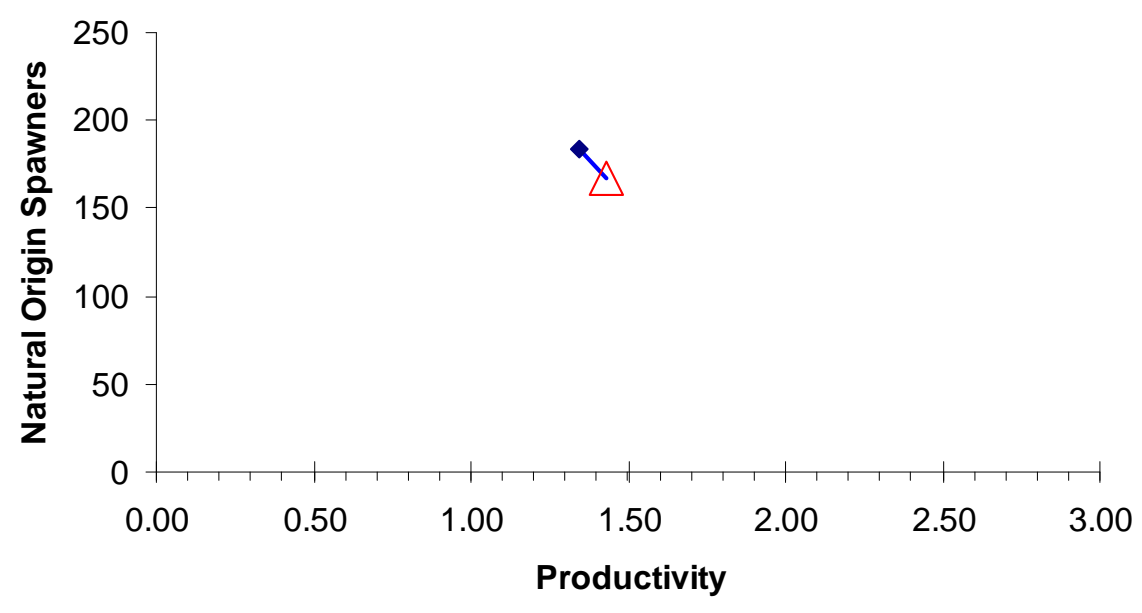

- Current

$\triangle$ HSRG Sol

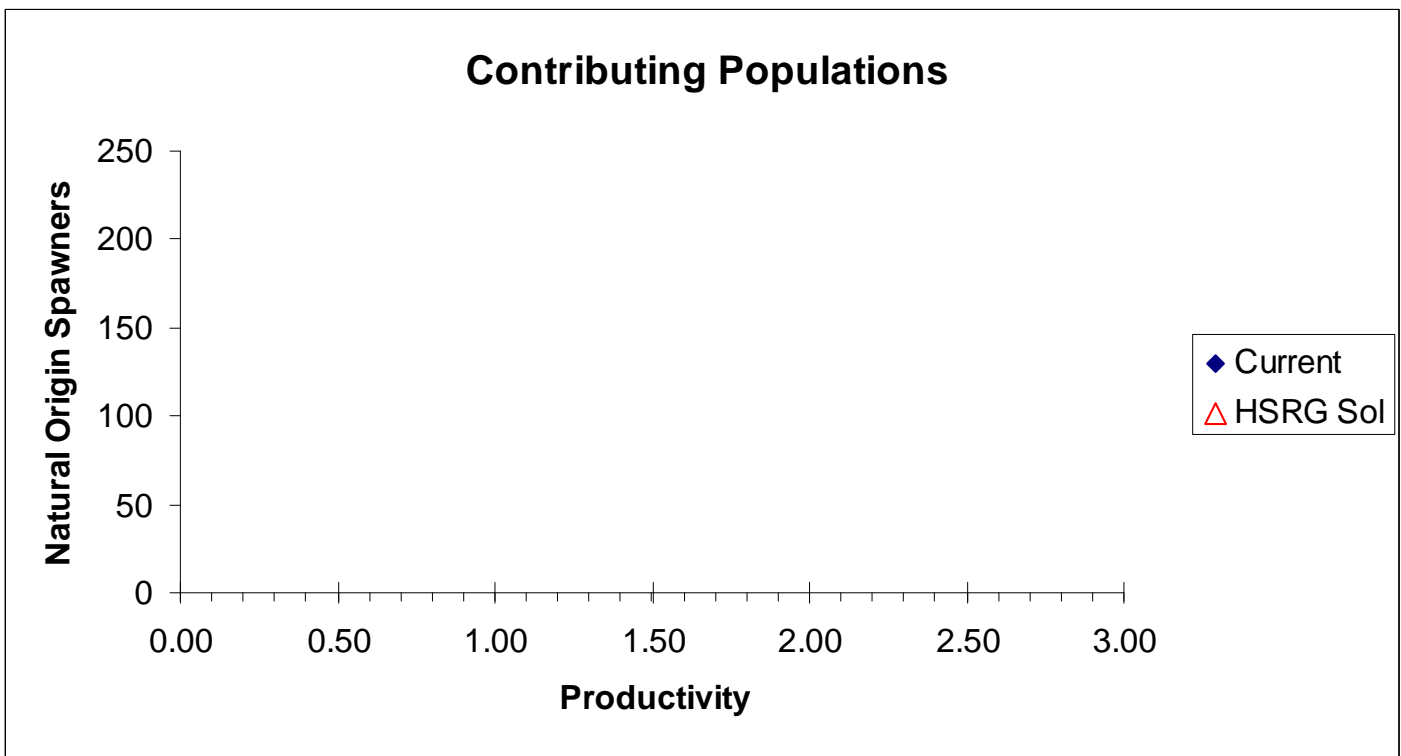

Figure 2. Productivity and spawner abundance for Primary (top panel) and Contributing (bottom panel) Chinook populations in the Tucannon/Asotin MPG. Solid diamonds represent existing productivity and spawner abundance levels, and triangles represent the HSRG recommended hatchery management solution. Lines connect current with HSRG solution for a particular population. The HSRG recommended hatchery management solution includes projected improved fish passage survival in the Snake and Columbia mainstem migration corridor (FCRPS Biological Opinion May 5, 2008). 

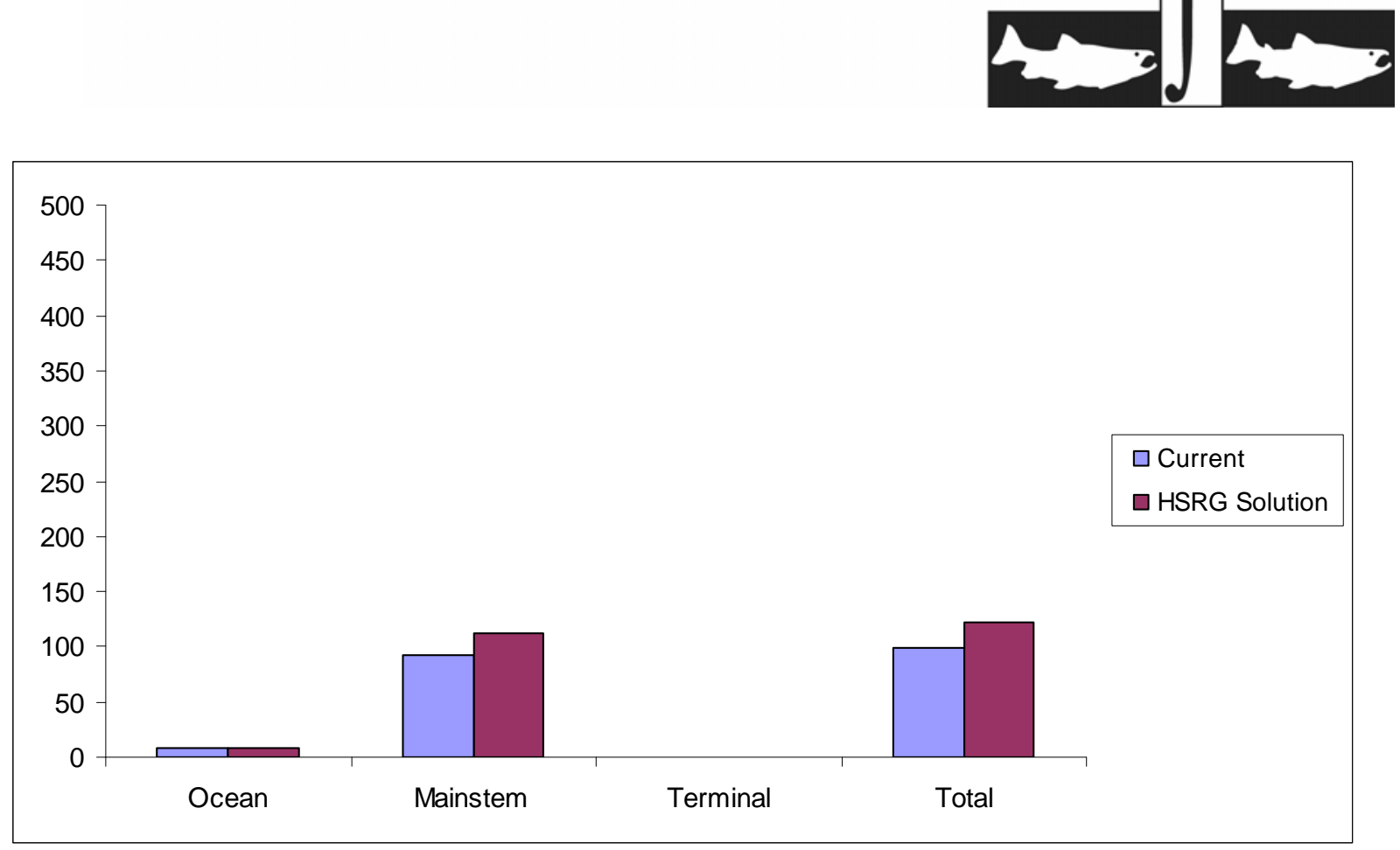

Figure 3. Estimated marine, mainstem Columbia, and terminal harvest under current and HSRG recommended hatchery management solution for Tucannon/Asotin Chinook MPG. The HSRG recommended hatchery management solution includes projected improved fish passage survival in the Snake and Columbia mainstem migration corridor (FCRPS Biological Opinion May 5, 2008).

\section{Clearwater River Spring Chinook MPG}

This section provides an overview of the Clearwater River Spring Chinook MPG. It contains a general description of the MPG, fisheries, habitat limitations and hatchery programs that affect it. Overall recommendations for MPG-wide hatchery program changes are summarized as are the results of implementing these changes on conservation and harvest goals. Detailed conclusions and recommendations for each population in the MPG can be found in the Appendix E.

\subsection{HSRG Population Guidelines}

In order to meet conservations goals for the MPG, numerous threats to these populations need to be addressed, including risks from hatchery programs. The key to controlling genetic and ecological risks due to straying and fitness loss is to manage hatchery broodstock and natural spawning escapement such that the natural habitat (and not the hatchery environment) drives the adaptation and productivity of the naturally spawning population. This is achieved by operating either (a) integrated programs where the proportion of natural-origin adults in the broodstock exceeds the proportion of hatcheryorigin fish on the spawning grounds ( $\mathrm{pNOB}>\mathrm{pHOS}$ ); or (b) segregated programs where the contribution of hatchery fish to natural spawning is kept low (pHOS $<5 \%$ to $<10 \%$ depending on the population designation). The HSRG developed criteria for hatchery influence for three population types based on the importance of the population to the recovery of the ESU. Using the naming protocol of the Lower Columbia River Salmon Recovery Plan (LCFRB 2004), populations were classified based on information provided to the HSRG as Primary, Contributing, or Stabilizing. These designations are 


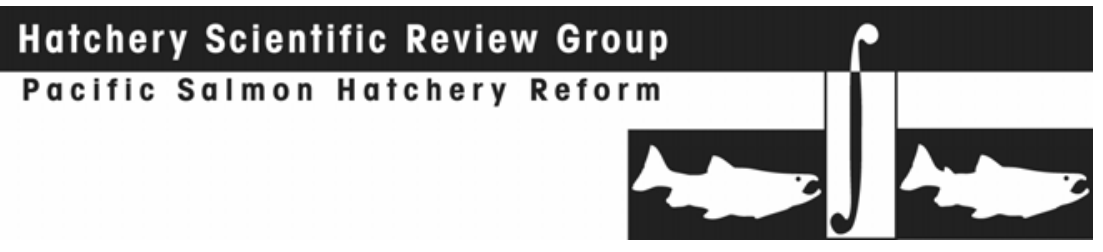

meant to reflect the conservation importance of a population within the ESU from most important (Primary), to moderately important (Contributing), to least important (Stabilizing). HSRG recommendations show how hatchery programs can be operated consistent with these designations based on the following standards:

HSRG criteria for hatchery influence on Primary populations

- For segregated programs, the proportion of effective hatchery-origin spawners on the spawning grounds (pHOS) should be less than $5 \%$ of the naturally spawning population.

- For integrated populations, the proportion of natural-origin adults in the broodstock (pNOB) should exceed pHOS by at least a factor of two, corresponding to a proportionate natural influence $(\mathrm{PNI})$ value of 0.67 or greater with pHOS levels no greater than $30 \%$.

HSRG criteria for hatchery influence on Contributing populations

- For segregated programs, the proportion of effective hatchery-origin spawners on the spawning grounds (pHOS) should be less than $10 \%$ of the naturally spawning population.

- For integrated populations, the proportion of natural-origin adults in the broodstock (pNOB) should exceed $\mathrm{pHOS}$, corresponding to a PNI value of $>0.50$ with $\mathrm{pHOS}$ levels no greater than $30 \%$ and pHOS should be less than 0.30 .

HSRG criteria for hatchery influence on Stabilizing populations

- The current operating conditions were considered adequate to meet conservation goals. No criteria were developed for proportion of effective hatchery-origin spawners (pHOS) or PNI.

\subsection{Current Conditions}

\section{Conservation}

Native populations of spring Chinook in the Clearwater River were extirpated in the mid1900s by Lewiston Dam (1927-1973), which blocked upstream migration of Chinook salmon for most of this period. Following removal of this dam, efforts to reintroduce spring Chinook salmon have resulted in naturally reproducing runs in Lolo Creek and in the Lochsa, Selway, and South Fork Clearwater rivers (Larson and Mobrand 1992). Dworshak Dam blocks access to the North Fork Clearwater River. NOAA Fisheries does not include Clearwater River spring/summer Chinook as part of the Snake River Spring/Summer Chinook salmon ESU.

The HSRG identified seven naturally spawning spring Chinook populations in the Clearwater Spring Chinook MPG, including two population components in the South Fork Clearwater. These are the Upper Selway River, Lolo Creek, Lower Selway River, South Fork Clearwater (Newsome Creek), Lochsa River, South Fork Clearwater River, and Lower Clearwater River populations.

For the purpose of this review, the HSRG assumed two populations as Primary (Upper Selway and Lolo Creek) (Table 1). The Lower Selway and Newsome Creek in the South 


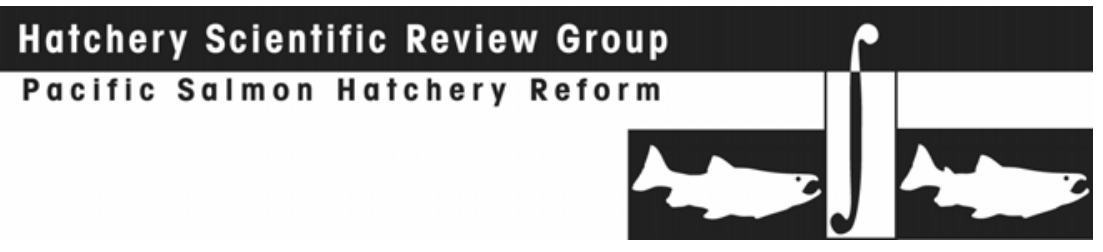

Fork Clearwater were assumed to be Contributing, and the Lochsa, Lower Clearwater populations and the South Fork populations were assumed to be Stabilizing.

Table 1. Population designations for the Clearwater Spring Chinook MPG and HSRG broodstock criteria achieved for each population under current conditions and the HSRG recommended hatchery management solution.

\begin{tabular}{|l|c|c|c|}
\hline \multirow{2}{*}{ Population } & \multirow{2}{*}{} & \multicolumn{2}{|c|}{ HSRG Criteria Met ${ }^{2}$} \\
\cline { 3 - 4 } & Designation ${ }^{1}$ & Current & HSRG Solution \\
\hline 3-Clearwater_Upper Selway Spring Chinook & Primary & Stabilizing & Stabilizing \\
\hline 5-Clearwater_Lolo Creek Spring Chinook & Primary & Stabilizing & Primary \\
\hline 2-Clearwater_Lower Selway Spring Chinook & Contributing & Stabilizing & Stabilizing \\
\hline 4-Clearwater_South Fork Clearwater_Newsome Creek Spring Chinook & Contributing & Stabilizing & Contributing \\
\hline 1-Clearwater_Lochsa Spring Chinook & Stabilizing & Stabilizing & Stabilizing \\
\hline 4-Clearwater_South Fork Clearwater Spring Chinook & Stabilizing & Stabilizing & Stabilizing \\
\hline 6-Clearwater_Lower Clearwater Spring Chinook & Stabilizing & Stabilizing & Stabilizing \\
\hline
\end{tabular}

1 Using the naming protocol of the Lower Columbia River Salmon Recovery Plan (LCFRB 2004), populations were classified based on information provided to the HSRG as Primary, Contributing, or Stabilizing. These designations are meant to reflect the conservation importance of a population within the MPG from most important (Primary- bold, red), to moderately important (Contributing-bold, blue), to least important (Stabilizing).

2 The HSRG developed criteria for hatchery influence for the three population designations from low influence (Primary), moderate influence (Contributing) to high influence (Stabilizing).

\section{Current Harvest}

Ocean fishery mortality on Snake River spring/summer and Upper Columbia spring Chinook is very low and for practical purposes, assumed to be near zero (NMFS 2008e). Harvest occurs predominately in the mainstem Columbia River and terminal areas. The 2008-2017 United States v. Oregon Management Agreement defines abundance-based harvest rates for the mainstem Columbia River and uses a sliding scale harvest rate schedule $(5.5 \%-17 \%)$ for natural-origin spring Chinook returning to the Snake River Basin. The incidental take of natural-origin upriver spring/summer Chinook has averaged 10.2\% since 2001 (NMFS 2008e).

\section{Current Habitat}

Primary factors limiting spring Chinook salmon within the Clearwater River MPG include reduced habitat carrying capacity due to the hydrologic effects of land management activities, high levels of sedimentation, reduced water quality, and the complete blockage of the North Fork Clearwater River by Dworshak Dam. Habitat productivity is low in every population in this MPG.

Excellent habitat typically occurs in the highest elevation headwater streams of the Lochsa and Selway. Good and fair spring Chinook habitat is widely intermixed and found throughout the middle reaches of the Lochsa River, South Fork, Clearwater River, and lower Selway River. Poor habitat conditions for spring Chinook are generally associated with lower mainstem reaches of major tributaries and the mainstem Clearwater River. The North Fork Clearwater River, prior to blockage by Dworshak Dam, historically provided excellent spawning and rearing habitat for spring Chinook. 


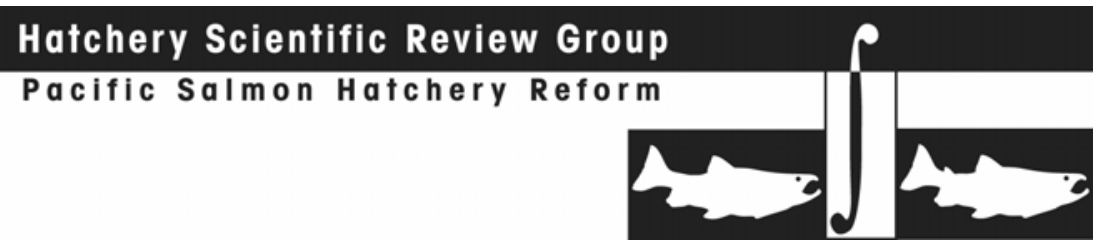

\section{Current Hatchery Programs}

There are currently 10 hatchery programs in the Clearwater River subbasin (three integrated and 7 segregated) (Table 2). The segregated programs release approximately 4.2 million juvenile Chinook per year and the integrated programs release about 650,000 Chinook per year. The programs were established to emphasize harvest opportunities on hatchery-origin fish while rebuilding natural populations via hatchery fish outplants. Stocks from the Rapid River Hatchery and Carson National Fish Hatchery were the primary stocks used to initially establish hatchery-supported runs in the subbasin (USFWS 2008). Broodstock goals typically are met for some programs. When goals are not met, broodstock is imported from the Rapid River Hatchery. In addition, Rapid River Hatchery adults have been outplanted into several natural populations in this MPG. Managers are also evaluating supplementation strategies by using parr outplants into selected populations to improve natural production of spring Chinook.

\section{Current Status of Populations Relative to HSRG Criteria}

Estimates of PNI and pHOS under current conditions show that none of the populations are consistent with HSRG hatchery influence criteria for Primary or Contributing designations (Table 1). Every population in this MPG is heavily influenced by hatchery fish, with the two Primary populations in the MPG having an average pHOS of $54 \%$ and programs that are poorly integrated. The two Contributing population designations do not meet HSRG criteria as PNI is much less than 0.5.

Table 2. Hatchery releases and types of programs for Clearwater Spring Chinook MPG.

\begin{tabular}{|c|c|c|c|c|c|c|}
\hline \multirow[b]{2}{*}{ Population/Program Name } & \multicolumn{3}{|c|}{ Current $(1,000 \mathrm{~s})$} & \multicolumn{3}{|c|}{ HSRG Solution $(1,000 s)$} \\
\hline & Type & Purpose & $\begin{array}{c}\# \\
\text { Released }\end{array}$ & Type & Purpose & $\begin{array}{c}\# \\
\text { Released }\end{array}$ \\
\hline 1-Clearwater-Lochsa Spring Chinook & None & NA & - & None & NA & - \\
\hline 1a-Clearwater-Lochsa Spring Chinook (Hatchery) & Seg & Harv & 700.8 & Seg & Harv & 700.8 \\
\hline 2-Clearwater-Lower Selway Spring Chinook & Int & Both & 429.8 & Int & Both & 429.8 \\
\hline $\begin{array}{l}\text { 2a-Clearwater-Lower Selway Spring Chinook } \\
\text { (Hatchery) }\end{array}$ & Seg & Harv & 300.3 & Seg & Harv & 300.3 \\
\hline 3-Clearwater-Upper Selway Spring Chinook & None & $\mathrm{Na}$ & - & None & $\mathrm{Na}$ & - \\
\hline $\begin{array}{l}\text { 3a-Clearwater-Upper Selway Spring Chinook } \\
\text { (Hatchery) }\end{array}$ & Seg & Harv & 300.3 & Seg & Harv & 300.3 \\
\hline 4-Clearwater-South Fork Clearwater Spring Chinook & None & NA & - & None & NA & - \\
\hline $\begin{array}{l}\text { 4-Clearwater-South Fork Clearwater-Newsome } \\
\text { Creek Spring Chinook }\end{array}$ & Int & Both & 75.4 & Int & Both & 75.3 \\
\hline $\begin{array}{l}\text { 4A-Clearwater-South Fork Clearwater Spring } \\
\text { Chinook (Hatchery) }\end{array}$ & Seg & Harv & $1,100.0$ & Seg & Harv & $1,100.0$ \\
\hline 5-Clearwater-Lolo Creek Spring Chinook & Int & Both & 148.8 & Int & Both & 99.7 \\
\hline 6-Clearwater-Lower Clearwater Spring Chinook & None & NA & - & None & NA & - \\
\hline $\begin{array}{l}\text { 6A-Clearwater-Middle Fork Clearwater Spring } \\
\text { Chinook (Kooskia-Hatchery) }\end{array}$ & Seg & Harv & 600.7 & Seg & Harv & 600.7 \\
\hline
\end{tabular}




\section{Hatchery Scientific Review Group}

Pacific Salmon Hatchery Reform

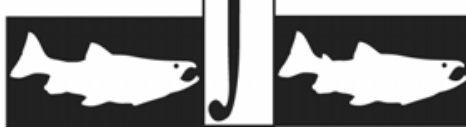

\begin{tabular}{|l|c|c|c|c|c|c|}
\hline \multirow{2}{*}{\begin{tabular}{|c|c|c|c|c|} 
Population/Program Name \\
\cline { 2 - 7 }
\end{tabular}} & \multicolumn{3}{|c|}{ Tyrrent (1,000s) } & \multicolumn{3}{|c|}{ HSRG Solution (1,000s) } \\
\cline { 2 - 7 } & Purpose & $\begin{array}{c}\# \\
\text { Released }\end{array}$ & Type & Purpose & $\begin{array}{c}\# \\
\text { Released }\end{array}$ \\
\hline $\begin{array}{l}\text { 6B-NF Clearwater-Spring Chinook (Dworshak- } \\
\text { Hatchery) }\end{array}$ & Seg & Harv & $1,051.1$ & Seg & Harv & $1,051.1$ \\
\hline $\begin{array}{l}\text { 6C-Clearwater-Lower Mainstem-Spring Chinook } \\
\text { (NPTH-Hatchery) }\end{array}$ & Seg & Harv & 124.6 & Seg & Harv & 124.6 \\
\hline Total all Populations/Programs & & & $\mathbf{4 , 8 3 1 . 9}$ & & & $\mathbf{4 , 7 8 2 . 6}$ \\
\hline
\end{tabular}

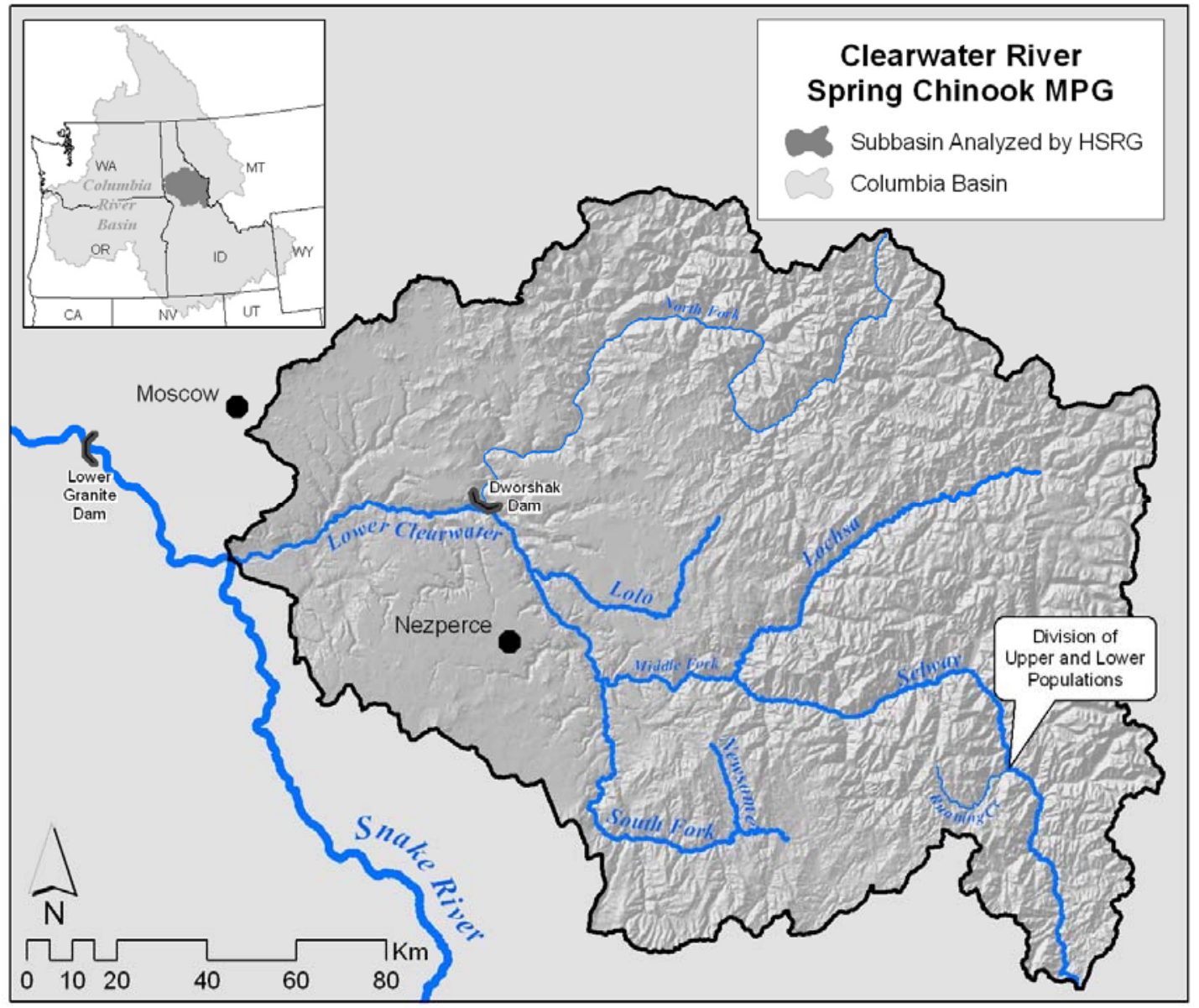

\subsection{HSRG Solutions}

Managers identified conservation and harvest goals for Clearwater River populations.

The HSRG solution improved integration for two of the programs (Lolo Creek and

Newsome Creek population component of the South Fork Clearwater). 
Recommendations for broodstock management meet criteria for a Primary designation for Lolo Creek and a Contributing designation for Newsome Creek (Table 1).

\section{Conservation Outcomes under the HSRG Solution}

Figure 1 compares the proportions of hatchery-origin fish on the spawning grounds (pHOS) and the proportionate natural influence (PNI) for the managers' goals and proposed HSRG solution for Primary and Contributing populations. The HSRG solution would achieve HSRG standards for one Primary and one Contributing population (Table 1). This is expected to increase natural spawner abundance and productivity (Figure 2).

No specific recommendations are made for the other two populations with identified conservation objectives. Opportunities to improve hatchery programs associated with these populations were limited due to low natural productivity and limited access to suitable acclimation sites. The HSRG supports the managers continued evaluation of parr outplants in selected areas.

\section{Harvest Outcomes under the HSRG Solution}

The overall result of HSRG recommendations is a slight increase in harvest benefits across all populations (Figure 3); however, this increase includes a projection of improved fish passage survival in the Snake and Columbia mainstem migration corridor (FCRPS 2008). Opportunities to increase terminal harvest are possible with increased returns of hatchery adults if a switch to smolt releases is accomplished in Lolo and Newsome creeks.

\section{Hatchery Program Changes under the HSRG Solution}

The HSRG recommends that current smolt releases be maintained in all programs and changing releases into Lolo Creek and Newsome Creek from parr to smolts to improve survival (Table 2).

Recommendations were made to replace the segregated program in Newsome Creek with an integrated one using the existing trapping facilities on this tributary to the South Fork Clearwater River. In addition, the HSRG recommends using hatchery returns to Newsome Creek as broodstock for smolt releases elsewhere in the South Fork Clearwater River.

To achieve the criteria for a Contributing population, the HSRG recommends transitioning the segregated program in Lolo Creek into an integrated program using adults returning to this tributary. In addition, this program should be converted from a 149,000 parr release to a smolt release of approximately 100,000 which should improve survival. This may require development of adequate adult collection facilities. 


\section{Hatchery Scientific Review Group}

Pacific Salmon Hatchery Reform
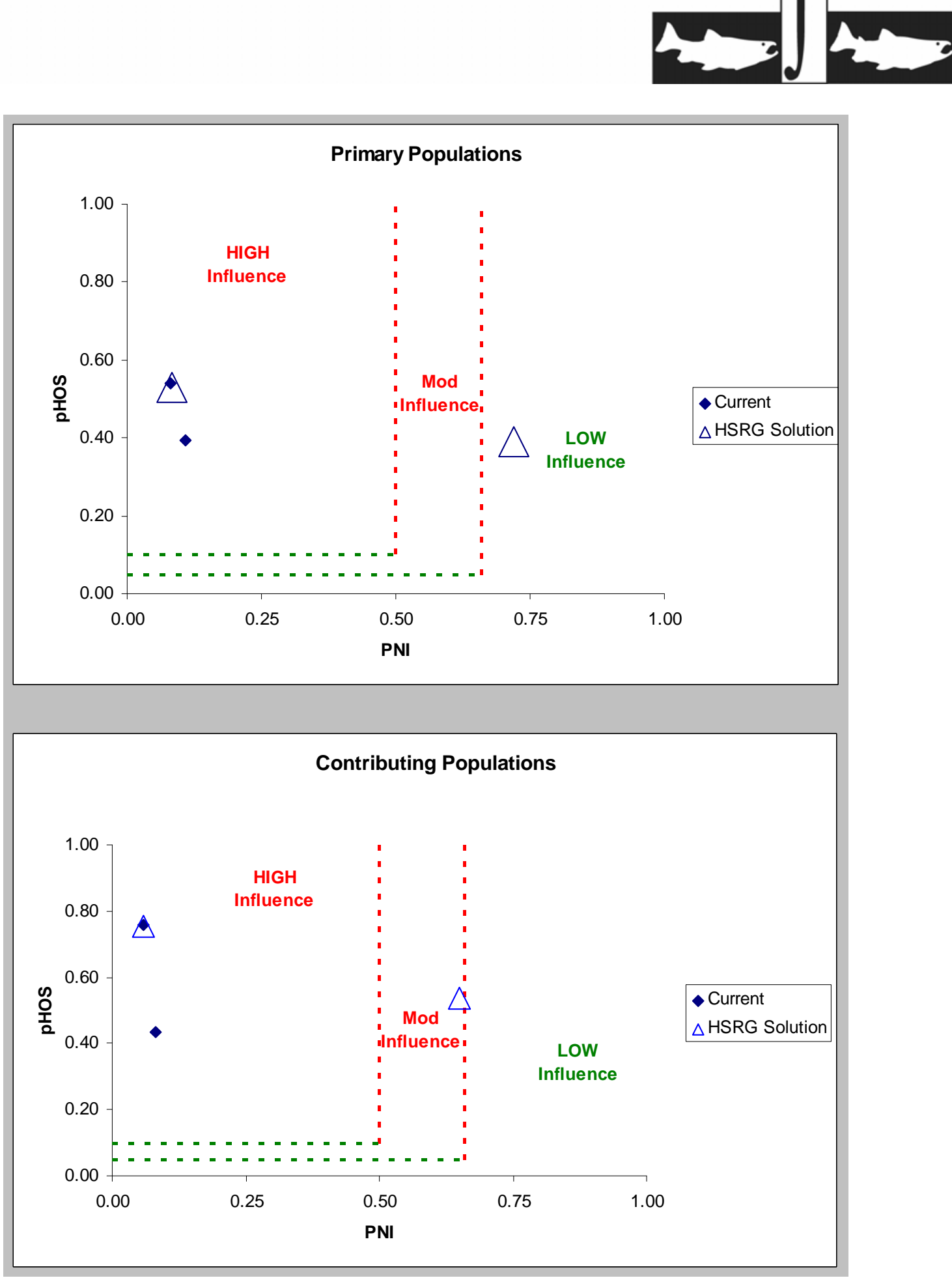

Figure 1. Relationship of the proportion of the fish on the spawning grounds that are of hatchery origin (pHOS) and the proportionate natural influence index (PNI) for Primary (top panel) and Contributing (bottom panel) spring Chinook populations in the Clearwater River MPG. Solid diamonds represent values for current programs and open triangles represent values for the HSRG recommended hatchery management solution. 


\section{Hatchery Scientific Review Group}

Pacific Salmon Hatchery Reform
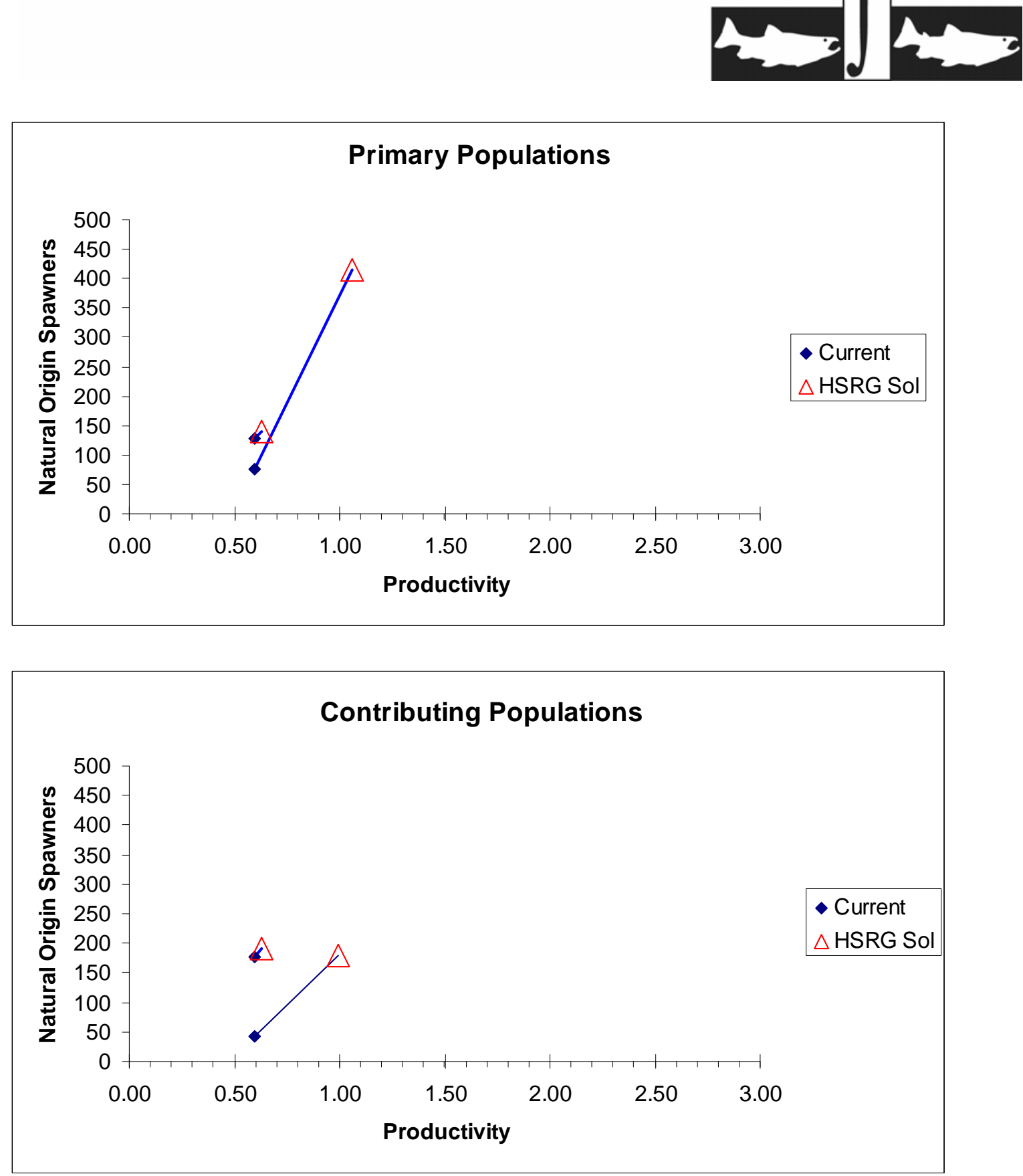

Figure 2. Productivity and spawner abundance for Primary (top panel) and Contributing (bottom panel) spring Chinook populations in the Clearwater River MPG. Solid diamonds represent existing productivity and spawner abundance levels, and triangles represent the HSRG recommended hatchery management solution. Lines connect current with HSRG solution for a particular population. The HSRG recommended hatchery management solution includes projected improved fish passage survival in the Snake and Columbia mainstem migration corridor (FCRPS Biological Opinion May 5, 2008). 

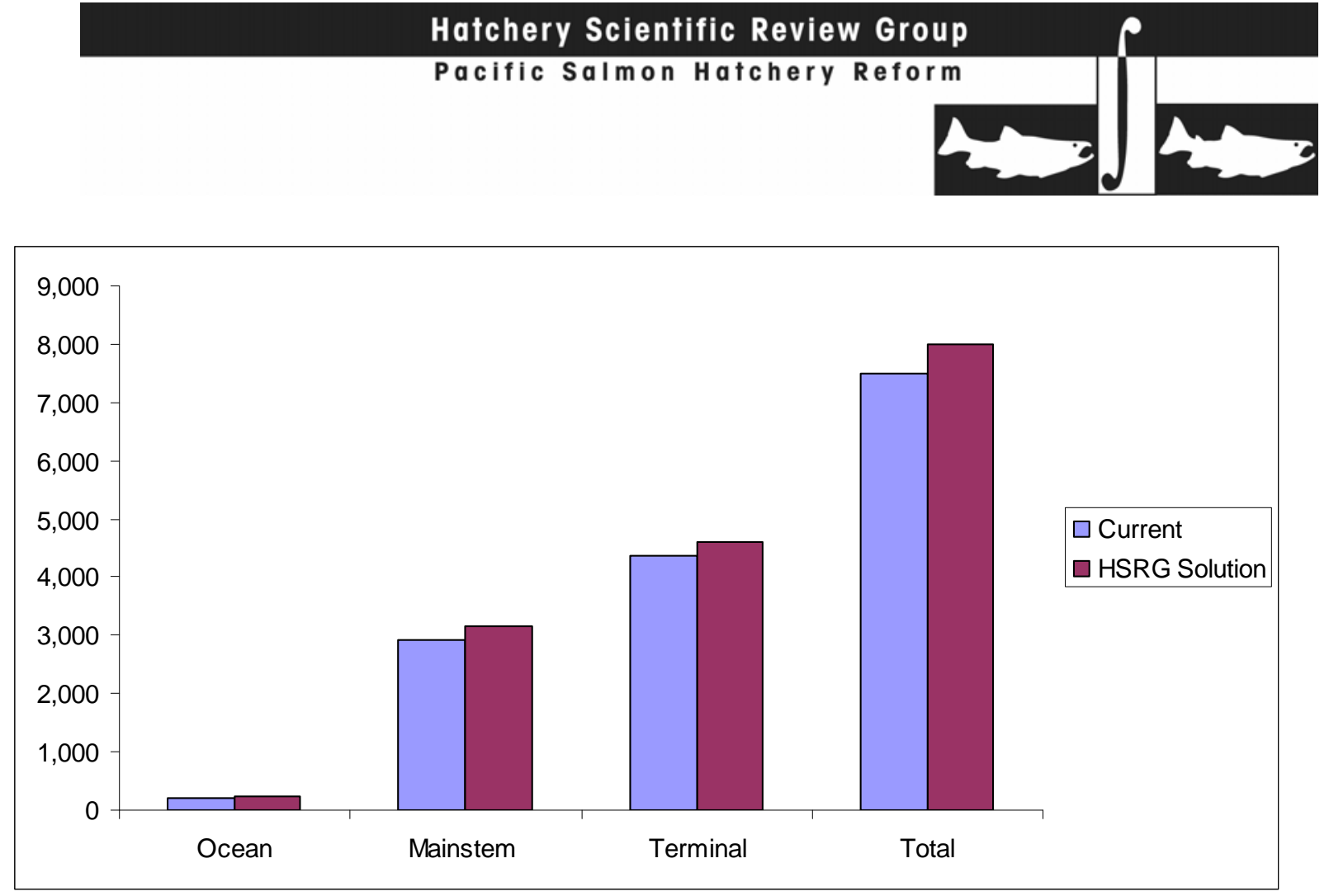

Figure 3. Estimated marine, mainstem Columbia, and terminal harvest under current and HSRG recommended hatchery management solution for Clearwater River Spring Chinook MPG. The HSRG recommended hatchery management solution includes projected improved fish passage survival in the Snake and Columbia mainstem migration corridor (FCRPS Biological Opinion May 5 , 2008).

\subsection{Summary and Conclusions}

This MPG is characterized by very low natural productivity, which limits the options available to manage these populations. Hatchery fish appear to provide a demographic benefit by increasing the abundance of natural-origin fish.

Clearwater spring Chinook were extirpated in the early to mid-1900s and have been introduced using various hatchery stocks. The HSRG recommends that management priority focus on promoting local adaptation of the hatchery programs and natural populations.

The HSRG provides solutions to improve integration of the hatchery programs for two populations (Lolo and Newsome creeks). The HSRG also recommends converting the parr releases to smolt releases in these programs to improve survival.

Analysis suggests that HSRG-recommended actions in populations in Lolo and Newsome creeks would increase the abundance of natural-origin adults by approximately $40 \%$ 
above that expected absent the hatchery programs. A key to achieving this benefit is improvement to population productivity associated with improved broodstock management.

Significant hatchery infrastructure is present within the subbasin and the HSRG encourages coordination among facility operators to maximize efficient use of these facilities. These facilities appear adequate to support the HSRG solutions. Poor access to the Upper Selway River in winter months to operate smolt rearing facilities limits management options for this Primary population.

The HSRG also concluded that the effectiveness of habitat actions (including fish passage) would increase if combined with hatchery and harvest reforms. Analysis of populations in Lolo and Newsome Creeks suggests that the benefits of habitat quality improvements would increase significantly if combined with hatchery reforms. Unless hatchery and harvest reforms are implemented, the potential benefits of current or improved habitat cannot be fully realized. 


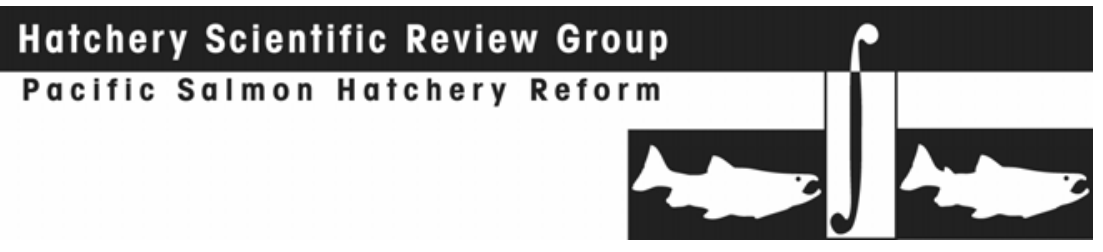

\subsection{Coho ESU}

\subsubsection{Lower Columbia River Coho Salmon ESU}

This section provides an overview of the Lower Columbia River Coho Salmon ESU. It contains a general description of the ESU, fisheries, habitat limitations and hatchery programs that affect it. Overall recommendations for ESU-wide hatchery program changes are summarized, as are the results of implementing those changes on conservation and harvest goals. Detailed conclusions and recommendations for each population in the ESU can be found in the Appendix E.

\subsubsection{HSRG Population Guidelines}

In order to meet conservations goals for the ESU, numerous threats to these populations need to be addressed, including risks from hatchery programs. The key to controlling genetic and ecological risks due to straying and fitness loss is to manage hatchery broodstock and natural spawning escapement such that the natural habitat (and not the hatchery environment) drives the adaptation and productivity of the naturally spawning population. This is achieved by operating either (a) integrated programs where the proportion of natural-origin adults in the broodstock (pNOB) exceeds the proportion of hatchery-origin fish on the spawning grounds (pHOS); or (b) segregated programs where the contribution of hatchery fish to natural spawning is kept low (pHOS $<5 \%$ to $<10 \%$ depending on the population designation). The HSRG developed criteria for hatchery influence for three population types based on the importance of the population to the recovery of the ESU. The Lower Columbia River Salmon Recovery Plan (LCFRB 2004) classified populations as Primary, Contributing, or Stabilizing. These designations are meant to reflect the conservation importance of a population within the ESU from most important (Primary), to moderately important (Contributing), to least important (Stabilizing). HSRG recommendations show how hatchery programs can be operated consistent with these designations based on the following standards:

HSRG criteria for hatchery influence on Primary populations

- The proportion of effective hatchery-origin spawners (pHOS) should be less than 5\% of the naturally spawning population, unless the hatchery population is integrated with the natural population.

- For integrated populations, the proportion of natural-origin adults in the broodstock should exceed pHOS by at least a factor of two, corresponding to a PNI (proportionate natural influence) value of 0.67 or greater and pHOS should be less than 0.30 .

HSRG criteria for hatchery influence on Contributing populations

- The proportion of effective hatchery-origin spawners (pHOS) should be less than $10 \%$ of the naturally spawning population, unless the hatchery population is integrated with the natural population.

- For integrated populations, the proportion of natural-origin adults in the broodstock should exceed $\mathrm{pHOS}$, corresponding to a PNI value of 0.50 or greater and $\mathrm{pHOS}$ should be less than 0.30 . 
HSRG criteria for hatchery influence on Stabilizing populations

- The current operating conditions were considered adequate to meet conservation goals. No criteria were developed for proportion of effective hatchery-origin spawners (pHOS) or PNI.

\subsubsection{Current Conditions}

\section{Conservation}

The Lower Columbia River coho salmon ESU was listed as threatened in 2005. It includes all naturally spawned coho populations in tributaries to the Columbia River in Washington and Oregon, from the mouth of the Columbia up to and including the White Salmon and Hood rivers. It also includes the Willamette River to Willamette Falls, as well as 21 artificial propagation programs. There are 24 historical populations in three major population groups (MPGs) in the ESU, but for the purposes of this analysis 29 populations were evaluated by the HSRG (Table 1). Most of the large natural runs have been replaced by hatchery populations in response to habitat changes and historic overharvest. The risk of extinction is "high" or "very high" for all populations except the Clackamas in the Cascade MPG (LCFRB 2004, McElhany et al 2007).

Historically, conservation has not been a high priority in this ESU. With the recent listing of these populations under the ESA, however, conservation has been elevated to a higher management priority, and will require changes in hatchery, harvest and habitat actions to be successful. Delisting criteria have not been established and a Draft Recovery Plan has not been released. It is likely that the plan will suggest recovery criteria similar to the preliminary plan released in 2004 (LCFRB 2004). The preliminary plan states:

- A specified number of populations in each of the three geographical strata (Coast, Cascade, and Gorge ecological zones) have a high probability of persistence.

- Representative populations need to be preserved, but not every historical population needs to be restored.

- Selected populations should include "core" populations that are highly productive, "legacy" populations that represent historical genetic diversity and dispersed populations that minimize susceptibility to catastrophic events.

The Lower Columbia River Recovery plan, although not specific to coho salmon, provides an example of a recovery scenario that categorizes individual populations in terms of three levels of contribution to recovery: Primary, Contributing and Stabilizing. Primary populations would be restored to high or "high+" viability. Contributing populations would be restored to medium viability, and Stabilizing populations would be maintained at current levels i.e., likely low viability (LCFRB 2004). In the absence of a recovery plan, the HSRG assumed ten populations met the standards of Primary coho populations and seven met the standards of Contributing populations. The remaining twelve populations were designated as Stabilizing populations (Table 1). 
Table 1. Population designations for the Lower Columbia Coho ESU and HSRG broodstock criteria achieved for each population under current condition and the HSRG recommended hatchery management solution.

\begin{tabular}{|c|c|c|c|}
\hline \multirow[b]{2}{*}{ Population } & \multirow[b]{2}{*}{ Designation $^{1}$} & \multicolumn{2}{|c|}{ HSRG Criteria Met $^{2}$} \\
\hline & & Current & HSRG Solution \\
\hline Columbia Estuary-Big Creek Coho & Primary & Stabilizing & Stabilizing \\
\hline Columbia Estuary-Scappoose Coho & Primary & Stabilizing & Stabilizing \\
\hline Grays Coho (Late-Type N) & Primary & Stabilizing & Primary \\
\hline Elochoman Coho (Late- Type N) & Primary & Stabilizing & Primary \\
\hline Cowlitz-Lower Cowlitz Coho (Type N) & Primary & Stabilizing & Primary \\
\hline Cowlitz-Coweeman Coho (Type N) & Primary & Primary & Primary \\
\hline Cowlitz-Toutle Coho (Early-Type S Natural) & Primary & Stabilizing & Primary \\
\hline Lewis-East Fork Lewis Coho & Primary & Primary & Primary \\
\hline Sandy Coho & Primary & Primary & Primary \\
\hline Willamette-Upper Clackamas Coho & Primary & Primary & Primary \\
\hline Columbia Estuary: Mill-Abernathy-Germany Cr Coho (Type N) & Contributing & Primary & Primary \\
\hline Cowlitz Upper Cowlitz Coho & Contributing & Stabilizing & Primary \\
\hline Kalama Coho (natural) & Contributing & Stabilizing & Stabilizing \\
\hline Washougal Coho & Contributing & Stabilizing & Contributing \\
\hline Lewis-North Fork Lewis Coho (Late-Type N) & Contributing & Contributing & Contributing \\
\hline White Salmon Coho (Early- Type S) & Contributing & Stabilizing & Stabilizing \\
\hline Hood Coho & Contributing & Stabilizing & Stabilizing \\
\hline Columbia Estuary-Youngs Bay Tribs Coho & Stabilizing & Stabilizing & Stabilizing \\
\hline Columbia Estuary-Gnat Creek Coho & Stabilizing & Stabilizing & Stabilizing \\
\hline Columbia Estuary-Clatskanie Coho (Late-Type N) & Stabilizing & Contributing & Contributing \\
\hline Columbia Estuary-Chinook River Coho & Stabilizing & Stabilizing & Stabilizing \\
\hline Lewis-North Fork Lewis Coho (Early-Type S) ${ }^{3}$ & Stabilizing & Primary & Primary \\
\hline Willamette-Lower Willamette Tribs Coho & Stabilizing & Stabilizing & Stabilizing \\
\hline Willamette-Lower Clackamas Coho & Stabilizing & Stabilizing & Stabilizing \\
\hline Willamette-Upper Willamette Tribs coho & Stabilizing & Stabilizing & Stabilizing \\
\hline Columbia Gorge-Columbia Gorge Tributaries Coho (Oregon) & Stabilizing & Stabilizing & Stabilizing \\
\hline Columbia Gorge-Columbia Gorge Tributaries Coho (WA) & Stabilizing & Stabilizing & Stabilizing \\
\hline Fifteenmile Creek Coho & Stabilizing & Stabilizing & Stabilizing \\
\hline Klickitat Coho & Stabilizing & Stabilizing & Stabilizing \\
\hline
\end{tabular}

1 Using the naming protocol of the Lower Columbia River Salmon Recovery Plan (LCFRB 2004), populations were classified based on information provided to the HSRG as Primary, Contributing, or Stabilizing. These designations are meant to reflect the conservation importance of a population within the ESU from most important (Primary- bold, red), to moderately important (Contributing-bold, blue), to least important (Stabilizing).

2 The HSRG developed criteria for hatchery influence for the three population designations from low influence (Primary), moderate influence (Contributing) to high influence (Stabilizing).

3 This is a planned reintroduction program when passage is established into the upper watershed.

\section{Current Harvest}

Lower Columbia River coho are commercially harvested in non-selective ocean fisheries and non-Treaty fisheries in the mainstem Columbia River below Bonneville Dam. 


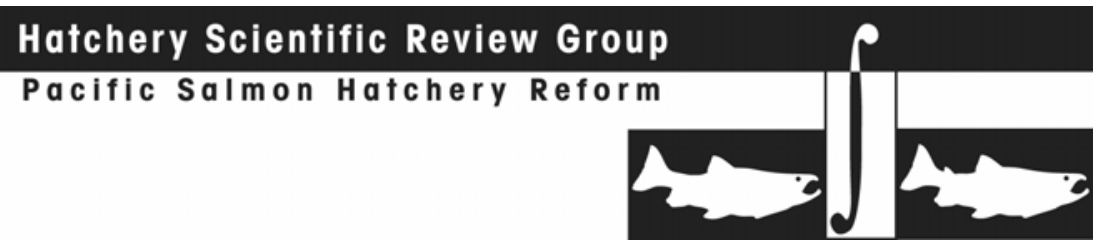

Recreational fisheries are selective and target marked hatchery fish. Until 1993 the total exploitation rates for Lower Columbia River coho fisheries were very high, fluctuating from approximately 60 to 90 percent, but rates have been reduced since ESA listing to 15 to 25 percent according to year-specific circumstances (LCRRB 2004, NMFS 2008e).

\section{Current Habitat}

Populations spawning above Bonneville Dam have been affected by both upstream and downstream passage and some by inundation of historical habitat by Bonneville pool. For populations found in tributaries below Bonneville, migration and habitat conditions in the mainstem and estuary have been affected by hydropower flow operations. Habitat degradation in tributaries is pervasive from land uses such as urbanization, agriculture, and timber harvest, increasing fine sediment in spawning reaches and dramatically reducing off-channel and complex habitats important for juvenile coho rearing. FERClicensed hydroelectric projects have blocked access to large expanses of coho spawning and rearing areas; however, improvements have been implemented since 2000. These range from improved passage with culvert replacement to reintroducing fish upstream of existing dams (e.g., on the Cowlitz River and planned on the Lewis River).

\section{Current Hatchery Programs}

Currently, 21 hatchery programs operate in the ESU, releasing approximately 17 million coho. Most of the programs are in tributary streams. Two net pen programs, located in Young's Bay and Deep River, operate in terminal fishing areas, releasing approximately 2.1 million fish for harvest. Seventeen of the current programs (releasing approximately 15.7 million fish) are classified as segregated programs (Table 2). Four of the current programs (releasing approximately 1.27 million fish) are classified as integrated programs (Table 2).

The original purpose of most programs in the lower Columbia River was to provide harvest; most are now inconsistent with current conservation objectives. The HSRG and others have concluded that a major concern with these programs is the effect hatchery strays have on the long-term fitness of naturally spawning populations. Currently in the lower Columbia River, hatchery fish make a sizeable contribution to natural coho escapement. The percentage of fish effectively spawning in the wild that are hatchery fish (pHOS) exceeds 40 percent for most populations important to recovery. Hatchery contribution to natural spawning is generally not as high in Primary populations (averaging nearly 30 percent), but is approximately 50 percent in Contributing populations. These programs provide significant harvest benefits, and in some cases, help preserve genetic resources in the ESU. However, the ESU is dominated by many poorly segregated and a few poorly integrated programs. Reintroduction efforts using hatchery-origin fish are occurring or are planned in the Cowlitz and Lewis rivers. 


\section{Hatchery Scientific Review Group \\ Pacific Salmon Hatchery Reform}

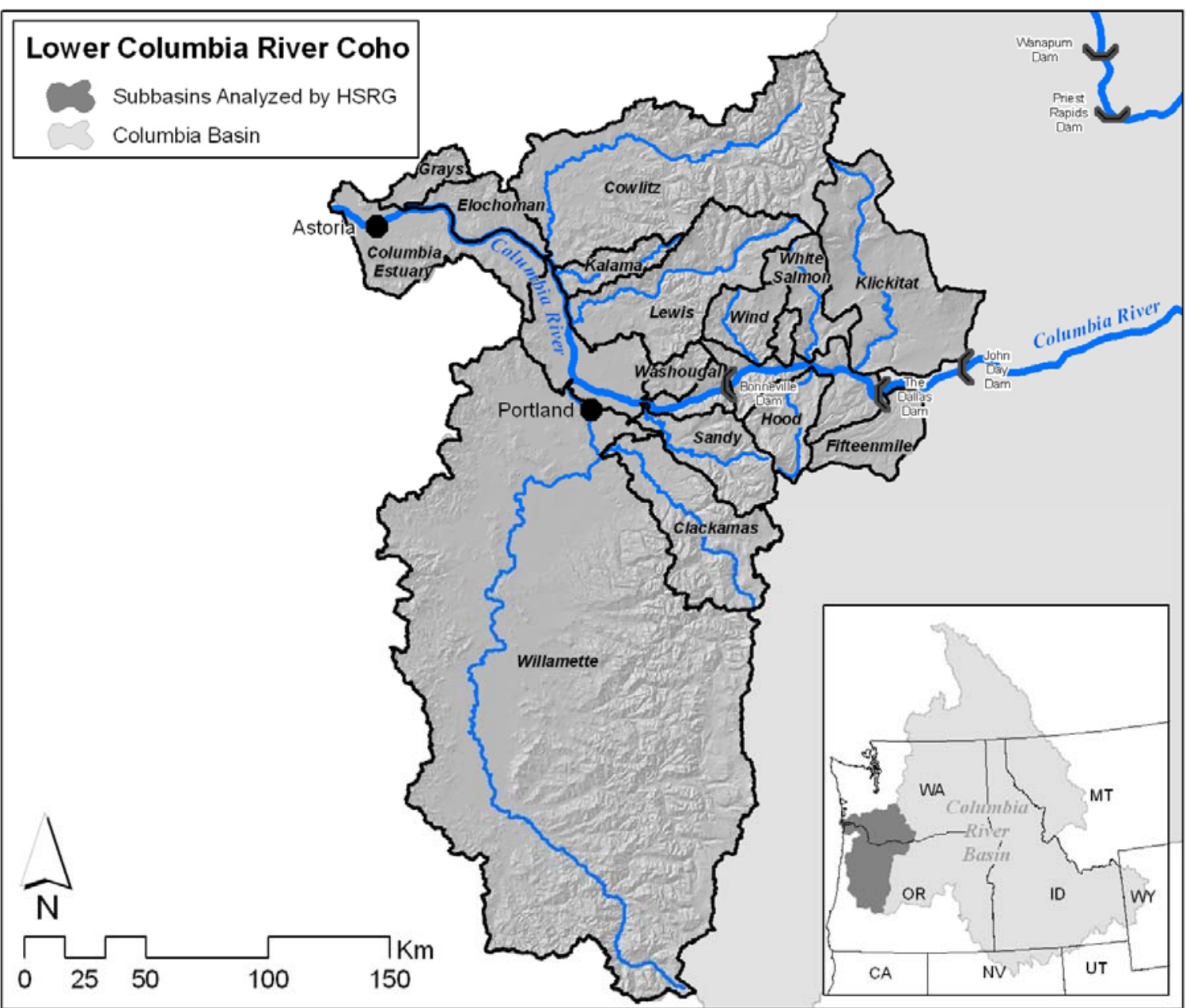

Estimates of PNI and pHOS under current conditions show that only four of the ten populations in the ESU designated as Primary currently meet those criteria. One of the seven populations designated as Contributing currently meets that standard; however, one of the Contributing populations (Mill-Abernathy-Germany Creeks) currently meets the higher conservation standard of a Primary population. One Stabilizing population (North Fork Lewis River Early Type-S) currently meets the standards of a Primary population. Another Stabilizing population (Clatskanie River) currently meets the higher standards of Contributing population. The remaining populations identified only meet the broodstock criteria for Stabilizing populations (Table 1). 
Table 2. Hatchery releases and types of programs for Lower Columbia River Coho ESU.

\begin{tabular}{|c|c|c|c|c|c|c|}
\hline \multirow[b]{2}{*}{ Population/Program Name } & \multicolumn{3}{|c|}{ Current $(1,000 \mathrm{~s})$} & \multicolumn{3}{|c|}{ HSRG Solution $(1,000 \mathrm{~s})$} \\
\hline & Type & & \# Released & Type & & \# Released \\
\hline $\begin{array}{l}\text { Columbia Estuary-Bernie Creek Coho (Late-Type N- } \\
\text { FFA) }\end{array}$ & Seg & Harv & 16.5 & Seg & Harv & 16.5 \\
\hline Columbia Estuary-Big Creek Coho & None & NA & - & Int & Cons & - \\
\hline Columbia Estuary-Big Creek Coho (Hatchery) & Seg & Harv & 582.1 & Seg & Harv & 582.1 \\
\hline Columbia Estuary-Chinook River Coho & None & NA & - & None & NA & - \\
\hline Columbia Estuary-Clatskanie Coho (Late-Type N) & None & NA & - & None & NA & - \\
\hline $\begin{array}{l}\text { Columbia Estuary-Deep River Coho (Early-Type S- } \\
\text { Grays-Hatchery) }\end{array}$ & Seg & Harv & 401.3 & Seg & Harv & 441.0 \\
\hline Columbia Estuary-Gnat Creek Coho & None & NA & - & None & NA & - \\
\hline Columbia Estuary-Mill-Aber-Germ Coho (Type N) & None & NA & - & None & NA & - \\
\hline Columbia Estuary-Scappoose Coho & None & NA & - & None & NA & - \\
\hline $\begin{array}{l}\text { Columbia Estuary-Youngs Bay Coho (Bonneville- } \\
\text { Sandy-Hatchery) }\end{array}$ & Seg & Harv & $1,726.2$ & Seg & Harv & $2,701.9$ \\
\hline Columbia Estuary-Youngs Bay Tribs Coho & None & NA & - & None & NA & - \\
\hline $\begin{array}{l}\text { Columbia Gorge-Columbia Gorge Tributaries Coho } \\
\text { (Oregon) }\end{array}$ & None & NA & - & None & NA & - \\
\hline $\begin{array}{l}\text { Columbia Gorge-Columbia Gorge Tributaries Coho } \\
\text { (WA) }\end{array}$ & None & NA & - & None & NA & - \\
\hline Cowlitz Upper Cowlitz Coho & Int & Harv & 238.8 & Int & Both & 501.3 \\
\hline Cowlitz-Coweeman Coho (Type N) & None & NA & - & None & NA & - \\
\hline Cowlitz-Lower Cowlitz Coho (Type N Hatchery) & Seg & Harv & $3,223.4$ & Seg & Harv & 840.5 \\
\hline Cowlitz-Lower Cowlitz Coho (Type N) & None & NA & - & Int & Harv & 850.0 \\
\hline Cowlitz-Toutle Coho (Early-Type S Hatchery) & Seg & Harv & 801.3 & Seg & NA & - \\
\hline Cowlitz-Toutle Coho (Early-Type S Natural) & None & NA & - & Int & Harv & 560.3 \\
\hline Elochoman Coho (Early- Type S Hatchery) & Seg & Harv & 415.0 & Seg & Harv & $1,201.1$ \\
\hline Elochoman Coho (Late- Type N) & Int & Both & 496.1 & Int & Both & 146.5 \\
\hline Fifteenmile Creek Coho & None & NA & - & None & NA & - \\
\hline Grays Coho (Early-Type S Hatchery) & Seg & Harv & 150.4 & Seg & NA & - \\
\hline Grays Coho (Late-Type N) & None & NA & - & Int & Both & 155.9 \\
\hline Hood Coho & None & NA & - & None & NA & - \\
\hline Kalama Coho (Early- Type S) & Seg & Harv & 353.1 & Seg & Harv & 353.1 \\
\hline Kalama Coho (Late- Type N) & Seg & Harv & 350.8 & Seg & Harv & 350.8 \\
\hline Kalama Coho (Natural) & None & NA & - & Int & NA & - \\
\hline Klickitat Coho & None & NA & - & None & NA & - \\
\hline Klickitat Coho (Lewis-Hatchery) & Seg & Harv & $1,238.6$ & Seg & Harv & $1,052.3$ \\
\hline Klickitat Coho (Washougal-Hatchery) & Seg & Harv & $2,461.9$ & Seg & NA & - \\
\hline Lewis-EF Lewis Coho & None & NA & - & None & NA & - \\
\hline Lewis-NF Lewis Coho (Early-Type S Hatchery) & Seg & Harv & 880.0 & Seg & Harv & 115.8 \\
\hline Lewis-NF Lewis Coho (Early-Type S) & None & NA & - & None & NA & - \\
\hline Lewis-NF Lewis Coho (Late-Type N Hatchery) & Seg & Harv & 815.1 & Seg & Harv & - \\
\hline Lewis-NF Lewis Coho (Late-Type N) & Int & Harv & 40.0 & Int & Cons & 231.6 \\
\hline
\end{tabular}




\begin{tabular}{|c|c|c|c|c|c|c|}
\hline \multirow[b]{2}{*}{ Population/Program Name } & \multicolumn{3}{|c|}{ Current $(1,000 \mathrm{~s})$} & \multicolumn{3}{|c|}{ HSRG Solution $(1,000 \mathrm{~s})$} \\
\hline & Type & & \# Released & Type & & \# Released \\
\hline Little White Salmon Coho (Hatchery) & Seg & Harv & - & Seg & NA & $1,059.1$ \\
\hline Lower Columbia-Bonneville Coho (Hatchery) & Seg & Harv & $1,247.7$ & Seg & Harv & 750.5 \\
\hline Sandy Coho & None & NA & - & Int & Harv & - \\
\hline Sandy Coho (Hatchery) & Seg & Harv & 700.1 & Seg & NA & 700.1 \\
\hline Washougal Coho & Int & Harv & 497.9 & Int & Both & 231.6 \\
\hline Washougal Coho (Stepping Stone Hatchery) & Seg & Harv & - & Seg & Harv & 280.2 \\
\hline White Salmon Coho (Early- Type S) & None & NA & - & None & NA & - \\
\hline Willamette-Upper Willamette Tribs coho & None & NA & - & None & NA & - \\
\hline Willamette-Clackamas-Eagle Creek Coho (Hatchery) & Seg & Harv & 349.1 & Seg & Harv & 349.1 \\
\hline Willamette-Lower Clackamas Coho & None & NA & - & None & NA & - \\
\hline Willamette-Lower Willamette Tribs Coho & None & NA & - & None & NA & - \\
\hline Willamette-Upper Clackamas Coho & None & NA & - & None & NA & - \\
\hline Total all Populations/Programs & & & $16,985.3$ & & & $13,471.3$ \\
\hline
\end{tabular}

\subsubsection{HSRG Solutions}

In this ESU, the HSRG made multiple recommendations to improve the contribution of hatchery programs to both harvest and conservation.

In the case of segregated programs, recommendations are made to improve the ability to control hatchery fish on the spawning grounds so that harvest benefits could be maintained while improving natural-origin spawning abundance and productivity. These recommendations include installing weirs or improvements in hatchery infrastructure on specific drainages where straying limited the ability to meet conservation goals.

Recommendations are also made to move production from some locations with limited terminal harvest access to Select Area Fishery Evaluation areas, where excess hatchery fish could be removed by applying higher harvest rates in those areas. In one location with a Stabilizing population (Little White Salmon), a new harvest program is suggested to increase harvest contribution without affecting conservation goals. In the Klickitat River, recommendations are made to reduce the reliance on imported out-of-basin broodstock and rearing.

For integrated programs in the ESU, the HSRG recommendations generally increase the proportion of natural-origin fish in hatchery broodstocks and control the contribution of hatchery-origin fish to natural spawning areas in order to improve natural-origin spawning abundance and productivity. In some cases, meeting the criteria for the population designation requires reducing program size (e.g., Toutle, Cowlitz and North Fork Lewis rivers). In two instances (Lower Cowlitz and Washougal rivers), harvest benefits could be maintained and conservation improved by developing highly integrated conservation programs with associated segregated harvest programs (stepping-stone programs). More emphasis on monitoring and evaluation programs to accurately estimate straying is also recommended.

In the HSRG solution, total hatchery production in the ESU is reduced from approximately 17 million coho salmon to approximately 14 million fish, a reduction of about 20 percent. Production from segregated programs is reduced by approximately 5.0 


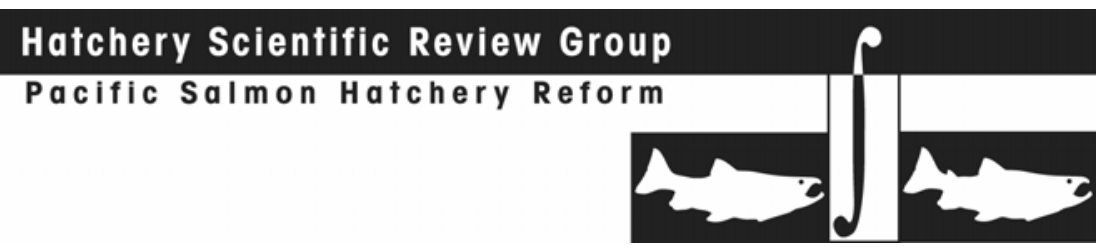

million fish, while production from integrated programs is increased by approximately 1.5 million fish.

The HSRG also evaluated how harvest changes could improve population viability and productivity, while maintaining or improving harvest. For its solution, the HSRG recommends increasing harvest rates on hatchery-origin fish in both marine and lower mainstem Columbia River fisheries. It also recommends reducing harvest on naturalorigin fish in the lower mainstem fishery by increasing the use of selective gears. To implement HSRG solutions, increased selective harvest in terminal areas is also necessary. Specific harvest rates in the HSRG solution can be found the individual population reports (Appendix E).

The HSRG also suggests managers consider population designations identified in Table 1 as the Lower Columbia Coho Recovery Plan is developed. The HSRG suggested designations differ from those in the 2004 preliminary plan for some populations where the available habitat appears to be inconsistent with the population goal.

\section{Conservation Outcomes under the HSRG Solutions}

Figure 1 compares the proportion of hatchery-origin fish on the spawning grounds (pHOS) and the proportionate natural influence (PNI) for current and proposed (HSRG) scenarios for designated Primary populations. Under current conditions, only four Primary populations meet the hatchery influence criteria for this designation and one Contributing population meets Primary population standards.

Under the HSRG solution, eight populations (Table 1) designated as Primary meet the hatchery influence criteria for this designation. Two (Big Creek and Scappoose Creek) are consistent with designations as Stabilizing populations. Two populations (MillAbernathy-Germany Creek and Upper Cowlitz) designated as Contributing in the recovery plan, meet the hatchery influence criteria for Primary populations; therefore, the HSRG recommends that recovery planners adopt this designation in their plan. Similarly, the HSRG recommends that the North Fork Lewis River Early Type-S population be designated as Primary by recovery planners. The solution does not improve the hatchery influence for the remaining two Primary populations beyond their current status as Stabilizing populations.

Also shown in Figure 1 for the current and proposed (HSRG) scenarios are results for Contributing populations. Under current conditions, two of the populations designated as Contributing in the recovery plan meet those criteria for hatchery influence. Under the HSRG solution, two of the populations designated as Contributing meet the hatchery influence criteria for this designation. One population designated as Stabilizing (Clatskanie River) meets the hatchery influence criteria for a Contributing population and one Stabilizing population (North Fork Lewis River Early Type-S) meets the criteria for a Primary population. The HSRG recommends that recovery planners consider adopting these designations. The solution does not improve the hatchery influence for the remaining three Contributing populations beyond their current status as Stabilizing populations.

Figure 2 compares spawner abundance and productivity relationships between current and HSRG-proposed scenarios for the Primary and Contributing coho populations. For Primary populations, productivity increases significantly in seven of the ten populations, 
with an average increase across all populations of approximately 40 percent. In two of the populations, productivity under the HSRG solution is nearly double that of the current levels. For Contributing populations, productivity increases significantly in three of the populations and averages approximately 30 percent over all populations.

For Primary populations, the number of natural-origin spawners under the HSRG solution increases in four of the populations by an average of about 25 percent above the current condition. For Contributing populations, the HSRG's solution increases the number of natural-origin spawners in only one population, although other factors contributed to an average increase across populations of approximately 6 percent above current conditions. This limited increase in natural-origin spawners, despite increased productivity for Contributing populations, is primarily due to limited habitat capacity for these populations. Making significant improvements in abundance will require habitat improvements along with the solutions suggested by the HSRG. For the combined Primary and Contributing populations across the ESU, the HSRG solution has the potential to increase natural-origin spawning by approximately 4,000 fish.

\section{Harvest Outcomes under the HSRG Solutions}

Figure 3 describes current and estimated changes in harvest (marine, mainstem Columbia River and terminal areas) that could occur following implementation of the management solutions proposed by the HSRG.

Compared to the current condition, the total ocean, mainstem Columbia River, and terminal area harvest increases by approximately 20 percent under the HSRG solution, while still improving the conservation status of some populations. Distribution in fisheries remains relatively unchanged, with a slightly higher increase in ocean and mainstem fisheries resulting from increased selective harvest. 


\section{Hatchery Scientific Review Group}

Pacific Salmon Hatchery Reform
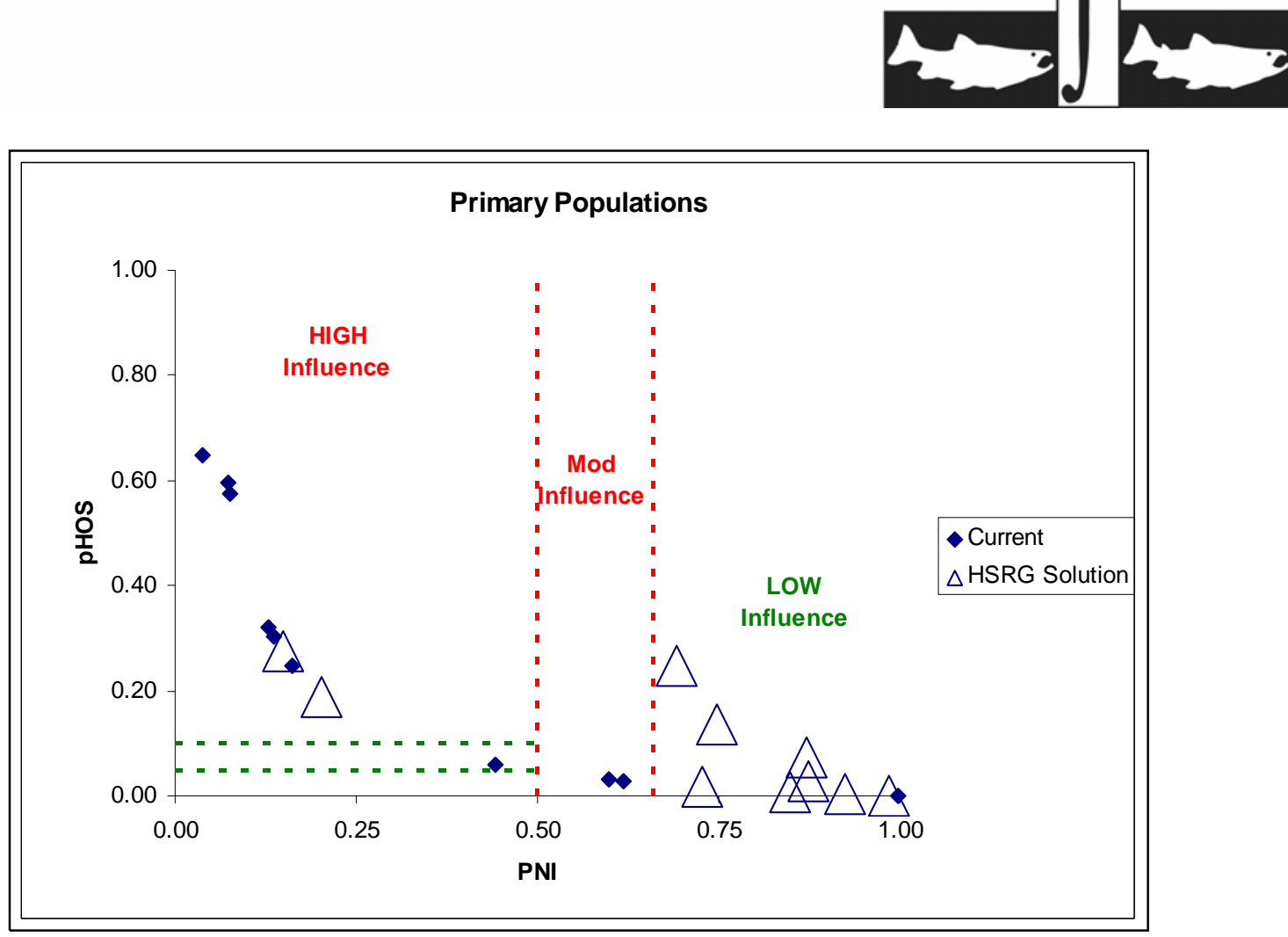

Contributing Populations

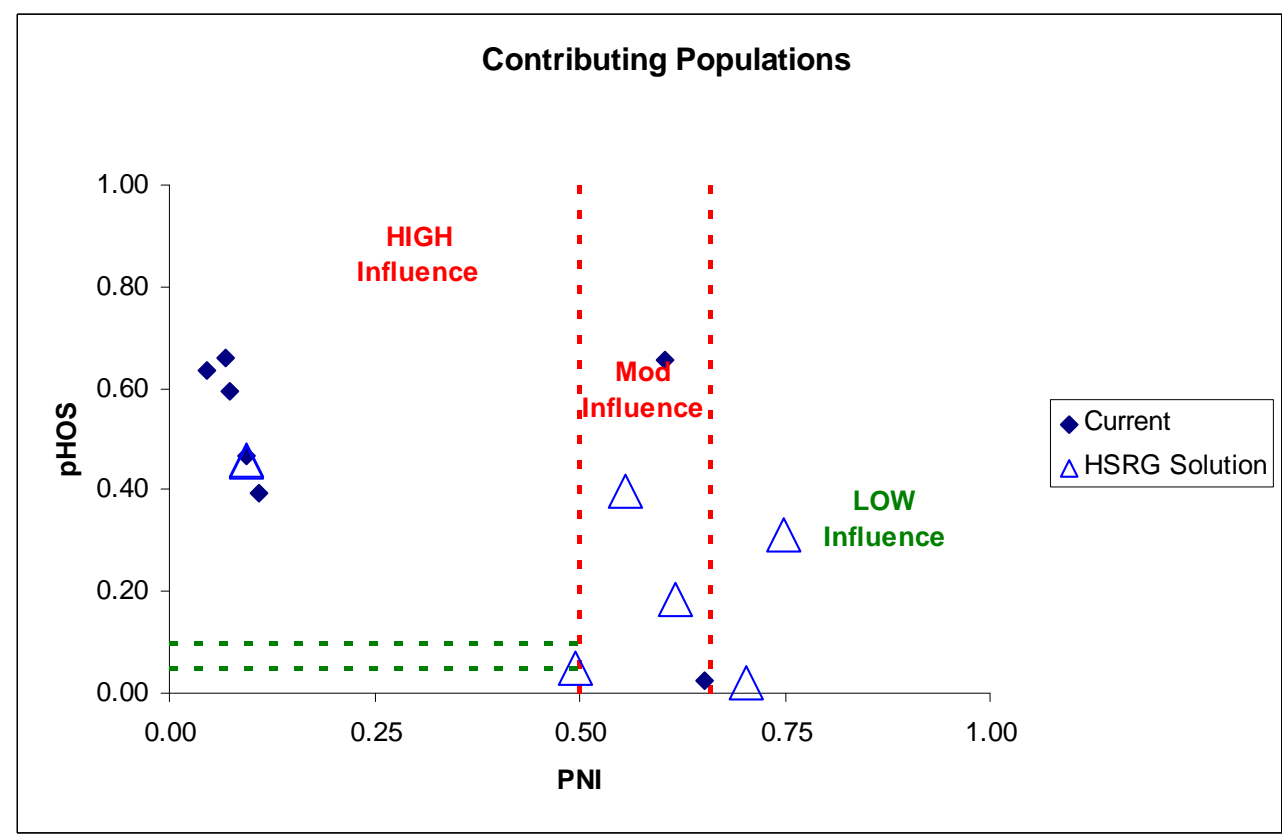

Figure 1. Relationship of the proportion of the fish on the spawning grounds that are of hatchery origin (pHOS) and the proportionate natural influence index (PNI) for Primary (top panel) and Contributing (bottom panel) coho populations in the Lower Columbia River ESU. Solid diamonds represent values for current programs and open triangles represent values for the HSRG recommended hatchery management solution. 

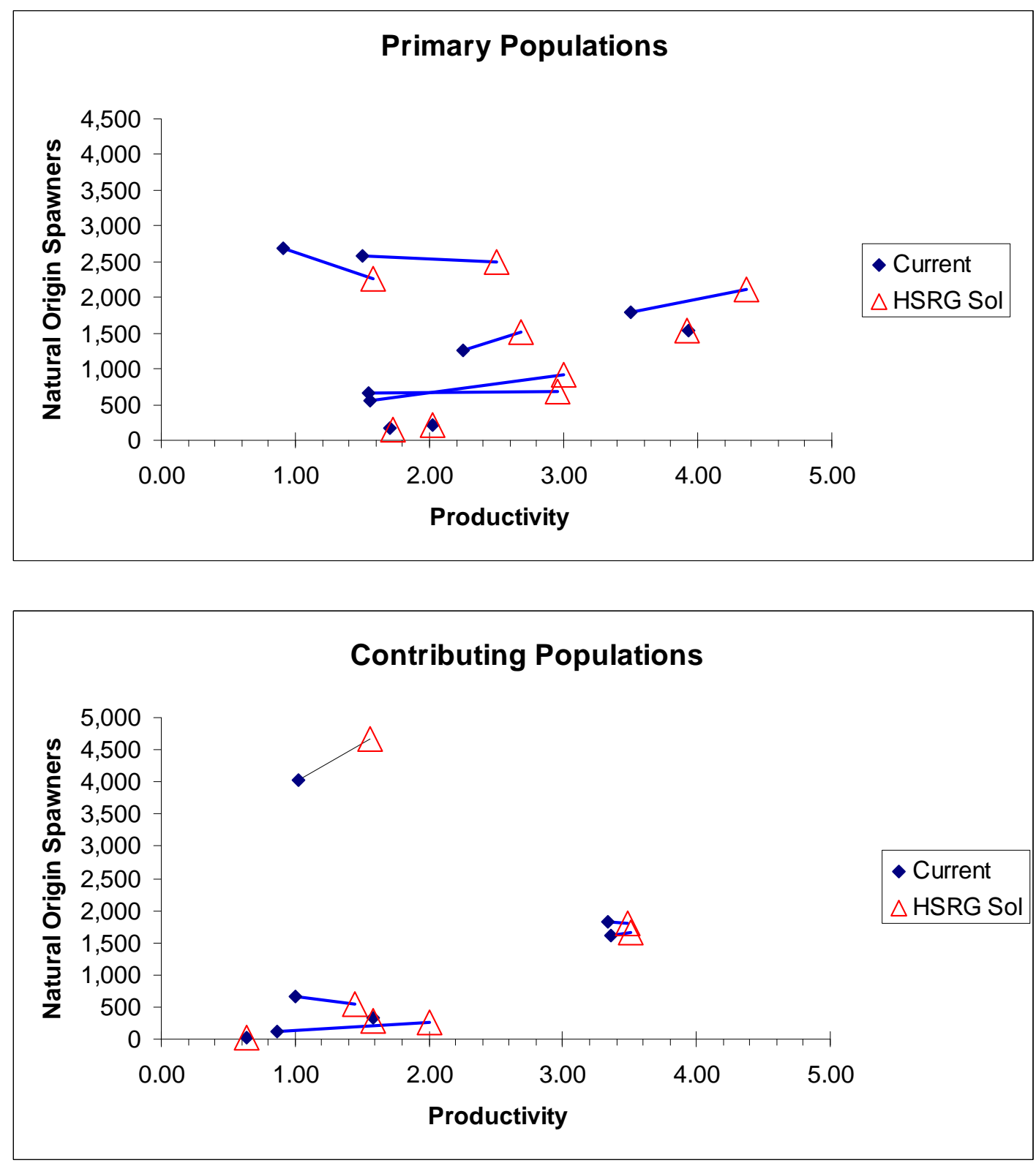

Figure 2. Productivity and spawner abundance for Primary (top panel) and Contributing (bottom panel) coho populations in the Lower Columbia River ESU. Solid diamonds represent existing productivity and spawner abundance levels, and triangles represent the HSRG recommended hatchery management solution. Lines connect current with HSRG solution for a particular population. 


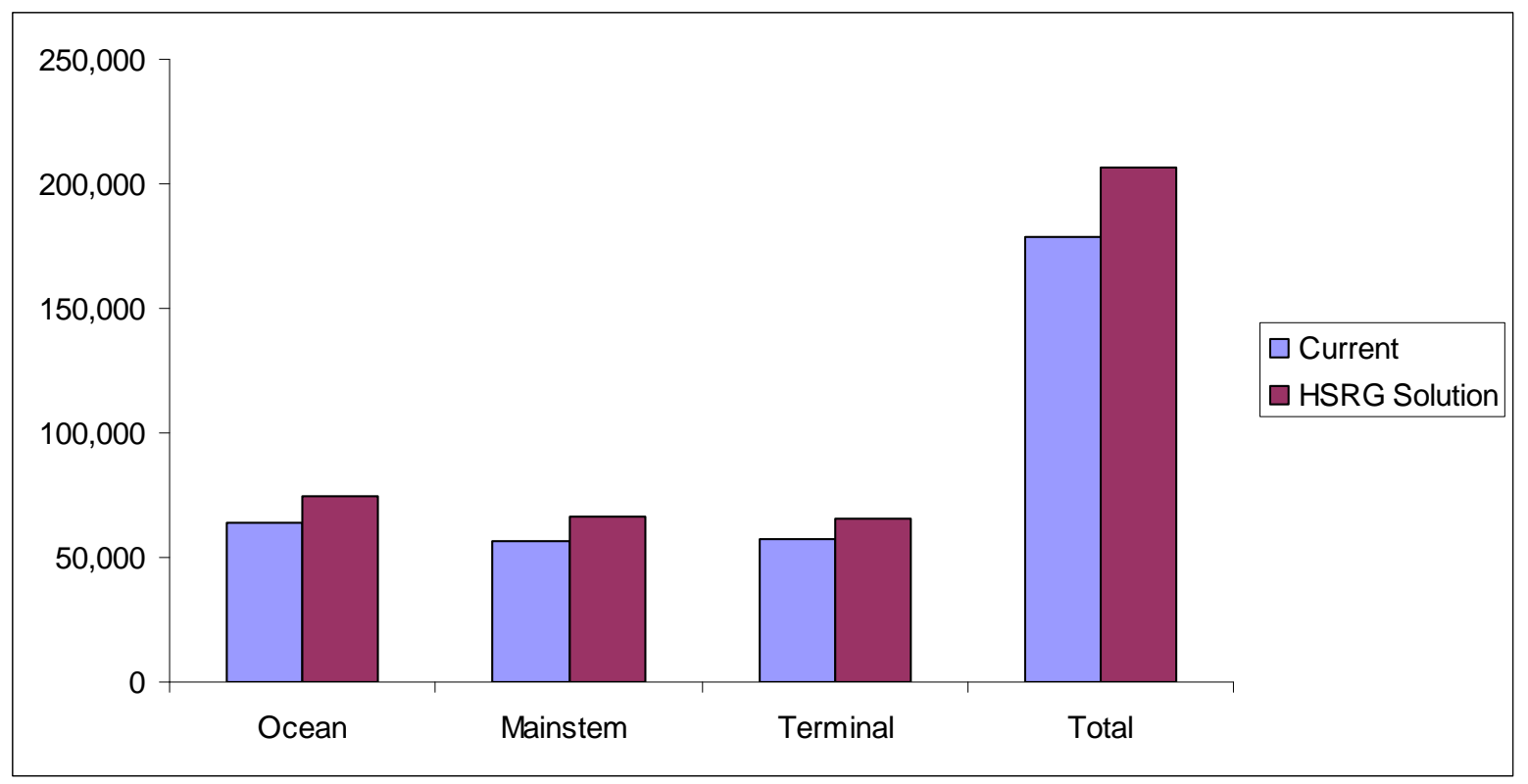

Figure 3. Estimated marine, mainstem Columbia, and terminal harvest under current and HSRG recommended hatchery management solution for Lower Columbia River Coho ESU.

\section{Summary and Conclusions}

In order to achieve conservation goals, it is recommended that managers implement both hatchery and harvest reforms. This will require implementing effective integrated or segregated hatchery broodstock protocols to achieve the standards described by the HSRG. For segregated programs, this means limiting the number of hatchery-origin fish spawning naturally. In some cases this will require nearly total exclusion of hatchery fish from natural populations through use of weirs or a combination of weirs and selective harvest. For integrated programs, this means including the appropriate number of natural-origin fish in hatchery broodstock as well as controlling the contribution of hatchery fish to natural spawning areas. Hatchery infrastructure modifications will be needed to accomplish this. New or improved weirs for broodstock and escapement management are recommended in the Toutle, Elochoman and Grays rivers, and in Abernathy Creek. Implementing these reforms in the Lower Columbia Coho ESU increases productivity and abundance of natural populations and can maintain harvest at current levels.

Expanding selective harvest in marine and lower Columbia River areas and moving some production to terminal Select Area Fishery sites would allow an increase in harvest despite a 20 percent reduction in total hatchery releases. Developing commercial harvest methods and gear that enable selective removal of hatchery fish with low mortality to natural fish will be required to achieve these harvest benefits. Maintaining harvest levels in this ESU also requires increasing the availability and harvest of fish where they are spatially and temporally segregated from natural populations (i.e., Select Area Fishery sites). Without increasing selective fisheries, solutions to meet conservation goals will require reducing hatchery production and catch. 


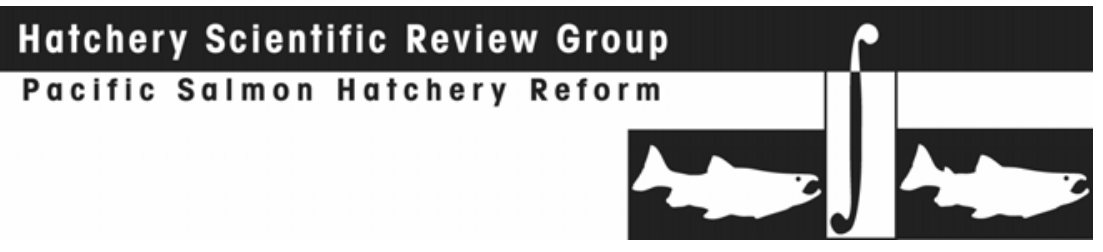

The HSRG also concluded that the effectiveness of habitat actions will be greatly increased if combined with hatchery and harvest reforms. Analysis of the Primary populations in the Lower Columbia Coho ESU suggests that the benefits of habitat improvements would more than double if combined with hatchery reforms. Unless hatchery and harvest reforms are implemented, the potential benefits of current or improved habitat cannot be fully realized.

\subsubsection{Upper Columbia River Coho Salmon}

This section provides an overview of Upper Columbia River Coho Salmon. It contains a general description of the area, fisheries, habitat limitations and hatchery programs that affect it. Overall recommendations for Upper Columbia River coho hatchery program changes are summarized, as are the results of implementing those changes on conservation and harvest goals. Detailed conclusions and recommendations for each population can be found in the Appendix E.

\subsubsection{HSRG Population Guidelines}

In order to meet conservations goals, numerous threats to these populations need to be addressed, including risks from hatchery programs. The key to controlling genetic and ecological risks due to straying and fitness loss is to manage hatchery broodstock and natural spawning escapement such that the natural habitat (and not the hatchery environment) drives the adaptation and productivity of the naturally spawning population. This is achieved by operating either (a) integrated programs where the proportion of natural-origin adults in the broodstock exceeds the proportion of hatcheryorigin fish on the spawning grounds ( $\mathrm{pNOB}>\mathrm{pHOS})$; or (b) segregated programs where the contribution of hatchery fish to natural spawning is kept low (pHOS $<5 \%$ to $<10 \%$ depending on population designation). The HSRG developed criteria for hatchery influence for three population types based on the importance of the population to the recovery of the species. This was done to provide a consistent method of reviewing populations and programs across the Columbia River Basin. The population designations used by the HSRG (Primary, Contributing, or Stabilizing) were adopted after discussions with managers and followed those developed in the Lower Columbia River Salmon Recovery Plan (LCFRB 2004). These designations are meant to reflect the conservation importance of a population within the region from most important (Primary), to moderately important (Contributing), to least important (Stabilizing). HSRG recommendations show how hatchery programs can be operated consistent with these designations based on the following standards:

\section{HSRG criteria for hatchery influence on Primary populations:}

- For segregated programs, the proportion of effective hatchery-origin spawners on the spawning grounds (pHOS) should be less than $5 \%$ of the naturally spawning population.

- For integrated populations, the proportion of natural-origin adults in the broodstock (pNOB) should exceed pHOS by at least a factor of two, corresponding to a proportionate natural influence (PNI) value of 0.67 or greater and pHOS levels should be no greater than $30 \%$. 


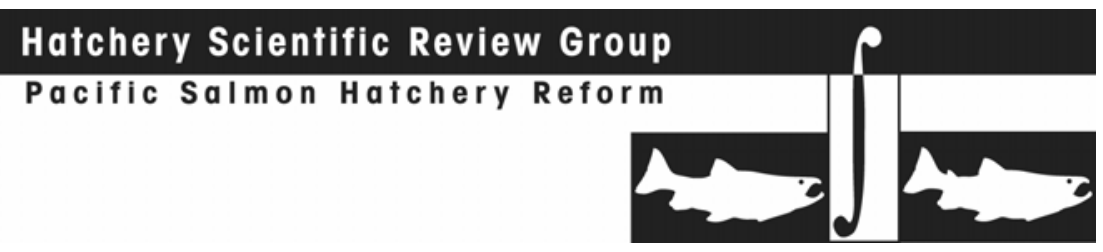

HSRG criteria for hatchery influence on Contributing populations:

- For segregated programs, the proportion of effective hatchery-origin spawners on the spawning grounds (pHOS) should be less than $10 \%$ of the naturally spawning population.

- For integrated populations, the proportion of natural-origin adults in the broodstock (pNOB) should exceed pHOS, corresponding to a PNI value of 0.50 or greater and pHOS should be less than 0.30 .

HSRG criteria for hatchery influence on Stabilizing populations:

- The current operating conditions were considered adequate to meet conservation goals. No criteria were developed for proportion of effective hatchery-origin spawners (pHOS) or PNI.

\subsubsection{Current Conditions}

\section{Conservation}

There are five coho populations in the Upper Columbia River Basin, including coho from the Clearwater, Methow, Umatilla, Wenatchee and Yakima rivers. These populations have not been defined formally by Endangered Species Act petitions or listings because these populations are derived from reintroduced non-native stocks. All of the historic populations of coho in the Upper Columbia River Basin are now extinct. Because all of these populations are considered extinct and are subject to reintroduction efforts, the HSRG designated all populations as Stabilizing (Table 1).

Table 1. Upper Columbia River coho population designations and HSRG broodstock criteria achieved for each population under current condition and the HSRG recommended hatchery management solution.

\begin{tabular}{|l|c|c|c|}
\hline \multirow{2}{*}{ Population } & \multirow{2}{*}{ Designation $^{1}$} & \multicolumn{2}{|c|}{ HSRG ${\text { Criteria } \text { Met }^{2}}^{2}$} \\
\cline { 3 - 4 } & Current & HSRG Solution \\
\hline Umatilla Coho & Stabilizing & Stabilizing & Stabilizing \\
\hline Yakima_Upper Yakima-Naches Coho & Stabilizing & Stabilizing & Contributing \\
\hline Wenatchee Coho & Stabilizing & Stabilizing & Stabilizing \\
\hline Methow Coho & Stabilizing & Stabilizing & Stabilizing \\
\hline Clearwater Coho & Stabilizing & Stabilizing & Stabilizing \\
\hline
\end{tabular}

1 Using the naming protocol of the Upper Columbia River Salmon Recovery Plan (LCFRB 2004), populations were classified based on information provided to the HSRG as Primary, Contributing, or Stabilizing. These designations are meant to reflect the conservation importance of a population from most important (Primary- bold, red), to moderately important (Contributing-bold, blue), to least important (Stabilizing).

2 The HSRG developed criteria for hatchery influence for the three population designations from low influence (Primary), moderate influence (Contributing) to high influence (Stabilizing).

\section{Current Harvest}

Upper Columbia River coho are commercially harvested in non-selective ocean fisheries and non-Treaty fisheries in the mainstem Columbia River below Bonneville Dam.

Recreational fisheries are selective and target marked hatchery fish. Until 1993 the total 


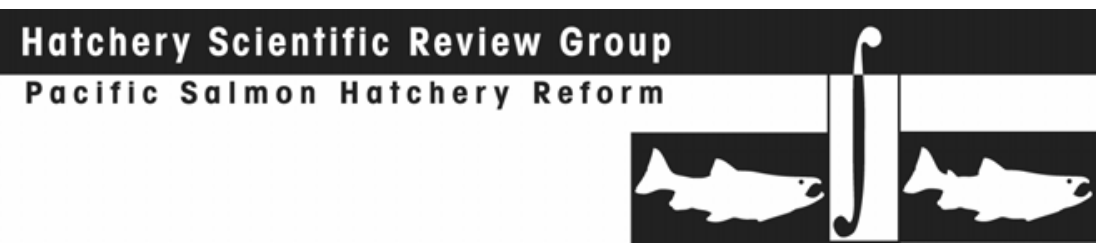

exploitation rates for Lower Columbia River coho fisheries were very high, fluctuating from approximately 60 to 90 percent, but rates have been reduced to 15 to 25 percent since ESA listing of lower Columbia coho according to year-specific circumstances (LCRRB 2004, NMFS 2008e). The terminal fishery on Yakima coho is estimated at 1 percent by Yakama Nation biologists. The overall goal for all populations is to produce naturally self-sustaining populations that can expand harvest opportunities for tribal and non-tribal fisheries.

\section{Current Habitat}

The quality of coho habitat in the upper Columbia varies from highly degraded to poor quality. Mainstem Columbia River dams disrupt migration corridors and affect flow regimes and estuarine habitat (Myers et al. 1998). Within the range of the Upper Columbia River Coho, spawning and rearing habitat has been reduced by agriculture including water withdrawals, grazing, and riparian vegetation management. Diking to increase and protect farmland and developed land has depleted off-channel habitat, which is particularly important to coho salmon. Forestry and logging practices have increased erosion and sedimentation of spawning and rearing habitat.

\section{Current Hatchery Programs}

Currently there are four integrated coho programs operating in the Upper Columbia River (Clearwater, Methow, Wenatchee, and Upper Yakima-Naches) that release approximately 2.9 million hatchery coho smolts per year (Table 2). Two segregated programs (Umatilla and Yakima) release approximately 2 million smolts annually. Hatchery fish do not affect native local runs of coho because the native populations are all extirpated.

All of the coho populations in Upper Columbia River are derived from hatchery fish reintroductions using non-native stocks. Estimates of PNI and pHOS under current conditions show that none of the populations meet the broodstock criteria for either Primary or Contributing populations, but are only consistent with the HSRG population designation for Stabilizing populations (Table 1). 

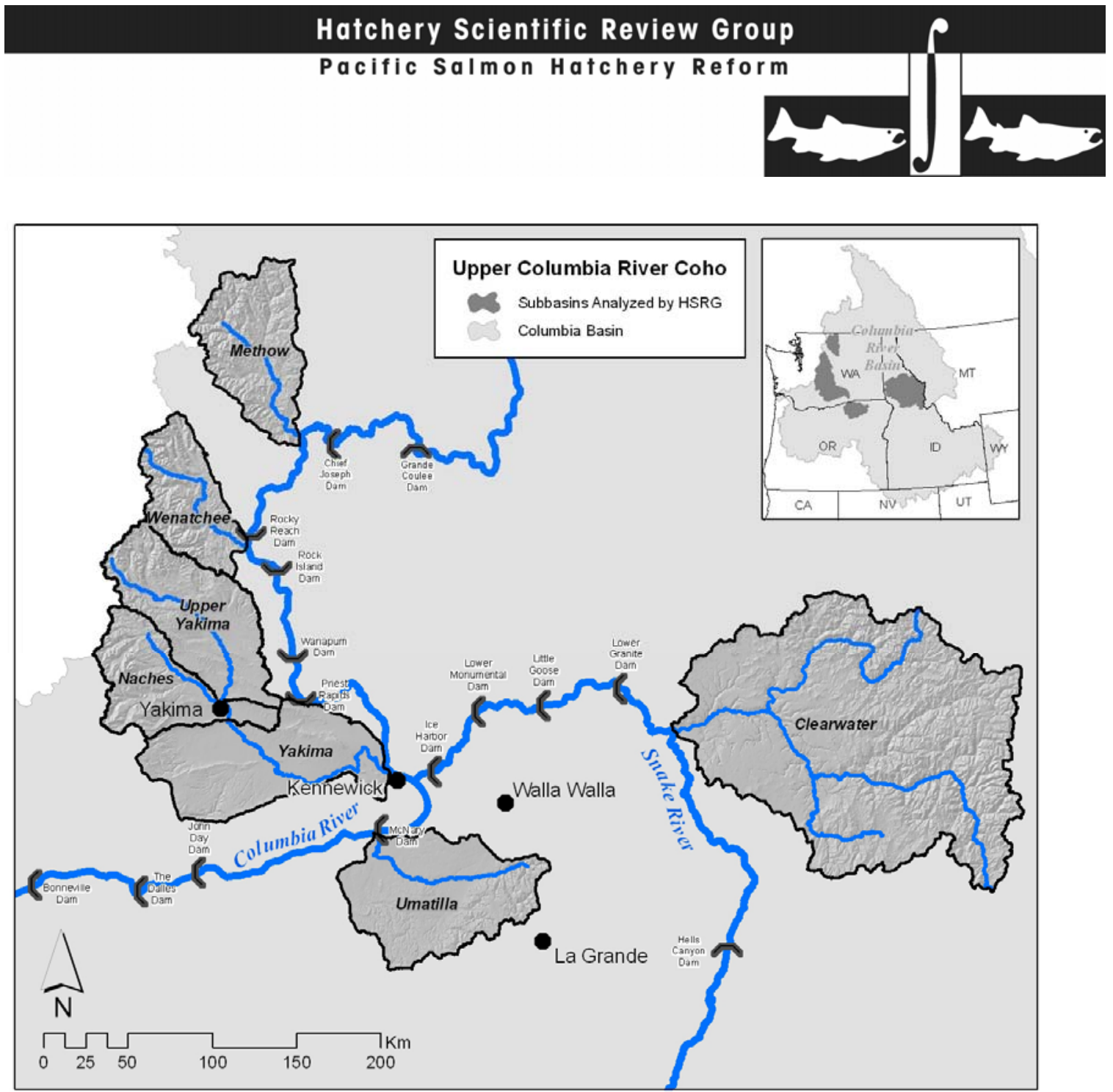

Table 2. Hatchery releases and types of programs for Upper Columbia River Coho.

\begin{tabular}{|l|c|c|c|c|c|c|}
\hline \multirow{2}{*}{ Population/Program Name } & \multicolumn{3}{|c|}{ Current (1,000s) } & \multicolumn{3}{c|}{ HSRG Solution (1,000s) } \\
\cline { 2 - 7 } & Type & Purpose & \# Released & Type & Purpose & \# Released \\
\hline Umatilla Coho & None & NA & - & None & NA & - \\
\hline Umatilla Coho (Bonneville-Cascade-Oxbow-Hatchery) & Seg & Both & $1,530.0$ & Seg & Both & $1,530.0$ \\
\hline Yakima-Upper Yakima-Naches Coho & Int & Cons & 452.1 & Int & Cons & 452.1 \\
\hline Yakima-Coho (Hatchery) & Seg & Harv & 427.9 & Seg & Harv & 427.9 \\
\hline Wenatchee Coho & Int & Cons & $1,048.0$ & Int & Cons & $1,048.0$ \\
\hline Methow Coho & Int & Cons & 495.4 & Int & Cons & 495.4 \\
\hline Clearwater Coho & Int & Cons & 833.9 & Int & Cons & 830.1 \\
\hline Total all Populations/Programs & & & $\mathbf{4 , 7 8 7 . 3}$ & & & $\mathbf{4 , 7 8 3 . 5}$ \\
\hline
\end{tabular}




\subsubsection{HSRG Solutions}

Most of the HSRG solutions involve recommendations to improve broodstock management in segregated and integrated programs and to transition the reintroduction programs to allow local adaptation in hatchery and natural populations. Local adaptation in hatchery programs could be improved by reducing the reliance on out-of-basin hatchery returns and collecting hatchery broodstock locally. Improvements could be made in the reintroduction program in the Yakima River by increasing the proportion of natural-origin broodstock (pNOB) in the conservation program. Additionally the HSRG recommendations include increasing marking of hatchery fish to allow monitoring of hatchery composition on the spawning grounds and to provide additional harvest access. Recommendations are also made to begin or reestablish monitoring and evaluation programs.

\section{Conservation Outcomes from HSRG Solution}

Currently there are no Primary or Contributing populations in the Upper Columbia River; however, the HSRG solution improves the status of one of the currently Stabilizing populations (Yakima River) so that this population meets the HSRG criteria for a Contributing population. Because the remaining reintroduction programs (Umatilla, Wenatchee, Methow and Clearwater rivers) are in different phases of their development, the HSRG recommendations focused on developing local hatchery broodstocks as a first step. This change would not be expected to show any difference in hatchery influence until the programs transition to collection of natural-origin broodstock.

Improvements in broodstock management in the Yakima River lead to a greater than 30 percent improvement in productivity in this population. Improvements in productivity in the other populations would be expected once they can reduce the proportion of hatchery fish spawning naturally and transition to better integrated programs.

\section{Harvest Outcomes}

Figure 1 describes current and estimated changes in harvest (marine, mainstem Columbia River and terminal harvest areas) that would occur following implementation of the management solutions proposed by the HSRG. In this case, total harvest as well as ocean and terminal area harvest increases by a total of approximately 30 percent. This is primarily due to increased marking and expanded selective harvest on hatchery fish.

\section{Hatchery Program Changes under HSRG Solution}

Table 2 shows the current size of each hatchery program as well as their size under the HSRG solution. The total number of smolts released under the HSRG solution remains the same as current programs (approximately 4.8 million fish). HSRG recommendations focus on transitioning the reintroduction programs to area-specific broodstock to allow local adaptation of hatchery and natural populations. 


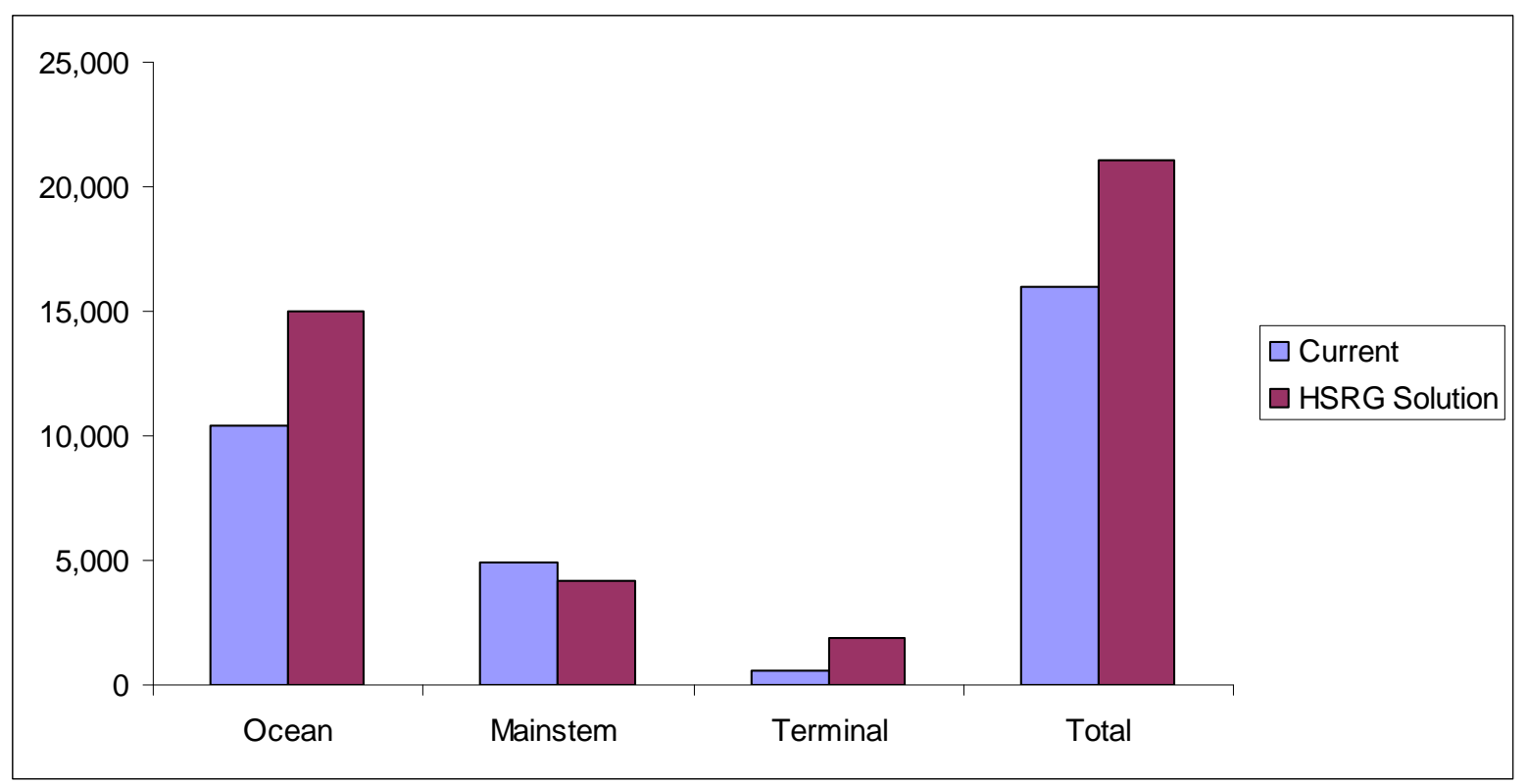

Figure 1. Estimated marine, mainstem Columbia, and terminal harvest under current and HSRG recommended hatchery management solution for Upper Columbia River Coho.

\section{Summary and Conclusions}

The purpose of these hatchery programs is to reintroduce coho back into historic habitat to meet conservation and harvest goals. The reintroduction programs are in various states of implementation, but all would benefit by promoting local adaptation of hatchery and natural spawning populations. Implementing the HSRG recommendations would improve the status of one population (Yakima River) to meet the standards of a Contributing population and would promote local adaptation in the remaining programs. Monitoring and evaluation of some of the programs needs to be improved and this can be assisted by increasing the marking of hatchery fish. This will also lead to improved harvest benefits by making these previously unmarked fish identifiable for harvest. 


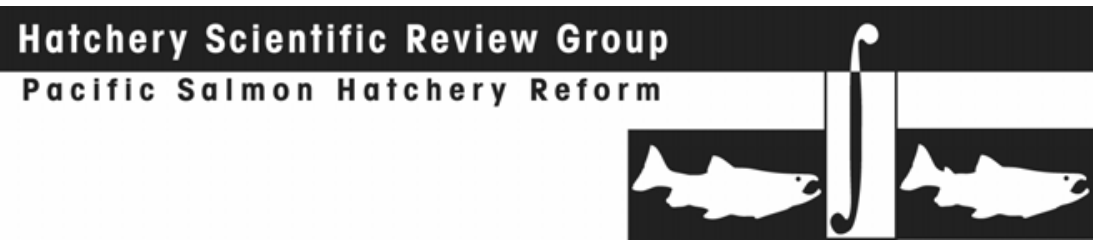

\subsection{Chum ESU}

\subsubsection{Lower Columbia River Chum ESU}

This section provides an overview of the Columbia River Chum ESU. It contains a general description of the ESU, fisheries, habitat limitations and hatchery programs that affect it. Overall recommendations for ESU-wide hatchery program changes are summarized as are the results of implementing these changes on conservation and harvest goals. Detailed conclusions and recommendations for each population in the ESU can be found in Appendix E. Populations in this ESU extend from the Grays and Chinook rivers near the estuary, upstream to tributaries in the Columbia River Gorge, Hood and Wind rivers, and Fifteenmile Creek.

\subsubsection{HSRG Population Guidelines}

In order to meet conservations goals for the ESU, numerous threats to these populations need to be addressed, including risks from hatchery programs. The key to controlling genetic and ecological risks due to straying and fitness loss is to manage hatchery broodstock and natural spawning escapement such that the natural habitat (and not the hatchery environment) drives the adaptation and productivity of the naturally spawning population. This is achieved by operating either (a) integrated programs where the proportion of natural-origin adults in the broodstock (pNOB) exceeds the proportion of hatchery-origin fish on the spawning grounds (pHOS); or (b) segregated programs where the contribution of hatchery fish to natural spawning is kept low (pHOS $<5 \%$ to $<10 \%$ depending on the population designation). The HSRG developed criteria for hatchery influence for three population types based on the importance of the population to the recovery of the ESU. This was done to provide a consistent method of reviewing populations and programs across the Columbia River Basin. The population designations used by the HSRG (Primary, Contributing, or Stabilizing) were adopted after discussions with managers and followed those developed in the Lower Columbia River Salmon Recovery Plan (LCFRB 2004). These designations are meant to reflect the conservation importance of a population within the ESU from most important (Primary), to moderately important (Contributing), to least important (Stabilizing). HSRG recommendations show how hatchery programs can be operated consistent with these designations based on the following standards:

\section{HSRG criteria for hatchery influence on Primary populations}

- The proportion of effective hatchery-origin spawners (pHOS) should be less than 5\% of the naturally spawning population, unless the hatchery population is integrated with the natural population.

- For integrated populations, the proportion of natural-origin adults in the broodstock should exceed pHOS by at least a factor of two, corresponding to a proportionate natural influence (PNI) value of 0.67 or greater and pHOS should be less than 0.30 . 
HSRG criteria for hatchery influence on Contributing populations

- The proportion of effective hatchery-origin spawners (pHOS) should be less than $10 \%$ of the naturally spawning population, unless the hatchery population is integrated with the natural population.

- For integrated populations, the proportion of natural-origin adults in the broodstock should exceed pHOS, corresponding to a PNI value of 0.50 or greater and $\mathrm{pHOS}$ should be less than 0.30 .

HSRG criteria for hatchery influence on Stabilizing populations

- The current operating conditions were considered adequate to meet conservation goals. No criteria were developed for proportion of effective hatchery-origin spawners (pHOS) or PNI.

\subsubsection{Current Conditions}

\section{Conservation}

The Columbia River chum salmon ESU was originally listed as endangered in 1999 under the Endangered Species Act. The ESU includes all naturally-spawned populations of chum salmon in the Columbia River and its tributaries as well as one current artificial propagation program. There were 16 historical populations in three major population groups (MPGs) in Oregon and Washington between the mouth of the Columbia River and the Cascade crest. Most populations (88 percent) in this ESU are extirpated or nearly so (NMFS 2008e). Core populations include Grays, Elochoman, Youngs Bay, Big Creek, Cowlitz, Lewis, Clackamas, and the Lower Gorge. Grays and Lower Gorge are both genetic legacy populations (NMFS 2005b, Myers et al. 2006). For the purposes of the HSRG analysis, 17 populations were identified, including all the populations from the TRT/Lower Columbia River Recovery Plan plus the Columbia Estuary Chum identified by the HSRG (Table 1). The risk of extinction is "high" or "very high" for all populations except the Washington portion of the Lower Gorge. The Upper Gorge population, and all four populations on the Oregon side of the Columbia in the Coastal MPG, are extirpated or nearly so (McElhany et al. 2007).

The managers' objectives for chum are primarily focused on conservation. While there are no current harvest goals or expectations for chum salmon, there is concern about the effects of incidental harvest of chum salmon in commercial coho fisheries.

For the purposes of this review, the HSRG defined eight populations as Primary, seven as Contributing, and two as Stabilizing (Table 1). 
Table 1. Population designations for the Lower Columbia River Chum ESU and HSRG broodstock criteria achieved for each population under current conditions and the HSRG recommended hatchery management solution.

\begin{tabular}{|l|c|c|c|}
\hline \multirow{2}{*}{ Population } & \multirow{2}{*}{ Designation $^{1}$} & \multicolumn{2}{|c|}{ HSRG Criteria Met ${ }^{2}$} \\
\cline { 3 - 4 } & Current & HSRG Solution \\
\hline Columbia Estuary: Grays-Chinook River Chum & Primary & Stabilizing & Contributing \\
\hline Columbia Estuary: Mill-Aber-Germ Chum & Primary & Primary & Primary \\
\hline Columbia Estuary-Youngs Bay Tribs Chum & Primary & Contributing & Contributing \\
\hline Elochoman Chum & Primary & Primary & Primary \\
\hline Lewis Chum & Primary & Primary & Primary \\
\hline Lower Columbia-Duncan Creek Chum & Primary & Contributing & Primary \\
\hline Sandy Chum & Primary & Stabilizing & Contributing \\
\hline Washougal Chum & Primary & Primary & Primary \\
\hline Columbia Estuary-Big Creek Chum & Contributing & Stabilizing & Stabilizing \\
\hline Columbia Estuary-Clatskanie Creek Chum & Contributing & Stabilizing & Stabilizing \\
\hline Cowlitz Chum & Contributing & Primary & Contributing \\
\hline Kalama Chum & Contributing & Primary & Stabilizing \\
\hline Willamette-Clackamas Chum & Contributing & Primary & Primary \\
\hline Columbia Gorge-Tributaries Chum (Lower Gorge) & Contributing & Primary & Primary \\
\hline Columbia Gorge-Tributaries Chum (Upper Gorge) & Contributing & Primary & Primary \\
\hline Columbia Estuary-Chum (Sea Resources) & Stabilizing & Primary & Stabilizing \\
\hline Salmon Creek Chum & Stabilizing & Contributing & Stabilizing \\
\hline
\end{tabular}

1 Using the naming protocol of the Lower Columbia River Salmon Recovery Plan (LCFRB 2004), populations were classified based on information provided to the HSRG as Primary, Contributing, or Stabilizing. These designations are meant to reflect the conservation importance of a population within the ESU from most important (Primary- bold, red), to moderately important (Contributing-bold, blue), to least important (Stabilizing).

2 The HSRG developed criteria for hatchery influence for the three population designations from low influence (Primary), moderate influence (Contributing) to high influence (Stabilizing).

\section{Current Harvest}

Due to severe population declines, commercial chum salmon fisheries have been closed. Harvest of chum salmon is incidental, occurring primarily in the lower Columbia River commercial coho fishery. Sport harvest of chum in the Columbia and tributaries has been closed since 1992 in Oregon and since 1995 in Washington. The presumption is that chum salmon are not harvested in the ocean or in the Columbia River above Bonneville Dam. Fishery managers set a five percent maximum incidental harvest mortality on Columbia River chum. Recent harvest rates are reported to have averaged about 1.6 percent annually (FCRPS 2008).

\section{Current Habitat}

Widespread development and land use activities have severely degraded stream habitats, water quality, and watershed processes affecting anadromous salmonids in most lower Columbia River subbasins, particularly in the low to moderate elevation habitats most often used by chum. In the lower Columbia River and its tributaries, major factors affecting chum survival are altered channel morphology and stability; lost/degraded 
floodplain connectivity; loss of habitat diversity; excessive sediment; degraded water quality; increased stream temperatures; reduced stream flow; and reduced access to spawning and rearing areas (LCFRB 2004, ODFW 2006, PCSRF 2006). Another important factor has been the inundation of historical spawning areas by reservoirs in all three MPGs. In the Coastal MPG, tide gates, dikes, culverts, and hatchery weirs all impede passage of chum salmon. The Bonneville Dam impoundment eliminated mainstem and lower tributary habitat for the Upper Gorge MPG (WLCTRT et al. 2004).

In the Cascade MPG, chum salmon habitat was inundated by Mayfield Lake in the Cowlitz River and by Lake Merwin in the North Fork Lewis River. The Cowlitz River Project FERC license requires minimum flows to be released from Mayfield Dam to protect chum habitat during spawning, incubation, and emergence, and to implement gravel augmentation projects below the dam (NMFS 2004a). The Lewis River Project FERC licenses stipulate that PacifiCorp may fund projects to benefit chum salmon (NMFS 2007a).

The HSRG notes that 13 of 16 historical populations of Columbia River chum salmon are severely depressed even though Washington's Lower Columbia River Recovery Plan indicates habitat is available to support much larger populations. Under current habitat conditions, managers estimate an ESU abundance of 24,000 chum salmon can be supported. With habitat improvements to tributaries, much larger populations of chum salmon are possible (LCFRB 2004).

Hatchery Programs

Two artificial propagation programs produced chum in recent years, but one has recently ended (Duncan Creek). The currently operated program is designed to augment natural production in the Grays River and to reintroduce chum to the Chinook River. These are integrated programs that release a total of about 299,000 juvenile chum salmon annually (Table 2). Hatchery influence on populations in this ESU is low.

Four of the eight Primary populations currently meet the criteria for this population designation, although abundance is critically low. In addition, a number of the populations designated as Contributing also meet the standards for a Primary population (Table 1).

Table 2. Hatchery releases and types of programs in the Lower Columbia River Chum ESU.

\begin{tabular}{|l|c|c|c|c|c|c|}
\hline \multirow{2}{*}{ Population/Program Name } & \multicolumn{3}{|c|}{ Current (1,000s) } & \multicolumn{3}{c|}{ HSRG Solution (1,000s) } \\
\cline { 2 - 8 } & Type & Purpose & \# Released & Type & Purpose & \# Released \\
\hline Columbia Estuary: Youngs Bay Tribs Chum & None & NA & - & Int & Cons & 96.1 \\
\hline Columbia Estuary: Big Creek Chum & None & NA & - & None & NA & - \\
\hline Columbia Estuary: Chum (Sea Resources) & None & NA & - & Int & Cons & 64.0 \\
\hline Columbia Estuary: Grays-Chinook River Chum & Int & Cons & 200.1 & Int & Cons & 115.3 \\
\hline Columbia Estuary: Mill-Aber-Germ Chum & None & NA & - & Int & Cons & 61.4 \\
\hline Columbia Estuary: Clatskanie Creek Chum & None & NA & - & None & NA & - \\
\hline Elochoman Chum & None & NA & - & Int & Cons & 182.0 \\
\hline Cowlitz Chum & None & NA & - & None & NA & - \\
\hline Kalama Chum & None & NA & - & None & NA & - \\
\hline Willamette-Clackamas Chum & None & NA & - & None & NA & - \\
\hline
\end{tabular}


Hatchery Scientific Review Group

Pacific Salmon Hatchery Reform

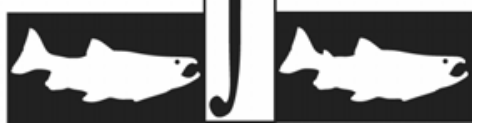

\begin{tabular}{|l|c|c|c|c|c|c|}
\hline \multirow{2}{*}{ Population/Program Name } & \multicolumn{3}{|c|}{ Current (1,000s) } & \multicolumn{3}{c|}{ HSRG Solution (1,000s) } \\
\cline { 2 - 8 } & Type & Purpose & \# Released & Type & Purpose & \# Released \\
\hline Sandy Chum & None & NA & - & Int & Cons & 96.1 \\
\hline Washougal Chum & None & NA & - & Int & Cons & 217.9 \\
\hline Salmon Creek Chum & None & NA & - & None & NA & - \\
\hline Lower Columbia: Duncan Creek Chum & Int & Cons & 99.9 & Int & Cons & 99.9 \\
\hline Lewis Chum & None & NA & - & Int & Cons & 256.4 \\
\hline Columbia Gorge: Tributaries Chum (Lower Gorge) & None & NA & - & None & NA & - \\
\hline Columbia Gorge: Tributaries Chum (Upper Gorge) & None & NA & - & None & NA & - \\
\hline Total all Populations/Programs & & & 299.9 & & & $1,189.0$ \\
\hline
\end{tabular}

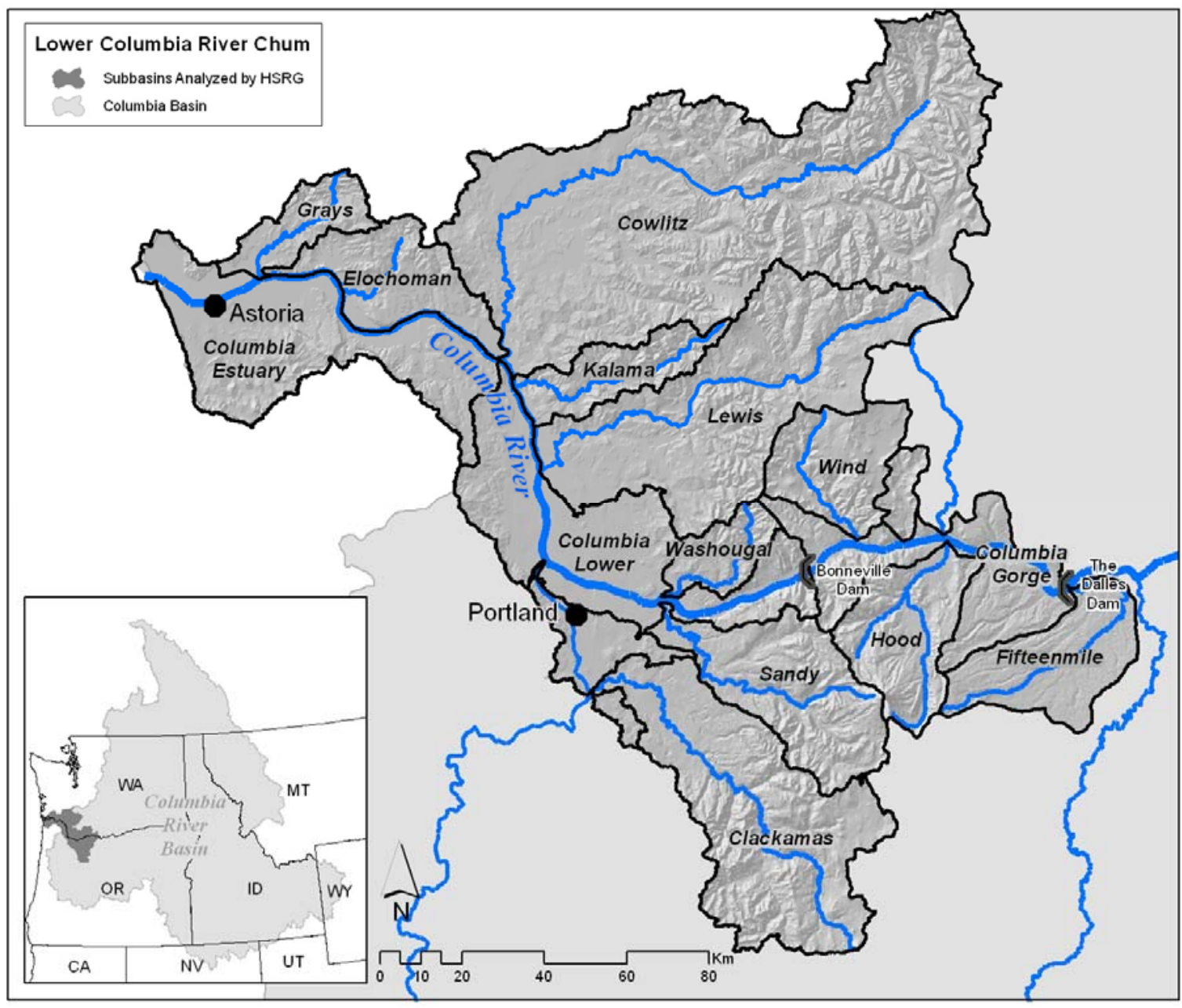




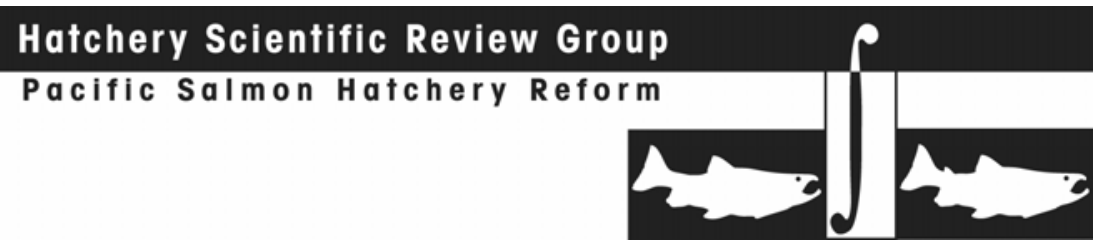

3.3.1.3

HSRG Solutions

Hatchery intervention can reduce demographic risk by boosting abundance. Additional conservation propagation programs should be promptly initiated within each of the ESU's three geographic strata to reduce this risk. Existing and candidate populations for hatchery conservation programs are identified in Table 2. Chum conservation programs can be implemented at existing facilities at modest cost, should be sized at 100,000 to 200,000 fry releases, and last up to three generations. Broodstock should be selected from the target population, or in the case of reintroductions, from the most suitable available population.

\section{Conservation Outcomes under the HSRG Solutions}

Figure 1 compares the proportion of hatchery-origin fish on the spawning grounds (pHOS) and the proportionate natural influence (PNI) for current and proposed (HSRG) scenarios for Primary and Contributing populations. Some reduction in PNI is estimated due to an increase in pHOS, caused by initiating new hatchery programs. These are recommended in order to overcome the high demographic risk associated with critically low abundance for many of these populations. Little or no loss in productivity results from increasing the number of hatchery-origin fish (pHOS) due to the high PNI maintained in the new programs (Figure 2).

\section{Harvest Outcomes under the HSRG Solutions}

None of the hatchery programs (current or proposed) has harvest as an identified goal. While estimated harvest increases slightly under the HSRG solutions, it is based on the current incidental catch rates and does not include any directed harvest (Figure 3).

\section{Hatchery Program Changes under the HSRG Solutions}

The HSRG had no recommendations to improve on the Grays River program and recommends its continued operation as an important safety net in the lower Columbia. In addition, planning should be initiated leading to one or two additional safety net programs in each of the three strata. 


\section{Hatchery Scientific Review Group}

Pacific Salmon Hatchery Reform
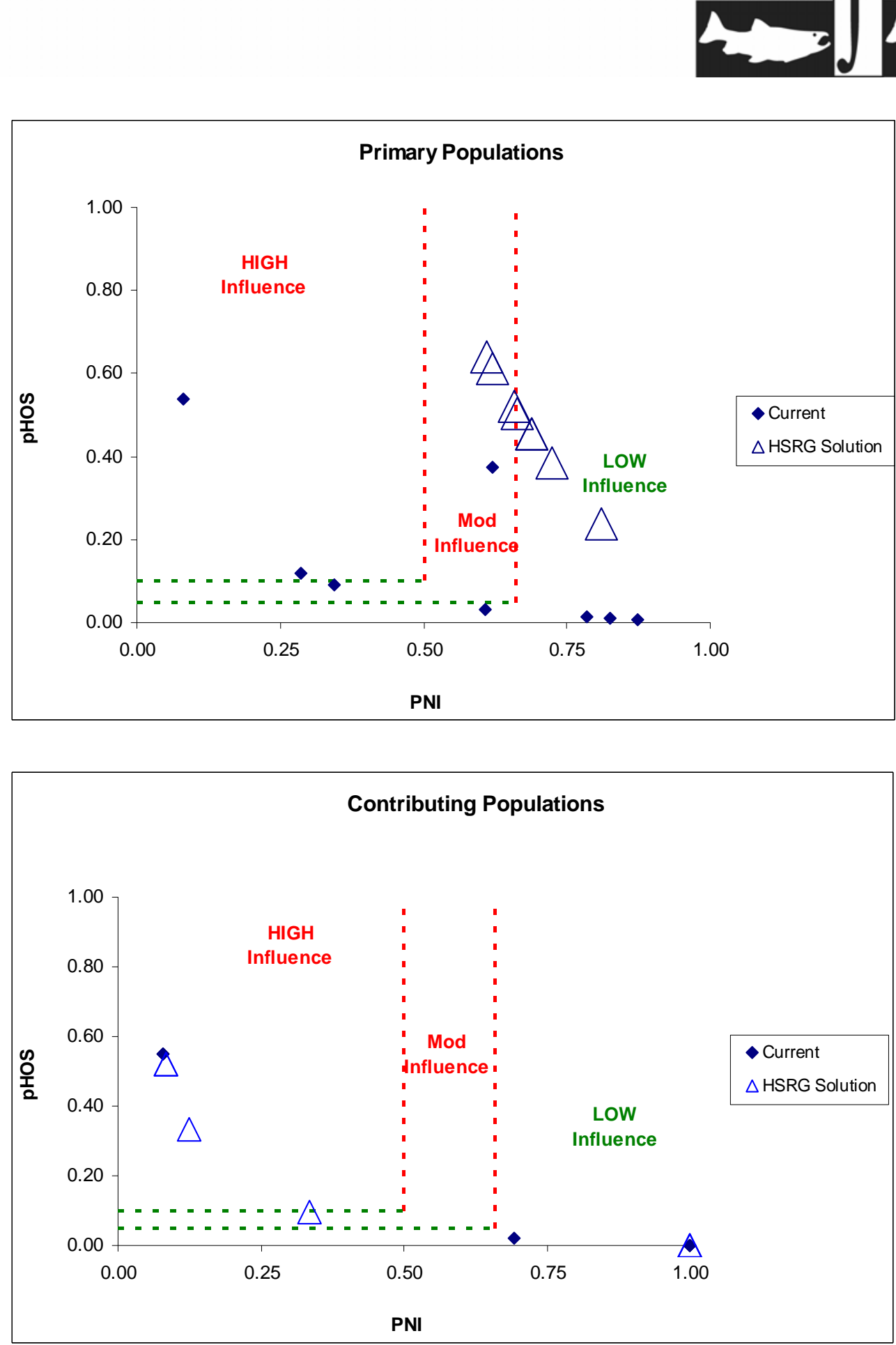

Figure 1. Relationship of the proportion of the fish on the spawning grounds that are of hatchery origin (pHOS) and the proportionate natural influence index (PNI) for Primary (top panel) and Contributing (bottom panel) chum populations in the Lower Columbia River Chum ESU. Solid diamonds represent values for current programs and open triangles represent values for the HSRG recommended hatchery management solution. 


\section{Hatchery Scientific Review Group}

Pacific Salmon Hatchery Reform
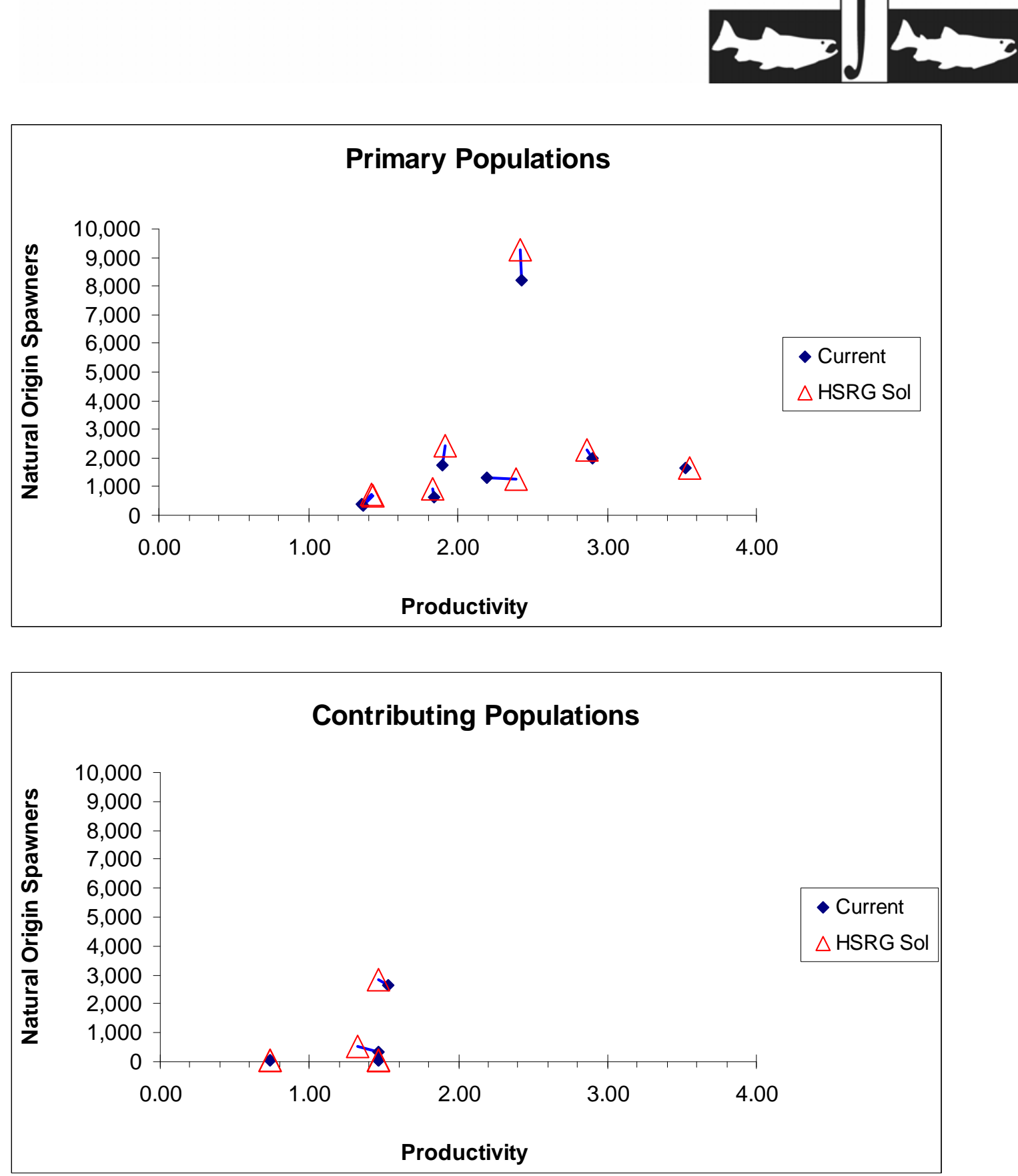

Figure 2. Productivity and spawner abundance for Primary (top panel) and Contributing (bottom panel) chum populations in the Lower Columbia River Chum ESU. Solid diamonds represent existing productivity and spawner abundance levels, and triangles represent the HSRG recommended hatchery management solution. Lines connect current with HSRG solution for a particular population. 


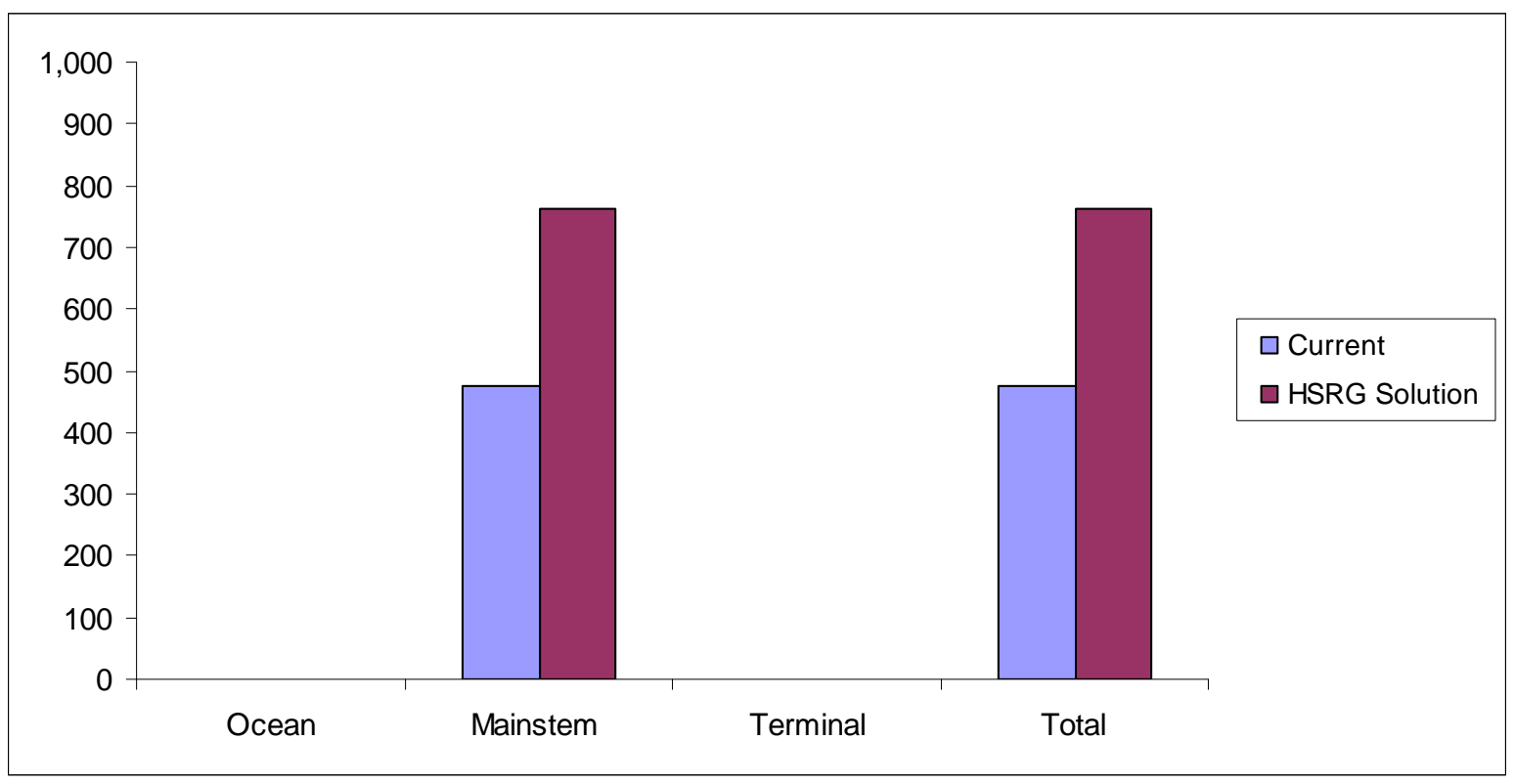

Figure 3. Estimated marine, mainstem Columbia, and terminal harvest under current and HSRG recommended hatchery management solution for Lower Columbia River Chum ESU.

\section{Summary and Conclusions}

In summary, chum conservation programs should be viewed as an important short-term risk management strategy to preserve the genetic legacy of depressed chum populations. The HSRG recommends immediately initiating planning for one or two additional programs in each stratum.

Managers also need to better understand what has caused the overall chum decline and what ecological and/or demographic factors are continuing to keep the ESU at such low abundance levels given the apparent available habitat capacity and propensity for salmon populations to be highly productive at low abundances. Managers should avoid maintaining this ESU only through artificial propagation due to long-term hatchery risks of domestication and fitness loss.

The HSRG reviewed options for chum conservation in the lower Columbia River in the context of conservation goals for other salmon and steelhead ESUs as well as the objectives of fisheries managers for Chinook and coho harvest. The HSRG notes that conservation goals for the chum population in the Youngs Bay tributaries (designated as a Primary population) may be in conflict with conservation and harvest goals for coho salmon in this area. Timing of intensive gill-net fisheries in Youngs Bay to fully harvest hatchery-origin coho overlaps with the return of adult chum salmon. Furthermore, the release of large numbers of juvenile Chinook and coho salmon from net pens in this area may also cause excessive predation on migrant chum fry. Other chum populations in the Coast stratum are more likely to achieve the status of a Primary population in a manner that is compatible with the managers' goals for Chinook and coho. 
The HSRG recommends the fishery managers implement the following actions to achieve their chum conservation goals as part of a plan to meet conservation and harvest goals for all salmon species in the Columbia River Basin:

- Intensify enumeration of incidental chum harvest in the commercial coho fishery.

- Continue the current chum conservation program in Grays River.

- Programs should include a sunset clause that would suspend the hatchery program after three generations, unless evidence suggests suspending releases earlier or extending the program beyond three generations would benefit the populations.

- All hatchery-origin fish should be marked and the proportion of hatchery fish on the spawning grounds monitored.

- Investigate ecological variables that might be constraining the viability of the chum salmon in the Columbia River and develop one or more plausible hypotheses.

- Based on results of the initial propagation programs and the plausible hypotheses about the cause of decline, consider additional reintroduction programs to achieve, at a minimum, preservation of the genetic identity and reduction of demographic extinction risks. 


\subsection{Steelhead Distinct Population Segments}

\subsubsection{Southwest Washington Steelhead DPS}

This section provides an overview of the Southwest Washington Steelhead Distinct Population Segment (DPS). It contains a general description of the DPS, fisheries, habitat limitations and hatchery programs that affect it. Overall recommendations for DPS-wide hatchery program changes are summarized, as are the results of implementing those changes on conservation and harvest goals. Detailed conclusions and recommendations for each population in the DPS can be found in the Appendix E.

\subsubsection{HSRG Population Guidelines}

In order to meet conservations goals for the DPS, numerous threats to these populations need to be addressed, including risks from hatchery programs. The key to controlling genetic and ecological risks due to straying and fitness loss is to manage hatchery broodstock and natural spawning escapement such that the natural habitat (and not the hatchery environment) drives the adaptation and productivity of the naturally spawning population. This is achieved by operating either (a) integrated programs where the proportion of natural-origin adults in the broodstock (pNOB) exceeds the proportion of hatchery-origin fish on the spawning grounds (pHOS); or (b) segregated programs where the contribution of hatchery fish to natural spawning is kept low (pHOS $<5 \%$ to $<10 \%$ depending on the population designation). The HSRG developed criteria for hatchery influence for three population types based on the importance of the population to the recovery of the DPS. This was done to provide a consistent method of reviewing populations and programs across the Columbia River Basin. The population designations used by the HSRG (Primary, Contributing, or Stabilizing) were adopted after discussions with managers and followed those developed in the Lower Columbia River Salmon Recovery Plan (LCFRB 2004). These designations are meant to reflect the conservation importance of a population within the DPS from most important (Primary), to moderately important (Contributing), to least important (Stabilizing). HSRG recommendations show how hatchery programs can be operated consistent with these designations based on the following standards:

\section{HSRG criteria for hatchery influence on Primary populations}

- The proportion of effective hatchery-origin spawners (pHOS) should be less than 5\% of the naturally spawning population, unless the hatchery population is integrated with the natural population.

- For integrated populations, the proportion of natural-origin adults in the broodstock should exceed pHOS by at least a factor of two, corresponding to a proportionate natural influence (PNI) value of 0.67 or greater and pHOS should be less than 0.30 .

HSRG criteria for hatchery influence on Contributing populations

- The proportion of effective hatchery-origin spawners (pHOS) should be less than $10 \%$ of the naturally spawning population, unless the hatchery population is integrated with the natural population. 
- For integrated populations, the proportion of natural-origin adults in the broodstock should exceed $\mathrm{pHOS}$, corresponding to a PNI value of 0.50 or greater and $\mathrm{pHOS}$ should be less than 0.30 .

HSRG criteria for hatchery influence on Stabilizing populations

- The current operating conditions were considered adequate to meet their conservation goals. No criteria were developed for proportion of effective hatchery-origin spawners (pHOS) or PNI.

\subsubsection{Current Conditions}

\section{Conservation}

The Southwest Washington steelhead DPS, as defined by the Endangered Species Act, includes all steelhead from tributaries to Grays Harbor, Willapa Bay, and the Columbia River below the Cowlitz River in Washington and below the Willamette River in Oregon. In 1996, NMFS determined that Southwest Washington steelhead did not warrant listing under the ESA. For the purposes of the HSRG analysis, seven populations are included in the Columbia River Estuary steelhead DPS. Two of these populations meet criteria as Primary, one as Contributing, and four as Stabilizing populations (Table 1).

\section{Current Harvest}

No targeted commercial steelhead fisheries occur in the lower Columbia River or ocean fisheries. They are taken incidentally in the commercial fisheries targeting other salmon species. Lower Columbia River steelhead are harvested in Columbia River and tributary freshwater recreational fisheries of Oregon and Washington. Fishery impacts on wild Lower Columbia River steelhead have been limited to less than 10 percent since the implementation of mark-selective fisheries during the 1980s. Mainstem summer and fall fisheries do not affect Lower Columbia River steelhead.

\section{Current Habitat}

Habitat degradation in tributaries is pervasive from land uses and development such as urbanization, agriculture, and timber harvest, which has increased fine sediment in spawning reaches and dramatically reduced complex habitats important for juvenile steelhead rearing. 

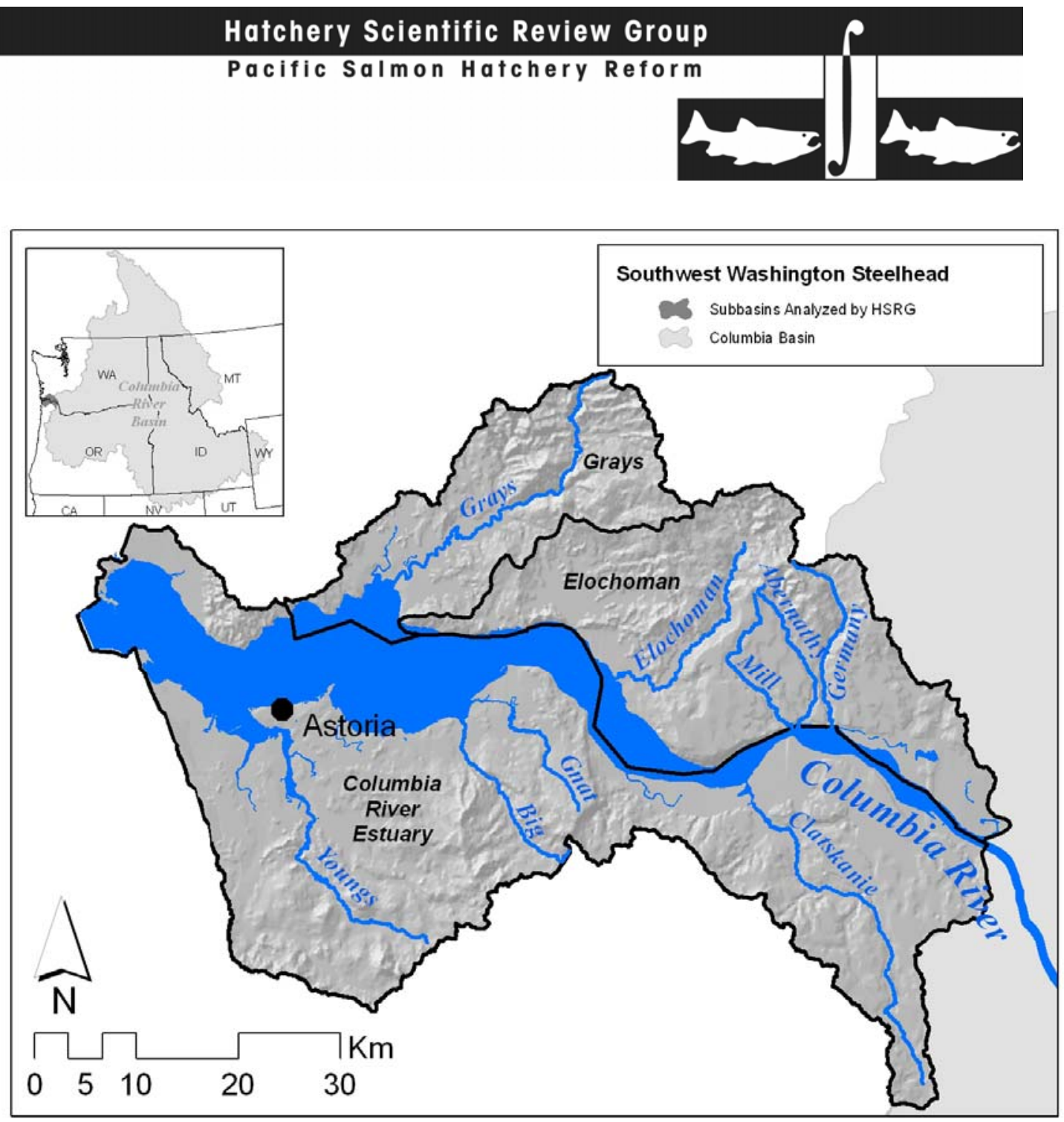

Table 1. Population designations for the Southwest Washington Steelhead DPS and HSRG broodstock criteria achieved for each population under current conditions and the HSRG recommended hatchery management solution.

\begin{tabular}{|c|c|c|c|}
\hline \multirow[b]{2}{*}{ Population } & \multirow[b]{2}{*}{ Designation ${ }^{1}$} & \multicolumn{2}{|c|}{ HSRG Criteria Met $^{2}$} \\
\hline & & Current & HSRG Solution \\
\hline Columbia Estuary: Mill-Aber-Germ Winter Steelhead (Late) & Primary & Primary & Primary \\
\hline Grays Winter Steelhead (Late) & Primary & Primary & Primary \\
\hline Elochoman Winter Steelhead (Late) & Contributing & Primary & Primary \\
\hline Columbia Estuary: Big Creek Winter Steelhead (Late) & Stabilizing & Primary & Primary \\
\hline Columbia Estuary: Clatskanie Winter Steelhead (Late) & Stabilizing & Primary & Primary \\
\hline Columbia Estuary: Gnat Creek Winter Steelhead (Late) & Stabilizing & Stabilizing & Stabilizing \\
\hline Columbia Estuary: Youngs Bay Tribs Winter Steelhead (Late) & Stabilizing & Stabilizing & Stabilizing \\
\hline \multicolumn{4}{|c|}{$\begin{array}{l}1 \text { Using the naming protocol of the Lower Columbia River Salmon Recovery Plan (LCFRB 2004), populations were classified based on } \\
\text { information provided to the HSRG as Primary, Contributing, or Stabilizing. These designations are meant to reflect the conservation } \\
\text { importance of a population within the DPS from most important (Primary- bold, red), to moderately important (Contributing-bold, blue), to } \\
\text { least important (Stabilizing). }\end{array}$} \\
\hline \multicolumn{4}{|c|}{$\begin{array}{l}2 \text { The HSRG developed criteria for hatchery influence for the three population designations from low influence (Primary), moderate influence } \\
\text { (Contributing) to high influence (Stabilizing). }\end{array}$} \\
\hline
\end{tabular}




\section{Current Hatchery Programs}

There is widespread production of hatchery steelhead within this DPS, largely from parent stocks outside the DPS. Currently there are six segregated programs in the DPS that release approximately 320,000 steelhead smolts per year within the Columbia River estuary (Table 2). Currently there are no integrated programs in this DPS. Both summer and winter races of steelhead are reared and released from hatcheries.

Estimates of PNI and pHOS under current conditions indicate that both of the Primary populations in the DPS (Grays River and Mill-Abernathy-Germany Creek) meet the broodstock criteria for their population designation (Table 1). In addition, the HSRG believes that three other populations (Elochoman, Big Creek and Clatskanie) also currently meet the HSRG standards for a Primary designation even though they are identified by managers as either Contributing or Stabilizing.

Table 2. Hatchery releases and types of programs for Southwest Washington Steelhead DPS.

\begin{tabular}{|l|c|c|c|c|c|c|}
\hline \multirow{2}{*}{ Population/Program Name } & \multicolumn{3}{|c|}{ Current (1,000s) } & \multicolumn{2}{c|}{ HSRG Solution (1,000s) } \\
\cline { 2 - 8 } & Type & Purpose & $\begin{array}{c}\text { No. } \\
\text { Released }\end{array}$ & Type & Purpose & $\begin{array}{c}\text { No. } \\
\text { Released }\end{array}$ \\
\hline Columbia Estuary_Big Creek Winter Steelhead (Late) & None & NA & - & None & NA & - \\
\hline Columbia Estuary_Big Creek Winter Steelhead (Hatchery) & Seg & Harv & 60.0 & Seg & Harv & 60.0 \\
\hline Columbia Estuary_Youngs Bay Tribs Winter Steelhead (Late) & None & NA & - & None & NA & - \\
\hline Columbia Estuary_Youngs Bay Tribs Winter Steelhead (Hatchery) & Seg & Harv & 60.0 & Seg & Harv & 60.0 \\
\hline Columbia Estuary_Gnat Creek Winter Steelhead (Late) & None & NA & - & None & NA & - \\
\hline Columbia Estuary_Gnat Creek Winter Steelhead (Hatchery) & Seg & Harv & 40.0 & Seg & Harv & 40.0 \\
\hline Columbia Estuary_Clatskanie Winter Steelhead (Late) & None & NA & - & None & NA & - \\
\hline Columbia Estuary_Mill-Aber-Germ Winter Steelhead (Late) & None & NA & - & None & NA & - \\
\hline Grays Winter Steelhead (Late) & None & NA & - & None & NA & - \\
\hline Grays Winter Steelhead (Early-Elochoman-Hatchery) & Seg & Harv & 40.0 & Seg & Harv & 40.0 \\
\hline Elochoman Winter Steelhead (Late) & None & NA & - & None & NA & - \\
\hline Elochoman Winter Steelhead (Early-Hatchery) & Seg & Harv & 90.7 & Seg & Harv & 90.7 \\
\hline Elochoman Summer Steelhead (Merwin-Hatchery) & Seg & NA & 30.9 & Seg & NA & 30.9 \\
\hline Total all Populations/Programs & & & $\mathbf{3 2 1 . 6}$ & & & $\mathbf{3 2 1 . 6}$ \\
\hline
\end{tabular}

\subsubsection{HSRG Solutions}

The HSRG identified a need for additional monitoring to determine the number of unharvested hatchery-origin fish from the existing segregated programs and to assess how these fish may impact natural populations through both genetic and ecological effects.

\section{Conservation Outcomes under the HSRG Solutions}

Figure 1 compares the proportion of hatchery-origin fish on the spawning grounds $(\mathrm{pHOS})$ and the proportionate natural influence (PNI) for Primary and Contributing populations under current and proposed (HSRG) scenarios. The HSRG solutions make 
no changes to the hatchery programs, so the amount of hatchery influence and corresponding productivity (Figure 2 ) is unchanged in the Primary populations.

\section{Harvest Outcomes under the HSRG Solutions}

Figure 3 describes current and estimated changes in harvest (marine, mainstem Columbia River and terminal areas) that would occur following implementation of the management solutions proposed by the HSRG. The HSRG solutions make no changes to the size of the hatchery programs or harvest assumptions, so the amount of harvest is unchanged.

\section{Hatchery Program Changes under the HSRG Solutions}

Table 2 identifies the current size of each hatchery program as well as the size under the HSRG solution. For this DPS, the total number of smolts released under both scenarios remains the same. 


\section{Hatchery Scientific Review Group}

Pacific Salmon Hatchery Reform
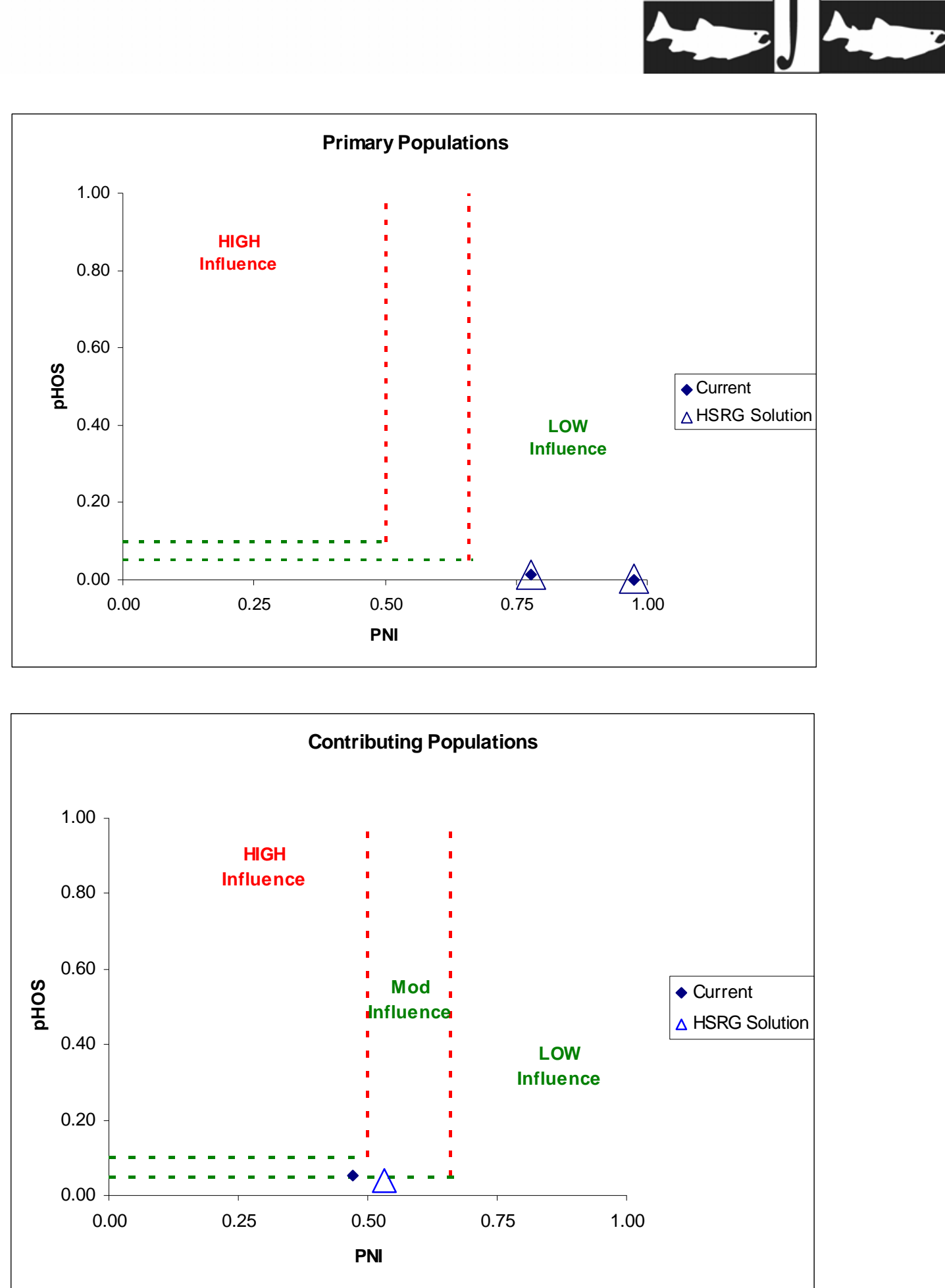

Figure 1. Relationship of the proportion of the fish on the spawning grounds that are of hatchery origin (pHOS) and the proportionate natural influence index (PNI) for Primary (top panel) and Contributing (bottom panel) steelhead populations in the Southwest Washington DPS. Solid diamonds represent values for current programs and open triangles represent values for the HSRG recommended hatchery management solution. 


\section{Hatchery Scientific Review Group}

Pacific Salmon Hatchery Reform
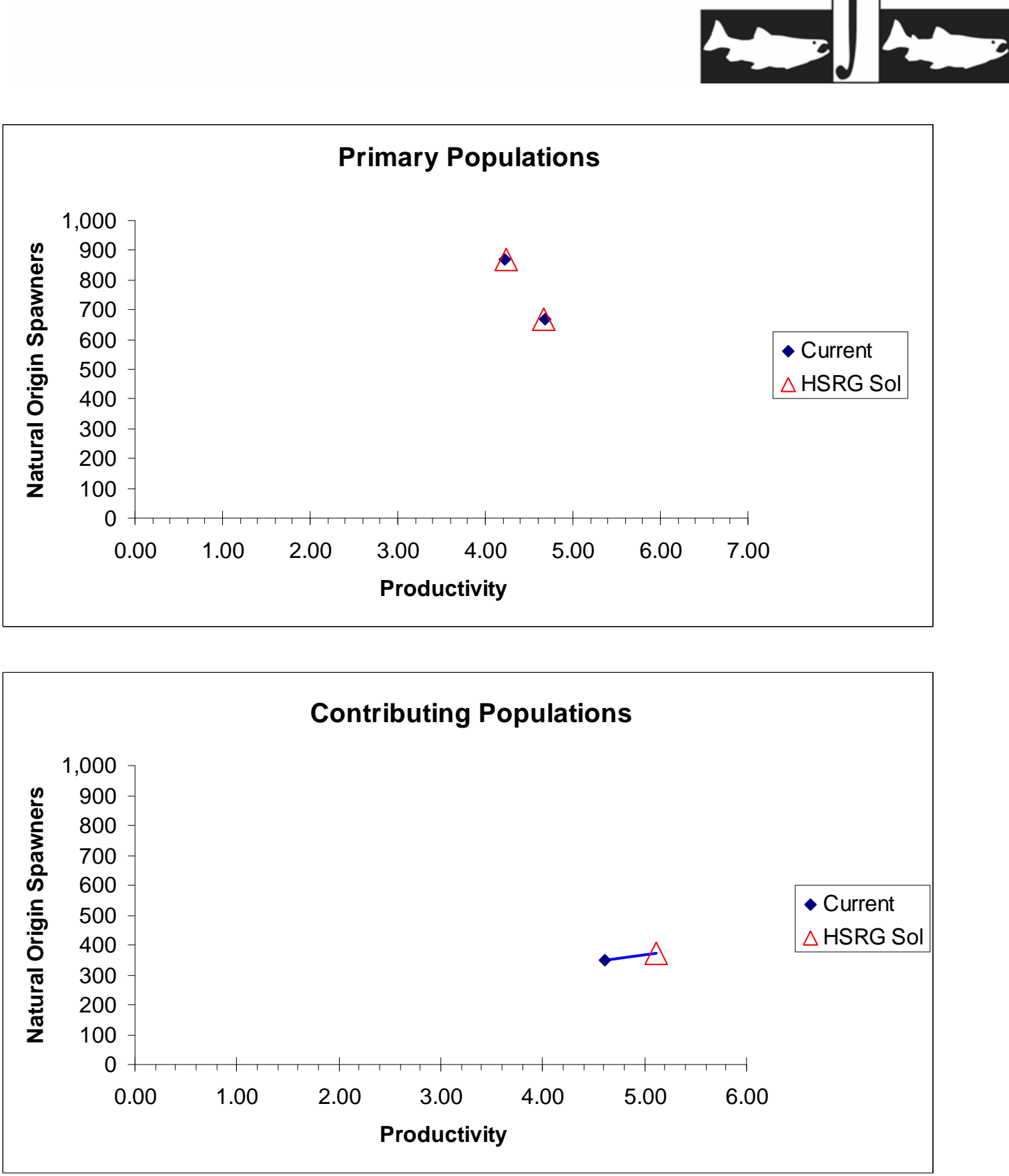

Figure 2. Productivity and spawner abundance for Primary (top panel) and Contributing (bottom panel) steelhead populations in the Southwest Washington DPS. Solid diamonds represent existing productivity and spawner abundance levels, and triangles represent the HSRG recommended hatchery management solution. Lines connect current with HSRG solution for a particular population. 


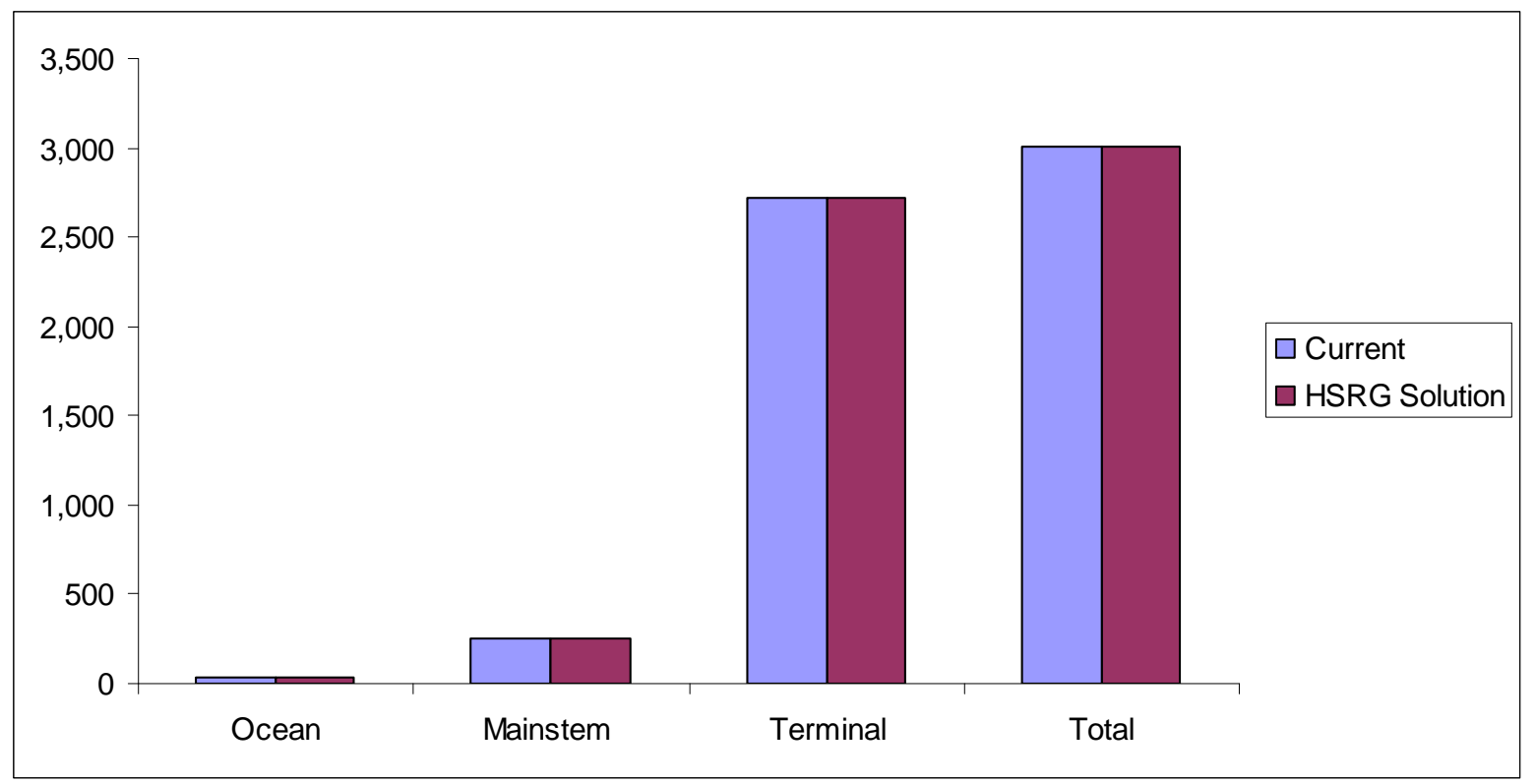

Figure 3. Estimated marine, mainstem Columbia, and terminal harvest under current and HSRG recommended hatchery management solution for Southwest Washington DPS.

\section{Summary and Conclusions}

All populations in this DPS meet or exceed the HSRG criteria for their population designation. The HSRG provided no recommendations to change programs.

Due to uncertainty about the number of unharvested hatchery-origin fish from segregated programs that remain in the natural environment, the HSRG identified a need for additional monitoring to further clarify these values and to aid in assessing the ecological impacts to the natural populations.

\subsubsection{Lower Columbia River Steelhead DPS}

This section provides an overview of the Lower Columbia River Steelhead DPS which was listed as Threatened under the ESA in 1999. It contains a general description of the DPS, fisheries, habitat limitations and hatchery programs that affect it. Overall recommendations for DPS-wide hatchery program changes are summarized as are the results of implementing those changes on conservation and harvest goals. Detailed conclusions and recommendations for each population in the DPS can be found in the Appendix E.

\subsubsection{HSRG Population Guidelines}

In order to meet conservations goals for the DPS, numerous threats to these populations need to be addressed, including risks from hatchery programs. The key to controlling 


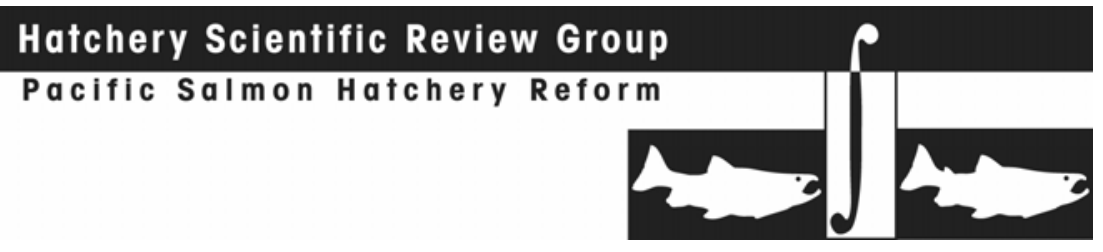

genetic and ecological risks due to straying and fitness loss is to manage hatchery broodstock and natural spawning escapement such that the natural habitat (and not the hatchery environment) drives the adaptation and productivity of the naturally spawning population. This is achieved by operating either (a) integrated programs where the proportion of natural-origin adults in the broodstock ( $\mathrm{pNOB}$ ) exceeds the proportion of hatchery-origin fish on the spawning grounds (pHOS); or (b) segregated programs where the contribution of hatchery fish to natural spawning is kept low (pHOS $<5 \%$ to $<10 \%$ depending on the population designation). The HSRG developed criteria for hatchery influence for three population types based on the importance of the population to the recovery of the DPS. This was done to provide a consistent method of reviewing populations and programs across the Columbia River Basin. The population designations used by the HSRG (Primary, Contributing, or Stabilizing) were adopted after discussions with managers and followed those developed in the Lower Columbia River Salmon Recovery Plan (LCFRB 2004). These designations are meant to reflect the conservation importance of a population within the DPS from most important (Primary), to moderately important (Contributing), to least important (Stabilizing). HSRG recommendations show how hatchery programs can be operated consistent with these designations based on the following standards:

\section{HSRG criteria for hatchery influence on Primary populations}

- The proportion of effective hatchery-origin spawners (pHOS) should be less than 5\% of the naturally spawning population, unless the hatchery population is integrated with the natural population.

- For integrated populations, the proportion of natural-origin adults in the broodstock should exceed pHOS by at least a factor of two, corresponding to a proportionate natural influence (PNI) value of 0.67 or greater and pHOS should be less than 0.30 .

HSRG criteria for hatchery influence on Contributing populations:

- The proportion of effective hatchery-origin spawners (pHOS) should be less than $10 \%$ of the naturally spawning population, unless the hatchery population is integrated with the natural population.

- For integrated populations, the proportion of natural-origin adults in the broodstock should exceed $\mathrm{pHOS}$, corresponding to a PNI value of 0.50 or greater and $\mathrm{pHOS}$ should be less than 0.30 .

HSRG criteria for hatchery influence on Stabilizing populations:

- The current operating conditions were considered adequate to meet their conservation goals. No criteria were developed for proportion of effective hatchery-origin spawners (pHOS) or PNI.

\subsubsection{Current Conditions}

\section{Conservation}

The Lower Columbia River steelhead DPS was listed as threatened under the Endangered Species Act (ESA) in 1998. The ESA-defined DPS includes all naturally spawned steelhead populations below natural and manmade impassable 


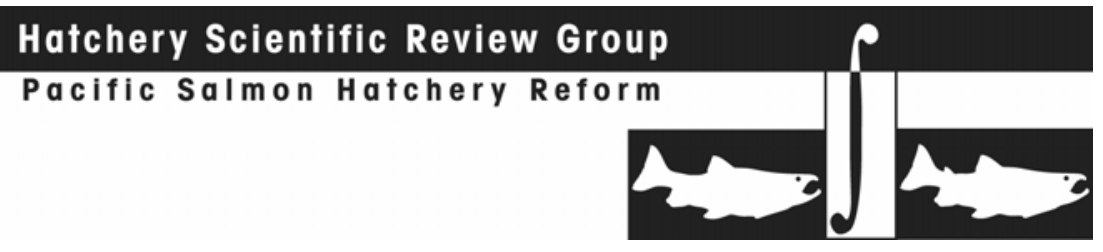

barriers in streams and tributaries to the Columbia River between the Cowlitz and Wind Rivers, Washington (inclusive), and the Willamette and Hood rivers, Oregon (inclusive), as well as ten artificial propagation programs. There are 23 historical populations in four major population groups in the DPS. For the purposes of the HSRG analysis, 21 populations were defined (Table 1). The longterm extinction risk is "high" or "very high" for most populations of Lower Columbia River steelhead; only five populations have a long-term extinction risk of "low" or "moderate" (LCFRB 2004, McElhany et al 2007). Core populations include Kalama, Washougal, Wind, Upper Cowlitz, Cispus, North Fork Lewis, Clackamas, Sandy, and Hood.

For the purposes of this review, the HSRG designated 14 populations as Primary, five as Contributing, and two as Stabilizing (Table 1).

\section{Current Harvest}

No targeted commercial steelhead fisheries occur in the lower Columbia River or ocean fisheries. Steelhead are taken incidentally in commercial fisheries targeting other salmon species. Lower Columbia River steelhead are harvested in Columbia River and tributary freshwater recreational fisheries of Oregon and Washington. Fishery impacts on wild Lower Columbia River steelhead have been limited to less than 10 percent since the implementation of mark-selective fisheries during the 1980s. Treaty Indian fisheries only target populations above Bonneville Dam.

\section{Current Habitat}

Habitat issues for most populations in this DPS are similar to those in adjacent DPSs. For example, timber harvest has been extensive throughout most watersheds in this area, leading to increased sedimentation of spawning streams and loss of riparian vegetation. Steelhead access to tributary headwaters has been restricted or blocked by FERC-licensed dams built without passage facilities or facilities that were inadequate for steelhead. Four populations (Wind River summer run, Hood River summer run, Upper Gorge winter run, and Hood River winter run) are affected by passage conditions at Bonneville Dam. Hydroelectric projects on the Cowlitz and Lewis rivers block access to approximately 80 percent of the historical steelhead spawning and rearing habitat within these subbasins (LCFRB 2004), although reintroduction efforts are underway in the Cowlitz and planned in the Lewis River.

Table 1. Population designations for the Lower Columbia Steelhead DPS and HSRG broodstock criteria achieved for each population under current conditions and the HSRG recommended hatchery management solutions.

\begin{tabular}{|l|c|c|c|}
\hline \multirow{2}{*}{ Population } & & \multicolumn{2}{|c|}{ HSRG Criteria Met $^{2}$} \\
\cline { 3 - 4 } & Designation & Current & HSRG Solution \\
\hline Cowlitz_Coweeman Winter Steelhead (Late) & Primary & Primary & Primary \\
\hline Cowlitz_NF Toutle Winter Steelhead (Late) & Primary & Contributing & Primary \\
\hline Cowlitz_SF Toutle Winter Steelhead (Late) & Primary & Primary & Primary \\
\hline Hood Summer Steelhead & Primary & Primary & Primary \\
\hline
\end{tabular}




\begin{tabular}{|l|c|c|c|}
\hline \multirow{2}{*}{ Population } & & \multicolumn{2}{|c|}{ HSRG Criteria Met ${ }^{2}$} \\
\cline { 3 - 4 } & Designation ${ }^{1}$ & Current & HSRG Solution \\
\hline Hood Winter Steelhead & Primary & Primary & Primary \\
\hline Kalama Summer Steelhead & Primary & Stabilizing & Primary \\
\hline Kalama Winter Steelhead (Late) & Primary & Primary & Primary \\
\hline Lewis_East Fork Lewis Summer Steelhead & Primary & Primary & Primary \\
\hline Lewis_East Fork Lewis Winter Steelhead (Late) & Primary & Stabilizing & Primary \\
\hline Sandy Winter Steelhead (Late) & Primary & Primary & Primary \\
\hline Washougal Summer Steelhead & Primary & Contributing & Primary \\
\hline Willamette_Lower Clackamas Winter Steelhead (Late) & Primary & Stabilizing & Primary \\
\hline Willamette_Upper Clackamas Winter Steelhead (Late) & Primary & Primary & Primary \\
\hline Wind Summer Steelhead & Primary & Primary & Primary \\
\hline Columbia Gorge_Wind River Winter Steelhead (Late) & Contributing & Primary & Primary \\
\hline Cowlitz_Lower Cowlitz Winter Steelhead (Late) & Contributing & Stabilizing & Stabilizing \\
\hline Cowlitz_Upper Cowlitz Winter Steelhead (Late) & Contributing & Primary & Primary \\
\hline Lewis_North Fork Lewis Winter Steelhead (Late) & Contributing & Stabilizing & Stabilizing \\
\hline Washougal Winter Steelhead (Late) & Contributing & Primary & Primary \\
\hline Lewis_NF Lewis Summer Steelhead & Stabilizing & Stabilizing & Stabilizing \\
\hline Lower Columbia_Salmon Creek Winter Steelhead (Late) & Stabilizing & Stabilizing & Stabilizing \\
\hline
\end{tabular}

1 Using the naming protocol of the Lower Columbia River Salmon Recovery Plan (LCFRB 2004), populations were classified based on information provided to the HSRG as Primary, Contributing, or Stabilizing. These designations are meant to reflect the conservation importance of a population within the DPS from most important (Primary- bold, red), to moderately important (Contributing-bold, blue), to least important (Stabilizing).

2 The HSRG developed criteria for hatchery influence for the three population designations from low influence (Primary), moderate influence (Contributing) to high influence (Stabilizing).

\section{Current Hatchery Programs}

The role of most steelhead hatchery programs in the Lower Columbia River steelhead DPS is to provide harvest. Currently there are eight integrated hatchery programs releasing approximately 970,000 juvenile steelhead annually and 18 segregated hatchery programs releasing about 2.1 million juvenile steelhead annually (Table 2). Of these 26 programs, NOAA Fisheries identified only one that improves population viability by increasing spatial distribution (NMFS 2004b). Four were identified as reducing shortterm risk, and helping to preserve genetic resources important to DPS survival and recovery. In Washington, the Kalama, North and South Fork Toutle, and East Fork Lewis winter-run populations have few hatchery fish spawning in natural spawning areas, while most other populations have a substantial fraction of hatchery-origin spawners. In Oregon, the upper Clackamas and Sandy rivers have few hatchery-origin spawners.

HSRG estimates of PNI and pHOS under current conditions show that 12 populations meet the standards for a Primary population designation, two meet the standards for Contributing populations and seven meet the standards for Stabilizing populations (Table $1)$. 


\section{Hatchery Scientific Review Group}

Pacific Salmon Hatchery Reform
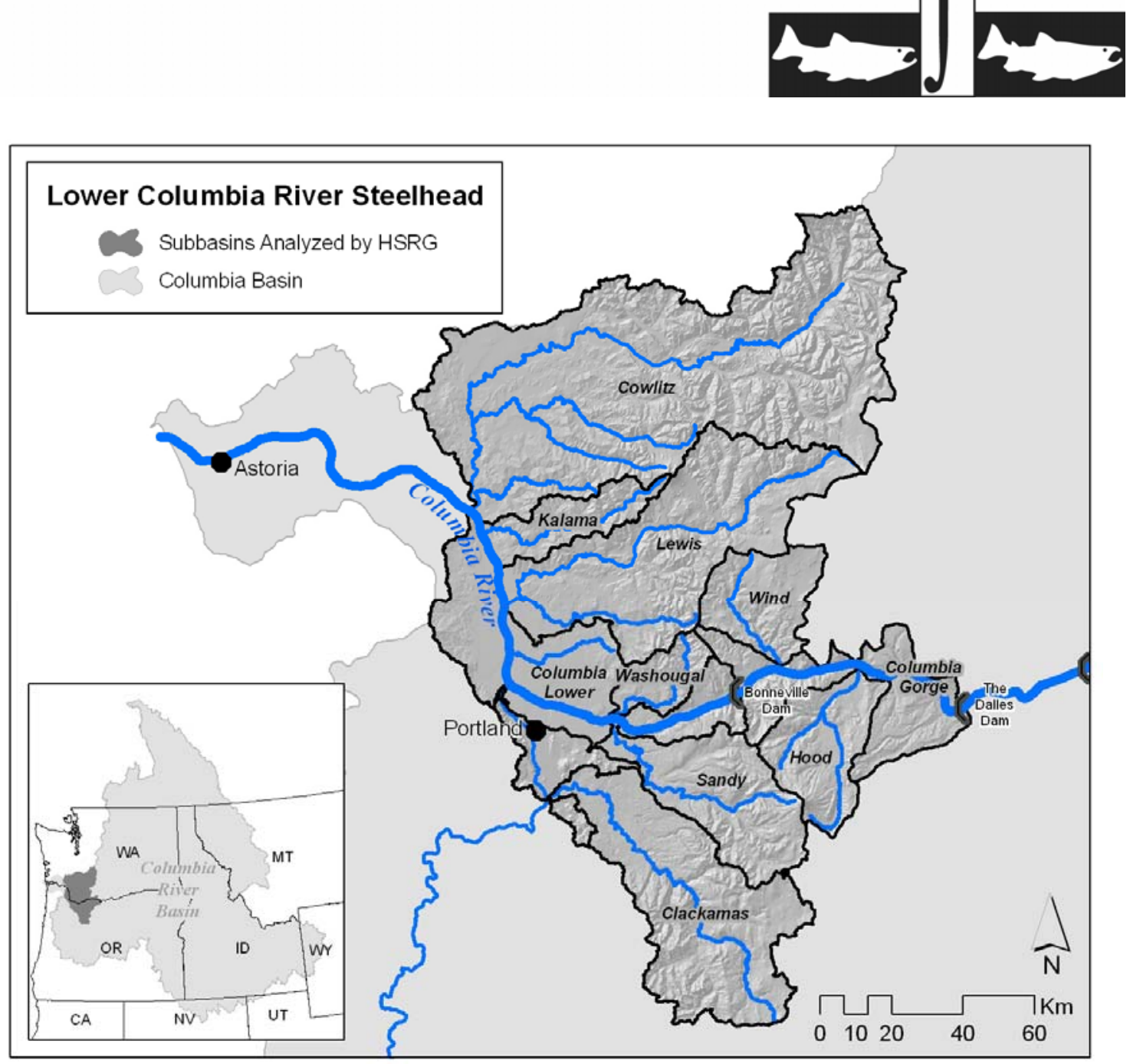

Table 2. Hatchery releases and types of programs for Lower Columbia Steelhead DPS.

\begin{tabular}{|l|c|c|c|c|c|c|}
\hline \multirow{2}{*}{\begin{tabular}{l} 
Population/Program Name \\
\cline { 2 - 7 }
\end{tabular}} & \multicolumn{3}{|c|}{ Current (1,000s) } & \multicolumn{3}{c|}{ HSRG Solution (1,000s) } \\
\cline { 2 - 7 } & Type & Purpose & $\begin{array}{c}\text { No. } \\
\text { Released }\end{array}$ & Type & Purpose & $\begin{array}{c}\text { No. } \\
\text { Released }\end{array}$ \\
\hline Cowlitz_Lower Cowlitz Winter Steelhead (Late) & Int & Both & 288.7 & Int & Both & 288.7 \\
\hline $\begin{array}{l}\text { Cowlitz_Lower Cowlitz Summer Steelhead (Skamania- } \\
\text { Hatchery) }\end{array}$ & Seg & Harv & 549.2 & Seg & Harv & 549.2 \\
\hline Cowlitz_Lower Cowlitz Winter Steelhead (Early-Hatchery) & Seg & Harv & 302.4 & Seg & Harv & 302.4 \\
\hline Cowlitz_Coweeman Winter Steelhead (Late) & None & NA & - & None & NA & - \\
\hline $\begin{array}{l}\text { Cowlitz_Coweeman Winter Steelhead (Early Elochoman- } \\
\text { Hatchery) }\end{array}$ & Seg & Harv & 20.2 & Seg & Harv & 22.1 \\
\hline Cowlitz_Upper Cowlitz Winter Steelhead (Late) & Int & Both & 199.1 & Int & Both & 99.3 \\
\hline Cowlitz_NF Toutle Winter Steelhead (Late) & None & NA & - & Int & Harv & 142.2 \\
\hline Cowlitz_NF Toutle Summer Steelhead (Hatchery) & Seg & Harv & 24.7 & None & NA & - \\
\hline Cowlitz_SF Toutle Winter Steelhead (Late) & None & NA & - & None & NA & - \\
\hline Cowlitz_SF Toutle Summer Steelhead (Hatchery) & Seg & Harv & 24.7 & Seg & Harv & 23.9 \\
\hline Kalama Summer Steelhead & Int & Cons & 30.7 & Int & Cons & 86.7 \\
\hline
\end{tabular}




\begin{tabular}{|c|c|c|c|c|c|c|}
\hline \multirow[b]{2}{*}{ Population/Program Name } & \multicolumn{3}{|c|}{ Current $(1,000 \mathrm{~s})$} & \multicolumn{3}{|c|}{ HSRG Solution $(1,000 \mathrm{~s})$} \\
\hline & Type & Purpose & $\begin{array}{c}\text { No. } \\
\text { Released }\end{array}$ & Type & Purpose & $\begin{array}{c}\text { No. } \\
\text { Released }\end{array}$ \\
\hline Kalama Summer Steelhead (Skamania-Hatchery) & Seg & Harv & 30.7 & None & NA & - \\
\hline Kalama Winter Steelhead (Late) & Int & Harv & 45.2 & Int & Harv & 99.7 \\
\hline Kalama Winter Steelhead (Early-Hatchery) & Seg & Harv & 45.8 & None & NA & - \\
\hline Washougal Summer Steelhead & None & NA & - & Int & Harv & 100.4 \\
\hline Washougal Summer Steelhead (Skamania-Hatchery) & Seg & Harv & 60.3 & Seg & Harv & 28.7 \\
\hline Washougal Winter Steelhead (Late) & None & NA & - & None & NA & - \\
\hline Washougal Winter Steelhead (Early-Skamania-Hatchery) & Seg & Harv & 59.4 & Seg & Harv & 63.0 \\
\hline Lower Columbia_Salmon Creek Winter Steelhead (Late) & None & NA & - & None & NA & 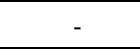 \\
\hline $\begin{array}{l}\text { Lower Columbia_Salmon Creek Winter Steelhead } \\
\text { (Skamania-Hatchery) }\end{array}$ & Seg & Harv & 24.7 & Seg & Harv & 24.7 \\
\hline Lewis_EF Lewis Summer Steelhead & None & NA & - & Int & Harv & 40.7 \\
\hline $\begin{array}{l}\text { Lewis_EF Lewis Summer Steelhead (Skamania- } \\
\text { Hatchery) }\end{array}$ & Seg & Harv & 24.7 & None & NA & - \\
\hline Lewis_EF Lewis Winter Steelhead (Late) & None & NA & - & Int & Both & 40.3 \\
\hline Lewis_EF Lewis Winter Steelhead (Skamania-Hatchery) & Seg & Harv & 90.7 & None & NA & - \\
\hline Lewis_NF Lewis Winter Steelhead (Late) & None & NA & - & None & NA & - \\
\hline Lewis_NF Lewis Winter Steelhead (Merwin-Hatchery) & Seg & Harv & 100.2 & Seg & Harv & 100.2 \\
\hline Lewis_NF Lewis Summer Steelhead & None & NA & - & None & NA & \\
\hline Lewis_NF Lewis Summer Steelhead (Merwin-Hatchery) & Seg & Harv & 284.8 & Seg & Harv & 284.8 \\
\hline Willamette Lower Clackamas Winter Steelhead (Late) & Int & Harv & 164.9 & Int & Harv & 80.4 \\
\hline Willamette Clackamas Summer Steelhead (Hatchery) & Seg & Harv & 174.8 & Seg & Harv & 174.8 \\
\hline $\begin{array}{l}\text { Willamette Clackamas-Eagle Creek Winter Steelhead } \\
\text { (Early-Hatchery) }\end{array}$ & Seg & Harv & 151.0 & Seg & Harv & 151.0 \\
\hline Willamette Upper Clackamas Winter Steelhead (Late) & None & NA & - & None & NA & - \\
\hline Sandy Winter Steelhead (Late) & Int & Harv & 159.9 & Int & Harv & 159.9 \\
\hline Sandy Summer Steelhead (South Santiam-Hatchery) & Seg & Harv & 75.0 & Seg & Harv & 75.0 \\
\hline Wind Summer Steelhead & None & NA & - & None & NA & - \\
\hline Columbia Gorge Wind River Winter Steelhead (Late) & None & NA & - & None & NA & \\
\hline Hood Summer Steelhead & Int & Cons & 31.4 & Int & Cons & 31.4 \\
\hline Hood Summer Steelhead (Santiam-Hatchery) & Seg & Harv & 31.5 & None & NA & - \\
\hline Hood Winter Steelhead & Int & Cons & 49.2 & Int & Cons & 49.2 \\
\hline Total all Populations/Programs & & & $3,043.7$ & & & $3,018.6$ \\
\hline
\end{tabular}

\subsubsection{HSRG Solutions}

In this DPS, the HSRG made multiple recommendations to improve the contribution of hatchery programs to both harvest and conservation. Most release programs remain unchanged while one segregated program is recommended to be discontinued (Hood River summers). In one program, releases are reduced (Washougal River summers), and six segregated programs are recommended to be converted to integrated programs (Coweeman, North Fork Toutle winters, Kalama River summers, East Fork Lewis River summers, East Fork Lewis winters and Washougal summers). One integrated release program is recommended to be increased (Kalama River summers) and two integrated 


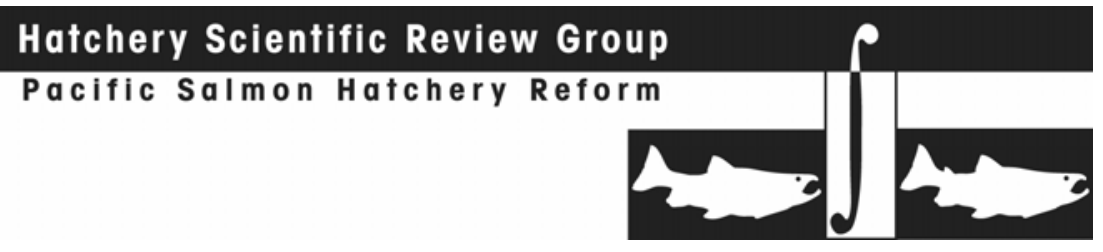

programs are recommended to be reduced (Lower Clackamas River winters and Upper Cowlitz River winters).

For integrated programs in the Lower Columbia Steelhead DPS, the HSRG recommendations generally increase the proportion of natural-origin fish used in hatchery broodstocks and control the contribution of hatchery-origin fish to natural spawning areas, improving natural-origin spawning abundance and productivity. More emphasis is recommended on monitoring and evaluation programs to accurately estimate straying.

The HSRG suggests the LCFRB consider changing some population designations in this DPS that currently appear to be inconsistent with available habitat information and population potential. The HSRG offers alternative population designations for the LCFRB to consider. More detail on recommended population designation changes is provided in the conservation outcome discussion below.

\section{Conservation Outcomes under the HSRG Solutions}

Figure 1 compares the proportion of fish on the spawning grounds that are hatchery origin (pHOS) and the proportionate natural influence (PNI) under current and HSRGproposed scenarios for recovery plan-designated Primary and Contributing populations. Under current conditions, nine of 14 populations designated as Primary meet the HSRG's hatchery influence criteria for this designation. Three populations designated as Contributing currently meet the HSRG's hatchery influence criteria for a Primary population. Two populations designated as Contributing currently meet the HSRG's criteria for a Stabilizing population.

Under the HSRG solutions, all 14 populations (Table 1) designated as Primary will meet the hatchery influence criteria for this designation. Additionally, three populations (Wind River winter steelhead, Upper Cowlitz winter steelhead and Washougal winter steelhead) designated as Contributing currently meet the criteria for Primary populations. Two populations are designated by the LCFRB as Contributing (Lower Cowlitz River winters, North Fork Lewis River summers) and currently meet the criteria for Stabilizing populations. Under HSRG recommendations, they remain Stabilizing.

Figure 2 compares spawner abundance and productivity relationships between current and HSRG-proposed scenarios for the Primary and Contributing steelhead populations in the Lower Columbia steelhead DPS. For Primary populations, productivity increases in seven populations by an average of about 50 percent, while productivity of five populations remains the same or improves slightly. For Contributing populations, productivity increases approximately 80 percent in the Lower Cowlitz winter steelhead population. In four other Contributing populations, productivity remains about the same.

For Primary populations under the HSRG solution, natural-origin spawners increase in nine of the populations by an average of about 30 percent above the current condition. For Contributing populations, natural-origin spawners increase by approximately the same percentage. For the combined Primary and Contributing population across the DPS, the HSRG solution has the potential to increase natural-origin spawning by nearly 1,700 fish. 


\section{Harvest Outcomes under the HSRG Solutions}

Figure 3 compares current harvest levels in ocean, mainstem and terminal areas with the harvest levels under the HSRG recommendations. Freshwater harvest of steelhead increases almost 10 percent overall under the HSRG recommendations. This trend is not consistent across all populations. In some, harvest levels decrease significantly while in others, harvest levels increase significantly.

\section{Hatchery Program Changes under HSRG Solutions}

Table 2 shows the current size of each hatchery program and the size under the HSRG solution. Currently, about 3,043,000 steelhead are released in this DPS from 26 programs, 18 of which are segregated. Currently 19 of the 21 populations in this DPS have releases of hatchery fish. Under the HSRG recommended solution, steelhead releases are reduced slightly (about 25,000) from 24 programs. Twelve integrated and 12 segregated programs operate under the HSRG solution

\subsubsection{Summary and Conclusions}

In order to achieve conservation goals, managers need to implement hatchery reforms. In the Lower Columbia Steelhead DPS, the HSRG reforms increase productivity and abundance of natural populations. Harvest reform through selective fisheries has already been used for several years to protect natural-origin adults and harvest hatchery adults.

Currently segregated broodstock management programs dominate the releases in this DPS. HSRG recommendations increase the number of integrated programs and improve some of the segregated programs. Implementing properly integrated and segregated hatchery broodstock protocols is needed to achieve the standards described by the HSRG. For segregated programs, this means limiting the number of hatchery-origin fish spawning naturally or in some cases converting them to integrated programs. For integrated programs, this means including the appropriate number of natural-origin fish in hatchery broodstock as well as controlling the number of hatchery fish in natural spawning areas.

\section{Harvest increases slightly under the HSRG solutions.}

The HSRG also concludes that the effectiveness of habitat actions would be greatly increased if combined with hatchery and harvest reforms. Analysis of the Primary populations in the Lower Columbia Steelhead DPS suggests that the benefits of habitat quality improvements would more than double if combined with hatchery reforms. Unless hatchery and harvest reforms are implemented, the potential benefits of current or improved habitat cannot be fully realized. 


\section{Hatchery Scientific Review Group}

Pacific Salmon Hatchery Reform
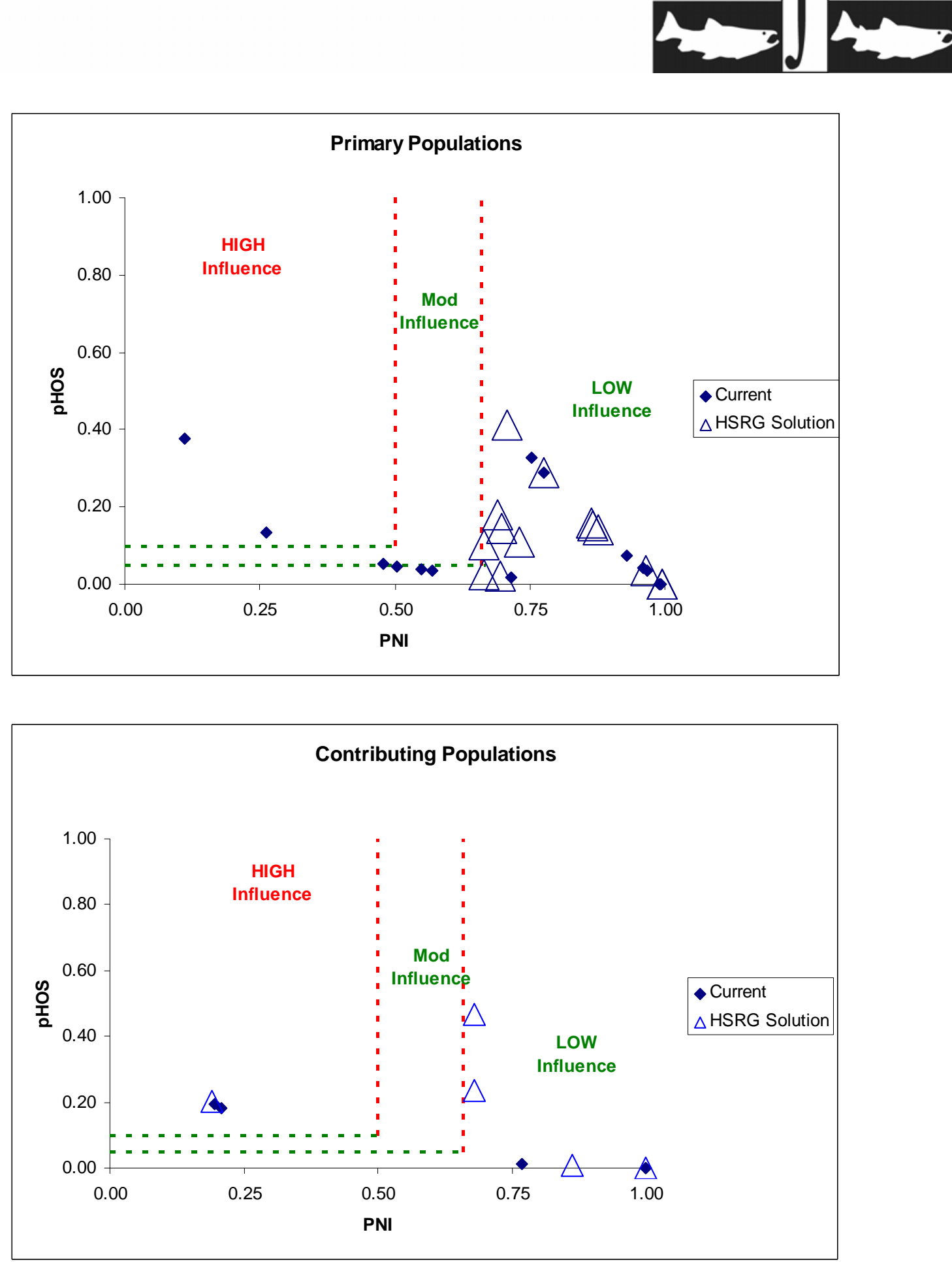

Figure 1. Relationship of the proportion of the fish on the spawning grounds that are of hatchery origin (pHOS) and the proportionate natural influence index (PNI) for Primary (top panel) and Contributing (bottom panel) steelhead populations in the Lower Columbia River DPS. Solid diamonds represent values for current programs and open triangles represent values for the HSRG recommended hatchery management solution. 


\section{Hatchery Scientific Review Group}

Pacific Salmon Hatchery Reform
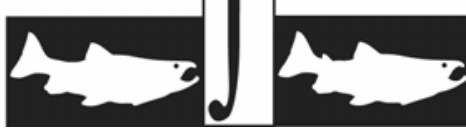

\section{Primary Populations}

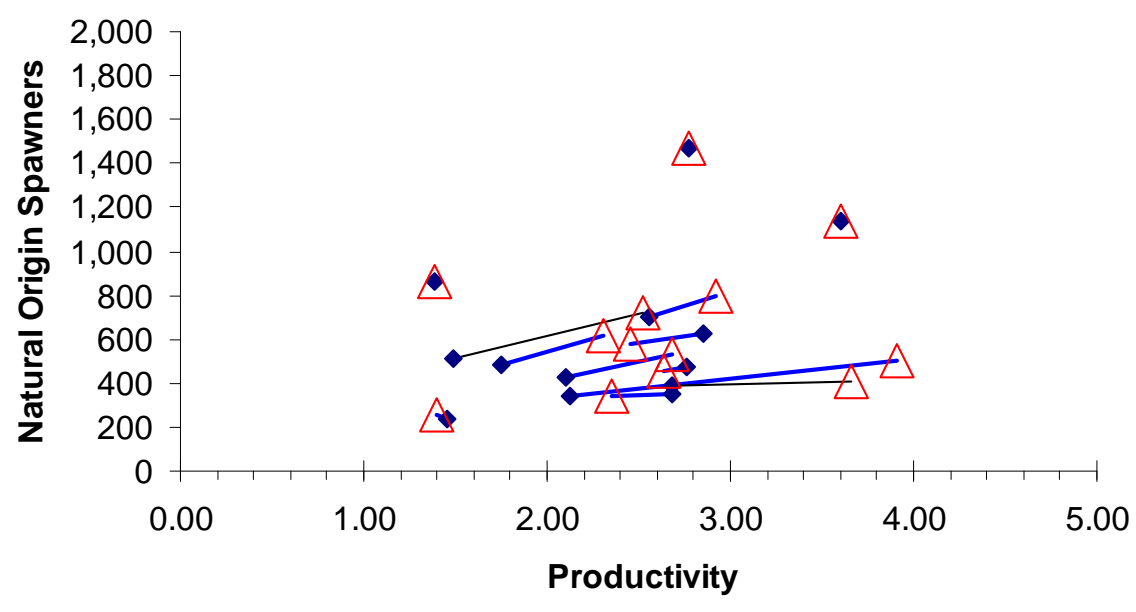

- Current

$\triangle$ HSRG Sol

\section{Contributing Populations}

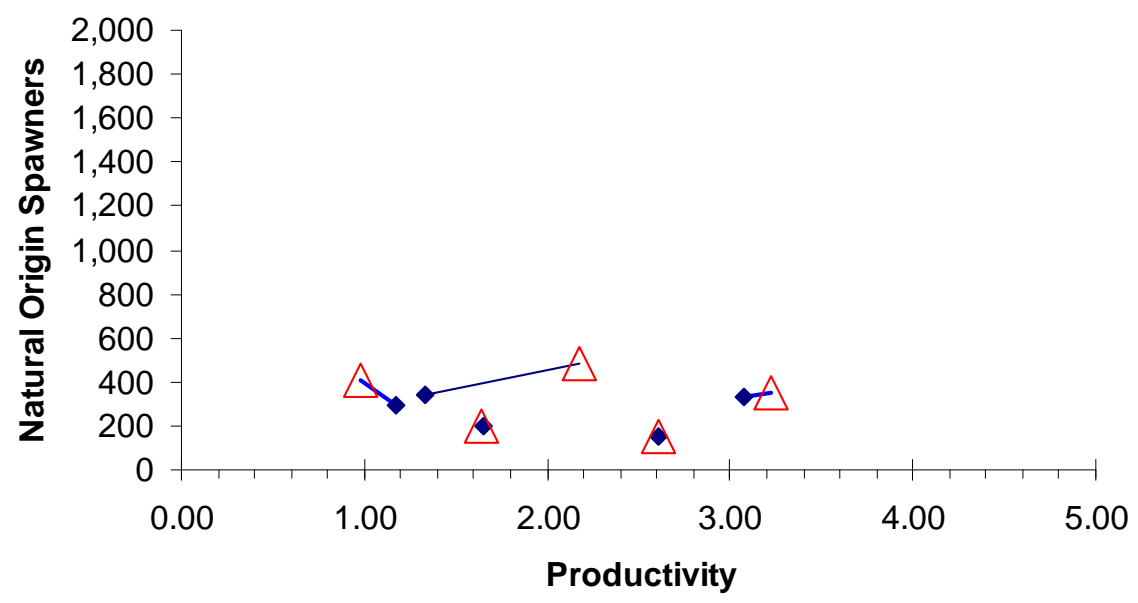

Figure 2. Productivity and spawner abundance for Primary (top panel) and Contributing (bottom panel) steelhead populations in the Lower Columbia DPS. Solid diamonds represent existing productivity and spawner abundance levels, and triangles represent the HSRG recommended hatchery management solution. Lines connect current with HSRG solution for a particular population. 


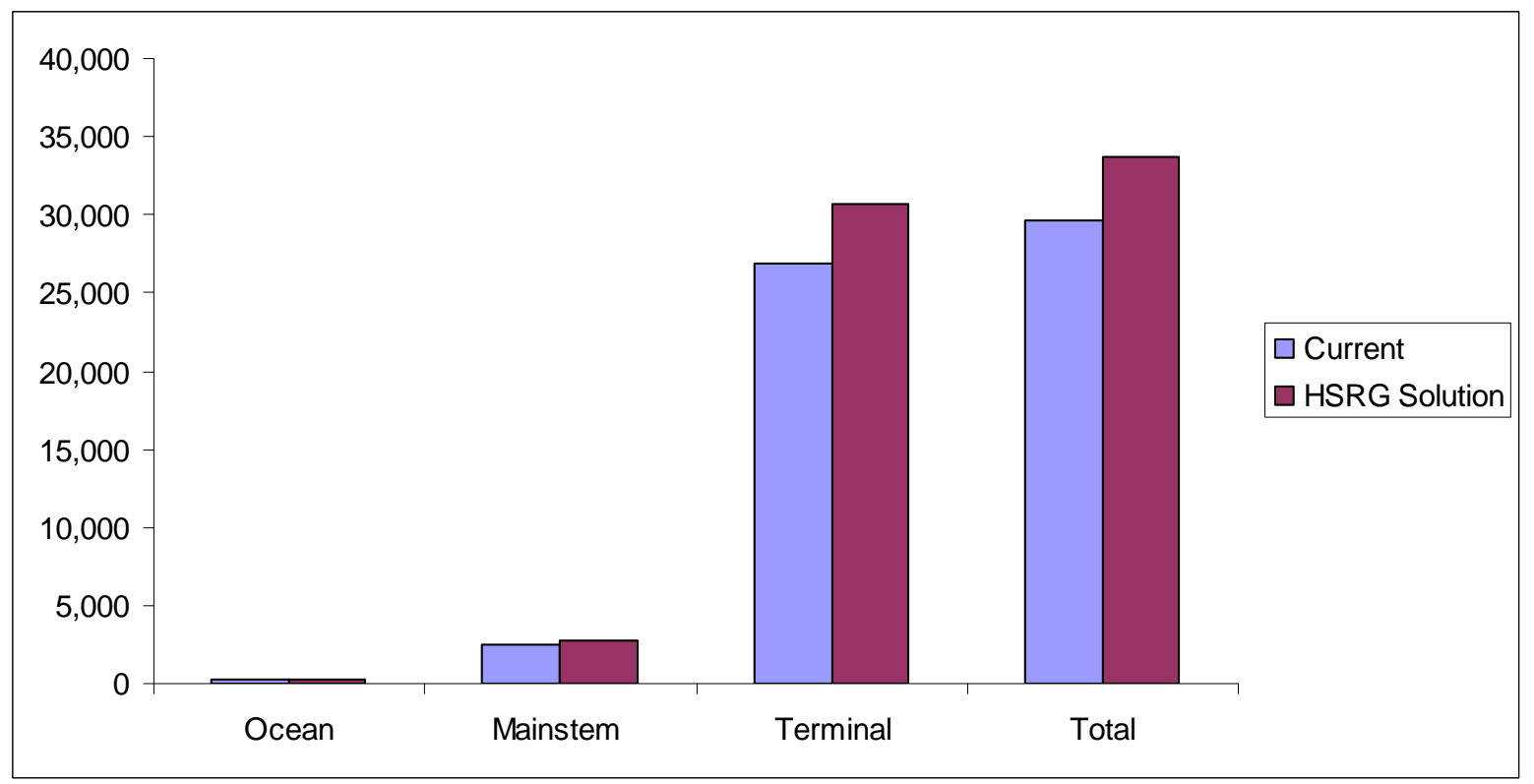

Figure 3. Estimated marine, mainstem Columbia, and terminal harvest under current and HSRG recommended hatchery management solution for Lower Columbia Steelhead DPS.

\subsubsection{Upper Willamette River Winter Steelhead DPS}

This section provides an overview of the Upper Willamette River Winter Steelhead DPS. It contains a general description of the DPS, fisheries, habitat limitations and hatchery programs that affect it. Overall recommendations for DPS-wide hatchery program changes are summarized as are the results of implementing these changes on conservation and harvest goals. Detailed conclusions and recommendations for each population in the DPS can be found in the Appendix E.

\section{HSRG Population Guidelines}

In order to meet conservations goals for the DPS, numerous threats to these populations need to be addressed, including risks from hatchery programs. The key to controlling genetic and ecological risks due to straying and fitness loss is to manage hatchery broodstock and natural spawning escapement such that the natural habitat (and not the hatchery environment) drives the adaptation and productivity of the naturally spawning population. This is achieved by operating either (a) integrated programs where the proportion of natural-origin adults in the broodstock (pNOB) exceeds the proportion of hatchery-origin fish on the spawning grounds (pHOS); or (b) segregated programs where the contribution of hatchery fish to natural spawning is kept low (pHOS $<5 \%$ to $<10 \%$ depending on the population designation). The HSRG developed criteria for hatchery influence for three population types based on the importance of the population to the recovery of the DPS. This was done to provide a consistent method of reviewing 


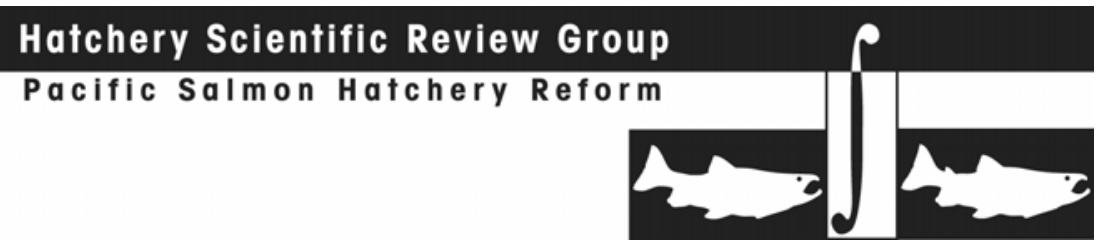

populations and programs across the Columbia River Basin. The population designations used by the HSRG (Primary, Contributing, or Stabilizing) were adopted after discussions with managers and followed those developed in the Lower Columbia River Salmon Recovery Plan (LCFRB 2004). These designations are meant to reflect the conservation importance of a population within the DPS from most important (Primary), to moderately important (Contributing), to least important (Stabilizing). HSRG recommendations show how hatchery programs can be operated consistent with these designations based on the following standards:

HSRG criteria for hatchery influence on Primary populations

- The proportion of effective hatchery-origin spawners (pHOS) should be less than 5\% of the naturally spawning population, unless the hatchery population is integrated with the natural population.

- For integrated populations, the proportion of natural-origin adults in the broodstock should exceed pHOS by at least a factor of two, corresponding to a proportionate natural influence (PNI) value of 0.67 or greater and pHOS should be less than 0.30 .

HSRG criteria for hatchery influence on Contributing populations

- The proportion of effective hatchery-origin spawners (pHOS) should be less than $10 \%$ of the naturally spawning population, unless the hatchery population is integrated with the natural population.

- For integrated populations, the proportion of natural-origin adults in the broodstock should exceed pHOS, corresponding to a PNI value of 0.50 or greater and $\mathrm{pHOS}$ should be less than 0.30 .

HSRG criteria for hatchery influence on Stabilizing populations

- The current operating conditions were considered adequate to meet conservation goals. No criteria were developed for proportion of effective hatchery-origin spawners (pHOS) or PNI.

\subsubsection{Current Conditions}

\section{Conservation}

The Upper Willamette River Winter Steelhead DPS was listed as threatened under the Endangered Species Act in 1999. The DPS includes one major population group (MPG) comprised of four historical populations (Molalla, North Santiam, South Santiam, and Calapooia), all of which are currently extant. This ESA-defined DPS does not include any artificially propagated winter steelhead. There are out-of-DPS hatchery summer-run steelhead programs in the Willamette subbasin. For the purposes of this analysis, the HSRG also identified the Willamette Westside Tributaries Winter Steelhead as a population component in this DPS.

While the abundance of Upper Willamette River steelhead is depressed from historical levels, moderate numbers of adults return each year. The long-term risk of extinction is considered "moderate" for all four populations (McElhany et al 2007). North Santiam and South Santiam populations are considered to be both core and genetic legacy populations (WLCTRT 2003). 


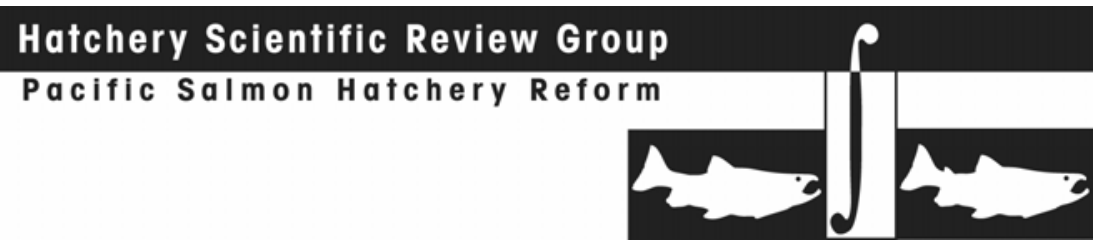

For the purpose of this review, the HSRG designated three populations as Primary, one as Contributing and one as Stabilizing (Table 1).

Table 1. Population designations for the Upper Willamette Winter Steelhead DPS and HSRG broodstock criteria achieved for each population under current conditions and the HSRG recommended hatchery management solution.

\begin{tabular}{|c|c|c|c|}
\hline \multirow[b]{2}{*}{ Population } & \multirow[b]{2}{*}{ Designation $^{1}$} & \multicolumn{2}{|c|}{ HSRG Criteria Met $^{2}$} \\
\hline & & Current & HSRG Solution \\
\hline Molalla Winter Steelhead & Primary & Primary & Primary \\
\hline North Santiam Winter Steelhead & Primary & Stabilizing & Primary \\
\hline South Santiam Winter Steelhead & Primary & Primary & Primary \\
\hline Calapooia Winter Steelhead & Contributing & Primary & Primary \\
\hline Willamette WestSide Tribs Winter Steelhead & Stabilizing & Stabilizing $^{3}$ & Stabilizing $^{3}$ \\
\hline
\end{tabular}

1 Using the naming protocol of the Lower Columbia River Salmon Recovery Plan (LCFRB 2004), populations were classified based on information provided to the HSRG as Primary, Contributing, or Stabilizing. These designations are meant to reflect the conservation importance of a population within the DPS from most important (Primary- bold, red), to moderately important (Contributing-bold, blue), to least important (Stabilizing).

2 The HSRG developed criteria for hatchery influence for the three population designations from low influence (Primary), moderate influence (Contributing) to high influence (Stabilizing).

3 Meets HSRG criteria for a Primary population for hatchery influence (pHOS $<0.05)$, but population size is less than 50 adults.

\section{Current Harvest}

Harvest includes direct and indirect fishery mortality. No targeted commercial steelhead fisheries exist in the freshwater or ocean fisheries; however, steelhead are taken incidentally in the existing commercial fisheries targeting other salmon species. Upper Willamette River steelhead are selectively harvested in Columbia River and tributary freshwater recreational fisheries of Oregon. Fishery impacts on natural Upper Willamette River steelhead have been limited to less than 10 percent since the implementation of mark-selective fisheries during the 1980s.

\section{Current Habitat}

Mainstem Willamette and tributary habitat degradation has been pervasive, particularly in the lower reaches of tributaries to the Willamette. Conditions in the upper tributary subbasins, although not pristine, are relatively good. Specific concerns vary by subbasin, but include impaired access on small streams, fine sediments in spawning gravel, reduced habitat complexity, reduced access to off-channel habitat, reduced floodplain function and connectivity, elevated water temperatures, insufficient stream flows, and toxic water pollutants (NMFS 2008e). Causes of these conditions include widespread development as well as the effects of large hydropower and flood control dams, smaller passage barriers, and bank hardening. Loss of habitat due to blockages has been especially severe in the North Santiam and Calapooia subbasins (NMFS 2008e).

Five of the largest tributaries to the Willamette River are blocked by the 13 dams operated by the Army Corps of Engineers (ACOE). These dams were identified by NOAA Fisheries as the upper limit of winter steelhead distribution in its recent status review, although historically these fish spawned in habitat above some of these dams (NMFS 2006b). Fish passage facilities at priority dams in four major tributaries will be 


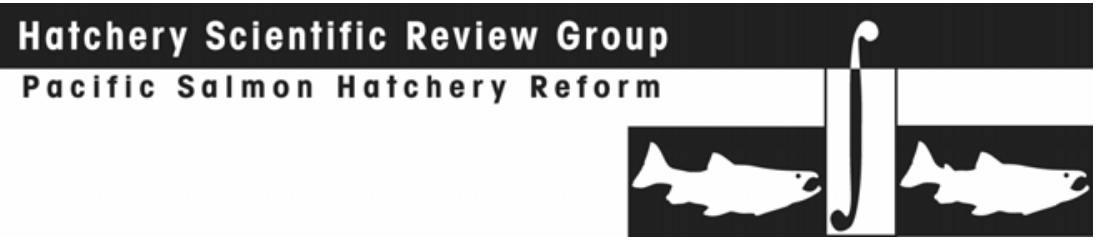

evaluated and modifications implemented over the next 15 years, as stipulated in a recent ESA consultation on the ACOE 13 dam complex. (NMFS 2008c).

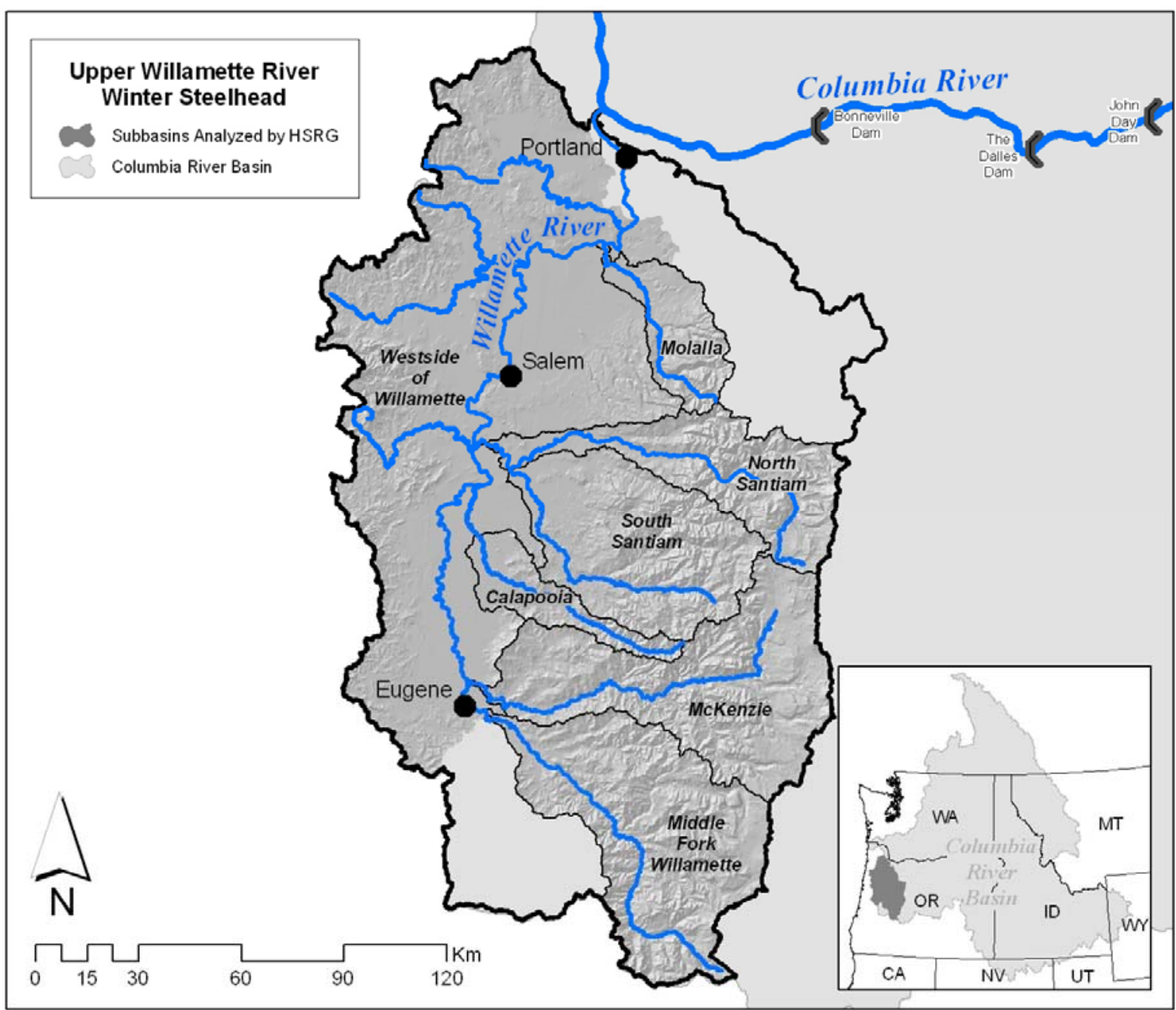

\section{Current Hatchery Programs}

Five segregated summer steelhead programs operate in the region (North Santiam, South Santiam, McKenzie, Middle Fork Willamette, and mainstem Willamette) that release approximately 600,000 summer steelhead smolts annually (Table 2). 
Table 2. Hatchery releases and types of programs for Upper Willamette Steelhead DPS.

\begin{tabular}{|c|c|c|c|c|c|c|}
\hline \multirow[b]{2}{*}{ Population/Program Name } & \multicolumn{3}{|c|}{ Current $(1,000 \mathrm{~s})$} & \multicolumn{3}{|c|}{ HSRG Solution $(1,000 \mathrm{~s})$} \\
\hline & Type & Purpose & $\begin{array}{c}\text { No. } \\
\text { Released }\end{array}$ & Type & Purpose & $\begin{array}{c}\text { No. } \\
\text { Released }\end{array}$ \\
\hline Willamette Molalla Winter Steelhead & None & NA & - & None & NA & - \\
\hline $\begin{array}{l}\text { Willamette: North Santiam Winter Steelhead } \\
\text { (Late) }\end{array}$ & None & NA & - & None & NA & - \\
\hline $\begin{array}{l}\text { Willamette: North Santiam Summer Steelhead (S. } \\
\text { Santiam Hatchery) }\end{array}$ & Seg & Harv & 161.1 & Seg & Harv & 161.1 \\
\hline Willamette: South Santiam Winter Steelhead & None & NA & - & None & NA & - \\
\hline $\begin{array}{l}\text { Willamette: South Santiam Summer Steelhead } \\
\text { (Hatchery) }\end{array}$ & Seg & Harv & 144.1 & Seg & Harv & 144.1 \\
\hline Willamette: Calapooia Winter Steelhead(Late) & None & NA & - & None & NA & - \\
\hline $\begin{array}{l}\text { Willamette: West Side Tribs Winter Steelhead } \\
\text { (Late) }\end{array}$ & None & NA & - & None & NA & - \\
\hline $\begin{array}{l}\text { Willamette: McKenzie Summer Steelhead } \\
\text { (S.Santiam-Hatchery) }\end{array}$ & Seg & Harv & 123.5 & Seg & Harv & 123.5 \\
\hline $\begin{array}{l}\text { Willamette: Middle Fork Willamette Summer } \\
\text { Steelhead (S.Santiam-Hatchery) }\end{array}$ & Seg & Harv & 114.5 & Seg & Harv & 114.5 \\
\hline $\begin{array}{l}\text { Willamette: Mainstem Willamette Summer } \\
\text { Steelhead (S.Santiam-Hatchery) }\end{array}$ & Seg & Harv & 51.2 & Seg & Harv & 51.2 \\
\hline Total all Populations/Programs & & & 594.4 & & & 594.4 \\
\hline
\end{tabular}

There are no winter steelhead hatchery programs in the upper Willamette subbasin; however, a non-native summer steelhead hatchery program is considered a threat to listed winter steelhead. Run and spawn timing are separate for hatchery-origin summer and wild winter steelhead, but the potential exists for genetic introgression.

The HSRG evaluated five natural populations of winter steelhead in the Upper Willamette DPS. Three of these populations, Molalla, North Santiam, and South Santiam, have been identified as Primary populations. The Molalla and South Santiam currently meet the HSRG criteria for Primary populations. The North Santiam, with a pHOS of approximately 20 percent, is only consistent with the criteria for a Stabilizing population. The Calapooia winter steelhead has been identified as a Contributing population, but actually meets the criteria of a Primary population under the HSRG guidelines, with a pHOS less than five percent.

The Westside Tributaries winter steelhead are currently designated as a Stabilizing population, but could achieve the standards of a Primary based on pHOS less than five percent. Historically this was a very small population and currently has an average natural-origin adult escapement of less than 50 adult spawners, which does not meet the minimum population size criterion of 500 adults for a Primary population. 


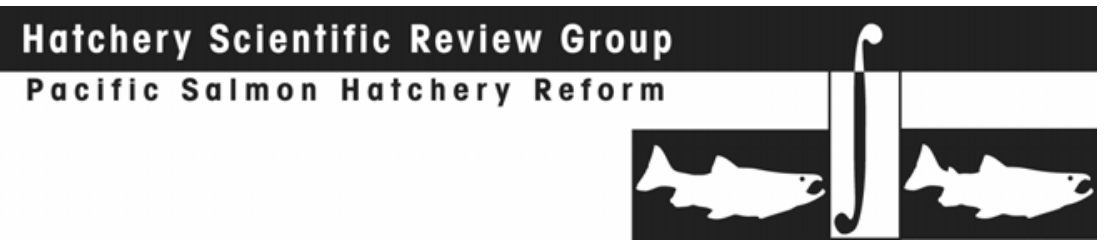

\subsubsection{HSRG Solutions}

All of the natural populations of steelhead in Upper Willamette are winter run while all of the hatchery programs are segregated summer run steelhead. While this run timing difference has reduced the impacts of hatchery programs on the natural populations, there are possible but unknown levels of interbreeding and competition between these different life histories that could have negative impacts on the natural winter steelhead populations. The HSRG recommends monitoring the impacts to the natural populations through interbreeding and competition, especially in the North Santiam where the pHOS is currently above the standards for a Primary population.

\section{Conservation Outcomes under the HSRG Solutions}

Figure 1 compares the proportion of hatchery-origin fish on the spawning grounds (pHOS) and the proportionate natural influence (PNI) for current and proposed (HSRG) scenarios for Primary and Contributing populations. The HSRG solution does not change the status of the Molalla or South Santiam Primary populations (pHOS less than 5 percent), but it does reduce the pHOS in the North Santiam from approximately 20 percent to less than 5 percent, thus moving it from a Stabilizing to a Primary population.

The HSRG recommendations do not change the status of the Calapooia population, which although designated as Contributing, actually meets the standards of a Primary population with a pHOS of less than 5 percent and a population size greater than 500 adults. The remnant Westside Tributaries population also meets the standards of a Primary population for hatchery influence based on a pHOS less than 5 percent; however, its designation is Stabilizing due to small population numbers ( $\sim 50$ adults).

Figure 2 compares spawner abundance and productivity relationships between current and HSRG-proposed scenarios for the three Primary and one Contributing winter steelhead population in the Upper Willamette DPS. The only population that significantly improves in productivity and abundance is the North Santiam by reducing the number of hatchery summer steelhead on the spawning grounds. Under the HSRG solution, the productivity and abundance increase significantly.

\section{Harvest Outcomes under the HSRG Solutions}

Figure 3 illustrates the current harvest and estimated changes in harvest (from marine, mainstem Columbia River and terminal harvest areas) that the analysis indicates would occur following implementation of the management solutions proposed by the HSRG. In this case, since none of the harvest augmentation hatchery programs were modified, the future harvest outcomes, both in terms of total harvest and harvest distribution, are essentially the same as under the current conditions.

\section{Hatchery Program Changes under the HSRG Solutions}

Table 2 shows the current size of each hatchery program as well as the size under the HSRG solutions. For this DPS, there were no proposed changes to program release numbers. Future program changes could be proposed for the North Santiam if the number of hatchery fish on the spawning grounds cannot be reduced to less than five percent. 
Hatchery steelhead are recycled through the lower North Santiam River to provide a second opportunity for sport harvest. This recycling contributes to a high $\mathrm{pHOS}$ in this population. To address this issue, the HSRG recommends discontinuing the recycling of hatchery steelhead. The HSRG also recommends that managers remove more returning hatchery adults, either through liberalized selective harvest or other methods. If these methods of reducing the hatchery fish on the spawning grounds are unsuccessful, the HSRG has identified a reduced program of $\sim 40,000$ summer steelhead smolts that would meet criteria for a Primary population with a pHOS less than five percent.

Under the proposed HSRG solutions, only one population, the North Santiam, improves from a Stabilizing to a Primary population. The other four populations, Molalla, South Santiam, Calapooia, and the West Side Tributaries remain at the Primary population level.

\subsubsection{Summary and Conclusions}

The HSRG solution improves the condition of one population from a Stabilizing to a Primary designation. HSRG standards for broodstock management are achieved or exceeded for every population in this DPS; however, abundance remains low.

The HSRG was unable to develop solutions that would significantly increase naturalorigin returns (abundance) for most of the populations in the DPS given the currently inaccessible habitat. Historic steelhead habitat occurs above many passage barriers in this watershed, and unless fish passage is provided at these tributary dams, the likelihood of achieving greater conservation benefits in this DPS is poor. If currently inaccessible habitat becomes available in the future, managers should reassess their programs and modify them to take advantage of additional habitat productivity and capacity.

The HSRG also concludes that (a) hatchery and harvest reforms alone will not achieve recovery of listed populations (habitat improvements are also necessary), and (b) effectiveness of habitat actions would be greatly increased if combined with hatchery and harvest reforms. Analysis of the Primary North Santiam steelhead population suggests that the benefits of habitat quality improvements would increase by six times if combined with hatchery reforms. Unless hatchery and harvest reforms are implemented, the potential benefits of current or improved habitat cannot be fully realized. 


\section{Hatchery Scientific Review Group}

Pacific Salmon Hatchery Reform
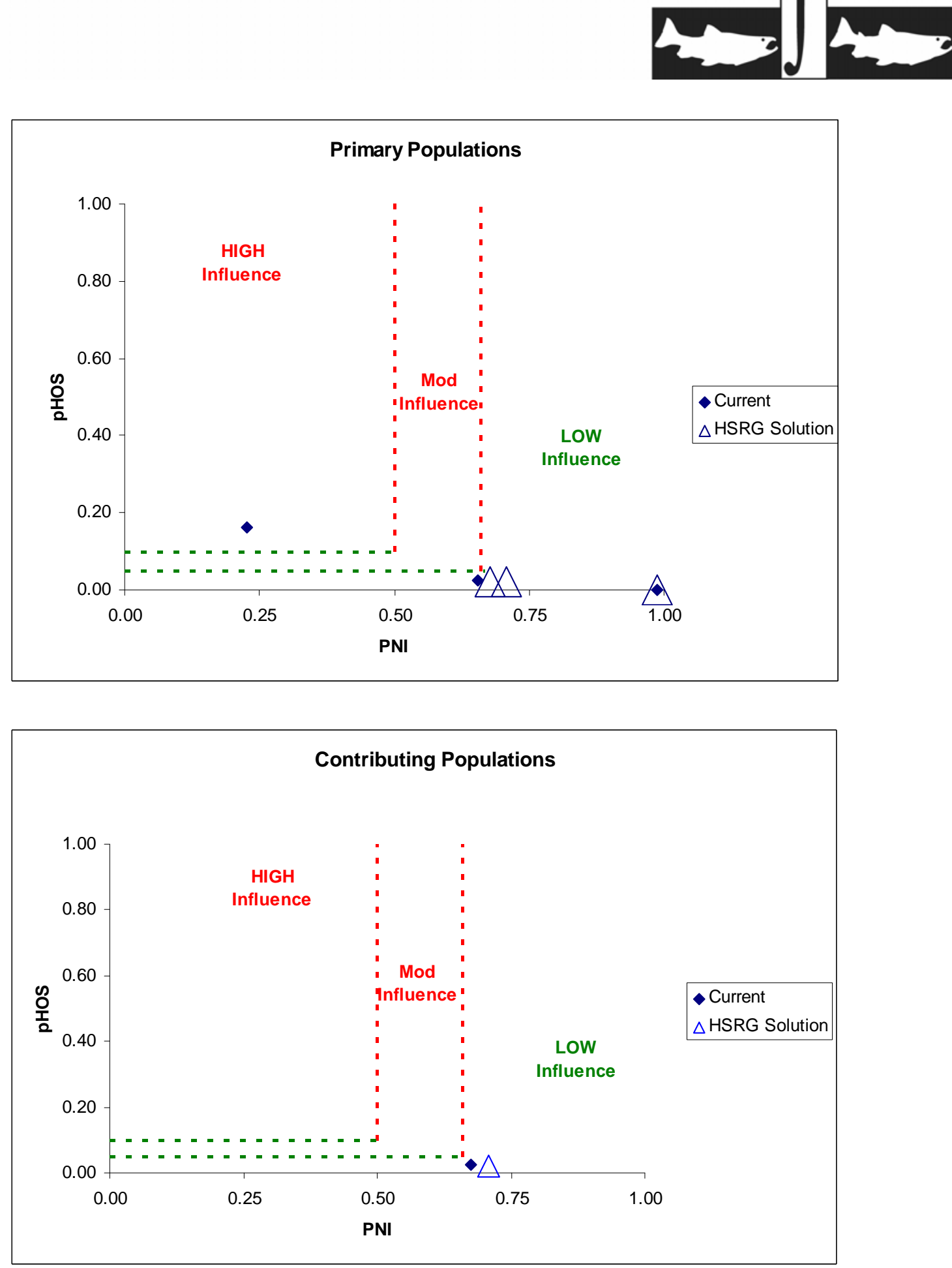

Figure 1. Relationship of the proportion of the fish on the spawning grounds that are of hatchery origin (pHOS) and the proportionate natural influence index (PNI) for Primary (top panel) and Contributing (bottom panel) steelhead populations in the Upper Willamette DPS. Solid diamonds represent values for current programs and open triangles represent values for the HSRG recommended hatchery management solution. 


\section{Hatchery Scientific Review Group}

Pacific Salmon Hatchery Reform
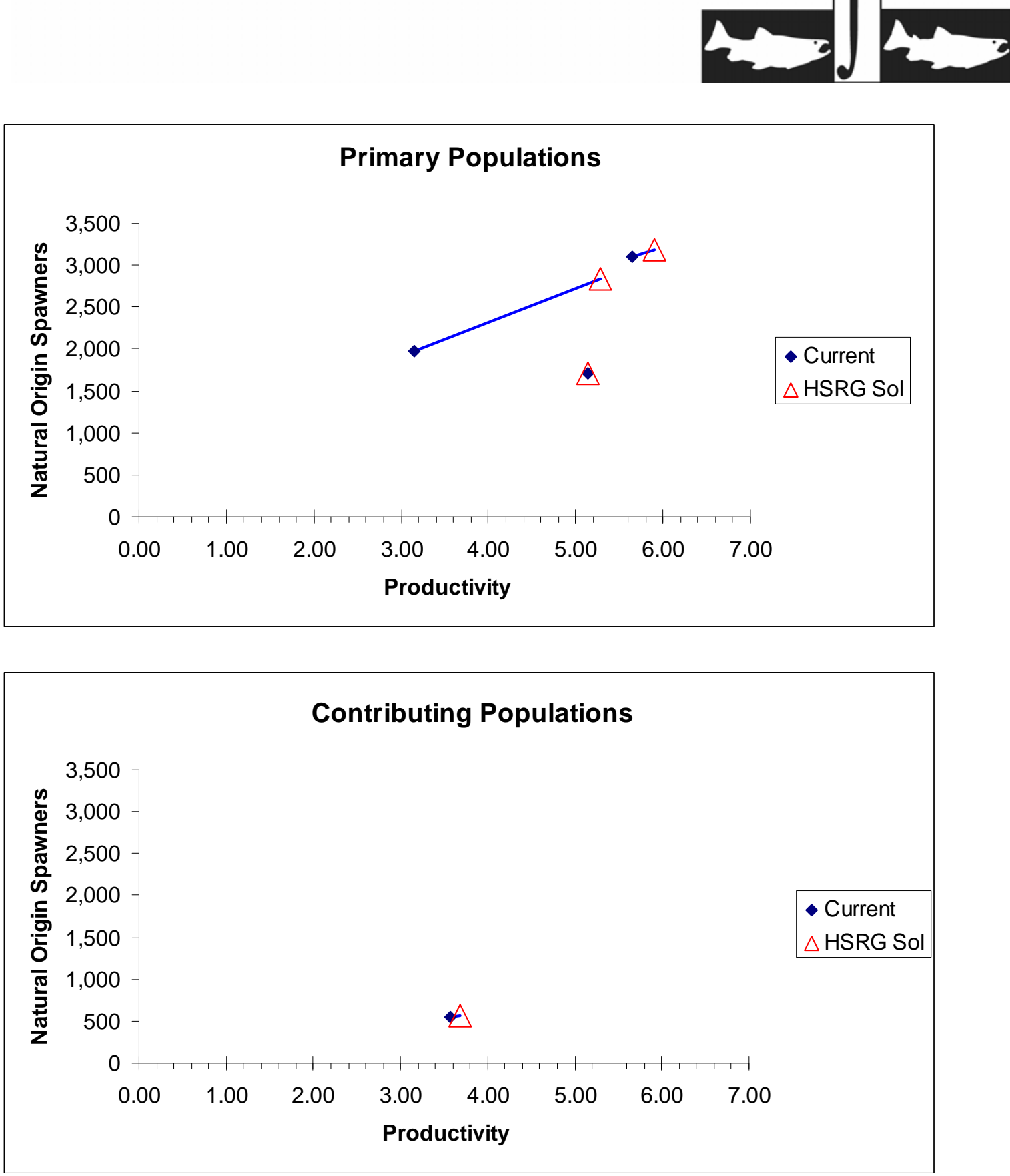

Figure 2. Productivity and spawner abundance for Primary (top panel) and Contributing (bottom panel) steelhead populations in the Upper Willamette DPS. Solid diamonds represent existing productivity and spawner abundance levels, and triangles represent the HSRG recommended hatchery management solution. Lines connect current with HSRG solution for a particular population. 

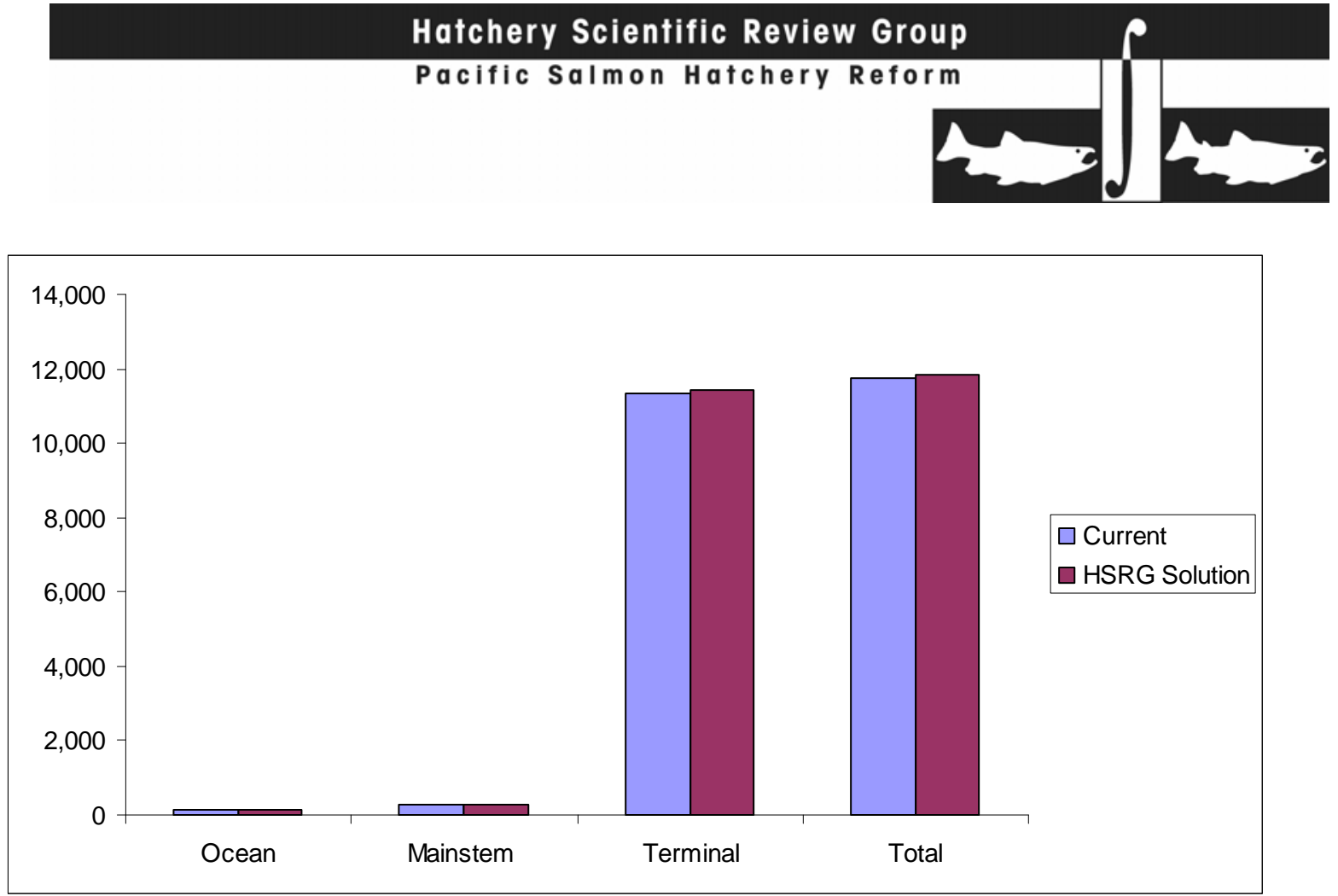

Figure 3. Estimated marine, mainstem Columbia, and terminal harvest under current and HSRG recommended hatchery management solution for Upper Willamette Steelhead DPS.

\subsubsection{Middle Columbia River Steelhead DPS}

This section provides an overview of the Middle Columbia River Steelhead DPS which was listed as Threatened under the ESA in 1999. It contains a general description of the DPS, fisheries, habitat limitations and hatchery programs that affect it. Overall recommendations for DPS-wide hatchery program changes are summarized as are the results of implementing those changes on conservation and harvest goals. Detailed conclusions and recommendations for each population in the DPS can be found in the Appendix E.

\subsubsection{HSRG Population Guidelines}

In order to meet conservations goals for the DPS, numerous threats to these populations need to be addressed, including risks from hatchery programs. The key to controlling genetic and ecological risks due to straying and fitness loss is to manage hatchery broodstock and natural spawning escapement such that the natural habitat (and not the hatchery environment) drives the adaptation and productivity of the naturally spawning population. This is achieved by operating either (a) integrated programs where the proportion of natural-origin adults in the broodstock (pNOB) exceeds the proportion of hatchery-origin fish on the spawning grounds (pHOS); or (b) segregated programs where the contribution of hatchery fish to natural spawning is kept low (pHOS $<5 \%$ to $<10 \%$ depending on the population designation). The HSRG developed criteria for hatchery influence for three population types based on the importance of the population to the recovery of the DPS. This was done to provide a consistent method of reviewing 


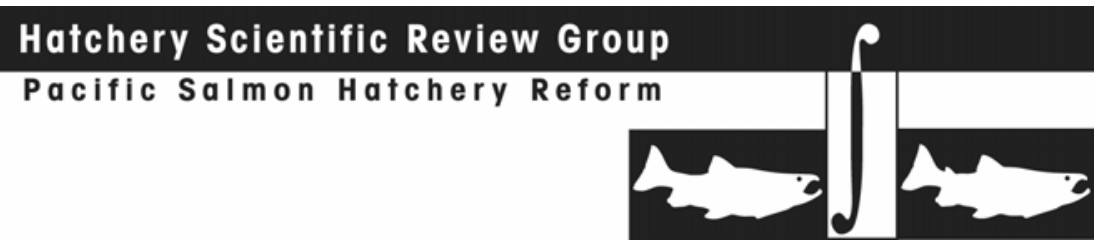

populations and programs across the Columbia River Basin. The population designations used by the HSRG (Primary, Contributing, or Stabilizing) were adopted after discussions with managers and followed those developed in the Lower Columbia River Salmon Recovery Plan (LCFRB 2004). These designations are meant to reflect the conservation importance of a population within the DPS from most important (Primary), to moderately important (Contributing), to least important (Stabilizing). HSRG recommendations show how hatchery programs can be operated consistent with these designations based on the following standards:

HSRG criteria for hatchery influence on Primary populations

- The proportion of effective hatchery-origin spawners (pHOS) should be less than 5\% of the naturally spawning population, unless the hatchery population is integrated with the natural population.

- For integrated populations, the proportion of natural-origin adults in the broodstock should exceed pHOS by at least a factor of two, corresponding to a proportionate natural influence (PNI) value of 0.67 or greater and pHOS should be less than 0.30 .

HSRG criteria for hatchery influence on Contributing populations

- The proportion of effective hatchery-origin spawners (pHOS) should be less than $10 \%$ of the naturally spawning population, unless the hatchery population is integrated with the natural population.

- For integrated populations, the proportion of natural-origin adults in the broodstock should exceed pHOS, corresponding to a PNI value of 0.50 or greater and $\mathrm{pHOS}$ should be less than 0.30 .

HSRG criteria for hatchery influence on Stabilizing populations:

- The current operating conditions were considered adequate to meet conservation goals. No criteria were developed for proportion of effective hatchery-origin spawners (pHOS) or PNI.

\subsubsection{Current Conditions}

\section{Conservation}

The Middle Columbia River steelhead DPS, as defined by the federal Endangered Species Act, includes all anadromous Oncorhynchus mykiss populations in Oregon and Washington subbasins upstream of the Hood and Wind river systems up to and including the Yakima River, and the populations of seven artificial propagation programs. The DPS includes four major population groups (MPGs) encompassing 17 populations. The Mid-Columbia River steelhead DPS was listed as threatened under the ESA in 1999. The draft ICTRT Current Status Summaries (ICTRT 2007) characterized the long-term extinction risk as "moderate" for most Middle Columbia River steelhead populations. North Fork John Day has a "very low" risk, and four populations (Rock Creek, Touchet, Toppenish, and Upper Yakima) are at "high" risk for extinction.

The ICTRT characterizes the diversity and spatial structure risks to Middle Columbia River steelhead populations as "very low" to "moderate" for all populations except the Upper Yakima. The Yakima population has "high" diversity risk because of 


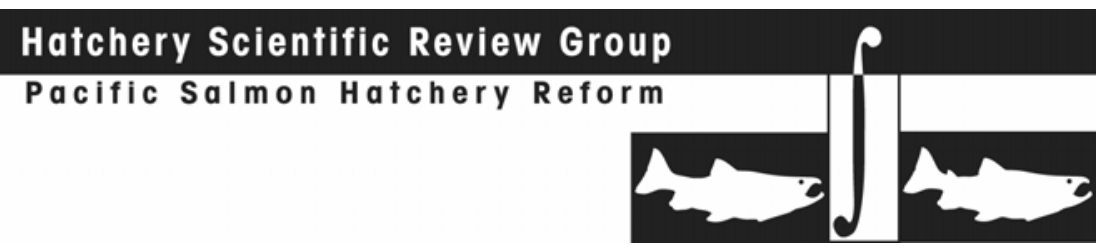

introgression with resident rainbow trout, loss of pre-smolt migration pathways and because 7 of 10 historical major spawning areas are not occupied.

For the purpose of this review, the HSRG designated 12 populations as Primary, four populations as Contributing, and one as Stabilizing (Table 1).

Table 1. Population designations for the Middle Columbia Summer Steelhead DPS and HSRG broodstock criteria achieved for each population under current conditions and the HSRG recommended hatchery management solution.

\begin{tabular}{|l|c|c|c|}
\hline \multirow{2}{*}{ Population } & & \multicolumn{2}{c|}{ HSRG Criteria Met ${ }^{2}$} \\
\cline { 3 - 4 } & Designation ${ }^{1}$ & Current & $\begin{array}{c}\text { HSRG } \\
\text { Solution }\end{array}$ \\
\hline Deschutes_Eastside Tributaries Summer Steelhead & Primary & Stabilizing & Primary \\
\hline Deschutes_Westside Tributaries Summer Steelhead & Primary & Stabilizing & Stabilizing \\
\hline Fifteenmile Creek Winter Steelhead & Primary & Primary & Primary \\
\hline John Day_Lower Mainstem Summer Steelhead & Primary & Contributing & Primary \\
\hline John Day_Middle Fork Summer Steelhead & Primary & Contributing & Primary \\
\hline John Day_North Fork Summer Steelhead & Primary & Primary & Primary \\
\hline Klickitat Summer-Winter Steelhead & Primary & Contributing & Primary \\
\hline Umatilla Summer Steelhead & Primary & Primary & Primary \\
\hline Walla Walla Summer Steelhead & Primary & Stabilizing & Contributing \\
\hline Walla Walla_Touchet Summer Steelhead & Primary & Primary & Primary \\
\hline Yakima_Naches Summer Steelhead & Primary & Primary & Primary \\
\hline Yakima_Satus Summer Steelhead & Primary & Primary & Primary \\
\hline John Day_South Fork Summer Steelhead & Contributing & Primary & Primary \\
\hline John Day_Upper Mainstem Summer Steelhead & Contributing & Primary & Primary \\
\hline Yakima_Toppenish Summer Steelhead & Contributing & Primary & Primary \\
\hline Yakima_Upper Yakima Summer Steelhead & Contributing & Stabilizing & Contributing \\
\hline White Salmon Summer-Winter Steelhead & Stabilizing & Stabilizing & Stabilizing \\
\hline
\end{tabular}

1 Using the naming protocol of the Lower Columbia River Salmon Recovery Plan (LCFRB 2004), populations were classified based on information provided to the HSRG as Primary, Contributing, or Stabilizing. These designations are meant to reflect the conservation importance of a population within the DPS from most important (Primary- bold, red), to moderately important (Contributing-bold, blue), to least important (Stabilizing).

2 The HSRG developed criteria for hatchery influence for the three population designations from low influence (Primary), moderate influence (Contributing) to high influence (Stabilizing).

\section{Current Harvest}

Hatchery programs within the DPS provide substantial harvest benefits in the mainstem Columbia River up through terminal areas and contribute to both sport and tribal fisheries. There are no freshwater recreational fisheries directly targeting natural-origin steelhead in the Middle Columbia DPS. Incidental mortality of natural-origin fish occurs in fisheries targeting hatchery-origin fish. Impacts to natural-origin fish are limited by ESA authorizations and management agreements. Steelhead generally do not contribute to ocean fisheries. 


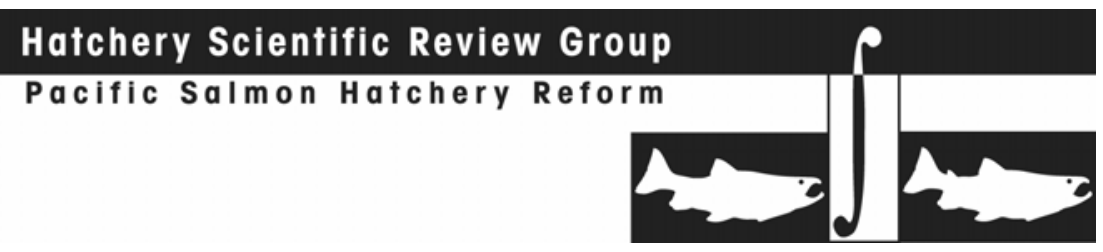

Current Habitat

Throughout the DPS, major habitat limiting factors are large tributary barriers that include push-up dams, culverts, withdrawals that dewater streams, and unscreened water diversions that entrain juvenile steelhead. Tributary habitat conditions vary widely among the various drainages occupied by Middle Columbia River steelhead, but generally habitat has been degraded by land uses, such as forestry and agriculture, resulting in reduced stream flow, riparian vegetation loss, excess sedimentation, and loss of off-channel habitat and complexity.

\section{Current Hatchery Programs}

Eight hatchery programs affect the Middle Columbia River steelhead DPS. Currently six segregated hatchery programs operate in the White Salmon, Klickitat, Deschutes, and Walla Walla River subbasins, releasing a total of approximately 480,000 steelhead smolts annually, most of which are summer steelhead (Table 2). Two integrated programs operate in the Umatilla and Walla Walla subbasins, releasing approximately 200,000 summer steelhead smolts each year.

Hatchery programs in the DPS were developed to provide harvest to mitigate for annual losses of steelhead caused by hydroelectric projects and to act as a genetic reserve for Middle Columbia River steelhead.

The HSRG estimates of PNI and pHOS indicate that under current conditions, six of the twelve Primary populations meet HSRG standards for Primary status (with three currently meeting Contributing and three meeting Stabilizing standards). Of the four populations designated as Contributing, three meet the HSRG's standards for a Primary population (with one at Stabilizing). The single population designated as Stabilizing is consistent with the HSRG's standards for that designation. Thus, of the populations in the DPS, eight currently meet Primary status, one meets Contributing status, and four meet Stabilizing status (Table 1).

Table 2. Hatchery releases and types of programs for Middle Columbia Summer Steelhead DPS.

\begin{tabular}{|l|c|c|c|c|c|c|}
\hline \multirow{2}{*}{ Population/Program Name } & \multicolumn{3}{|c|}{ Current (1,000s) } & \multicolumn{3}{c|}{ HSRG Solution (1,000s) } \\
\cline { 2 - 8 } & Type & Purpose & \# Released & Type & Purpose & \# Released \\
\hline White Salmon Summer-Winter Steelhead & None & NA & - & None & NA & - \\
\hline White Salmon Summer Steelhead (Skamania-Hatchery) & Seg & Harv & 20.1 & Seg & Harv & - \\
\hline White Salmon Winter Steelhead (Skamania-Hatchery) & Seg & Harv & 19.8 & Seg & Harv & - \\
\hline Klickitat Summer-Winter Steelhead & None & NA & - & Int & Both & 120.4 \\
\hline Klickitat Summer Steelhead (Skamania-Hatchery) & Seg & Harv & 100.5 & Seg & Harv & - \\
\hline Fifteenmile Creek Winter Steelhead & None & NA & - & None & NA & - \\
\hline Deschutes_Westside Tributaries Summer Steelhead & None & NA & - & None & NA & - \\
\hline Deschutes_Eastside Tributaries Summer Steelhead & None & NA & - & Int & NA & - \\
\hline Deschutes Summer Steelhead (Round Butte-Hatchery) & Seg & Harv & 162.1 & Seg & Harv & 162.1 \\
\hline John Day_Lower Mainstem Summer Steelhead & None & NA & - & None & NA & - \\
\hline John Day_Middle Fork Summer Steelhead & None & NA & - & None & NA & - \\
\hline John Day_North Fork Summer Steelhead & None & NA & - & None & NA & - \\
\hline John Day_South Fork Summer Steelhead & None & NA & - & None & NA & - \\
\hline John Day_Upper Mainstem Summer Steelhead & None & NA & - & None & NA & - \\
\hline
\end{tabular}




\section{Hatchery Scientific Review Group}

Pacific Salmon Hatchery Reform

\begin{tabular}{|l|c|c|c|c|c|c|}
\hline \multirow{2}{*}{ Population/Program Name } & \multicolumn{3}{|c|}{ Current (1,000s) } & \multicolumn{3}{c|}{ HSRG Solution (1,000s) } \\
\cline { 2 - 8 } & Type & Purpose & \# Released & Type & Purpose & \# Released \\
\hline Umatilla Summer Steelhead & Int & Both & 149.9 & Int & Both & 149.9 \\
\hline Walla Walla Summer Steelhead & None & NA & - & None & NA & - \\
\hline Walla Walla Summer Steelhead (Lyons Ferry-Hatchery) & Seg & Harv & 100.2 & Seg & Harv & 100.2 \\
\hline Walla Walla_Touchet Summer Steelhead & Int & Cons & 49.2 & Int & Cons & 49.2 \\
\hline Walla Walla Touchet Summer Steelhead (Lyons Ferry-Hatchery) & Seg & Harv & 84.4 & Seg & Harv & 21.1 \\
\hline Yakima_Naches Summer Steelhead & None & NA & - & None & NA & - \\
\hline Yakima_Satus Summer Steelhead & None & NA & - & None & NA & - \\
\hline Yakima_Toppenish Summer Steelhead & None & NA & - & None & NA & - \\
\hline Yakima_Upper Yakima Summer Steelhead & None & NA & - & None & NA & - \\
\hline Total all Populations/Programs & & & $\mathbf{6 8 6 . 2}$ & & & $\mathbf{6 0 2 . 9}$ \\
\hline
\end{tabular}

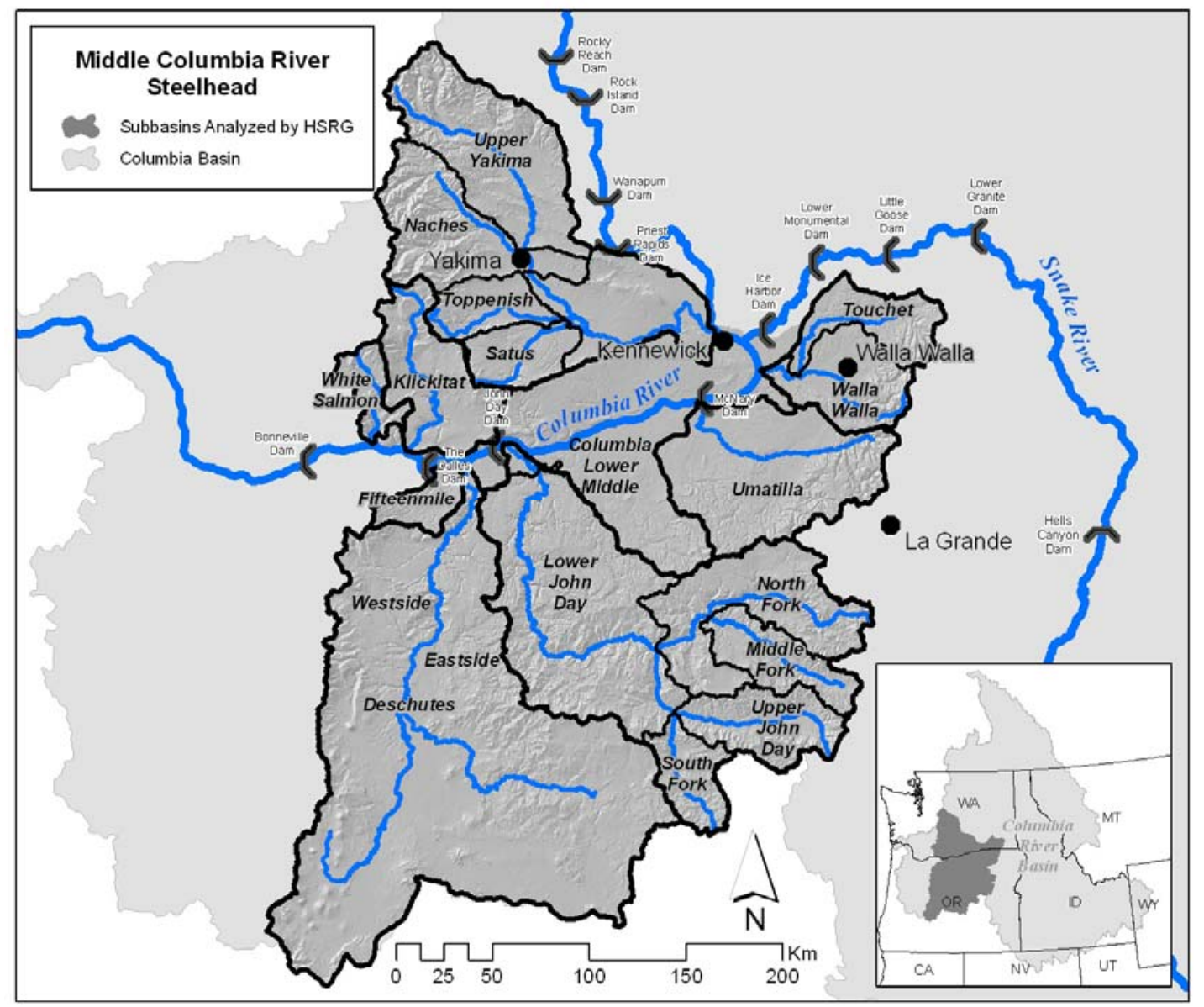




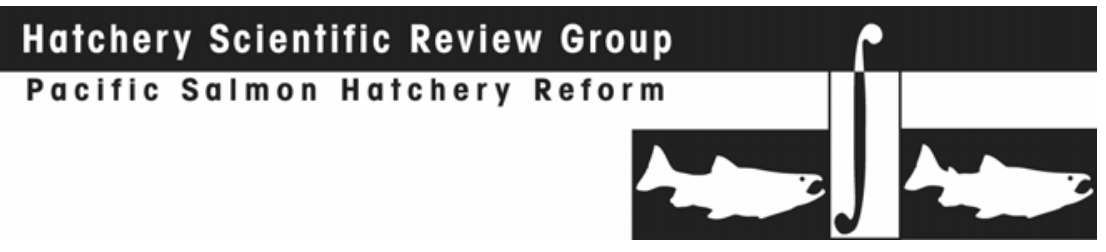

\subsubsection{HSRG Solutions}

HSRG solutions for the Middle Columbia Steelhead DPS include resizing some existing programs, terminating select programs, and changing focus of some programs to collect local broodstock and produce integrated release strategies.

\section{Conservation Outcomes under the HSRG Solutions}

The HSRG solutions make considerable improvements in productivity and spawner abundance (Figures 1 and 2). The number of populations currently meeting criteria for a Primary designation increases from 9 to 13 (Table 1). Major groupings within this DPS are managed as wild fish management zones (John Day and Yakima river basins).

For many natural populations, hatchery strays from out-of-basin reportedly have exceeded 5 percent of the natural spawning population (particularly for populations in the Deschutes and John Day rivers). For these populations, the HSRG recommends additional monitoring of spawning abundance and composition, and implementing actions to reduce the proportion of hatchery strays in the natural spawning populations.

\section{Harvest Outcomes under the HSRG Solutions}

Figure 3 depicts current and estimated changes in harvest (in marine, mainstem Columbia River and terminal areas) that would occur following implementation of the management solutions proposed by the HSRG. Overall, harvest opportunities are slightly reduced.

\section{Hatchery Program Changes under the HSRG Solutions}

Table 2 shows the current size of each hatchery program as well as their size under the HSRG solutions. For this DPS, the number of smolts released decreases from approximately 686,000 to 603,000 smolts and broodstock management changes for several programs.

Changes include discontinuing the segregated programs in the White Salmon River for both summer $(20,000)$ and winter $(20,000)$ steelhead to promote reestablishment of naturally-spawning populations from resident populations after removal of Condit Dam.

The direct release into the Klickitat River of 100,000 segregated summer steelhead from Skamania Hatchery is discontinued and shifted to an integrated 120,000 release from the Klickitat Hatchery.

The HSRG solution transitions Lyons Ferry Hatchery broodstock collection to sites within the Walla Walla and Touchet in place of current broodstock collection at Lyons Ferry Hatchery to aid in local adaptation. The solution maintains current release numbers in the Walla Walla but reduces them in the Touchet River (Table 2).

Current programs in the Deschutes (Round Butte Hatchery) and Umatilla (Umatilla Hatchery) rivers remain unchanged.

In addition to the above recommendations, the HSRG notes the need for additional adult collection facilities in several locations to improve the ability to collect unharvested hatchery-origin fish. Also, managers need to explore options to reduce the proportion of hatchery strays in some important natural spawning populations. 


\section{Hatchery Scientific Review Group}

Pacific Salmon Hatchery Reform
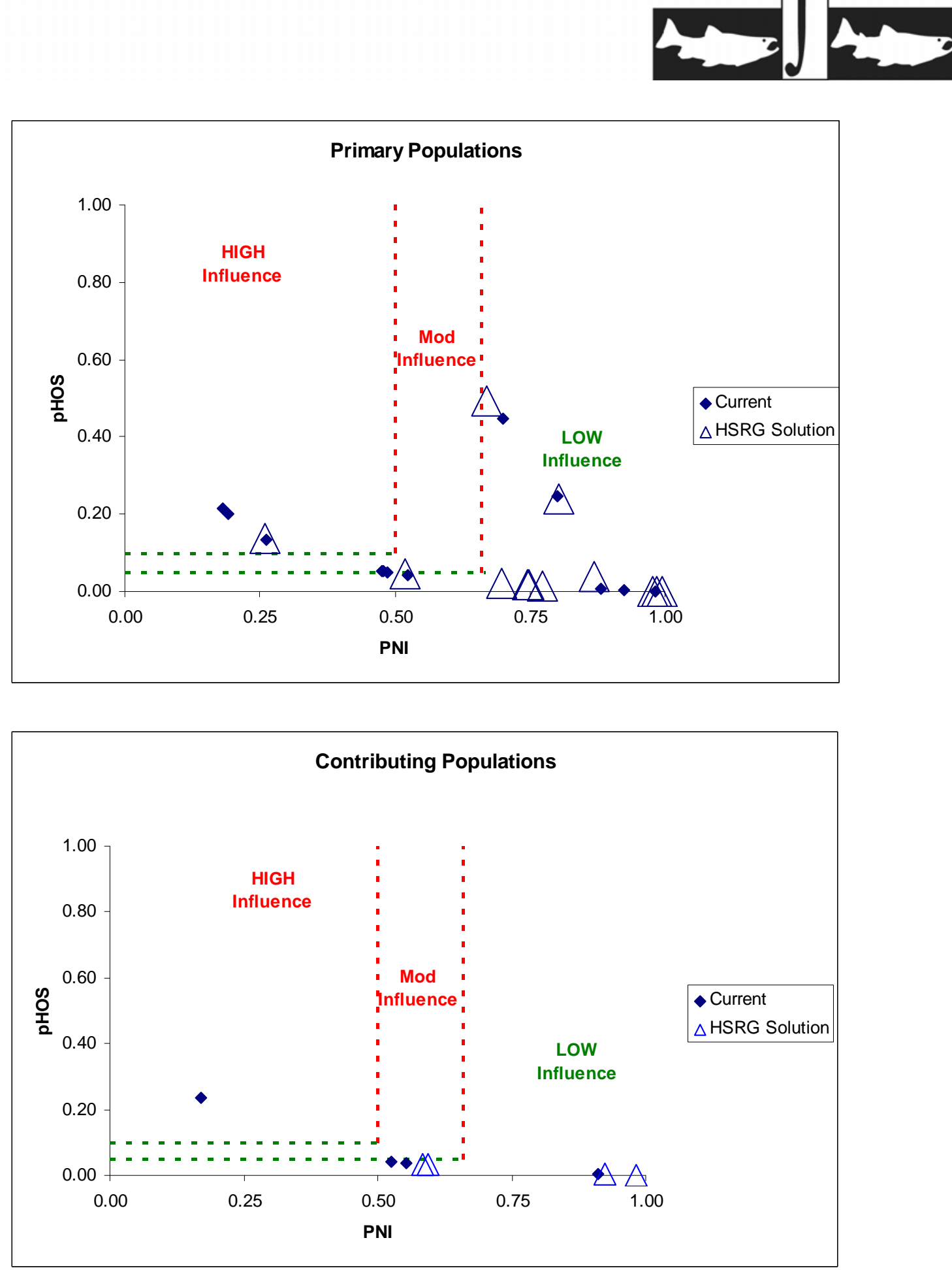

Figure 1. Relationship of the proportion of the fish on the spawning grounds that are of hatchery origin (pHOS) and the proportionate natural influence index (PNI) for Primary (top panel) and Contributing (bottom panel) summer steelhead populations in the Middle Columbia Steelhead DPS. Solid diamonds represent values for current programs and open triangles represent values for the HSRG recommended hatchery management solution. 


\section{Hatchery Scientific Review Group}

Pacific Salmon Hatchery Reform
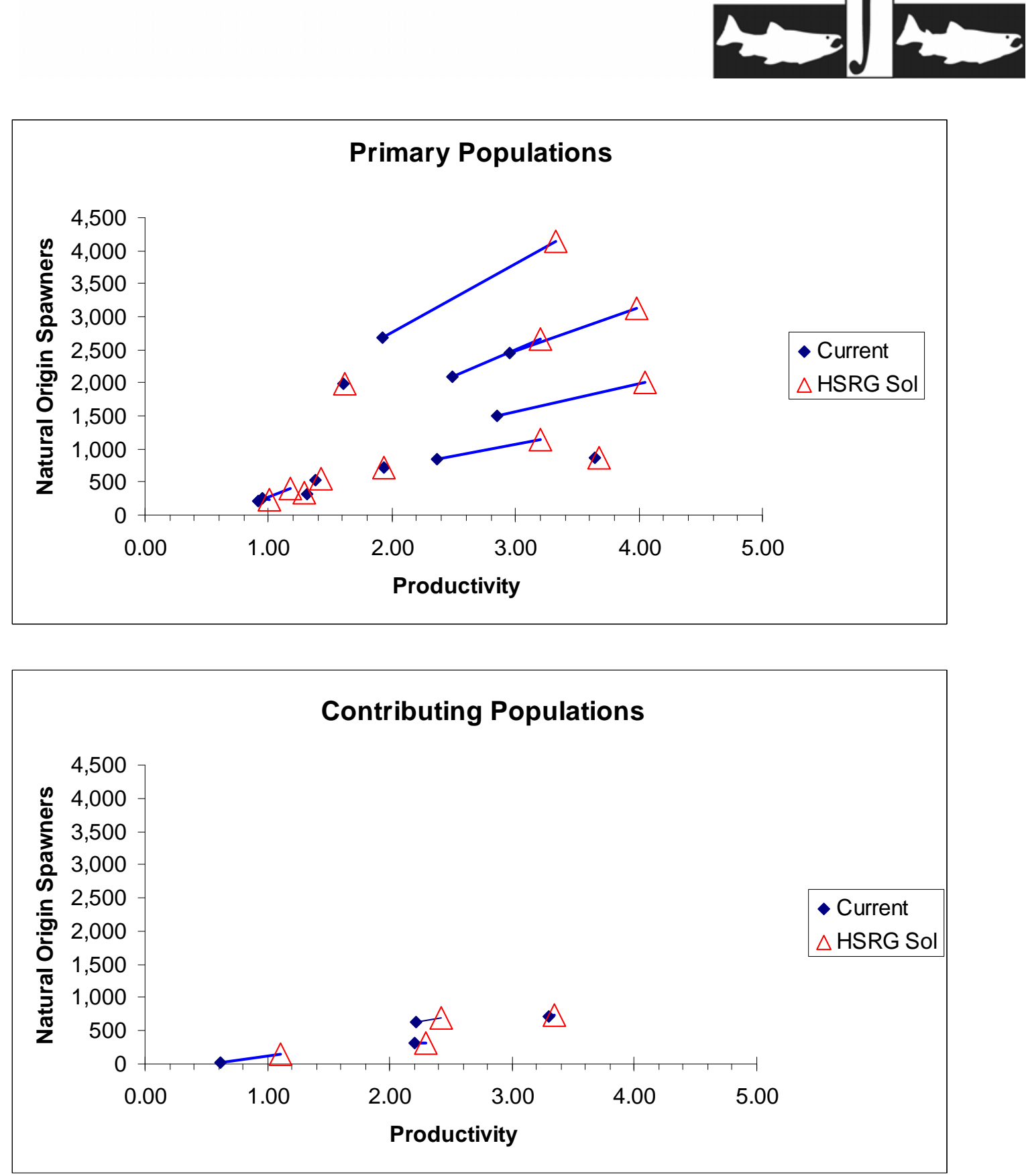

Figure 2. Productivity and spawner abundance for Primary (top panel) and Contributing (bottom panel) summer steelhead populations in the Middle Columbia Steelhead DPS. Solid diamonds represent existing productivity and spawner abundance levels, and triangles represent the HSRG recommended hatchery management solution. Lines connect current with HSRG solution for a particular population. The HSRG recommended hatchery management solution includes projected improved fish passage survival in the Snake and Columbia mainstem migration corridor (FCRPS Biological Opinion May 5, 2008). 


\section{Hatchery Scientific Review Group}

Pacific Salmon Hatchery Reform
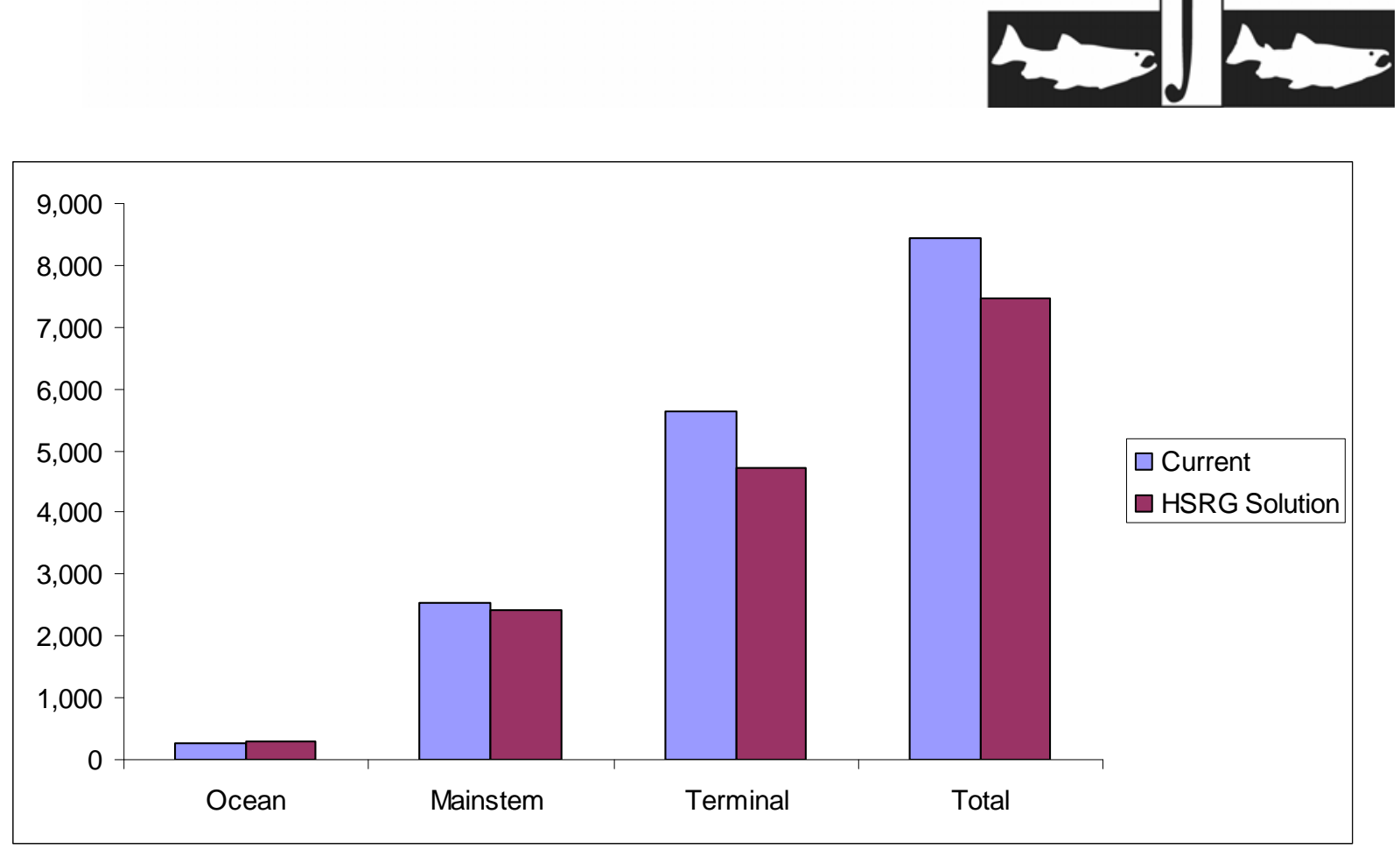

Figure 3. Estimated marine, mainstem Columbia, and terminal harvest under current and HSRG recommended hatchery management solution for Middle Columbia Summer Steelhead DPS. The HSRG recommended hatchery management solution includes projected improved fish passage survival in the Snake and Columbia mainstem migration corridor (FCRPS Biological Opinion May 5 , 2008).

\section{Summary and Conclusions}

The Middle Columbia River Steelhead DPS contains 17 populations. Under HSRG recommendations, four additional populations meet the standards for a Primary designation, and one additional population meets the standards for a Contributing designation. This results in 13 of the populations meeting a Primary designation, 2 meeting the standards for a Contributing designation and 2 meeting Stabilizing standards.

HSRG recommendations include a modest decrease in segregated hatchery production in this DPS; integrated program production would increase. These recommendations result in a slight decrease in harvest.

The HSRG recommends that managers explore options for reducing out-of-DPS strays into the Deschutes and John Day river systems.

The HSRG also concludes that (a) hatchery and harvest reforms alone will not achieve recovery of listed populations (habitat improvements are also necessary), and (b) the effectiveness of habitat actions would greatly increase if combined with hatchery and harvest reforms. Analysis of the Primary populations in the Mid-Columbia steelhead DPS suggests that the benefits of habitat quality improvements would nearly triple if combined with hatchery reforms. Unless hatchery and harvest reforms are implemented, the potential benefits of current or improved habitat cannot be fully realized. 


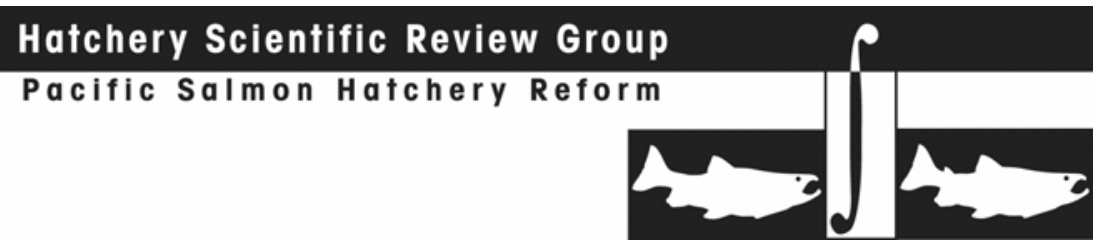

\subsubsection{Upper Columbia River Steelhead DPS}

This section provides an overview of the Upper Columbia River Steelhead DPS. It contains a general description of the DPS, fisheries, habitat limitations and hatchery programs that affect it. Overall recommendations for DPS-wide hatchery program changes are summarized as are the results of implementing those changes on conservation and harvest goals. Detailed conclusions and recommendations for each population in the DPS can be found in the Appendix E.

\subsubsection{HSRG Population Guidelines}

In order to meet conservations goals for the DPS, numerous threats to these populations need to be addressed, including risks from hatchery programs. The key to controlling genetic and ecological risks due to straying and fitness loss is to manage hatchery broodstock and natural spawning escapement such that the natural habitat (and not the hatchery environment) drives the adaptation and productivity of the naturally spawning population. This is achieved by operating either (a) integrated programs where the proportion of natural-origin adults in the broodstock (pNOB) exceeds the proportion of hatchery-origin fish on the spawning grounds (pHOS); or (b) segregated programs where the contribution of hatchery fish to natural spawning is kept low (pHOS $<5 \%$ to $<10 \%$ depending on the population designation). The HSRG developed criteria for hatchery influence for three population types based on the importance of the population to the recovery of the DPS. This was done to provide a consistent method of reviewing populations and programs across the Columbia River Basin. The population designations used by the HSRG (Primary, Contributing, or Stabilizing) were adopted after discussions with managers and followed those developed in the Lower Columbia River Salmon Recovery Plan (LCFRB 2004). These designations are meant to reflect the conservation importance of a population within the DPS from most important (Primary), to moderately important (Contributing), to least important (Stabilizing). HSRG recommendations show how hatchery programs can be operated consistent with these designations based on the following standards:

\section{HSRG criteria for hatchery influence on Primary populations}

- The proportion of effective hatchery-origin spawners (pHOS) should be less than 5\% of the naturally spawning population, unless the hatchery population is integrated with the natural population.

- For integrated populations, the proportion of natural-origin adults in the broodstock should exceed pHOS by at least a factor of two, corresponding to a proportionate natural influence (PNI) value of 0.67 or greater and pHOS should be less than 0.30 .

HSRG criteria for hatchery influence on Contributing populations:

- The proportion of effective hatchery-origin spawners (pHOS) should be less than $10 \%$ of the naturally spawning population, unless the hatchery population is integrated with the natural population.

- For integrated populations, the proportion of natural-origin adults in the broodstock should exceed $\mathrm{pHOS}$, corresponding to a PNI value of 0.50 or greater and $\mathrm{pHOS}$ should be less than 0.30 . 
HSRG criteria for hatchery influence on Stabilizing populations:

- The current operating conditions were considered adequate to meet conservation goals. No criteria were developed for proportion of effective hatchery-origin spawners (pHOS) or PNI.

\subsubsection{Current Conditions}

\section{Conservation}

The Upper Columbia River Steelhead DPS, as defined by the Endangered Species Act, includes all naturally spawned steelhead populations below natural and man-made impassable barriers in streams in the Columbia River Basin upstream from the Yakima River to the U.S.-Canada border, including the populations of six artificial propagation programs. The Upper Columbia River Steelhead DPS was listed as endangered under the ESA in 1997, upgraded to threatened in 2006, then reinstated as endangered in 2007. The DPS includes one major population group containing the Wenatchee, Entiat, Methow and Okanogan subbasins. The historical range of this DPS included the Crab Creek, San Poil, Spokane, Kettle, Pend Oreille, and Kootenai subbasins populations, which are now extinct. All four extant Upper Columbia River steelhead populations have a "high" longterm extinction risk (ICTRT 2007). Both the Methow and Wenatchee populations have recovery goals of 2,250 naturally-produced spawners, the Okanogan population has a goal of 1,000 naturally-produced spawners, and the Entiat population has a goal of 500 naturally-produced spawners.

The ICTRT has characterized the genetic diversity risk to all Upper Columbia River steelhead populations as "high." The high risk is a result of reduced genetic diversity from homogenization of populations that occurred during the Grand Coulee Fish Maintenance Project from 1939-1943 and then again from 1960 to as recently as 1981 (NMFS 2008e). Additionally, the Methow and Okanogan populations have particularly high proportions of hatchery-origin spawners (Table 2). Recent monitoring data suggests that hatchery fish may be straying into non-target areas, likely contributing to the continued homogenization of the population (NMFS 2008e).

For the purpose of this review, the HSRG designated all four populations as Primary (Table 1).

\section{Current Harvest}

All Upper Columbia River steelhead are categorized as A-run fish based on run timing, age and size characteristics. Few are caught in ocean fisheries and mortality is assumed to be zero (NMFS 2008e). Columbia River fisheries are limited to ensure that incidental take of ESA-listed Upper Columbia River steelhead does not exceed specified rates. Non-treaty fisheries are limited to a 2 percent harvest rate; treaty Indian fall fisheries are limited to a 15 percent harvest rate on B-run steelhead, but have no A-run harvest constraint since B-run steelhead are generally more limiting (NMFS 2008e). Recent harvest rates in non-treaty and treaty Indian fisheries ranged from 1.0 percent to 1.9 percent, and 4.1 percent to 12.4 percent, respectively (NMFS 2008e). 
Table 1. Population designations for the Upper Columbia Summer Steelhead DPS and HSRG broodstock criteria achieved for each population under current conditions and the HSRG recommended hatchery management solution.

\begin{tabular}{|l|c|c|c|}
\hline \multirow{2}{*}{ Population } & \multirow{2}{*}{} & \multicolumn{2}{|c|}{ HSRG Criteria Met $^{2}$} \\
\cline { 3 - 4 } & Designation & Current & HSRG Solution \\
\hline Wenatchee Summer Steelhead & Primary & Stabilizing & Primary \\
\hline Entiat Summer Steelhead & Primary & Stabilizing & Stabilizing \\
\hline Methow Summer Steelhead & Primary & Stabilizing & Primary \\
\hline Okanogan Summer Steelhead & Primary & Stabilizing & Stabilizing \\
\hline
\end{tabular}

1 Using the naming protocol of the Lower Columbia River Salmon Recovery Plan (LCFRB 2004), populations were classified based on information provided to the HSRG as Primary, Contributing, or Stabilizing. These designations are meant to reflect the conservation importance of a population within the DPS from most important (Primary- bold, red), to moderately important (Contributing-bold, blue), to least important (Stabilizing).

2 The HSRG developed criteria for hatchery influence for the three population designations from low influence (Primary), moderate influence (Contributing) to high influence (Stabilizing).

\section{Current Habitat}

Critical habitats for the Upper Columbia River steelhead include the Columbia River estuary and river reaches up to Chief Joseph Dam, as well as spawning reaches in tributaries to the Methow, Entiat, Okanogan and Wenatchee rivers (NMFS 2008e). Factors such as dams, diversions, roads and railways, agriculture (including livestock grazing), residential development, and forest management all threaten the conservation value of critical habitat in some locations in the upper Columbia Basin. Major factors that have contributed to the decline of this DPS include physical passage barriers; reduced stream flows; excess sediment in spawning gravels; and the loss of habitat complexity, off-channel habitat and large, deep pools due to sedimentation and loss of pool-forming structures (NMFS 2008e).

\section{Current Hatchery Programs}

Currently, there are two segregated hatchery programs in the DPS, Wells Hatchery and Ringold, that release approximately 310,000 steelhead annually (Table 2 ). Three integrated programs release approximately 840,000 steelhead annually into the Wenatchee, Methow, and Okanogan rivers.

In 1998, the goal of all the hatchery programs in the Upper Columbia River steelhead DPS changed from providing fish for harvest to also conserving the genetic resources, reducing the short-term extinction risk and increasing hatchery-origin fish fitness or effectiveness.

Estimates of PNI and pHOS under current conditions show that none of the four Primary populations in the DPS meet the HSRG broodstock criteria for their designation (Table 1).

An expanded program is currently proposed in this DPS by the Colville Tribes. They propose to increase Cassimer Bar steelhead production to between 80,000 and 200,000 smolts, depending on the success of habitat restoration efforts in the subbasin. Initially, 80,000 smolts and a yet to be defined number of parr, will be released as part of an 


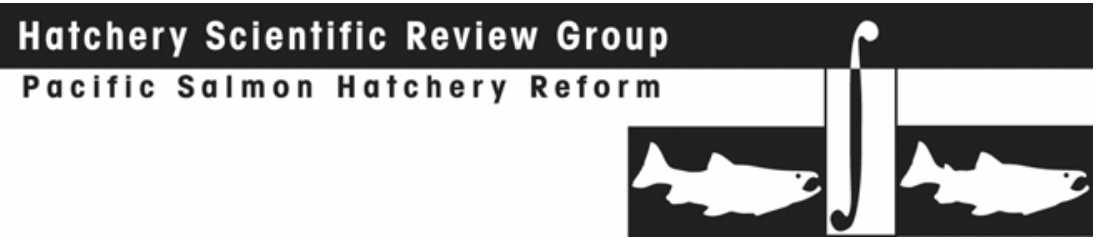

integrated conservation program. Also, an adult reconditioning program will be used to increase steelhead production.

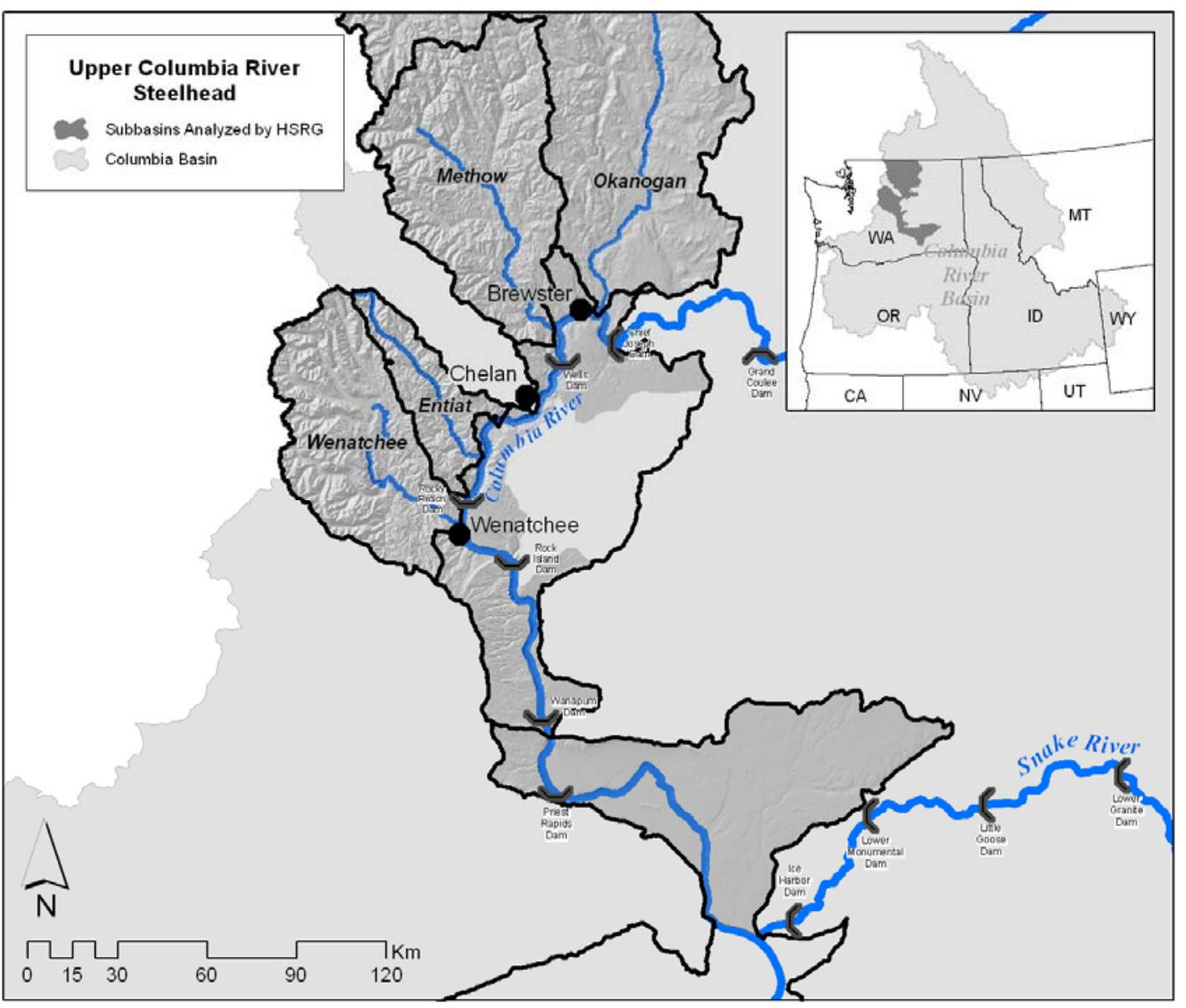

Table 2. Hatchery releases and types of programs for Upper Columbia Summer Steelhead DPS.

\begin{tabular}{|c|c|c|c|c|c|c|}
\hline \multirow[b]{2}{*}{ Population/Program Name } & \multicolumn{3}{|c|}{ Current $(1,000 \mathrm{~s})$} & \multicolumn{3}{|c|}{ HSRG Solution $(1,000 s)$} \\
\hline & Type & Purpose & $\begin{array}{c}\text { No. } \\
\text { Released }\end{array}$ & Type & Purpose & $\begin{array}{c}\text { No. } \\
\text { Released }\end{array}$ \\
\hline Columbia Lower Middle: Ringold Summer Steelhead (Wells) & Seg & Harv & 171.1 & Seg & Harv & 171.1 \\
\hline Wenatchee Summer Steelhead & Int & Both & 401.0 & Int & Both & 100.1 \\
\hline Wenatchee Summer Steelhead (stepping stone hatchery) & Seg & Harv & - & Seg & Harv & 300.7 \\
\hline Entiat Summer Steelhead & None & NA & - & None & NA & - \\
\hline Methow Summer Steelhead & Int & Both & 420.1 & Int & Both & 100.2 \\
\hline Methow Summer Steelhead (stepping stone hatchery) & Seg & Harv & - & Seg & Harv & 319.8 \\
\hline Okanogan Summer Steelhead & Int & Cons & 20.0 & Int & Cons & 199.9 \\
\hline Okanogan Summer Steelhead (Wells-Hatchery) & Seg & Harv & 138.9 & Seg & Harv & - \\
\hline Total all Populations/Programs & & & $1,151.1$ & & & $1,191.8$ \\
\hline
\end{tabular}




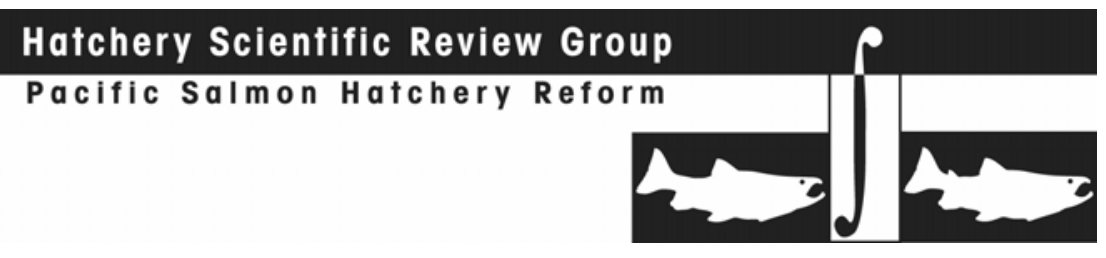

\subsubsection{HSRG Solutions}

Options for improving the integrated hatchery programs in this DPS are possible but limited by the low number of natural-origin fish. Contributions to conservation can be improved in the Wenatchee and Methow by improving broodstock collection and limiting hatchery-origin fish on the spawning grounds. In the Entiat and Okanogan subbasins, the HSRG analyzed various hatchery scenarios that could improve productivity of the subpopulations, but could not significantly increase abundance of natural-origin spawners under current habitat conditions. This is generally the result of limitations in habitat quality (productivity) and quantity (capacity).

\section{Conservation Outcomes under the HSRG Solutions}

Figure 1 compares the proportion of hatchery-origin fish on the spawning grounds (pHOS) and the proportionate natural influence (PNI) for current and proposed (HSRG) scenarios for Primary and Contributing populations. The HSRG solution reduces the hatchery influence in two of the four Primary populations (Wenatchee and Methow) and achieves the standards for a Primary population in these watersheds. Reducing hatchery influence increases productivity (Figure 2). The level of hatchery influence in the remaining Primary populations (Entiat and Okanogan) could not be improved to the level required to achieve Primary standards. The Okanogan program is considered to be a reintroduction program, but because of limited habitat availability, will continue to have high hatchery influence until habitat conditions improve. In order for the Entiat population to contribute to recovery, habitat productivity improvements are needed. Until this occurs, there is little managers can do to improve the condition of this population. Managers should consider a safety net conservation program, including a kelt reconditioning program from natural-origin fish returning to the Entiat and Okanogan.

\section{Harvest Outcomes under the HSRG Solutions}

Figure 3 describes current and estimated changes in harvest (in marine, mainstem Columbia River and terminal areas) that would occur following implementation of the management solutions proposed by the HSRG. HSRG solutions require removing a high percentage of hatchery fish. The increases in harvest in terminal fisheries results from increasing harvest rates to remove excess hatchery fish and adipose fin-clipping to identify fish for harvest.

\section{Hatchery Program Changes under the HSRG Solutions}

Table 2 shows the current size of each hatchery program as well as their size under the HSRG solution. For this DPS, the number of smolts released increases by approximately 40,000 . This slight increase occurs in the Okanogan where a larger integrated program is recommended to replace the existing segregated program. Other significant changes are the conversion of the current poorly integrated programs in the Wenatchee and Methow to two-stage "stepping stone" programs. Each contains a smaller properly-integrated conservation program using 100 percent $\mathrm{pNOB}$ and a larger segregated program to provide harvest using adult returns from the first program as brood (see individual population reports in Appendix E for detailed descriptions of these programs). The current segregated program at Ringold remains unchanged. 
In addition to the above recommendations, the HSRG notes the need for additional adult collection facilities in several locations (Methow, Entiat and Okanogan rivers) to improve collection of unharvested hatchery-origin fish.

The abundance of natural-origin escapement will vary from year to year. In order to balance the demographic risk (low overall abundance) against genetic risks (too much hatchery influence), the HSRG recommends managing pHOS and pNOB on a "sliding scale", while still assuring that PNI and pHOS objectives are met on average over generations.

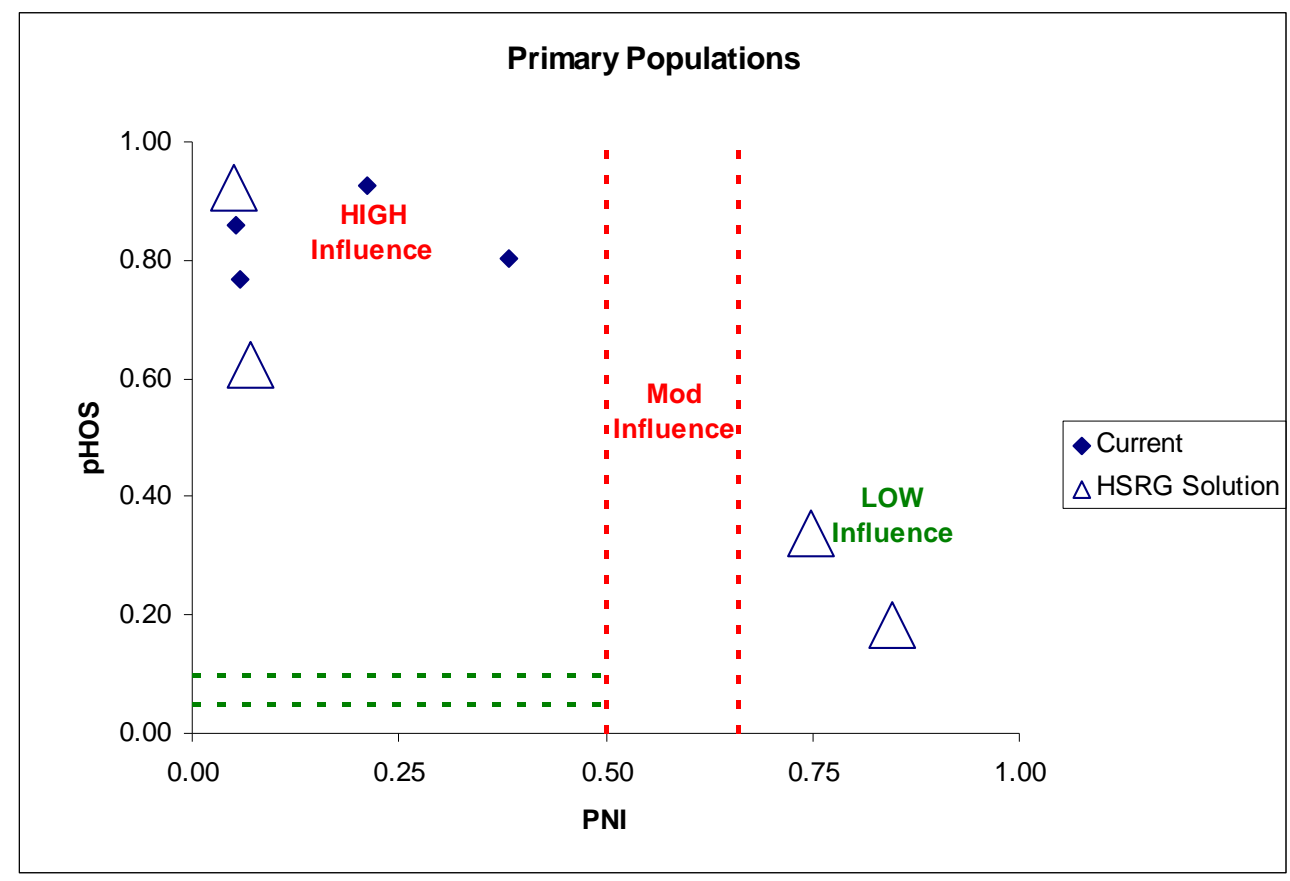

Figure 1. Relationship of the proportion of the fish on the spawning grounds that are of hatchery origin (pHOS) and the proportionate natural influence index (PNI) for Primary summer steelhead populations in the Upper Columbia Steelhead DPS. Solid diamonds represent values for current programs and open triangles represent values for the HSRG recommended hatchery management solution. 


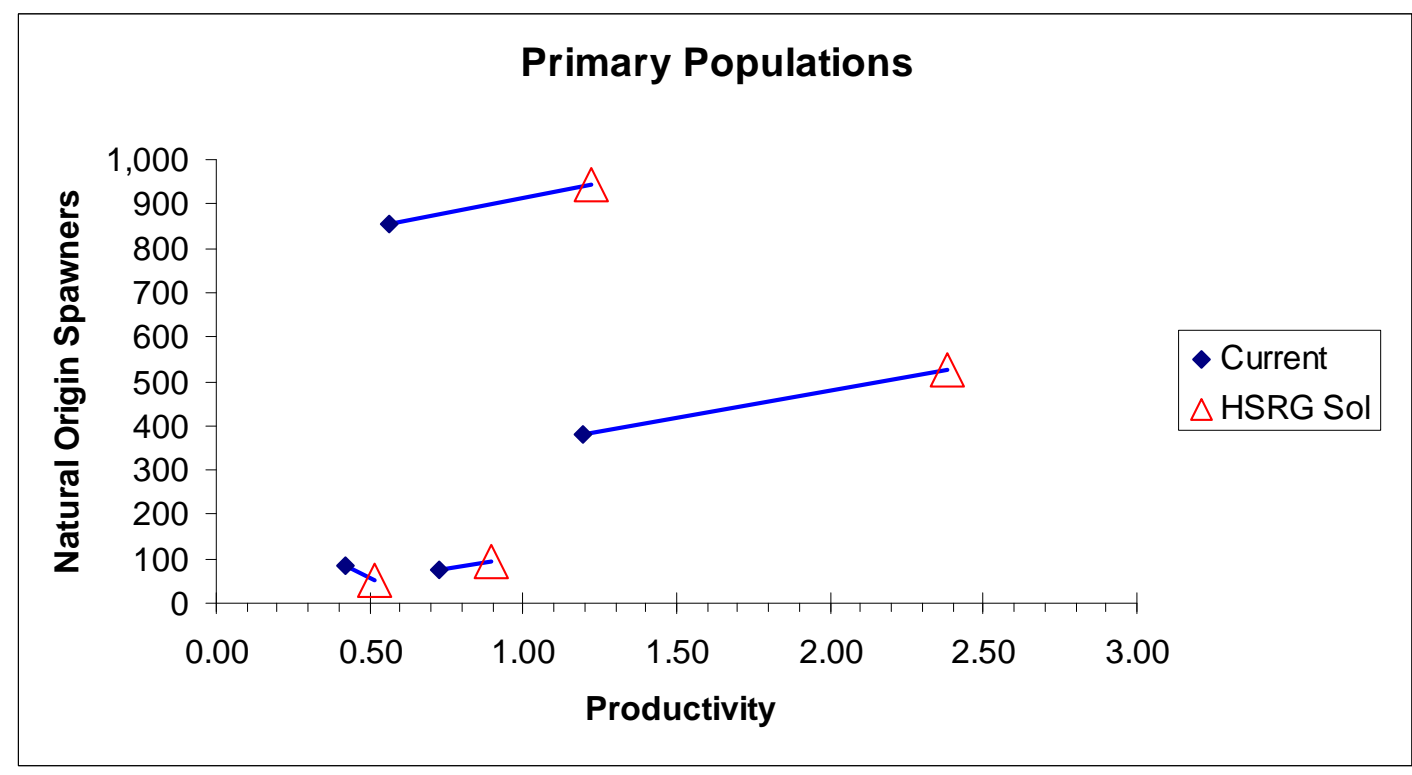

Figure 2. Productivity and spawner abundance for Primary summer steelhead populations in the Upper Columbia DPS. Solid diamonds represent existing productivity and spawner abundance levels, and triangles represent the HSRG recommended hatchery management solution. Lines connect current with HSRG solution for a particular population. The HSRG recommended hatchery management solution includes projected improved fish passage survival in the Snake and Columbia mainstem migration corridor (FCRPS Biological Opinion May 5, 2008).

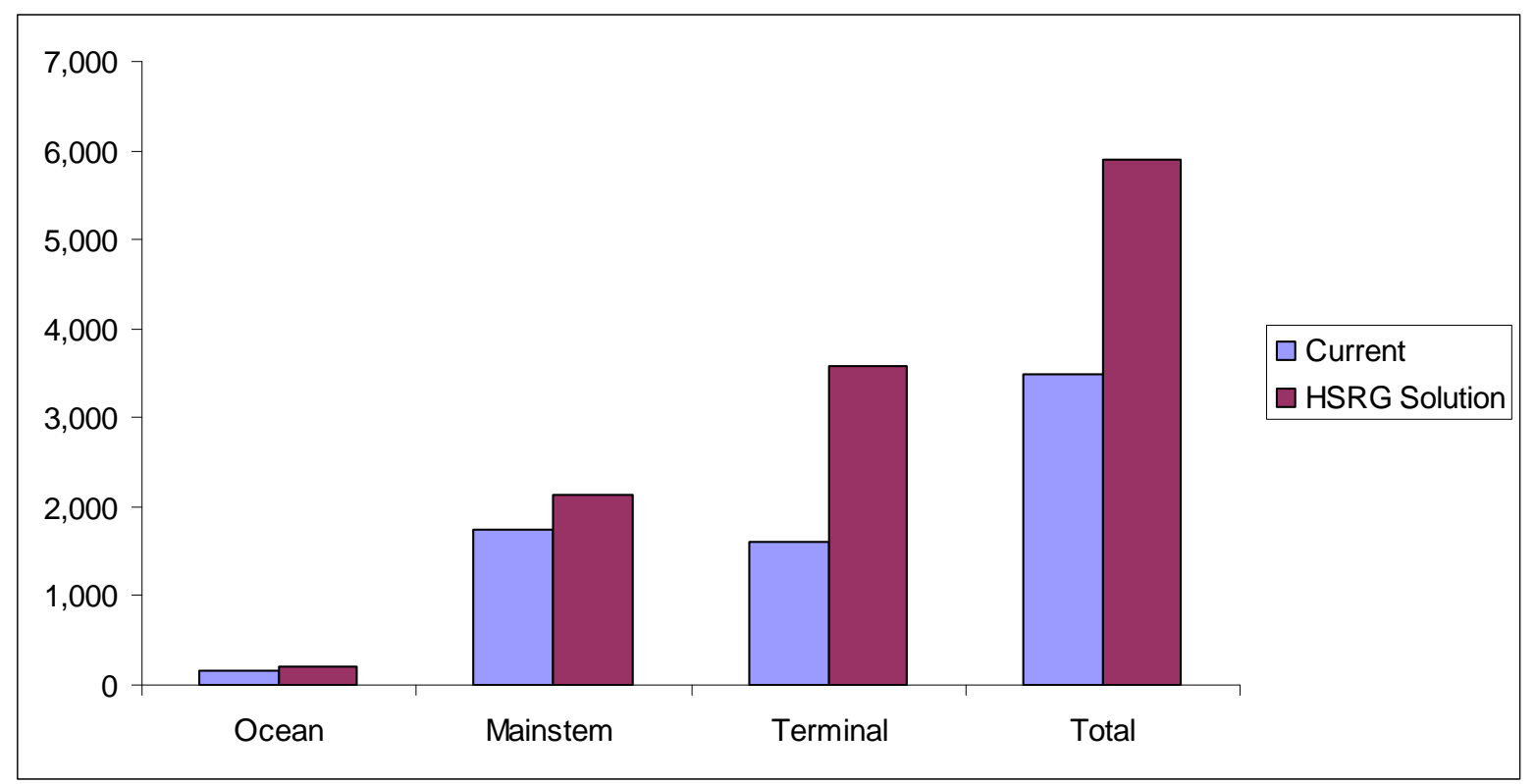

Figure 3. Estimated marine, mainstem Columbia, and terminal harvest under current and HSRG recommended hatchery management solution for Upper Columbia Steelhead DPS. The HSRG recommended hatchery management solution includes projected improved fish passage survival in the Snake and Columbia mainstem migration corridor (FCRPS Biological Opinion May 5, 2008). 


\section{Summary and Conclusions}

The Upper Columbia River Steelhead DPS contains four extant populations that have been identified as Primary (Methow, Wenatchee, Okanogan and Entiat). Currently none of these populations meet the guidelines for Primary designation. Implementing HSRG recommendations results in two of these populations meeting the Primary designation.

The HSRG recommendations improve integration and provide better segregation for the harvest components of the programs. The HSRG also recommends that managers implement an adult management sliding scale that balances genetic and demographic risks.

Harvest increases under the HSRG solution result from higher rates of harvest on excess hatchery fish and adipose fin-clipping to identify fish for harvest.

The HSRG also concludes that (a) hatchery and harvest reforms alone will not achieve recovery of listed populations (habitat improvements are also necessary), and (b) the effectiveness of habitat actions would be greatly increased if combined with hatchery and harvest reforms. Analysis of the Primary populations in this DPS suggests that the benefits of habitat quality improvements would increase if combined with hatchery reforms. Unless hatchery and harvest reforms are implemented, the potential benefits of current or improved habitat cannot be fully realized.

\subsubsection{Snake River Steelhead DPS}

\subsubsection{1}

\section{Salmon River Steelhead MPG}

This section provides an overview of the Salmon River Major Population Group (MPG). It contains a general description of the MPG, fisheries, habitat limitations and hatchery programs that affect it. Overall recommendations for MPG-wide hatchery program changes are summarized as are the results of implementing these changes on conservation and harvest goals. Detailed conclusions and recommendations for each population in the MPG can be found in the Appendix E.

\subsection{HSRG Population Guidelines}

In order to meet conservations goals for the MPG, numerous threats to these populations need to be addressed, including risks from hatchery programs. The key to controlling genetic and ecological risks due to straying and fitness loss is to manage hatchery broodstock and natural spawning escapement such that the natural habitat (and not the hatchery environment) drives the adaptation and productivity of the naturally spawning population. This is achieved by operating either (a) integrated programs where the proportion of natural-origin adults in the broodstock (pNOB) exceeds the proportion of hatchery-origin fish on the spawning grounds (pHOS); or (b) segregated programs where the contribution of hatchery fish to natural spawning is kept low (pHOS $<5 \%$ to $<10 \%$ depending on the population designation). The HSRG developed criteria for hatchery influence for three population types based on the importance of the population to the recovery of the MPG. This was done to provide a consistent method of reviewing 


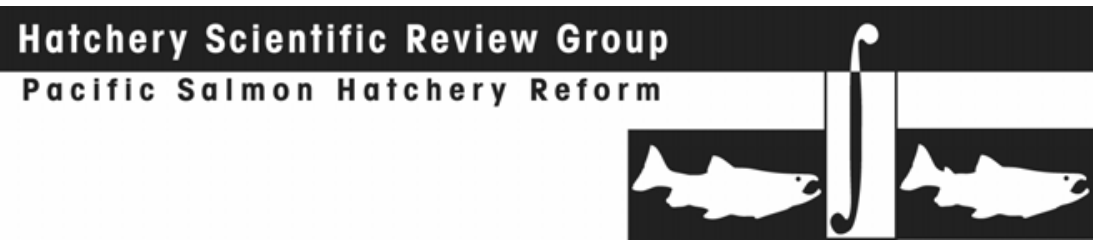

populations and programs across the Columbia River Basin. The population designations used by the HSRG (Primary, Contributing, or Stabilizing) were adopted after discussions with managers and followed those developed in the Lower Columbia River Salmon Recovery Plan (LCFRB 2004). These designations are meant to reflect the conservation importance of a population within the MPG from most important (Primary), to moderately important (Contributing), to least important (Stabilizing). HSRG recommendations show how hatchery programs can be operated consistent with these designations based on the following standards:

HSRG criteria for hatchery influence on Primary populations:

- The proportion of effective hatchery-origin spawners (pHOS) should be less than 5\% of the naturally spawning population, unless the hatchery population is integrated with the natural population.

- For integrated populations, the proportion of natural-origin adults in the broodstock should exceed pHOS by at least a factor of two, corresponding to a proportionate natural influence (PNI) value of 0.67 or greater and pHOS should be less than 0.30 .

HSRG criteria for hatchery influence on Contributing populations:

- The proportion of effective hatchery-origin spawners (pHOS) should be less than $10 \%$ of the naturally spawning population, unless the hatchery population is integrated with the natural population.

- For integrated populations, the proportion of natural-origin adults in the broodstock should exceed pHOS, corresponding to a PNI value of 0.50 or greater and $\mathrm{pHOS}$ should be less than 0.30 .

HSRG criteria for hatchery influence on Stabilizing populations:

- The current operating conditions were considered adequate to meet their conservation goals. No criteria were developed for proportion of effective hatchery-origin spawners (pHOS) or PNI.

\subsection{Current Conditions}

\section{Conservation}

The Salmon River Steelhead MPG is in the Snake River Distinct Population Segment (DPS) and was listed as threatened under the Endangered Species Act in 1997. This MPG includes the South Fork Salmon River, Secesh River, Big Creek, Camas Creek, Loon Creek, Upper and Lower Mainstem Middle Fork Salmon, Little Salmon and Rapid rivers, Chamberlain Creek, Panther Creek, North Fork Salmon River, Lemhi River, Pahsimeroi River, and the East Fork Salmon River populations. Spatial structure risk for all Salmon River MPG populations is designated as "very low" or "low," with the exception of Panther Creek (NMFS 2008e). Panther Creek steelhead occupy only 30 percent of the historical range and are significantly geographically separated from the closest spawning population. The diversity risk has been designated as either "low" or "moderate" for all steelhead populations in the DPS (NMFS 2008e). Most populations in the MPG have a "high" risk of extinction (ICTRT 2007). 
Managers classify steelhead returning to the Snake River as either "A-run" or "B-run" depending on mean age, size, and time of return of adults. B-run steelhead generally return later in the year and at a larger mean size and age than A-run steelhead. Both Arun and B-run steelhead are found in the Salmon River and are included in the Snake River Steelhead DPS.

In the Salmon River steelhead MPG, the ICTRT recommended combinations of populations within MPGs that need to meet viability criteria. For the MPG to be considered viable, a minimum of six of the twelve independent populations must be considered viable. Currently, viability criteria as defined by the ICTRT are not being met (ICTRT 2007).

For the purpose of this analysis, the HSRG designated 8 of the 12 populations as Primary, one population as Contributing (Pahsimeroi River), and 3 populations as Stabilizing (Table 1).

Table 1. Population designations for the Salmon River Steelhead MPG and HSRG broodstock criteria achieved for each population under current conditions and the HSRG recommended hatchery management solution.

\begin{tabular}{|l|c|c|c|}
\hline & & \multicolumn{2}{|c|}{ HSRG Criteria Met $^{2}$} \\
\cline { 3 - 4 } Population & Designation ${ }^{1}$ & Current & $\begin{array}{c}\text { HSRG } \\
\text { Solution }\end{array}$ \\
\hline 13-Salmon_South Fork Summer Steelhead (B-Run) & Primary & Primary & Primary \\
\hline 14-Salmon_Secesh Summer Steelhead (B-Run) & Primary & Primary & Primary \\
\hline 15-Salmon_Chamberlain Summer Steelhead (A-Run) & Primary & Primary & Primary \\
\hline 16-Salmon_Lower Middle Fork Salmon Summer Steelhead (B-Run) & Primary & Primary & Primary \\
\hline 17-Salmon_Upper Middle Fork Salmon Summer Steelhead (B-Run) & Primary & Primary & Primary \\
\hline 19-Salmon_North Fork Salmon Summer Steelhead (A-Run) & Primary & Primary & Primary \\
\hline 20-Salmon_Lemhi Summer Steelhead (A-Run) & Primary & Stabilizing & Primary \\
\hline 22-Salmon_East Fork Salmon Summer Steelhead & Primary & Stabilizing & Primary \\
\hline 21-Salmon_Pahsimeroi Summer Steelhead (A-Run) & Contributing & Contributing & Contributing \\
\hline 12-Salmon_Little Salmon Summer Steelhead (A-Run) & Stabilizing & Stabilizing & Stabilizing \\
\hline 18-Salmon_Panther Creek Summer Steelhead (A-Run) & Stabilizing & Primary & Primary \\
\hline 23-Salmon_Upper Salmon Summer Steelhead (A-Run) & Stabilizing & Stabilizing & Stabilizing \\
\hline
\end{tabular}

1 Using the naming protocol of the Lower Columbia River Salmon Recovery Plan (LCFRB 2004), populations were classified based on information provided to the HSRG as Primary, Contributing, or Stabilizing. These designations are meant to reflect the conservation importance of a population within the MPG from most important (Primary- bold, red), to moderately important (Contributing-bold, blue), to least important (Stabilizing).

2 The HSRG developed criteria for hatchery influence for the three population designations from low influence (Primary), moderate influence (Contributing) to high influence (Stabilizing).

\section{Current Harvest}

Hatchery programs within the MPG provide substantial harvest benefits in the mainstem Columbia River up through terminal areas and contribute to both sport and tribal fisheries. There are no freshwater recreational fisheries directly targeting natural-origin steelhead in the Salmon River (USFWS 2008). Incidental mortality of natural-origin fish 


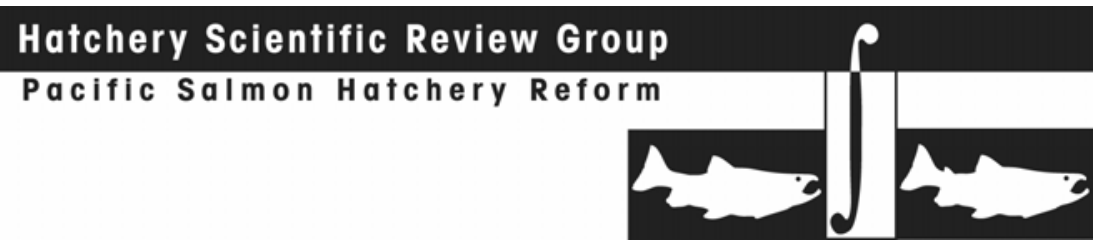

occurs in fisheries targeting hatchery-origin fish. Impacts to natural-origin fish are limited by ESA authorizations and management agreements. Steelhead generally do not contribute to ocean fisheries.

\section{Current Habitat}

Habitat conditions vary widely throughout the Salmon River subbasin. The upper subbasin has large areas where the composition, structure, and function of the aquatic, wetland, and riparian ecosystems have been relatively undisturbed by anthropogenic effects; however, mining, livestock grazing, and timber harvest, along with other human impacts, have negatively impacted habitat in portions of the MPG (USFWS 2008). Twelve percent of the total stream length in the Upper Salmon watershed is identified as being impaired by sedimentation. The North Fork region is characterized by altered riparian habitats, high water temperatures, and reduced stream bank stability. Other limiting factors in the MPG include low stream flows, disconnected tributaries and fish passage issues.

The Middle Fork Salmon River watershed was managed as a primitive area from 1930 until 1980 when it was designated the Frank Church - River of No Return Wilderness Area. Most tributaries are in relatively pristine condition. Bear Valley, Marsh, Camas, Marble, Big, and Loon creeks are outside the wilderness area and are recovering from the historical effects of mining, grazing, logging, and road building. During the summer of 2007, wildfires burned approximately 310,000 acres of forested habitat within the South Fork and Middle Fork Salmon River MPGs. NOAA Fisheries expects that instream habitats will experience increased temperatures, sedimentation, and large woody debris delivery in the near term (NMFS 2008e).

The South Fork Salmon River is recovering from catastrophic sediment impacts that occurred in the mid-1960s when unusually high precipitation, combined with logging and road construction, resulted in massive silt loads into the river. Twenty-one percent of the total stream length in the South Fork Salmon River watershed currently is impaired by sedimentation (USFWS 2008). Within the South Fork Salmon River, the East Fork is the most habitat-limited due to reduced riparian quality, decreased stream bank stability from roads, and residual impacts from mining, including heavy metals leaching from mine sites.

Planned projects that may affect habitat in the MPG include culvert replacements, construction or modification of bridges, riparian zone rehabilitation, bank stabilization, and fish passage barrier removal. The scheduled removal of a barrier on the Upper Lemhi River will restore fish passage to 144 miles of rearing habitat and will increase flows over at least three miles. In addition, federal agencies are implementing numerous projects within the range of Salmon River steelhead that will improve access to blocked habitat, prevent entrainment into irrigation pipes, increase channel complexity, and create thermal refuges. These projects will benefit the viability of the affected populations by improving abundance, productivity, and spatial structure. 

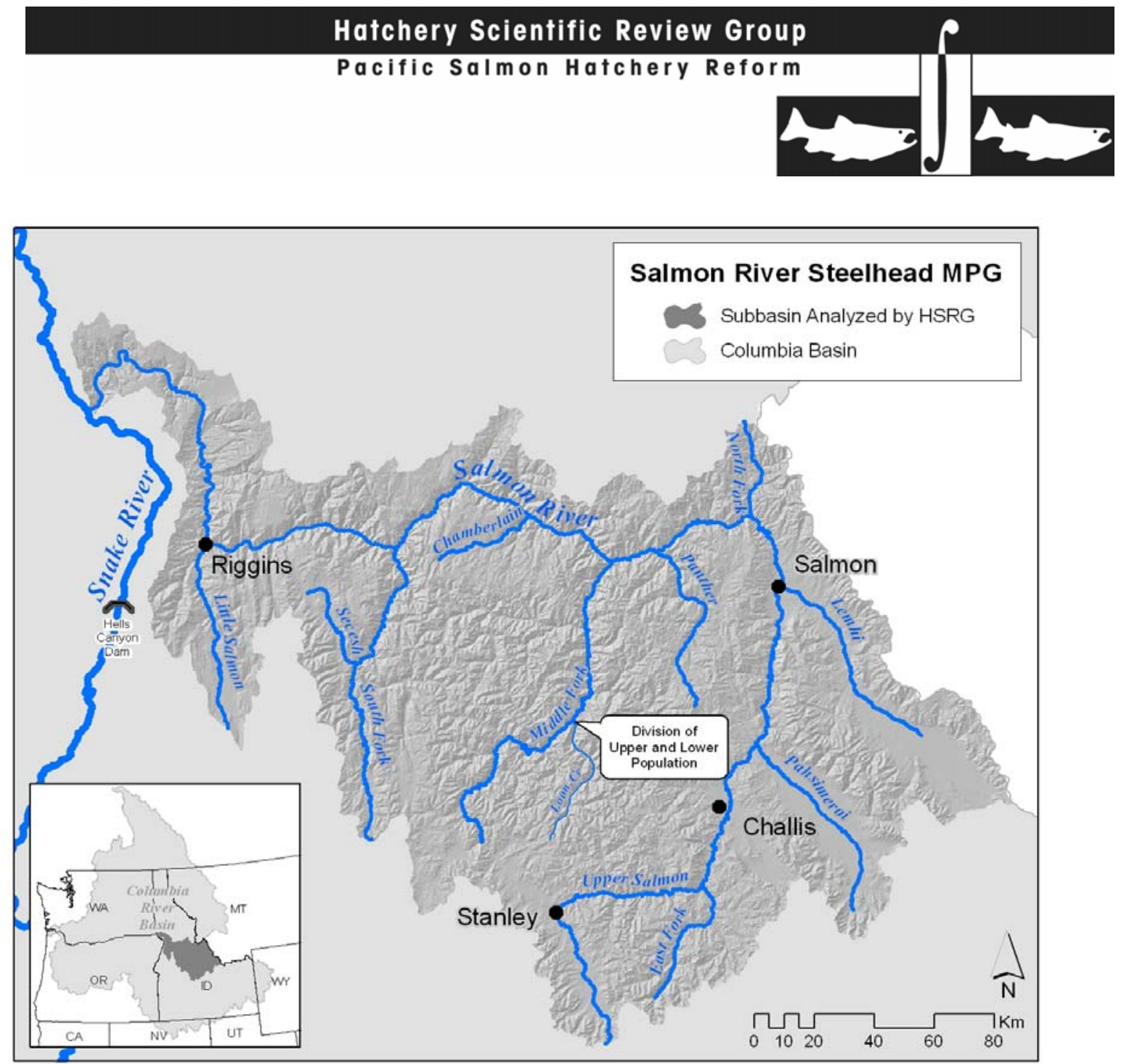

\section{Current Hatchery Programs}

The historically most productive steelhead habitat in this MPG is currently managed for natural production. Hatchery releases are restricted to that portion of this MPG that may not have historically supported abundant steelhead production. Currently, there are nine segregated harvest programs that release a total of approximately 4.3 million juvenile steelhead annually within the MPG (Table 2). One integrated program releases approximately 50,000 juvenile steelhead annually into the East Fork Salmon River.

Some tributaries, such as the East Fork, show genetic introgression of the hatchery gene pool into natural populations. There are currently no hatchery programs in the Chamberlain Creek or the South or Middle Fork Salmon rivers; however, hatchery steelhead were released into the South Fork Salmon River from 1973 through 1981, although not in all years (USFWS 2008). The purpose of individual hatchery programs ranges from harvest to conserving the population and contributing to research.

Six of the eight primary populations currently meet the HSRG's criteria for Primary designation (Table 1). In addition, one population designated as Stabilizing (Panther Creek) currently meets the HSRG's criteria as a Primary population. No hatchery-origin steelhead are released within the geographic ranges of the seven populations currently meeting the Primary criteria. Two populations designated as Primary (Lemhi River and 


\section{Hatchery Scientific Review Group}

Pacific Salmon Hatchery Reform

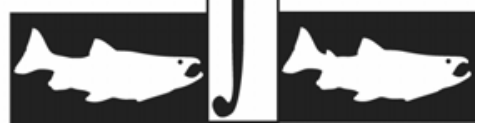

East Fork Salmon River) currently do not meet the HSRG's criteria for Primary or Contributing.

Table 2. Hatchery releases and types of programs for Salmon River Steelhead MPG.

\begin{tabular}{|c|c|c|c|c|c|c|}
\hline \multirow[b]{2}{*}{ Population/Program Name } & \multicolumn{3}{|c|}{ Current $(1,000 \mathrm{~s})$} & \multicolumn{3}{|c|}{ HSRG Solution $(1,000 \mathrm{~s})$} \\
\hline & Type & Purpose & $\begin{array}{c}\text { No. } \\
\text { Released }\end{array}$ & Type & Purpose & $\begin{array}{c}\text { No. } \\
\text { Released }\end{array}$ \\
\hline 12-Salmon:Little Salmon Summer Steelhead (A-Run) & Int & NA & - & Int & NA & - \\
\hline $\begin{array}{l}\text { 12A-Salmon: Little Salmon Summer Steelhead (A- } \\
\text { Run-Pahsimeroi-Oxbow-Hatchery) }\end{array}$ & Seg & Harv & 645.0 & Seg & Harv & 645.0 \\
\hline $\begin{array}{l}\text { 12B-SalmonL Little Salmon Summer Steelhead (B- } \\
\text { Run-Dworshak-Hatchery) }\end{array}$ & Seg & Harv & 316.3 & Seg & Harv & 316.3 \\
\hline 13-Salmon: South Fork Summer Steelhead (B-Run) & None & NA & - & None & NA & - \\
\hline 14-Salmon: Secesh Summer Steelhead (B-Run) & None & NA & - & None & NA & - \\
\hline 15-Salmon: Chamberlain Summer Steelhead (A-Run) & None & NA & - & None & NA & - \\
\hline $\begin{array}{l}\text { 16-Salmon: Lower Middle Fork Salmon Summer } \\
\text { Steelhead (B-Run) }\end{array}$ & None & NA & - & None & NA & - \\
\hline $\begin{array}{l}\text { 17-Salmon: Upper Middle Fork Salmon Summer } \\
\text { Steelhead (B-Run) }\end{array}$ & None & NA & - & None & NA & - \\
\hline $\begin{array}{l}\text { 18-Salmon: Panther Creek Summer Steelhead (A- } \\
\text { Run) }\end{array}$ & None & NA & - & None & NA & - \\
\hline $\begin{array}{l}\text { 19-Salmon: North Fork Salmon Summer Steelhead } \\
\text { (A-Run) }\end{array}$ & None & NA & - & None & NA & - \\
\hline 20-Salmon: Lemhi Summer Steelhead (A-Run) & None & NA & - & None & None & - \\
\hline $\begin{array}{l}\text { 20A-Salmon: Lemhi Summer Steelhead (A-Run- } \\
\text { Pahsimeroi Hatchery) }\end{array}$ & Seg & Harv & 119.7 & Seg & Harv & 119.7 \\
\hline 21-Salmon: Pahsimeroi Summer Steelhead (A-Run) & None & NA & - & None & NA & - \\
\hline $\begin{array}{l}\text { 21A-Salmon: Pahsimeroi Summer Steelhead (A-Run- } \\
\text { Pahsimeroi-Hatchery) }\end{array}$ & Seg & Harv & $1,086.8$ & Seg & Harv & $1,081.3$ \\
\hline 22-Salmon: East Fork Salmon Summer Steelhead & Int & Cons & 49.5 & Int & Cons & 100.1 \\
\hline $\begin{array}{l}\text { 22B-Salmon: East Fork Salmon Summer Steelhead } \\
\text { (B-Run Dworshak-Hatchery) }\end{array}$ & Seg & Harv & 324.8 & Seg & Harv & 324.8 \\
\hline $\begin{array}{l}\text { 22C-Salmon: East Fork Salmon Summer Steelhead } \\
\text { (A-Run Pahsimeroi-Hatchery) }\end{array}$ & Seg & Harv & 180.5 & Seg & Harv & 180.5 \\
\hline $\begin{array}{l}\text { 23-Salmon: Upper Salmon Summer Steelhead (A- } \\
\text { Run) }\end{array}$ & None & NA & - & None & NA & - \\
\hline $\begin{array}{l}\text { 23A-Salmon: Upper Salmon Summer Steelhead (A- } \\
\text { Run Sawtooth-Pahsimeroi-Hatchery) }\end{array}$ & Seg & Harv & $1,284.6$ & Seg & Harv & $1,284.6$ \\
\hline $\begin{array}{l}\text { 23B-Salmon: Upper Salmon Summer Steelhead (B- } \\
\text { Run Dworshak-Hatchery) }\end{array}$ & Seg & Harv & 250.3 & Seg & Harv & 250.3 \\
\hline $\begin{array}{l}\text { 23C-Salmon: Upper Salmon Summer Steelhead } \\
\text { (Upper Salmon B-Run Program) }\end{array}$ & Seg & Harv & 59.2 & Seg & Harv & 134.6 \\
\hline Total all Populations/Programs & & & $4,316.8$ & & & $4,437.2$ \\
\hline
\end{tabular}




\subsection{HSRG Solutions}

\section{Conservation Outcomes under the HSRG Solutions}

Under the HSRG's recommended solutions, the Lemhi and East Fork river populations would move from the Stabilizing to Primary categories (Figure 1). The predicted value of $\mathrm{pHOS}$ for the Lemhi population decreases. Similarly, the predicted value of pHOS for the East Fork population decreases and PNI increases. The predicted productivity of both populations increases (Figure 2). However, the HSRG was unable to develop any solution that would increase the number of natural-origin fish returning to the Salmon River subbasin (Figure 2).

\section{Harvest Outcomes under the HSRG Solutions}

Under the HSRG's proposed solution, total harvest of Salmon River steelhead remains largely unchanged (Figure 3).

\section{Hatchery Program Changes under the HSRG Solutions}

The HSRG solution for the Lemhi River population is to terminate releases in the mainstem Salmon River downstream from the Lemhi River and/or construct a conservation weir in the lower reach of the Lemhi River to preclude upstream migration of stray hatchery-origin fish.

The HSRG's solution for the East Fork population is to (a) relocate the existing weir (or build a new one) in a location near its terminus with the Salmon River, (b) expand the current integrated program from 50,000 to 100,000 smolts, and (c) use the East Fork broodstock as the exclusive source of A-run steelhead released into the mainstem Salmon River between the confluences of the Pahsimeroi and East Fork Salmon rivers.

The HSRG recommends developing local broodstock and phasing out the outplanting of Dworshak steelhead in the upper Salmon and East Fork Salmon rivers with subsequent development of a local broodstock at a location where adults can be reliability trapped.

The HSRG recommends that steelhead returning to the Pahsimeroi Hatchery be the sole broodstock source of all hatchery-origin A-run steelhead released downstream of the Pahsimeroi River and upstream of the North Fork Salmon River. Similarly, the HSRG recommends that steelhead returning to the Sawtooth Hatchery be the sole source of all hatchery-origin A-run steelhead upstream of the East Fork Salmon River.

The HSRG has no recommendations for the Little Salmon River population. 


\section{Hatchery Scientific Review Group}

Pacific Salmon Hatchery Reform
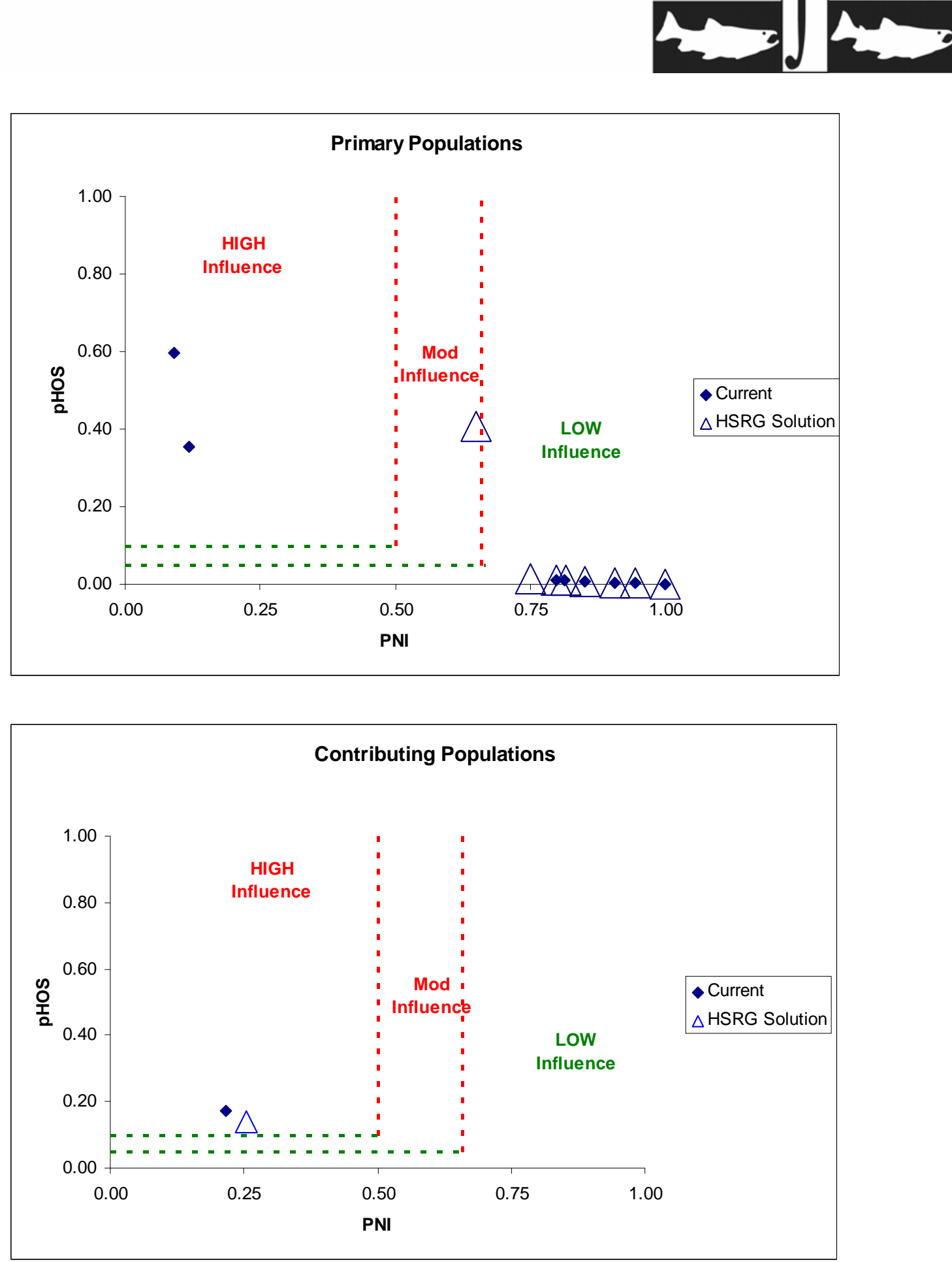

Figure 1. Relationship of the proportion of the fish on the spawning grounds that are of hatchery origin (pHOS) and the proportionate natural influence index (PNI) for Primary (top panel) and Contributing (bottom panel) steelhead populations in the Salmon River Steelhead MPG. Solid diamonds represent values for current programs and open triangles represent values for the HSRG recommended hatchery management solution. 


\section{Hatchery Scientific Review Group}

Pacific Salmon Hatchery Reform
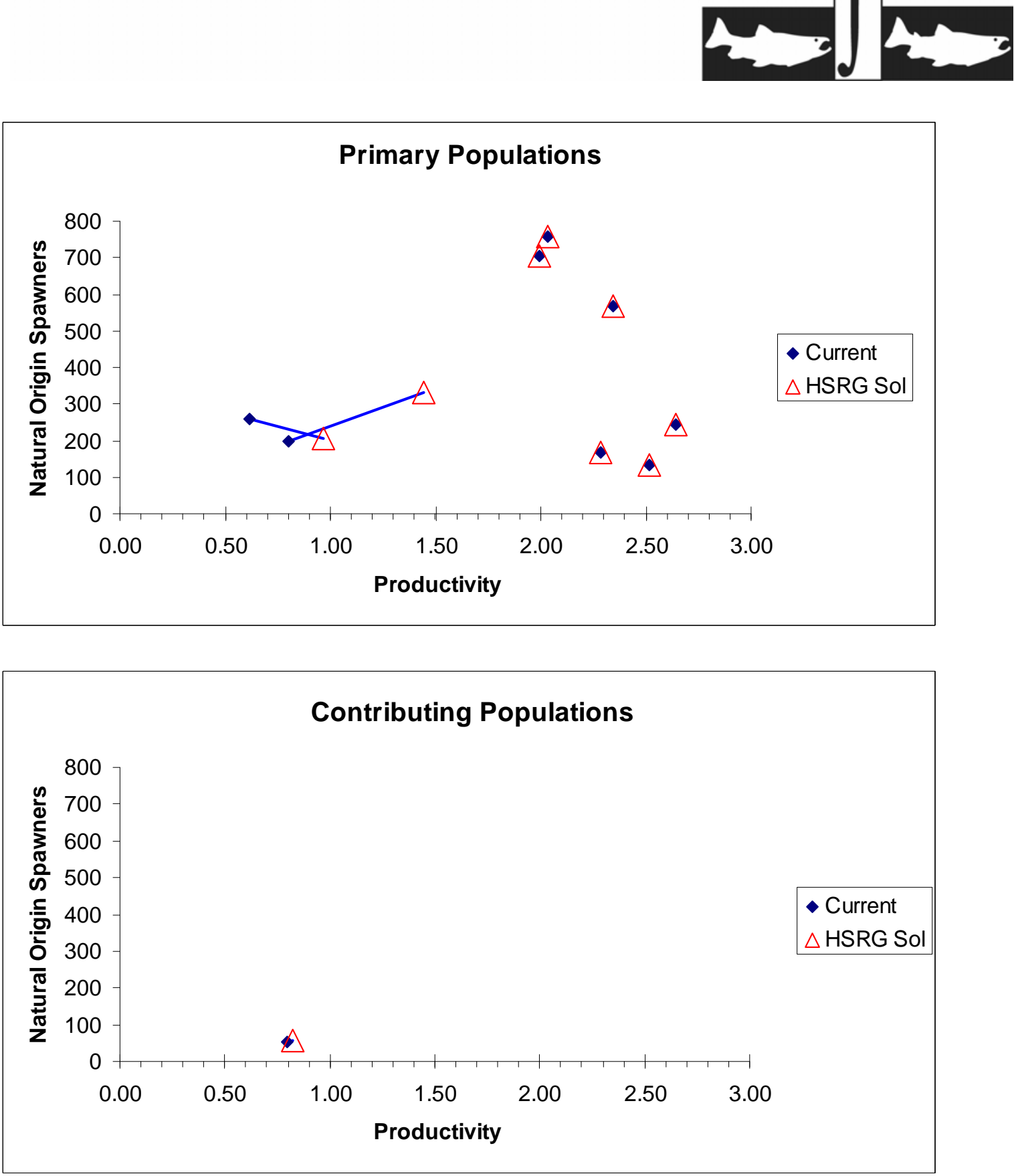

Figure 2. Productivity and spawner abundance for Primary (top panel) and Contributing (bottom panel) steelhead populations in the Salmon River Steelhead MPG. Solid diamonds represent existing productivity and spawner abundance levels, and triangles represent the HSRG recommended hatchery management solution. Lines connect current with HSRG solution for a particular population. The HSRG recommended hatchery management solution includes projected improved fish passage survival in the Snake and Columbia mainstem migration corridor (FCRPS Biological Opinion May 5, 2008). 

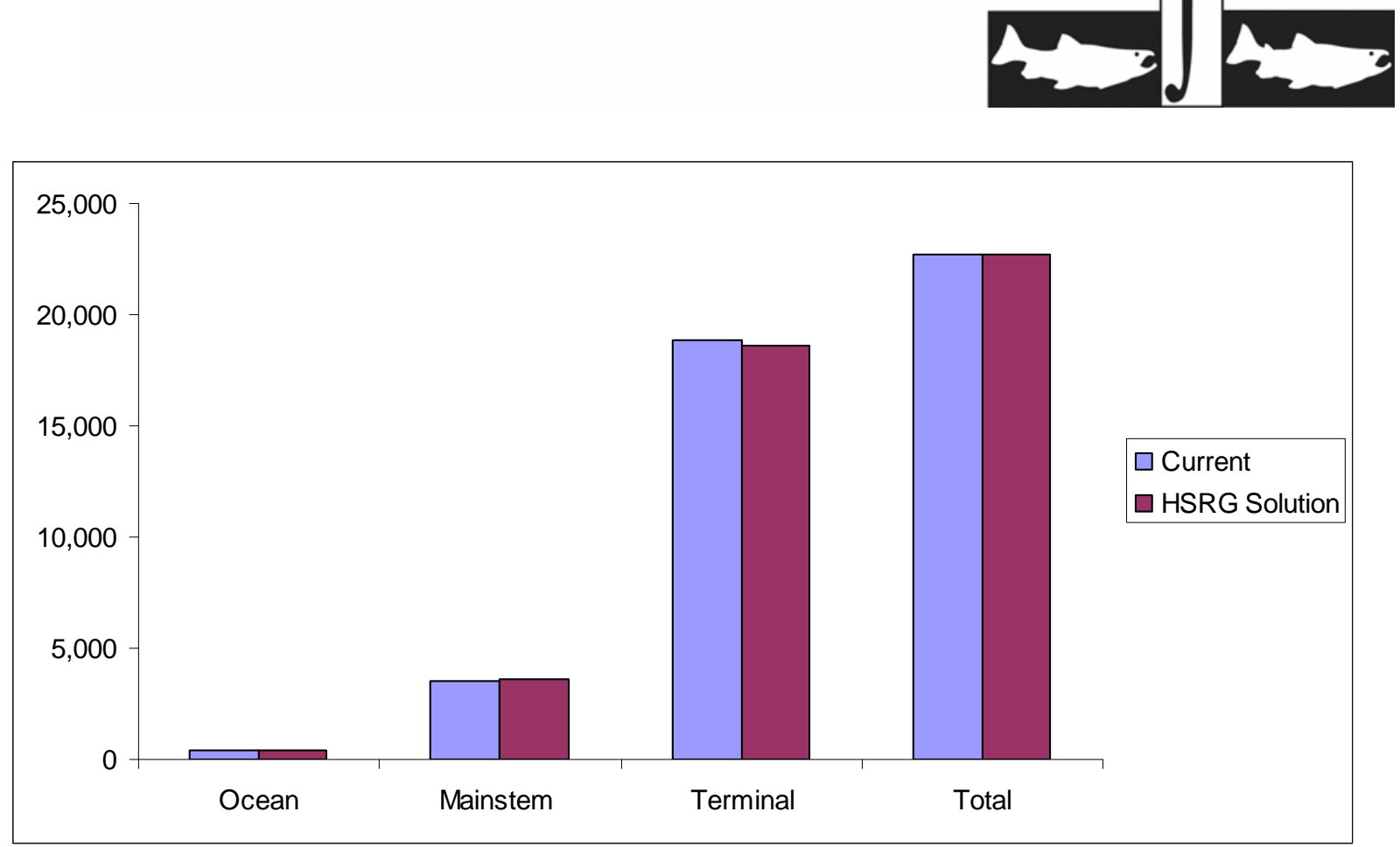

Figure 3. Estimated marine, mainstem Columbia, and terminal harvest under current and HSRG recommended hatchery management solution for Salmon River Steelhead MPG. The HSRG recommended hatchery management solution includes projected improved fish passage survival in the Snake and Columbia mainstem migration corridor (FCRPS Biological Opinion May 5, 2008).

The historically most productive steelhead habitat in this MPG is currently managed for natural production. Hatchery releases are restricted to the portion of this MPG that historically may not have supported abundant steelhead production.

The HSRG recognizes and supports the strategic use of wild salmon management zones as an important component to a balanced conservation strategy for the Snake River Steelhead DPS.

This MPG is composed of 12 populations, 8 of which the HSRG assumed to be Primary. Six of the eight Primary populations currently meet the HSRG's criteria for Primary designation. No hatchery-origin steelhead are released within the geographic ranges of the six populations currently meeting the Primary criteria. Two populations designated as Primary (Lemhi River and East Fork Salmon River) currently do not meet the HSRG's criteria for Primary or Contributing populations.

The HSRG solutions improve two populations (Lemhi and East Fork Salmon) by significantly reducing the number of hatchery-origin steelhead straying into these drainages. This results in the two populations meeting the HSRG's criteria for Primary populations. The productivity of these two populations improves but abundance does not increase.

Conservation of the MPG can be improved while harvest is maintained at approximately current levels under the HSRG solution. 
This section provides an overview of the Clearwater River Steelhead MPG. It contains a general description of the MPG, fisheries, habitat limitations and hatchery programs that affect it. Overall recommendations for MPG-wide hatchery program changes are summarized, as are the results of implementing those changes on conservation and harvest goals. Detailed conclusions and recommendations for each population in the MPG can be found in the Appendix E.

3.4.6.2.1 HSRG Population Guidelines

In order to meet conservations goals for the MPG, numerous threats to these populations need to be addressed, including risks from hatchery programs. The key to controlling genetic and ecological risks due to straying and fitness loss is to manage hatchery broodstock and natural spawning escapement such that the natural habitat (and not the hatchery environment) drives the adaptation and productivity of the naturally spawning population. This is achieved by operating either (a) integrated programs where the proportion of natural-origin adults in the broodstock (pNOB) exceeds the proportion of hatchery-origin fish on the spawning grounds (pHOS); or (b) segregated programs where the contribution of hatchery fish to natural spawning is kept low (pHOS $<5 \%$ to $<10 \%$ depending on the population designation). The HSRG developed criteria for hatchery influence for three population types based on the importance of the population to the recovery of the MPG. This was done to provide a consistent method of reviewing populations and programs across the Columbia River Basin. The population designations used by the HSRG (Primary, Contributing, or Stabilizing) were adopted after discussions with managers and followed those developed in the Lower Columbia River Salmon Recovery Plan (LCFRB 2004). These designations are meant to reflect the conservation importance of a population within the MPG from most important (Primary), to moderately important (Contributing), to least important (Stabilizing). HSRG recommendations show how hatchery programs can be operated consistent with these designations based on the following standards:

HSRG criteria for hatchery influence on Primary populations:

- The proportion of effective hatchery-origin spawners (pHOS) should be less than 5\% of the naturally spawning population, unless the hatchery population is integrated with the natural population.

- For integrated populations, the proportion of natural-origin adults in the broodstock should exceed pHOS by at least a factor of two, corresponding to a proportionate natural influence (PNI) value of 0.67 or greater and pHOS should be less than 0.30 .

HSRG criteria for hatchery influence on Contributing populations:

- The proportion of effective hatchery-origin spawners (pHOS) should be less than $10 \%$ of the naturally spawning population, unless the hatchery population is integrated with the natural population. 
- For integrated populations, the proportion of natural-origin adults in the broodstock should exceed $\mathrm{pHOS}$, corresponding to a PNI value of 0.50 or greater and $\mathrm{pHOS}$ should be less than 0.30 .

HSRG criteria for hatchery influence on Stabilizing populations:

- The current operating conditions were considered adequate to meet their conservation goals. No criteria were developed for proportion of effective hatchery-origin spawners (pHOS) or PNI.

\subsection{Current Conditions}

\section{Conservation}

Co-managers classify steelhead returning to the Snake River as either "A-run" or "B-run" depending on mean age, size, and time of adult returns. B-run steelhead generally return later in the year and at a larger mean size and age than A-run fish. Both A-run and B-run steelhead trout exist in the Clearwater River and are included in the Snake River Steelhead DPS.

NOAA Fisheries and the Interior Columbia Technical Recovery Team (ICTRT) have identified six demographically independent populations within the Clearwater River Steelhead MPG: (1) Lower Clearwater Mainstem, including the Middle Fork (A-run); (2) Lolo Creek (A- and B-run); (3) South Fork Clearwater River (B-run); (4) Lochsa River (B-run); (5) Selway River (B-run); and (6) North Fork Clearwater River (B-run). For the purposes of this analysis, the HSRG subsequently divided the South Fork Clearwater population into two sub-components: the Crooked River B-run steelhead and the mainstem South Fork Clearwater River B-run population. Steelhead in the North Fork Clearwater River were extirpated by construction of Dworshak Dam (late 1960s) which blocked all upstream migration of salmon and steelhead. The North Fork Clearwater stock has subsequently been maintained continuously as a segregated hatchery stock since 1969 at Dworshak National Fish Hatchery (NFH) and is referred to as Dworshak NFH (B-run) steelhead.

Native populations of steelhead in the South Fork Clearwater River upstream of river mile 22 are believed to have been extirpated by Harpster Dam. This dam completely blocked upstream migration of salmon and steelhead after its construction in 1910. Since 1963 when the dam was removed, large numbers of hatchery-origin steelhead have been released in the South Fork Clearwater River drainage.

Lola Creek supports a mix of both A- and B-run fish that spawn in the lower and upper basins, respectively, separated by a deep canyon.

The ICTRT excluded the North Fork Clearwater River population from their viability analyses for ESA recovery planning because the population currently exists only as a segregated hatchery stock maintained at Dworshak NFH. Current recovery strategies require that four of the five extant populations must be viable for the MPG to be deemed viable. The initial recovery planning objective is to achieve viable status for the Lower Clearwater Mainstem, Lolo Creek, Lochsa and South Fork Clearwater populations. 
For the purpose of this review, the HSRG designated three populations as Primary (Lochsa B-run, Selway B-run, and Lower Clearwater A-run), two populations as Contributing (Crooked River (B-run) sub-component of the South Fork population and Lolo Creek [A+B run]), and one population as Stabilizing (mainstem South Fork [B-run] sub-component).

Table 1. Population designations for the Clearwater River Steelhead MPG and HSRG broodstock criteria achieved for each population under current conditions and the HSRG recommended hatchery management solution.

\begin{tabular}{|c|c|c|c|}
\hline \multirow[b]{2}{*}{ Population } & \multirow[b]{2}{*}{ Designation $^{1}$} & \multicolumn{2}{|c|}{ HSRG Criteria Met ${ }^{2}$} \\
\hline & & Current & $\begin{array}{c}\text { HSRG } \\
\text { Solution }\end{array}$ \\
\hline 1-Clearwater_Lochsa Summer Steelhead (B-Run) & Primary & Primary & Primary \\
\hline 2-Clearwater Selway Summer Steelhead (B-Run) & Primary & Primary & Primary \\
\hline 6-Clearwater_Lower Clearwater Summer Steelhead (A-Run) & Primary & Primary & Primary \\
\hline 3-Clearwater_SF Clearwater_Crooked River Summer Steelhead (B-Run) & Contributing & Contributing & Contributing \\
\hline 4-Clearwater_Lolo Summer Steelhead (A+B-Run) & Contributing & Stabilizing & Contributing \\
\hline 3-Clearwater_SF Clearwater Summer Steelhead (B-Run) & Stabilizing & Stabilizing & Stabilizing \\
\hline
\end{tabular}

1 Using the naming protocol of the Lower Columbia River Salmon Recovery Plan (LCFRB 2004), populations were classified based on information provided to the HSRG as Primary, Contributing, or Stabilizing. These designations are meant to reflect the conservation importance of a population within the MPG from most important (Primary- bold, red), to moderately important (Contributing-bold, blue), to least important (Stabilizing).

2 The HSRG developed criteria for hatchery influence for the three population designation from low influence (Primary), moderate influence (Contributing) to high influence (Stabilizing).

\section{Current Harvest}

Steelhead released from Dworshak NFH, including fish outplanted into the South Fork Clearwater River, contribute significantly to sport and tribal fisheries in the Clearwater. Some harvest may occur in size-selective gillnet fisheries in the Columbia River.

Fisheries in the mainstem Columbia River have been managed to limit incidental take to two percent year-round for non-Indian fisheries (NMFS 2008e). Sport harvest in the Clearwater is restricted to marked hatchery steelhead. Treaty Indian fisheries have a 15 percent limit on B-run steelhead (NMFS 2008e). Recent harvest rates on Snake River steelhead generally have been less than allowed and ocean fishing mortality on the ESA listed Snake River steelhead DPS is assumed to be zero (NMFS 2008e).

\section{Current Habitat}

Primary factors limiting steelhead within the Clearwater River MPG are reduced habitat carrying capacity due to land management activities that affect hydrology, levels of sedimentation, and water quality; and the complete blockage of the North Fork Clearwater River by Dworshak Dam.

Very little habitat currently accessible to steelhead within the Clearwater River subbasin has been classified as excellent. Generally speaking, excellent habitat is limited to the highest elevation headwater streams within the Lochsa and Upper Selway. The North Fork Clearwater River, prior to blockage by Dworshak Dam, historically provided excellent steelhead spawning and rearing habitat. Good and fair steelhead habitat is 


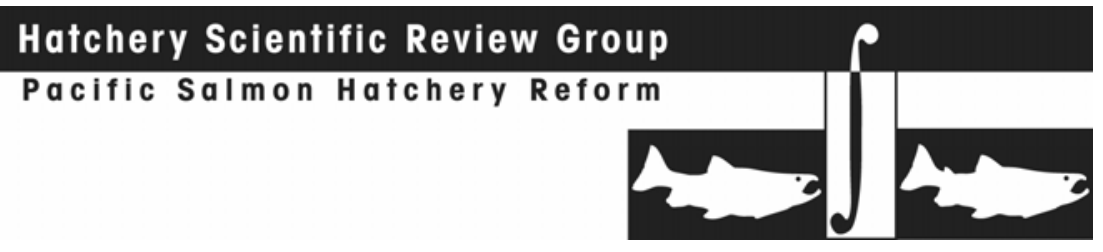

widely intermixed and found throughout the majority of the usable mainstem and tributary reaches of the Lochsa River, South Fork, Clearwater River, and upper and lower Selway River. Poor habitat conditions are generally associated with lower mainstem reaches of major tributaries and the mainstem Clearwater River.

\section{Current Hatchery Programs}

There are currently three segregated hatchery programs in the DPS that release a total of about 2.4 million juvenile steelhead into the Clearwater River subbasin annually (Table 2). Three integrated programs also release about 0.5 million steelhead per year. There is no evidence of hatchery influence on natural run genetic composition. There are no hatchery programs that directly affect the Lochsa or Selway rivers.

None of the independent populations within the Clearwater River Steelhead MPG meet the viability criteria of NOAA Fisheries. The Lochsa, Selway, and lower mainstem Clearwater currently meet the HSRG's hatchery management criteria as Primary populations (pHOS $<0.05$; Table 1). Those three populations (Lochsa, Selway, and lower mainstem Clearwater rivers) do not receive any direct releases of hatchery fish and are managed for natural reproduction only. Neither the South Fork Clearwater, Crooked River nor Lolo Creek populations currently meet the HSRG's criteria for Contributing or Sustaining, although the ICTRT concluded that the Lolo Creek population must be viable before the MPG can be considered viable.

Table 2. Hatchery releases and types of programs for Clearwater River Steelhead MPG.

\begin{tabular}{|c|c|c|c|c|c|c|}
\hline \multirow[b]{2}{*}{ Population/Program Name } & \multicolumn{3}{|c|}{ Current $(1,000 \mathrm{~s})$} & \multicolumn{3}{|c|}{ HSRG Solution $(1,000 s)$} \\
\hline & Type & Purpose & $\begin{array}{c}\text { No. } \\
\text { Released }\end{array}$ & Type & Purpose & $\begin{array}{c}\text { No. } \\
\text { Released }\end{array}$ \\
\hline 1-Clearwater_Lochsa Summer Steelhead (B-Run) & None & NA & - & None & NA & - \\
\hline 2-Clearwater Selway Summer Steelhead (B-Run) & None & NA & - & None & NA & - \\
\hline $\begin{array}{l}\text { 3-Clearwater_South Fork Clearwater Summer } \\
\text { Steelhead (B-Run) }\end{array}$ & Int & Harv & 399.8 & Int & Harv & 248.3 \\
\hline $\begin{array}{l}\text { 3-Clearwater_South Fork Clearwater-Crooked } \\
\text { River Summer Steelhead (B-Run) }\end{array}$ & Int & Harv & 84.2 & Int & Harv & 123.9 \\
\hline $\begin{array}{l}\text { 3A-Clearwater_South Fork Clearwater Summer } \\
\text { Steelhead (B-Run Hatchery) }\end{array}$ & Seg & Harv & 911.3 & Seg & Harv & 911.3 \\
\hline 4-Clearwater_Lolo Summer Steelhead (A+B-Run) & Int & Cons & 49.7 & Int & Cons & 49.4 \\
\hline $\begin{array}{l}\text { 5-Clearwater_North Fork Clearwater Summer } \\
\text { Steelhead (B-Run-Hatchery) }\end{array}$ & Seg & Harv & $1,199.3$ & Seg & Harv & $1,199.3$ \\
\hline $\begin{array}{l}\text { 6-Clearwater_Lower Clearwater Summer } \\
\text { Steelhead (A-Run) }\end{array}$ & None & NA & - & None & NA & - \\
\hline $\begin{array}{l}\text { 6A-Clearwater_Lower Clearwater Summer } \\
\text { Steelhead (B-Run-Hatchery) }\end{array}$ & Seg & Harv & 298.0 & Seg & Harv & 298.0 \\
\hline Total all Populations/Programs & & & $2,942.2$ & & & $2,830.2$ \\
\hline
\end{tabular}



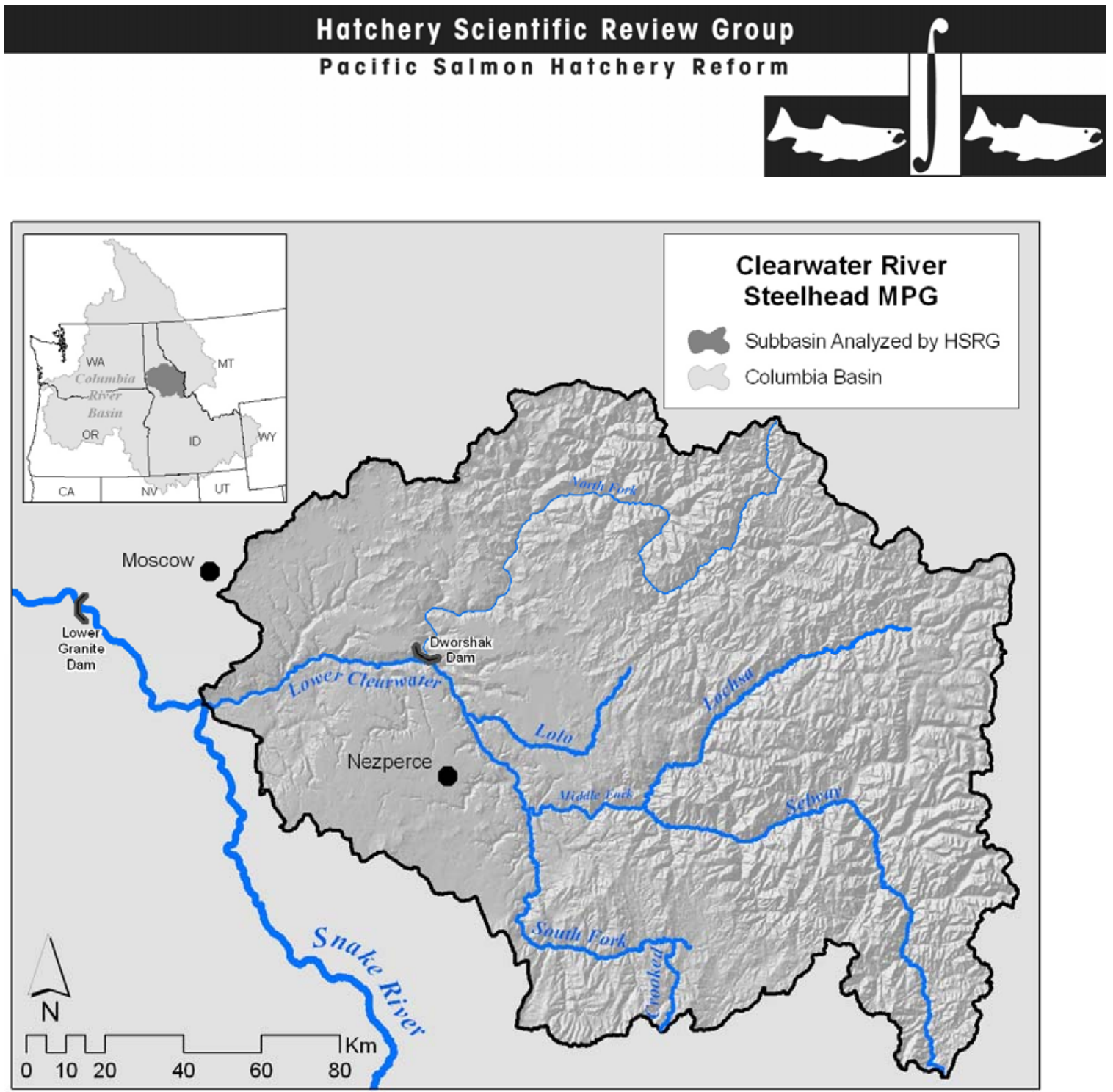

\subsection{HSRG Solutions}

\section{Conservation Outcomes under the HSRG Solutions}

Under the HSRG's recommended solution, the three Primary populations (Lochsa, Selway, and lower Clearwater mainstem) will continue to exhibit a predicted pHOS from 0.0 to 0.02 with a slight increase in productivity from 3.9 to 4.0 for the lower mainstem population (Figure 1). The HSRG's solution results in both the Lolo Creek and the Crooked River populations moving from Stabilizing ( $\mathrm{PNI}=0 ; \mathrm{pHOS} \approx 0.7$ to 0.8 ) to Contributing with a PNI $\approx 0.55$ for both populations (Figure 1 ). The South Fork Clearwater River population will continue to be a Stabilizing population under the HSRG solution. The predicted productivity of the Lolo Creek population will increase (Figure 2). The HSRG was unable to develop a solution that would increase the number of natural-origin recruits returning to the Clearwater subbasin under current habitat and hydropower conditions (Figure 2). 


\section{Harvest Outcomes under the HSRG Solutions}

Under the HSRG's proposed solution, total harvest of Clearwater River steelhead will remain largely unchanged (Figure 3). The only real change will be a slight increase in the contribution of Crooked River steelhead to harvest and a slight decrease in the contribution of other tributaries in the upper South Fork subbasin resulting from elimination of Dworshak outplants in that upper portion of the South Fork watershed.

\section{Hatchery Program Changes under the HSRG Solutions}

The HSRG solution continues to manage the Lochsa, Selway, and lower mainstem Clearwater populations as natural population "reserves" in the Clearwater River with no direct releases of hatchery-origin steelhead (Table 2).

The HSRG recommends subdividing the current steelhead hatchery programs in the South Fork Clearwater River into two programs that address harvest and conservation goals separately (Table 2 ). The current program involves outplanting nearly 1.4 million Dworshak NFH smolts among several sites in the South Fork. The HSRG recommends developing a new integrated broodstock program for the Crooked River derived from natural-origin adults trapped at the existing satellite weir to assist with restoration of a naturally spawning population in the upper South Fork watershed. Outplants of steelhead smolts from Dworshak NFH in the upper South Fork Clearwater River would be terminated upstream of, and including Newsome Creek to protect naturally spawning populations in the upper watershed from hatchery influence. The existing segregated program, that currently depends on outplants of Dworshak NFH steelhead, would continue, but those latter outplants (approximately 900,000 smolts) would be restricted to the area around the Red House release site to reduce straying risks in the upper watershed.

Approximately 50,000 steelhead smolts from Dworshak NFH are currently outplanted into Lolo Creek annually which results in a PNI of 0 and a predicted pHOS of 0.68 . The HSRG was unable to develop a solution for Lolo Creek that would achieve the HSRGdefined standards of a Primary population. The HSRG recommends terminating outplants from Dworshak NFH and developing an integrated hatchery program from natural-origin recruits within the Lola Creek subbasin, up to the size of the current program of 50,000 smolts (Table 2). 


\section{Hatchery Scientific Review Group}

Pacific Salmon Hatchery Reform
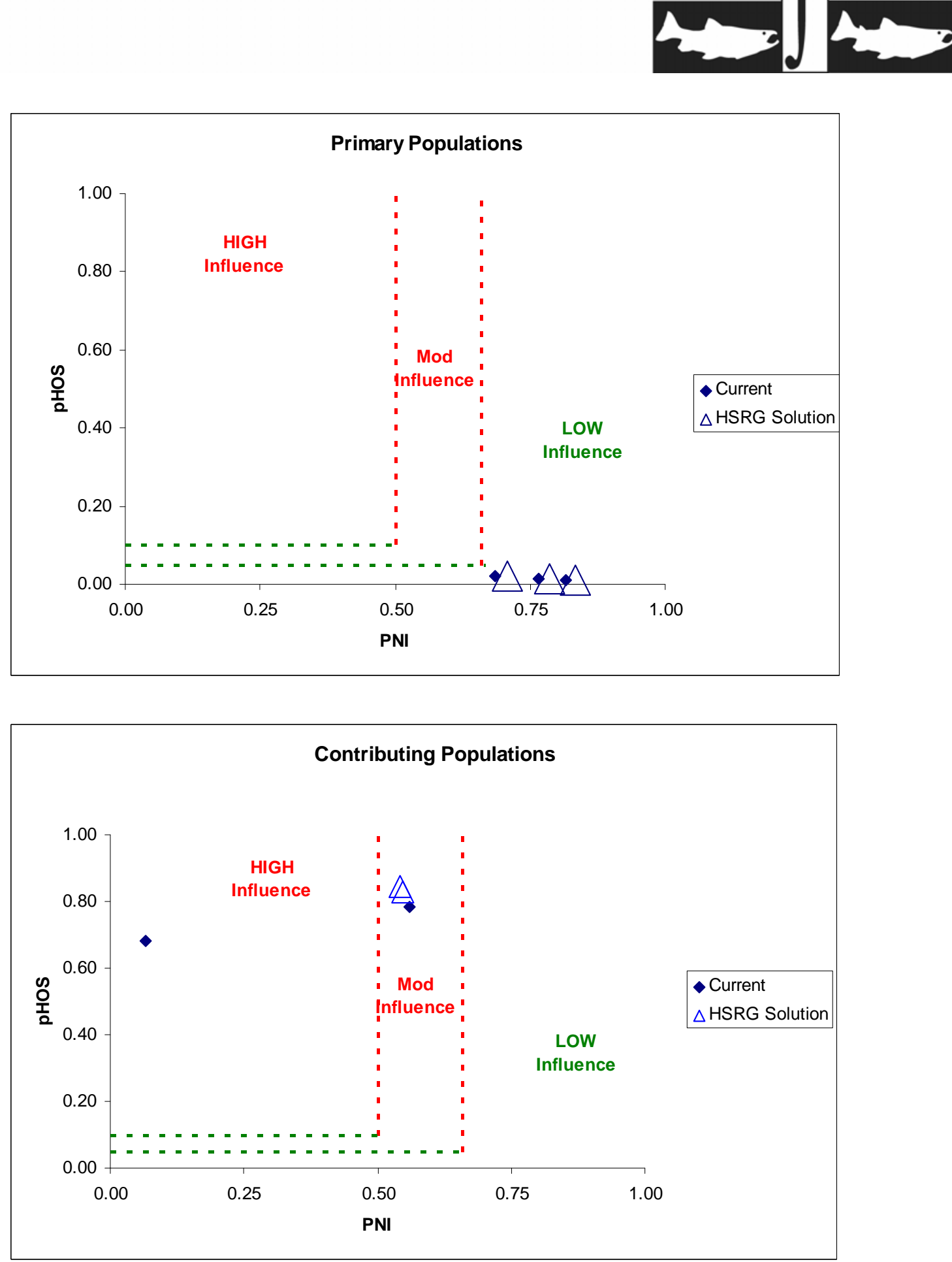

Figure 1. Relationship of the proportion of the fish on the spawning grounds that are of hatchery origin (pHOS) and the proportionate natural influence index (PNI) for Primary (top panel) and Contributing (bottom panel) steelhead populations in the Clearwater River MPG. Solid diamonds represent values for current programs and open triangles represent values for the HSRG recommended hatchery management solution. 


\section{Hatchery Scientific Review Group}

Pacific Salmon Hatchery Reform
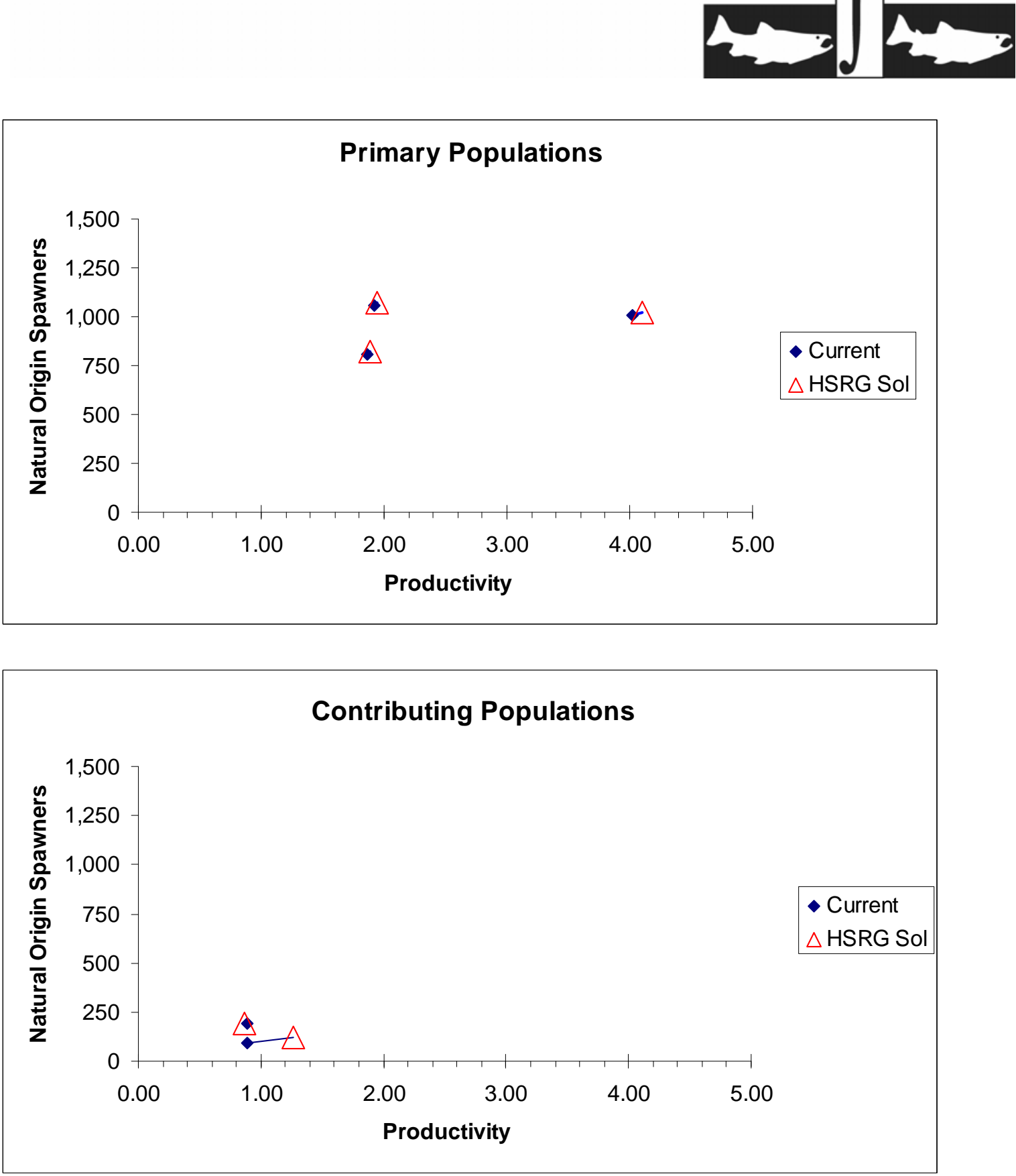

Figure 2. Productivity and spawner abundance for Primary (top panel) and Contributing (bottom panel) steelhead populations in the Clearwater River MPG. Solid diamonds represent existing productivity and spawner abundance levels, and triangles represent the HSRG recommended hatchery management solution. Lines connect current with HSRG solution for a particular population. The HSRG recommended hatchery management solution includes projected improved fish passage survival in the Snake and Columbia mainstem migration corridor (FCRPS Biological Opinion May 5, 2008). 

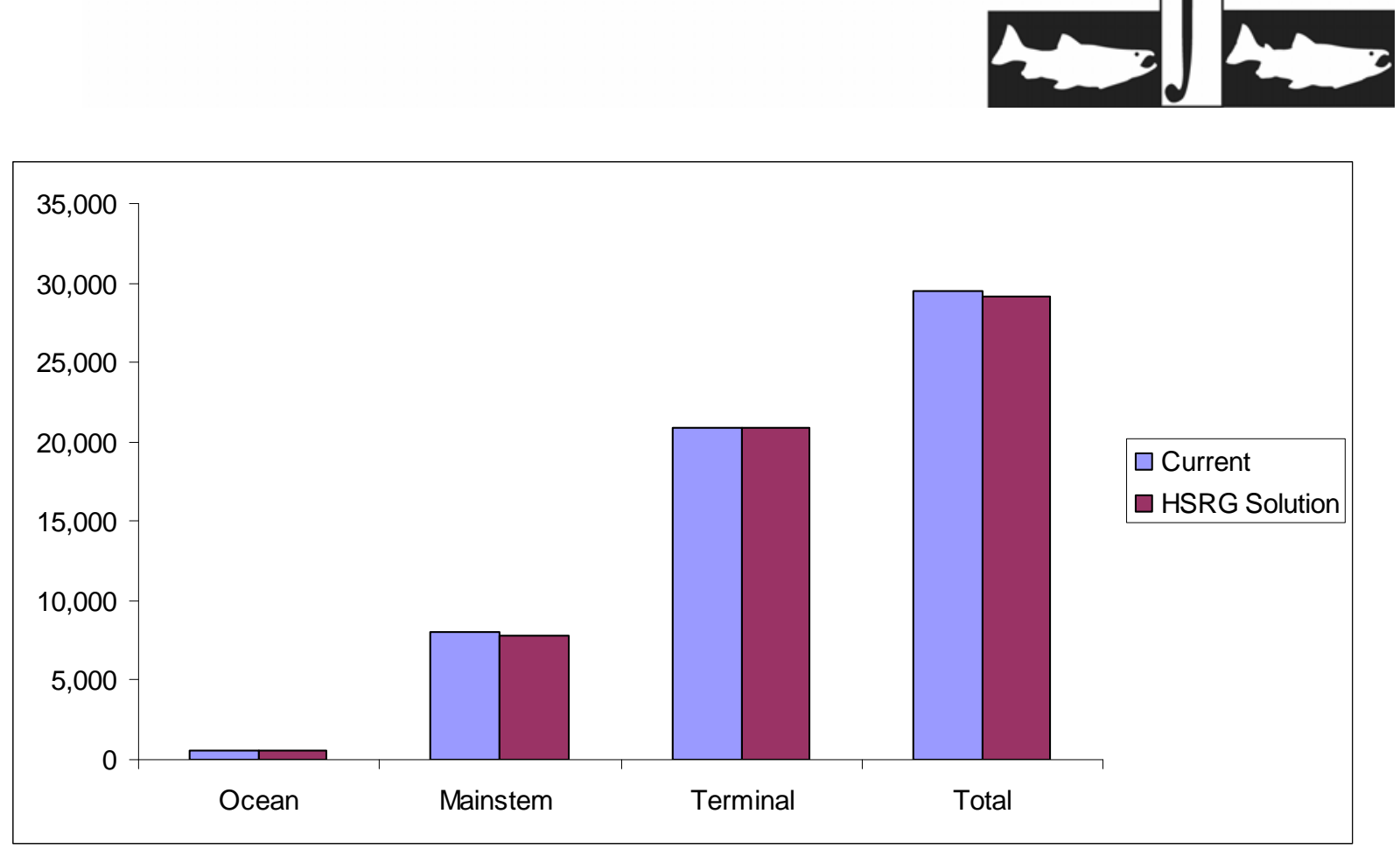

Figure 3. Estimated marine, mainstem Columbia, and terminal harvest under current and HSRG recommended hatchery management solution for Clearwater River Steelhead MPG. The HSRG recommended hatchery management solution includes projected improved fish passage survival in the Snake and Columbia mainstem migration corridor (FCRPS Biological Opinion May 5, 2008).

\subsection{Summary and Conclusions}

The HSRG recognizes and supports the strategic use of wild salmon management zones as an important component to a balanced conservation strategy for the Snake River Steelhead DPS.

Three of the five populations in his MPG are managed for natural production consistent with a Primary population designation; the HSRG solutions do not affect these populations. The solutions improve conditions for two populations, Lolo Creek and the South Fork Clearwater River. Hatchery risks to natural populations in these streams are reduced by eliminating some Dworshak outplants and developing localized broodstock. Replacing segregated outplanting programs with integrated local broodstock programs allows the Crooked River and Lolo Creek populations to each meet the HSRG's criteria for Contributing populations while maintaining harvest contributions. The HSRG was unable to develop a solution that increases the abundance of natural-origin recruits back to the Clearwater River.

Harvest is maintained at the current level. 


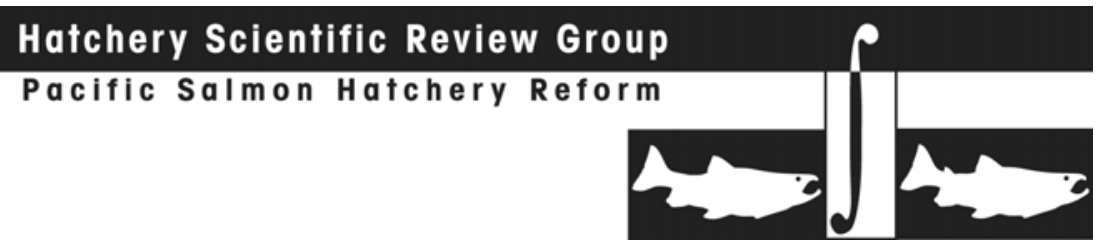

\subsubsection{Grande Ronde Steelhead MPG}

The Grande Ronde Steelhead major population grouping (MPG) includes steelhead populations in the lower and upper Grande Ronde River, Joseph Creek and the Wallowa River. This report contains a general description of the MPG, fisheries, habitat limitations and hatchery programs that affect it. It generally describes HSRG recommendations for hatchery program changes for the MPG and the results of implementing those changes on conservation and harvest goals. More detailed conclusions and recommendations of the HSRG can be found in population reports in Appendix E.

3.4.6.3.1

\section{HSRG Population Guidelines}

In order to meet conservations goals for the MPG, numerous threats to these populations need to be addressed, including risks from hatchery programs. The key to controlling genetic and ecological risks due to straying and fitness loss is to manage hatchery broodstock and natural spawning escapement such that the natural habitat (and not the hatchery environment) drives the adaptation and productivity of the naturally spawning population. This is achieved by operating either (a) integrated programs where the proportion of natural-origin adults in the broodstock (pNOB) exceeds the proportion of hatchery-origin fish on the spawning grounds (pHOS); or (b) segregated programs where the contribution of hatchery fish to natural spawning is kept low (pHOS $<5 \%$ to $<10 \%$ depending on the population designation). The HSRG developed criteria for hatchery influence for three population types based on the importance of the population to the recovery of the MPG. This was done to provide a consistent method of reviewing populations and programs across the Columbia River Basin. The population designations adopted by the HSRG (Primary, Contributing, or Stabilizing) occurred after discussions with managers and followed those developed in the Lower Columbia River Salmon Recovery Plan (LCFRB 2004). These designations are meant to reflect the conservation importance of a population within the MPG from most important (Primary), to moderately important (Contributing), to least important (Stabilizing). HSRG recommendations show how hatchery programs can be operated consistent with these designations based on the following standards:

HSRG criteria for hatchery influence on Primary populations:

- The proportion of effective hatchery-origin spawners (pHOS) should be less than $5 \%$ of the naturally spawning population, unless the hatchery population is integrated with the natural population.

- For integrated populations, the proportion of natural-origin adults in the broodstock should exceed pHOS by at least a factor of two, corresponding to a proportionate natural influence (PNI) value of 0.67 or greater and pHOS should be less than 0.30 .

HSRG criteria for hatchery influence on Contributing populations:

- The proportion of effective hatchery-origin spawners (pHOS) should be less than $10 \%$ of the naturally spawning population, unless the hatchery population is integrated with the natural population. 


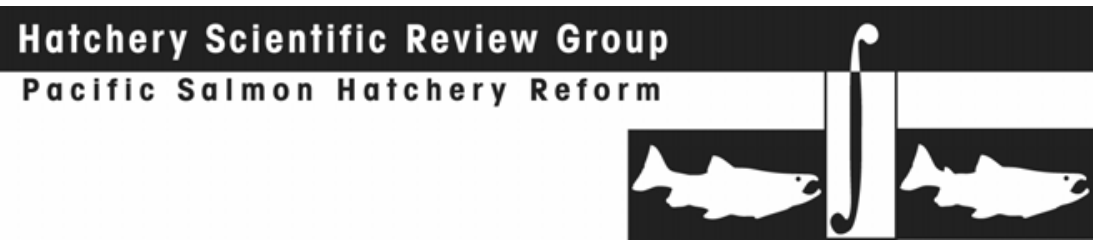

- For integrated populations, the proportion of natural-origin adults in the broodstock should exceed pHOS, corresponding to a PNI value of 0.50 or greater and $\mathrm{pHOS}$ should be less than 0.30 .

HSRG criteria for hatchery influence on Stabilizing populations:

- The current operating conditions were considered adequate to meet their conservation goals. No criteria were developed for proportion of effective hatchery-origin spawners (pHOS) or PNI.

\subsection{Current Conditions}

\section{Conservation}

The Grande Ronde Steelhead MPG is in the Snake River Steelhead Distinct Population Segment (DPS) and was listed as threatened under the Endangered Species Act in 1997. As defined by the ESA and the HSRG, the MPG includes the Wallowa River, Joseph Creek, and the Upper and Lower Mainstem Grande Ronde River populations. The diversity risk has been designated as either "low" or "moderate" for all steelhead populations in the DPS (NMFS 2008e). The Joseph Creek population has been designated a "low" risk of long-term extinction. Other populations have been designated at "moderate" risk of long-term extinction.

For the purpose of this review, the HSRG designated all four populations as Primary (Table 1).

Table 1. Population designations for the Grande Ronde Steelhead MPG and HSRG broodstock criteria achieved for each population under current conditions and the HSRG recommended hatchery management solution.

\begin{tabular}{|c|c|c|c|}
\hline \multirow[b]{2}{*}{ Population } & \multirow[b]{2}{*}{ Designation $^{1}$} & \multicolumn{2}{|c|}{ HSRG Criteria Met ${ }^{2}$} \\
\hline & & Current & HSRG Solution \\
\hline 10-Grande Ronde_Wallowa Summer Steelhead & Primary & Primary & Primary \\
\hline 11-Grande Ronde_Upper Grande Ronde Summer Steelhead & Primary & Primary & Primary \\
\hline 8-Grande Ronde_Lower Grande Ronde Summer Steelhead & Primary & Primary & Primary \\
\hline 9-Grande Ronde Joseph Summer Steelhead & Primary & Primary & Primary \\
\hline
\end{tabular}

1 Using the naming protocol of the Lower Columbia River Salmon Recovery Plan (LCFRB 2004), populations were classified based on information provided to the HSRG as Primary, Contributing, or Stabilizing. These designations are meant to reflect the conservation importance of a population within the MPG from most important (Primary- bold, red), to moderately important (Contributing-bold, blue), to least important (Stabilizing).

2 The HSRG developed criteria for hatchery influence for the three population designations from low influence (Primary), moderate influence (Contributing) to high influence (Stabilizing).

\section{Current Harvest}

There are no freshwater recreational fisheries directly targeting natural-origin steelhead from the Grande Ronde River. Incidental mortalities occur in some fisheries targeting hatchery-origin fish. Some harvest may occur in size-selective gillnet fisheries in the Columbia River. Fisheries in the mainstem Columbia River have been managed to limit incidental take to two percent year-round for non-Indian fisheries (NMFS 2008e). Treaty 


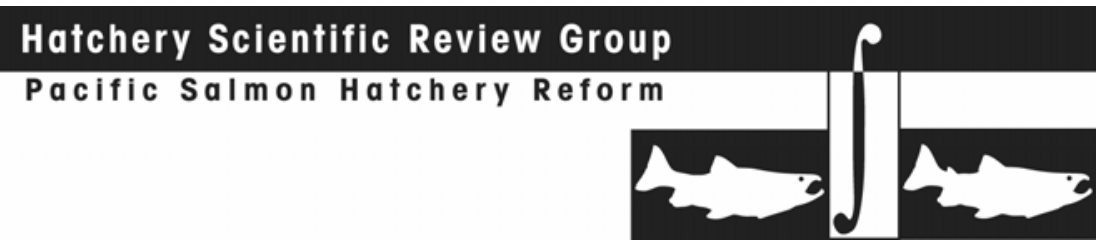

Indian fisheries have a 15\% limit on B-run steelhead (NMFS 2008e). Recent harvest rates on Snake River steelhead have been less than allowed and ocean fishing mortality on the ESA listed Grande Ronde steelhead MPG is assumed to be zero (NMFS 2008e).

\section{Current Habitat}

Land uses such as agriculture, forestry, mining and grazing have altered habitat throughout the MPG. For example, re-routing and diking the Grande Ronde River eliminated over 50 miles of habitat in the Grande Ronde Valley. Some watersheds, such as the Wenaha, have been protected for over 100 years and are in nearly pristine condition. In general, land uses have increased erosion and sedimentation, degraded riparian condition, reduced stream flows and channel complexity, and increased water temperature and water quality degradation.

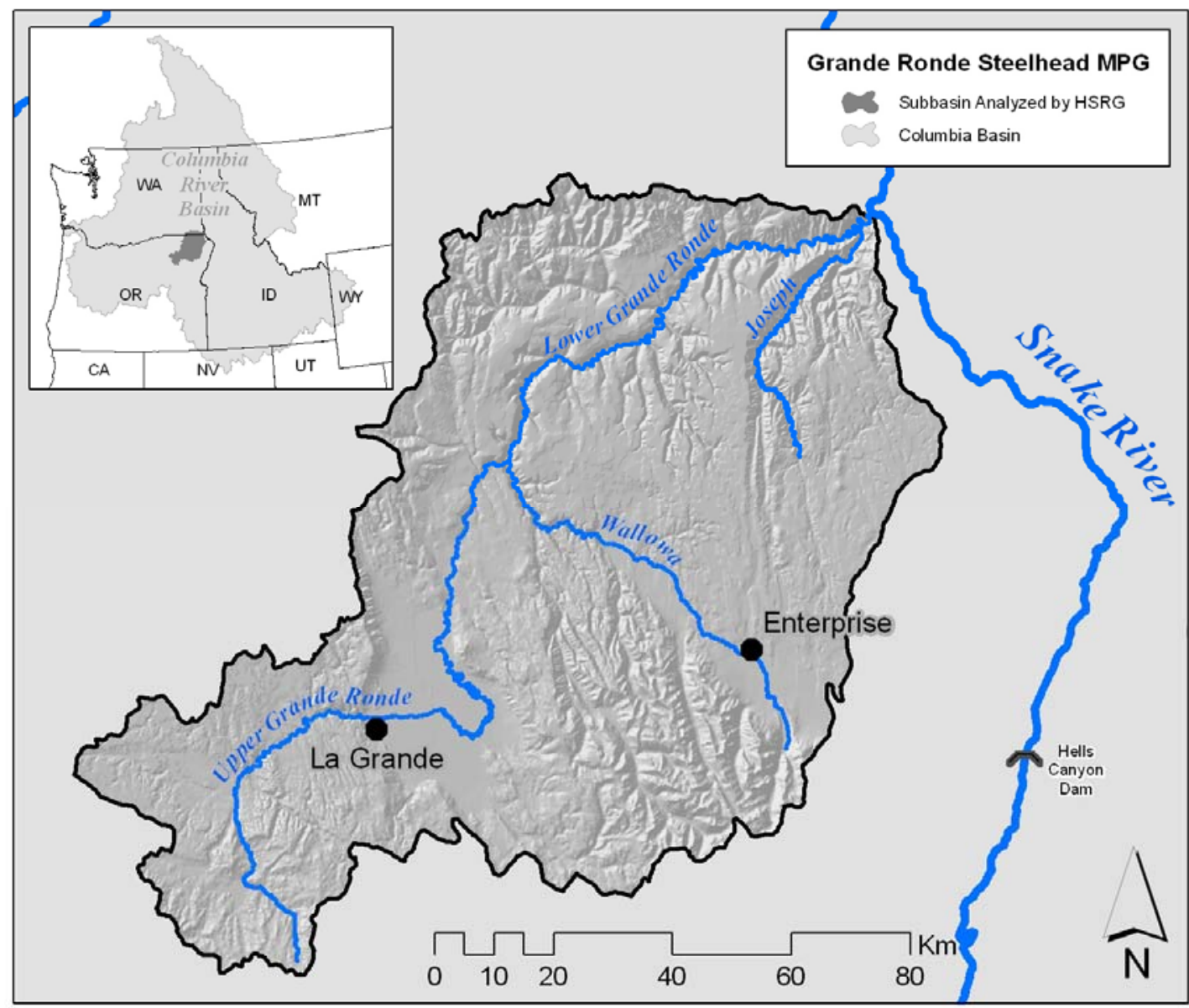

\section{Current Hatchery Programs}

Segregated hatchery programs release steelhead into both the Wallowa River and the Grande Ronde mainstem annually to compensate for the effects of hydroelectric projects on the Snake River fisheries. Combined, these programs release approximately 960,000 steelhead annually in the Grande Ronde subbasin (Table 2). Joseph Creek and the Upper Grande Ronde mainstem have been reserved for natural steelhead production only and 


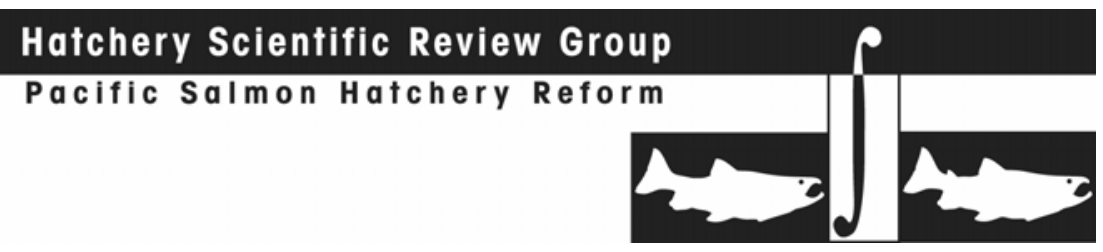

hatchery strays are minimal in these populations. The few strays to the Upper Grande Ronde are removed at weirs; however, these segregated programs contribute to straying outside the Grande Ronde subbasin into Deschutes and John Day rivers.

Estimates of proportionate natural influence (PNI) and proportion of hatchery-origin spawners (pHOS) under current conditions show that all four Primary populations in the MPG meet the broodstock criteria for their population designation (Table 1).

Table 2. Hatchery releases and types of programs for Grande Ronde Steelhead MPG.

\begin{tabular}{|c|c|c|c|c|c|c|}
\hline \multirow[b]{2}{*}{ Population/Program Name } & \multicolumn{3}{|c|}{ Current $(1,000 \mathrm{~s})$} & \multicolumn{3}{|c|}{ HSRG Solution $(1,000 \mathrm{~s})$} \\
\hline & Type & Purpose & $\begin{array}{c}\# \\
\text { Released }\end{array}$ & Type & Purpose & $\begin{array}{c}\# \\
\text { Released }\end{array}$ \\
\hline $\begin{array}{l}\text { 8-Grande Ronde_Lower Grande Ronde Summer } \\
\text { Steelhead }\end{array}$ & None & NA & & None & NA & \\
\hline $\begin{array}{l}\text { 8A-Grande Ronde_Cottonwood Creek Summer } \\
\text { Steelhead (Wallowa-Lyons Ferry-Hatchery) }\end{array}$ & Seg & Harv & 160.1 & Seg & Harv & 160.1 \\
\hline 9-Grande Ronde_Joseph Summer Steelhead & None & NA & - & None & $\mathrm{NA}$ & \\
\hline 10-Grande Ronde_Wallowa Summer Steelhead & None & NA & - & None & NA & \\
\hline $\begin{array}{l}\text { 10A-Grande Ronde_Wallowa Summer Steelhead } \\
\text { (Hatchery) }\end{array}$ & Seg & Harv & 799.3 & Seg & Harv & 799.3 \\
\hline $\begin{array}{l}\text { 11-Grande Ronde_Upper Grande Ronde Summer } \\
\text { Steelhead }\end{array}$ & None & NA & & None & NA & \\
\hline Total all Populations/Programs & & & 959.3 & & & 959.3 \\
\hline
\end{tabular}

\subsection{HSRG Solutions}

The HSRG recommends that existing fish weirs continue to be used to collect data and monitor steelhead populations. There are no specific changes recommended for the hatchery smolt release programs. In order to decrease hatchery-origin spawners, the HSRG recommends eliminating passing hatchery-origin adults above the rack at the Cottonwood Creek adult trap and increasing harvest of hatchery steelhead in the sport fisheries. Managers should continue to explore ways to reduce straying into the John Day and Deschutes rivers.

\section{Conservation Outcomes under the HSRG Solutions}

Figure 1 compares the proportion of hatchery-origin fish on the spawning grounds (pHOS) and the proportionate natural influence for current and proposed (HSRG) scenarios for Primary populations. All populations currently meet the HSRG standards for Primary population designations.

Figure 2 compares the number of natural-origin spawners on the spawning grounds to their productivity for current and proposed (HSRG solution) scenarios for Primary populations. Hatchery-origin spawners will be reduced by eliminating hatchery-origin adults above the Cottonwood Creek weir, slightly increasing productivity of the natural population. Steelhead populations in Joseph Creek and the upper Grande Ronde River are unaffected by the hatchery programs because the hatchery programs produce very few strays. 
Harvest Outcomes under the HSRG Solutions

Figure 3 describes current and estimated changes in harvest (in marine, mainstem Columbia River and terminal areas) following implementation of the management solutions proposed by the HSRG. In this case, total harvest increases, with the majority of the increase in the terminal harvest area. The HSRG recommends increasing catch limits of hatchery-origin fish. This would occur primarily in terminal harvest areas in Cottonwood Creek and the Wallowa River.

Hatchery Program Changes under the HSRG Solutions

Table 2 shows the current size of each hatchery program as well as their size under the HSRG solution. The HSRG has no specific recommendations for these segregated hatchery programs.

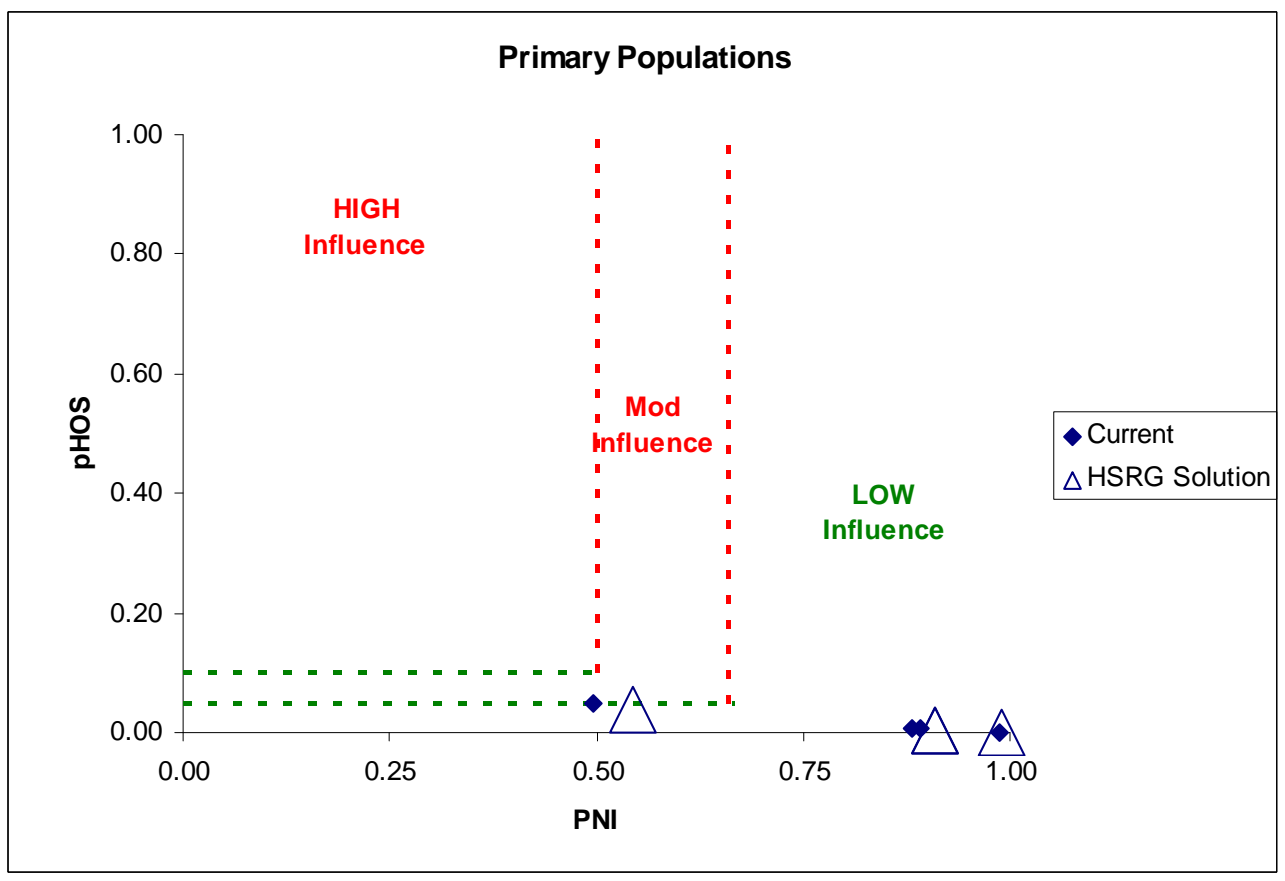

Figure 1. Relationship of the proportion of the fish on the spawning grounds that are of hatchery origin (pHOS) and the proportionate natural influence index (PNI) for Primary (top panel) and Contributing (bottom panel) steelhead populations in the Grande Ronde Steelhead MPG. Solid diamonds represent values for current programs and open triangles represent values for the HSRG recommended hatchery management solution. 


\section{Hatchery Scientific Review Group}

Pacific Salmon Hatchery Reform
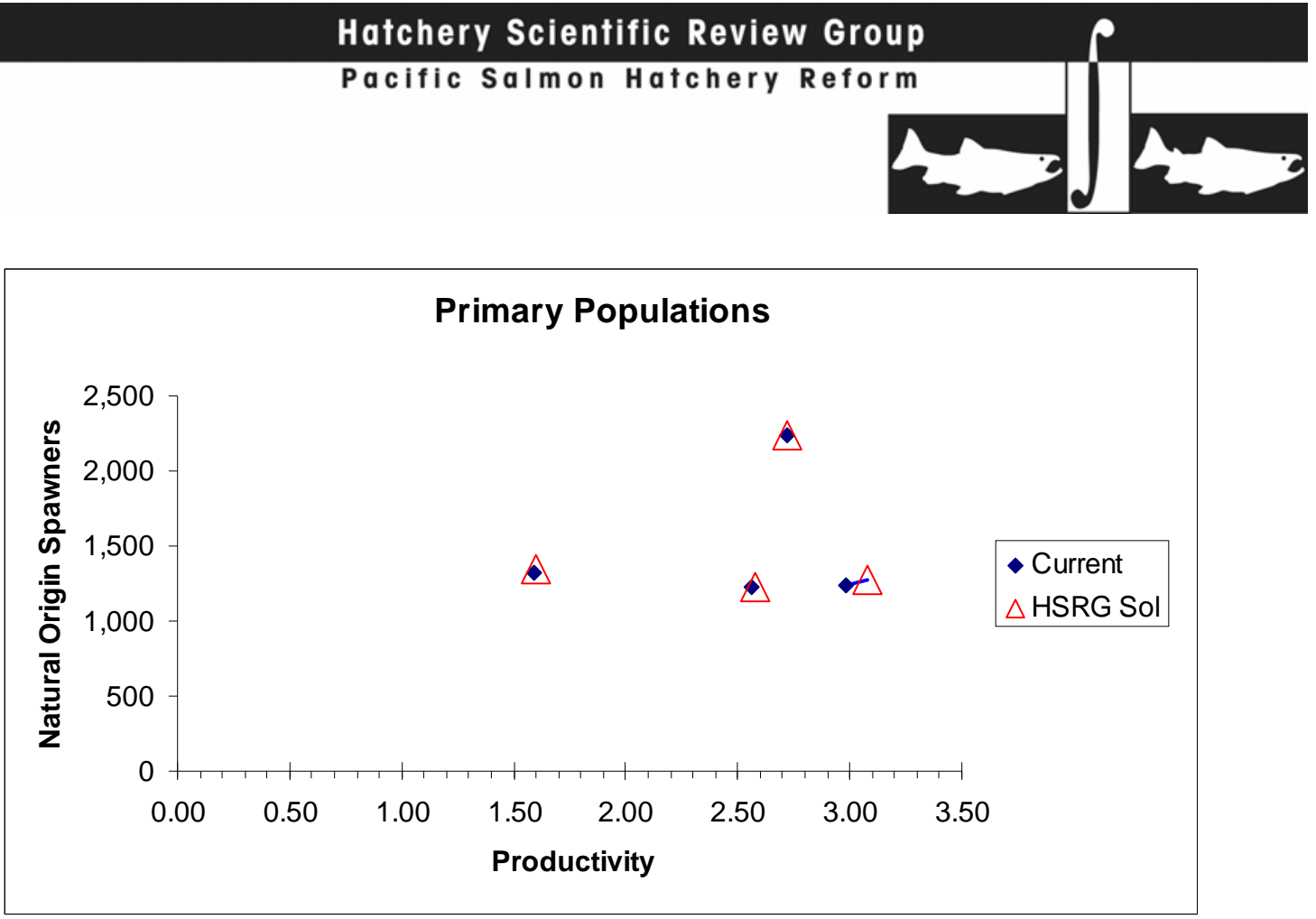

Figure 2. Productivity and spawner abundance for Primary (top panel) and Contributing (bottom panel) steelhead populations in the Grande Ronde River MPG. Solid diamonds represent existing productivity and spawner abundance levels, and triangles represent the HSRG recommended hatchery management solution. Lines connect current with HSRG solution for a particular population. The HSRG recommended hatchery management solution includes projected improved fish passage survival in the Snake and Columbia mainstem migration corridor (FCRPS Biological Opinion May 5, 2008).

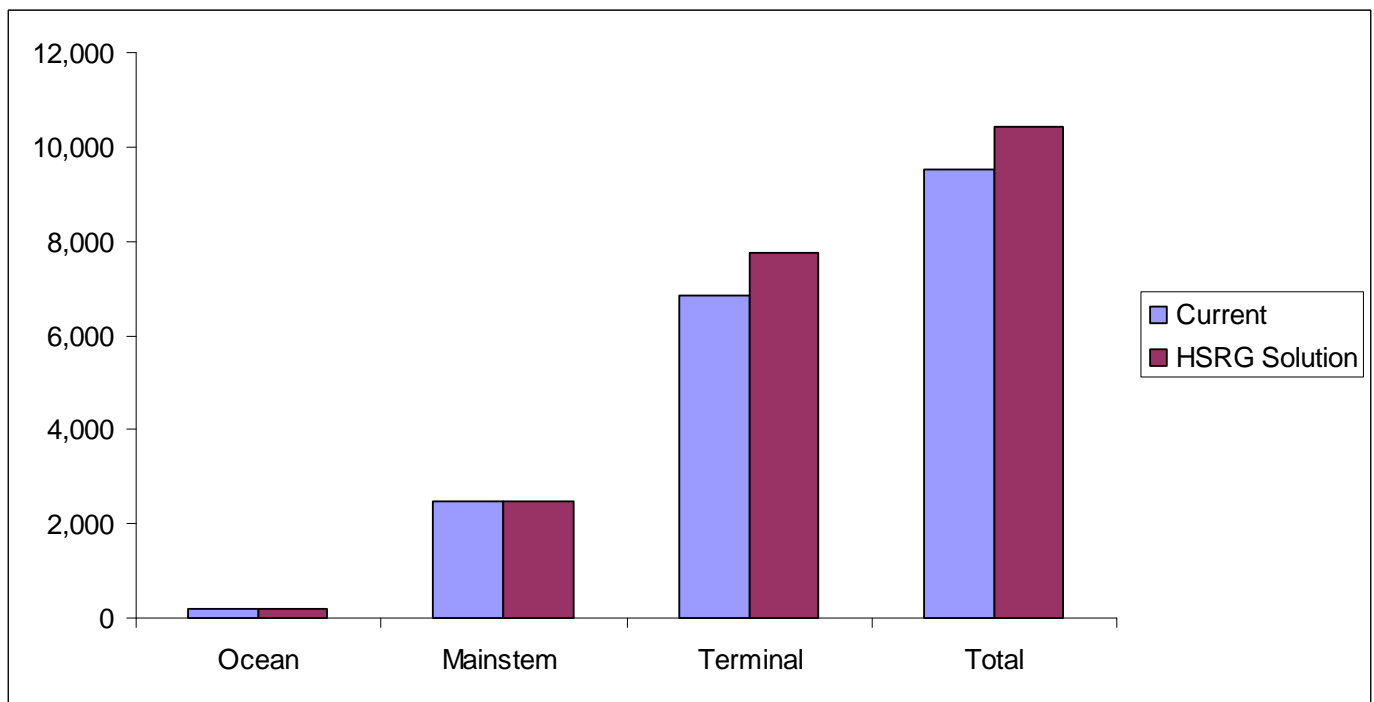

Figure 3. Estimated marine, mainstem Columbia, and terminal harvest under current and HSRG recommended hatchery management solution for Grande Ronde Steelhead MPG. The HSRG recommended hatchery management solution includes projected improved fish passage survival in the Snake and Columbia mainstem migration corridor (FCRPS Biological Opinion May 5, 2008). 


\section{Summary and Conclusions}

Currently all populations in this MPG meet the standards for a Primary designation. The HSRG has no significant recommendations to change hatchery programs in this MPG.

The HSRG solution should slightly increase harvest through suggested changes in fishing regulation changes.

The HSRG also recommends maintaining monitoring and data collection for steelhead populations in the Grande Ronde River. The three existing weirs provide one of the few locations for consistent monitoring of long-term steelhead population trends in the Snake River Basin.

\subsubsection{4}

\section{Imnaha Steelhead MPG}

This section provides an overview of the Imnaha Steelhead Major Population Grouping (MPG). It contains a general description of the MPG, fisheries, habitat limitations and hatchery programs that affect it. Overall recommendations for MPG-wide hatchery program changes are summarized as are the results of implementing these changes on conservation and harvest goals. Detailed conclusions and recommendations for each population in the MPG can be found in the Appendix E.

\subsection{HSRG Population Guidelines}

In order to meet conservations goals for the MPG, numerous threats to these populations need to be addressed, including risks from hatchery programs. The key to controlling genetic and ecological risks due to straying and fitness loss is to manage hatchery broodstock and natural spawning escapement such that the natural habitat (and not the hatchery environment) drives the adaptation and productivity of the naturally spawning population. This is achieved by operating either (a) integrated programs where the proportion of natural-origin adults in the broodstock (pNOB) exceeds the proportion of hatchery-origin fish on the spawning grounds (pHOS); or (b) segregated programs where the contribution of hatchery fish to natural spawning is kept low (pHOS $<5 \%$ to $<10 \%$ depending on the population designation). The HSRG developed criteria for hatchery influence for three population types based on the importance of the population to the recovery of the DPS. This was done to provide a consistent method of reviewing populations and programs across the Columbia River Basin. The population designations used by the HSRG (Primary, Contributing, or Stabilizing) were adopted after discussions with managers and followed those developed in the Lower Columbia River Salmon Recovery Plan (LCFRB 2004). These designations are meant to reflect the conservation importance of a population within the DPS from most important (Primary), to moderately important (Contributing), to least important (Stabilizing). HSRG recommendations show how hatchery programs can be operated consistent with these designations based on the following standards:

\section{HSRG criteria for hatchery influence on Primary populations:}

- The proportion of effective hatchery-origin spawners (pHOS) should be less than 5\% of the naturally spawning population, unless the hatchery population is integrated with the natural population. 


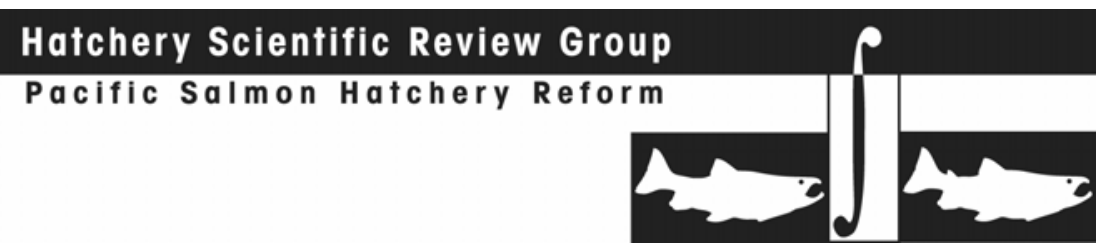

- For integrated populations, the proportion of natural-origin adults in the broodstock should exceed pHOS by at least a factor of two, corresponding to a proportionate natural influence (PNI) value of 0.67 or greater and pHOS should be less than 0.30 .

HSRG criteria for hatchery influence on Contributing populations:

- The proportion of effective hatchery-origin spawners (pHOS) should be less than $10 \%$ of the naturally spawning population, unless the hatchery population is integrated with the natural population.

- For integrated populations, the proportion of natural-origin adults in the broodstock should exceed pHOS, corresponding to a PNI value of 0.50 or greater and $\mathrm{pHOS}$ should be less than 0.30 .

HSRG criteria for hatchery influence on Stabilizing populations:

- The current operating conditions were considered adequate to meet their conservation goals. No criteria were developed for proportion of effective hatchery-origin spawners (pHOS) or PNI.

\subsection{Current Conditions}

\section{Conservation}

The Imnaha River steelhead Major Population Group (MPG) is in the Snake River steelhead Distinct Population Segment (DPS) and was listed as threatened under the Endangered Species Act (ESA) in 1997. As defined by the ESA and the HSRG, the MPG includes only the Imnaha River population. The Imnaha MPG is designated a "moderate" risk for long-term extinction (NMFS 2008e). For the purposes of this analysis, the HSRG defined and evaluated two population sub-components, the Imnaha summer steelhead and Imnaha-Little Sheep summer steelhead sub-components.

For the purpose of its review, HSRG designated the Imnaha River steelhead subcomponent as Primary and the Imnaha-Little Sheep population as Contributing (Table 1).

\section{Current Harvest}

There are no freshwater recreational fisheries directly targeting natural-origin steelhead in the Imnaha River although incidental mortalities occur in some fisheries targeting hatchery-origin fish. Some harvest may occur in size-selective gillnet fisheries in the Columbia River. Fisheries in the mainstem of the Columbia River have been managed to limit incidental take to two percent year-round for non-Indian fisheries (NMFS 2008e). Treaty Indian fisheries have a 15 percent limit on B-run steelhead (NMFS 2008e). Recent harvest rates on Snake River steelhead have generally been less than allowed and ocean fishing mortality on the ESA listed Snake River steelhead DPS is assumed to be zero (NMFS 2008e).

Table 1. Population designations for the Imnaha Steelhead MPG and HSRG broodstock criteria achieved for each population under current conditions and the HSRG recommended hatchery management solution.

\begin{tabular}{|l|l|l|l|}
\hline \multirow{2}{*}{ Population } & & \multicolumn{2}{|c|}{ HSRG Criteria Met $^{2}$} \\
\cline { 3 - 4 } & Designation $^{1}$ & Current & HSRG Solution \\
\hline
\end{tabular}




\begin{tabular}{|l|c|c|c|}
\hline 24-Imnaha Summer Steelhead & Primary & Primary & Primary \\
\hline 24A-Imnaha_Little Sheep Summer Steelhead & Contributing & Stabilizing & Contributing \\
\hline
\end{tabular}

1 Using the naming protocol of the Lower Columbia River Salmon Recovery Plan (LCFRB 2004), populations were classified based on information provided to the HSRG as Primary, Contributing, or Stabilizing. These designations are meant to reflect the conservation importance of a population within the MPG from most important (Primary- bold, red), to moderately important (Contributing-bold, blue), to least important (Stabilizing).

2 The HSRG developed criteria for hatchery influence for the three population designations from low influence (Primary), moderate influence (Contributing) to high influence (Stabilizing).

\section{Current Habitat}

Land uses such as agriculture, forestry, mining and grazing have altered habitat throughout the MPG. In general, land use practices have increased erosion and sedimentation, degraded riparian condition, reduced stream flows, reduced channel complexity, increased water temperature, and degraded water quality.

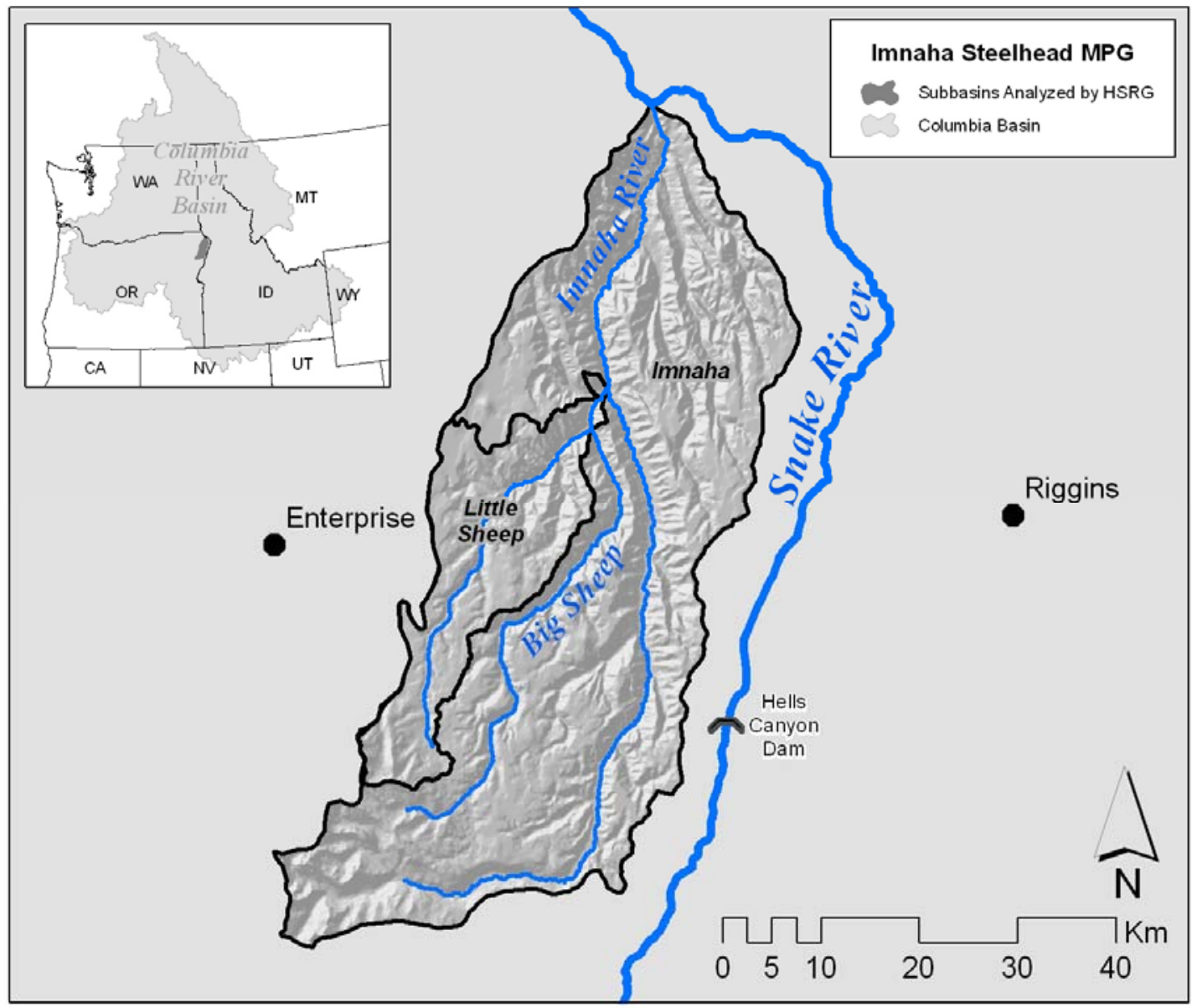

\section{Current Hatchery Programs}

This is a single population MPG managed with two sub-components. The larger subcomponent (the Imnaha and tributaries, excluding Big Sheep and Little Sheep creeks) is managed for natural production while the other component (Big Sheep and Little Sheep) 


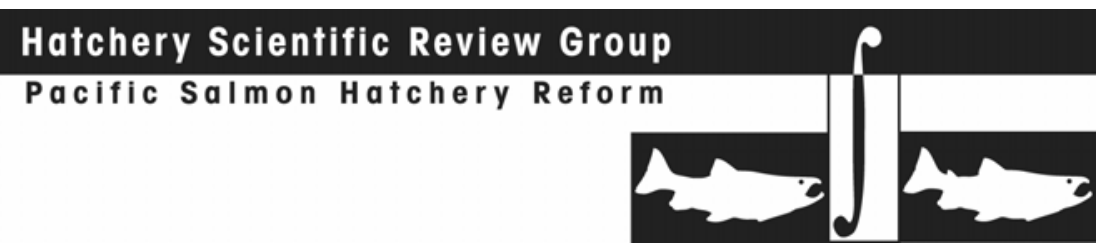

has an associated hatchery program. Little Sheep Creek has a poorly integrated hatchery program that provides juveniles and adults for outplanting into Big Sheep Creek as well as releases into Little Sheep Creek. The integrated hatchery program releases about 212,000 steelhead smolts annually intended to provide harvest and to increase naturally spawning populations in this subbasin (Table 2).

Estimates of PNI and pHOS under current conditions show that the Imnaha MPG populations meet the standards for a Primary population. The Little Sheep Creek subcomponent has been designated as a Contributing population and is not currently meeting the standards for that designation (Table 1).

Table 2. Hatchery releases and types of programs for Imnaha Steelhead MPG.

\begin{tabular}{|l|c|c|c|c|c|c|}
\hline \multirow{2}{*}{ Population/Program Name } & \multicolumn{2}{|c|}{ Current (1,000s) } & \multicolumn{3}{c|}{ HSRG Solution (1,000s) } \\
\cline { 2 - 7 } & Type & Purpose & \# Released & Type & Purpose & \# Released \\
\hline 24-Imnaha Summer Steelhead & None & NA & - & None & NA & - \\
\hline 24A-Imnaha_Little Sheep Summer Steelhead & Int & Both & 212.3 & Int & Both & 87.7 \\
\hline $\begin{array}{l}\text { 24b-Imnaha_Little Sheep Summer Steelhead } \\
\text { (stepping stone hatchery) }\end{array}$ & Seg & Harv & - & Seg & Harv & 126.3 \\
\hline Total all Populations/Programs & & & $\mathbf{2 1 2 . 3}$ & & & $\mathbf{2 1 4 . 0}$ \\
\hline
\end{tabular}

\subsection{HSRG Solutions}

The HSRG solutions for this MPG involve eliminating the transfer of adults and juveniles to Big Sheep Creek and converting the current poorly integrated program (Little Sheep Creek) to a stepping stone program (containing both an integrated and a segregated component).

In addition, the managers should identify specific conservation objectives for the Big Sheep Creek steelhead component of the Imnaha steelhead population. In order to accomplish this, managers need to develop abundance and productivity estimates for this population component and determine the current population status. Managers should suspend the existing smolt and adult plants into Big Sheep Creek until the above has been achieved. Once this is complete, a properly integrated program (using either adult or juvenile outplants) could be developed using the appropriate PNI, pNOB and pHOS to achieve the conservation standards developed by the managers.

\section{Conservation Outcomes under the HSRG Solutions}

Figure 1 compares the proportion of fish on the spawning grounds that are of hatchery origin (pHOS) and the proportionate natural influence for current and proposed (HSRG) scenarios for Primary and Contributing populations. The HSRG solutions make no changes to the level of hatchery influence overall for this MPG although the hatchery influence of the Little Sheep Creek component is reduced and productivity increased (Figure 2). 


\section{Harvest Outcomes under the HSRG Solutions}

Figure 3 identifies current and estimated changes in harvest (marine, mainstem Columbia River and terminal areas) that would occur following implementation of the management solutions proposed by the HSRG. The HSRG solutions make no changes to the amount of harvest provided by these programs.

\section{Hatchery Program Changes under the HSRG Solutions}

Table 2 shows the current size of this hatchery program as well as its size under the HSRG solution. For this MPG, the total number of smolts released remains approximately the same; however, the HSRG recommends converting the existing integrated program into a "stepping stone" program for Little Sheep Creek. This "stepping stone" program includes a small integrated program to achieve the conservation benefit and a segregated program to achieve the harvest objective (see individual population report for a detailed description of a "stepping stone" program). 


\section{Hatchery Scientific Review Group}

Pacific Salmon Hatchery Reform
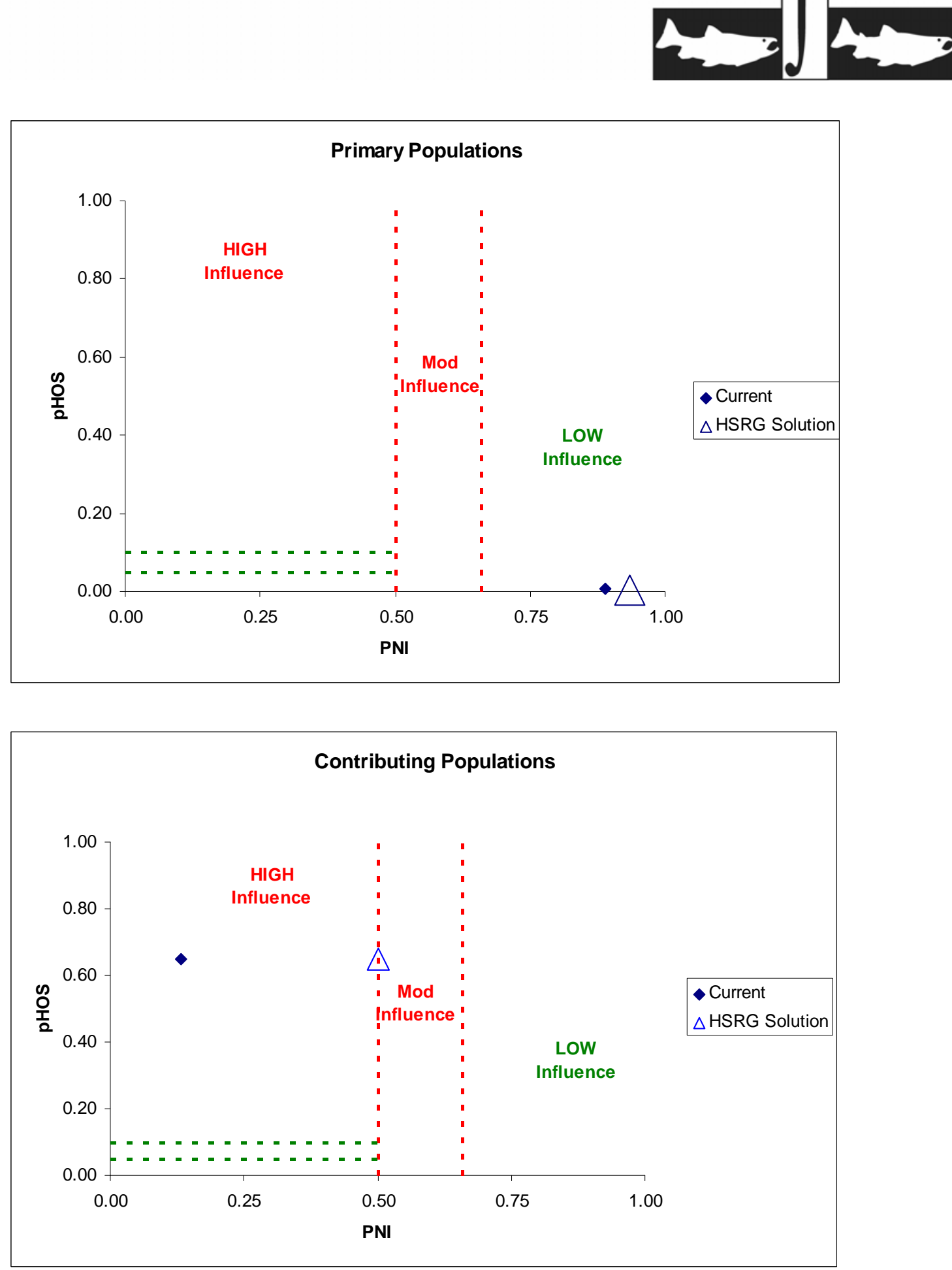

Figure 1. Relationship of the proportion of the fish on the spawning grounds that are of hatchery origin (pHOS) and the proportionate natural influence index (PNI) for Primary (top panel) and Contributing (bottom panel) steelhead populations in the Imnaha MPG. Solid diamonds represent values for current programs and open triangles represent values for the HSRG recommended hatchery management solution. 


\section{Hatchery Scientific Review Group}

Pacific Salmon Hatchery Reform
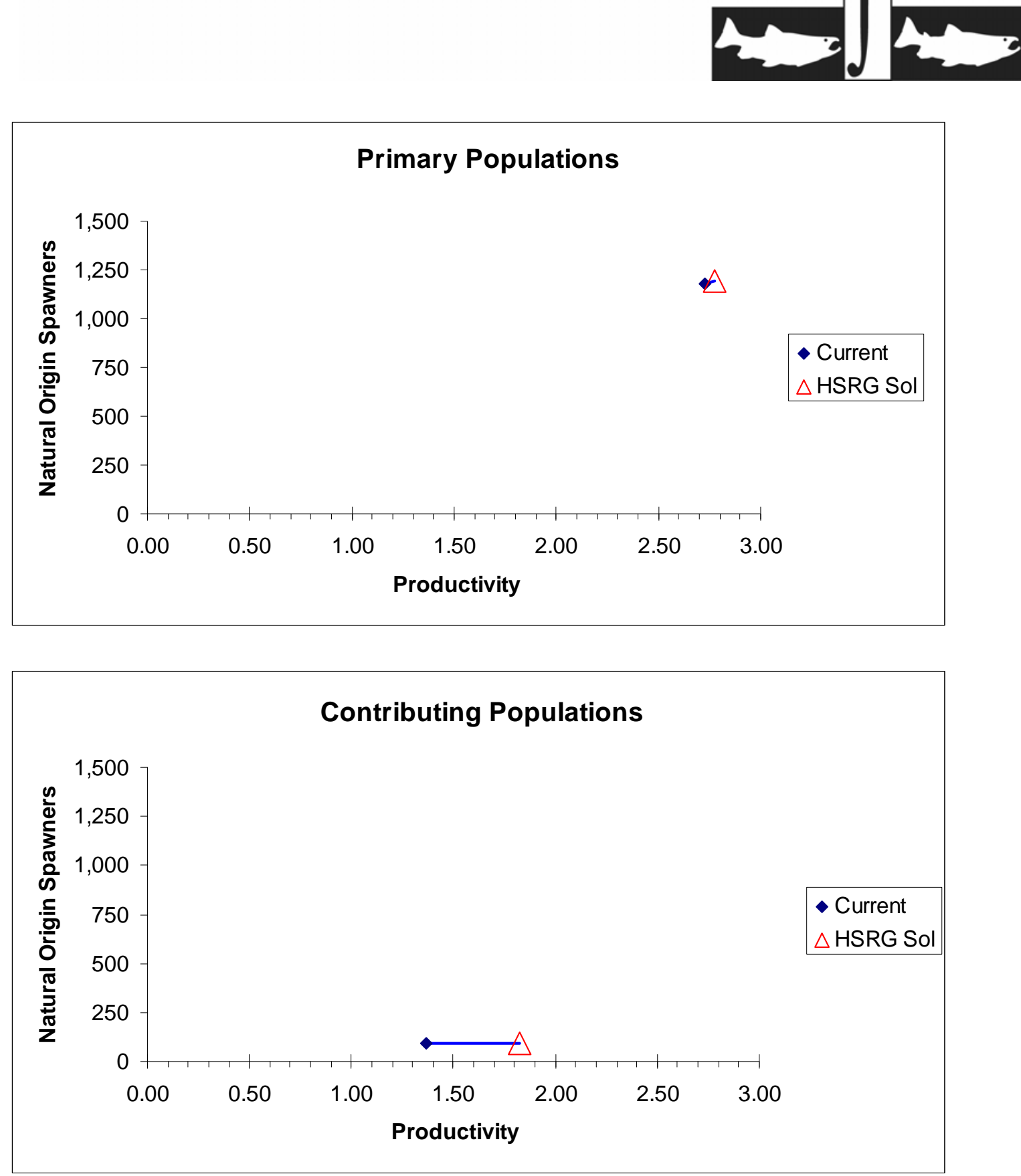

Figure 2. Productivity and spawner abundance for Primary (top panel) and Contributing (bottom panel) steelhead populations in the Imnaha MPG. Solid diamonds represent existing productivity and spawner abundance levels, and triangles represent the HSRG recommended hatchery management solution. Lines connect current with HSRG solution for a particular population. The HSRG recommended hatchery management solution includes projected improved fish passage survival in the Snake and Columbia mainstem migration corridor (FCRPS Biological Opinion May 5 , 2008). 

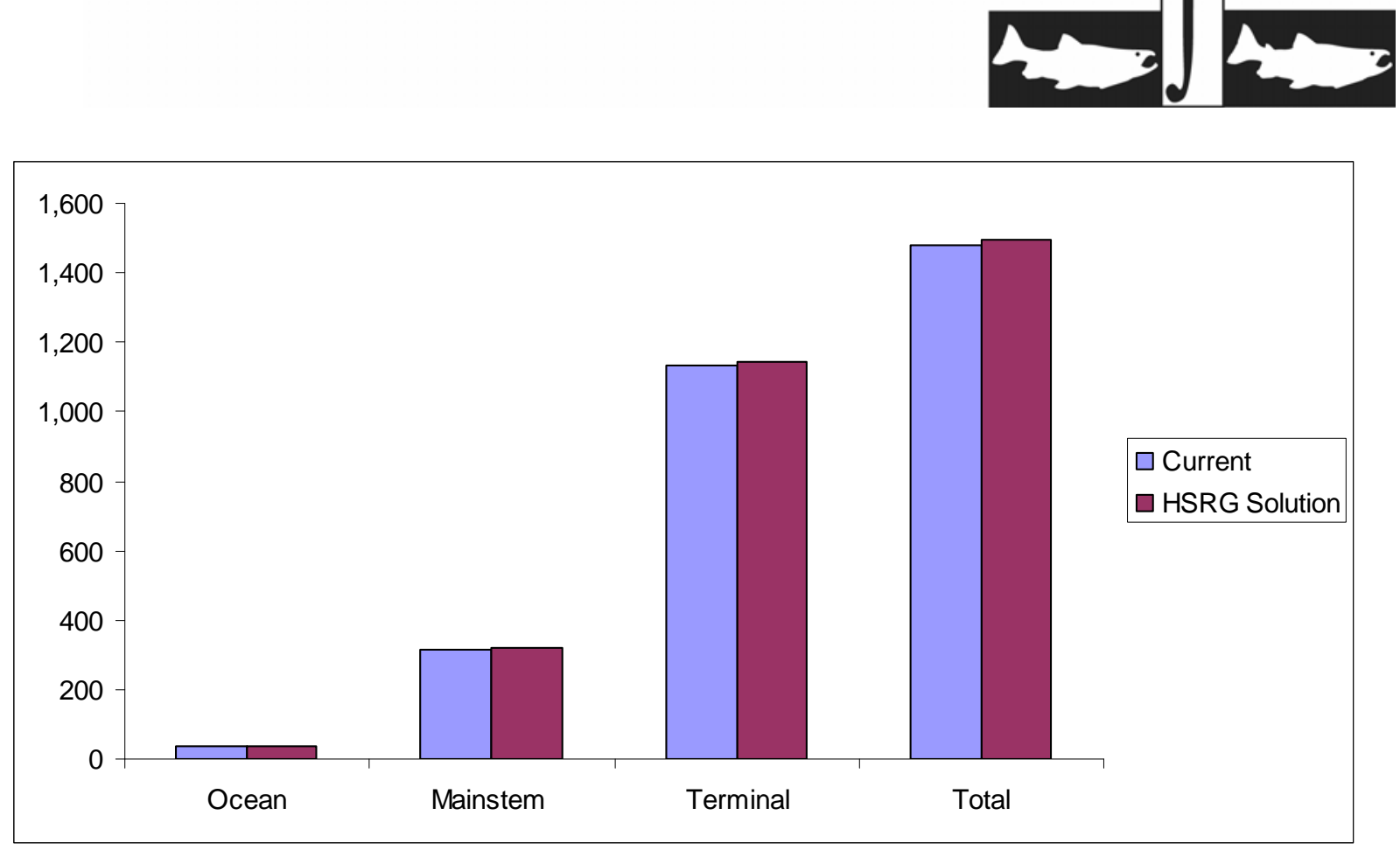

Figure 3. Estimated marine, mainstem Columbia, and terminal harvest under current and HSRG recommended hatchery management solution for Imnaha MPG. The HSRG recommended hatchery management solution includes projected improved fish passage survival in the Snake and Columbia mainstem migration corridor (FCRPS Biological Opinion May 5, 2008).

Summary and Conclusions

In this single population MPG, managers identified conservation and harvest objectives. The HSRG solution maintains harvest while increasing the conservation benefit for the Little Sheep Creek population component. The HSRG notes that there is a general lack of information about steelhead abundance, productivity, spatial structure and diversity as well as straying of hatchery fish into natural production areas and recommends that efforts be undertaken to improve this information base.

The HSRG made recommendations to improve integration and reduce outplanting of hatchery fish. These recommendations maintain production and harvest.

The HSRG also concludes that hatchery and harvest reforms alone will not achieve recovery of listed populations. Habitat improvements are also necessary. 


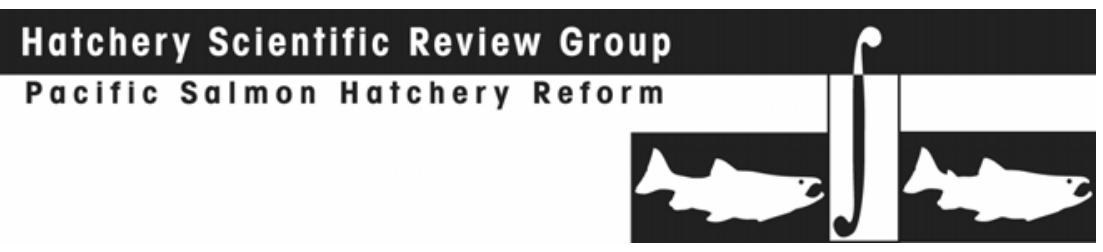

3.4.6.5

Tucannon-Asotin Steelhead MPG

This section provides an overview of the Tucannon-Asotin Steelhead Major Population Grouping (MPG). It contains a general description of the MPG, fisheries, habitat limitations and hatchery programs that affect it. Overall recommendations for MPG-wide hatchery program changes are summarized, as are the results of implementing those changes on conservation and harvest goals. Detailed conclusions and recommendations for each population in the MPG can be found in the Appendix E.

3.4.6.5.1 HSRG Population Guidelines

In order to meet conservations goals for the MPG, numerous threats to these populations need to be addressed, including risks from hatchery programs. The key to controlling genetic and ecological risks due to straying and fitness loss is to manage hatchery broodstock and natural spawning escapement such that the natural habitat (and not the hatchery environment) drives the adaptation and productivity of the naturally spawning population. This is achieved by operating either (a) integrated programs where the proportion of natural-origin adults in the broodstock (pNOB) exceeds the proportion of hatchery-origin fish on the spawning grounds (pHOS); or (b) segregated programs where the contribution of hatchery fish to natural spawning is kept low (pHOS $<5 \%$ to $<10 \%$ depending on the population designation). The HSRG developed criteria for hatchery influence for three population types based on the importance of the population to the recovery of the MPG. This was done to provide a consistent method of reviewing populations and programs across the Columbia River Basin. The population designations used by the HSRG (Primary, Contributing, or Stabilizing) were adopted after discussions with managers and followed those developed in the Lower Columbia River Salmon Recovery Plan (LCFRB 2004). These designations are meant to reflect the conservation importance of a population within the MPG from most important (Primary), to moderately important (Contributing), to least important (Stabilizing). HSRG recommendations show how hatchery programs can be operated consistent with these designations based on the following standards:

HSRG criteria for hatchery influence on Primary populations:

- The proportion of effective hatchery-origin spawners (pHOS) should be less than 5\% of the naturally spawning population, unless the hatchery population is integrated with the natural population.

- For integrated populations, the proportion of natural-origin adults in the broodstock should exceed pHOS by at least a factor of two, corresponding to a proportionate natural influence (MPG) value of 0.67 or greater and pHOS should be less than 0.30 .

HSRG criteria for hatchery influence on Contributing populations:

- The proportion of effective hatchery-origin spawners (pHOS) should be less than $10 \%$ of the naturally spawning population, unless the hatchery population is integrated with the natural population. 


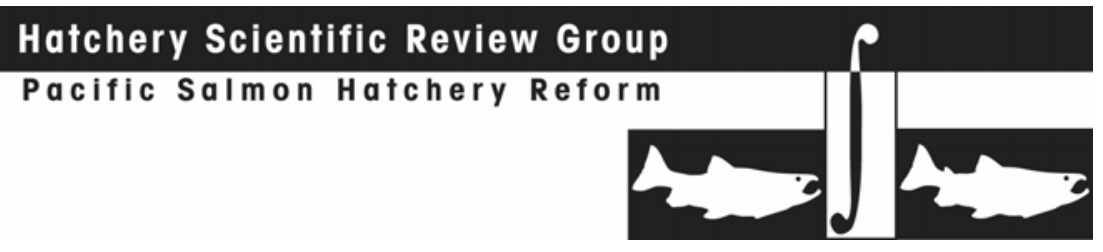

- For integrated populations, the proportion of natural-origin adults in the broodstock should exceed pHOS, corresponding to a PNI value of 0.50 or greater and $\mathrm{pHOS}$ should be less than 0.30 .

HSRG criteria for hatchery influence on Stabilizing populations:

- The current operating conditions were considered adequate to meet their conservation goals. No criteria were developed for proportion of effective hatchery-origin spawners (pHOS) or PNI.

\subsection{Current Conditions}

\section{Conservation}

The Tucannon-Asotin Steelhead MPG is in the Snake River Steelhead Distinct Population Segment (DPS) and was listed as threatened under the Endangered Species Act (ESA) in 1997. As defined by the ESA and the HSRG, the MPG includes the Tucannon River and Asotin Creek populations, both of which are designated a "high" risk for long-term extinction (NMFS 2008e).

For the purpose of this review, the HSRG designated the Tucannon population as Primary and the Asotin population as Contributing (Table 1).

Table 1. Population designations for the Tucannon/Asotin Steelhead MPG and HSRG broodstock criteria achieved for each population under current conditions and the HSRG recommended hatchery management solution.

\begin{tabular}{|l|c|c|c|}
\hline \multirow{2}{*}{ Population } & & \multicolumn{3}{|c|}{ HSRG Criteria Met $^{2}$} \\
\cline { 3 - 4 } & Designation $^{1}$ & Current & HSRG Solution $^{-}$ \\
\hline 2-Asocannon Summer Steelhead & Primary & Contributing & Primary \\
\hline
\end{tabular}

${ }_{1}^{1}$ Using the naming protocol of the Lower Columbia River Salmon Recovery Plan (LCFRB 2004), populations were classified based on information provided to the HSRG as Primary, Contributing, or Stabilizing. These designations are meant to reflect the conservation importance of a population within the MPG from most important (Primary- bold, red), to moderately important (Contributing-bold, blue), to least important (Stabilizing)

2 The HSRG developed criteria for hatchery influence for the three population designations from low influence (Primary), moderate influence (Contributing) to high influence (Stabilizing).

\section{Current Harvest}

There are no freshwater recreational fisheries directly targeting natural- origin steelhead in the Tucannon or Asotin rivers. Incidental mortalities occur in some fisheries targeting hatchery-origin fish. Some harvest may occur in size-selective gillnet fisheries in the Columbia River. Fisheries in the mainstem of the Columbia River have been managed to limit incidental take to two percent year-round for non-Indian fisheries (NMFS 2008e). Treaty Indian fisheries have a 15 percent limit on B-run steelhead (NMFS 2008e). Recent harvest rates on Snake River steelhead have generally been less than allowed and ocean fishing mortality on the ESA listed Snake River steelhead DPS is assumed to be zero (NMFS 2008e). 


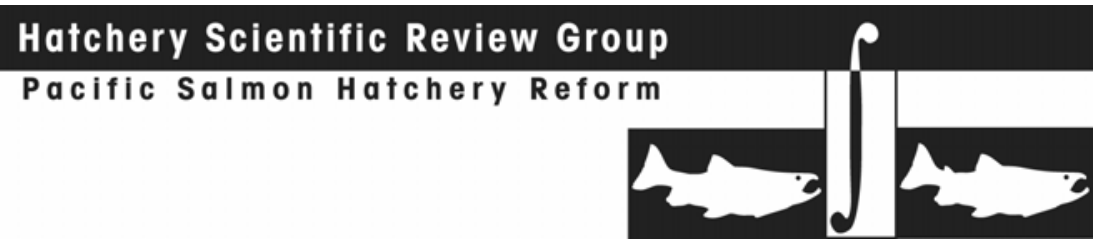

Current Habitat

Conversion of floodplains and riparian forest buffers to agricultural fields and residences, and channel modifications including straightening, diking, and bank armoring have dramatically altered the lower portions of the Tucannon River and Asotin Creek. Logging, conversion of perennial grasslands to annually planted dry cropland, and grazing have led to increased runoff and erosion of fine sediment throughout the region. Habitat conditions are generally fair to poor on private lands in the lower portions of these watersheds. Mid-elevation reaches are generally in fair condition, with patches of degradation. Conditions on public lands in headwater areas, particularly the WenahaTucannon Wilderness Area are generally fair to good. Unfortunately, the largest pools and significant levels of spawning gravel are generally found in the middle or lower portions of the watersheds where alterations of stream channels, removal of riparian vegetation, and surface water withdrawals (which exacerbate naturally low summer stream flows) have combined to increase water temperatures above the tolerance levels of salmonids. Fine sediment deposition is also a problem in these low gradient stream reaches. However, habitat restoration efforts have been taking place since the mid-1990s, largely beginning with the development of "Model Watershed Plans" for the Asotin Creek, Tucannon River, and Pataha Creek watersheds.

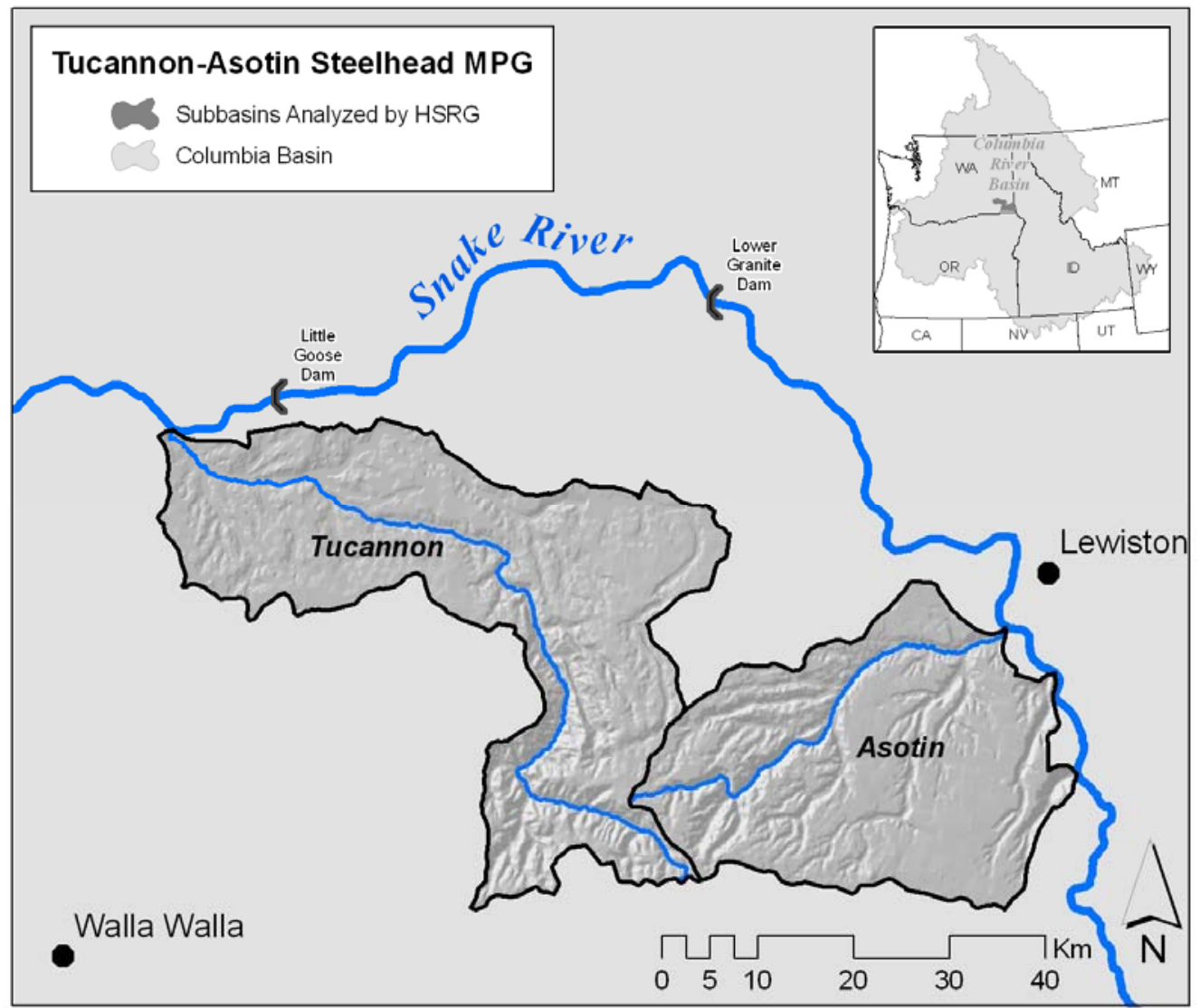




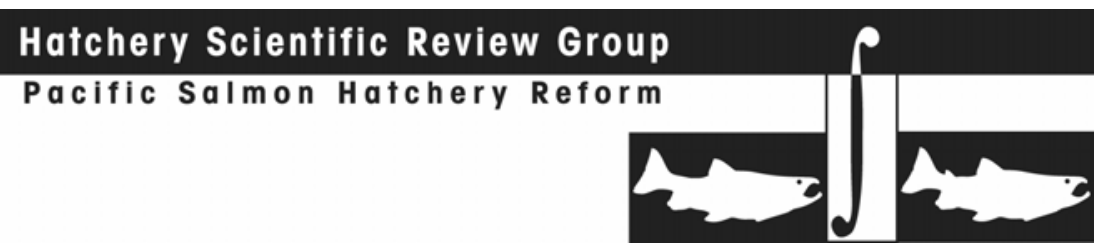

\section{Current Hatchery Programs}

The Tucannon River natural steelhead population is affected by both an integrated and a segregated hatchery program from the Lyons Ferry Fish Hatchery and Tucannon Fish Hatchery (Table 2). Currently, the integrated program release goal is about 50,000 steelhead annually, which rarely has been achieved. The segregated program releases about 100,000 steelhead annually (reduced in 2008 to 80,000). Genetic sampling has shown that the segregated Lyons Ferry hatchery fish have introgressed with the endemic population. A high number of hatchery-origin fish spawn naturally in the lower portion of the Tucannon subbasin.

There are currently no hatchery programs in Asotin Creek, which is managed for natural steelhead production.

There are two populations in this MPG. The endemic Tucannon River summer steelhead population has been designated as a Primary population, although it currently is not meeting the standards for this designation. Managers have not assigned a population designation to the Asotin Creek summer steelhead population; however, the HSRG assumed a Contributing designation. Currently, this population is managed for natural production and is consistent with standards of a Contributing population (Table 1).

Table 2. Hatchery releases and types of programs for Tucannon/Asotin MPG.

\begin{tabular}{|l|c|c|c|c|c|c|}
\hline \multirow{2}{*}{\begin{tabular}{l} 
Population/Program Name \\
\cline { 2 - 7 }
\end{tabular}} & \multicolumn{3}{|c|}{ Current (1,000s) } & \multicolumn{2}{c|}{ HSRG Solution (1,000s) } \\
\hline Snake Lower Summer Steelhead (Lyons Ferry) & Seg & Purpose & $\begin{array}{c}\text { No. } \\
\text { Released }\end{array}$ & Type & Purpose & $\begin{array}{c}\text { No. } \\
\text { Released }\end{array}$ \\
\hline 1-Tucannon Summer Steelhead & Int & Cons & 50.6 & Seg & Harv & 60.6 \\
\hline 1A-Tucannon Summer Steelhead (Lyons Ferry) & Seg & Harv & 100.7 & Seg & NA & - \\
\hline 2-Asotin Summer Steelhead (A-run) & None & NA & - & None & NA & - \\
\hline Total all Populations/Programs & & & 151.5 & & & $\mathbf{5 0 . 9}$ \\
\hline
\end{tabular}

\subsection{HSRG Solutions}

The HSRG provided a number of recommendations with conservation benefits for this MPG. In order to improve fitness and limit genetic introgression, releases of Lyons Ferry stock (a segregated program) are eliminated under the HSRG solution in the Tucannon River. In the near term, managers should continue to operate the current endemic (integrated) program. Because of low productivity and carrying capacity of the habitat, it is not possible to implement planned smolt increases and still meet HSRG standards for a Primary population.

The abundance of natural-origin escapement will vary from year to year. In order to balance the demographic risk (low overall abundance) against genetic risks (too much hatchery influence), the HSRG recommends managing pHOS and pNOB on a "sliding scale", while still assuring that PNI and pHOS objectives are met on average over generations.

Managers have documented that a high proportion (50 percent or more) of returning adults (both hatchery- and natural-origin fish) bypass the Tucannon River and stray above Lower Granite Dam. The HSRG recommends that managers investigate ways to address 


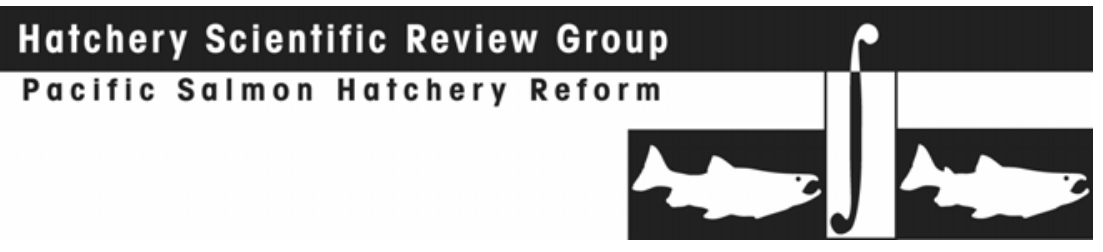

this problem including operating the adult trap continually at Lyons Ferry Hatchery throughout the return timing.

If the natural Asotin Creek population is managed as a Primary or Contributing population, methods will be required to control hatchery strays. The managers need to improve the information base for this steelhead population.

\section{Conservation Outcomes under the HSRG Solutions}

The HSRG analysis shows that under the recommended solutions, the Tucannon and Asotin Creek populations both show reduced hatchery influence (Figure 1) and achieve HSRG standards for hatchery influence for a Primary population. Productivity is predicted to increase for both populations, accompanied by an increase in abundance of the natural Asotin Creek population when pHOS is reduced (Figure 2). While productivity in the Tucannon increases, abundance decreases.

\section{Harvest Outcomes under the HSRG Solutions}

Figure 3 depicts current harvest and estimated changes in harvest (in marine, mainstem Columbia River, and terminal areas) that would occur following implementation of the management solutions proposed by the HSRG. In this case, implementing the HSRG's recommendations reduces harvest down to several hundred fish for this MPG, compared to about 2,500 harvested annually under current conditions.

\section{Hatchery Program Changes under the HSRG Solutions}

Eliminating releases of Lyons Ferry stock in the Tucannon would allow the Tucannon population to meet the standards of a Primary population for hatchery influence but does not achieve the population size criterion of more than 500 adults for a Primary steelhead population.

\subsection{Summary and Conclusions}

Implementing the HSRG solutions would result in both populations in this MPG achieving the broodstock standards for a Primary designation. However, achieving these conservation benefits would be accompanied by a large reduction in harvest benefits.

The HSRG solution eliminates the segregated program in the Tucannon River which reduces straying and emphasizes a sliding scale adult management protocol for the endemic program.

Options for managing this population are limited by the low habitat productivity and capacity. The Tucannon population is receiving some demographic benefit from hatchery production.

The HSRG also concludes that (a) hatchery and harvest reforms alone will not achieve recovery of listed populations (habitat improvements are also necessary), and (b) effectiveness of habitat actions will be greatly increased if they are combined with hatchery and harvest reforms. Unless hatchery and harvest reforms are implemented, the potential benefits of current or improved habitat cannot be fully realized. 


\section{Hatchery Scientific Review Group}

Pacific Salmon Hatchery Reform
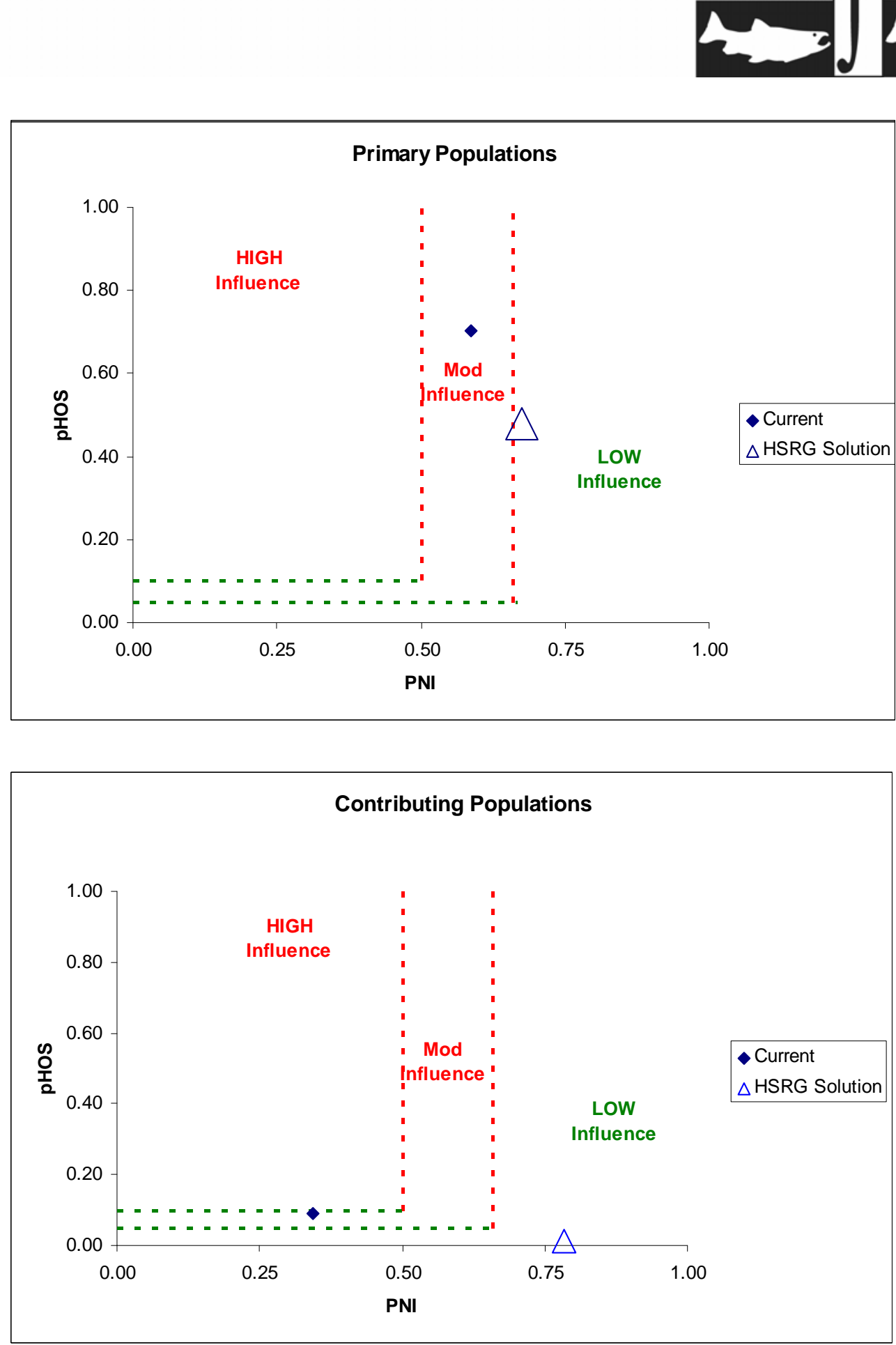

Figure 1. Relationship of the proportion of the fish on the spawning grounds that are of hatchery origin (pHOS) and the proportionate natural influence index (PNI) for Primary (top panel) and Contributing (bottom panel) steelhead populations in the Tucannon/Asotin Steelhead MPG. Solid diamonds represent values for current programs and open triangles represent values for the HSRG recommended hatchery management solution. 


\section{Hatchery Scientific Review Group}

Pacific Salmon Hatchery Reform
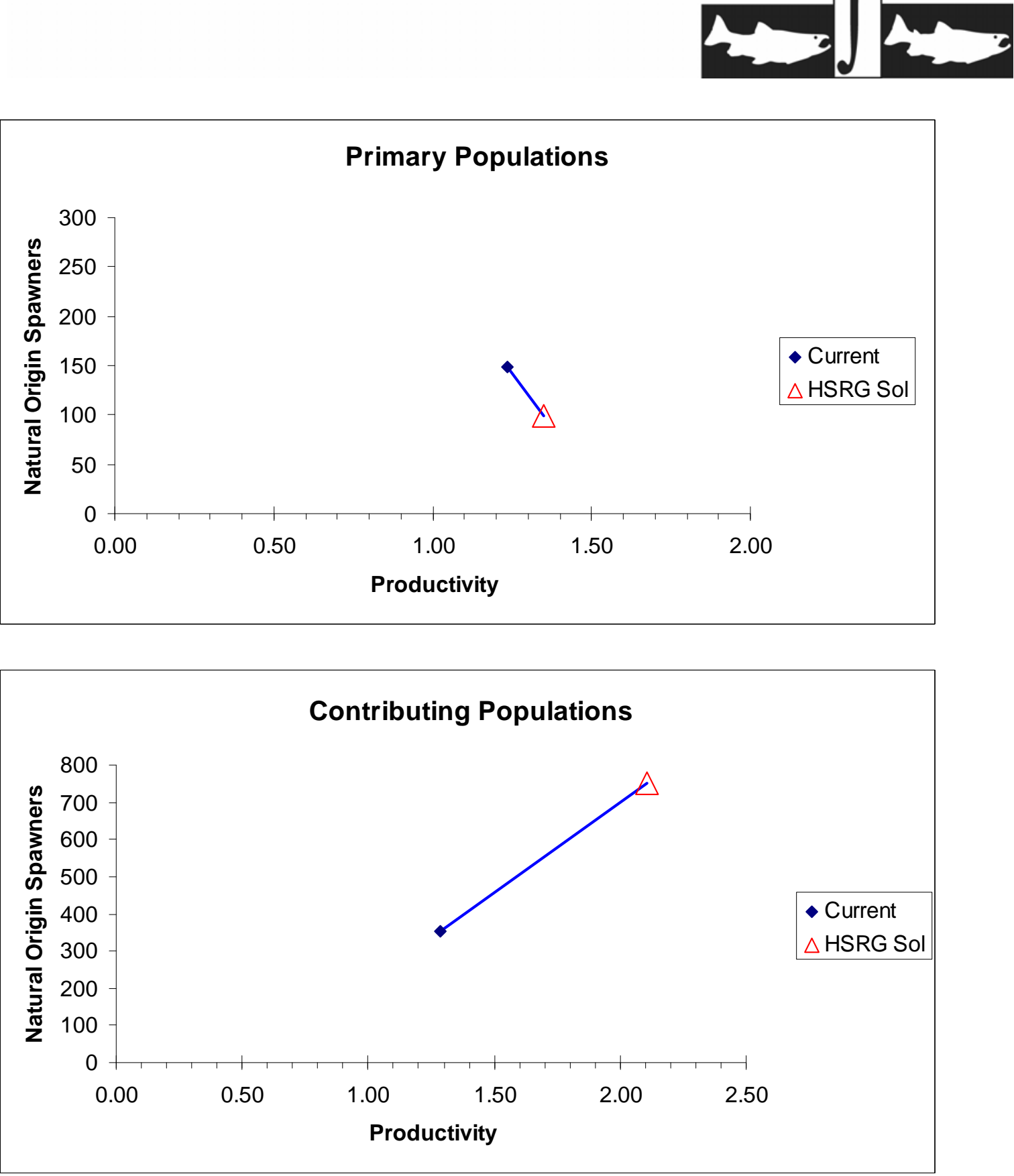

Figure 2. Productivity and spawner abundance for Primary (top panel) and Contributing (bottom panel) steelhead populations in the Tucannon/Asotin Steelhead MPG. Solid diamonds represent existing productivity and spawner abundance levels, and triangles represent the HSRG recommended hatchery management solution. Lines connect current with HSRG solution for a particular population. The HSRG recommended hatchery management solution includes projected improved fish passage survival in the Snake and Columbia mainstem migration corridor (FCRPS Biological Opinion May 5, 2008). 


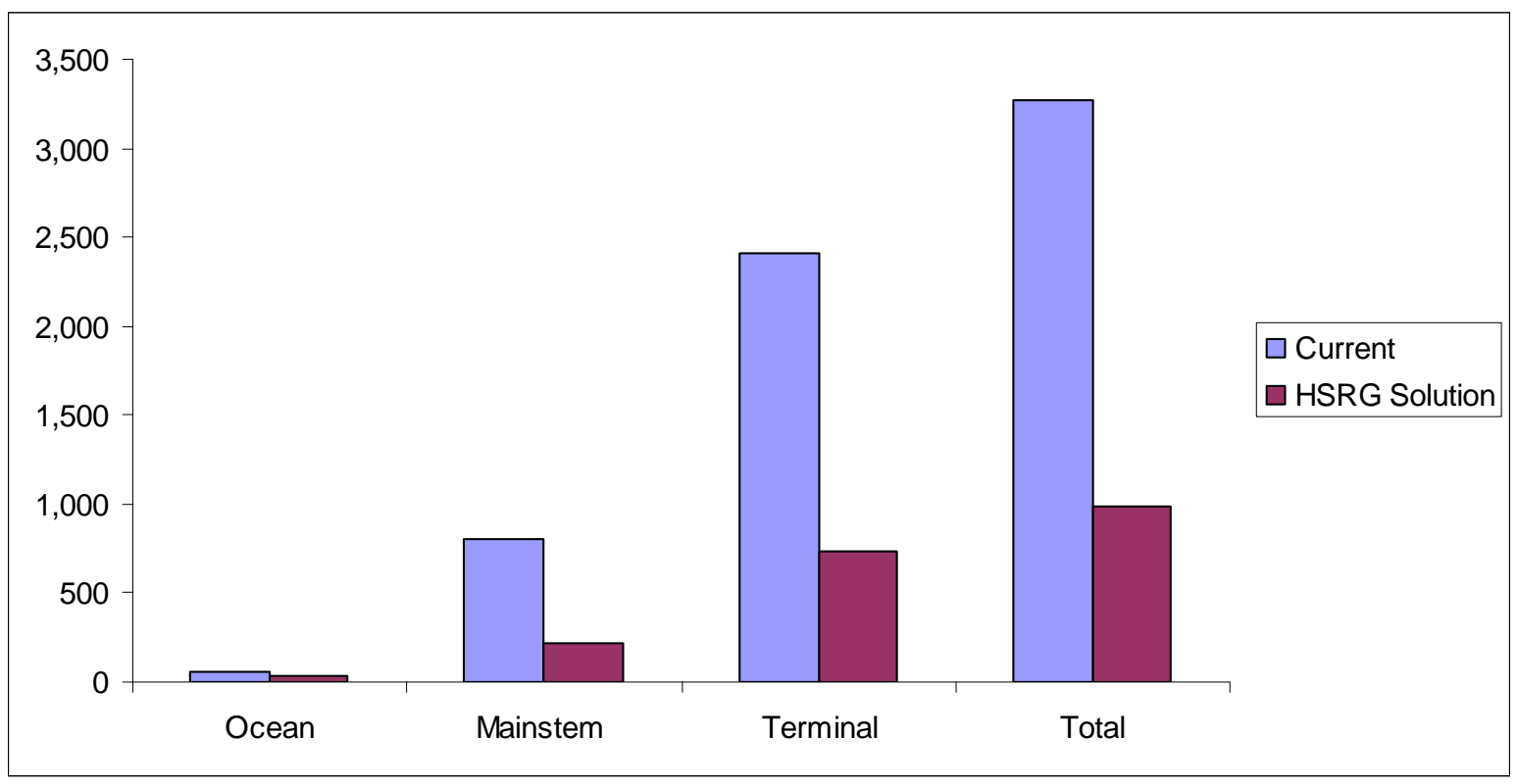

Figure 3. Estimated marine, mainstem Columbia, and terminal harvest under current and HSRG recommended hatchery management solution for Tucannon/Asotin Steelhead MPG. The HSRG recommended hatchery management solution includes projected improved fish passage survival in the Snake and Columbia mainstem migration corridor (FCRPS Biological Opinion May 5, 2008).

This section provides an overview of the Hells Canyon Steelhead MPG which includes a number of Distinct Population Segments (DPS). It contains a general description of the MPG, fisheries, habitat limitations and hatchery programs that affect it. Overall recommendations for MPG-wide hatchery program changes are summarized, as are the results of implementing those changes on conservation and harvest goals. Detailed conclusions and recommendations for each population in the MPG can be found in the Appendix E.

\subsection{HSRG Population Guidelines}

In order to meet conservations goals for the MPG, numerous threats to these populations need to be addressed, including risks from hatchery programs. The key to controlling genetic and ecological risks due to straying and fitness loss is to manage hatchery broodstock and natural spawning escapement such that the natural habitat (and not the hatchery environment) drives the adaptation and productivity of the naturally spawning population. This is achieved by operating either (a) integrated programs where the proportion of natural-origin adults in the broodstock (pNOB) exceeds the proportion of hatchery-origin fish on the spawning grounds (pHOS); or (b) segregated programs where the contribution of hatchery fish to natural spawning is kept low (pHOS $<5 \%-<10 \%$ depending on the population designation). The HSRG developed criteria for hatchery influence for three population types based on the importance of the population to the 


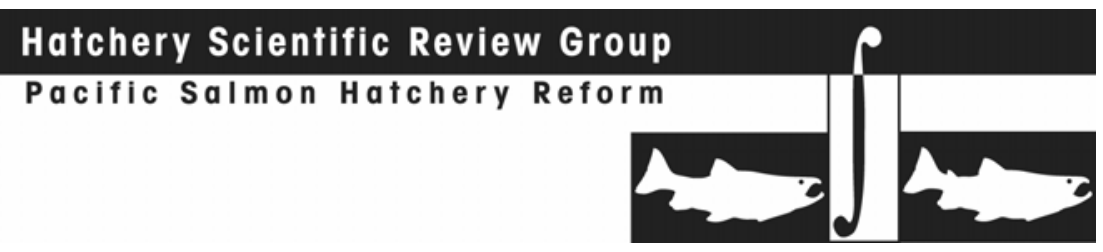

recovery of the MPG. This was done to provide a consistent method of reviewing populations and programs across the Columbia River Basin. The population designations adopted by the HSRG (Primary, Contributing, or Stabilizing) occurred after discussions with managers and followed those developed in the Lower Columbia River Salmon Recovery Plan (LCFRB 2004). These designations are meant to reflect the conservation importance of a population within the DPS from most important (Primary), to moderately important (Contributing), to least important (Stabilizing). HSRG recommendations show how hatchery programs can be operated consistent with these designations based on the following standards:

HSRG criteria for hatchery influence on Primary populations:

- The proportion of effective hatchery-origin spawners (pHOS) should be less than 5\% of the naturally spawning population, unless the hatchery population is integrated with the natural population.

- For integrated populations, the proportion of natural-origin adults in the broodstock should exceed pHOS by at least a factor of two, corresponding to a PNI (proportionate natural influence) value of 0.67 or greater and $\mathrm{pHOS}$ should be less than 0.30 .

HSRG criteria for hatchery influence on Contributing populations:

- The proportion of effective hatchery-origin spawners (pHOS) should be less than $10 \%$ of the naturally spawning population, unless the hatchery population is integrated with the natural population.

- For integrated populations, the proportion of natural-origin adults in the broodstock should exceed pHOS, corresponding to a PNI value of 0.50 or greater and $\mathrm{pHOS}$ should be less than 0.30 .

HSRG criteria for hatchery influence on Stabilizing populations:

- The current operating conditions were considered adequate to meet their conservation goals. No criteria were developed for proportion of effective hatchery-origin spawners (pHOS) or PNI.

\subsection{Current Conditions}

\section{Conservation}

The Hells Canyon steelhead MPG is in the Snake River DPS and was listed as threatened under the Endangered Species Act (ESA) in 1997. As defined by the ESA and the HSRG, the MPG includes the Powder River, Burnt River, Weiser River, and Hells Canyon. Construction of the Hells Canyon Complex (1958-1967) extirpated all natural salmon and steelhead populations above Hells Canyon Dam, including those from the Hells Canyon steelhead MPG. A few steelhead occupy small tributaries within Hells Canyon representing the only naturally spawners; however, these populations are considered functionally extirpated. The vast majority of steelhead in Hells Canyon are summer steelhead originating from the Oxbow Hatchery, known as the Snake Hells Canyon summer steelhead (A-run) population. While the Oxbow Hatchery is not included within the Snake River Steelhead DPS, the hatchery stock represents the 
remaining genetic legacy of all steelhead populations indigenous to the Snake River basin upstream of Hells Canyon Dam (USFWS 2008).

The ICTRT classified the Snake Hells Canyon population as "extirpated". For the HSRG review, the population has been classified as Stabilizing (Table 1).

Table 1. Population designations for the Hells Canyon Steelhead MPG and HSRG broodstock criteria achieved for each population under current conditions and the HSRG recommended hatchery management solution.

\begin{tabular}{|c|c|c|c|}
\hline \multirow[b]{2}{*}{ Population } & \multirow[b]{2}{*}{ Designation $^{1}$} & \multicolumn{2}{|c|}{ HSRG Criteria Met ${ }^{2}$} \\
\hline & & Current & HSRG Solution \\
\hline Snake Hells Canyon Summer Steelhead (A-run) & Stabilizing & Stabilizing & Stabilizing \\
\hline \multicolumn{4}{|c|}{$\begin{array}{l}1 \text { Using the naming protocol of the Lower Columbia River Salmon Recovery Plan (LCFRB 2004), populations were classified based on } \\
\text { information provided to the HSRG as Primary, Contributing, or Stabilizing. These designations are meant to reflect the conservation } \\
\text { importance of a population within the MPG from most important (Primary- bold, red), to moderately important (Contributing-bold, blue), to } \\
\text { least important (Stabilizing). }\end{array}$} \\
\hline $\begin{array}{l}\text { The HSRG developed criteria for hatchery influence fo } \\
\text { (Contributing) to high influence (Stabilizing). }\end{array}$ & & & ary), moderate influen \\
\hline
\end{tabular}

\section{Current Harvest}

The primary purpose of the Oxbow Hatchery program is to provide harvest. Releases from the Oxbow Hatchery contribute to both sport and tribal fisheries in the Little Salmon River, lower Snake River, and the lower Columbia River (Figure 1). For brood years 1992 to 1999, the sport fishery annually harvested an average of 220 steelhead released from the Oxbow Hatchery, and 1,580 steelhead released from Hagerman National Fish Hatchery (USFWS 2008). Recent harvest rates on Snake River steelhead have generally been less than allowed and ocean fishing mortality on the ESA listed Snake River steelhead DPS is assumed to be zero (NMFS 2008e).

\section{Current Habitat}

The majority of historical spawning and rearing habitat for steelhead is blocked by the Hells Canyon Dam complex. Fish passage, water flows and temperature in the downstream migration corridor have been greatly impacted by dams on the Snake and Columbia rivers. Major factors that affect steelhead habitat in the few small tributaries below Hells Canyon Dam include degraded tributary channel morphology, physical passage barriers; excess sediment in gravel; degraded riparian condition; reduced tributary stream flow due to irrigation withdrawals, which limits usable stream area and alters channel morphology by reducing the likelihood of scouring flows; and degraded riparian vegetation which elevates summer water temperatures. 

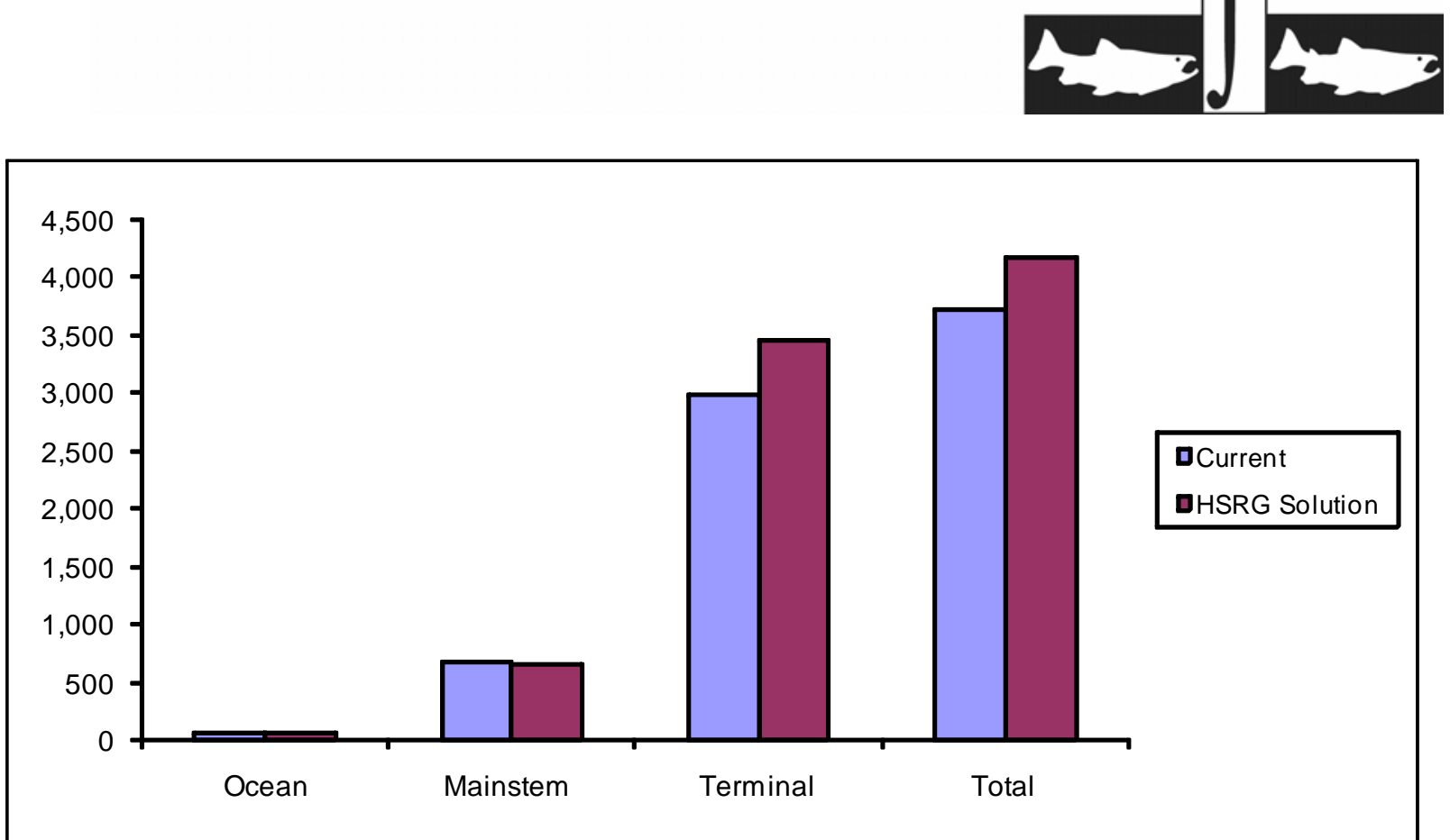

Figure 1. Estimated marine, mainstem Columbia, and terminal harvest under current and HSRG recommended hatchery management solution for Snake River Steelhead Hells Canyon MPG. The HSRG recommended hatchery management solution includes projected improved fish passage survival in the Snake and Columbia mainstem migration corridor (FCRPS Biological Opinion May 5, 2008).

\section{Current Hatchery Programs}

The Oxbow Hatchery segregated program was developed as mitigation for the construction of Hells Canyon Dam. The program's goal for the Snake River (a segregated harvest program) is to release approximately 525,000 A-run steelhead smolts into the Snake River below Hells Canyon Dam. The program also releases 275,000 smolts to the Little Salmon River (Table 2). Up to about 1,000 hatchery adults may be collected at Hells Canyon Dam and released to the Boise River by IDFG. Approximately the same number of adults are made available to ODFW and the Nez Perce Tribe. Broodstock originated from Pahsimeroi Hatchery stock, which was developed from natural-origin adult steelhead trapped at Oxbow and Hells Canyon dams from 1966 through 1970 (USFWS 2008). No natural-origin fish are incorporated in the broodstock design. Natural-origin adults trapped at Hells Canyon are returned to the river downstream of the dam. While the primary purpose of the program is harvest contributions, the stock also represents the genetic legacy of steelhead populations that previously spawned above Hells Canyon Dam (USFWS 2008). 


\section{Hatchery Scientific Review Group}

Pacific Salmon Hatchery Reform

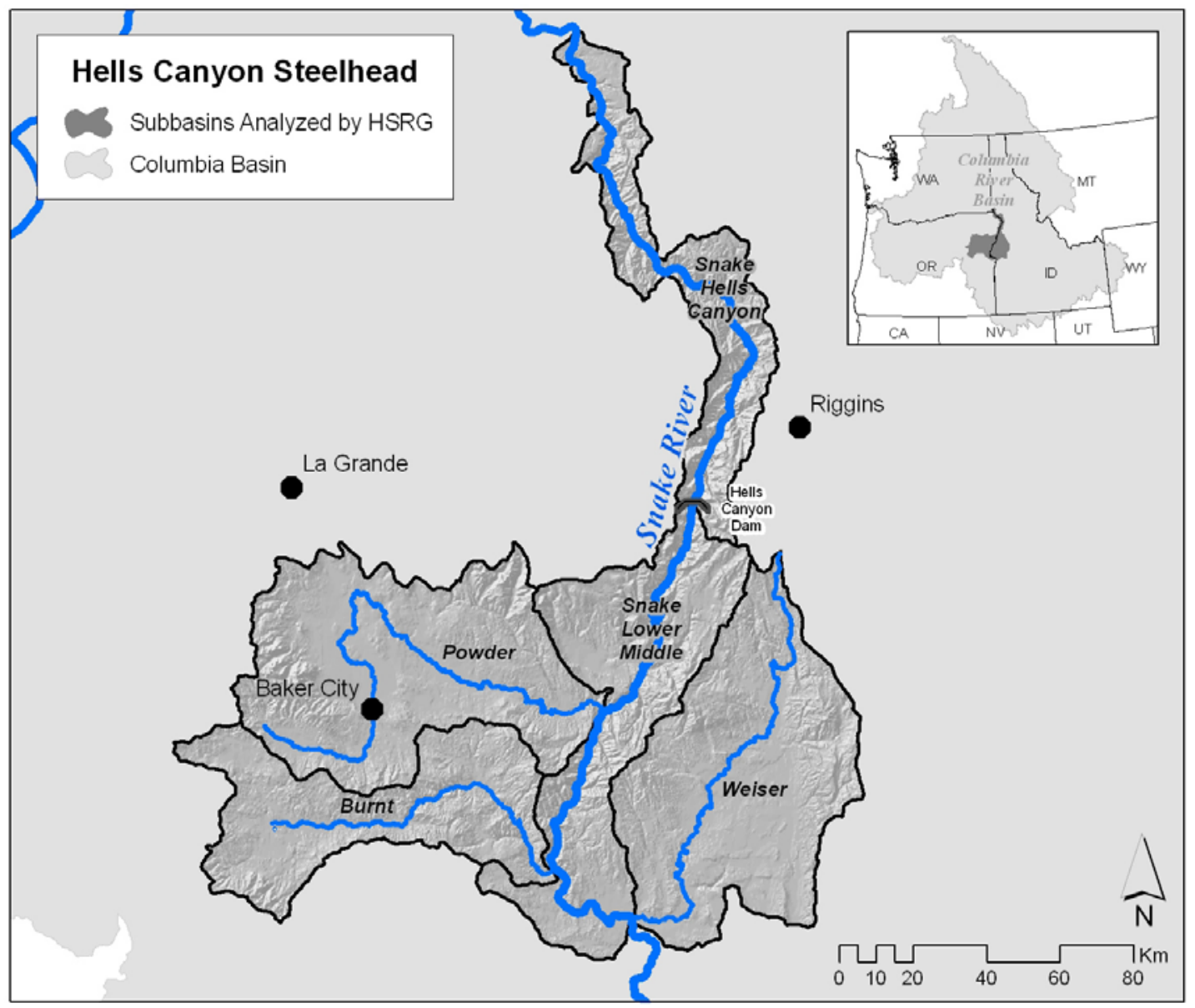

Table 2. Hatchery releases and types of programs for Snake River Hells Canyon Steelhead MPG.

Program type refers to genetic broodstock management strategy - integrated programs are a composite population of fish of natural and hatchery origin, whereas segregated programs are a distinct population reproductively isolated from natural populations. Purpose refers to the program goals - harvest, conservation, or both.

\begin{tabular}{|l|c|c|c|c|c|c|}
\hline \multirow{2}{*}{ Population/Program Name } & \multicolumn{3}{|c|}{ Current (1,000s) } & \multicolumn{3}{c|}{ HSRG Solution (1,000s) } \\
\cline { 2 - 7 } & Type & Purpose & \# Released & Type & Purpose & \# Released \\
\hline $\begin{array}{l}\text { 25-Snake Hells Canyon Summer } \\
\text { Steelhead }\end{array}$ & None & NA & - & None & NA & - \\
\hline $\begin{array}{l}\text { 25A-Snake Hells Canyon Summer } \\
\text { Steelhead (Oxbow-Hatchery) }\end{array}$ & Seg & Harv & 525.4 & Seg & Harv & 525.4 \\
\hline Total All Programs/Populations & & & $\mathbf{5 2 5 . 4}$ & & & $\mathbf{5 2 5 . 4}$ \\
\hline
\end{tabular}




\subsection{HSRG Solutions}

\section{Conservation Outcomes under the HSRG Solutions}

The HSRG made no specific recommendations for this MPG. Steelhead populations upstream of Hells Canyon Dam are extirpated. Downstream of Hells Canyon Dam, spawning habitat is limited and natural-origin populations that utilize tributary systems are considered functionally extirpated.

\section{Harvest Outcomes under the HSRG Solutions}

The HSRG recommended that managers explore opportunities to further maximize harvest of hatchery-origin steelhead in the Snake River downstream of Hells Canyon Dam.

\section{Hatchery Program Changes under the HSRG Solutions}

The HSRG made no specific recommendations to modify the one segregated hatchery program that operates within this MPG (Table 2)

\subsection{Summary and Conclusions}

The majority of historic habitat within this MPG has been lost due to the construction and operation of the Hells Canyon Dam complex. While some tributary habitat exists downstream of Hells Canyon Dam, it is considered limiting and steelhead are classified as functionally extirpated. Managers have developed a segregated steelhead hatchery program that provides significant annual harvest opportunity for both sport and tribal fishers. 


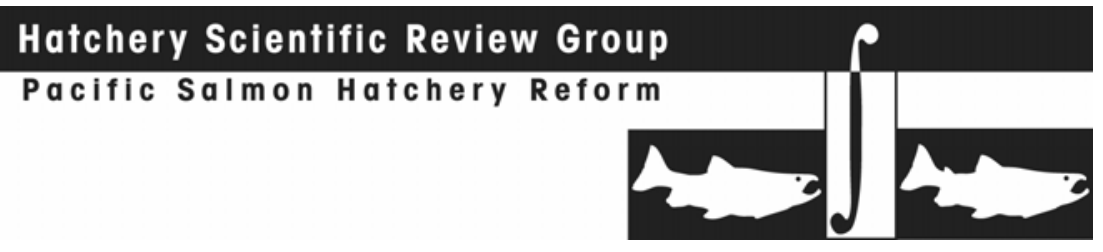

\subsection{Sockeye ESUs}

\subsubsection{Lake Wenatchee Sockeye ESU}

This section provides an overview of the Lake Wenatchee Sockeye Salmon ESU. It contains a general description of the ESU, fisheries, habitat limitations, and hatchery programs that affect it. Overall recommendations for ESU-wide hatchery program changes are summarized, as are the results of implementing those changes on conservation and harvest goals. Detailed conclusions and recommendations for each population in the ESU can be found in the Appendix E.

\subsubsection{HSRG Population Guidelines}

In order to meet conservations goals for the ESU, numerous threats to these populations need to be addressed, including risks from hatchery programs. The key to controlling genetic and ecological risks due to straying and fitness loss is to manage hatchery broodstock and natural spawning escapement such that the natural habitat (and not the hatchery environment) drives the adaptation and productivity of the naturally spawning population. This is achieved by operating either (a) integrated programs where the proportion of natural-origin adults in the broodstock (pNOB) exceeds the proportion of hatchery-origin fish on the spawning grounds (pHOS); or (b) segregated programs where the contribution of hatchery fish to natural spawning is kept low (pHOS $<5 \%$ to $<10 \%$ depending on the population designation). The HSRG developed criteria for hatchery influence for three population types based on the importance of the population to the recovery of the ESU. This was done to provide a consistent method of reviewing populations and programs across the Columbia River Basin. The population designations used by the HSRG (Primary, Contributing, or Stabilizing) were adopted after discussions with managers and followed those developed in the Lower Columbia River Salmon Recovery Plan (LCFRB 2004). These designations are meant to reflect the conservation importance of a population within the ESU from most important (Primary), to moderately important (Contributing), to least important (Stabilizing). HSRG recommendations show how hatchery programs can be operated consistent with these designations based on the following standards:

HSRG criteria for hatchery influence on Primary populations:

- The proportion of effective hatchery-origin spawners (pHOS) should be less than 5\% of the naturally spawning population, unless the hatchery population is integrated with the natural population.

- For integrated populations, the proportion of natural-origin adults in the broodstock should exceed pHOS by at least a factor of two, corresponding to a proportionate natural influence (PNI) value of 0.67 or greater and pHOS should be less than 0.30 .

HSRG criteria for hatchery influence on Contributing populations:

- The proportion of effective hatchery-origin spawners (pHOS) should be less than $10 \%$ of the naturally spawning population, unless the hatchery population is integrated with the natural population. 


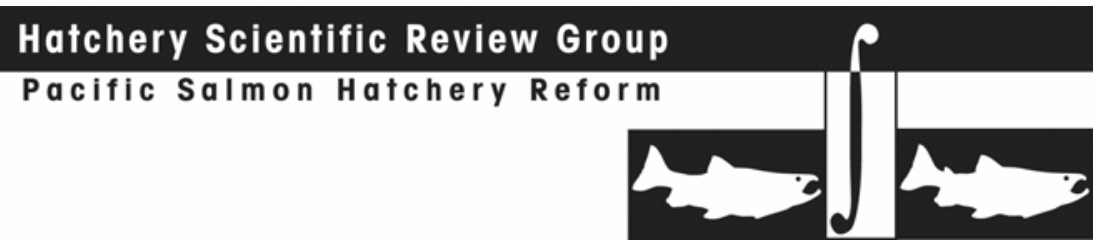

- For integrated populations, the proportion of natural-origin adults in the broodstock should exceed $\mathrm{pHOS}$, corresponding to a PNI value of 0.50 or greater and $\mathrm{pHOS}$ should be less than 0.30 .

HSRG criteria for hatchery influence on Stabilizing populations:

- The current operating conditions were considered adequate to meet their conservation goals. No criteria were developed for proportion of effective hatchery-origin spawners (pHOS) or PNI.

\subsubsection{Current Conditions}

\section{Conservation}

The Lake Wenatchee ESU consists of a single population, the Wenatchee River sockeye. The sockeye spawn in tributaries to the Wenatchee River (the White and Little Wenatchee rivers) and rear in Lake Wenatchee. This ESU was determined by NMFS to not warrant listing under the ESA in 1998. In 1998, WDFW rated the Lake Wenatchee population as healthy, but in 2002 rated it as depressed because of a short-term severe decline in escapements in 1998 and 1999 (WDFW 2002). The spawning escapement goal for this stock is approximately 23,000 fish. The return of sockeye to Lake Wenatchee in 2008 was over 28,000 (Tumwater Dam counts) and was part of the highest sockeye run in the Columbia River in over 50 years. More than 200,000 sockeye passed Bonneville Dam, most bound for the Canadian portion of the Okanogan River subbasin. The management goal for the Lake Wenatchee sockeye is to obtain returns of 65,000 adults measured at Priest Rapids Dam which, under average conditions, requires 75,000 sockeye passing Bonneville Dam.

For the purposes of this review, the HSRG designated the one population in this ESU as a Primary population (Table 1).

Table 1. Population designations for the Lake Wenatchee Sockeye ESU and HSRG broodstock criteria achieved for each population under current conditions and the HSRG recommended hatchery management solution.

\begin{tabular}{|c|c|c|c|}
\hline \multirow[b]{2}{*}{ Population } & \multirow[b]{2}{*}{ Designation $^{1}$} & \multicolumn{2}{|c|}{ HSRG Criteria Met ${ }^{2}$} \\
\hline & & Current & HSRG Solution \\
\hline Wenatchee Sockeye & Primary & Primary & Primary \\
\hline \multicolumn{4}{|c|}{$\begin{array}{l}1 \text { Using the naming protocol of the Lower Columbia River Salmon Recovery Plan (LCFRB 2004), populations were classified based on } \\
\text { information provided to the HSRG as Primary, Contributing, or Stabilizing. These designations are meant to reflect the conservation } \\
\text { importance of a population within the ESU from most important (Primary- bold, red), to moderately important (Contributing-bold, blue), to } \\
\text { least important (Stabilizing). }\end{array}$} \\
\hline \multicolumn{4}{|c|}{$\begin{array}{l}2 \text { The HSRG developed criteria for hatchery influence for the three population designations from low influence (Primary), moderate influence } \\
\text { (Contributing) to high influence (Stabilizing). }\end{array}$} \\
\hline
\end{tabular}

\section{Current Harvest}

Non-Indian and commercial and recreational impacts are managed to minimize harvest effects on listed Snake River sockeye and are limited to one percent or less of the river mouth run. Treaty Indian harvest is limited to 5 percent at runs less than 50,000 sockeye 
and 7 percent when runs exceed 50,000 sockeye. Commercial harvest of sockeye has not occurred since 1988 except for small fisheries in 2000 and 2004. The 2008 escapement was large enough to allow a recreational and commercial sockeye fishery in the Columbia River and a sport fishery in the Wenatchee subbasin.

\section{Current Habitat}

Human alterations in the Wenatchee subbasin are exacerbating naturally limiting conditions by reducing habitat quality and quantity. These alterations have primarily occurred in the lower gradient, lower reaches of watersheds in the lower portions of the subbasin and include road building and placement, conversion of riparian habitat to agriculture and residential development, water diversion, reduced large woody debris recruitment, and flood control efforts that include large woody debris removal, berm construction, and stream channelization. One of the primary limiting factors for sockeye is the natural oligotrophic nature of Lake Wenatchee.

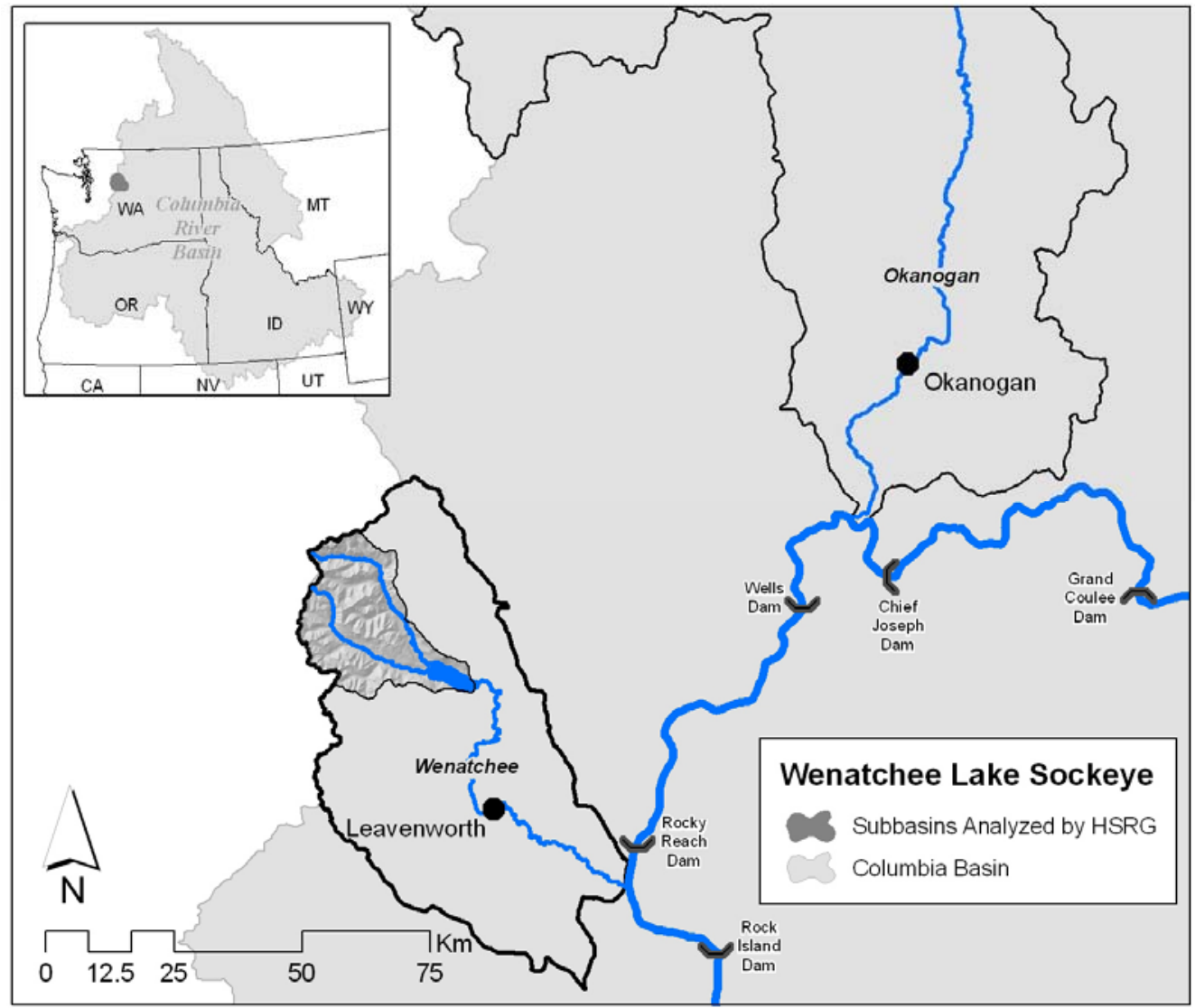

\section{Current Hatchery Programs}

A single hatchery program operates in the Lake Wenatchee ESU. The current population is a mixture of native sockeye and descendants of transfers during the Grand Coulee Dam 
Fish Maintenance Project (1939 to 1943). Quinault River sockeye have also been used in the past in Lake Wenatchee (WDFW 2002).

The current integrated hatchery program releases about 211,000 sub-yearling sockeye to Lake Wenatchee each year (Table 2). All hatchery juveniles released are adipose finclipped and a portion may be marked with PIT-tags or coded-wire tags. Only naturalorigin sockeye salmon are used in the broodstock.

The program is intended to increase the abundance of the population while ensuring appropriate spatial distribution, genetic stock integrity, and productivity. It is also intended to provide more consistent harvest opportunities. Run size in recent years has averaged approximately 15,000 fish, and hatchery-origin fish make up less than 5 percent of the escapement due to poor survival of the hatchery fish.

Table 2. Hatchery releases and types of programs for Lake Wenatchee Sockeye ESU.

\begin{tabular}{|l|c|c|c|c|c|c|}
\hline \multirow{2}{*}{ Population/Program Name } & \multicolumn{3}{|c|}{ Current (1,000) } & \multicolumn{3}{c|}{ HSRG Solution (1,000s) } \\
\cline { 2 - 7 } & Type & Purpose & \# Released & Type & Purpose & \# Released \\
\hline Wenatchee Sockeye & Int & Both & 211.7 & Int & Both & 211.7 \\
\hline
\end{tabular}

\subsubsection{3}

\section{HSRG Solutions}

The HSRG analyzed the current condition and a range of hatchery program options that might address the managers' conservation and harvest goals for this population. It was observed that the replacement rate of hatchery-origin fish has averaged less than that of natural-origin fish $(0.89$ versus 1.24$)$. This situation greatly limits the options available for meeting both conservation and harvest goals. The HSRG provides no recommendations for changes to program operations.

\section{Conservation Outcome under the HSRG Solutions}

Since the HSRG makes no suggestions to change the size of the hatchery program, hatchery influence (Figure 1) remains unchanged. The HSRG's recommended hatchery management solution reflects projected improved fish passage survival in the Snake and Columbia mainstem migration corridor (FCRPS Biological Opinion May 5, 2008), thus explaining the change in productivity and abundance shown in Figure 2.

\section{Harvest Outcomes under the HSRG Solutions}

Since the HSRG makes no suggestions to change the size of the hatchery program, harvest outcomes are unchanged; however, Figure 3 shows harvest increases that can be attributed to improved mainstem passage survival in response to the FCRPS Biological Opinion (2008).

\section{Hatchery Program Changes under the HSRG Solutions}

Operational program changes that improve survival of the hatchery releases will be necessary if there is to be any benefit in continuing the hatchery program (e.g., changing the rearing and the release strategies). 


\section{Hatchery Scientific Review Group}

Pacific Salmon Hatchery Reform
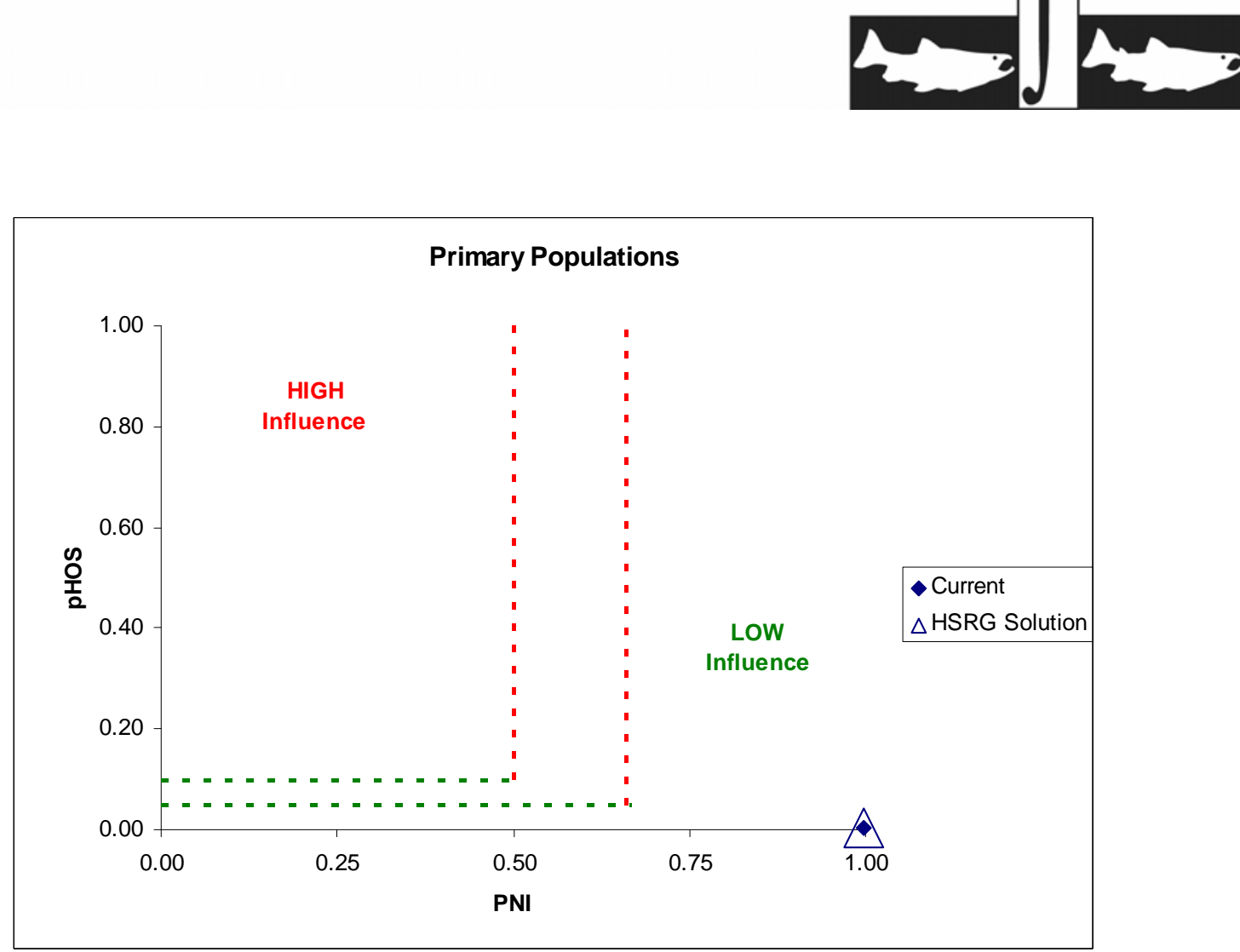

Figure 1. Relationship of the proportion of the fish on the spawning grounds that are of hatchery origin (pHOS) and the proportionate natural influence index (PNI) for the Primary sockeye population in the Lake Wenatchee Sockeye ESU. Solid diamonds represent values for current programs and open triangles represent values for the HSRG recommended hatchery management solution.

\section{Primary Populations}

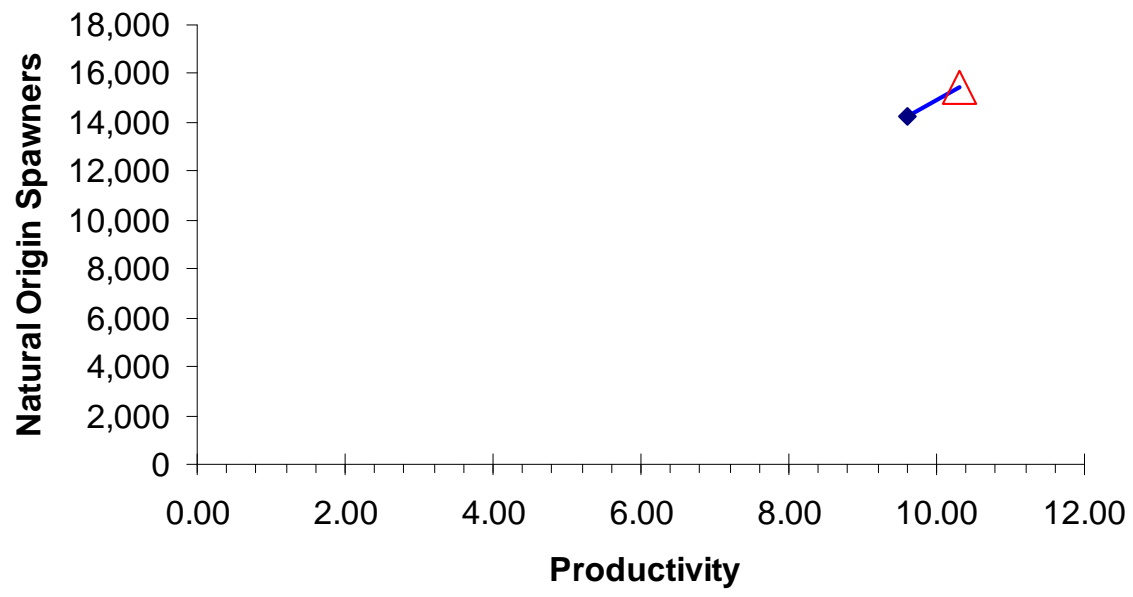

Figure 2. Productivity and spawner abundance for Primary sockeye population in the Lake Wenatchee Sockeye ESU. Solid diamonds represent existing productivity and spawner abundance 
levels, and triangles represent the HSRG recommended hatchery management solution. Lines connect current with HSRG solution for a particular population. The HSRG recommended hatchery management solution includes projected improved fish passage survival in the Snake and Columbia mainstem migration corridor (FCRPS Biological Opinion May 5, 2008).

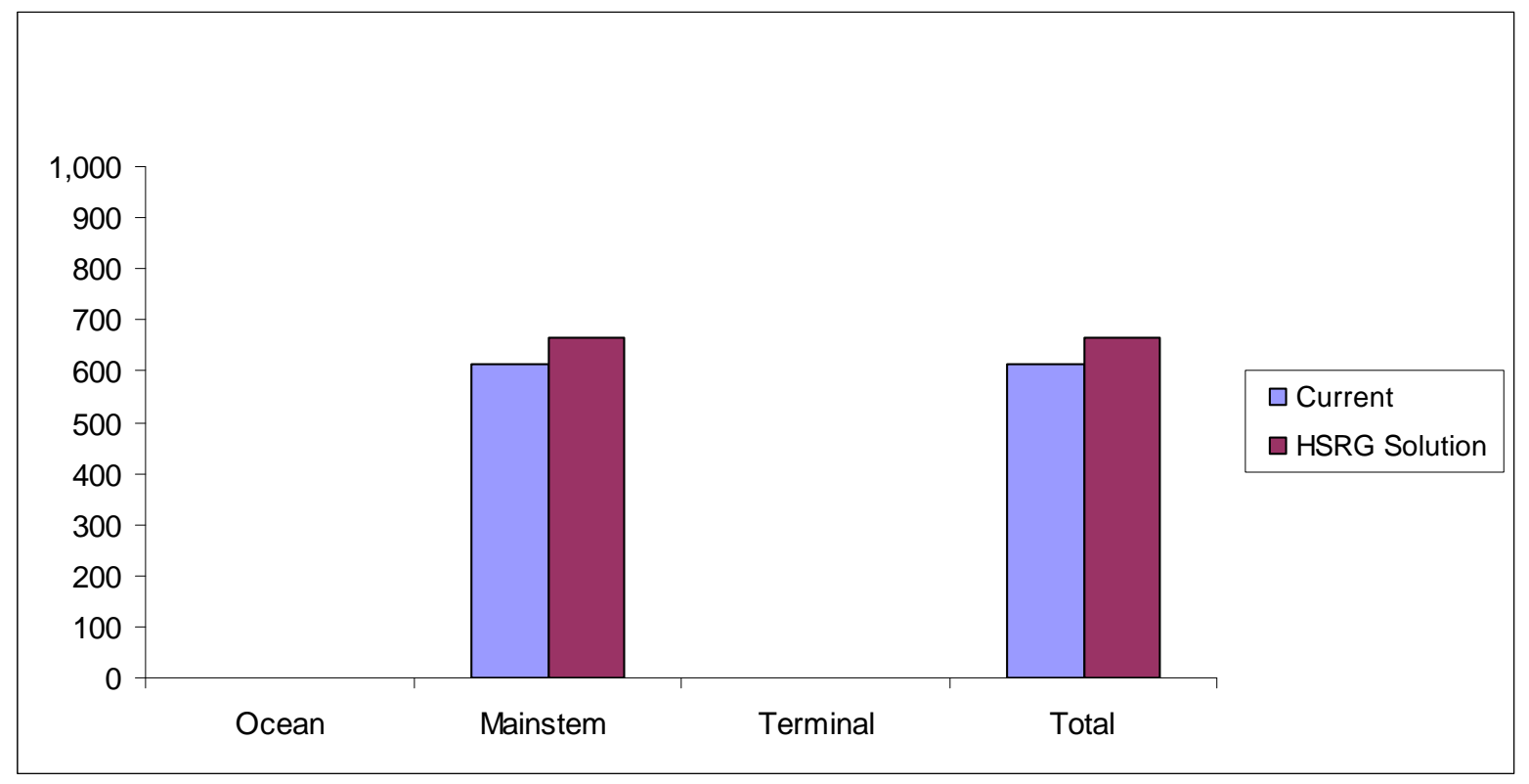

Figure 3. Estimated marine, mainstem Columbia, and terminal harvest under current and HSRG recommended hatchery management solution for Lake Wenatchee Sockeye ESU. The HSRG recommended hatchery management solution includes projected improved fish passage survival in the Snake and Columbia mainstem migration corridor (FCRPS Biological Opinion May 5, 2008).

\subsubsection{Summary and Conclusions}

The Lake Wenatchee sockeye population is the only population in the ESU and it is therefore important that this stock not be lost. The population is not listed but the escapement goal of 23,000 fish is not being consistently met.

Based on 11 years of data, the observation that the replacement rate for hatchery-origin fish averaged less than that for natural-origin fish (0.89 versus 1.24) led the HSRG to recommend that the program be discontinued if this situation cannot be reversed, possibly by making operational changes to the program. The HSRG recommends closer monitoring of out-migrating hatchery releases and returning hatchery adults to determine whether operational changes to the program improve replacement rates for hatchery releases.

\subsubsection{Snake River Sockeye ESU}

This section provides an overview of the Snake River sockeye ESU which was listed as Endangered under the ESA in 1991. It contains a general description of the ESU, 


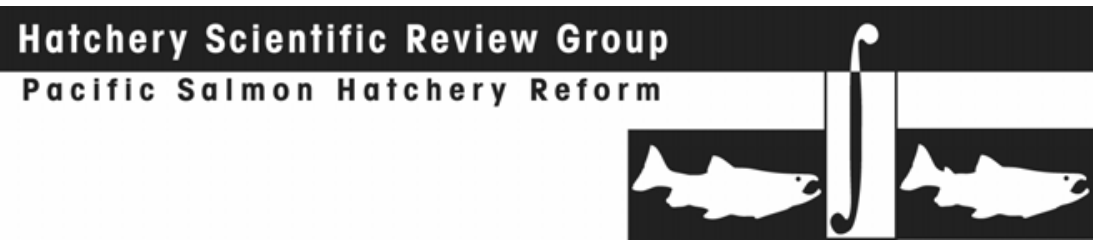

fisheries, habitat limitations and hatchery programs that affect it. Overall recommendations for ESU-wide hatchery program changes are summarized as are the results of implementing those changes on conservation and harvest goals. Detailed conclusions and recommendations for each population in the ESU can be found in the Appendix E.

\subsubsection{1}

\section{HSRG Population Guidelines}

In order to meet conservations goals for the ESU, numerous threats to these populations need to be addressed, including risks from hatchery programs. The key to controlling genetic and ecological risks due to straying and fitness loss is to manage hatchery broodstock and natural spawning escapement such that the natural habitat (and not the hatchery environment) drives the adaptation and productivity of the naturally spawning population. This is achieved by operating either (a) integrated programs where the proportion of natural-origin adults in the broodstock (pNOB) exceeds the proportion of hatchery-origin fish on the spawning grounds (pHOS); or (b) segregated programs where the contribution of hatchery fish to natural spawning is kept low (pHOS $<5 \%$ to $<10 \%$ depending on the population designation). The HSRG developed criteria for hatchery influence for three population types based on the importance of the population to the recovery of the ESU. This was done to provide a consistent method of reviewing populations and programs across the Columbia River Basin. The population designations used by the HSRG (Primary, Contributing, or Stabilizing) were adopted after discussions with managers and followed those developed in the Lower Columbia River Salmon Recovery Plan (LCFRB 2004). These designations are meant to reflect the conservation importance of a population within the ESU from most important (Primary), to moderately important (Contributing), to least important (Stabilizing). HSRG recommendations show how hatchery programs can be operated consistent with these designations based on the following standards:

HSRG criteria for hatchery influence on Primary populations:

- The proportion of effective hatchery-origin spawners (pHOS) should be less than 5\% of the naturally spawning population, unless the hatchery population is integrated with the natural population.

- For integrated populations, the proportion of natural-origin adults in the broodstock should exceed pHOS by at least a factor of two, corresponding to a proportionate natural influence (PNI) value of 0.67 or greater and pHOS should be less than 0.30 .

HSRG criteria for hatchery influence on Contributing populations:

- The proportion of effective hatchery-origin spawners (pHOS) should be less than $10 \%$ of the naturally spawning population, unless the hatchery population is integrated with the natural population.

- For integrated populations, the proportion of natural-origin adults in the broodstock should exceed pHOS, corresponding to a PNI value of 0.50 or greater and $\mathrm{pHOS}$ should be less than 0.30 . 


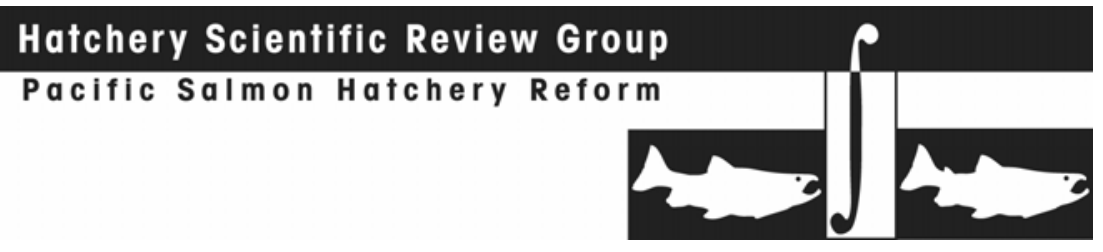

HSRG criteria for hatchery influence on Stabilizing populations:

- The current operating conditions were considered adequate to meet their conservation goals. No criteria were developed for proportion of effective hatchery-origin spawners (pHOS) or PNI.

\subsubsection{Current Conditions}

\section{Conservation}

The Snake River sockeye salmon ESU was listed under the federal Endangered Species Act in 1991 and includes all anadromous and residual sockeye salmon from the Snake River Basin, Idaho, as well as artificially propagated sockeye salmon from the Redfish Lake captive brood propagation program. The ESU contains three populations within the Stanley Lakes subbasin: one extant spawning population in Redfish Lake and at least two extinct populations formerly found in Alturas Lake and Stanley Lake. Sockeye populations were also present in other regions of the Snake River Basin, such as the Payette, South Fork Salmon, and Grande Ronde subbasins, but these populations are extirpated. The relatively long distance between these systems suggests that each of these subbasins would likely have been separate major population groups and may have been separate ESUs. The recovery goal for abundance is 1,000 naturally-produced adults returning to Redfish Lake and 500 naturally-produced adults returning to two additional lakes. Even though the 2008 adult sockeye return was the highest on record for decades (636 anadromous adults returning to the Stanley subbasin), the numbers are far short of recovery goals. This ESU has a very high risk of extinction (NMFS 2008e).

The Interior Columbia Technical Recovery Team (ICTRT) designated at least three historical populations within the Stanley Lakes subbasin: Redfish Lake (including Little Redfish), Alturas Lake and Stanley Lake. The Redfish Lake sockeye population includes both anadromous and residualized sockeye that spawn synchronously with the anadromous fish. In addition, two more lakes - Pettit Lake and Yellowbelly Lake - may have supported independent populations; however, currently available information did not allow the ICTRT to determine their status with certainty. The ICTRT therefore regarded them as potential populations.

Currently, there is one population described in this ESU (Redfish Lake sockeye salmon). For the purpose of this review, the HSRG designated it as a Primary population (Table 1).

Table 1. Population designations for the Snake River Sockeye ESU and HSRG broodstock criteria achieved for each population under current conditions and the HSRG recommended hatchery management solution.

\begin{tabular}{|c|c|c|c|}
\hline \multirow[b]{2}{*}{ Population } & \multirow[b]{2}{*}{ Designation $^{1}$} & \multicolumn{2}{|c|}{ HSRG Criteria Met ${ }^{2}$} \\
\hline & & Current & HSRG Solution \\
\hline Snake River Sockeye & Primary & Stabilizing & Stabilizing \\
\hline
\end{tabular}

1 Using the naming protocol of the Lower Columbia River Salmon Recovery Plan (LCFRB 2004), populations were classified based on information provided to the HSRG as Primary, Contributing, or Stabilizing. These designations are meant to reflect the conservation importance of a population within the ESU from most important (Primary- bold, red), to moderately important (Contributing-bold, blue), to least important (Stabilizing).

2 The HSRG developed criteria for hatchery influence for the three population designations from low influence (Primary), moderate influence (Contributing) to high influence (Stabilizing). 


\section{Current Harvest}

Ocean fishing mortality on Snake River sockeye is assumed to be zero (NMFS 2008e). Fisheries in the mainstem Columbia River that affect this population are now managed subject to the terms of the U.S. v. Oregon Columbia River Fish Management Plan. For the period of 2005-2007, these fisheries were limited to ensure that the incidental take of ESA-listed Snake River sockeye did not exceed one percent in the non-treaty fisheries. Treaty tribal fisheries were limited to a harvest rate of 5 to 7 percent depending on the run size of upriver sockeye stocks. Actual harvest rates have ranged from 0 to 0.95 percent for non-treaty fisheries, and 2.8 to 6.1 percent for treaty fisheries since 2001 (NMFS 2008e).

\section{Current Habitat}

At the time of the initial listing, the greatest habitat issue in the ESU was the lack access to spawning habitat in some Stanley Basin lakes, and passage challenges at the mainstem Columbia and Snake River dams. Access to spawning and rearing areas in other parts of the ESU, such as Wallowa and Payette lakes, was blocked by irrigation dams in the early 1900s. Anadromous sockeye returns to Pettit, Yellowbelly, and Stanley lakes were generally extirpated by the 1950s. The IDFG chemically treated these three lakes between 1955 and 1965 to manage recreational fisheries for trout (NMFS 2008e).

Currently, large portions of the migration corridor in the Salmon River (i.e., between Redfish Lake Creek and Yankee Fork Creek and between Thompson Creek and Squaw Creek) are water quality limited for temperature (IDEQ 2005), which may reduce the survival of adult sockeye returning to the Stanley subbasin in late July and August. The US Forest Service recommends several measures to improve limiting factors for sockeye, including reducing lakeshore recreation pressure, particularly in shallow areas where sockeye spawn; restoring and maintaining native vegetation that provides naturally resilient and productive shoreline habitats; and taking corrective actions to address sediment and water temperature issues (USDA 2003). The NPCC (2004) also recommended that the natural hydrograph of the Salmon River be mimicked between the East Fork confluence and the headwaters.

\section{Current Hatchery Programs}

A captive broodstock hatchery program was initiated in 1991 to safeguard the remnant population (conserve the genome) and begin a population rebuilding process. All 16 anadromous adults that returned to Redfish Lake in the 1990s (1992 through 1998) were trapped and incorporated in the broodstock program. Other "founders" included residual sockeye salmon trapped in Redfish Lake and several hundred juvenile outmigrants trapped while emigrating from Redfish Lake.

A full-term captive broodstock is maintained at the IDFG Eagle Fish Hatchery and at NOAA's Burley Creek Fish Hatchery and the Manchester Research Station in Puget Sound. Spawning occurs annually at these locations and is guided by an inbreeding avoidance matrix developed at the IDFG genetics lab. Every effort is made to spawn all maturing adults and to equalize their representation in subsequent generations (within the captive safety net). 


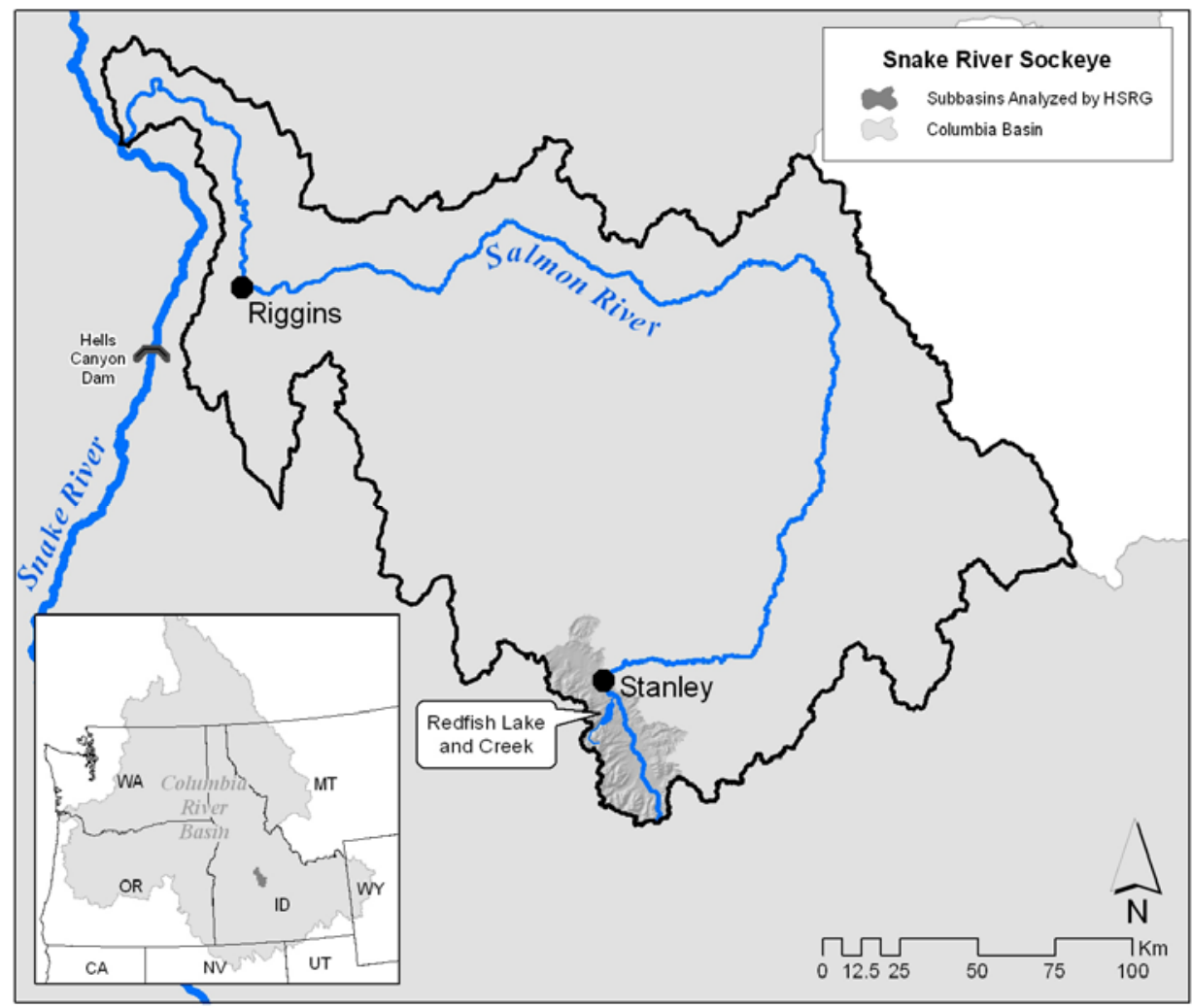

Annually, the program replaces the captive broodstock at IDFG and NOAA facilities by selecting eggs from all spawning crosses and by equalizing individual representation. The program also produces eggs and fish for reintroduction to natal waters using multiple strategies. These include approximately 50,000 eyed-eggs planted in egg boxes in Pettit Lake; 120,000 pre-smolts planted in Redfish, Alturas, and Pettit lakes (combined release); and 80,000 smolts planted in the outlet of Redfish Lake and in the upper Salmon River immediately upstream of the Sawtooth Fish Hatchery (equal split). The combined production from eyed-eggs, pre-smolts, and smolts results in a typical total out-migration of approximately 150,000 smolts. Additionally, the program produces up to 500 fullterm hatchery adults that are planted primarily in Redfish Lake for natural spawning.

Efforts are underway to locate and acquire additional production rearing space for planned increases in the size of this program (500,000 to 1 million capacity). Recent modifications were also made to the IDFG and NOAA broodstock stations. Over the last three years, program smolt releases have increased from an average of 10,000 to 20,000 annually to over 100,000 .

Table 2. Hatchery releases and types of programs for Snake River Sockeye ESU.

\begin{tabular}{|l|c|c|c|c|c|c|}
\hline \multirow{2}{*}{ Population/Program Name } & \multicolumn{3}{|c|}{ Current (1,000s) } & \multicolumn{3}{c|}{ HSRG Solution (1,000s) } \\
\cline { 2 - 7 } & Type & Purpose & \# Released & Type & Purpose & \# Released \\
\hline Redfish Lake Sockeye & Int & Cons & 151.7 & Int & Cons & 750.8 \\
\hline
\end{tabular}




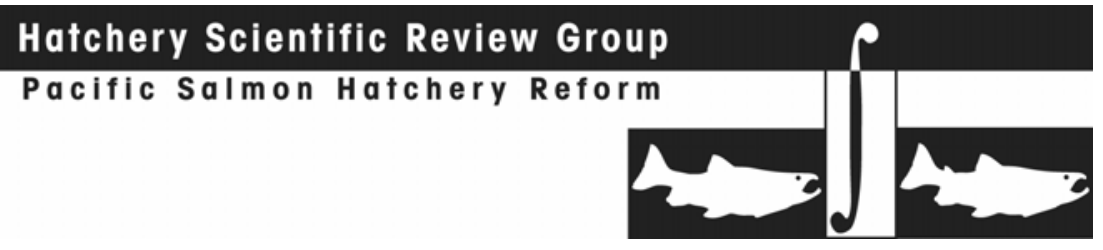

The HSRG's current estimates of PNI and pHOS indicate that under current conditions the population meets the criteria for a Stabilizing population (Table 1).

3.5.2.3

HSRG Solutions

The HSRG solutions for the Snake River sockeye ESU recommend increasing the size of the Snake River sockeye smolt program.

\section{Conservation Outcomes under the HSRG Solutions}

The HSRG solution makes rather large modifications to hatchery production for Snake River sockeye (Table 2). However, this solution is unable to improve hatchery influence criteria or productivity and spawner abundance (Figures 1 and 2) because all remaining fish are from the hatchery program and potential for local adaptation is reduced. Low out-of-basin survival is the primary limiting factor for this population.

Harvest Outcomes under the HSRG Solutions

Figure 3 describes current and estimated changes in harvest (marine, mainstem Columbia River and terminal areas) that would occur following implementation of the management solutions proposed by the HSRG. Overall, harvest opportunities increase slightly. Figure 4 shows the total returns of anadromous sockeye to the Snake River.

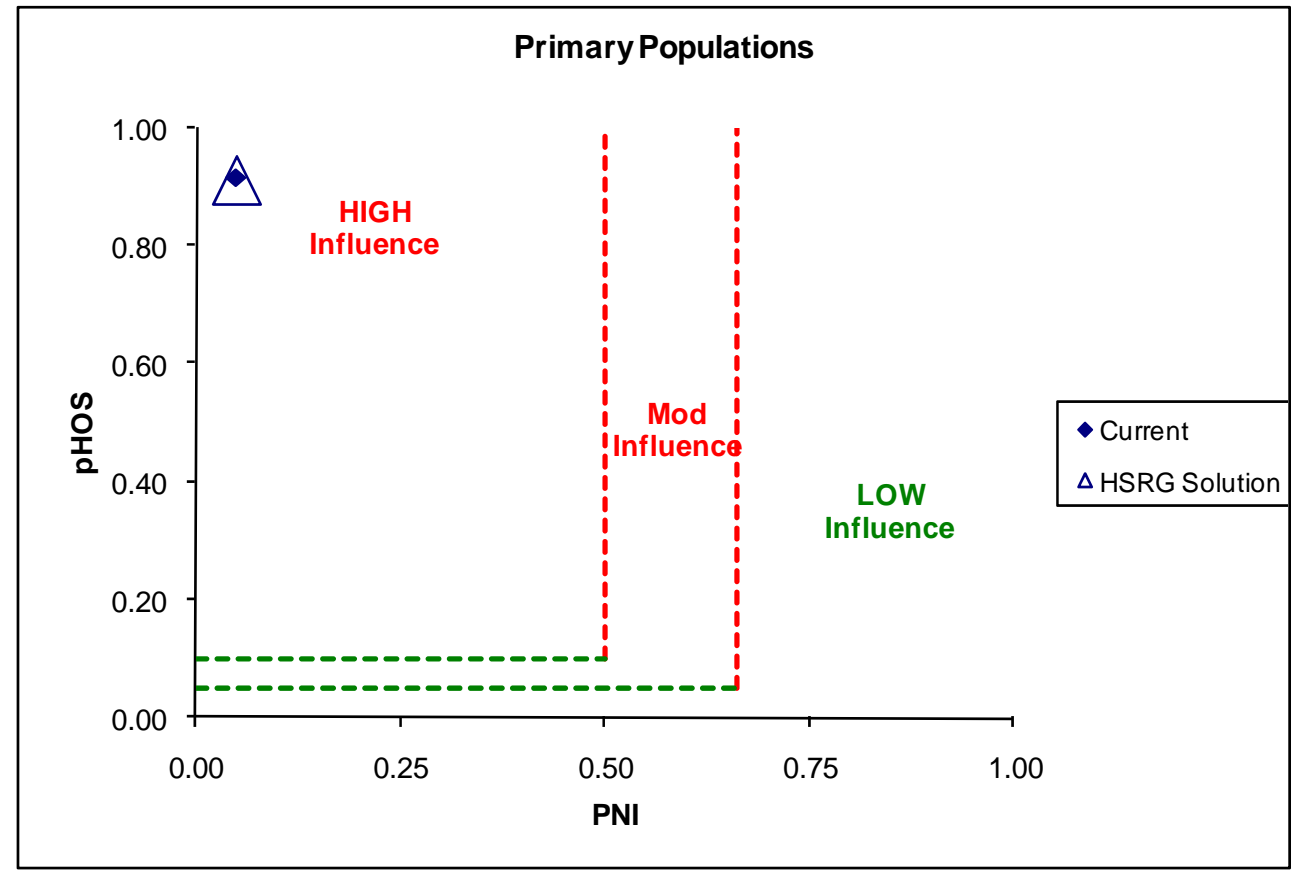

Figure 1. Relationship of the proportion of the fish on the spawning grounds that are of hatchery origin (pHOS) and the proportionate natural influence index (PNI) for Primary sockeye population in the Snake River ESU. Solid diamonds represent values for current programs and open triangles represent values for the HSRG recommended hatchery management solution. 


\section{Hatchery Scientific Review Group \\ Pacific Salmon Hatchery Reform

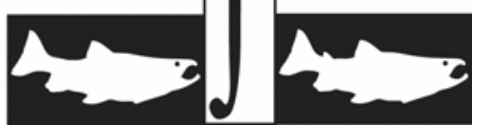

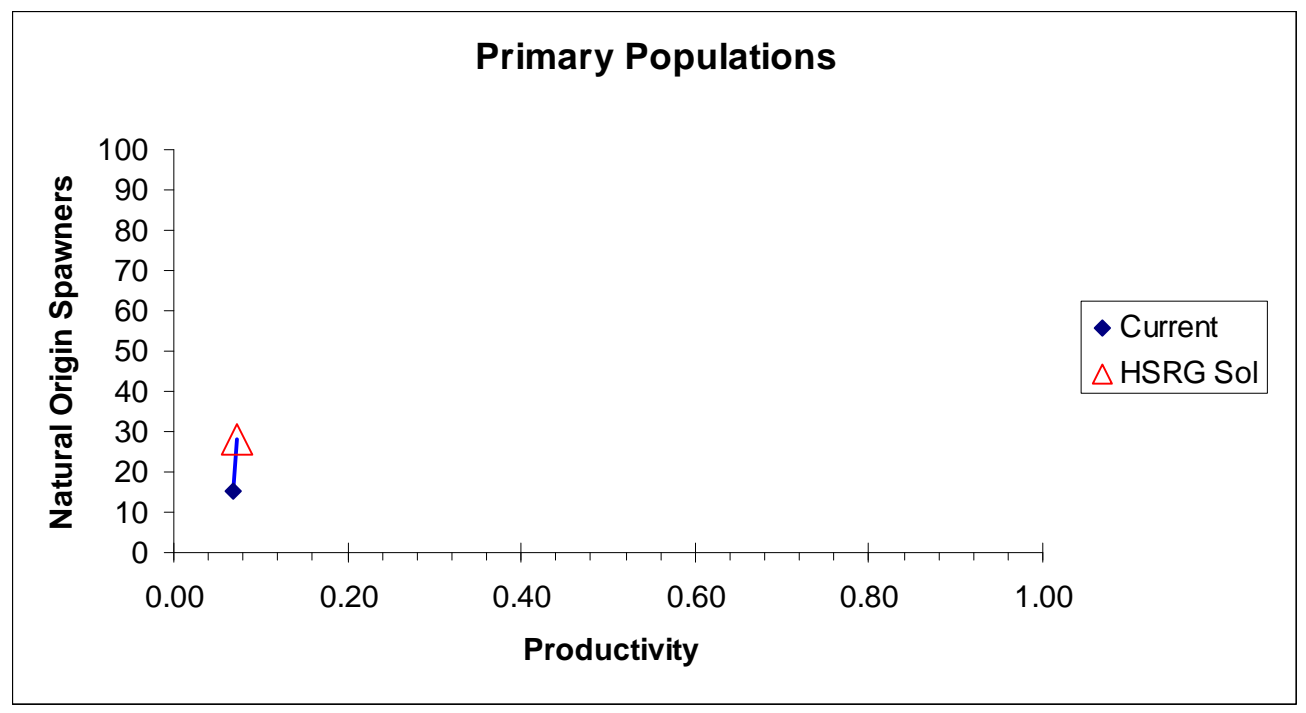

Figure 2. Productivity and spawner abundance for Primary sockeye populations in the Snake River ESU. Solid diamonds represent existing productivity and spawner abundance levels, and triangles represent the HSRG recommended hatchery management solution. Lines connect current with HSRG solution for a particular population. The HSRG recommended hatchery management solution includes projected improved fish passage survival in the Snake and Columbia mainstem migration corridor (FCRPS Biological Opinion May 5, 2008).

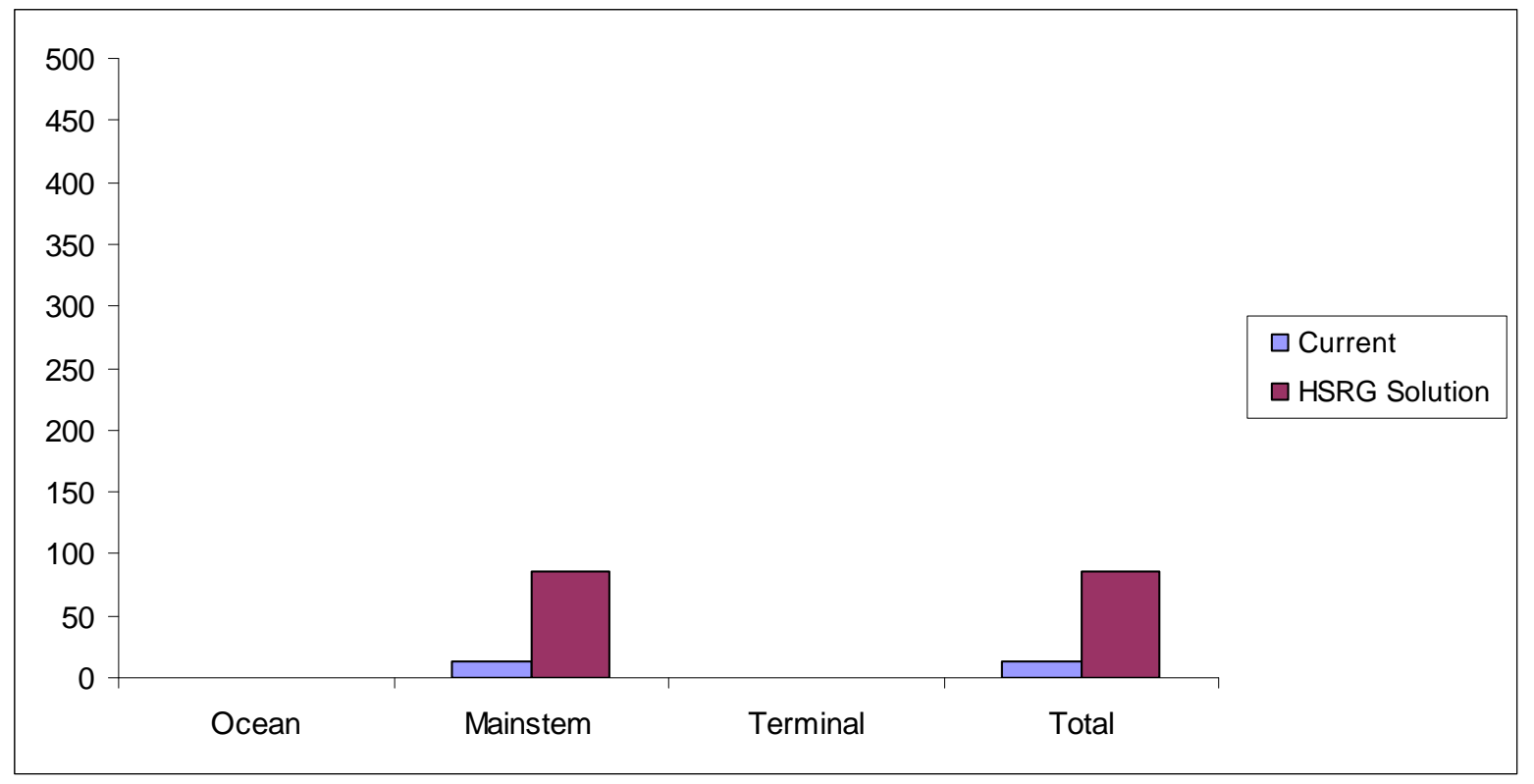

Figure 3. Estimated marine, mainstem Columbia, and terminal harvest under current and HSRG recommended hatchery management solution for Snake River Sockeye ESU. 


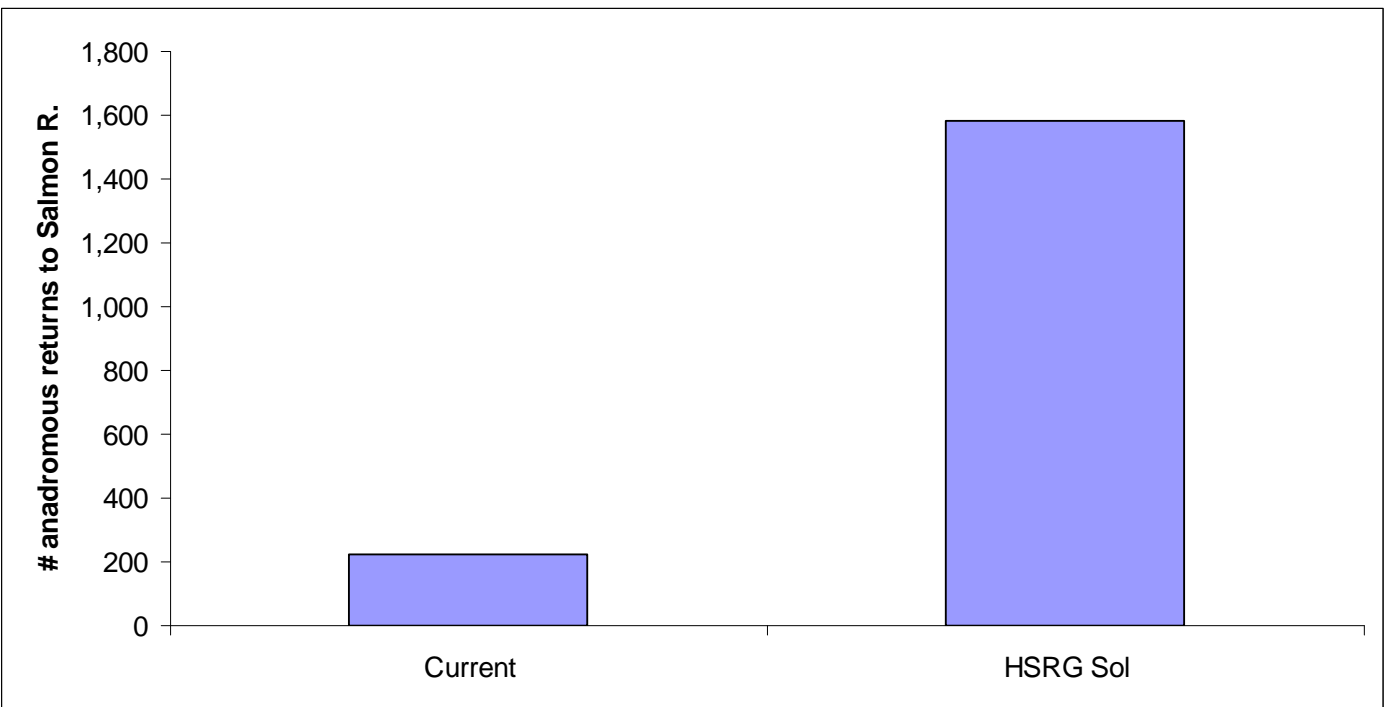

Figure 4. Total returns of anadromous sockeye to the Salmon River for the current scenario and the HSRG recommended hatchery management solution for the Snake River sockeye ESU. 


\section{Hatchery Program Changes under the HSRG Solutions}

Table 2 shows current smolt production from the captive broodstock program as well as the proposed increase under the HSRG solution. For this ESU, the total number of smolts produced from all strategies (pre-spawning adults, eyed eggs, pre-smolt, and smolt release) increases from 151,700 to 750,800. Expansion of smolt releases is supported by language in the 2008 Federal Columbia River Power System Biological Opinion and the 2008 Fish Accords signed by the Bonneville Power Administration and the State of Idaho.

\section{Summary and Conclusions}

Without the boost provided by the hatchery program, this population likely would be extinct. This population has been supported almost entirely by a captive brood program and is characterized by low population productivity. The initial priority for this program should be to transition away from a captive brood program to one reliant upon natural returns. Long-term successful reintroduction into the wild will require addressing the low productivity problem.

The HSRG concurs with the decision initiated by managers to increase smolt releases from the program. This action to increase smolt production $(500,000$ to 1 million fish) is identified in the 2008 FCRPS Biological Opinion. Increased releases should increase anadromous adult returns that will be incorporated into hatchery broodstock or released to the habitat to increase natural production.

Additionally, the HSRG recommends that managers pursue other actions that have the potential to increase the availability of anadromous adults. One option is to capture adult Snake River sockeye salmon at Lower Granite Dam for transport back to Idaho. This action is also identified in the 2008 FCRPS Biological Opinion.

In addition to the above, the HSRG recommends that managers implement a downstream anadromous release and adult capture program at an appropriate lower Columbia River hatchery integrated with the expanded upriver program. This option would generate a more consistent return of anadromous sockeye salmon that could be spawned to augment the production of eggs and juveniles for incorporation into the suite of release strategies.

The overarching goal for implementing any or all of the above strategies is to return more anadromous adults that could be used selectively in spawning designs or released to the habitat to improve the fitness of this closed population. The HSRG also recommends that managers tag/mark all fish released by this program to facilitate subsequent collection and identification. The HSRG recommends finding alternative means of identifying fish and discontinuing the practice of ventral fin clipping. 


\subsection{Citations}

Chapman, D.A., A. Giorgi, T. Hillman, D. Deppert, M. Erho, S. Hays, C. Peven, B. Suzumoto, and R. Klinge. 1994. Status of summer/fall Chinook salmon in the mid-Columbia region. Don Chapman Consultants, Boise, Idaho.

Cooney, T., and M. Ford. 2007. Snake River Fall Chinook: Summary of Status and Hatchery Considerations. National Marine Fisheries Service, Northwest Fisheries Science Center, Seattle, Washington.

Draft Recovery Plan (anonymous). 2007. Draft Upper Willamette River Chinook salmon ESU Recovery Plan, Sections 1\&2: Introduction and Background to the Upper Willamette Recovery Plan dated August 22, 2007. located at http://www.dfw.state.or.us/fish/esa/upper-willamette/

Flagg, T.A., W. C. McAuley, P.A. Kline, M.S. Powell, D. Taki, and J.C. Gislason. 2004. Application of captive broodstocks to preservation of ESA-listed stocks of Pacific Salmon: Redfish Lake sockeye salmon case example. Pages 387-400 in M.J. Nickum, P.M. Mazik, J.G. Nickum, and D.D. MacKinlay, editors. Propagated fish in resource management. American Fisheries Society, Symposium 44, American Fisheries Society, Bethesda, Maryland.

Good, T.P., R.S. Waples, and P. Adams (editors). 2005. Updated status of federally listed ESUs of West Coast salmon and steelhead. U.S. Dept. Commerce, NOAA Tech. Memo., NMFS-NWFSC-66, 598 p.

Hagar, R.C. and R.J. Costello (eds). 1995. Optimal Conventional and Semi-Natural Treatments for the Upper Yakima Spring Chinook Salmon Supplementation Project: Treatment Definitions and Descriptions and Biological Specifications for Facility Design. Final Report to BPA. Project 9506404. BPA Report DOE/BP-64878-2.

ICTRT (Interior Columbia Technical Recovery Team). 2007. Current ICTRT draft population status reports. Memorandum to C. Toole, National Marine Fisheries Service, from T. Cooney, National Marine Fisheries Service, Northwest Fisheries Science Center, Seattle, Washington.

IPC (Idaho Power Company). 2003. New license application for the Hells Canyon FERC Project No. 1971, chapter E.3.1.1.1. Threatened and endangered species. IPC, Boise, Idaho.

Kostow, K. 2008. Factors that contribute to the ecological risks of salmon and steelhead hatchery programs and some mitigating strategies. Rev Fish Biol Fisheries. 2008.

Larson, R.E. and L. Mobrand. 1992. Nez Perce Tribal Hatchery Master Plan and appendices. Bonneville Power Administration. Project No. 83-350. Contract No. DE-AI79BP36809.

LCFRB (Lower Columbia Fish Recovery Board). 2004. Lower Columbia salmon recovery and fish and wildlife subbasin plan, volume 1. LCFRB, Longview, Washington.

McElhany, P., T. Backman, C. Busack, S. Heppell, S. Kolmes, A. Maule, J. Myers, D. Rawding, D. Shively, A. Steel, C. Steward, and T. Whitesel. 2003. Interim report on viability criteria for Willamette and Lower Columbia Basin Pacific salmonids. Willamette/Lower Columbia Technical Recovery Team (W/LC TRT). Northwest Fisheries Science Center, Seattle, WA. March 31. 
McElhany, P., M. Chilcote, J. Myers, and R. Beamesderfer. 2007. Viability status of Oregon salmon and steelhead populations in the Willamette and Lower Columbia Basins. Prepared for Oregon Department of Fish and Wildlife and National Marine Fisheries Service. National Marine Fisheries Service, Northwest Fisheries Science Center, Seattle, Washington.

Mattson, C.R. 1948. Spawning ground studies of Willamette River spring Chinook salmon. Fish Commission Research Briefs, Oregon Fish Commission, Clackamas 1(2):21-32.

Meyers, J., C. Busack, D. Rawdling, A. Marshall, D. Teel, D.M. Van Doornik, and M.T. Maher. 2006. Historical population structure of Pacific salmonids in the Willamette River and lower Columbia River basins. Dept. of Commerce, NOAA Tech. Memo., NMFS-NWFSC-73, 311p.

Myers, J.M., R.G. Kope, G.J. Bryant, D. Teel, L.J. Lierheimer, T.C. Wainwright, W.S. Grant, F.W. Waknitz, K. Neely, S.T. Lindley and R.S. Waples. 1998. Status review of Chinook salmon from Washington, Idaho, Oregon, and California. U.S. Department of Commerce, NOAA Tech. Memo. NMFS-NWFSC-35, 443 p.

Nehlsen, W. 1995. Historical salmon and steelhead runs of the upper Deschutes River and their environments. Portland General Electric Company, Hydro Licensing Department, Portland, OR.

National Marine Fisheries Service (NMFS). 1991. Endangered status for Snake River sockeye salmon. Final rule. Federal Register 56:224 (20 November 1991):58619-58624.

NMFS (National Marine Fisheries Service). 2004a. Endangered Species Act - Section 7 Consultation Biological Opinion and Magnuson-Stevens Fishery Conservation and Management Act Consultation on operation of the Cowlitz River Hydroelectric Project (FERC No. 2016) through 2038. NMFS, Portland, Oregon.

NMFS. 2004b. Salmon hatchery inventory and effects evaluation report: an evaluation of the effects of artificial propagation on the status and likelihood of extinction of West Coast salmon and steelhead under the Federal Endangered Species Act. U.S. Dept. of Commerce, Tech. Memo., NMFS-NWR/SWR, 557p.

NMFS. 2004c. Endangered and threatened species: proposed listing determination for 27 ESUs of West Coast salmonids; proposed rule. Federal Register 69:113(14 June 2004):22102-33179.

NMFS.2005a. Endangered and threatened species; designation of critical habitat for 12 evolutionarily significant units of West Coast salmon and steelhead in Washington, Oregon, and California. Final rule. Federal Register 70:170(2 September 2005):52630-52858.

NMFS. 2005b. Endangered and threatened species: final listing determinations for 16 evolutionarily significant units of West Coast salmon, and final 4(d) protective regulations for threatened salmonid ESUs. Final rule. Federal Register 70:123(28 June 2005):37160-37204.

NMFS. 2006a. Endangered Species Act - Section 7 Consultation Biological Opinion and Section 10 Statement of Findings and Magnuson-Stevens Fishery Conservation and Management Act Essential Fish Habitat Consultation on the Washington State Forest Practices Habitat Conservation Plan. NMFS, Portland, Oregon.

NMFS. 2006b. Endangered and threatened species: final listing determinations for 10 distinct population segments of West Coast Steelhead. Final rule. Federal Register 71:3(5 January 2006):834-862. 
NMFS. 2007a. Endangered Species Act - Section 7 Consultation Biological Opinion and MagnusonStevens Fishery Conservation and Management Act Consultation on the operation of PacifiCorp and Cowlitz PUD's Lewis River hydroelectric projects for 50 years from the new licenses issue date(s). NMFS, Portland, Oregon.

NMFS. 2008a. Endangered Species Act - Section 7 Consultation Biological Opinion and MagnusonStevens Fishery Conservation and Management Act Consultation on remand for operation of the Federal Columbia River Power System and 19 Bureau of Reclamation Projects in the Columbia Basin. NMFS, Portland, Oregon.

NMFS. 2008b. Endangered Species Act - Section 7 Consultation Biological Opinion and MagnusonStevens Fishery Conservation and Management Act Consultation on the Willamette River Basin Flood Control Project. NMFS, Portland, Oregon.

NMFS. 2008c. Endangered Species Act - Section 7 Consultation Biological Opinion and MagnusonStevens Fishery Conservation and Management Act Consultation on the Dorena Lake Dam Hydroelectric Project (FERC No. 11945-001) application for an original license. NMFS, Portland, Oregon.

NMFS. 2008d. Endangered Species Act - Section 7 Consultation Biological Opinion and MagnusonStevens Fishery Conservation and Management Act Consultation on Treaty Indian and NonIndian Fisheries in the Columbia River Basin Subject To the 2008-2017 US v. Oregon Management Agreement. NMFS, Portland, Oregon.

NMFS. 2008e. Supplemental Comprehensive Analysis of the Federal Columbia River Power System and Mainstem Effects of the Upper Snake and other Tributary Actions - Section 8 Effects Analysis for Salmonids. NMFS, Portland, Oregon.

Northwest Power and Conservation Council (NPCC). 2004. White Salmon subbasin management plan. NPCC, Portland, Oregon.

ODFW (Oregon Department of Fish and Wildlife). 2006. Draft guidance regarding the relative impact of limiting factors and threats to viability of seven species of Federally listed salmon and steelhead in Oregon, methodology and results of an expert panel process. Edited by J. Nicholas and J. Rodgers. ODFW, Salem, Oregon.

PCSRF (Pacific Coastal Salmon Recovery Fund). 2006. Report to Congress: Pacific Coastal Salmon Recovery Fund FY 2000-2005. National Marine Fisheries Service, Seattle, Washington.

PFMC (Pacific Fishery Management Council). 2008. Preseason report III: analysis of council adopted management measures for 2008 ocean salmon fisheries. Prepared by the Salmon Technical Team for PFMC, Portland, Oregon.

RASP (Regional Assessment of Supplementation Project). Regional assessment of supplementation project. Portland, Oregon: Bonneville Power Administration; 1991.

USDA (U.S. Department of Agriculture). 2003. Final forest plan revision: Sawtooth National Forest. Pages III:1-123. USDA, Payette and Sawtooth National Forests, Twin Falls, Idaho. 
USFWS (U.S. Fish \& Wildlife Service). 2008. Lower Snake National Fish Hatcheries Review:

Dworshak, Kooskia, and Hagerman National Fish Hatcheries, Assessments and

Recommendations Report. Pacific Region. Portland, OR

http://www.fws.gov/pacific/fisheries/hatcheryreview/team.html

Washington Department of Fisheries (WDF), Washington Department of Wildlife, and Western

Washington Treaty Indian Tribes (WWTIT). 1993. 1992 Washington State salmon and steelhead stock inventory (SASSI). Wash. Dep. Fish Wildl., Olympia, 212 p. +5 regional volumes. (Available from Washington Department of Fish and Wildlife, 600 Capitol Way N., Olympia, WA 9850 1-1 09 P 1.)

Washington Department of Fish and Wildlife (WDFW). 2008. Oncorhynchus mykiss: Assessment of Washington State's Steelhead Populations and Programs, Preliminary Draft for Fish \& Wildlife Commission. J.B. Scott and W.T. Gill editors. Washington Department of Fish and Wildlife, Olympia, Washington.

WLCTRT (Willamette/Lower Columbia Technical Recovery Team). 2003. Interim report on viability criteria for Willamette and Lower Columbia basin Pacific salmonids.

WLCTRT. 2004. Status evaluation of salmon and steelhead populations in the Willamette and lower Columbia River basins.

Willamette Restoration Initiative. 2004. Draft Willamette Basin Subbasin Plan. Prepared for the Northwest Power and Conservation Council.

Yakama Nation (YN). 2009. Draft Hatchery and Genetic Management Plan for Yakima River Summer and Fall Run Chinook Production Program. Yakima-Klickitat Fisheries Project. Yakima, WA. 


\section{Columbia River Hatchery Reform System-Wide Report}

Prepared by:

Hatchery Scientific Review Group

(c)2009

With Funding Support from:

Bonneville Power Administration

National Oceanic and Atmospheric Administration

Northwest Power and Conservation Council

Pacific States Marine Fisheries Commission

U.S. Congress
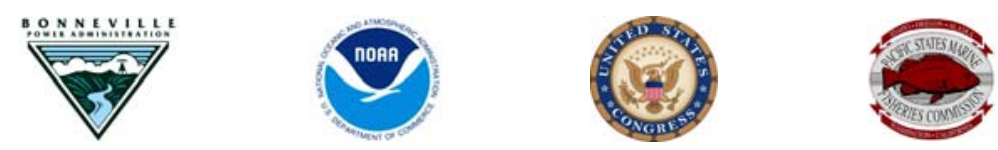

Northwest

Power and

Conservation

Council 